\title{
Transforming U.S. Energy Innovation
}

\section{Citation}

Anadon, Laura Diaz, Matthew Bunn, Gabriel Chan, Melissa Chan, Charles Jones, Ruud Kempener, Audrey Lee, Nathaniel Logar, and Venkatesh Narayanamurti. Transforming U.S. Energy Innovation. Cambridge, Mass.: Report for Energy Technology Innovation Policy research group, Belfer Center for Science and International Affairs, Harvard Kennedy School, November 2011.

\section{Published Version}

http://belfercenter.ksg.harvard.edu/publication/21528/

transforming_us_energy_innovation.html?breadcrumb=\%2Fexperts $\% 2 F 368 \% 2$ Fmatthew_bunn $\% 3 F p a g e \% 3 D 2$

\section{Permanent link}

http://nrs.harvard.edu/urn-3:HUL.InstRepos:10594301

\section{Terms of Use}

This article was downloaded from Harvard University's DASH repository, and is made available under the terms and conditions applicable to Other Posted Material, as set forth at http:// nrs.harvard.edu/urn-3:HUL.InstRepos:dash.current.terms-of-use\#LAA

\section{Share Your Story}

The Harvard community has made this article openly available.

Please share how this access benefits you. Submit a story.

\section{Accessibility}




\section{TRANSFORMING U.S. ENERGY INNOVATION}

Laura Diaz Anadon, Matthew Bunn, Gabriel Chan, Melissa Chan, Charles Jones,

Ruud Kempener, Audrey Lee, Nathaniel Logar, \& Venkatesh Narayanamurti
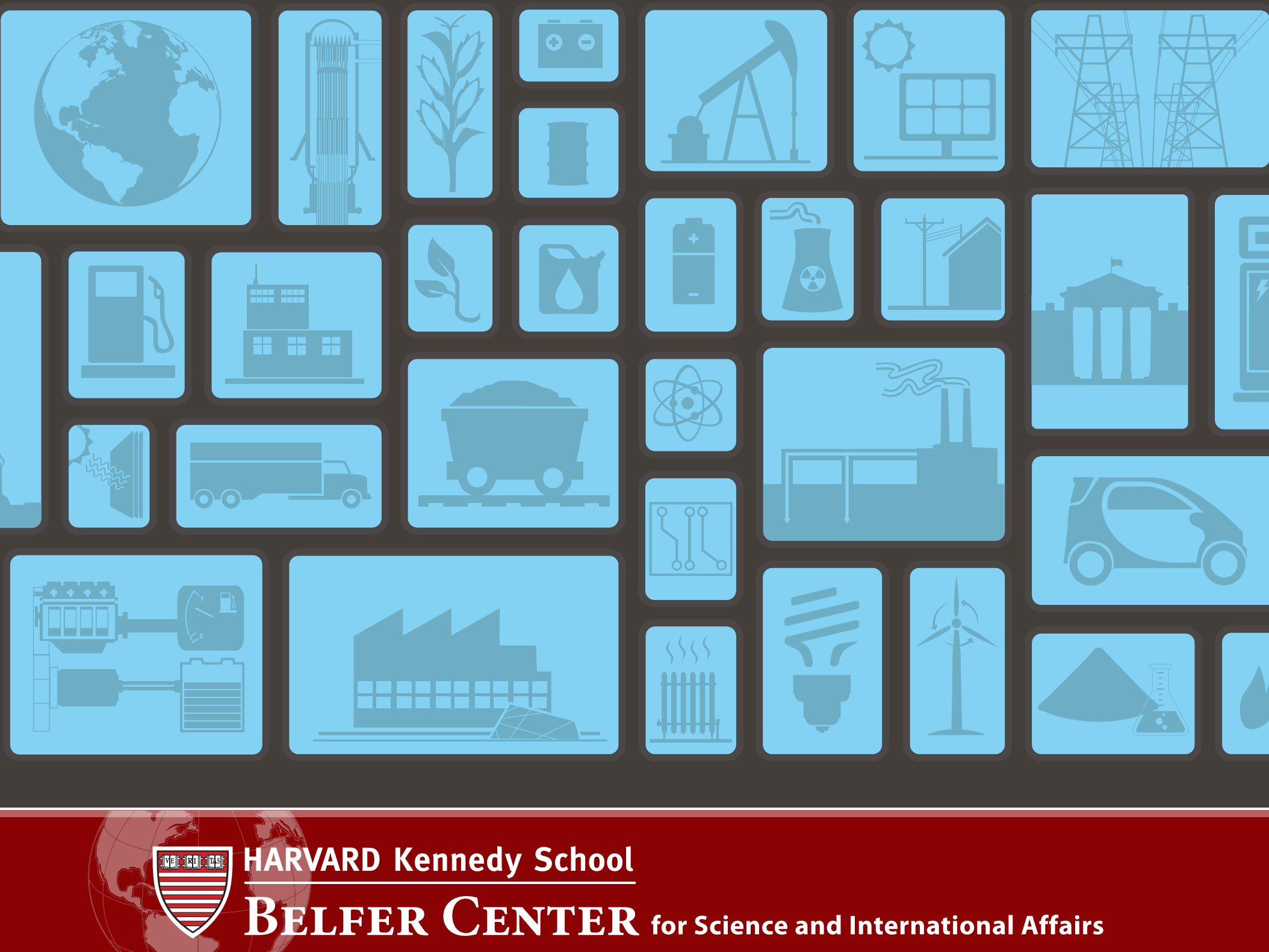

HARVARD Kennedy School BELFER CENTER for Science and International Affairs

NOVEMBER 2011 

Energy Technology Innovation Policy Research Group

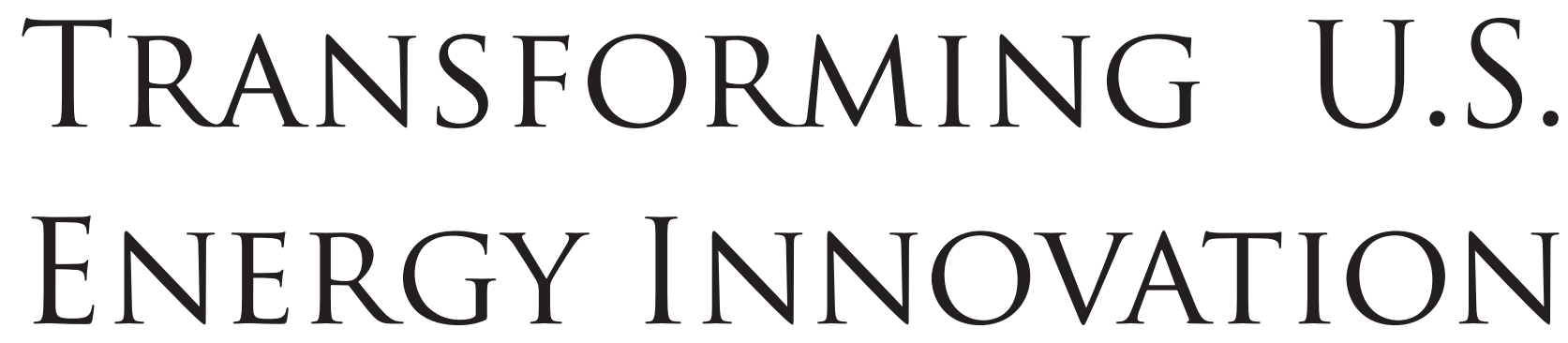

Laura Diaz Anadon, Matthew Bunn, Gabriel Chan, Melissa Chan, Charles Jones,

Ruud Kempener, Audrey Lee, Nathaniel Logar, \& Venkatesh Narayanamurti 


\section{Energy Technology Innovation Policy Research Group \\ Belfer Center for Science and International Affairs \\ Harvard Kennedy School \\ 79 JFK Street \\ Cambridge, MA 02138 \\ Fax: (617) 495-8963 \\ Email: belfer_center@harvard.edu \\ Website: http://belfercenter.org}

This report may be cited as: Anadon, Laura Diaz, Matthew Bunn, Gabriel Chan, Melissa Chan, Charles Jones, Ruud Kempener, Audrey Lee, Nathaniel Logar, and Venkatesh Narayanamurti, Transforming U.S. Energy Innovation, a report of the findings of the Energy Technology Innovation Policy (ETIP) research group, Belfer Center for Science and International Affairs, Harvard Kennedy School, November 2011.

Design and Layout Tim Duffy

(c) 2011 President and Fellows of Harvard College

Supported by a generous grant from the Doris Duke Charitable Foundation 


\section{ACKNOWLEDGEMENTS}

The research for this report by the Energy Technology Innovation Policy (ETIP) research group was generously supported by a grant from the Doris Duke Charitable Foundation whose mission is to improve the quality of peoples' lives through grants supporting the performing arts, environmental conservation, medical research, and the prevention of child abuse, and through the preservation of the cultural and environmental legacy of Doris Duke's properties.

Our efforts have been greatly enriched by the time and the wisdom that our ERD3 Board has so generously provided over the course of this project.

We also thank John P. Holdren and Kelly Sims Gallagher for their invaluable guidance and assistance in the early stages of this project; Henry Lee for his thoughtful feedback and helpful suggestions throughout the project; Gregory Nemet both for his feedback on the report and for sharing his time and knowledge so generously while he was with us as a visiting scholar from January through July of 2011; Paul Friley, Tom Alfstad, and Savvas Politis at the Energy Sciences and Technology Department at Brookhaven National laboratory for their work implementing out samples in MARKAL; and Pat McLaughlin for her help with editing and organizing the publishing process, without which this report would not have been possible.

All responsibility for any errors or misjudgments rests solely with the authors. 


\section{THE ENERGY RESEARCH, DEVELOPMENT, DEMONSTRATION \& DEPLOYMENT (ERD3) POLICY PROJECT}

The goal of the ERD3 project, which was funded by a generous grant from the Doris Duke Charitable Foundation, was to produce and to promote a comprehensive set of recommendations to help the U.S. administration accelerate the development and deployment of low-carbon energy technologies.

The core members of the ERD3 project are:

Venkatesh “Venky” Narayanamurti, Co-Principal Investigator

Matthew Bunn, Co-Principal Investigator

Laura Diaz Anadon, Director of ETIP group and ERD3 Project Manager

Melissa Chan, Research Fellow (until December 2010)

Charles Jones, Research Fellow

RuUd KeMpener, Research Fellow

Audrey LeE, Research Fellow

NATHANiel Logar, Research Fellow

Gabriel Chan, Research Assistant 


\section{The ERD3 project began in 2008 with three primary, and related, goals:}

(a) to develop a methodology for assessing opportunities in energy research, development, and demonstration (ERD\&D) investment, and to produce a set of comprehensive recommendations for the U.S. administration's investment in ERD\&D;

(b) to prepare an annual analysis of and set of recommendations for the Department of Energy's ERD\&D budget, including, but not limited to, climate-change-related technologies; and

(c) to understand the private sector's current role in the carrying out and funding of ERD\&D, and in the drawing of conclusions about effective structures of public-private undertakings, areas of opportunity, and strategies for international cooperation in energy technology innovation.

Over the past three years, the ERD3 project has worked to develop and to implement a methodology for designing an expanded portfolio of federal ERD\&D activities; has investigated the role that the private sector and public-private partnerships play in energy innovation in the United States; has identified ways to improve the effectiveness of public energy innovation institutions; and has analyzed how the U.S. government could improve the effectiveness of its international collaboration efforts on energy innovation. This research was informed by interviews, surveys, modeling exercises, and literature reviews. In addition to this report, the members of the ERD3 project evaluated the U.S. federal annual spending on energy research, development, and demonstration. The project's assessments were released with policy recommendations on how the appropriations could be improved in order to better align with the national and global need to develop and to deploy clean energy technologies. This effort built on earlier efforts of the Energy Technology Innovation Policy (ETIP) group, which has been monitoring the federal ERD\&D expenditures since 1978.

The ERD3 project has benefitted from the advice of a distinguished Advisory Committee with members from academia, industry, and the nonprofit sector (listed below).

This report contains the project's final analysis and recommendations on how to transform U.S. energy innovation. 


\section{ERD3 PROJECT ADVISORY BOARD MEMBERS}

\section{Dan Arvizu}

Director of the National Renewable

Energy Laboratory

\section{SALly M. Benson}

Executive Director, Global Climate \&

Energy Project

Professor at the School of Earth Sciences

Stanford University

MARILYN BROWN

Ivan Allen College

Professor at the School of Public Policy

Georgia Tech University

JAMES A. EDMONDS

Chief Scientist

Joint Global Change Research Institute

Pacific Northwest National Laboratory

MiCHAEL T. ECKHART

Managing Director

Citigroup

\section{Robert A. Frosch}

Senior Research Associate

Belfer Center for Science and

International Affairs

Harvard Kennedy School of Government

\section{Bonifacio Garcia Porras}

Member of the Cabinet

EU Energy Commission

\section{JUdi GREENWALD}

Vice President of Innovative Solutions

Pew Center on Global Climate Change

DANIEL M. KAMMEN

Professor at the Energy and Resources Group and the Goldman School of Public Policy

University of California, Berkeley

Daniel Lashof

Director, Climate Center

Natural Resources Defense Council

RICHARD LESTER

Professor of Nuclear Science and Engineering Director of the Industrial Performance Center Massachusetts Institute of Technology

\section{EDWARD LOWE}

General Manager

Renewable Energy Market Development

GE Energy 


\section{ERNEST J. MONIZ}

Professor of Physics and Cecil and Ida Green Distinguished Professor

Massachusetts Institute of Technology

\section{Donald L. Paul}

Executive Director of the University of Southern California Energy Institute and William M. Keck Chair in Energy Resources;

Senior Advisor to the Center for Strategic and International Studies;

Founder and President of Energy and Technology

Strategies

\section{DAN W. REICHER}

Professor of the Practice of Law

Executive Director of the Steyer-Taylor

Center for Energy Policy and Finance

Stanford University

\section{Ambuj Sagar}

Professor of Technology and Policy Dept. of Humanities and Social Sciences, Indian Institute of Technology Delhi, India

\section{Daniel Schrag}

Director, Harvard University Center for the Environment

Professor of Earth and Planetary Sciences

Harvard University

\section{Jennie C. STEPhens}

Professor of Environmental Science \& Policy

Department of International Development, Community, and Environment

Clark University

\section{DAVID H. WELls}

Partner

Kleiner Perkins Caufield \& Byers

\section{ROBERT E. WiLLIAMS}

Senior Research Scientist

The Energy Group

Princeton University 



\section{CONTENTS IN BRIEF}

Executive Summary.

Chapter 1: Introduction and Motivation

Chapter 2: Government Investments in Energy Research, Development, and Demonstration. .79

Chapter 3: Managing Innovation Institutions. 181

Chapter 4: Innovation in the Private Sector and Public-Private Partnerships 217

Chapter 5: International Cooperation on ERD3: Transforming the U.S. Approach 273

About the Authors .336 


\section{CONTENTS IN DETAIL}

EXeCUTIVe Summary

\section{CHAPTER 1}

\section{INTRODUCTION AND Motivation}

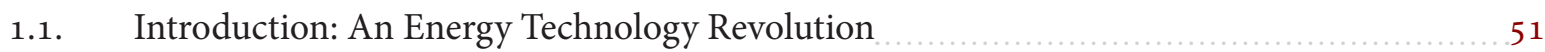

1.2. Interlinked Crises

1.3. The Need for a Portfolio of New Energy Technologies 58

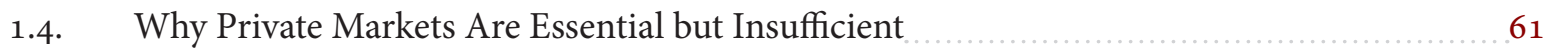

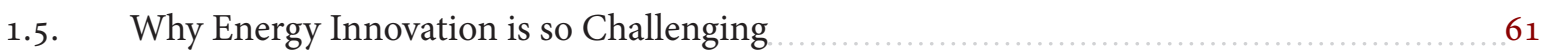

1.6. The Energy Innovation System

1.7. Successful Innovation Requires a Willingness to Fail-And an Ability to

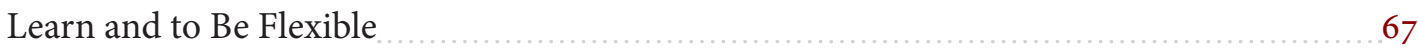

1.8. Scope of the Work $\quad 68$

References

\section{ChAPTER 2}

Government Investments in Energy Research, Development, and Demonstration

2.1. Introduction

2.2. Status Quo $\quad 79$

2.2.1. Energy RD\&D investments or technology "push" $\ldots \ldots \ldots . . \ldots 79$

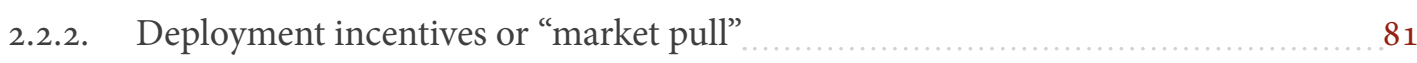

2.2.2.1. Power generation standards 82

2.2.2.2. Building codes

2.2.2.3. Transportation sector policies: fuel economy standards, biofuels mandates, and vehicle tax credits $\quad 84$

2.2.2.4. Climate change mitigation targets 84

2.2.2.5. Market conditions for oil and natural gas 85

2.3. Review of Calls for More Energy Innovation

2.4. Methods to Evaluate Budgets for Energy Technology Innovation $\quad 87$

2.5. Method and Rationale of This Work

2.5.1. Description of expert elicitations

2.5.2. Important features of this expert elicitation $\ldots$

2.5.2.1. Experts are human

2.5.2.2. Relationship between federal and private spending unclear _......... 96 
2.5.2.3. Selecting expert answers for simulation

2.5.3. From expert elicitation responses to model-ready scenarios of joint technology cost trajectories

2.5.3.1. Marginal distributions of technology costs _.......................... 98

2.5.3.2. Technology cost sampling and induced cross-technology dependence $\ldots 9$

2.5.3.3. Longitudinal dependence and extrapolation to $2050 \ldots \ldots \ldots \ldots \ldots \ldots \ldots . \ldots . \ldots . \ldots 2$

2.5.4. Description of energy system modeling and scenarios modeled _ 104

2.6. Quantitative Expert Elicitation Results $\ldots \ldots \ldots$

2.6.1. Bioenergy 108

2.6.2. Storage 110

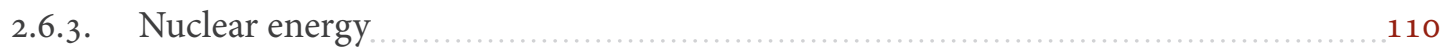

2.6.4. Fossil energy and CCS

2.6.5. Commercial buildings

2.6.6. Vehicles

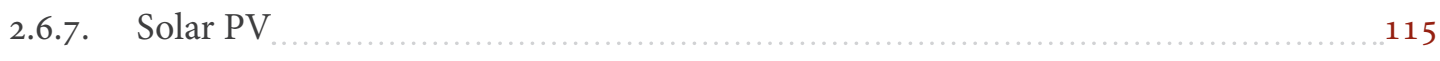

2.6.8. Summary of RD\&D budget recommendations from elicitations $\ldots 117$

2.7. Insights About Non-RD\&D Policies from Expert Elicitations

2.7.1. Bioenergy 120

2.7.2. Storage 120

2.7.3. Nuclear energy $\ldots \ldots \ldots \ldots \ldots \ldots$

2.7.4. Fossil energy $\ldots 121$

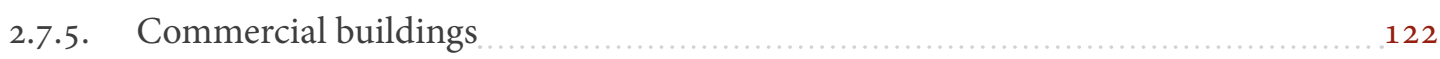

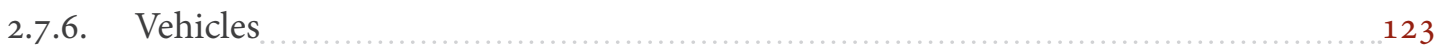

2.7.7. Solar PV 123

2.8. Results Estimating the Benefits of RD\&D Investments

2.8.1. Combined benefits of different levels of RD\&D investments 124

2.8.2. Impact of RD\&D on the diffusion of particular technologies $\ldots 136$

2.8.3. Insights from optimizing the allocation of $\mathrm{RD} \& \mathrm{D}$ investments

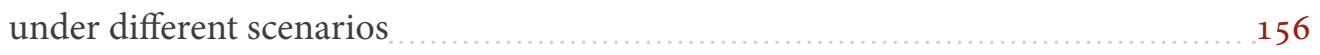

2.8.3.1. The technology cost-technology area RD\&D relationship _.......... 156

2.8.3.2. Inferring technology area RD\&D levels _...................... 158

2.8.3.3. The technology area RD\&D levels-output variable relationship _....... 159

2.8.3.4. Optimizing the RD\&D portfolio under a total funding constraint _...... 160 
2.8.3.5. Limitations of this methodology

2.8.4. Summary of recommendations for the seven technology areas covered by elicitations and modeling

2.8.5. Estimates of RD\&D investments for areas not covered by the elicitations _.......... 165

2.8.6. Total budget recommendation 169

2.8.7. Investing for the future in a time of budget constraints 170

2.9. Recommendations for Budget Decision-Making Process $\quad 170$

2.9.1. Recommendations from this chapter 170

2.9.2. Cross-cutting recommendations from the full report $\ldots \ldots \ldots \ldots \ldots \ldots \ldots \ldots \ldots \ldots \ldots \ldots \ldots \ldots$

References

\section{ChAPTER 3}

MANAGING INNOVATION INSTITUTIONS

3.1. Summary

3.2. Introduction and Motivations

3.3. Methods $\quad$. 185

3.4. NREL $\quad 186$

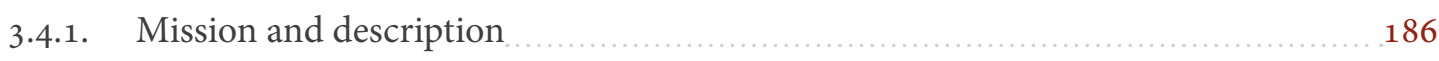

3.4.2. NREL performance

3.5. Semiconductor Research Corporation 199

3.5.1. Mission and description $\ldots \ldots \ldots$

3.5.2. SRC programs

3.5.3. SRC performance 204

3.5.4. Applying lessons from SRC 205

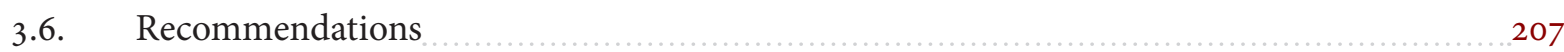

3.6.1. Recommendations for NREL 207

3.6.2. Recommendations beyond NREL

3.7. Conclusions 212

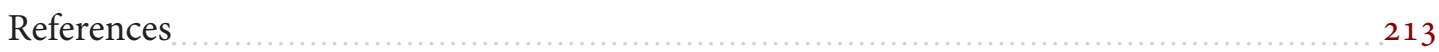

Chapter 4

Innovation in the Private Sector and Public-Private Partnerships

4.1. Introduction $\quad 217$

4.2. Background 219

4.2.1. Uncertainty in energy technology innovation investment 219

4.2.2. Underinvestment in energy technology innovation 221

4.2.3. Funding and performance of energy R\&D 223 
4.3. Methods 228

4.3.1. Database on DOE support for energy technology innovation $\quad 228$

4.3.2. Interviews 228

4.3.3. Survey of energy innovation in U.S. businesses 229

4.4. Private Sector Activities in Energy Innovation $\ldots 231$

4.4.1. Energy innovation landscape $\quad 231$

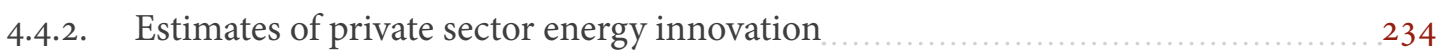

4.4.3. Process of private sector energy innovation 237

4.4.4. Reflections on private sector energy innovation 238

4.5. DOE and Partnership Activities in Energy Innovation 239

4.5.1. Types of DOE activities 239

4.5.2. Trends in DOE activities

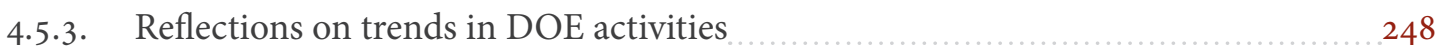

4.6. Project Management for Public-Private Partnerships 248

4.7. Strategic Planning in Both Public and Private Sectors and in Partnerships 252

4.7.1. Current process for making decisions about energy innovation partnerships at DOE

4.7.2. Improving DOE decision-making process on partnerships $\ldots 256$

4.8. Learning and Adaptation $\quad 260$

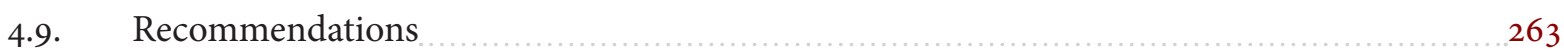

References

\section{ChAPTER 5}

International Cooperation on ERD3: Transforming the U.S. Approach

5.1. Motivation and Outline 273

5.2. Research Questions and Methodology 275

5.3. Changing Dynamics in a Global ERD3 Landscape 276

5.3.1. The critical importance of the private sector 277

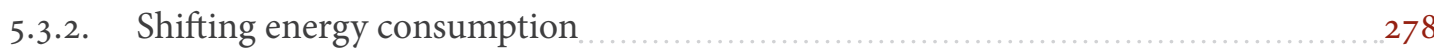

5.3.3. Shifting patterns of ERD\&D 279

5.3.4. Expanding and shifting scientific collaborations 281

5.3.5. Increasing import and export values for energy technologies 282

5.3.6. Heightened global competition in energy technology markets _.................... 283

5.3.7. More bilateral and multilateral agreements 284

5.3.8. Intensified debate over intellectual property rights and global trade rules _.......2 285

5.3.9. Consequences for government involvement in international

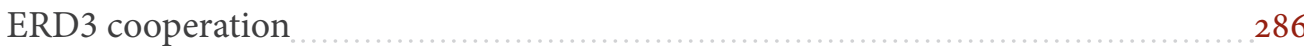


5.4. International ERD3 Cooperation Activities within the U.S. Government 287

5.4.1. Current U.S. government ERD3 cooperation initiatives 287

5.4.2. A new analytical perspective for international ERD3 cooperation 288

5.4.3. Platforms for government international ERD3 cooperation activities _................291

5.4.4. U.S. agencies involved in international ERD3 cooperation _..................... 296

5.4.5. Activities in government international ERD3 cooperation _....................298

5.4.6. Coordinating ERD3 cooperation within the U.S. government $\ldots \ldots \ldots \ldots \ldots \ldots \ldots \ldots \ldots \ldots \ldots \ldots$

5.4.7. Summary of current state of government-supported international ERD3 cooperation

5.5. The Challenge of Selecting, Executing, and Evaluating International

ERD3 Cooperation

5.5.1. Decision criteria for international ERD3 cooperation 304

5.5.2. Designing international ERD3 cooperation activities 306

5.5.3. Structural versus procedural criteria for designing cooperation projects …........308

5.5.4. Evaluating the impacts of ERD3 cooperation 310

5.6. Managing International Cooperation in a Complex World $\quad 313$

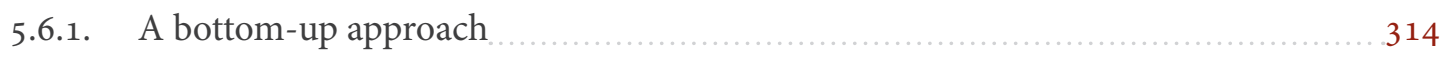

Managing Projects

Managing Programs

Managing Agreements $\ldots \ldots \ldots \ldots \ldots \ldots$

5.6.2. A top-down approach $\quad 319$

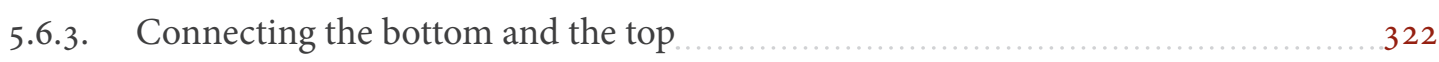

5.7. Conclusions and Recommendations

References

Aвout the Authors 



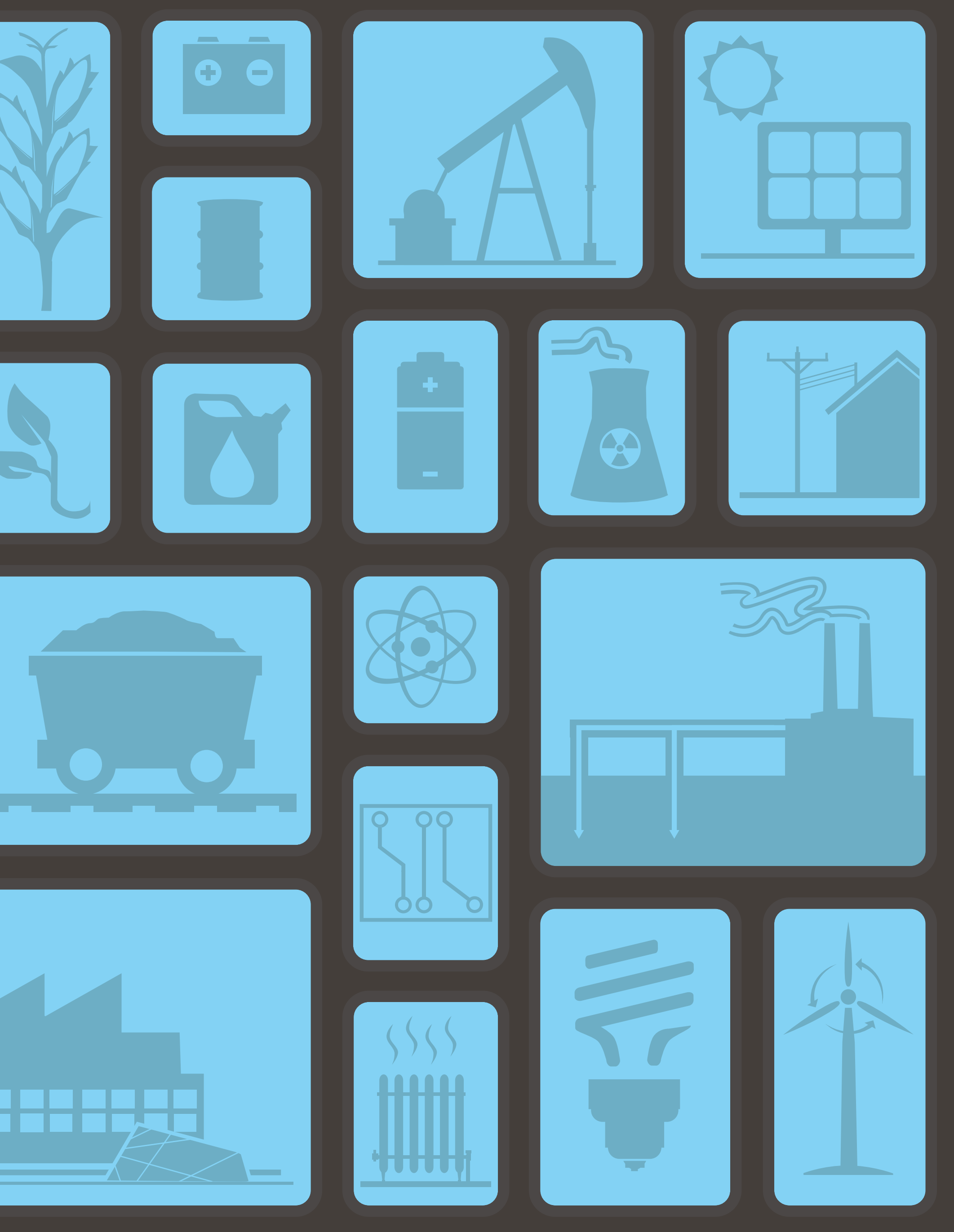




\section{EXECUTIVE SUMMARY}

The United States and the world need a revolution in energy technology-a revolution that would improve the performance of our energy systems to face the challenges ahead. A dramatic increase in the pace of energy innovation is crucial to meet the challenges of:

- Energy and national security, to address the dangers of undue reliance on dwindling supplies of oil increasingly concentrated in some of the most volatile regions of the world, and to limit the connection between nuclear energy and the spread of nuclear weapons;

- Environmental sustainability, to reduce the wide range of environmental damages due to energy production and use, from fine particulate emissions at coal plants, to oil spills, to global climate disruption; and

- Economic competitiveness, to seize a significant share of the multi-trillion-dollar clean energy technology market and improve the balance of payments by increasing exports, while reducing the hundreds of billions of dollars spent every year on importing oil.

In an intensely competitive and interdependent global landscape, and in the face of large climate risks from ongoing U.S. reliance on a fossil-fuel based energy system, it is important to maintain and expand long-term investments in the energy future of the U.S. even at a time of budget stringency. It is equally necessary to think about how to improve the efficiency of those investments, through strengthening U.S. energy innovation institutions, providing expanded incentives for private-sector innovation, and seizing opportunities where international cooperation can accelerate innovation. The private sector role is key: in the United States the vast majority of the energy system is owned by private enterprises, whose innovation and technology deployment decisions drive much of the country's overall energy systems. Efficiently utilizing government investments in energy innovation requires understanding the market incentives that drive private firms to invest in advanced energy technologies, including policy stability and predictability.

The U.S. government has already launched new efforts to accelerate energy innovation. In particular, the U.S. Department of Energy is undertaking a Quadrennial Technology Review to identify the most promising opportunities and provide increased coherence and stability. Our report offers analysis and recommendations designed to accelerate the pace at which better energy technologies are discovered, developed, and deployed, and is focused in four key areas:

- Designing an expanded portfolio of federal investments in energy research, development, demonstration (ERD\&D), and complementary policies to catalyze the deployment of novel energy technologies; 
- Increasing incentives for private-sector innovation and strengthening federal-private energy innovation partnerships;

- Improving the management of energy innovation institutions to maximize the results of federal investments; and

- Expanding and coordinating international energy innovation cooperation to bring ideas and resources together across the globe to address these global challenges.

\section{MeTHODOLOgY}

For each of these separate questions, we have used a different approach. To develop recommended portfolios of federal ERD\&D investments, we surveyed experts and incorporated their projections into an energy-economic model to assess key outcomes such as greenhouse gas emissions or oil imports, looking for portfolios that would offer the greatest progress against key goals for a given level of investment. This also allowed us to explore the impact of demand-side policies such as a carbon cap or a clean energy standard. The process of energy technology innovation is inherently uncertain; no one, including the surveyed experts, can predict exactly where the most important energy technology breakthroughs may arise. Hence a broad portfolio of investments is essential. Unlike many other studies, we explicitly asked the surveyed experts to assess the uncertainty in their estimates, and incorporated that uncertainty in our modeling and subsequent projections.

To assess private sector innovation, we conducted an initial pilot-scale survey of enterprises engaged in energy innovation - going well beyond previously available data and surveys - and studied partnerships between private firms and the U.S. Department of Energy (DOE) to explore how they might be made more effective.

To examine approaches to managing federal energy innovation institutions, we employed a case-study approach (combined with the experience of some of the actors managing such institutions), looking in depth at the National Renewable Energy Laboratory (NREL) and the Semiconductor Research Corporation (SRC) to draw upon lessons learned.

To explore international cooperation on energy innovation (which we define as including ERD\&D and deployment (ERD3)), we developed a number of datasets on current and past collaborations (ranging from energy publications with international authors to joint international energy private sector ventures), examined the state-directed ERD3 investments of major emerging economies, and investigated current U.S. government approaches to international ERD3 cooperation and how they might be improved. 


\section{Designing A Portfolio of Federal Energy Innovation Investments}

\section{FINDINGS}

Finding: Experts in a broad range of energy technology fields recommend increases of a factor of 3-10 depending on the area in federal research, development, and demonstration investments.

We conducted expert elicitations for four energy supply technology areas (nuclear energy, bio-energy, fossil energy with and without carbon capture and sequestration, and solar photovoltaic (PV) energy), one enabling technology area (utility-scale energy storage), and two key areas of energy efficiency (buildings and vehicles). Experts in each of the technology areas covered recommended large increases in federal ERD\&D investments. The average recommended increases over fiscal year (FY) 2009 appropriations ranged from $186 \%$ for solar photovoltaic to $963 \%$ for utility-scale storage (where the base for comparison is small and the potential is large). In absolute terms, the average recommended increases in spending ranged from $\$ 221$ million per year for storage to $\$ 1.65$ billion per year for fossil energy. See Table ES-1. As we discuss later, experts also expressed the opinion that there are points of diminishing returns for investments in each technology—-that increasing funds well beyond this particular amount in the short term may not result in significant benefits. Current federal energy ERD\&D investments, however, are well below what the experts recommend.

\begin{tabular}{|c|c|c|c|c|c|}
\hline Technology & $\begin{array}{c}2009 \\
\text { spending } \\
\text { (million \$) }\end{array}$ & $\begin{array}{l}2009 \\
\text { ARRA spending } \\
\text { (million \$) }\end{array}$ & $\begin{array}{l}\text { Average } \\
\text { recommended } \\
(\text { million \$) }\end{array}$ & $\begin{array}{l}\text { Average increase } \\
\text { over } 2009 \\
\text { recommended } \\
\text { by experts in } \%\end{array}$ & $\begin{array}{l}\text { Absolute increase } \\
\text { over } 2009 \text { in } \\
\text { \$million }\end{array}$ \\
\hline Bioenergy & 214 & 777 & 682 & $219 \%$ & 468 \\
\hline Energy storage & 23 & 185 & 244 & $963 \%$ & 221 \\
\hline Nuclear & 466 & 0 & 1,833 & $293 \%$ & 1,367 \\
\hline Fossil & 701 & 3,390 & 2,354 & $236 \%$ & 1,653 \\
\hline Solar PV & 143 & 86 & 409 & $186 \%$ & 266 \\
\hline Vehicles & 432 & 2,839 & 2,050 & $375 \%$ & 1,618 \\
\hline Buildings & 144 & 319 & 678 & $371 \%$ & 534 \\
\hline $\begin{array}{l}\text { Total of technologies } \\
\text { studied }\end{array}$ & 2,123 & 7,596 & 8,251 & $289 \%$ & 6,128 \\
\hline
\end{tabular}

TABLE ES-1. Expert recommended RD\&D spending and 2009 federal spending, per technology area (or industry). 


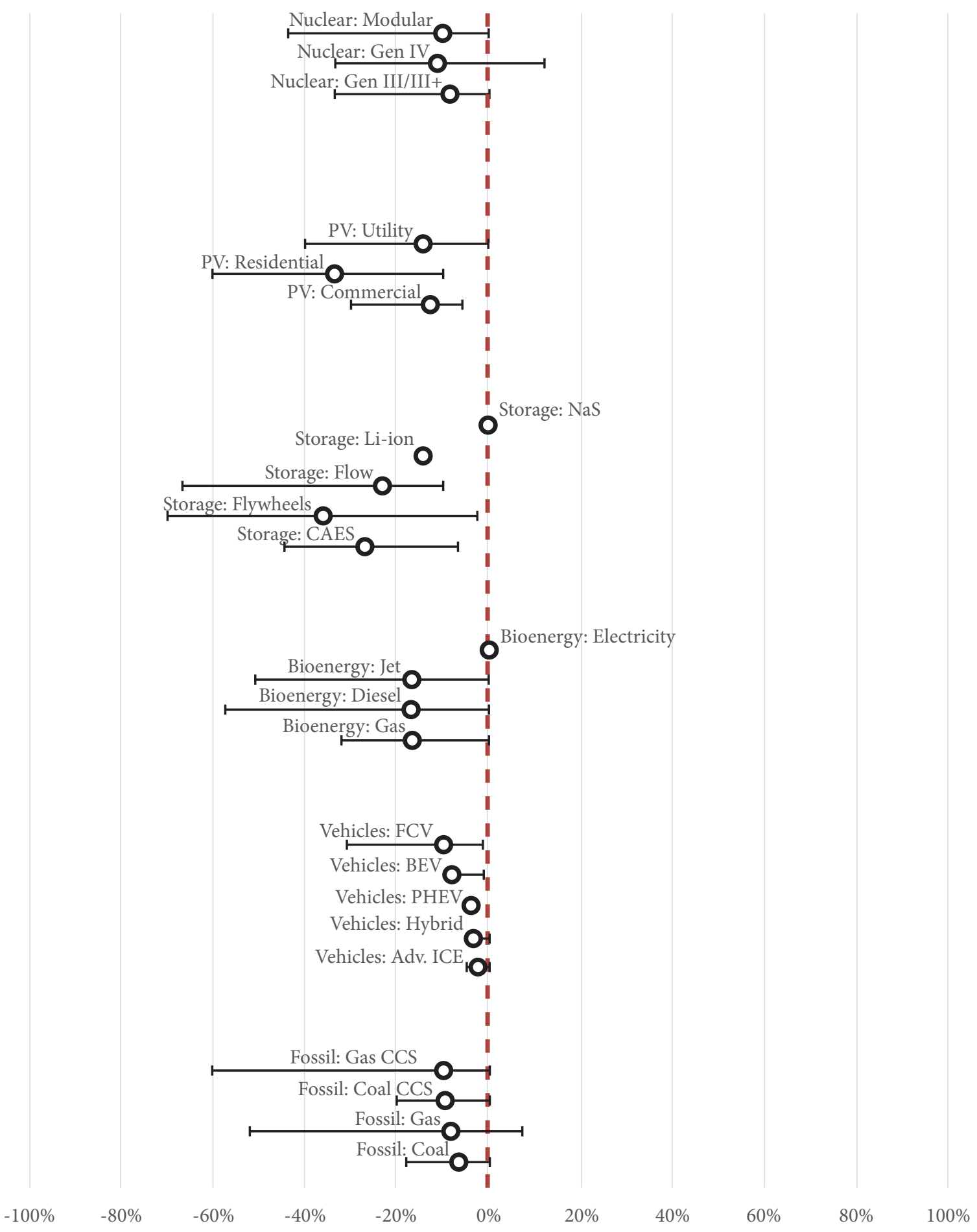

2030 Cost Reduction from BAU at Recommended RD\&D Funding Level

FIGURE ES-1. Range of median cost reduction per technology predicted by each expert under his or her recommended RD\&D spending per industry. Costs cover overnight capital costs for SMR, Generation IV, and Generation III/III+ nuclear power plants; overnight capital costs for grid level energy storage technologies; production costs for biomass-based electricity $(\$ / \mathrm{kWh})$ and substitutes for jet fuel, diesel, and gasoline (\$/gallon); unit costs for advanced ICE, hybrid, plug-in hybrid, electric, and fuel cell vehicles (\$/unit); overnight capital costs of coal and natural gas power plants with and without CCS (\$/kW); and module costs for residential, commercial, and utility scale PV panels $(\$ / \mathrm{kW})$. 
As mentioned earlier, in spite of U.S. fiscal challenges, investments today are essential building blocks for future growth and prosperity. Good mechanisms need to be in place to make decisions about investments, and also to find avenues for paying for essential long-term investments like those for ERD\&D. This report aims at beginning to explore those mechanisms.

Finding: Experts in most of the technology areas surveyed believe that federal energy innovation investments, at the levels they recommend, would lead to substantial improvements in performance and reductions in cost by 2030.

Our surveys asked experts to estimate the cost and performance that technologies in their area would be likely to achieve by 2030 if federal ERD\&D investments continued at current levels, and at three levels of potential increased investment. For each technology area and funding level, experts estimated a range of cost and performance improvements that could be achieved over two decades, and judged the uncertainty bounds in those estimates.

For most technologies, the experts projected greater improvements in cost and performance by 2030 with increasing levels of federal ERD\&D investments. Figure ES-1 shows the experts' median projections of the additional cost reduction that would result from their recommended ERD\&D investments compared to maintaining current levels of federal investment. The figure also shows the range of opinion among the experts surveyed. The median of experts' estimated cost reduction over the cost under a businessas-usual (BAU) ERD\&D funding scenario in 2030 ranged from no cost reduction in the case of sodium sulfur batteries (for which only a small number of experts provided estimates), to around $35 \%$ in the case of residential-scale solar PV and flywheel energy storage technologies. The cost reduction catalyzed by federal ERD\&D funding beyond the BAU scenario is estimated the lowest for vehicle technologies, ranging from a $2 \%$ cost reduction for advanced internal combustion engine (ICE) vehicles to a $10 \%$ cost reduction for fuel cell vehicles (although this may reflect a judgment that investments by private firms, rather than federal spending, will be the major driver of improvement in vehicle technologies.)

Finding: The surveyed experts recommend a portfolio approach within their technology areas, with investments spread across a range of technologies and a range of technology innovation stages (from basic research to large-scale technology demonstrations).

Within each of the seven technology areas, experts generally recommended supporting a range of technologies. For example, in the case of solar PV, experts recommended funding crystalline silicon, thin film, concentrator, excitonic, and novel high-efficiency technologies (among others) but focused mainly on thin film, concentrator, and novel high-efficiency technologies (see Figure ES-2). Experts also recommended funding efforts across different stages of technology development. In this solar PV example, the average allocation of funding from experts across basic research, applied research, experiments and pilots, and commercial demonstration was $27 \%, 37 \%, 25 \%$, and $11 \%$, respectively. 


\begin{tabular}{|c|c|c|c|c|c|c|c|c|}
\hline & 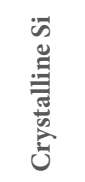 & $\begin{array}{l}\text { 豆 } \\
\text { 湆 }\end{array}$ & 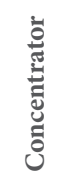 & 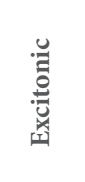 & 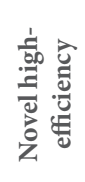 & 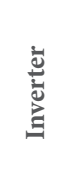 & 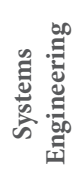 & 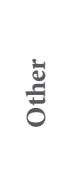 \\
\hline Basic Research & $2.4 \%$ & $5.1 \%$ & $3.6 \%$ & $3.2 \%$ & $6.6 \%$ & $2.8 \%$ & $1.4 \%$ & $2.2 \%$ \\
\hline Applied Research & $5.5 \%$ & $6.1 \%$ & $5.4 \%$ & $2.2 \%$ & $5.6 \%$ & $4.8 \%$ & $4.4 \%$ & $3.0 \%$ \\
\hline Experiments and Pilots & $2.5 \%$ & $4.3 \%$ & $5.1 \%$ & $1.3 \%$ & $2.5 \%$ & $3.4 \%$ & $3.5 \%$ & $2.2 \%$ \\
\hline Commercial Demonstration & $0.5 \%$ & $1.4 \%$ & $3.5 \%$ & $0.6 \%$ & $1.1 \%$ & $1.3 \%$ & $1.5 \%$ & $1.5 \%$ \\
\hline Total & $10 \%$ & $17 \%$ & $18 \%$ & $7 \%$ & $16 \%$ & $12 \%$ & $11 \%$ & $10 \%$ \\
\hline
\end{tabular}

FIGURE ES-2. Average allocation of recommended annual federal solar PV technology RD\&D budget for 2010-2030 (percentage of total). The percentages may not add to $100 \%$ due to rounding.

Finding: Experts in all technology areas expected decreasing marginal returns from federal ERD\&D investments in terms of both improved technology costs and performance for very large ERD\&D funding increases. These are further reflected in decreasing marginal returns for $\mathrm{CO}_{2}$ emissions under no policy, $\mathrm{CO}_{2}$ allowance price reductions under a $\mathrm{CO}_{2}$ cap-andtrade program, and clean energy standard (CES) credit prices under a power sector CES, illustrated by the energy system modeling results.

Experts generally expected ERD\&D increases over current funding levels to lead to cost reductions over a BAU federal ERD\&D funding scenario. However, when asked about the impact of a federal ERD\&D budget ten times larger than the BAU scenario, almost all experts expected less progress per dollar invested.

Figure ES-3 shows that decreasing marginal returns to ERD\&D investment occur when consumer surplus increases resulting from different levels of RD\&D funding under the CO2 cap policy scenario (Figure ES-3). The median benefits in investing in RD\&D at the full recommended level compared to the BAU level are significant, especially by 2050, though the uncertainties are large. The median result shows that increasing RD\&D funding from the BAU to the FULL scenario under a CO2 cap policy results in an increase in consumer and producer surplus in 2050 of about $\$ 35$ per dollar invested in energy $\mathrm{RD} \& \mathrm{D}$. Note that, as a measure of the impact of $\mathrm{RD} \& \mathrm{D}$, consumer and producer surplus is a metric that encompasses more factors than other studies measuring the returns to $\mathrm{RD} \& \mathrm{D}$, but does not consider the opportunity cost of investing the energy RD\&D funds elsewhere in the economy. However, in our models, based on the experts' projections, dramatic further expansions of RD\&D beyond the recommended level would offer little benefit. 


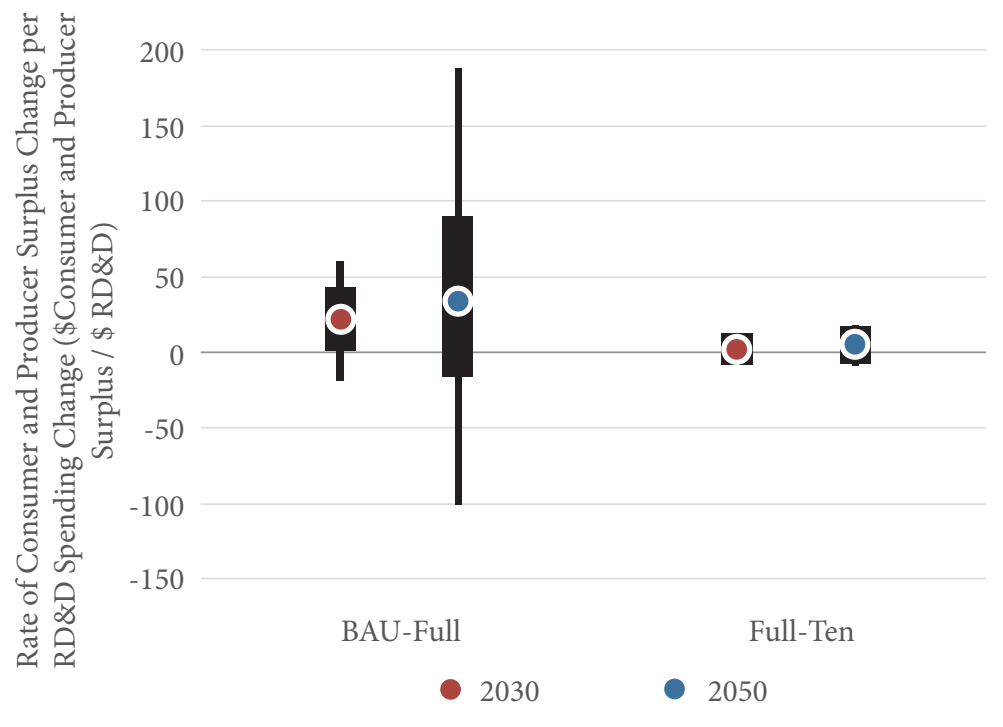

FIGURE ES-3. Average increase in consumer and producer surplus per \$RD\&D invested when comparing MFULLCO2 with MBAUCO2 and MTENCO2 with MFULLCO2 in 2030 and 2050. The dot corresponds to the 50th percentile, the black rectangle encompasses the 25 th and 75th percentiles, and the line encompasses the 5th and 95th percentiles.

Finding: It is very unlikely that the goal of reducing carbon dioxide emissions by $83 \%$ below 2005 levels by 2050 can be met without both increased ERD\&D investments and policies that price carbon emissions (along with sector-specific demand-side policies) to create strong incentives for the private sector to develop and deploy carbon-reduction technologies.

Modeling results using the technology cost and performance inputs from the experts indicate that, without new demand-side (or deployment) policies-such as an economy-wide $\mathrm{CO}_{2}$ cap-and-trade program or sectoral policies like a power sector clean energy standard-ERD\&D investments are exceptionally unlikely to lead to $\mathrm{CO}_{2}$ emissions reductions from the U.S. energy sector consistent with the goal of limiting global average temperature rise to about $2^{\circ} \mathrm{C}$. An $83 \%$ reduction in greenhouse gas emissions when compared to 2005 levels would require emissions in 2050 to be around one billion metric tons of $\mathrm{CO}_{2}$ or equivalent per year (U.S. greenhouse gas emissions in 2005 were 6.1 billion metric tons). As shown in Figure ES-3, in our models, neither a BAU scenario of federal funding ERD\&D for the seven areas covered (around $\$ 2.1$ billion per year), nor a 23- to 49-fold increase (between $\$ 49$ billion and $\$ 82$ billion), even under optimistic technology assumptions, have any significant chance of achieving this level of $\mathrm{CO}_{2}$ emissions without substantial demand-side policies. In these models, projections from the "middle of the road" experts suggest that even large increases in ERD\&D funding, in the absence of any price on carbon, still lead to a roughly $95 \%$ probability that emissions in 2050 would be greater than those in 2010 , far from the goal of more than five-fold reductions. The uncertainty shown in Figure ES-4 only includes the experts' estimates of the uncertainty around the cost and performance of the seven technology areas covered in our surveys, not the myriad other factors that will affect U.S. emissions between now and 2050. 

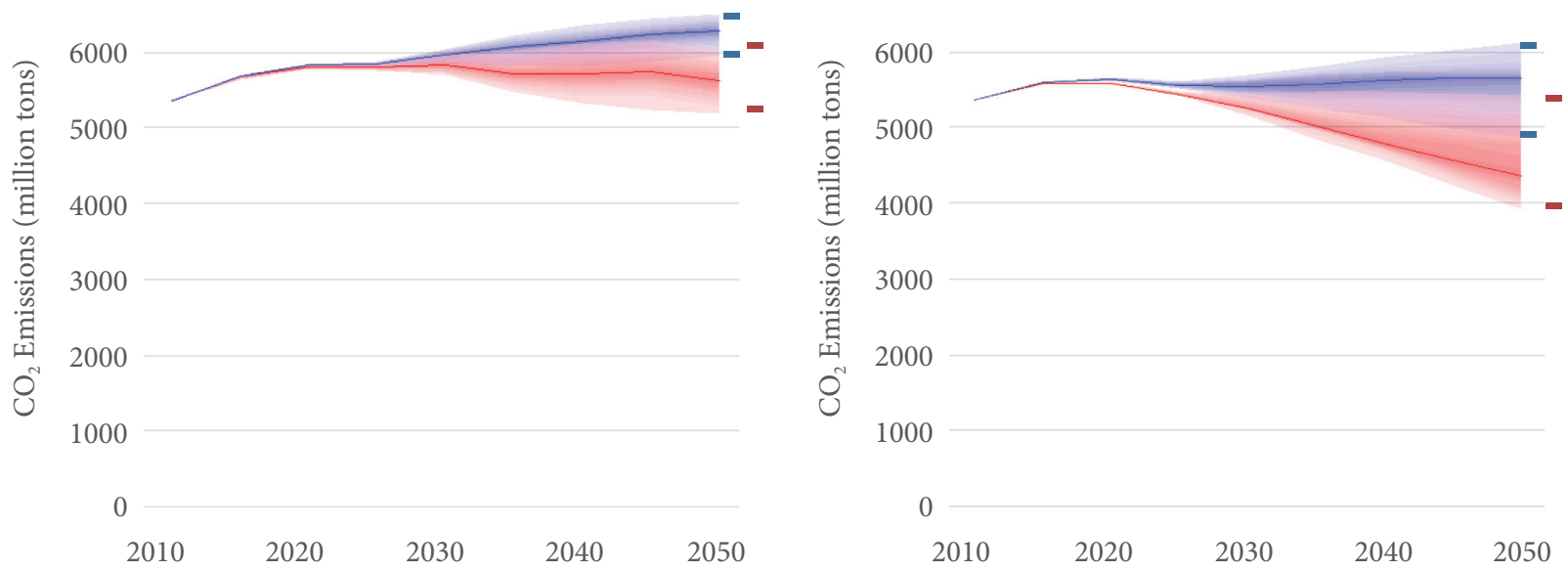

FIGURE ES-4. U.S. energy-related $\mathrm{CO}_{2}$ emissions under (a) business-as-usual federal energy RD\&D investment and no additional demand-side policies (blue) and (b) ten times the experts' average recommended federal energy RD\&D investments (somewhere between $\$ 49$ and $\$ 82$ billion/year) (red), with no additional demand-side policies, using "middle of the road" and "optimistic" experts' technology cost projections. Note that optimistic experts were optimistic about technological progress in general, and not necessarily optimistic about the effects of RD\&D.

Nevertheless, it is clear that necessary ERD\&D investments must be complemented with demand-side policies to encourage widespread deployment of new energy technologies.

Finding: The technology improvements projected by the surveyed experts from their recommended ERD\&D investments would probably lead to significant, but not dramatic, improvements in the cost and feasibility of fueling a growing U.S. economy while meeting targets for reduced greenhouse gas emissions or oil imports.

Our economic modeling suggests that an investment of a few extra billion dollars a year today could develop technologies that could save the economy over a hundred billion dollars a year by 2050, in scenarios where there are stringent policies limiting how much carbon can be emitted. In our models, a robust ERD\&D investment reduces the total cost of the U.S. energy system, expands consumer surplus, and reduces the carbon prices needed to meet a tight cap on carbon emissions. As Figure ES-5 shows, if the projections of the middle-of-the-road technology experts prove to be correct, expanding ERD\&D from the BAU level to the full recommended level would reduce carbon prices by over $\$ 30$ per ton, saving some $\$ 30$ billion a year in 2050 for those purchasing emission allowances. Under the optimistic technology assumptions, the $\mathrm{CO}_{2}$ price also declines with higher levels of $\mathrm{RD} \& \mathrm{D}$ funding, but the uncertainty in the price also decreases.

It is important to note that the modeling did not incorporate the results of the expanded private-sector investments in clean energy innovation that would be provoked by a price on carbon emissions or a clean energy standard due to the lack of empirical data on the size of this effect. Private sector innovation is likely to invent new approaches that make complying with stringent carbon policies cheaper than it ap- 
pears to be in our models. In addition, the modeling did not include benefits that may occur after 2050, when novel technology may have the largest impact on controlling mitigation costs.

Finding: The optimal level of RD\&D for many technology areas is highly contingent on adopted policies, which means that having a balanced portfolio across different technology options is very important.

We sought to develop optimized $\mathrm{RD} \& \mathrm{D}$ portfolios by relating projections of future technology costs (from experts' surveys) and resulting economic benefits (from the energy system modeling results) to RD\&D portfolios. Optimized RD\&D portfolios among six of the seven technology areas are shown in Figure ES-6 at two total budget levels ( $\$ 5$ billion, left; $\$ 7.5$ billion, right) for three policy scenarios: no climate policy, $\mathrm{CO}_{2}$ cap and trade, and standards-based sectoral policy (note that the $\$ 5$ billion and $\$ 7.5$ billion figures are for these particular six technologies, corresponding to substantially larger ERD\&D investments for a complete portfolio of energy technologies). In our modeling, we sought to optimize the three policy scenarios using different outcome metrics: $\mathrm{CO}_{2}$ emissions, $\mathrm{CO}_{2}$ allowance prices, CES credit prices, and consumer and producer surplus. Figure ES- 6 reveals that investments in some technologies are much more important in some policy scenarios than in others. Given the large uncertainties in both future policies and future progress in each technology, investment in a broad

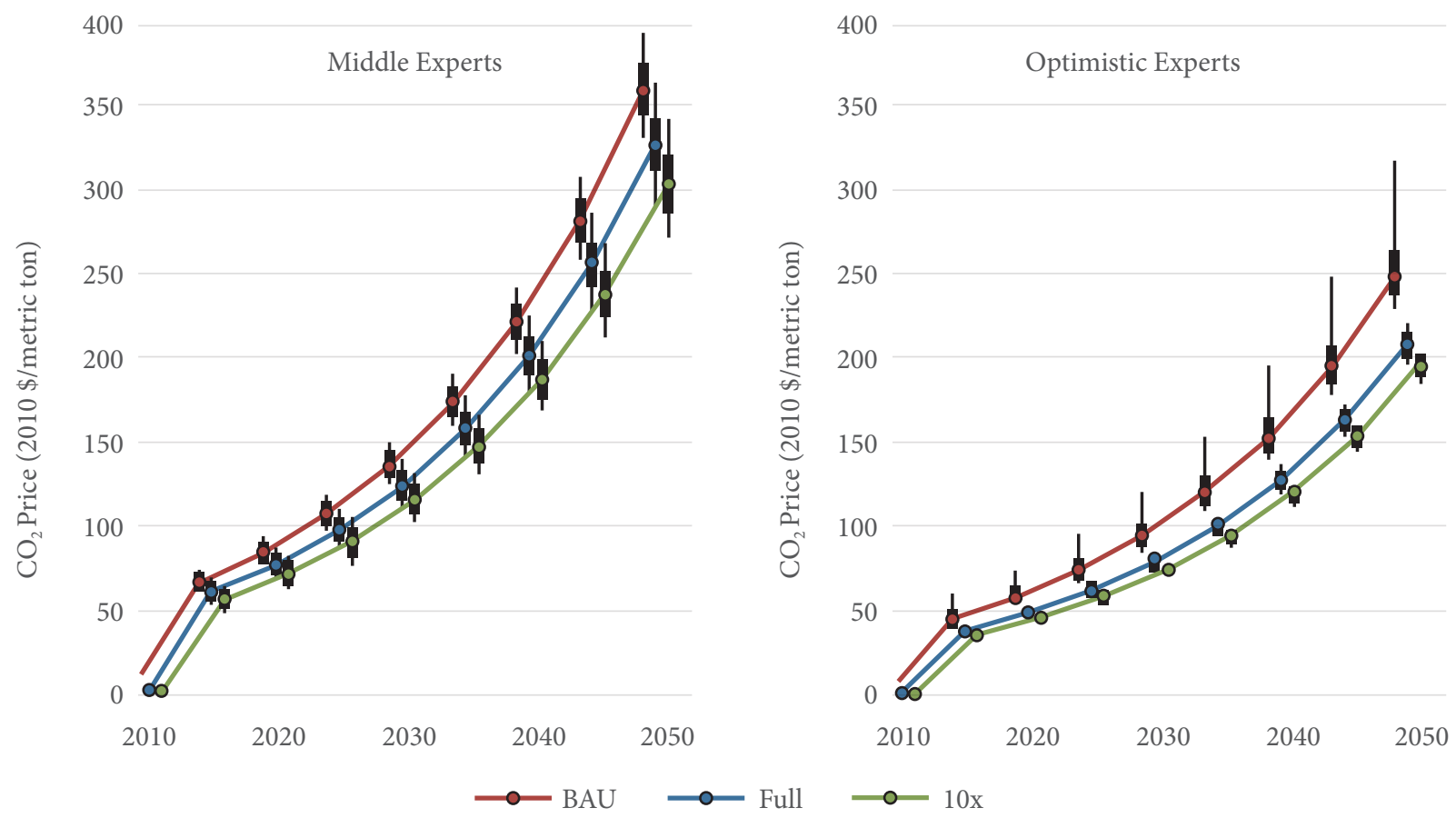

FIGURE ES-5. Trajectory of $\mathrm{CO}_{2}$ prices (\$/metric ton of $\mathrm{CO}_{2}$ ) under a $\mathrm{CO}_{2}$ cap limiting emissions to $83 \%$ of 2005 levels in 2050, with no international offsets (note that this is a very stringent policy). Three RD\&D funding scenarios are shown-business-as-usual level (red), full recommended level (blue), and ten times the recommended level (green). The "middle-of-the-road" (left) and "optimistic" (right) technology assumptions are compared. The dot corresponds to the 50th percentile, the black rectangle encompasses the 25 th and 75 th percentiles, and the line encompasses the 5 th and 95 th percentiles. 


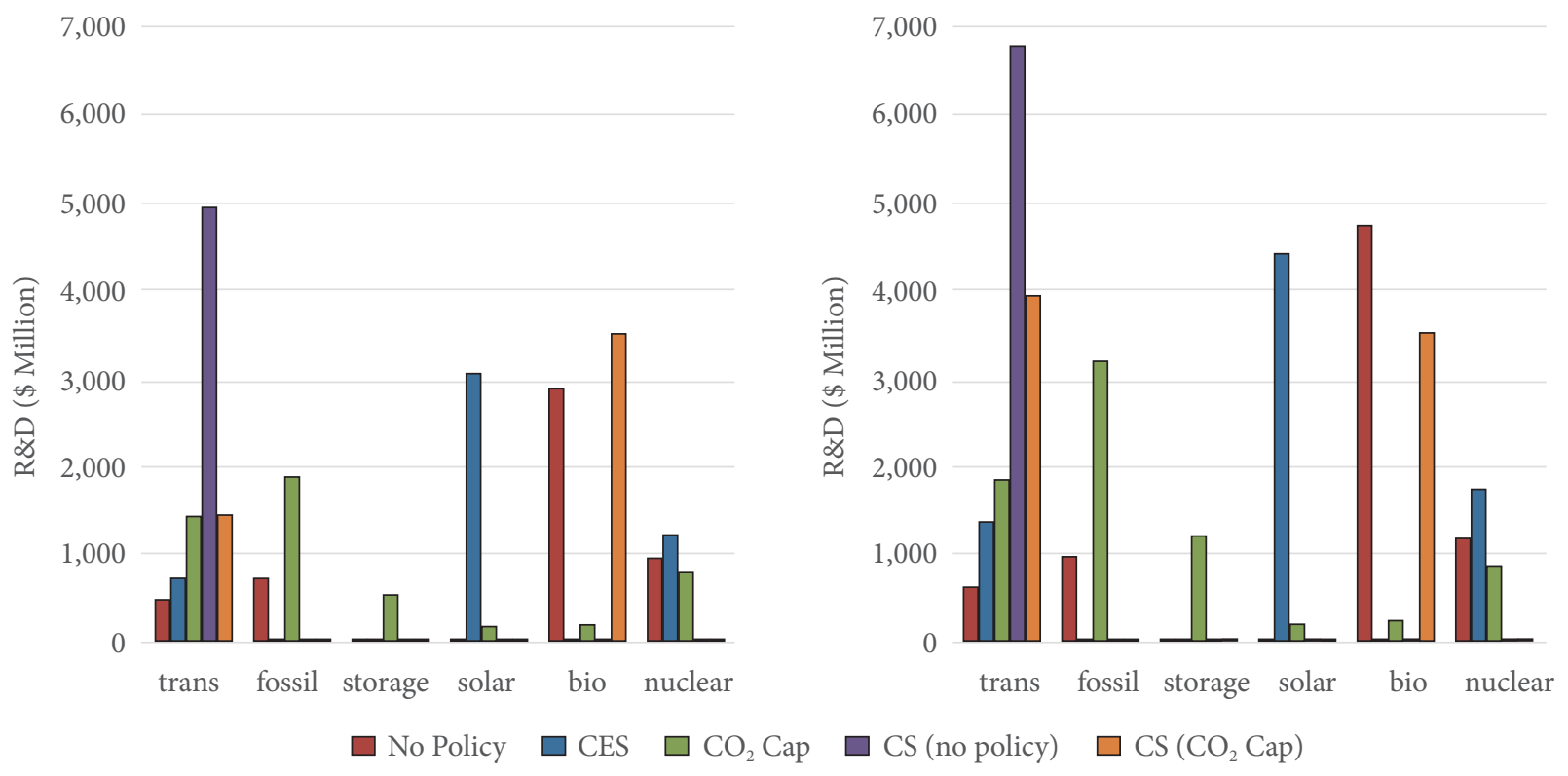

FIGURE ES-6. Optimized budget allocation under different scenarios: no policy optimized for total $\mathrm{CO}_{2}$ emissions), standards policy (CES) optimized for CES credit price, $\mathrm{CO}_{2}$ cap and trade $\left(\mathrm{CO}_{2}\right.$ cap $)$ optimized for $\mathrm{CO}_{2}$ price, no policy optimized for consumer and producer surplus (CS (no policy)), and $\mathrm{CO}_{2}$ cap and trade optimized for consumer and producer surplus ( $\mathrm{CS}\left(\mathrm{CO}_{2} \mathrm{cap}\right)$ ). The left figure optimizes in these scenarios under a $\$ 5$ billion budget and the right figure optimizes the same scenarios under a $\$ 7.5$ billion budget.

portfolio of ERD\&D would provide more confidence in producing substantial results than attempting to pick a few winning technologies.

\section{RECOMMENDATIONS}

Recommendation: We recommend that the U.S. federal government increase its annual investment in ERD\&D to $\$ 10.0$ billion, a 92\% increase over the FY 2009 appropriations. This increase should proceed at the maximum rate consistent with efficient expenditure of the funds.

The combination of the technology expert's recommendations and our energy-economic modeling (which incorporates the experts' estimates of the uncertainty around the technical outcomes of those investments), suggests that $\$ 5.2$ billion (2.5 times FY2009 appropriations) in ERD\&D funding is necessary for the seven technology areas covered in this report. Recommended increases in funding for Basic Energy Sciences, ARPA-E, and the other technology areas not covered by our expert elicitations (based on a review of other analyses of these programs) total approximately $\$ 4.8$ billion, a $40 \%$ increase from FY 2009 levels, excluding “environmental and biological R\&D." We based our recommended allocation (see Table ES-2) on an analysis of technology deployment under different RD\&D budget levels and on an optimization of RD\&D allocation under different policy scenarios. 
While the United States faces a period of severe budget stringency, such long-term investments in the U.S. energy future must not be sacrificed. There are a variety of options for raising additional funds for ERD\&D outside the usual appropriations process, some of which have been used with success in the past, as described in a recent report of the President's Council of Advisors on Science and Technology, and these should be explored.

Recommendation: This increased investment should be targeted at a broad portfolio of different technologies and at different stages of technology development, from basic research to large-scale technology demonstrations, implemented by a portfolio of different institutions appropriate for the different stages of innovation.

Tables ES-2 and ES-3 shows our recommended federal ERD\&D investment portfolio compared to the FY 2009 budget. The recommendations in Table ES-2 are based on our expert surveys and modeling, combining the experts' recommendations with analyses of which investments offer the greatest returns in terms of reducing $\mathrm{CO}_{2}$ emissions and oil imports in cases with no new carbon policies or sectoral policies, or the greatest contributions to reducing $\mathrm{CO}_{2}$ emissions allowance prices in scenarios with a $\mathrm{CO}_{2}$ cap-and-trade policy. The recommendation to increase funding for DOE's Basic Energy Sciences (BES) program in Table ES-3 from \$1.5 billion in 2009 to $\$ 2.4$ billion going forward

\begin{tabular}{|c|c|c|c|c|c|c|c|c|c|c|}
\hline $\begin{array}{l}\text { DOE } \\
\text { program }\end{array}$ & $\begin{array}{c}\text { FY } \\
2009 \\
\text { appr. }\end{array}$ & $\begin{array}{l}\text { Mean of } \\
\text { experts } \\
\text { (std. dev.) }\end{array}$ & $\begin{array}{l}\text { Median of } \\
\text { experts }\end{array}$ & $\begin{array}{c}\text { Min } \\
\text { of experts }\end{array}$ & $\begin{array}{c}\text { Max } \\
\text { of experts }\end{array}$ & $\begin{array}{c}\text { Middle } \\
\text { expert }\end{array}$ & $\begin{array}{l}\text { Optim. } \\
\text { expert }\end{array}$ & $\begin{array}{c}\text { Pessim. } \\
\text { expert }\end{array}$ & $\begin{array}{l}\text { ERD3 } \\
\text { recs. }\end{array}$ & $\begin{array}{c}\text { Percent } \\
\text { change over } \\
\text { FY } 2009 \text { appr. }\end{array}$ \\
\hline $\begin{array}{l}\text { Bio- } \\
\text { energy }\end{array}$ & 214 & $680(286)$ & 640 & 300 & 1,000 & 300 & 600 & 680 & 680 & $218 \%$ \\
\hline $\begin{array}{l}\text { Energy } \\
\text { storage }\end{array}$ & $23^{a}$ & $240(391)$ & 120 & 50 & 2,000 & 103 & 128 & 103 & 240 & $943 \%$ \\
\hline Nuclear & 466 & $\begin{array}{c}1800 \\
(1,397)\end{array}$ & 1,200 & 800 & 8,000 & 1,200 & 8,000 & 1,200 & 1,200 & $158 \%$ \\
\hline $\begin{array}{l}\text { Fossil and } \\
\text { CCS }\end{array}$ & 701 & $\begin{array}{c}2300 \\
(1,980)\end{array}$ & 2,000 & 600 & 7,500 & 1,550 & 1,550 & 7,500 & 1,000 & $43 \%$ \\
\hline Buildings & 144 & $680(315)$ & 700 & 200 & 1,000 & 900 & 1,000 & 500 & 680 & $372 \%$ \\
\hline $\begin{array}{l}\text { Vehicles } \\
\text { (inc. fuel } \\
\text { cells) }\end{array}$ & 432 & $\begin{array}{c}2050 \\
(3,050)\end{array}$ & 1,000 & 400 & 10,000 & 650 & 1,000 & 650 & 1,000 & $131 \%$ \\
\hline Solar PV & 143 & $\begin{array}{c}337 \\
(226)\end{array}$ & 300 & 200 & 1,000 & 200 & 500 & 300 & 400 & $180 \%$ \\
\hline Total & 2,123 & 8,159 & 5,960 & 2,350 & 29,500 & 4,903 & 12,778 & 10,933 & 5,200 & $145 \%$ \\
\hline
\end{tabular}

TABLE ES-2. Summary information for areas covered by elicitations. From left to right: FY 2009 appropriations from DOE; statistics of the RD\&D recommendations of experts in each technology area (mean and standard deviation, median value, maximum value, and minimum value); recommended values of the experts chosen as "middle of the road", "optimistic," and "pessimistic;" recommendations from this report; and percentage change in recommendations over FY 2009 appropriations. All numbers are in millions U.S.2010\$. 
is driven by the large known benefits of basic research both in terms of spillovers to various technology areas and in terms of training a scientifically capable workforce that can then work in the private sector. Given the large benefits of basic research, in two to five years it would become important to reconsider an additional increase for the BES program.

Table ES-2 shows that while the largest absolute recommended investments would go to nuclear, vehicles, and fossil and CCS (these technologies are capital intensive and some of them are closer to commercialization), the largest increases in terms of percentage change would go to energy storage, buildings, bioenergy, and solar PV. Funding for fossil and CCS should probably be increased further if policymakers do not expect nuclear energy expansion. If the U.S. shale gas industry develops as quickly as some predict, and if gas prices remain low for the next 5-10 years, the U.S. government would need to consider reassessing its investment portfolio, since low-carbon technologies in the electricity sector would have to compete against gas-a cheap and flexible incumbent under this scenario.

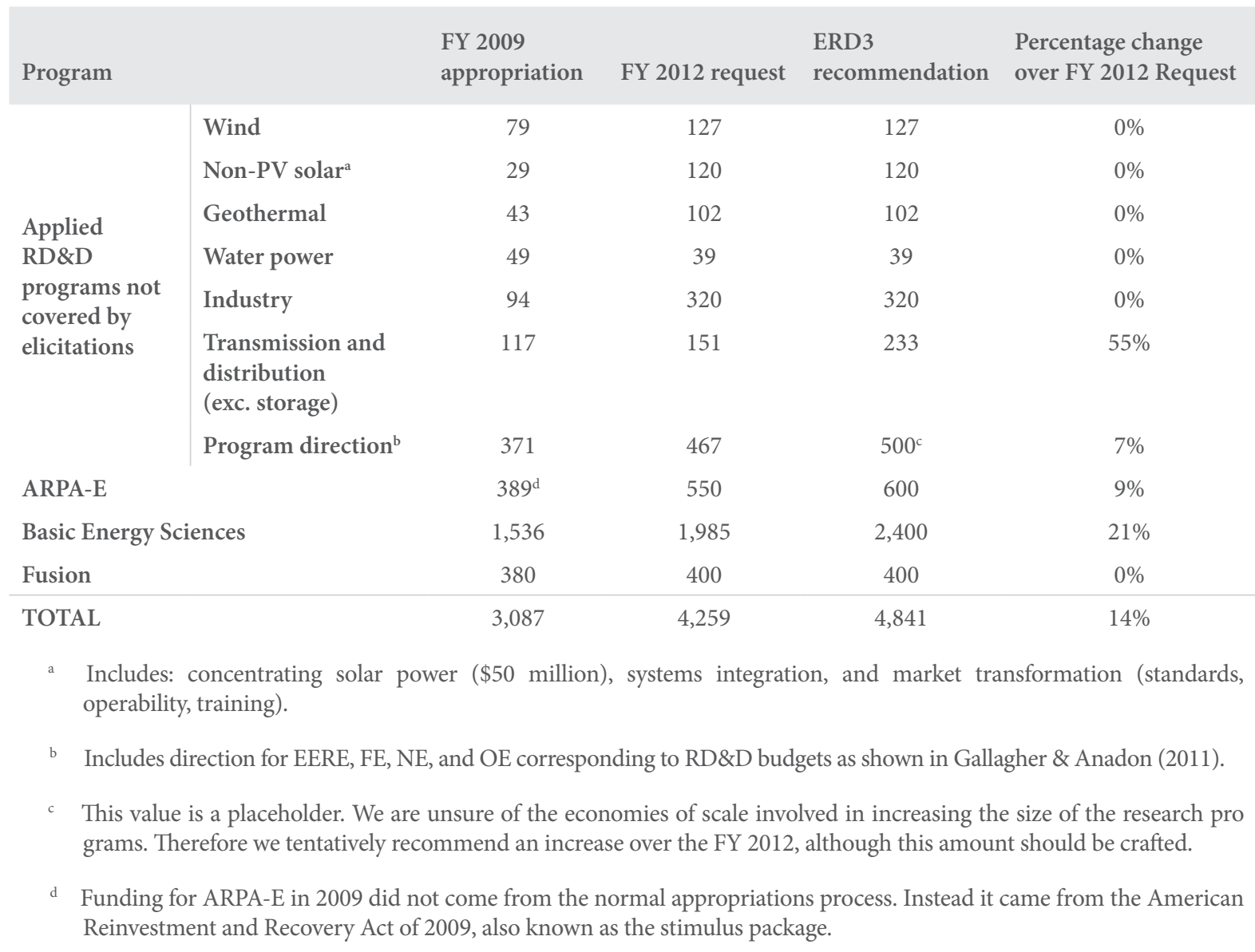

TABLE ES-3. Summary of FY 2009 appropriations, FY 2012 request, ERD3 recommendation, and percentage change of recommendation over the FY 2012 request for applied RD\&D programs not covered by the elicitations, ARPA-E, Basic Energy Sciences, and Fusion. 
We also recommend investing in a portfolio of different technological approaches and stages of innovation within each technology area. Figure ES-2, as an example, showed the experts' recommendations across technological approaches and innovation stages for solar PV. (Similar figures for other technologies are provided in the Chapter 2 Appendix.)

Recommendation: As soon as possible, the U.S. government should put in place policies that have the effect of creating a substantial price on carbon emissions (either through a cap-and-trade system or through a tax on greenhouse gas emissions) to increase incentives for the private sector to invest in clean energy innovation and to encourage large-scale deployment of clean energy technologies. In addition, the U.S. government as well as state and local governments, should adopt a range of sector-specific policies to overcome market failures that are limiting the deployment of energy efficiency and clean-energy technologies as part of a coordinated energy strategy.

As previously indicated, large increases in ERD\&D alone are very unlikely to result in the emissions reductions needed to meet climate mitigation goals. Increased ERD\&D investments must be complemented by policies that reflect the $\mathrm{CO}_{2}$ emissions reduction benefits of low-carbon technologies and enable them to compete in the marketplace earlier. Although economy-wide policies such as a cap or a tax on $\mathrm{CO}_{2}$ emissions would be the most cost-effective approach, this report also considers a clean energy standard such as that proposed by President Obama, as well as vehicle fuel efficiency and commercial buildings standards that go beyond those in place today.

In addition, other market failures will require other policies to address them. In the buildings sector, for example, it is often the case that the business or unit that would get the benefit of lower energy bills is not the same as the one paying the cost of more expensive, energy-efficient designs - one reason why even efficiency measures that would pay for themselves do not get built. Similarly, consumers purchasing energy-efficient products often have insufficient information or expect very short payback times, limiting the adoption of more energy-efficient appliances and vehicles. Labeling, performance standards, and other sector-specific policies will be needed to overcome these barriers.

Recommendation: The U.S. government should match its ERD\&D programs and deployment programs to maximize the effectiveness of these policies in leading to large-scale deployment of improved energy technologies.

Currently, the U.S. government is making large investments in deployment policies ranging from tax subsidies to loan guarantees, often with little coordination with energy research and development programs, and using efficiency or other standards (e.g., vehicle economy standards). To maximize the contribution of federal investments and standards to accelerating energy innovation, these efforts should 
be closely coordinated, with targeted and appropriate support for each phase of innovation from basic research to initial deployment. Federal support should be phased out as technologies become commercially viable, rather than continuing indefinitely. To enable the phase down of government support for programs or specific projects, the U.S. government should have clear goals and mechanisms to collect and evaluate information about the progress and contribution of projects and technologies from the start. Support programs can also be designed to decrease gradually over time and to include covenants that allow for program changes based on new information.

\section{InCreasing Incentives for Private Sector Innovation}

\section{FINDINGS}

Finding: Private sector investments and approaches are critical to energy innovation in the United States.

Though the Department of Energy is the largest single investor in energy technology innovation, the private sector collectively funds and carries out the majority of ERD\&D in the United States. New energy technologies can only make significant contributions to the major energy challenges if they are adopted on a broad scale by the private sector. From the information available on private-sector investments in ERD\&D (which is limited to utilities and oil companies) it would seem that these investments are low compared to energy expenditures and to R\&D in other industries. Government policies that shape private sector incentives for energy innovation investments are particularly important in determining the pace at which new energy technologies will be developed and deployed. The long-term stability and predictability that private sector actors need to make investments is currently lacking.

Finding: Previously available data on private sector energy innovation are insufficient as a basis for policy decisions.

Data on private sector energy innovation are limited, incomplete, and superficial. The surveys of energy innovation performed for the National Science Foundation include only a little over 100 of the largest firms, which collectively invest a total of about $\$ 3$ billion per year in ERD\&D. These surveys do not provide the information needed to understand ERD\&D investment beyond these largest firms, or to identify funding gaps by industry sector. Estimates based on venture capital spending for new energy startup companies do not distinguish between research and development and other spending by new ventures. No data source offers detailed information on the key drivers of private sector energy innovation decisions or on the role government policies play in shaping them.

Finding: Private sector energy innovation activities are more widespread than previously understood. 
The pilot-scale survey performed for this report provides a lower-bound estimate that at least $2.4 \%$ ( \pm $1.3 \%$ ) of the ten million non-farm business establishments in the United States (about 240,000 business establishments) are involved in energy technology innovation. (The true figure is very likely higher than this lower bound, which assumes that the rate of energy innovation among non-respondent firms is zero.) These establishments cover the spectrum from small start-ups to massive multinational corporations. A larger survey would be very useful to provide estimates of total private sector ERD\&D investment by industry sector, and to help identify trends by industry, but total private ERD\&D investment is certain to be larger than previously known, although still low compared to the technology opportunities and society's need for improved energy technologies.

Finding: Costs are more important than other factors in promoting private sector decisions to invest in energy innovation. Lack of market demand and specific innovation process issues are also important barriers.

Firms react to price signals by innovating and shifting their investments. The survey of energy innovation in U.S. businesses revealed that cost-related issues, most importantly energy prices, are the most important drivers of energy innovation. Market opportunities and market-creation policies also drive innovation. Private-sector respondents often cited the absence of market opportunities as a barrier to innovation in new energy technologies. Along with poorly-functioning markets, the difficulties and uncertainties inherent in the innovation process are the most commonly mentioned barriers to investing in innovation.

Finding: Private firms are overwhelmingly focused on short-term returns in making their energy innovation investments.

Many of the energy innovators participating in the survey do not formally measure the economic impacts of their energy innovation investments. Of those that do, two-thirds expected to recoup investments in only two to three years. For a large fraction of the establishments engaged in energy innovation, there appears to be little room for long-term investment-reinforcing the rationale for the U.S. government to make long-term investments toward improved energy technologies for the long haul. As mentioned earlier, the U.S. energy system is owned by private firms, that have profit-making (and not the provision of public good) as their main objective. Thus, firms will not invest in developing or deploying new energy technologies contributing to security, competitiveness, and environmental goals unless government policies structure market incentives so that they see prospects for creating a business around these technologies.

Finding: Government, academia, and the national labs play a major role in shaping private sector energy innovation decisions. 
Participants in the survey cited government, academia, and the national labs as important sources of funding, information, and innovation. On average, they report that $25 \%$ of the funding for the ERD\&D work they do comes from the government, and government grants and contracts are the next most important drivers of innovation after costs. Some $60 \%$ of firms use government or university information to make their own investment decisions. As sources of innovation, $65 \%$ of respondents cite universities or national labs as being next in importance after their own industry. Cooperation with government and cooperation with universities are reported as the two most beneficial trends in energy innovation. Therefore, private and public-sector decisions regarding energy technology are fundamentally connected.

Finding: Various forms of partnership with the private sector account for a major portion of DOE ERD\&D funding and attract substantial private sector investment.

The two main mechanisms DOE uses to fund or collaborate with non-federal partners are grants and cooperative agreements, which together make up over 99\% of DOE's energy innovation expenditure with the private sector. As a whole, funding to private firms and universities is a large fraction of the DOE budget for ERD\&D, at about $30 \%$ of the funding in the applied DOE offices and $55 \%$ of the funding in the Office of Science, making it important to treat it strategically. Most of the funding from the Office of Science goes to universities, but a greater fraction of the applied DOE office funding goes to private firms.

From 2000 through 2009, the DOE awarded $\$ 9.1$ billion to support science, and $\$ 7.2$ billion to support applied ERD\&D. ERD\&D projects attracted $\$ 9.5$ billion in outside matching funds, more than matching the federal investment, which represents a measure of the value placed on these projects by the private sector (Fig. ES-7). There is little information available regarding the outcomes of these projects.

Finding: The DOE does not collect sufficient data on the approaches its programs take to working with the private sector, and their successes and failures, to serve as the basis for policy-making and learning. The DOE appears to have no focused strategy shaping its energy innovation partnerships with the private sector.

The DOE's own program managers cannot readily determine from the available data systems how many projects have been funded with which private sector firms, for what amounts of money-much less the technologies, development stages, processes, and outcomes associated with them. Record-keeping and reporting requirements are more burdensome than in the private sector, but still do not produce the data and analysis that would be most useful to managers for planning future projects. DOE strategic plans, budget documents, and multi-year program plans all state the importance of the public-private partnership, but none provide guidance on selecting or managing partnerships in practice. 


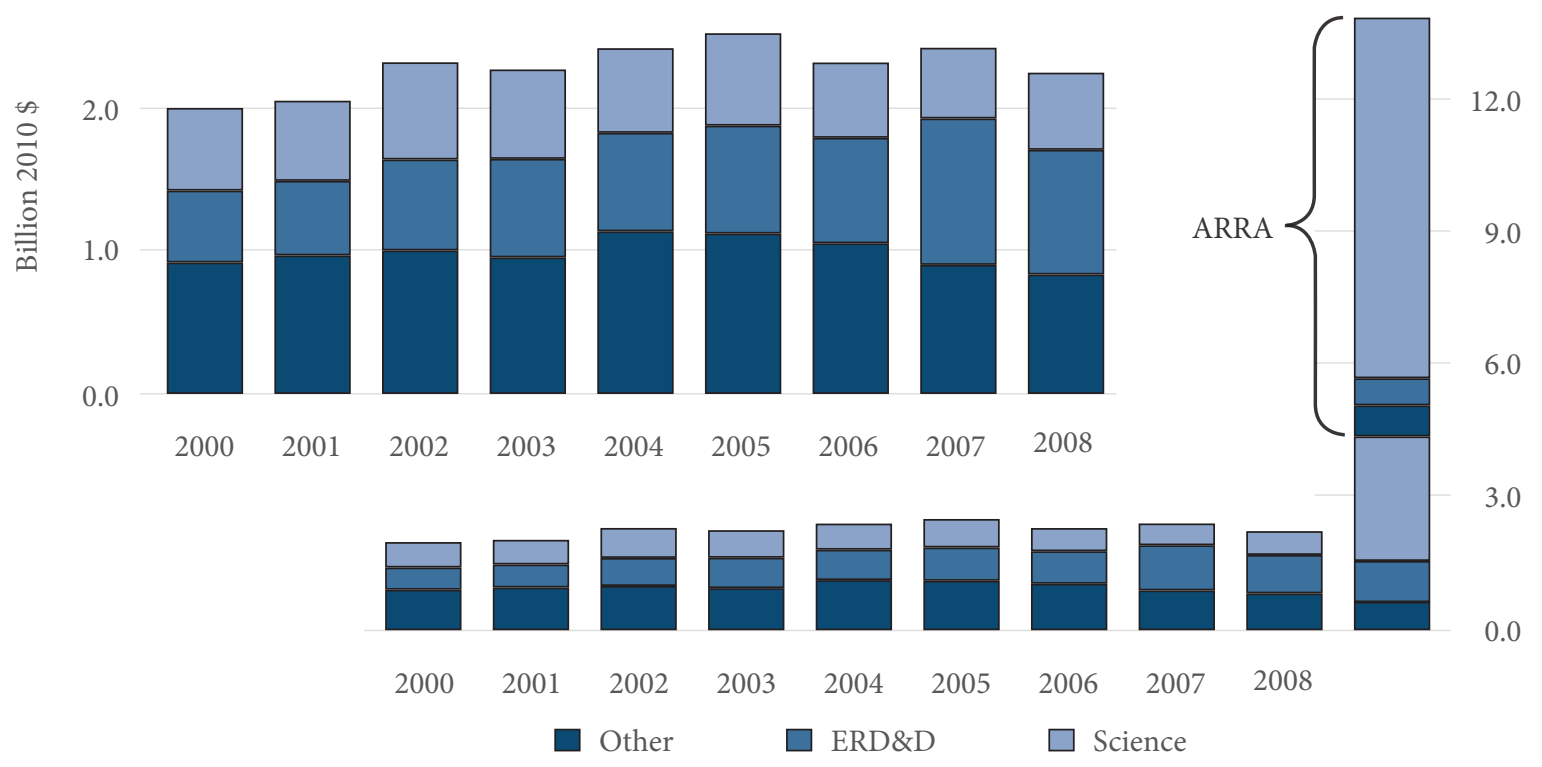

FIGURE ES-7. Funding for assistance, mostly in the form of cooperative agreements and grants, to private firms, academic institutions, and other institutions, by DOE in major categories (ERD\&D, Science, and "other").

\section{RECOMMENDATIONS}

Recommendation: The U.S. federal government should implement policies that create market incentives to develop and deploy new energy technologies, including policies that have the effect of creating a substantial price on carbon emissions, and sector-specific policies to overcome other market failures. These policies should be aggressive enough to create substantial incentives for private-sector innovation.

Substantial and lasting prices on carbon emissions are needed to increase private incentives to invest in inventing, developing, and deploying new approaches to avoiding emissions. Additional sector-specific policies will be needed to overcome particular market failures and maximize the net benefit to society from new energy technologies.

Recommendation: The U.S. government should provide additional incentives for privatesector investments in energy innovation.

Given the many market failures impeding private sector investment in energy innovation, additional incentives are justified if they could cost-effectively leverage additional private sector spending. Our survey indicated that government cost-sharing and deployment-related incentives (such as production tax credits) are generally more important in private sector innovation investment decisions than $\mathrm{R} \& \mathrm{D}$ tax credits, but further research is needed to design the optimal package of incentives for private sector energy innovation. 
Recommendation: The U.S. government should establish an Energy Innovation Advisory Board (EIAB) with representation from the private sector, academia, the national laboratories, and other key stakeholders, to advise on how best to accelerate private sector energy technology innovation.

This advisory board would supplement the existing Secretary of Energy Advisory Board by providing a specific focus on policies to accelerate the pace of improvement in energy technologies in collaboration with the private sector. It would also complement and inform the Quadrennial Technology Review, which is currently being undertaken. It should include private sector innovators from both large and small firms. The board's mission should include consideration not only of DOE investments in energy technologies but also of the broader set of U.S. government policies that affect the pace of energy technology innovation.

Recommendation: The Department of Energy should develop and implement an integrated strategy for its partnerships with the private sector, which should include the data collection and analysis needed for the effort to learn over time.

To enable managers to incorporate strategic priorities into project decisions, the DOE should articulate how each of its functions contributes to its missions and goals, and set forth principles for when and how to use different mechanisms of support. The ongoing Quadrennial Technology Review is potentially a good start, but more focus in needed on how to use different types of cooperation mechanisms (e.g., cooperative agreements, CRADAs, work-for-others, etc.). The portfolio of support mechanisms that are used should in turn be accounted for during budget development and other strategic planning. To support continuous improvement of its programs, the DOE must improve its data collection and analysis system to include information on practices, problems, solutions, and outcomes for partnerships with the private sector.

Recommendation: The U.S. government should establish a mechanism for working with the private sector to financially support and implement large-scale energy technology demonstrations, where such demonstrations are essential to enable private sector adoption of clean energy technologies that have the potential to significantly contribute to reducing $\mathrm{CO}_{2}$ emissions and oil imports.

Commercial scale demonstrations of unproven technologies are currently the rate-limiting step in the commercialization of some important energy technologies, and they provide critical information to all stakeholders (government, financial community, and industry) by testing not only technologies but also new business models. The Department of Energy, as currently constituted, does not appear to be well-suited for carrying out commercial-scale technology demonstrations in close partnership with the 
private sector. The creation of some new office or institution may be necessary to achieve this goal. One option is the proposed Clean Energy Development Administration (CEDA), which has already received some bipartisan support. The DOE Quadrennial Technology Review, which was underway at the time of the writing this report, may be able to help outline the necessary institutional arrangements, the level of funding required, and some of the most promising technology areas that could be supported.

\section{MANAging ENERgY InNOVATION INSTITUTions}

\section{FINDingS}

Finding: The United States government is supporting a range of energy innovation from basic research to deployment, and has recently established a number of new energy innovation institutions focused on particular technology states, although some gaps remain.

In the past, the U.S. government has not only provided too little funding for energy innovation, but it has left major gaps in the innovation chain, reducing the effectiveness of its investments. The creation of several new institutions at the DOE-namely, the loan guarantee program, the Advanced Research Projects Agency - Energy division (ARPA-E), the Energy Frontier Research Centers (EFRCs), and the Energy Innovation Hubs-since 2005 were intended to fill some of these gaps in the innovation system. Figure ES- 8 includes a visualization of the older institutions (depicted in blue) and the newer institutions (depicted in red).

Finding: There has been insufficient systematic study of the effectiveness of U.S. energy innovation institutions, and how their effectiveness might be improved.

Many funders, other decision makers, and scholars have assumed that there is a strong relationship between research funding and societal benefit. This is certainly the case when innovation institutions are managed effectively and focused on meeting major societal needs. But in-depth, independent assessments are needed to identify areas that are being managed effectively and those that are not, and what new steps are needed to improve these institutions' effectiveness so that the U.S. government gets the maximum return on its investments into these institutions. Of course, funders and other parties already undertake some assessments of energy innovation institutions. For example, several groups regularly evaluate the National Renewable Energy Laboratory (NREL), the subject of a case study in this report, including technical advisory boards and decision-makers at the DOE. These reviews certainly help, bringing outside knowledge and perspective to the organization reviewed. However, one limitation of them seems to be that the participants conducting the reviews rarely have the time, resources, or incentives needed for in-depth, comprehensive evaluation-including challenging existing U.S. government approaches where necessary. 
Finding: ARPA-E has won strong reviews for its focus on high-risk, high-payoff energy technology concepts, and it fills an important gap in U.S. energy innovation.

ARPA-E was authorized in 2007 and funded with the 2009 Recovery Act. As designed, ARPA-E is a nimble organization, free of some of the hiring and contracting hurdles encountered at the DOE, and possesses experienced and knowledgeable employees. In addition to the projects it has chosen to fund, it has launched several new initiatives, such as the ARPA-E Summit, in which winners and finalists of ARPA-E awards are showcased to attract further funding. In funding both early-stage innovation and facilitating pathways for its awardees to reach commercialization, it is attempting to take a more holistic view of innovation. Finally, ARPA-E has worked to communicate its mission and progress to Congress, and has collected metrics, such as follow-on data on the VC funding its projects attract, that help to build its legitimacy.

Finding: The U.S. national laboratories play a critical role in energy technology innovation and are likely to continue to do so in the future.

The U.S. national laboratories contain an enormous amount of talent and knowledge, and are an asset to the United States. Some examples of ways in which the national labs contribute to energy technology innovation include: (a) the support from national labs personnel during the oil spill in 2010; (b) the fact that international researchers generally value the U.S. national labs and attempt to collaborate with them; (c) reports and expertise from the national labs are often used by private companies; and (d) test facilities at the labs are generally considered to be useful in reducing costs for private firms.

However, as may be indicated by the range of institutions created outside the labs, there are areas in which the labs are lacking, such as funding for some research areas, undertaking high-risk, long-term, application-inspired research, bridging the basic and applied research divide, and managing large-scale demonstration projects. In spite of these flaws, the national labs have made contributions to developing and commercializing energy technologies (e.g., they played a key role in the development of the thin film technology underlying First Solar, the largest U.S. photovoltaic company). And over time, it is likely that some of the investments made in the labs throughout the years will result in more benefits, particularly if some of their barriers to working efficiently are removed.

Finding: Programs funded by the DOE and, in turn, the national laboratories are faced with volatile funding that often impedes research programs' ability to move forward effectively.

DOE programs (e.g., solar, wind, industrial technologies, vehicle technologies, nuclear, hydrogen, etc.) have experienced very volatile funding over the past few decades. This translates to an uncertain funding environment for national labs, private firms, and other research performers. In particular, NREL has faced severe budget cuts or shortfalls over the years (in 1981, 1996, and 2006, for example), which 


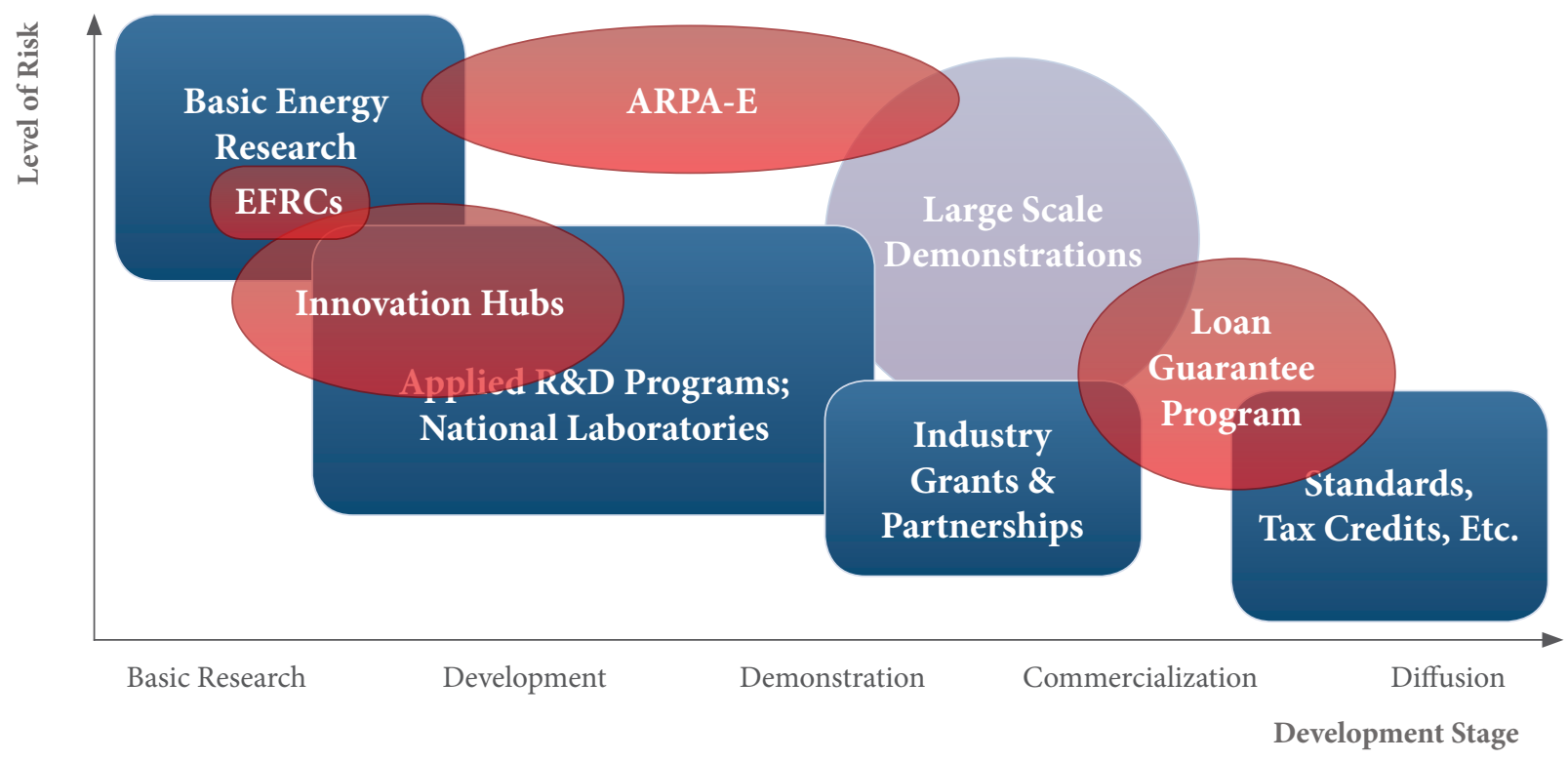

FIGURE ES-8. Schematic of the current U.S. government institutions and policies whose primary mandate is to accelerate energy innovation. Blue boxes denote programs that existed before 2005. The other institutions (with the exception of the "large scale demonstrations", which is an area we have identified as a gap) are more recent: the EFRCs, the Hubs, and ARPA-E were funded in 2009, and the loan guarantee program was instituted in 2005, although the first loan guarantee was issued in 2009. (Adapted from various presentations from the U.S. Department of Energy.)

led to several rounds of layoffs, significant impact on morale, and a reduced ability to attract the best researchers. While research programs should be closely evaluated and phased out if they are not working, or if they have not achieved enough success that the private sector can carry the technology forward without further federal help, the overall effectiveness of the national labs will be improved with more stable funding.

Finding: To be effective, energy innovation institutions require a clearly defined mission; strong leadership with proven technical and managerial excellence; an entrepreneurial culture that accepts risk and encourages both competition and collaboration; sufficient flexibility for the leadership to build the right culture and seize opportunities as they arise (including a significant fraction of lab-directed funds); reasonably stable and predictable funding; balance and linkages between basic and applied research; and strong connections to the private sector.

For too long, U.S. policymakers have focused too little attention on these essential steps to maximize the performance of U.S. energy innovation institutions, including the national laboratories.

An analysis of NREL in particular, the primary national lab for renewable energy and energy efficiency, shows that the above principles are not currently as prominent as they should be. NREL's mission implementation has been volatile over time and its structure does not sufficiently integrate basic and applied research efforts. In addition, the lab director does not have enough flexible funding to take advantage of important opportunities as they arise, and the lab employees have to deal with constantly shifting 
budgets imposed from outside the lab. Finally, NREL employees' technical knowledge and experience with the private sector activities are not sufficiently utilized at the DOE.

We complemented our case study of NREL with a case study of the Semiconductor Research Corporation (SRC) in order to explore alternative models of coupling research between the government and private sector. The study of the SRC indicates that a stronger connection with industry contributes to technology relevance and private sector uptake. The SRC's efforts to build the future workforce of the semiconductors industry also provide a useful model for the DOE and other innovation institutions.

\section{RECOMMENDATIONS}

Recommendation: The U.S. government should restructure its management of the national laboratories to maximize their innovation potential, based on the principles just described.

The original design of the national labs had a clear mission, stellar leadership, an entrepreneurial culture, block funding, and a structure that allowed researchers to be accountable and independent, yet connected. Over time, the mission of the multiprogram national labs has become more diffuse. Arguably, for-profit management of some labs has increased the emphasis on corporate priorities, sometimes at the expense of national priorities. In the case of NREL, even though its mission has remained stable, the lab has not had the ability to make decisions about how to best serve the mission and has had a volatile budget. Moreover, it has been subject to control from decision-makers in Congress and the Executive branch, with sometimes conflicting priorities. In some periods, decision makers have pushed the laboratory's focus toward basic research, while at other times, they have expected NREL to work mainly on technology deployment and commercialization.

Of course, the DOE must also take steps to ensure that its other innovation institutions and processes, such as ARPA-E, its partnerships with industry, the Joint BioEnergy Institute (a partnership of national labs, universities, and NGOs with a mission to advance the development of the next generation of biofuels), and the Energy Innovation Hubs, are all operating as effectively as possible. But the role of the national labs is particularly important, both in energy technology and in other areas. Indeed, the national labs are the repository of most of the technical expertise available to the DOE. The bottom line is that, in addition to creating new important institutions, the DOE should also try to better utilize the national laboratories. Although this task will require a large effort, it could yield large returns.

Recommendation: The administration and Congress should provide support for a portfolio of energy innovation institutions designed to ensure that all stages of the innovation chain have appropriate support, avoiding technology gaps and finding "valleys of death." In particular, the administration and Congress should provide sustained support for ARPA-E to pursue the high-risk technologies that could lead to major energy breakthroughs. 
To meet the energy challenges the United States faces, from climate change to oil dependence and beyond, it will be necessary to use a wide range of technologies, including some that are close to being commercialized and some that may not be commercialized for decades to come. Major gaps at any point in the innovation chain can disrupt the process of developing and deploying a new technology, reducing investment throughout the innovation chain. Hence, the U.S. government must provide appropriate support for a broad range of technologies and stages of innovation.

ARPA-E has a clear mission and has shown technical and managerial excellence. It also has a unique organizational model that allows it to act quickly, identifying areas of opportunity, hiring staff, and making decisions about how to allocate funding. In its task to fund potentially transformative energy technologies and to pave the way for their commercialization, it has been effective and innovative in forming partnerships with the private sector and other government departments. The number of meritorious, innovative proposals ARPA-E has received is far larger than it has been able to support with the budgets it has had available thus far. The U.S. government should substantially increase funding for ARPA-E, and maintain stable support for at least 10 years to give it a fair chance to succeed in some areas of study. This is because innovation takes time, and not all of the high-risk technologies ARPA-E is pursuing will succeed. The value of the successful technologies developed with ARPA-E funds, combined with the value of lessons learned from the projects that do not reach commercialization, is likely to far outweigh the cost of supporting ARPA-E.

The Energy Innovation Hubs are an important initiative to create a critical mass of researchers working on problems requiring an integration of fundamental science breakthroughs and inventive engineering. Because of their likely contributions to technological progress and to developing the science and technology workforce of the future, the U.S. government should also expand funding for the Energy Innovation Hubs, and provide stable support for an extended period of time.

The Energy Frontier Research Centers (EFRCs) comprise another relatively new and focused initiative that could make a large contribution to meeting the world's energy challenges and should also be expanded and provided with stable funding. The EFRCs are located within universities, national laboratories, nonprofit organizations, and for-profit firms, singly or in partnerships, and are selected by scientific peer review and funded for a 5-year initial award period. EFRCs add to the portfolio of mechanisms supporting energy RD\&D by conducting fundamental research with stable funding for 5 years, encouraging multiple investigators to work together, and focusing on one or more of the "grand challenges" and "basic research needs" identified in a major strategic planning effort by the scientific community.

Recommendation: The U.S. government should strengthen the connections between its energy innovation institutions and the private sector throughout the innovation chain, but particularly as technologies move toward the development, demonstration, and deployment phases. 
The case study of the SRC highlighted the value of involving private sector members in developing technology roadmaps and in the high-level direction of the institution. As technologies get closer to commercialization, private sector input is even more crucial. Advisory boards, workshops, and incorporating members of the user community into the research process are ways to increase private sector participation in decisions. Additionally, finding ways to build relationships beyond the structured mechanisms can facilitate informal, mutually beneficial partnerships. User facilities, either for research and development or for demonstrations, have proven their value at several institutions, allowing laboratory and private-sector employees to work together and understand each other's priorities and approaches. Cost-sharing and more complex financial mechanisms involving an even closer publicprivate partnership (e.g., equity stakes or reverse auctions) could play important roles in technology demonstrations and early deployment.

\section{Strengthening ENERgy InNovation CoOperation with Other Countries}

\section{FINDINGS}

Finding: Energy technology innovation is a global undertaking with a larger number of countries engaging in scientific, private, and public energy innovation activities than ever before. This creates both new competitive threats and new opportunities for cooperation.

In many technological areas, including some nuclear reactor, solar, battery, and advanced coal technologies, the United States' share of the scientific and technological output of new energy technologies is slowly decreasing and the United States is no longer the clear technological leader.

Finding: Collectively, the investments in energy RD\&D by governments and state-owned enterprises in the emerging economies of Brazil, Russia, India, Mexico, China, and South Africa (the BRIMCS countries) are now as large or larger than those of the developed countries in the Organization for Economic Cooperation and Development (OECD). Out of these emerging economies, the bulk of the energy RD\&D investment is being made by state-owned enterprises in China.

Finding: Global energy technology markets have changed dramatically in the last two decades, with both energy demand and manufacturing capabilities of clean energy technologies expanding rapidly in emerging economies.

Over the past decade, China has become the largest energy consumer in the world, and several other emerging economies (such as Brazil, Russia, India, Mexico and South Africa) have become major energy consumers and producers, and major players in energy technology innovation. In addition, nearly all of the projected growth of energy demand over the next quarter of a century will take place in de- 
veloping countries, making their markets-and the cooperation needed to help ensure the U.S. role in them-particularly crucial.

Countries are not only cooperating but are also competing in global energy markets. The import and export values of energy technologies continue to increase, and the value of U.S. exports is growing at a slower rate than that of other countries. China, in particular, has clearly made a strategic decision to compete aggressively in the markets for solar, wind, nuclear, and other clean-energy technologies, and the United States must respond to that competitive challenge-yet the opportunities for cooperation are enormous as well. Choosing where to work together and where to compete is difficult, and must be decided on a case-by-case basis.

Finding: The most important forms of international energy technology cooperation are not directed by governments but arise organically from the activities of private firms, academic and research institutions, and individual scientists and engineers. Governments have key roles to play in facilitating and supporting, rather than hindering, these forms of cooperation.

Much international cooperation on ERD3 takes place without direct government involvement. Private sector cooperation efforts will generally be larger, more dynamic, and more responsive to immediate private-sector needs than government efforts. One of government's most important roles is to enable this bubbling flow of bottom-up cooperation and avoid creating unnecessary barriers. This can be achieved by limiting the obstacles posed by tariffs, export controls, visa restraints, and the like (the surest way to stop any technical cooperation is to require that governments must negotiate a legally binding agreement covering every step to be taken before it can begin).

Because environmental protection and energy security are public goods and are not priced in the market, and because firms cannot capture all the benefits arising from their innovations, private firms alone will always invest less in energy technology innovation than would be best for society, overall. For this reason, governments should support cooperation with other countries through agreements, programs, or individual projects; particularly in cases where such cooperation results in:

- $\quad$ shared or lower costs in research, development, and demonstration projects through the sharing of information, facilities, and personnel;

- $\quad$ access to complementary expertise and facilities;

- increased business prospects for American companies through a better understanding of new markets and their needs; or

- environmental, security, and economic benefits to the United States from an accelerated development and deployment of advanced energy technologies globally. 
Finding: The U.S. government undertakes international cooperation on energy technologies for many different reasons. No single set of criteria can adequately capture all of the different motivations for cooperation on energy technology.

A brief historic analysis of the drivers of international cooperation on energy technology innovation revealed that new political drivers for international cooperation appear over time, and that old drivers, and the networks formed to support them rarely completely disappear. As a result, U.S. government decisions to engage in international cooperation are shaped by multiple objectives: (1) accessing knowledge on high-tech energy technologies; (2) retaining or gaining technological competitiveness; (3) increasing energy security; (4) accelerating the commercialization of new energy technologies; (5) reducing the negative environmental impacts of the production and consumption of energy; (6) promoting reforms in the energy sector; (7) providing energy access to the poor; and (8) increasing U.S. access to emerging markets.

Finding: The U.S. government does not appear to have an overall strategy for its international energy technology cooperation efforts; has no systematic approach to coordinate the many different efforts underway; and does not collect or analyze data on the successes and failures of international energy technology cooperation that would make it possible to strengthen these programs over time by learning from experience.

There are several factors that make it difficult for the U.S. government (and many other governments throughout the world) to undertake an effective and flexible effort on ERD3 international cooperation. These factors include: (1) the multiplicity of objectives that drive ERD3 cooperation; (2) the wide range of activities involved (e.g., information sharing, standard design, joint R\&D projects, etc.); (3) the large number of platforms and channels through which it takes place; (4) the large number of government stakeholders; (5) the lack of information about the activities taking place within existing bilateral and multilateral platforms; (6) the growing number of non-government international cooperation activities by scientists, national laboratories, industry, and non-governmental organizations; (7) the wide range of technologies that are needed to meet the energy challenge; (8) the difficulty of balancing cooperation versus protecting intellectual property and potential competitive advantages.

There are at least nine U.S. government departments and at least ten U.S. agencies involved in international cooperation on ERD3. Some coordination of international cooperation activities takes place within the different U.S. agencies and across agencies through a network of personal contacts, but a coordination effort that encompasses the majority of the relevant government activities has not yet been found. 
This complexity has contributed to a lack of direction and systematic coordination among government agencies, which results in:

- Little continuation and follow up between activities;

- Duplication and repetition of activities supported across governmental organizations;

- $\quad$ Restructuring of existing projects with little evaluation;

- A large number of inactive agreements; and

- Limited efforts to extract lessons from international cooperation activities and provide them to the wider community.

Finding: Funding for most U.S. energy technology cooperation efforts is limited and comes with administrative and procedural burdens. Most of these cooperation programs focus on very limited objectives such as outlining standards for new technologies. In most cases these programs do not have the resources for actual joint technology development.

An analysis of the activities taking place in each of the international cooperation platforms-the International Energy Agency, the Global Environmental Facility, the Asia Pacific Partnership, and others-shows that the focus of the cooperation programs is limited in most cases. Most international cooperation projects focused on energy technology supported by the U.S. government are small-scale deployment activities for existing technologies in developing countries. They include cooperation on the development of databases, handbooks, best practice examples, state-of-the-art literature reviews, standards and codes, computer models, regulatory issues, or policy reform advice. This is to be expected, because generally these activities are cheaper and easier to arrange than projects in which equipment is being purchased and new processes are being developed. There are several international cooperation projects that support the exchange of experimental data and the coordination of experimental testing in facilities, but only a small number of international cooperation projects actually work on the development of new energy technologies.

\section{RECOMMENDATIONS}

Recommendation: The expanding and increasingly diversified global ERD3 landscape implies that the United States needs to develop and implement an effective strategy for cooperation with other countries, to pursue global sources for the best ideas and innovation opportunities, while also targeting investments to maintain its competitive position and future market share. 
The changes in global energy technology markets in the last two decades, with both energy demand and manufacturing capabilities of clean energy technologies expanding rapidly in emerging economies, require U.S. policy makers to take the global interdependence of ERD3 activities into consideration, and to evaluate their actions in the context of the global market.

Recommendation: The U.S. government should expand funding for international energy technology cooperation in three ways: (a) by setting aside a portion of the budgets of each major energy RD\&D program for international cooperation to finance efforts identified bottom-up by program officers or project managers involved in international energy RD\&D efforts; (b) by providing incubator funding to support the procedural aspects for creating technologyfocused cooperation projects; and (c) by providing funding for programs that represent strategic priorities identified top-down by a new interagency committee.

In an increasingly complex, diverse, and fast-changing global landscape of ERD3 activities, innovators who are connected to international networks must be relied upon to identify new opportunities for international ERD3 cooperation. These bottom-up projects (which are already taking place to some extent), increase the ability of both U.S. policy makers and U.S. innovators with contacts in other countries to respond to needs and opportunities in a flexible and timely manner. We therefore recommend instructing departments and agencies to set aside a portion of their ERD3 program funding to support bottom-up energy technology innovation cooperation projects. This approach would significantly increase the total funding directed to international cooperation efforts.

Simultaneously, the United States needs a more prioritized and efficient approach to international energy technology cooperation to meet the challenges of energy innovation in a rapidly changing international landscape. We recommend that the U.S. government adopt a two-track approach designed to create coherence and synergies between bottom-up activities through a top-down strategic planning process. This top-down process requires a more diligent and systematic effort of collecting information about what projects are currently supported, what problems they address, and what solutions they may provide. The next two recommendations detail the top-down portion of our proposal.

Recommendation: The U.S. government should establish an interagency working group under the National Science and Technology Council (NSTC) to coordinate international energy technology cooperation.

The U.S. government should create a working group focused on international energy technology cooperation that would be co-chaired by the DOE and the Office of Science and Technology Policy (OSTP) and have active participation from the other agencies involved, including the State Department, the U.S. Department of Agriculture, and the U.S. Agency for International Development, as well as private sector actors. The Working Group would be housed under the Committee on International Science, Engineer- 
ing, and Technology (CISET) within the (NSTC). The Working Group should be guided by an "adaptive strategy" that (1) compares existing international ERD3 cooperation activities and instigates projects that create coherence between them; and (2) identifies activities that create synergies or seize opportunities between U.S. national ERD3 activities and those of its partnering countries. It would be responsible for identifying and communicating strategic guidelines for cooperation on energy technology innovation every year, and produce a report to Congress, the White House, and the different departments.

Moreover, the Working Group should work with agencies, the Office of Management and Budget, and Congress to ensure that these recommendations are included in agency budgets.

Recommendation: The U.S. government should establish a focused effort to collect and analyze data on its international energy RD\&D cooperation activities, creating an information platform at the Energy Information Administration (EIA).

To aid the work of the Working Group at NSTC, as well as the other departments engaged in ERD3 and other stakeholders who may be interested in cooperating with other parties internationally, a platform to share information on international ERD3 cooperation projects should be created. This platform could be hosted by the EIA. The platform should collect information about the technical and strategic dimensions of existing international cooperation projects, programs, and high-level agreements at different government levels across the different U.S. agencies, and how they relate to each other. Incentives should be put in place to ensure that those responsible for the projects consistently introduce information on the details of the projects and their progress on a yearly basis. Incentives could include followup funding for projects being contingent upon providing information, and/or including information sharing in personnel evaluations. The platform should also enable private firms and not-for-profit organizations to share information about their projects, and should make it possible for information to be made comparable at different levels and across agencies, and accessible to both U.S. policy makers and U.S. organizations who may be interested in cooperating with other parties internationally.

\section{Cross-Cutting Issues}

As we pursued our research, several themes arose repeatedly. We believe these principles are important to improve the effectiveness of U.S. energy innovation policy.

The first of these themes is the need for stable long-term policies that allow the private sector to plan and make investments and that provide researchers with time to collect sufficient information and to explore different research avenues efficiently. The Quadrennial Technology Review that the DOE was undertaking at the time of writing this report is a first step that can help provide more stability by identifying multi-year programs for different technologies. Long-term stability is also needed for policies to pull technologies into the market place, such as standards or carbon prices. 
The second theme is the need for improved coordination between agencies. Again, the Quadrennial Technology Review will help provide coordination within the DOE, but ultimately, a government-wide review (such as the Quadrennial Energy Review recommended by the President's Committee of Advisors in Science and Technology) will be needed to align DOE programs with government-wide initiatives. For example, a price on carbon or a clean-energy standard will affect private sector activity in energy innovation and therefore the investments that the DOE should make.

The third theme that emerged is the need to have a balanced portfolio of: (a) investments in different technologies, (b) investments in different stages of technology development, and (c) mechanisms to interact with the private sector and universities. The outcome of innovation is uncertain, and, as a result, managing risks requires spreading bets across a range of projects while expecting failures. At the same time, given that budgets are constrained, and that bets that are too small are unlikely to yield results, not everything can be supported.

A fourth theme that emerged was the need to strengthen the interaction between government and the private sector. Although members of the private sector testify to Congress, participate in advisory boards, and respond to requests for information, it would be useful to integrate private sector perspectives more fully in the design of policies and research programs. An extended use of advisory boards-such as the Energy Innovation Advisory Board we propose-could help strengthen connections between the public and private sectors.

Finally, a fifth theme our research indicated is that there is a lot of work to be done to design an energy technology innovation strategy that is guided by learning. Today, program managers are often unaware of which approaches worked and which did not in areas of research related to their own, making it difficult to strengthen or expedite their efforts by learning lessons from past experience. Much more work can be done to collect and analyze data on the different approaches that are being implemented and to determine which ones seem to work best, and under what circumstances. For example, better information is needed for program planning and the budget process. Information required includes: (1) the portfolio of mechanisms and projects that are in place; (2) multi-year program plans that take into account what capabilities and resources will be needed; (3) managers' experience with what partners are able to contribute and what the DOE has to contribute (this is as important as the state of technology in deciding what actions to take); (4) the pace of technology development and the challenges that are being encountered by those involved in projects; and (5) the impacts of the programs. ARPA-E is placing an increased emphasis on self-evaluation and data collection, and is an example of an institution that is adopting this "learning" principle. 


\section{CHAPTER 1}

\section{INTRODUCTION AND MOTIVATION}

\subsection{Introduction: An Energy Technology Revolution}

America and the world face profound energy challenges_challenges that can only be surmounted through a revolution in energy technology. Promoting technological change in the United States is a necessary element to ensure energy security, sustain economic growth, avoid environmental degradation, reduce the risks of unmanageable climate change, and supply modern energy to those around the world who have no access to energy supplies beyond wood, crop wastes, and dung.

This report provides analysis and recommendations intended to help launch such an energy technology revolution in the United States, focusing in particular on four areas:

- Strengthening federal energy research, development, and demonstration (RD\&D) and its coordination with deployment policies. This report explores how much the U.S. federal government should spend on energy RD\&D, on what stages of development of which technologies, and what deployment policies would contribute to reducing greenhouse gas emissions, oil imports, and energy costs.

- Encouraging innovation in the private sector. This report provides new data on the role of the private sector in energy technology innovation, and investigates both how the U.S. government can structure incentives to accelerate private sector work on new energy technologies and how the U.S. government can better manage its partnership for energy innovation with the private sector , in the Department of Energy's use of grants, contracts, and partnerships with private firms.

- Utilizing international cooperation in energy innovation. This report assesses the investments and policies of industrialized countries and emerging economies in energy technology innovation, and analyzes how the U.S. government can leverage joint action with other countries, balancing competition and cooperation to address U.S. and global energy-related challenges.

- Increasing the effectiveness of the U.S. energy innovation institutions and facilitating technology demonstration. This report explores how the U.S. government should manage its energy innovation institutions, particularly the national laboratories, and what type of mechanisms can best incentivize large-scale technology demonstrations of new energy technologies where needed. 
A wide range of recent studies, from bodies ranging from the National Academy of Sciences and the President's Committee of Advisors on Science and Technology (PCAST) to groups of business leaders and non-government analysts, has called for steps to accelerate U.S. energy technology innovation, including expanded federal investments in energy RD\&D (American Energy Innovation Council 2010; PCAST 2010; American Enterprise Institute, Brookings Institution, and Breakthrough Institute 2010; NAS 2009). ${ }^{1}$ The PCAST study, in particular, urged the President to establish a Quadrennial Energy Review, and the Department of Energy (DOE) has since launched a Quadrennial Technology Review (QTR) focused on developing an integrated, prioritized approach to the DOE's efforts to develop and demonstrate new energy technologies (DOE 2011). Our report is intended to contribute to such reviews and to the broader national discussion of how U.S. energy goals can best be achieved.

While all of these studies recommended steps to accelerate the pace of energy technology innovation in the United States, our work adds to the previous literature in significant ways:

1. We undertook a major study to quantify the likely impact of federal RD\&D programs on the cost and performance of various energy technologies (a total of 25). We first conducted written surveys asking over 100 technical experts ${ }^{2}$ to estimate the role that government energy RD\&D investments may play in improving the cost and performance of seven energy technology areas. These formal surveys were developed in consultation with other experts and involved the collection of all published information on current and future costs of energy technologies. The experts who participated in our extensive surveys spanned academia, national labs, non-profit organizations, and the private sector. The answers from these experts were then reviewed by an additional set of 21 experts with vast experience in thinking about allocating funding to a multiplicity of technologies and projects representing a variety of sectors. Our recommendations about how much funding should be devoted to energy RD\&D and how that funding should be allocated was therefore the combined result of: the formal written surveys by industry experts, the reviews by the second set of experts, and our assessment of the possible benefits from those investments in terms of future $\mathrm{CO}_{2}$ emissions, $\mathrm{CO}_{2}$ prices (in the case of a carbon policy), and oil imports reductions, among other metrics.

1 Other recent studies that have informed our work include some that have made valuable contributions to the field of energy innovation policy. A newly published book (May 2011), Accelerating Energy Innovation: Insights from Multiple Sectors edited by Rebecca M. Henderson and Richard G. Newell, explores the role that policies and markets have played in stimulating rapid innovation in six sectors, and points to the importance of efficient public support for RD\&D, the existence of demand-induced innovation, and the importance of competition (partly enabled by antitrust and intellectual property policies; Henderson, Newell, May 2011). The sectors investigated in this upcoming book are agriculture, chemicals, semiconductors, computers, the internet, and biopharmaceuticals. A November 2009 report by Professor Richard Lester at MIT summarized some of the key principles-diversity, openness/ability to self-correct, specialization, capacity to conduct large-scale demonstrations, capacity to fill the "post-demonstration" gap, and political viability (Lester 2009).

2 Bioenergy (12 experts, 5 reviewers), utility scale storage (25 experts, 7 reviewers), fossil energy (12 experts, 3 reviewers), nuclear (30 experts, 2 reviewers), vehicles ( 9 experts, 1 reviewer), buildings ( 9 experts, 2 reviewers), and photovoltaic power (11 experts, 1 reviewer). 
2. Our methodology for recommending an investment of at least $\$ 5.2$ billion for the applied energy $\mathrm{RD} \& \mathrm{D}$ areas considered also accounted for the fact that the outcomes of $\mathrm{RD} \& \mathrm{D}$ are uncertain, and that the benefits will depend on the "deployment policies" in place that would accelerate the entrance of the technologies into the market. We also recommend at least an additional $\$ 4.4$ billion for other energy RD\&D programs for a total of about $\$ 9.6$ billion.

3. We conducted novel in-depth case studies of a prominent national laboratory in the area of renewable energy (NREL), and of a successful, private R\&D consortium (SRC). These case studies were used to extract lessons about how to increase the effectiveness of the DOE's national laboratories' ability to develop and introduce novel energy technologies in the market.

4. We present data on the DOE's funding for energy RD\&D in the private sector through grants and cooperative agreements. Based on the data available, we make recommendations about how to better integrate these mechanisms for supporting innovation into the decision-making processes at the DOE.

5. We conducted a survey of energy innovation in the private sector in the United States to estimate what fraction of business establishments have a stake in energy innovation, to improve our understanding of how firms make a decision, and to investigate what federal policies may stimulate private sector innovation. This pilot scale survey indicates that energy innovation is important for a large fraction of large and small U.S. businesses, and represents a first step toward evaluating the role of policy in energy innovation in different segments of the private sector.

6. We created a set of databases to analyze trends in international cooperation in energy technology RD\&D through scientific publications, inter-firm projects, and inter-governmental agreements. We also studied where decisions about international cooperation on energy innovation take place in the federal government, and estimated the size of the investments in energy RD\&D of some of the major emerging economies. We developed a set of recommendations to allow a more informed bottom-up generation of international cooperation initiatives throughout the many U.S. government agencies involved in energy technology innovation cooperation, and to identify new projects of high strategic importance that would not take place without a high-level interagency structure.

This report presents new data, new analysis, and new modeling work. Recognizing the complexity of national innovation systems, we strove to evaluate the opportunities for the U.S. federal government to accelerate innovation through different avenues, including: direct RD\&D investments, deployment policies, partnerships with the private sector, the role of the national laboratories, cooperation with other countries, and improved coordination and strategy. 


\subsection{INTERLinked Crises}

Providing the growing supplies of secure, reliable, and affordable energy needed to fuel prosperity for all without causing environmental consequences is perhaps the greatest challenge facing human civilization in the twenty-first century. The energy problem is simultaneously a security crisis, an economic crisis, an environmental crisis, and an energy access crisis:

- A security crisis. A wide range of current and former senior national security officials have made it clear that both the U.S. and global addictions to fossil fuels pose a severe security challenge (CNA 2009, Daniel 2010). The U.S. and world economies are increasingly dependent on oil supplies located in some of the most politically volatile regions of the world (though suppliers and consumers are deeply dependent on each other, making the "oil weapon" difficult to wield). High energy prices fill the coffers of some of the world's most hostile governments. Militaries around the world are deeply dependent on fossil fuels that compromise operations (Defense Science Board 2008) and raise security concerns-as the casualties from fuel supply trucks in Iraq and the recent terrorist attacks on fuel shipments in Pakistan to provide fuel to NATO troops in Afghanistan make clear (Simeone 2009, BBC 2010). With most population growth taking place in those regions with limited energy access or low energy use, a scarcer energy market could also lead to civil unrest in many places around the world and could threaten national and international security. It is becoming increasingly clear that the natural disasters, refugee flows, and intensification of poverty that will result in some regions if climate change is not addressed will pose risks to international peace and security (CNA 2007). In addition, a global expansion of nuclear power without improvements in technology and institutional controls could increase the danger of nuclear proliferation and terrorism (as well as the risks of nuclear accidents).

- An economic crisis. The United States sends $\$ 700$ million dollars a day overseas just to purchase petroleum, an amount representing roughly half the U.S. trade deficit (U.S. Census Bureau 2010). Volatile oil and gas prices disrupt investment planning, drive businesses into bankruptcy, and push families into sudden poverty. Where once the United States was the undisputed world leader in clean energy technology, other countries are now making progress, particularly in the areas of manufacturing and commercialization, in some technologies: China is now the world's largest producer of both solar cells and wind turbines, and China, Europe, and other countries, such as South Korea and Japan, are investing heavily in developing new energy technologies. ${ }^{3}$

3 According to a recent report, in 2009, for the first time, "core clean energy" (i.e., new renewables, biofuels, and energy efficiency) private investments in Asia and Oceania ( $\$ 40.8$ billion) were larger than those in the Americas ( $\$ 32.3$ billion). These estimates of private investments include asset finance, IPOs, private equity, venture capital, and estimates of corporate RD\&D 
Large investments in the world's energy infrastructure are expected between 2010 and 2030, on the order of tens of trillions of dollars, ${ }^{4}$ and clean energy investments are expected to grow over time. ${ }^{5}$ Capturing a large share of this market could lead to new jobs and increased revenues, but this will depend in part on the United States' success in developing innovative new energy products and services.

- An environmental crisis. From oil spills in the ocean to air pollution choking many cities around the world, to global climate disruption, production and use of energy causes most of the worst environmental problems the world faces, at local, regional, and global scales. Climate disruption and ocean acidification, in particular, are heavily driven by the carbon emissions from burning fossil fuels. ${ }^{6}$ The environmental impacts of the energy sector are already slowing economies, which results in the deaths of thousands of people globally every day ${ }^{7}$, and adding to the burden of human misery-and these impacts are accelerating. Climate change could result in increasing damages from climate disruption for decades to come.

- An energy access crisis. Energy innovation also has an important role to play in increasing access to modern forms of energy (electricity and liquid and gaseous fuels) to about one third of the world's population. The current inefficient and dirty indoor combustion of coal and biomass has large health, economic development, and environmental costs.

These huge, interlinked challenges must be met, for affordable and reliable energy supplies are the lifeblood of the economy of the United States. ${ }^{8}$

investments. Private investments in Europe were already larger than those in the Americas, totaling \$43.7 billion in 2009 (UNEP SEFI, Bloomberg New Energy Finance 2010). Moving on to public investments, the IEA statistics show that in 2008, a group of European countries including Austria, Belgium, Denmark, Finland, France, Germany, Greece, Hungary, Ireland, Italy, Luxembourg, the Netherlands, Norway, Portugal, Spain, Sweden, Switzerland, Turkey, and the United Kingdom had invested $\$ 4.7$ billion in energy RD\&D; Japan $\$ 4.3$ billion; and the United States $\$ 4.4$ billion (IEA 2010b). In terms of public investment as a fraction of GDP, in 2007, Australia, Denmark, France, Japan, Korea, and China were making greater investments than the United States (AEIC 2010).

4 In a "business as usual" scenario in which energy-related $\mathrm{CO}_{2}$ emissions would double by 2030 globally, total investments in energy supply and use would be about $\$ 26$ trillion between 2010 and 2030. An additional $\$ 10.5$ trillion would be necessary to realize a $50 \%$ reduction in global annual $\mathrm{CO}_{2}$ emissions (IEA 2009b).

5 Joint reports from the United Nations Environment Program (UNEP) and the Renewable Energy Policy Network for the 21st Century (REN21) estimated that, in 2009, global investment in "core clean energy" (i.e., new renewables, biofuels, and energy efficiency) were \$162 billion (UNEP SEFI, Bloomberg New Energy Finance 2010).

6 Today, some $80 \%$ of the world's energy supply comes from burning fossil fuels, which is the largest contributor to emissions of heat-trapping gases, with oil providing the single largest contribution to global energy supply.

$7 \quad$ The World Health Organization estimated in 2006 that, every year, 1.5 million people die from inhaling indoor pollutants that exceed accepted guideline limits from the burning of coal and biomass such as wood, dung, and crop residue (Rehfuess, Corvalan \& Neira 2006).

8 Today, an estimated 2.4 billion people, more than a third of the world's population, rely on wood, charcoal, and dung as their principal energy sources, and an estimated 1.6 billion have no access to electricity (UNDP 2005). Expanding the supply of modern energy will be a critical element of lifting billions of people out of abject poverty. 
With a growing world population and growing economies, however, the latest scenarios ${ }^{9}$ suggest that global primary energy consumption may increase to 1.5-3 times the current demand by 2050, making these challenges far more difficult to address. These scenarios also indicate that fossil fuels are likely to provide most of the world's energy supply for decades to come. Indeed, despite projected growth in renewable energy supplies, in its "new policies scenario," ${ }^{10}$ the International Energy Agency expects the use of natural gas to grow faster than any other energy source in the decades ahead, and the use of coal to increase until 2019. See Figure 1.1. ${ }^{11}$

This ever-growing reliance on burning fossil fuels simply cannot be sustained-the economic, security, and environmental costs will all prove to be unacceptably high. Indeed, it may simply not be possible to meet growing projected demands for oil and gas at an acceptable cost. While there is debate over when "peak oil" will occur, there is little debate that, at some point in the decades to come, oil production will stop growing and eventually decline, even as energy demand continues to grow. Price spikes, supply disruptions, and political tensions over scarce supplies are likely to become increasingly common. At the same time, there is a growing scientific consensus that, in order to avoid catastrophic climate disruption, steep reductions in global emissions of heat-trapping gases, perhaps in the range of 50\% below today's levels, must be achieved by roughly $2050 .{ }^{12}$ The need to develop alternatives to fossil fuels that can be deployed at a massive scale-especially for transportation fuels-is real and urgent.

As the International Energy Agency has put it: "Current global trends in energy supply and use are unsustainable-environmentally, economically, socially.... It is not an exaggeration to claim that the future of human prosperity depends on how successfully we tackle the... central energy challenges facing us.... What is needed is nothing short of an energy technology revolution" (IEA 2009a). To meet the challenges, both major innovations in energy technology and new international policies and institu-

9 The "Baseline" scenario of the International Energy Agency of the Organization for Economic Cooperation and Development (IEA/OECD), for example, envisions a global, primary energy supply growing $1.4 \%$ per year on average from 2007 to 2050 , increasing by almost exactly a factor of two, from 12,020 million tons of oil equivalent (Mtoe, equivalent to 503 exajoules) to 22,078 Mtoe (924 exajoules) in 2050. In this scenario, global electricity production increases by $134 \%$. See (IEA 2010a). Similarly, the U.S. Energy Information Administration (EIA) reference case envisions 1.5\% annual growth in world energy demand from 2006-2030, resulting in 678 quadrillion British Thermal Units (BTU) (715 exajoules) of world primary energy demand by 2030. If this annual growth continued to 2050, it would result in a global demand of some 960 exajoules, nearly twice 2006 demand and very similar to the IEA/OECD baseline scenario. The EIA reference case envisions central station electricity generation growing by $2.4 \%$ per year, which would nearly triple global production by 2050. See EIA 2009, OECD 2008. Other relevant scenarios are found in Metz et al. 2007, IAEA 2008, and European Commission 2006. Under the new policies scenario of the recently released IEA's World Energy Outlook 2010, world primary energy demand would increase by $36 \%$ between 2008 and 2035 , growing at $1.2 \%$ per year on average (IEA 2010c).

10 The "New Policies" scenario is a new feature of the IEA's World Energy Outlook 2010, and takes into account the broad policy commitments and plans that have been announced by countries around the world, including the national pledges to reduce greenhouse gas emissions and plans to phase out fossil-energy subsidies, even where the measures to implement these commitments have yet to be identified or announced.

11 It is worth mentioning that these projections assume oil supply availability that is more optimistic than other scenarios. It is hard to say what estimate is more accurate (IEA 2009b).

12 For a reflection of this growing consensus, see, for example G8+5 Academies 2009. 


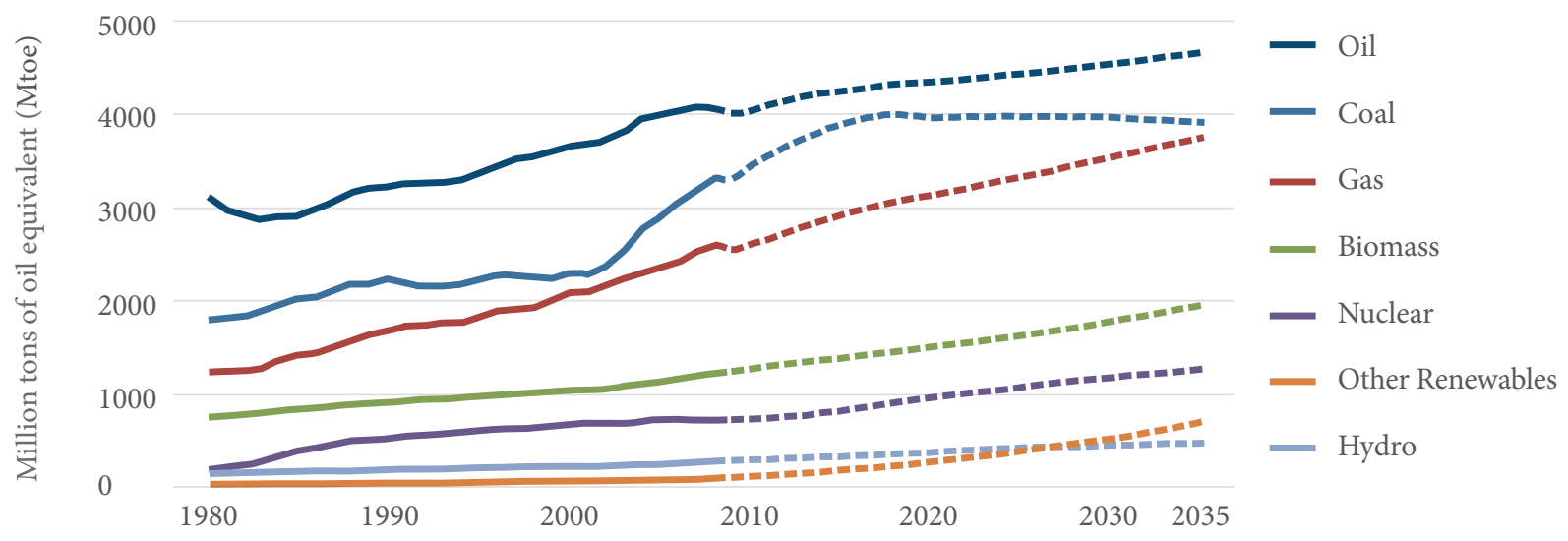

FIGURE 1.1. Energy demand by fuel type in the New Policies Scenario. (IEA 2010c)

tions will be needed. ${ }^{13}$ Broad international action and cooperation will be essential: no separate solution implemented within a single country, or even region, will suffice.

The scale of what must be done to meet these challenges is staggering, as the global energy system (the infrastructure of exploration facilities, transmission lines, pipelines, power plants, buildings, vehicles, etc.) is huge. The International Energy Agency estimates that simply maintaining "business as usual" will require $\$ 26$ trillion in energy-related investments between now and 2030. To begin getting on a path to stabilize long-term concentrations of greenhouse gases in the atmosphere at 450 parts per million of $\mathrm{CO}_{2^{-}}$ equivalent would require an additional \$10.5 trillion in global energy investments by 2030 (IEA 2009c).

Some recent reports have suggested that expanded investments in energy RD\&D alone will be enough to meet these challenges (American Enterprise Institute, Brookings Institution, and Breakthrough Institute, 2010), that by developing lower-cost low-carbon energy sources, societies can avoid painful steps such as putting a substantial price on dumping carbon into the atmosphere, which could increase energy prices to consumers. ${ }^{14}$ Our work makes clear that this view is deeply wrong, for two key reasons.

First, the challenges are so great that there will be a need to deploy both technologies that can compete on their own with entrenched, incumbent technologies without any account taken for externalities such as carbon emissions and technologies that cannot yet overcome the market barriers to widespread deployment without some form of demand-side policies. In the modeling described in Chapter 2 and the appendices, we found that even a dramatic expansion of federal funding for energy RD\&D, and the most optimistic expert predictions of the results of that innovation investment, would simply not be enough

13 For recent discussions, see, for example, IEA 2009b, IEA 2010a, Gallagher 2009, and Velikhov et al. 2006.

14 In addition to $\mathrm{RD} \& \mathrm{D}$, this report also refers to several other steps designed to provide limited support for initial deployments of several classes of new energy technologies, including initial military procurements, and a reform of deployment subsidies designed to focus on driving down costs. The report holds open the possibility of only a very small carbon price, designed to fund RD\&D rather than to give the private sector strong incentives to deploy low-carbon technologies. 
to achieve the dramatic reductions in U.S. carbon emissions (or the dramatic reductions in U.S. oil use) likely to be needed by 2050 unless this expanded RD\&D is coupled with demand-side policies that have the effect of putting a substantial price on carbon emissions. (Indeed, a broader suite of demand-side policies will ultimately be needed, given the different market barriers to deployment of low-carbon technologies that exist in different sectors.) In fact, entire classes of technology that are likely to be crucial to achieving deep reductions in emissions-such as capturing and sequestering carbon from the burning of fossil fuels-are unlikely to ever be economically competitive if the costs to society of dumping carbon into the atmosphere are not taken into account.

Second, in the absence of a substantial carbon price, innovation itself will be slowed, because the private sector will have little incentive to invest in developing low-carbon technologies. The survey of private sector energy innovation described in Chapter 3 makes it clear that expected prices and their effect on potential profits are the dominant factors affecting private sector energy innovation investment decisions. In July 2011, American Electric Power announced that it would abandon its plans to carry out a large-scale demonstration of technology to capture and sequester carbon from an existing coal plant because, in the absence of a carbon price, the concept was simply not economically viable. As this report makes clear, to accelerate the full cycle of innovation from invention to deployment will require substantial government support on both the "supply side" and the "demand side" of energy technologies.

Of course, in recommending major new federal investments in ERD3, we are conscious of the huge U.S. federal deficit and the need to bring government revenues and spending into better balance over the long term. But just as a private firm borrows to make investments that are critical to its future profitability, the U.S. government must not neglect critically needed, long-term investments in the rush to balance the budget. As the PCAST report suggested, it may make sense to achieve a substantial portion of the needed investment through new approaches and revenue streams outside the usual appropriations process-as was done in the past when the Federal Energy Regulatory Commission approved a small surcharge on interstate transportation of natural gas that was used to finance gas RD\&D (PCAST 2010, p. 16). But one way or another, a central theme of this report is that the United States must make a larger investment in new energy technologies if it is to meet the energy challenges of the twenty-first century.

\subsection{The Need for a Portfolio of New Energy Technologies}

A major part of these challenges can be met with better use of technologies that already exist- particularly energy efficiency. ${ }^{15}$ Indeed, it is unlikely that technologies requiring radical jumps in technology and large infrastructures-from nuclear fusion to solar power beamed to earth from satellites-could

15 A recent study from the Massachusetts Institute of Technology, for example, concluded that the combination of reducing energy use and switching from coal to natural gas could cut greenhouse gas emissions from the U.S. economy in half from the 2005 level, without even considering the impact of nuclear or renewables (MIT 2010). 
be developed and deployed fast enough to make much of a difference in the dramatic shift away from fossil fuels that must be accomplished by 2050 if climate disruption is to be avoided. Such new technologies may, however, be very important in the second half of the twenty-first century, when still-growing energy demand will have to be met with still-lower carbon emissions and may be encountering more problematic availability and security of adequate supplies of oil.

The world urgently needs:

- New designs and materials that can drastically reduce energy use in buildings, industry, appliances, and vehicles;

- Low-cost, non-polluting sources of light, heat, and electricity for the billions of people who still rely on wood, crop waste, and dung as their principal energy sources;

- Fuel and vehicle systems that do not rely on oil, but can compete head-to-head with gasoline and diesel-powered vehicles;

- $\quad$ Cost-effective energy storage for both vehicles and electric power systems;

- Solar, wind, and other renewable energy sources at prices competitive with fossil fuels from a broad range of sites;

- Competitive approaches to using fossil fuels while controlling emissions of carbon and other pollutants, such as carbon capture and sequestration (CCS);

- New nuclear designs that can provide cost-effective power and process heat with reduced safety, security, and proliferation risks; and

- Smart grid technology that can manage electricity producers and users to efficiently meet demand, smoothly incorporating intermittent and distributed sources of energy and reducing unneeded uses when costs are high.

One of the results of the work presented in this report are estimates of the extent to which energy RD\&D investments and the resulting improvements in technology can address the interlinked crises of security, the economy, and the environment. We deal with the uncertainty on the future outcomes of incremental and radical innovation by representing the costs of meeting a particular demand (gallons of liquid fuel, electric power, and automobile) as a range of possible outcomes; in essence, the representation of $\mathrm{RD} \& \mathrm{D}$ outcomes as distributions assumes that there is some probability of radical breakthroughs.

What is clear from all of the studies conducted over the past 20 years is that today's pace of energy innovation is simply not enough to meet the current and near-future challenges. The world's energy in- 
frastructure represents an investment of tens of trillions of dollars, much of it in systems that last for decades. It is like a supertanker that takes miles to change direction, no matter how energetically one turns the wheel. Even the most attractive energy technologies of the past, which offered dramatic new services-from oil to electricity - took decades of growth before they represented a substantial fraction of total energy use. ${ }^{16}$ Over the past 60 years, countries around the world have poured tens of billions of dollars into research and development and subsidies for nuclear energy-yet nuclear energy provides only about $6 \%$ of primary energy worldwide. Renewable sources such as solar and wind have been under development for decades, yet they provide an even smaller portion of the world's energy needs. A dramatic improvement in the pace of energy technology innovation and diffusion is essential to be able to meet the energy challenges of the twenty-first century. Inventing new energy technologies is not enough-these technologies must be widely deployed if they are to make a difference in meeting security, economic, and environmental energy challenges.

Indeed, there is general acceptance that the government has a positive role to play in support of basic and applied science $(\mathrm{R} \& D)$. It is also generally accepted that the private sector is ultimately responsible for deployment, but the energy system depends on an infrastructure of transmission lines, pipelines, roads, and railways that are also shaped by government policy. The government can also play an important role in overcoming the "valley of death," or in helping un-funded prospects for novel energy technologies to obtain financing, and to enable commercial-scale demonstrations of capital-intensive facilities (Narayanamurti et al. 2011).

The immense scale of the energy challenge and the heterogeneity in the energy sector, make clear that there will be no single solution. The world is likely to need many different approaches to energy-efficiency and low-carbon energy generation, developed and deployed as fast and at as large a scale as it is practicable and cost-effective to do so. This fact, combined with the huge uncertainty over through what channel future breakthroughs may come, makes it essential for the U.S. government to invest in a broad portfolio of energy technologies. It is also crucial to invest in a broad portfolio of technological stages of those technologies, ranging from basic science that could lead to long-term future breakthroughs, to commercial-scale demonstration and early deployment of technologies that are almost ready for commercial deployment today. This emphasis on a portfolio approach for technologies, stages of research, and partnership mechanisms (among others), is a central theme throughout this report.

16 Technologies clustered with other technologies and infrastructures, such as oil-based transportation, home electrification, and the construction of railways, took more than 40 years to diffuse in the market place. Other technologies, like the oxygen steel furnace, households with radio, and railway electrification took between 20 and 40 years to diffuse. And typically demand-side technologies such as air conditioners, color TVs, and vehicles may take one or two decades to diffuse (Grübler, Nakicenovic, \& Victor 1999). 


\subsection{Why Private Markets are Essential but Insufficient}

In the United States and most other countries, private firms are the main drivers of the economy, of innovation, and of energy production and use. The private sector will clearly play a central role in developing and deploying the new energy technologies the world needs. However, there are several fundamental reasons why private markets alone, without government support or regulation, cannot develop and deploy the technologies we need to meet the world's energy challenges.

First, the cost of many of the most critical of the world's energy challenges-emissions, the needs of the global poor, the national security impact of over-reliance on imported oil-are not appropriately priced in current markets. For example, when oil, natural gas, and coal provide cheap energy and the negative environmental problems associated with their consumption are not reflected in prices, the private sector has only modest incentives to invest and innovate to develop or utilize alternatives.

Second, the social benefits of energy research and development (R\&D) are far greater than the benefits that would accrue to any particular company (or country) investing in such $\mathrm{R} \& \mathrm{D}$, even if all the security, economic, and environmental issues were fully reflected in market prices. As research has clearly proven, other companies (or countries) benefit from the good inventions of one company (or country). The end result of this is that companies, overall, invest less in innovation than would be best for the interests of society as a whole. ${ }^{17}$

Third, the energy market is not a well-defined entity. A large part of the innovation potential is the endusers of energy, and for most end-use companies, energy reduction is not a top-priority. Energy costs are often too small a fraction of the operational expenditure to warrant any significant efforts in energy innovation, and there is often limited knowledge about how much energy is actually used and how it can be reduced through energy innovation.

Indeed, the economic literature emphasizes that it is necessary to use a combination of price and $\mathrm{R} \& \mathrm{D}$ policies in order to achieve the most cost-efficient transition to low-carbon energy systems (Stavins 2010) with which to address the aforementioned market failures of the environmental externality and the spillovers from $\mathrm{RD} \& \mathrm{D}$.

\subsection{Why ENERgy InNOvation is SO Challenging}

Unfortunately, low investment in innovation seems to be particularly severe in the energy sector. Firms from the energy sector, for which data are available, spend a smaller portion of their revenues on innova-

17 Empirical evidence suggests that the social rates of return to R\&D are substantially in excess of the private returns to R\&D. While estimates of social rates of return to R\&D in the United States range from 0 to $160 \%$, those of private return range from 0 to $43 \%$ (Griliches 1992; Margolis, Kammen 1999). 
tion than do firms in a broad range of other industries ${ }^{18}$ (though, as the new data provided in this report makes clear, past estimates have understated the full amount of private investment in energy innovation). ${ }^{19}$ A look at the incentives for innovation in different industries makes clear why this is the case.

The primary role of private companies is to seek profits. They invest in R\&D only when doing so appears to be the way to garner the best risk-adjusted rate of return for their shareholders. If a company is in the cell phone industry, for example, the pressure to innovate is extreme. Customers buy new phones frequently, choosing on the basis of features, style, and price. Thus, competitors are developing and bringing to market new phones with new features so steadily that the entire life-cycle of a particular phone model, from "cradle to grave," may be only a year or two. In the cell phone industry, a company that does not invest in innovation-and does not do it successfully—will soon be swept aside by its competitors.

Similarly, consider a large pharmaceutical firm. Such a firm would typically have many drugs to sell, but only a few that would bring in the majority of its profits. Those profits tend to decline greatly when the patent on a drug expires and other makers can compete with generic versions, driving prices down. Here, too, if the company is not constantly investing in developing new drugs to provide a stream of profits in the future, it will soon be out-competed by companies that do make such investments.

By contrast, consider an electric utility. It is in the business of selling electricity for slightly more than it can make electricity, primarily using large power plants that cost billions of dollars to build and that last for decades. Electricity is a commodity product-it does not come with special new features in the way a cell phone does. Any interruption of electricity supply could cost the utility millions of dollars a day. Its incentives are to focus on operating its existing facilities as cheaply and reliably as possible, and on buying new, reliable, and cheap facilities as needed. Neither the utility nor the companies that might hope to entice it to purchase a new power plant have much incentive to focus on innovation that goes beyond cost and reliability-except when government regulations and other policies create such incentives. Moreover, the timescale of change is measured in decades, rather than months. The telecommunications sector between the 1920s and the 1980s provides an example of innovativeness in

18 Electric utilities in particular, which include establishments engaged in the provision of electric power, natural gas, steam, water, and the removal of sewage, spend a very small fraction $(0.1 \%)$ of net sales in R\&D. Mining and extraction companies spend about $2 \%$ of sales in R\&D. Manufacturers of motor vehicles, trailers, and parts invest $2.5 \%$ of sales in R\&D. The pharmaceuticals, electronics, and computer equipment manufacturers all invest over 10\% of sales in R\&D (NSF 2008b). But even though it is hard to come up with the precise R\&D intensity for the energy sector as a whole, utilities are certainly considered to be very technically conservative, and are likely to be on the low end of R\&D intensity within industries in energy (NSF $2008 \mathrm{a}$ ).

19 As discussed in Chapter 4, the National Science Foundation statistics on industrial R\&D only include 85 or 86 industrial energy R\&D performers in 2002, 2003, and 2004, and estimates private sector R\&D in industry in the United States at $\$ 2.4$ billion in 2004 (NSF 2010). This value seems low, considering that the U.S. Department of Energy was spending approximately $\$ 2.8$ billion in 2004 (including funding for applied energy R\&D and for the Basic Energy Sciences program) (Gallagher \& Anadon 2010 ) and that on average in the United States $66 \%$ of all R\&D is traditionally funded by the private sector and $28 \%$ by the federal government (with the remaining $7 \%$ being funded by state and local governments and not-for-profit institutions) (NSF 2008a). The private sector energy R\&D data from the NSF Industrial R\&D survey is based on a small number of firms and was not designed to be representative of all firms in the United States. 
a heavily regulated, integrated utility. Part of the success in the sector is due to the fact that $\mathrm{R} \& \mathrm{D}$ and manufacturing were very closely linked, hinting at the importance of linkages to advance innovation.

Much the same logic would apply to a large oil company. Such a company is in the business of producing oil and products made from oil at a somewhat lower cost than it can sell them. Here, too, the business is based on oil and natural gas fields, exploration and extraction rigs, and refining plants whose development and construction cost billions of dollars, and which last for decades. In this case, products are also commodity products, much the same as what other companies are selling, not something like a cell phone or a cancer drug that can be sold for a higher price because it has features or capabilities that cannot be found elsewhere. An oil company has incentives to innovate in ways that allow it to find and produce more oil, or to produce oil and oil products more cheaply-but generally little incentive to invest in alternatives that today are more costly. (Because the large oil companies are wealthy firms, some of them have had the luxury of making some investments in new energy technologies such as biofuels.)

In addition, companies in the energy sector need to operate within an extensive enabling infrastructure. Pipelines, transmission lines, roads, and gas stations are essential components of today's energy system. In the future, other infrastructures will need to be developed to enable new technologies. For example, depending on what novel technologies end up contributing to reducing emissions and oil consumption in the transportation sector, different supporting infrastructures will need to be developed, such as power charging stations for electric vehicles, compressed natural gas (CNG) stations for CNG vehicles, or hydrogen pipelines for fuel cell vehicles.

On the demand side, there are also several barriers, albeit of a different scale and with different timelines. Taking residential buildings (which account for $21 \%$ of U.S. energy use), as an example, behavioral research has indicated that consumers do not know how much energy appliances or their homes use or where energy comes from, that they assume new appliances are efficient, do not consider energy when they make purchasing decisions, and focus on up-front costs rather than costs over time (Lutzenhiser 2009; McKeown 2007; Brown et al. 2009). In addition, the building industry is highly fragmented, with a noticeable lack of energy efficiency knowledge in the workforce (Brown et al. 2008).

In summary, the complexity of the innovation process for energy technologies makes it particularly challenging, for a number of reasons:

- The large scale, high capital cost, and slow turnover time of many energy technologies, and the long timeframes over which their development takes place, further hinder the participation of the private sector in the development of such technologies. In addition, there are strong economies of scale in many energy supply technologies, which means that constructing first-of-a-kind commercial scale plants is very expensive. 
- There are financial pressures on corporations to allocate resources to functions with more predictable benefits than RD\&D for the short-term bottom line. Established firms tend to focus resources preferentially on existing competencies and incremental improvement, and away from innovative alternatives that could make their present products obsolete.

- Positive feedback loops within a system, network, or infrastructure can "lock-in" existing technological solutions, making power-incumbent technologies difficult to displace and locking-out the integration of alternative technologies. There is a "chicken and egg" problem associated with the large investments in new infrastructure needed to make some of the new technologies effective at scale.

- Energy, by nature, is a commodity and is thus subject to price fluctuations that impose large uncertainties on the returns to be expected from investment in innovation (Anadon \& Holdren 2009).

The energy industry, with its focus on commodities produced using expensive facilities designed to last for decades, is inevitably an industry inclined toward a slow pace of technological change. Although venture capital (VC) investors have increased their support for companies in the "clean tech" sector from $\$ 234$ million in 2000 to $\$ 6.1$ billion in 2008 in the United States (BNEF 2008), it is not clear that the VC model will be as successful commercializing energy technologies as it was with information technology (IT) companies. In fact, the only real successes using the VC model in clean tech have been technologies that have business models similar to those in the IT business, and different from those in the energy sector, which is characterized by larger capital investments.

Private markets will be essential drivers of the needed energy innovations, but they will have to be private markets with new funds, regulations, and other incentives established by government policies.

\subsection{The ENERgy InNOVATion SyStem}

How does energy innovation work? Can the commercialization of energy technologies be accelerated? These are hard questions that scholars all over the world will continue to investigate. We do know that energy innovation can best be thought of as an ecosystem; that the ecosystem will only be productive if it has enough nutrients (funds, ideas, and appropriately trained and motivated people); and that all the various elements of the ecosystem, namely the actors, institutions, and linkages between them, need to be in balance. ${ }^{20}$ To be effective, innovation institutions (which include institutions responsible for crafting policies) must strengthen or create all of the elements of this ecosystem in a balanced way. This work

20 Institutions include businesses, industry associations, institutions facilitating technology transfer, organizations performing R\&D (e.g., universities, national laboratories, etc.), entities "guiding" innovation (institutions creating policies and regulation, such as the Department of Energy, Congress and the Environmental Protection Energy; Nelson \& Rosenberg 1993) as well as established habits, practices, and norms. Actors or agents include entrepreneurs, scientists, consumers, activists, etc. (Lundvall 1992). 


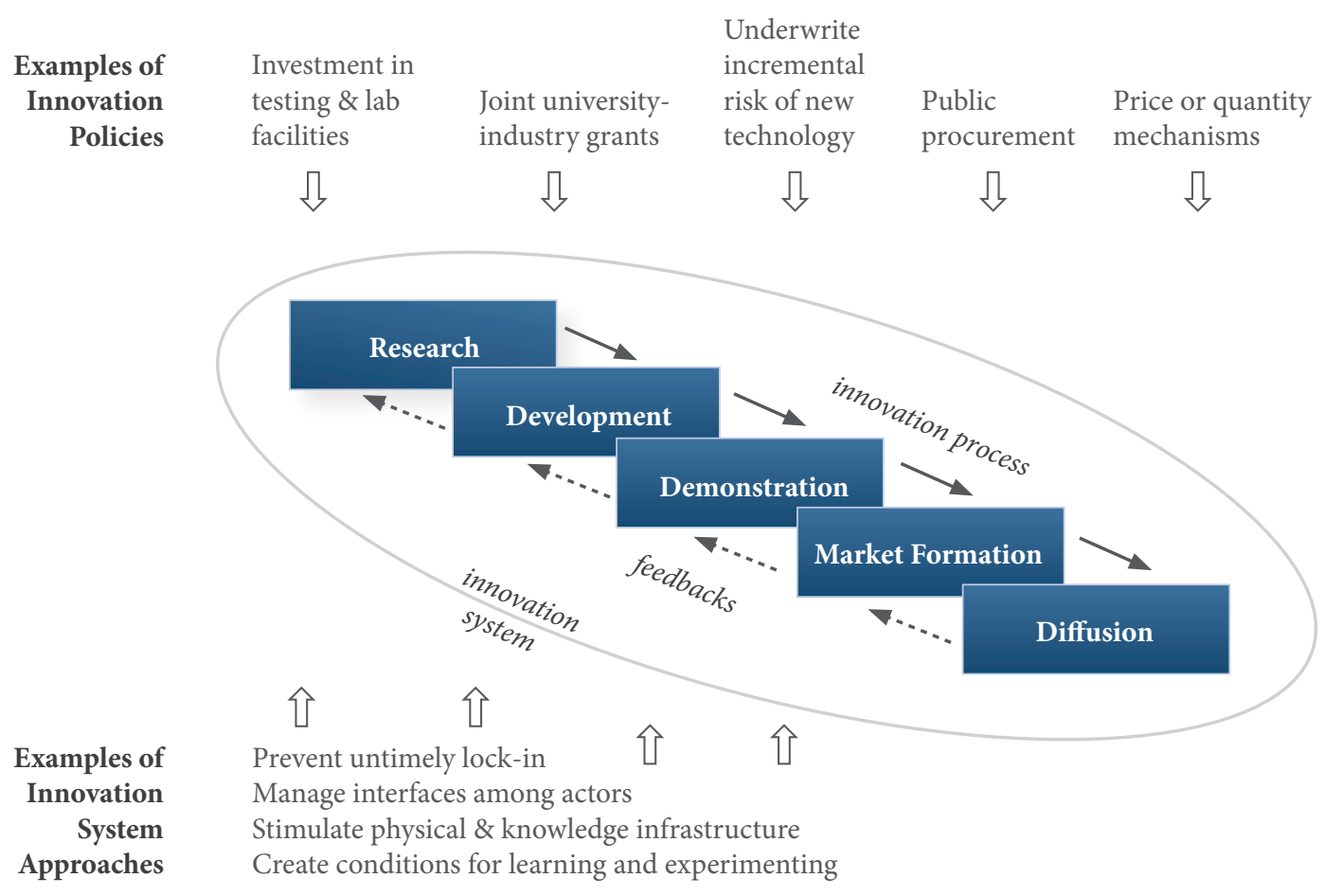

FIGURE 1.2 Schematic of stages and linkages of the energy innovation system. (GEA 2011)

attempts to provide recommendations about how to stimulate innovation by different actors, and how to strengthen the linkages between major innovation, the actors, and institutions.

Innovation has often been described as a linear process in which technologies move from basic research to applied research, applied research to development, development to large-scale demonstration, and demonstration to commercial deployment and diffusion. In reality, it is much more like a food web in an ecosystem, with technologies and resources flowing both forward and backward, as shown in Figure 1.2. The users of a new technology may come up with ideas that lead to modifications in the next version, or even to new basic or applied research; researchers may come up with ideas that will be directly incorporated into the next generation of deployed technology.

Major gaps at any point can disrupt the entire system, just as removing a top predator or a crucial food species can have cascading effects throughout an ecosystem. For example, if private firms see no way to finance the risk of a commercial-scale demonstration of a new technology, and there is little prospect of government support for such a demonstration, they will have little incentive to invest in early-stage research and development that might lead to such a demonstration-even if there are reasonable prospects that the technology could someday be commercially successful.

Government policies have an important role in strengthening different parts of the innovation ecosystem. First, they must ensure that sufficient financing is available at each "technology development stage," from basic research to deployment; avoiding any "valleys of death" between one type of available 
financing and another is crucial. Second, they must ensure that there is a sufficient supply of trained scientists and engineers. Third, strong cultures of innovation that foster a focus on new ideas and a willingness to take risks are of central importance in innovation institutions supported by the federal government (Narayanamurti, Anadon, \& Sagar 2009). Fourth, policies can contribute to the creation of environments and mechanisms to exchange ideas and forge agreements among different actors in the system-opportunities for strengthening the linkages. Start-up firms, large energy companies, research universities, venture capital, private equity, investment banks, government agencies, non-government organizations, legislatures, the media, and the public all have important roles to play.

Policymakers must also recognize that there are important feedback scenarios among all the elements of the energy innovation ecosystem. For example, policies that create market demand for the deployment of clean energy systems (such as a substantial carbon price or renewable portfolio standards) will lead to increased R\&D and the formation of new start-ups seeking to profit from meeting the new demands, although quantifying what policies are most efficient at stimulating innovation in different parts of the energy sector is far from straightforward. In Chapter 4 we make a first attempt at studying how important different government activities are at stimulating innovation by asking business establishments participating in our "energy innovation survey" what government policies affect their decisions about energy RD\&D.

It is the recognition of the need for strengthening many elements of the system that has led the Obama administration and others to propose new energy innovation institutions-taking, in effect, a portfolio approach to institutions as well. Proposed institutions include.

- The Advanced Research Projects Agency - Energy (ARPA-E) is intended to offer a new focus on high-risk but potentially high-payoff ideas (ARPA-E 2010).

- The Energy Frontier Research Centers are intended to focus on basic but use-inspired research targeted on "grand challenges" in energy technology, pulling together expertise and ideas from different universities and laboratories (DOE 2010a).

- The Energy Innovation Hubs are intended to bring researchers and engineers together to develop technologies in particular areas to the point where they can be taken over by the private sector (DOE 2010b).

- The RE-ENERGYSE (Regaining our Energy Science and Engineering Edge) program is intended to increase the pool of scientists and engineers focused on energy.

- A major program of loan guarantees authorized in 2005, but reinvigorated during the Obama administration, is supposed to support initial commercial deployment of new energy technologies. 


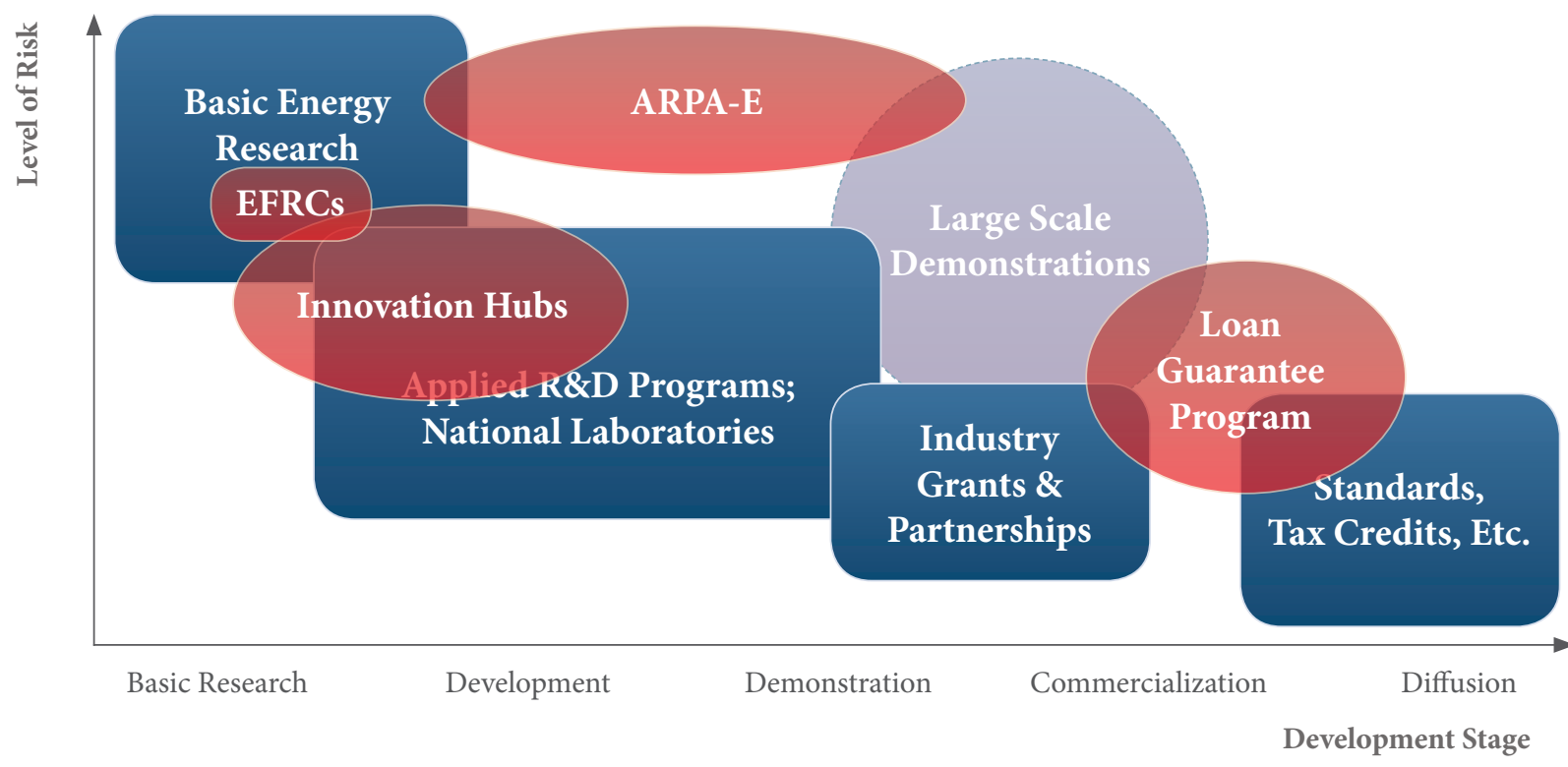

FIGURE 1.3. Schematic of U.S. government institutions and policies with a primary mandate to accelerate energy innovation. Blue boxes denote programs that existed before 2005. The other institutions (with the exception of the "large scale demonstrations", which is an area we have identified as a gap) are more recent: the EFRCs, the Hubs, and ARPA-E were funded in 2009, and theloan guarantee program was instituted in 2005, although the firstloan guarantee was issued in 2009. (Adapted from various presentations from the U.S. Department of Energy.)

In addition, Congress is considering the establishment of a new Clean Energy Deployment Administration that would provide low-cost financing for a range of energy demonstration and deployment projects, and several experts have put forward proposals for a new institution to handle large-scale commercial demonstrations of new energy technologies (Ogden, Podesta, \& Deutch 2008). Figure 1.3 shows the main government programs and institutions-old and new-with a primary mandate to spur energy innovation. Whether and how all of these initiatives will gain support and work together remains uncertain.

\subsection{Successful Innovation Requires a Willingness to Fail-And an Ability TO LEARN AND TO BE FLEXible}

Successful innovation requires a willingness to take risks-which means that some projects will fail. Venture capital firms often expect that nine out of every ten projects they fund will fail—while the tenth will pay off many times over, providing the returns that keep the firm running. Indeed, a "failed" project has value in that it may provide new insights about what works and what does not that may make future projects far more likely to succeed. A central theme of this report is that rapid innovation requires an acceptance of risk. Policymakers in Washington must be willing to accept that a significant portion of projects will fail, and be willing to continue support for innovation efforts even in the face of such failures. Knowledge gained through this experience provides the ability to terminate projects gracefully, and helps to identify new ventures that might be of interest for the U.S.'s energy future. 
The structure of DOE technology programs from the Fossil Energy, Nuclear Energy, Energy Efficiency and Renewable Energy, and Electricity Delivery and Energy Reliability Offices, however, can be interpreted to penalize failure in a way that impedes innovation. With yearly budget cycles and an ever-watchful Congress, DOE officers may rightfully feel that if their projects do not appear to be succeeding quickly enough, their budgets could be cut. This fear of budget cuts could cause the project managers to become excessively cautious and therefore focused only on small, incremental improvements that have a very high chance of success but ones that will not be significant enough to address the energy challenges that face the U.S. As mentioned earlier, ARPA-E was established to try to overcome these problems, creating a new, risktolerant culture in a new institution. But even then, there is the danger that Congress' appetite for "big and early wins" will curtail future funding if early wins do not materialize soon enough. The need for stability and certainty in research, development, and demonstration funding, but also in deployment policies, is discussed in several sections of this report.

At the same time, none of these energy innovation efforts will succeed if they do not learn from both successes and failures over time. Another central theme of this report is that major reforms are needed to allow effective learning. For example, this work highlights that, to date, the Department of Energy (DOE) has not kept accurate centralized information on what kinds of partnerships and contracts with private industry it has used for what purposes, or how well those efforts worked out, making it impossible for new officials to learn from their predecessors' experiences.

\subsection{SCOPE OF THE WORK}

Our research and this report were structured to obtain insights about how the U.S. government could leverage different innovators. This report proceeds in several stages, each focusing on a key element of the energy innovation system.

- Innovation stimulated through federal energy RD\&D budgets and deployment

How much should the U.S. federal government invest in energy research, development and demonstration (ERD\&D)? What benefits might the United States expect from this investment under different deployment policies? How should this investment be allocated across technology areas to address the global threat of climate and to improve U.S. energy security?

Chapter 2 offers recommendations for an expanded and retargeted U.S. federal investment in energy RD\&D. These are based on expert elicitations in a range of key energy technologies, which assessed how much RD\&D funding the experts believed each technology required, how those funds should be allocated, and how much progress they believed would result from their 
recommended RD\&D budgets; that is, how their recommended budgets would shift the spectrum of possible cost and performance that technology might achieve by 2030. We supplemented these expert elicitations with in-depth interviews with individuals who are actively involved in making funding decisions related to that technology. We then used the MARKAL (Market Allocation) economic model to explore how the uncertainties around improved cost and performance projected by the experts might affect commercial deployment of these technologies, in a range of different policy scenarios, and how those deployments might affect goals such as reducing greenhouse gas emissions or dependence on imported oil. Based on the expert surveys and modeling, we offer recommendations for U.S. energy RD\&D investments in a range of energy technologies.

- Innovation at DOE innovation institutions, including national laboratories and ARPA-E

What is the role of the private sector in the United States in supporting ERD\&D? How is the private investment distributed by technology area, by type of firm and industry? What can we learn about areas that are in need of more government support? What incentives would be effective to encourage more private sector innovation activity? What is the U.S. Department of Energy's strategy to partner with the private sector and to leverage its investments in energy innovation? How could the Department of Energy improve its effectiveness? What are the determinants of the innovative performance of national innovation institutions, such as the DOE and the national labs? What information is used for decision making at these institutions? How can these institutions be more effective? How can these institutions implement mechanisms for connecting research to innovation and technology use?

Chapter 3 outlines our recommended approach to strengthening the national laboratories' energy innovation efforts-one key element of making the recommended funding increases, described in Chapter 2, more effective. These recommendations are based, in part, on an in-depth case study of the work of the National Renewable Energy Laboratory and the Semiconductors Research Corporation.

- Innovation in the private sector stimulated through partnerships between the government and industry, stimulated by other policies, and support for technology demonstration projects

Chapter 4 describes how the U.S. government can structure incentives to accelerate energy innovation in the private sector which is likely to be a critical source of the innovations needed to meet twenty-first-century energy challenges. This chapter also provides new data from a pilot-scale survey of private sector energy innovation in the United States, which significantly expands the data available on the scope of private sector energy innovation and the incentives that are most effective in driving it. This chapter also describes the government's efforts toward leveraging private sector innovation through grants and cooperative agreements, and how these 
partnerships could be managed more effectively. In addition, this chapter outlines our recommendations for a strengthened approach to managing large-scale commercial demonstrations of new technologies, pulling together insights from both the government and private sector perspectives. These recommendations are based on the results of a high-level executive session held in December 2010, and include a specific discussion of institutional approaches.

- Innovation with partners in countries outside the United States

How can the government analyze, categorize, and evaluate opportunities for international cooperation in energy technology innovation through a framework? How can we systematically transfer lessons learned from government-led international cooperation to national energy technology innovators? Are there any institutional or informational gaps that need to be addressed to promote learning and to ensure that high potential cooperation projects are taking place?

Chapter 5 lays out recommendations for using international cooperation to accelerate energy innovation. It provides a brief description of historical and current U.S. government engagements in international cooperation on energy technology innovation, and analyzes how international cooperation has evolved over time, using new datasets on international energy technology cooperation between governments, corporations, and individual scientists. It also offers a new approach to identifying and promoting strategic opportunities for international cooperation, while allowing the origination of projects also at the agency and national laboratory level.

The strengths of this report are the following:

- It provides a systematic analysis of the interaction of government support and other deployment policies and their impact on $\mathrm{CO}_{2}$ emissions, oil imports, and price of energy reductions. It estimates the benefits of RD\&D investments and deployment policies while accounting for uncertainty.

- It provides several new pieces of information crucial to designing government policies, including: an estimate of the prevalence of energy innovation in U.S. business establishments; a summary of the DOE's activities in partnering with the private sector over the past ten years; the first overview of the support of government in the large emerging economies for energy technology innovation; and an analysis of the management and decision-making processes in a national laboratory.

- It provides recommendations about how to stimulate private sector innovation, and how to manage international collaboration.

- This report, however, is only one contribution to the energy innovation debate, and there is a wide range of important issues that it does not address: 
- We were not able to include several important energy technologies in our expert surveys, because of resource limitations.

- Our analysis does not consider local and state policy contributions to the promotion of energy innovation. State and local governments, which often function as a subsidy to indigenous companies rather than a targeted support for innovation, also play a role supporting innovation and entrepreneurial activities (through the provision of funds and the creation of institutions), and incentivizing the deployment of novel technologies (through, for example, tax policies and mandates), but they were outside of the scope of our work.

- The report is not comprehensive in its analysis of the role of agencies in the government other than the DOE and its national laboratories. Even though our recommendations related to integrating ERD3 efforts and about how to structure international cooperation in energy innovation apply to departments outside of the DOE, this work did not investigate, in depth, the role of other departments. For example, we did not study how the Department of Defense may be able to create niche markets for energy technologies through procurement-a topic of recent interest (John et al. 2010).

- The report does not discuss the role of behavioral change in addressing our energy problem. Behavioral change is of direct relevance to this report, because changing attitudes impact the acceleration or limitations of deploying new energy technologies, and may impact the kinds of technologies that can be developed. Furthermore, behavioral change (in particular, changes in consumption patterns) has important implications for future energy needs, and therefore energy technology innovation.

In addition, there are also some methodological shortcomings:

(a) Predicting the outcome of RD\&D is very difficult, and past experience suggests a high probability that the consensus of experts on what is promising will be wrong in some areas. Even though our expert consultation also asked experts to think about technology improvements that have low probabilities of occurring, things will happen that the experts could not or did not predict.

(b) Even though we considered the role of the private sector as a source of innovation, more research is needed to understand how government policies affect private innovation, and in particular the impact of government energy RD\&D investments on private entities' RD\&D investments-whether government investments encourage additional private investments in those areas ("crowding in") or lead to lower private investments ("crowding out"). Similarly, the opportunity costs from the government investing in energy RD\&D and that money not being spent elsewhere in the economy are not explored in this analysis. 
(c) Our private sector survey was a pilot survey; a full survey would be needed to allow us to estimate energy innovation investments by sub-sector, as well as differences in energy innovation decision-making by sub-sector. A full survey would also allow us to identify the policies that would be most effective at encouraging energy innovation in different industries.

(d) Our modeling included the impact of deployment policies, including a price on carbon and a low-carbon electricity standard on the deployment of technologies, but it did not include the impact that a carbon price may have on private sector investments in innovation, and hence the pace at which new technologies may become available.

(e) Moreover, the model we used incorporated a variety of constraints on the pace at which deployment of various technologies could expand, even once they became cost-competitive; these model constraints may turn out to be either tighter than is realistic (meaning that technologies are able to expand more rapidly than the model projects) or looser than is realistic (meaning that the non-cost difficulties in achieving widespread deployment are even greater than those incorporated in the model).

(f) The recommendations on energy RD\&D funding allocation are based only on benefits of technologies developed in the United States for deployment within the United States. In reality, of course, there will be technologies developed in other countries which will be deployed in the United States (which might then reduce the need for the United States to invest in them, except from a competitive perspective), and technologies developed in the United States that will be deployed globally (which would increase the benefit of investing in them, either in economic terms or in terms of climate objectives).

(g) Our analysis of international cooperation activities is based on aggregated and often incomplete datasets with limited information about the objectives, reasons, or detailed descriptions of the actual activities within each activity. Furthermore, not all agencies involved in international cooperation activities were interviewed. Finally, more work is required to understand the motives, needs, and mechanisms for international cooperation on energy technology innovation in other countries, and our current analysis of international cooperation activities without U.S. involvement is limited. Detailed case studies would be necessary to understand which international cooperation activities provide more effective support for U.S. companies. 


\section{REFERENCES}

American Energy Innovation Council (2010). A Business Plan for America's Energy Future. Full Report. June. Washington, D.C., United States.

American Enterprise Institute, Brookings Institution \& Breakthrough Institute (2010). Post Partisan Power: How a Limited Approach to Energy Innovation Can Deliver Cheap Energy, Economic Productivity, and National Prosperity. October. Washington, D.C., United States.

Anadon, L. D., \& Holdren, J. P. (2009). “Chapter 5: Policy for Energy-Technology Innovation.” In Acting in Time on Energy Policy. Edited by Kelly Sims Gallagher. Brookings Press, Washington D.C., United States.

ARPA-E (2010). Home Website. Advanced Research Projects Agency - Energy. Available: http://arpa-e. energy.gov/ [2010, 10/20].

BBC (2010). NATO tankers torched in Pakistan. October 1, 2010. www.bbc.co.uk/news/world-southasia-^^US0011

BNEF (2008). “New Energy Finance Desktop 3.0," Bloomberg New Energy Finance.

Brown, M.A., Chandler, J., Lapsa, M.V. \& Moonis, A. 2009, Making Homes Part of the Climate Solution: Policy Options to Promote Energy Efficiency, U.S. Climate Change Technology Program. Oak Ridge, Tennessee, United States.

Brown, M. A., Chandler, S., Lapsa, M. V., and Sovacool, B. K. (2008). Carbon Lock-In: Barriers to the Deployment of Climate Change Mitigation Technologies, Oak Ridge National Laboratory, Oak Ridge, Tennessee, United States.

CNA (2007). National Security and the Threat of Climate Change. Alexandria, Virginia, United States.

CNA 2009, Powering America's Defense: Energy and the Risks to National Security. Report from the CNA's Military Advisory Board. May. Alexandria, Virginia, United States.

Daniel, L. (2010). New Office Aims to Reduce Military's Fuel Usage. American Forces Press Service. www.defense.gov/newsarticle.aspx?id=60131 July 22, 2010.

Defense Science Board 2008, More Fight - Less Fuel. Office of the Under Secretary for Acquisition Technology and Logistics. February.

DOE (2010a). Energy Frontier Research Centers. Main Website. Office of Science. U.S. Department of Energy. Available: http://www.er.doe.gov/bes/EFRC/index.html [2010, 10/22] .

DOE 2010b, Energy Innovation Hubs. Main Website. U.S. Department of Energy. Available: http://www. energy.gov/hubs/ [2010, 10/22] . 
DOE (2011). U.S. Department of Energy, Department of Energy Quadrennial Technology Review

Framing Document (Washington, D.C.: March 14, 2011), http://www.energy.gov/qtr/documents/

DOE-QTR_Framing.pdf

EIA (2009). International Energy Outlook 2009 [Homepage of U.S. Energy Information

Administration. Department of Energy], [Online]. Available: http://www.eia.doe.gov/oiaf/ieo/ pdf/0484(2009).pdf [2009, 7/17].

European Commission (2006). World Energy Technology Outlook - 2050 (WETO - H2), European

Commission. Directorate General for Research, Brussels, Belgium.

G8+5 Academies (2009). G8+5 Academies' Joint Statement: Climate Change and the Transformation of Energy Technologies for a Low-Carbon Future. May.

Gallagher, K.S. (2009). "Acting in Time on Climate Policy" in Acting in Time on Energy Policy, Brookings Institution Press, Washington, DC, United States.

Gallagher, K.S. \& Anadon, L.D. (2010). DOE Budget Authority for Energy Research, Development, \& Demonstration Database. Available: http://belfercenter.ksg.harvard.edu/publication/20013/ [2010, $10 / 20]$.

GEA (2011). Global Energy Assessment. Knowledge Module 24: The Energy Technology Innovation System, Cambridge University Press, Cambridge, United Kingdom.

Griliches, Z. (1992). “The Search for R\&D Spillovers,” Scandinavian Journal of Economics, vol. 94, pp. S29:S47.

Grübler, A., Nakicenovic, N. \& Victor, D.G. (1999). "Dynamics of energy technologies and global change", Energy Policy, vol. 27, pp. 247-280.

Henderson, R.M. \& Newell, R.G. (eds) (2011). Accelerating Energy Innovation: Insights from Multiple Sectors, University of Chicago Press, Chicago, Illinois, United States.

IAEA (2008). Energy, Electricity and Nuclear Power Estimates for the Period up to 2030, OECD, Vienna, Austria.

IEA (2009a). World Energy Outlook, International Energy Agency, Organization for Economic Cooperation and Development., Paris, France.

IEA (2009b). World Energy Outlook 2009, International Energy Agency, Organization for Economic Cooperation and Development. Paris, France.

IEA (2009c). World Energy Outlook 2009 - Executive Summary, Organization for Economic Cooperation and Development. International Energy Agency, Organization for Economic Cooperation and Development. Paris, France. 
IEA (2010a). Energy Technology Perspectives 2010:Scenarios \& Strategies to 2050. International Energy Agency, OECD, Paris, France.

IEA (2010b). International Energy Agency Energy Re D Statistics. International Energy Agency, Organization for Economic Cooperation and Development www.iee.org/stats/rd.asp

IEA (2010c). World Energy Outlook 2010, International Energy Agency, Organization for Economic Cooperation and Development. Paris, France.

John, A., Sarewitz, D., Weiss, C. \& Bonvillian, W. (2010). “A new strategy for energy innovation," Nature, vol. 466, pp. 316-317.

Lester, R.K. (2009). America's Energy Innovation Problem (and How to Fix It).

Lundvall, B.A. 1992, National Systems of Innovation. Towards a Theory of Interactive Learning, Pinter, London, United Kingdom.

Lutzenhiser, L. (2009). Behavioral Assumptions Underlying California Residential Sector Energy Efficiency Programs, California Institute for Energy and Environment, Oakland, California, United States.

Margolis, R.M. \& Kammen, D.M. (1999). "Evidence of under-investment in energy R\&D in the United States and the impact of Federal policy," Energy Policy, vol. 27, pp. 575-584.

McKeown, R. (2007). "Energy Myth Two - The Public is Well Informed About Energy" in Energy and American society - Thirteen myths, eds. B.K. Sovacool \& M.A. Brown, pp. 51-57. Springer, Dordrecht, The Netherlands.

Metz, B., Davidson, O.R., Bosch, P.R., Dave, R. \& Meyer, R.A. (eds) (2007). Climate Change 2007: Mitigation, Contribution of Working Group III to the Fourth Assessment Report of the Intergovernmental Panel on Climate Change, Cambridge University Press, Cambridge, United Kindom.

MIT (2010). The Future of Natural Gas. An Interdisciplinary MIT Study. Interim Report, Cambridge, MA, United States.

Narayanamurti, V., Anadon, L.D. \& Sagar, A. (2009). “Transforming Energy Innovation,” Issues in Science and Technology, , no. Fall, pp. 57-64.

Narayanamurti, V., Diaz Anadon, L., Breetz, H., Bunn, M., Lee, H. \& Mielke, E. (2011). Transforming the Energy Economy: Options for Accelerating the Commercialization of Advanced Energy Technologies, Energy Technology Innovation Policy group. Belfer Center for Science and International Affairs, Cambridge, MA, United States.

NAS (2009). America's Energy Future: Technology and Transformation, National Academies Press, Washington D.C., United States. 
Nelson, R., \& Rosenberg, N. (1993). National innovation ecosystems: a comparative analysis, Oxford University Press, Oxford, United Kingdom.

NSF (2008a). Science and Engineering Indicators 2008. Chapter 4 - Research and Development: National Trends and International Linkages. National R\&D Trends. National Science Foundation. Available: http://www.nsf.gov/statistics/seind08/c4/c4s1.htm\#c4s12 [2010, 10/20] .

NSF (2008b). Science and Engineering Indicators 2008. Chapter 4 - Research and Development: National Trends and International Linkages. Business R\&D. National Science Foundation. Available: http:// www.nsf.gov/statistics/seind08/c4/c4s3.htm [2010, 10/20] .

NSF (2010). Business Research and Development and Innovation Survey (BRDIS). National Science Foundation. Available: http://www.nsf.gov/statistics/srvyindustry/ [2010, 10/20] .

OECD (2008). Nuclear Energy Outlook, OECD, Paris, France.

Ogden, P., Podesta, J. \& Deutch, J. 2008, “A New Strategy to Spur Energy Innovation,” Issues in Science and Technology, Winter.

PCAST (2010). Report to the President on Accelerating the Pace of Change in Energy Technologies Through an Integrated Federal Energy Policy, President's Council of Advisors on Science and Technology. Executive Office of the President.

Rehfuess, E., Corvalan, C. \& Neira, M. (2006). "Indoor air pollution: 4,000 deaths a day must no longer be ignored," Bulletin of the World Health Organization, vol. 85, no. 7.

Simeone, N. (2009). Defense Department Reduces Dependence on Fossil Fuels.

Stavins, R. 2010, 10/21-last update, Both Are Necessary, But Neither is Sufficient: Carbon-Pricing and Technology R\&D Initiatives in a Meaningful National Climate Policy. Available:

http://belfercenter.ksg.harvard.edu/analysis/stavins/?p=827 [2010, 11/14] .

UNEP SEFI \& Bloomberg New Energy Finance (2010). Global Trends in Sustainable Energy Investment 2010 Report.

UNDP (2005). “Energizing the Millennium Development Goals: A Guide to Energy’s Role in Reducing Poverty," United Nations Development Programme. Ney York, pp. 5

U.S. Census Bureau (2010). U.S. International Trade Data. Available: http://www.census.gov/foreigntrade/data/index.html [2010, 11/12] .

Velikhov, E., P., Gagarinksi, A.Y., Subbotin, S.A. \& Tsibulski, V.F. (2006). Russia in the World Energy of the XXI Century, Izdat Nuclear Science and Engineering Publishers, Moscow, Russia. 

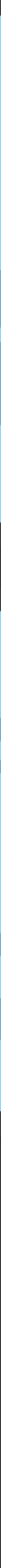


\section{CHAPTER 2}

\section{GOVERNMENT INVESTMENTS IN ENERGY RESEARCH, DEVELOPMENT, AND DEMONSTRATION}

\subsection{INTRODUCTION}

Despite the dire need for advanced energy technologies, for the majority of the last 25 years the U.S. government has made only modest investments in energy research, development, and demonstration (RD\&D). From 1986 to 2008, the U.S. Department of Energy's annual RD\&D spending - the main single funder of energy RD\&D in the United States-was a third of its annual spending in the wake of the global oil crisis during the late 1970s (Figure 2.1). Ironically, the U.S. Department of Energy spending nadir occurred in 1998, just after the President's Committee of Advisors in Science and Technology (PCAST) issued a plea to double funding by 2003 to meet 21 st century energy challenges (PCAST 1997). By 2007, however, applied energy RD\&D funding from DOE finally doubled in as spent dollars when compared to 1998 , and continues to rise.

\subsection{Status Quo}

\subsubsection{Energy RD\&D investments or technology "push"}

It is widely recognized that U.S. government-funded technology development programs have contributed to large technological successes in defense programs, space exploration, and in seeding the IT revolution through the creation of the internet. Recent research underscores the importance of government programs in other industrial sectors. Publicly-funded fundamental research has played a very important role in the growth of the agriculture, chemicals, life sciences, and information technology industrial sectors in the United States over the past 50 years either seeding the industry by supporting foundational science and/or providing continuing support for research (Henderson, Newell 2011; Mowery, Nelson \& Martin 2010). Research on the returns of publicly funded energy research and development has found that a few successful programs can bring about benefits that outweigh the costs of larger programs (see for example, NRC 2001). There are two clear market failures that lead the private sector to systematically underinvest in developing new energy technologies: (a) in the absence of effective government policies, the environmental benefits of new technologies are not priced in the market, and (b) companies can appropriate only a fraction of the overall societal benefit of the new technologies they develop (Jaffe, Newell \& Stavins 2005). 
Since 2005, funding for basic energy sciences and applied energy RD\&D in the United States has been on the rise. Between 2005 and 2008, funding increased at an average annual rate of $12 \%$ in real dollars. Funding rose by $20 \%$ between 2008 and 2009 , reaching $\$ 5.1$ billion, of which $\$ 3.6$ billion was for applied energy RD\&D. The 2009 Stimulus package included about $\$ 6.1$ billion, and the budget for FY 2010 was $\$ 5.3$ billion. Figure 2.1 shows the budget distribution for energy technology RD\&D in the applied offices of DOE: Fossil Energy (FE), Energy Efficiency and Renewable Energy (EERE), Electricity Delivery and Energy Reliability (OE), and Nuclear Energy (NE). The FY 2010 appropriation included \$516 million for nuclear fission; \$380 million for nuclear fusion; \$203 million for hydrogen; \$975 million for renewables; $\$ 159$ million for electricity transmission and distribution; $\$ 644$ million for fossil energy, including a clean coal technology demonstration; and $\$ 657$ million for energy efficiency programs in the vehicles, buildings, and industry sectors. ARPA-E received no funds in the FY 2010 appropriation as it was still funded with the $\$ 389$ million it received in the 2009 Stimulus package to support high-risk and groundbreaking energy technology. In our recent analysis of this budget and allocation (Anadon et al. 2010), we found the requested funding increase for FY 2011 compared to FY 2010 appropriations encouraging, but it still falls short of the large and sustained investment likely both to be required to transform U.S. and global energy use and production and to meet the climate, energy availability, and energy security demands of the twenty-first century. In real terms, the support for basic and applied energy RD\&D would remain 30\% below the 1978 level, the peak of government funding for energy $\mathrm{RD} \& \mathrm{D}$ in the United States.

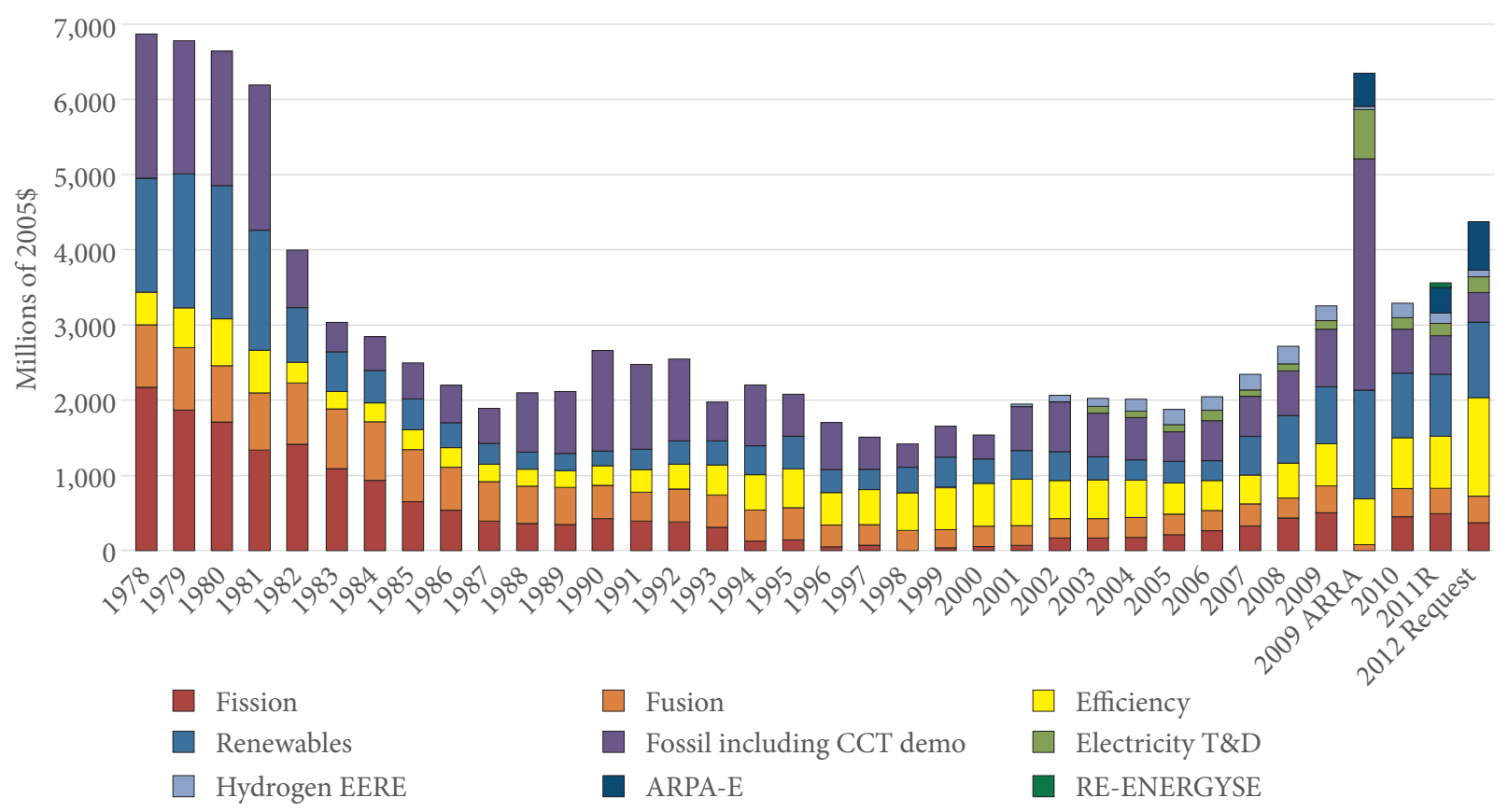

FIGURE 2.1. Energy RD\&D funding by DOE between 1978 and the FY 2011 Request excluding funding for basic energy sciences (Gallagher \& Anadon, 2011). 
In this Chapter we present our methodology for estimating the benefits of investing in a range of energy technologies, and the results of our surveys of technology experts and our economic modeling. Using this methodology and the estimates elicited from experts, we discuss the overall level and allocation of investment that would be needed to increase the probability of achieving certain targets $\left(\mathrm{CO}_{2}\right.$ emissions and oil import reductions, among others), taking into account uncertainties in technological progress and interactions between technologies in the marketplace.

\subsubsection{Deployment incentives or "market pull"}

As highlighted by the literature, RD\&D by itself will not be sufficient to catalyze the necessary changes in the U.S. energy system cost-effectively (Mowery, Rosenberg 1979; Goulder, Schneider 1999; Lester 2009; Fischer, Newell 2008; Anadon, Holdren 2009; Holdren, Baldwin 2001). Before achieving widespread diffusion, novel energy technologies are often faced with barriers, which can include cost above that of incumbent technologies, lack of supporting infrastructure, slow capital stock turnover of incumbent technologies, the lack of information about new technologies for consumers, and financing constraints (Gallagher, Holdren \& Sagar 2006; Sagar, D. J., van der Zwan, B. 2006; Sagar 2004). Deployment policies, including carbon prices, efficiency or pollution standards, and tax policies, can reduce the barriers to deployment (Brown 2001), but they can also affect the pace and direction of RD\&D. On the one hand, deployment policies can provide support for $\mathrm{RD} \& \mathrm{D}$ efforts by providing investors with the certainty that there is a supportive deployment framework for their technologies. On the other hand, unstable or unpredictable deployment policies can discourage investments in innovation, and counteract RD\&D efforts (Wiser, Pickle 1998; Bolinger et al. 2009; DSIRE 2010).

An analysis of the expected benefits of energy RD\&D investments can therefore not be complete without an analysis of complementary deployment policies, which we explore through policy scenarios using an energy system model (MARKAL). The benefits of RD\&D investments will also depend on other market conditions, including oil and gas prices, which we also analyze through market scenarios.

In this work, however, we do not incorporate the effect that "demand pull" policies have on stimulating RD\&D in the private sector. While it is clear that policies such as putting a price on carbon emissions would stimulate additional private investment in finding cost-effective ways to reduce those emissions - and indeed, the private-sector energy innovators we surveyed reported that expected prices were by far the largest drivers of their investment decisions-there is currently insufficient empirical evidence to determine how large the increases in private innovation that would result from particular policies would be, and how much such private investments would affect the future cost and performance of energy technologies. Because our modeling does not include this phenomenon, it understates the benefit of demand-side policies, and likely overstates the costs of reaching particular climate targets in the future; the new market opportunities that would be created by a substantial price on carbon are likely to provoke 
innovation that will ease the path toward reducing carbon emissions, though the scale of that effect is unknown. In our modeling, we consider instead how these "demand pull" policies affect the diffusion through their impact on relative prices of technologies whose progress is not driven by prices.

We now turn to describing some of the federal "deployment" or "demand pull" policies that are currently in place and are most relevant to clean-energy deployment. These status quo policies are captured in the business-as-usual (BAU) scenario and include all deployment policies modeled in the Energy Information Administration's (EIA) Annual Energy Outlook (EIA 2010a). A more detailed discussion may be found in the associated report on assumptions (EIA 2010d). After summarizing the status quo policies in the BAU scenario, we describe other policies that are not currently in place but may affect the benefits of RD\&D investments that we consider in our analysis and model through scenarios.

\subsubsection{Power generation standards}

State regulations in the power generation sector have largely focused on renewable portfolio standards (RPS), which require utilities to produce a certain percentage of their electricity through renewable sources, though other regulations, such as energy efficiency resource standards (EERS) (Laitner 2009) and GHG emissions limits at new and existing power plants (Ramseur 2007), have also been deployed. RPSs are in place in 29 states (plus the District of Columbia and Puerto Rico), and seven states have renewable portfolio goals that are not legally binding. In addition, the state RPSs are diverse with targets that range from $10 \%$ to $33 \%$ of electricity sales and targets years of 2000 to 2035 . Some RPSs include non-renewable alternative resources, require or give extra credit for minimum solar or customer-sited generation, or make solar water heating eligible (DSIRE 2010). It has been estimated that these 29 states with an RPS represent 52\% of US electric sector GHG emissions, 59\% of total US GHG emissions, and $59 \%$ of US electric power generation (Lutsey, Sperling 2008). In addition, 24 states have enacted an EERS (Sciortino 2010). The RPS in these 29 states plus the District of Columbia are represented in the BAU scenario, while state EERSs are not.

A national combined efficiency and renewable electricity standard (CERES) was passed in the Waxman-

Markey bill (H.R. 2454) in the U.S. House of Representatives. CERES would require all retail electricity suppliers with annual sales above 4 million MWh to meet $20 \%$ of their load with qualified renewable energy sources or electricity efficiency savings by 2020. Small utilities, hydroelectric generation, new nuclear plants, and new fossil plants with CCS are exempted from the baseline. One-fifth of the requirement can initially be met with efficiency savings, with the possibility of an additional $20 \%$ if approved by the Federal Energy Regulatory Commission. However, the Energy Information Administration found that the level of the CERES was non-binding in the context of existing state RPS (EIA 2009). In addition, Senator Graham Howell proposed a clean electricity standard (CES) (Howell 2010). A CES operates 
like a CERES, but it allows nuclear, coal with CCS, and newly-retired carbon-intensive power plants to qualify for the clean electricity target calculation (Bird et al. 2010).

In this work we estimate the effects of complementing increased RD\&D investments with a binding federal CES.

\subsubsection{Building codes}

In the buildings sector, for example, it is often the case that the business or unit that would get the benefit of lower energy bills is not the same as the one paying the cost of more expensive energy-efficient designs - so even efficiency measures that would pay for themselves do not get built. Similarly, consumers purchasing energy-efficient products often have insufficient information or expect very short payback times, limiting the adoption of more energy-efficient appliances and vehicles. Labeling, performance standards, and other sector-specific policies will be needed to overcome these barriers.

The Energy Policy Act (EPAct) of 1992 established a role for DOE to determine whether or not new building codes would improve energy efficiency for residential and commercial buildings. If DOE finds that the newest version of building codes are more energy efficient than the previous versions, states are required to certify that their building energy codes meet the requirements of the new standards within two years. DOE issued a preliminary determination in September 2010 that the 2009 International Energy Conservation Code (IECC) would achieve greater energy efficiency in low-rise residential buildings than the previous editions of the IECC, and that the Standard 90.1-2007 would achieve greater energy efficiency in commercial buildings subject to the code than the 2004 edition (75 Federal Register 54131 (2010 09 03) and 74 Federal Register 54117 (2010 09 03)). In the BAU scenario,. all states are assumed to adopt the 2006 IECC code by 2017 and commercial building shell efficiency improves 5\% and $7 \%$ by 2030 for existing buildings and new construction, respectively (EIA 2010d).

The low rate of technical progress in building construction is partly due to fragmentation in the market; regulatory, pricing, and fee barriers; intermediaries in the decision-making; insufficient and imperfect information; technology unavailability; and large variations in local regulations (Oster, Quigley 1977; Brown, Southworth \& Stovall 2005). Implementation and enforcement efforts are inconsistent from state to state or from jurisdiction to jurisdiction, relying on state agencies, jurisdictional authorities, or self-certification by builders. In some places, anecdotal evidence suggests that energy-efficiency codes are a much lower priority for enforcement than the health and safety codes, such as fire codes. The evidence from energy code evaluation studies suggests that the full potential of energy and cost savings from the implementation of building codes is not being achieved (Yang 2005). This gap in savings impedes the deployment of more energy-efficient building technologies. 
In our deployment policy scenarios, we test the impact of progressively more efficient building codes, assuming that their implementation and enforcement leads to the construction of new buildings and retrofits of existing buildings compliant with the new code.

\subsubsection{Transportation sector policies: fuel economy standards, biofuels mandates, and vehicle tax credits}

The corporate average fuel economy (CAFE) standard requires manufacturers to produce vehicles whose average fuel economy meets a minimum Federal standard and was created in the Energy Policy Conservation Act of 1975. Cars and light trucks are regulated separately with attribute- or footprintbased standards. The current model year CAFE standard for cars is $27.5 \mathrm{mpg}$. The car standard is unchanged through 2011. The 2008 CAFE standard for light trucks is $22.5 \mathrm{mpg}$, increasing to $23.1 \mathrm{mpg}$ in 2009, 23.5 mpg in 2010, and $24.1 \mathrm{mpg}$ in 2011 (71 Federal Register 17566 (2006 04 06) and 68 Federal Register 16868 (2003 04 07)). In May 2010, the EPA and the National Highway Traffic Safety Administration (NHTSA) published the final rulemaking for model year 2012-2016 light-duty vehicle greenhouse gas emissions standards and CAFE standards, which will require an estimated combined average emissions level of 250 grams of carbon dioxide per mile, equivalent to 35.5 miles per gallon (75 Federal Register 25324 (2010 05 07)). The standard is assumed to increase to $40.0 \mathrm{mpg}$ for cars and $29.6 \mathrm{mpg}$ for light trucks in 2020 (Energy Independence and Security Act of 2007, Title 1, Section 102). These standards to 2020 are modeled in the BAU scenario. Higher standards for vehicle fuel economy beyond 2020 and the interplay with $\mathrm{RD} \& \mathrm{D}$ investment benefits are explored in policy scenarios.

The Energy Independence and Security Act also requires the use of 36 billion ethanol equivalent gallons of biofuel per year by 2022, with corn ethanol limited to 15 billion gallons by amending the renewable fuels standard. Of the 36 billion gallons, 16 billion gallons per year must be cellulosic biofuel by 2022 and 1 billion gallons per year must be biodiesel by 2012. This is included in the BAU scenario; however, the cellulosic biofuel requirement is adjusted downward, consistent with waiver provisions in the law (EIA 2010d).

To encourage the initial deployment of electric vehicles, a tax credit of $\$ 2,500$ is available for the first 200,000 light-duty plug-in hybrid electric vehicles (PHEV) sold by each manufacturer with a battery capacity of at least $4 \mathrm{kWh}$, with an additional tax credit depending on battery capacity, up to a maximum of \$7,500 (American Recovery and Reinvestment Act of 2009). This tax credit is included in the BAU scenario.

\subsubsection{Climate change mitigation targets}

Lutsey and Sperling (2008) compiled (as of September 2007) a database of: (a) 684 cities with a target to reduce cities' GHG emissions to 7\% below 1990 GHG levels by 2012 and (b) seventeen states with tar- 
gets to reduce states' GHG emissions to specific emission levels in future years (generally to 1990 GHG emissions levels by 2020). While policy at the local level contributes to the deployment of technologies that are mature and provides a signal to the private sector that new technologies reducing GHG emissions may have more value than that in a world without local climate policies, a clear national policy to limit GHG emissions would provide a much stronger signal, and would create an easier regulatory environment for businesses (NCEP 2009). The President's goal is to reduce GHG emissions by $83 \%$ from 2005 levels by the year 2050 (The White House 2009). The American Clean Energy and Security Act of 2009 H.R. 2454-also known as the Waxman-Markey bill-passed by the House in June 2009 would set an economy-wide GHG emissions cap of $83 \%$ below 2005 levels by 2050. GHG emission reduction targets are not assumed in the BAU scenario, but the impact of the target in the Waxman-Markey bill combined with $\mathrm{RD} \& \mathrm{D}$ benefits is analyzed in policy scenarios.

\subsubsection{Market conditions for oil and natural gas}

Natural gas prices (annual average lower 48 U.S. wellhead) have risen from \$2.09 per thousand cubic feet (tcf) in 1995 to $\$ 8.05$ per tcf in 2005 , before falling to $\$ 3.67$ per tcf in 2009 , and rising to $\$ 4.16$ per tcf in 2010 (all in 2009 U.S.\$) (EIA 2011a, EIA 2010b). Such dramatic changes illustrate the uncertainty about the long-term trend for natural gas prices, particularly due to the growing development of shale gas resources (EIA 2010a). Average worldwide crude oil prices reached a high of $\$ 137$ per barrel in the first week of July 2008 but fell to $\$ 35$ per barrel in the first week of January 2009. At mid-July 2011 prices had risen back to $\$ 114$ per barrel (all in nominal U.S.\$) (EIA 2011b). While the BAU scenario assumes natural gas and oil prices projected in the AEO 2010 reference case, we also analyze sensitivities of RD\&D benefits to other AEO scenarios of low and high natural gas and oil prices.

\subsection{Review of Calls for More Energy InNovation}

Federal funding is an invaluable mechanism to support high-risk, high-social premium projects that would not otherwise attract private investors (American Energy Innovation Council 2010). Several studies have called for larger U.S. government spending on energy technology RD\&D over the past 13 years, as well as consideration of a portfolio of technologies to reduce uncertainty about the ability to reduce emissions as a result of the RD\&D investments. In 1997, the President's Council of Advisors on Science and Technology (PCAST) recommended increasing spending in applied energy RD\&D by 8\% per year from 1997 to $\$ 2.8$ billion 2010\$ in 2003 (a doubling in as-spent dollars) (PCAST 1997). In 2004, the National Commission on Energy Policy (NCEP) recommended doubling annual RD\&D investments from $\$ 2.0$ billion of $2010 \$$ in 2004 to $\$ 3.7$ billion $\$ 2010$ in 2010 (for comparison, investments in applied RD\&D in 2010, excluding funding from the Recovery Act, were about $\$ 3.7$ billion in $2010 \$$, although the allocation is different from that recommended) (NCEP 2004). In 2008, the American Physi- 
cal Society (APS) recommended a return to 1980s building efficiency RD\&D budget levels ( $\$ 256$ million in 2010\$) (APS 2008). In 2010, the Brookings Institution, the American Enterprise Institute, and the Breakthrough Institute recommended investing \$25 billion per year in RD\&D via a network of innovation institutes, ARPA-E, expanded energy technology demonstration by the U.S. Department of Defense, and modular nuclear reactor RD\&D. Also in 2010, the American Energy Innovation Council (AEIC) recommended $\$ 16$ billion per year in federal energy RD\&D (American Energy Innovation Council 2010). Along those lines, PCAST recommended that the President support annual expenditures on energy RDD\&D ${ }^{21}$ of about $\$ 16$ billion per year (PCAST 2010).

While the APS report focuses on means to improve vehicles and buildings technology, the NCEP and PCAST reports emphasize the need for "...a much more systematic effort in R\&D portfolio analysis: portraying the diverse characteristics of different energy options in a way that facilitates comparisons and the development of appropriate portfolio balance, in light of the challenges facing energy R\&D and in light of the nature of the private sector and international efforts and the interaction of U.S. government R\&D with them"(PCAST 1997). Although all of the studies discussed press for additional attention and resources to be devoted to accelerating energy technology innovation, none of them offer analytic insight into the potential outcomes of additional government investment, which could contribute to making decisions about the level of investment and allocation. In other words, none of the studies

\begin{tabular}{|c|c|}
\hline Year & Recommendation \\
\hline 1997 & $\begin{array}{l}\text { PCAST recommended } \$ 2.8 \text { billion per year in } 2010 \$ \text { by } 2003 \text {, which represented a doubling in "as spent" } \\
\text { dollars from 1997, for energy efficiency, nuclear fission and fusion, fossil energy, and renewables. }\end{array}$ \\
\hline 2004 & $\begin{array}{l}\text { NCEP } 2004 \text { recommended an increase from } \$ 2.0 \text { billion } 2010 \$ \text { in } 2004 \text { to } \$ 3.7 \text { billion } 2010 \$ \text { in } 2010 \text { (al- } \\
\text { most a doubling) for oil security, energy efficiency, advanced coal, nuclear energy, and renewables. }\end{array}$ \\
\hline 2008 & APS recommended \$250 million per year for buildings efficiency. \\
\hline \multirow[t]{3}{*}{2010} & $\begin{array}{l}\text { Brookings Institution, American Enterprise Institute, and Breakthrough Institute recommended } \\
\$ 25 \text { billion per year for a national network of innovation institutions, expanded U.S. DOD en- } \\
\text { ergy technology procurement, ARPA-E, and nuclear power }\end{array}$ \\
\hline & $\begin{array}{l}\text { - The American Energy Innovation Council recommended } \$ 16 \text { billion per year in federal energy } \\
\text { RD\&D. }\end{array}$ \\
\hline & $\begin{array}{l}\text { - PCAST recommended that the President support annual expenditures on energy RDD\&D of } \\
\text { about } \$ 16 \text { billion per year. }\end{array}$ \\
\hline
\end{tabular}

TABLE 2.1. Timeline of major federal energy RD\&D spending recommendations. Note that, unlike the previous recommendations, the 2010 report by Brookings et al. covered a greater number of incentives for technology innovation, including funding for ARPA-E, a new network of centers, and government procurement.

21 The AEIC recommendation of $\$ 16$ billion represents an increase of $\$ 11$ billion to FY 2010 spending of $\$ 5$ million for basic energy sciences and technology RD\&D, which does not include Federal spending for deployment policies. The PCAST report explicitly supports the AEIC recommendation, however, uses the nomenclature of "RDD\&D". 
discuss how to think about allocating investments based on the expected benefits, accounting for the uncertainty inherent to RD\&D as well as the interplay between technologies in the marketplace, which affect the benefits of the investments.

\subsection{Methods to Evaluate Budgets for Energy Technology Innovation}

In this section, we review the approaches that have been proposed to aid decisions about investments in energy innovation. The next section explains our methodology of eliciting technology experts for RD\&D budgets and outcomes, and evaluating those estimates with a model of the U.S. energy system.

Most empirical studies have found that technology R\&D investments in general yield large returns to society. A review of studies estimating return on $\mathrm{R} \& \mathrm{D}$ investments found that there is $10 \%$ to $80 \%$ social return on investment for technology R\&D (Griliches 1992). A specific example of returns to government investments in energy research evaluating the benefits from DOE's programs on energy efficiency research from 1978 to 2000 found that the economic benefits of just 6 energy efficiency programs had been almost four times larger than the cost to the government of supporting all efficiency research programs during the time period considered (NRC 2001).

Several studies have tried to estimate the value of supporting energy technology R\&D:

(a) One paper calculated the value of low-carbon $\mathrm{R} \& \mathrm{D}$ as the difference between the cost of limiting $\mathrm{CO}_{2}$ emissions to different $\mathrm{CO}_{2}$ stabilization levels (no limit with a 35\% probability; 450 parts per million of $\mathrm{CO}_{2}$ by volume (ppmv) with a $5 \%$ probability; 550 ppmv with a $25 \%$ probability; 650 ppmv with a $20 \%$ probability; and 750 ppmv with a $15 \%$ probability) with advanced technologies and with BAU technologies and assuming a rate of R\&D success ranging from 0.1 to 1 (Schock et al. 1999). The potential value of U.S. low-carbon energy R\&D to reduce climate change mitigation costs was estimated to be $\$ 6.4-\$ 9$ billion annually in $2010 \$$ U.S. The paper also estimated the value of $R \& D$ to reduce the costs from oil price shocks and urban air pollution. Nemet and Kammen used the results from 550 ppmv $\mathrm{CO}_{2}$ stabilization scenario of Schock et al. (1999) to recommend that $\$ 6.7-\$ 30.1$ billion $2010 \$$ be invested in low-carbon technology R\&D (Kammen, Nemet 2005a; Kammen, Nemet 2005b). An important weakness of this approach is that it is based on speculative assumptions about the likely rate of R\&D success, and does not differentiate among different technologies in that respect.

(b) Another paper used the concept of real options to estimate the option value of investments in renewable energy R\&D. It considered the volatility of gas prices (and its impact on the price of gas power) and made assumptions about the effect of $\mathrm{R} \& \mathrm{D}$ on reducing the uncertainty around achieving particular technology improvements. The result of this estimate was that U.S. renew- 
able energy R\&D would be worth $\$ 5.4$ billion 2010\$ (Davis, Owens 2003). The authors then estimate, in a separate calculation, the optimum yearly level of renewable energy R\&D to be $\$ 1.4$ billion $2010 \$$ by making assumptions about how the rate of renewable electricity cost reductions would increase from $1 \%$ per year to $4 \%$ per year with increases in annual R\&D funding. This approach similarly is based on speculative assumptions about the degree of progress that will result from increased $\mathrm{R} \& \mathrm{D}$, and does not differentiate among different technologies.

(c) More recently, another paper estimated the optimal allocation of R\&D funds for renewable energy, nuclear energy, and coal with CCS by defining two states for the cost of those technologies (BAU and low), assuming that the probability of achieving the low-cost technology is an exponential function of $\mathrm{R} \& \mathrm{D}$ (with decreasing returns to scale and an asymptotic probability of success of 0.8 ), and maximizing the expected value of global GDP in a general equilibrium model (MERGE) (Blanford 2009). Here, there is a differentiation among three broad classes of technology, but there is the major simplifying assumption of only two possible future costs for these technologies, and the result is sensitive to the assumptions about how R\&D investments would affect the probability of those two future states.

In short, these analyses do not claim to present a robust methodology for linking R\&D investments and the uncertain technology outcomes.

Another group of studies has sought to forecast the impact of R\&D investments on future cost and performance of a technology. To the best of our knowledge, four methods have been used: (a) expert elicitation, which can be used to predict potential outcomes of hypothetical RD\&D programs, thus lending insight into uncertainty (Morgan, Henrion 1990); (b) decomposing long-term trends in technology cost (Nemet 2006; McNerney, Trancik \& Farmer 2011) and using them to infer future technology developments; (c) monitoring "precursors", or indicators that strengthen or weaken a hypothesis that a technological change will take place (Martino 1987); and (d) technology roadmapping, in which experts lay out particular technical barriers to be overcome and attempt to estimate the costs of programs to overcome those barriers (Garcia, Bray 1997).

Several studies have elicited expert opinions about the relationship between different levels of U.S. energy R\&D spending and the probability of achieving set cost and performance benchmarks for carbon capture and storage (Baker, Chon \& Keisler 2009b), photovoltaics (Baker, Chon \& Keisler 2009a; Curtright, Morgan \& Keith 2008), biofuels (Baker, Keisler 2009), nuclear energy (Baker, Chon \& Keisler 2008), and vehicle battery technologies (Baker, Chon \& Keisler 2010). These studies evaluate low-, medium-, and high-levels of funding, as defined by the consulted experts (Baker, Chon \& Keisler 2009a; Baker, Keisler 2009; Baker, Chon \& Keisler 2008; Baker, Chon \& Keisler 2010), and two- and ten-fold increases over current spending (Curtright, Morgan \& Keith 2008). In practice, the experts could also 
lend insight into other factors affecting innovation such as spillovers from other areas (see (Clarke, Weyant \& Birky 2006) for a discussion of spillovers), and the socio-technical dynamics of innovation (e.g., networks, community building) (see (Geels, Hekkert \& Jacobsson 2008) for a discussion of the importance of socio-technical factors).

Previous studies have combined expert elicitations about the relationship between R\&D investments and technical change with integrated assessment models, such as GCAM (previously MiniCAM) (Baker, Chon \& Keisler 2009b; Baker, Chon \& Keisler 2009a), to estimate the marginal cost of abating CO2 emissions under different R\&D investment scenarios for different technologies (advanced solar and carbon capture and storage) separately. Another group is conducting expert elicitations to account for technical uncertainty in analysis using the Witch integrated assessment model (Bosetti et al. 2009). Finally, researchers at the Climate Change Technology Program at the U.S. Department of Energy and the Pacific Northwest National Laboratory presented two approaches to help the budget process at DOE assess the tradeoffs in constructing a portfolio of technology acceleration goals: in one approach, the value of a technology is defined in terms of the quantity of reduced carbon emissions to which its use can be attributed; in the other, the value of a technology is defined as the cost reduction for which its use is responsible in meeting a fixed emission reduction target. The portfolio is then built by rank-ordering return-on investments also using GCAM. The same group of 8 policy and technology experts assessed the likelihood that each of the 8 technology areas considered would be in an advanced state (Pugh et al. 2010).

Our unique contributions to existing methodologies, described below, allow us to assess energy RD\&D allocations to different energy RD\&D stages and technology areas. We account for the uncertainty around the benefits of investing in a portfolio of technologies and examine a wide range of budget, deployment, and market scenarios.

\subsection{Method ANd Rationale OF This Work}

We arrived at our recommendation of the total federal budget and allocation for seven areas of energy technology RD\&D using the following multi-step method:

- First, we designed and conducted expert elicitations (or formal surveys) on seven technology areas: fuels and electricity from biomass (bioenergy, for short); different types of utility scale energy storage (or storage); residential, commercial, and utility scale photovoltaic technologies (solar); efficiency in commercial buildings (buildings); nuclear power from Generation III/III+, Generation IV, and small and medium reactors (nuclear);22 coal and natural gas electricity pro-

We did not include fusion technology in this work. 
duction with and without carbon capture and storage (fossil); and vehicle technologies (vehicles). We invited leading researchers and practitioners in each of the seven fields to give us their input. We asked experts to estimate technical cost and performance in 2030 under a businessas-usual scenario for federal RD\&D funding for that technology, to recommend the level of annual RD\&D funding and allocation that would be necessary to increase the commercial viability of the technology areas, and to revise their 2030 technology projections under different budgets. Because of time constraints, we were unable to cover the full range of technologies, and thus were unable to include in the analysis the benefits of $\mathrm{RD} \& \mathrm{D}$ in wind power, geothermal power, concentrated solar power, advanced lighting, and industrial energy efficiency.23

- Second, we asked an additional set of experts, with experience thinking about investments on a range of technology projects (their affiliations included DOE programs, venture capital firms, and U.S. Congressional committees), for their feedback on the results from each of the seven expert elicitations. These qualitative reviews helped us interpret the elicitation results and served to expand expert input in our work.

- Third, we selected the answers from three experts for each technology area, representing optimistic, "middle-of-the-road", and pessimistic forecasts (encompassing the full range of answers to the extent practical), to create three types of new technology profiles in the Brookhaven National Laboratory ten-region MARKet ALlocation (MARKAL) model. We chose this model because it is used by the U.S. DOE for energy policy and Government Performance and Results Act analyses. In addition to defining these three types of technology profiles, we also created four different RD\&D funding scenarios: business-as-usual, 1/2 of the recommended budget, the recommended budget, and 10 times the recommended budget. Each combination of technology profile and budget scenario has different technology cost and performance characteristics, as specified by the experts consulted. We also designed a sampling algorithm to allow us to estimate the uncertainty around the benefits of a portfolio of investments. Using MARKAL,

23 We prioritized updating MARKAL's technology profiles of seven technology classes with uncertainty over wind power because it is a technology where there is already substantial commercial deployment, and a recent report by NREL highlighted research priorities and technology potential for wind power (DOE 2008). Similarly, a comprehensive report provided recent insight into the future of geothermal power (MIT 2006). Our buildings elicitation asked experts about RD\&D investments in building technologies for both commercial and residential buildings, and for the necessary RD\&D investments on different parts of the building envelope, lighting technology, energy metering programs, building modeling studies, etc. Our questions about technology outcomes, however, were limited to the cost of reducing the energy demand for heating and cooling (or HVAC, which represents $39 \%$ of energy use in residential buildings and $32 \%$ of energy use in commercial buildings). Even thought lighting is the second largest energy user in both types of buildings, the improvements of lighting technologies resulting from the budgets recommended by the experts are were not included in the analysis. In addition, the experts consulted decided to provide their insight about the role of RD\&D on the cost of commercial and not residential buildings (commercial buildings used $18 \%$ of primary energy in the United States in 2006, while residential buildings used 21\% (EIA 2010e)). Therefore, the benefits from the RD\&D investments in buildings represent a lower-bound estimate. 
we calculated the following benefits of budget scenarios beyond BAU funding accounting for uncertainty: reductions in $\mathrm{CO}_{2}$ emissions, $\mathrm{CO}_{2}$ prices, clean-energy standard credit prices, oil imports, and consumer surplus.

- $\quad$ Fourth, we defined policy and market scenarios to examine how the benefits of the RD\&D programs would change under different non-RD\&D policy scenarios. Particular policies evaluated include limits on $\mathrm{CO}_{2}$ emissions, a CES, more stringent building codes, and more stringent transportation fuel economy standards. Particular market scenarios include high oil and gas prices, and high oil and low gas prices.

We decided to obtain inputs about technical change resulting from government RD\&D investments, and the uncertainty around the technical change that would be catalyzed by those investments using expert elicitation, for two reasons. First, because extrapolation of cost reductions from historical data on the evolution of a technology excludes the possibility that technology may advance through new pathways and does not utilize the most recent knowledge in the field about possible breakthroughs. Second, expert elicitation allows for the quantification of uncertainty (or at least that portion of the uncertainty perceived by experts in the field) and can help decision makers collect information in cases where observable data is sparse or unreliable, and potentially useful data is unpublishable or proprietary (Chan et al. 2010).

It is also worth pointing out that, although the papers reviewed earlier using the concept of insurance and option value restricted their analyses to the early stages of innovation (i.e., research and development), the analysis presented in this work considers the federal funding necessary to support use-inspired basic research, applied research and development, pilot scale experiments, and commercial demonstration on energy technologies (from now on the combination of those categories will be referred to as $\mathrm{RD} \& \mathrm{D})$. We included use-inspired basic research and demonstration because, as discussed in Chapter 1.7, innovation is a complex and interconnected process, of which research and development are important, but only part of the whole (Gallagher, Holdren \& Sagar 2006). The intent of a commercial scale demonstration is to show that the technology can be effectively used at full commercial scale in an economically useful way (i.e., at reasonable cost). However, such a scale-up is also the first opportunity to learn how the technology works at full scale, and whether the design features are reasonably workable, controllable, and optimum. As such, the beginning of operations of a full-scale demonstration plant is an experiment, designed for learning and "debugging". A new plant needs adjustment, particularly in control systems and their use, sometimes in alterations in hardware (hopefully minor), and always requires some accumulation of experience in operating the plant. It is, in fact, a late stage of development. It provides an opportunity to learn what changes the builders of the next plant(s) should make.

While our elicitations did ask about basic research needs for specific technology areas, the recommendations were not meant to incorporate all needs in the BES program, which should be planned holistically 
to avoid stovepiping. While BES funding should continue to increase substantially, in line with what others have recommended, we did not design our elicitation to obtain insights on overall BES funding.

There are three main differences between our approach also using expert elicitations and that of Baker et al.: (a) our methodology takes into account the uncertainty around the benefits of investing in a portfolio of technologies, instead of a single technology area; (b) our elicitations asked experts to define three points of the distribution of costs in 2030, instead of the probability that particular costs would be reached, which allows us to approximate the full uncertainty around the costs; and (c) our analysis is limited to technology development, deployment, and benefits in the United States, and we make no assumptions about how technology would diffuse across borders or policies in other countries. There are also significant differences between our work and that of Pugh et al.: (a) their work uses a model of the world energy sector; (b) instead of asking one group of experts about the probability of reaching an advanced technology success stage for 8 technology areas, we relied on many technical experts from all sectors that differed by technology, discussed each of the expert elicitations with another set of program managers, and disclose the information from the elicitations; ${ }^{24}$ and (c) we represented aggregate benefits from portfolios by estimating the correlations between the costs of different technologies.

Along these lines, it is important to reiterate that RD\&D investments are only one of the many government actions that can catalyze innovation. As we describe in section 2.4.4 in more detail, to make final recommendations about the size and allocation of energy RD\&D investments, we combine the expert views on the link between $\mathrm{RD} \& \mathrm{D}$ and technology outcomes, with the environmental and economic benefits of those outcomes under different non-RD\&D policies (such as a carbon policy). In doing this, we also study the impact of non-RD\&D policies on the benefits of RD\&D investments through their impact on relative prices and the specification of minimum performance standards. However, the impact of non-RD\&D policies on the evolution of technology cost and performance (as hypothesized by Hicks (Hicks 1932)) over time was not considered. There was insufficient information from the literature to estimate how cost reductions would increase beyond those driven by RD\&D investments as specified by the experts. We thought that technology experts would have a lot of difficulty thinking about the impact of an RPS (for instance) on stimulating innovation and reducing the cost of a technology by a particular date. Our elicitations did, however, ask experts about their views on non-RD\&D policies.

Readers should also remember that there are very large uncertainties in economic modeling extending decades into the future. Technological and social changes will surely occur in the future that cannot readily be predicted today, and hence are not incorporated in existing models, including our own.

24 It is likely that Pugh et al.s ability to make their assumptions public about the probability of achieving an advanced technology scenario (or even what this advanced scenario is) was limited by the fact that they are a government agency. 
Integrated assessment models of future energy and economic trajectories continue to produce widely varying results, depending on the assumptions made and the structures of the particular models. As described in more detail later in this chapter, the MARKAL model we used, like other models of the energy economy, is based on a wide range of assumptions, some of which may prove to be invalid. Hence, the modeling results we present should be regarded as providing a general idea of plausible outcomes rather than specific predictions; probabilities we report are the probabilities of achieving certain results given specific sets of assumptions within the confines of this particular model. This large and irresolvable uncertainty about future economic trajectories represents another key reason for our recommendation that the U.S. government invest in a broad portfolio of energy technologies to maximize the chance of developing technologies that will prove to be attractive for widespread deployment in the broad range of possible circumstances that may exist in the future.

\subsubsection{Description of expert elicitations}

Expert elicitation is a formal means to obtain informed insight into nascent technologies and uncertain outcomes. We used expert elicitations to determine the relationship between federal energy technology RD\&D funding and the range of future technology cost and performance outcomes. Our seven elicitations were carried out using a consistent methodology, and are more comprehensive than previous studies in terms of the technology areas covered, as we examined four energy supply technology areas, two energy demand technology areas, and one enabling energy technology area. The elicitations were designed to encourage experts to think about technologies and research pathways that may not yet be in the mainstream research by not over-defining specific technologies within each technology area. We sought input from technical experts from the private sector, academia, and the national laboratories to obtain a range of perspectives. Experts were identified by examining the peer-reviewed literature, conferences, national laboratory programs, university research programs, and by referral from our advisory board.

Each elicitation took several months to design, write, and test to ensure that questions covered the key technical issues and were framed in the terms used in the field. Following the literature on elicitations (Curtright, Morgan \& Keith 2008), the elicitation instruments began with a technology primer of material on current technology cost and performance, fuel costs if applicable, and a summary of current government RD\&D investments in the particular technology area. This was done to ensure that all experts had the most recent literature fresh in their minds and to encourage them to think about the variables that we would ask them to estimate, including costs, efficiency, and government RD\&D investments and programs. 
The elicitation device was then divided into 4-5 sections of questions.

- In part 1, experts were asked to assess their expertise on specific technologies, components, and ancillary items such as feedstocks, specific technology areas, materials, products, and enabling technologies.

- In part 2, experts were asked to identify commercially viable technologies in 2010, as well as their cost and performance that would result from a continuation of 2010 federal funding and private investments through 2030, assuming no new government policies are implemented. This scenario was defined as the "business-as-usual" (BAU) scenario.

- In part 3, experts were asked to recommend a total annual federal RD\&D budget for the technology area in question. The experts were asked to allocate their recommended budget among basic research, applied research, development, and demonstration needs for specific technologies. Experts were also asked to indicate potential coordination with other areas of energy technology research, as well as industries that could provide "spillover" innovations. In most surveys, experts were also asked to provide their insights into the technological hurdles that could be overcome by research in the areas where they recommended the largest investments, and to recommend research areas for cooperation with other countries.

- In part 4, experts were asked to update their BAU 2030 technology cost and performance estimates for the case that their recommended annual federal RD\&D budget was implemented over the next 20 years. Experts were also asked to update their 2030 technology cost and performance estimates under two additional RD\&D scenarios: in one of them they were asked to assume that only half their recommended budget would be implemented, and in the other one they were asked to assume that a 10 -fold increase over their recommended budget would be implemented. We asked about these varying levels of funding to capture the sensitivity of experts' technology outcome estimates to funding availability.

- In part 5, which was not formally a part of all surveys, experts were asked to discuss deployment levels that could be achieved under the BAU and revamped budget scenarios, as well as to discuss deployment policies that would contribute to commercializing novel energy technologies. In those surveys where deployment was not examined in a separate section, experts were asked questions about deployment in parts 2 and 4.

The design of our elicitation allowed us to differentiate between exogenous and endogenous technical learning. Experts provided estimates of the current (2010) capital cost of a technology (for example, a Gen III/III+ nuclear plant) and the cost of the same technology in 2030 assuming four possible RD\&D scenarios. For each expert, we defined the endogenous rate of technical change from 2010 to 2030 as 
the ratio of the median BAU 2030 cost to the estimated median reference capital cost in 2010. This is endogenous in the sense that the cost reductions cannot directly be affected as they are due to changes in the macro-economy, spillovers from other technology areas, and learning-by-doing. The effectiveness of $\mathrm{RD} \& \mathrm{D}$ through accelerated federal $\mathrm{RD} \& \mathrm{D}$ is defined as the exogenous rate of technical change. We estimate this as the ratio of the median 2030 costs under an advanced RD\&D portfolio to the estimated median 2030 cost in the BAU scenario. This is exogenous in the sense that the factor driving this change is known and the inputs can be set by decision makers

Four of the elicitations (the bioenergy, fossil, storage, and vehicles surveys) were conducted using a written device, which was mailed to participants. The remaining three elicitations (the nuclear, buildings, and solar surveys) were conducted online. To the best of our knowledge, our three online expert elicitations represented an important innovation, as they have been the first formal elicitations about future technology cost and performance to be conducted online. Online elicitations improve the ability of experts to modify their answers and to visualize them, as they included several graphics that allowed experts to see the uncertainty ranges they specified and their estimates of cost and performance under different budget scenarios alongside each other. Online elicitations also accelerate the data collection and analysis process, which is an important attribute if elicitations are to be used to aid the RD\&D budget analysis process on a regular basis.

\subsubsection{Important features of this expert elicitation}

The results presented in this paper provide insight into U.S. expert opinion between July 2009 and December 2010 on the state of selected technologies in 2030 and its dependence on federal RD\&D investments. However, there are several limitations to an expert elicitation, which we will now discuss.

\subsubsection{Experts are human}

Experts are human and can have the same biases towards familiar subjects and overconfidence in their knowledge of unfamiliar subjects that laypeople have. This can have two effects. Experts may overestimate the probability that advances in their particular research area will take place because of availability heuristics, i.e., if one can think about a solution one can overestimate the probability that the solution will materialize (Tversky, Kahneman 1973). One could also argue that experts may have a motivational bias to overestimate the required federal RD\&D investments and their returns if they stand to gain from increased federal RD\&D funding for their specialty. However, as shown in the Appendix, we see no significant evidence that experts favored their own areas of expertise when recommending a budget allocation. However, there may be overconfidence in experts' estimates of future technology cost and performance. It is also possible that some experts, aware of projections in the literature (which were also included in the background information of the surveys), anchored their estimates to them. 
Another limitation of asking experts to think about how technologies may evolve in the future is that, like anyone else, experts can only base their estimates on the information that is available to them at the time the elicitation is made. While we asked experts to think of research beyond the technologies listed in the appendix per their technology area, it is impossible for anybody to estimate the likelihood that completely unknown developments will take place. Figure A-61 in the Appendix plots expert projections for the $90^{\text {th }}$ percentile minus the $10^{\text {th }}$ percentile, and then divided by the $50^{\text {th }}$ percentile; it shows slightly more projections of higher uncertainty for 2030 compared to 2010. Bioenergy and storage seem to dominate the projections that have the most uncertainty. It also seems that uncertainty is expertspecific, as noted above. If we believed that all experts had similar information, then the large ranges would come from their differing ability to estimate percentiles. Making assessments about probabilities is difficult and it is likely that one expert's $10^{\text {th }}$ percentile cost estimate is not entirely comparable to another expert's $10^{\text {th }}$ percentile cost estimate. One reason for this is that an expert's ability to, for example, differentiate between a $10^{\text {th }}$ percentile and a $25^{\text {th }}$ percentile estimate will depend on his or her experience dealing with probability distribution functions and creative thinking about possible future technology development scenarios. Finally, experts may be wrong. There are plenty of examples of wrong predictions, such as those in the field of oil and energy price forecasts (Craig, Gadgil \& Koomey 2002), although testing predictions is also not straightforward, since events such as war, weather, or natural disasters affect outcomes but forecasters are typically not asked to consider such events.

\subsubsection{Relationship between federal and private spending unclear}

The reader should also note the limitation of our scope, which is to focus on federal RD\&D investment recommendations and outcomes. We asked experts to estimate the impact of their recommended federal RD\&D program on technology costs and performance in 2030 assuming that only the federal budget changes as they recommend. Costs and performance, however, are shaped by public and private RD\&D funds. To the best of our knowledge, there is no analysis of the interaction between public and private RD\&D funds for energy technology-i.e., of the impact that an enhanced federal energy technology innovation program would have in private sector activities beyond the level of cost-share in DOE partnerships and beyond the venture capital funding leveraged by recipients of ARPA-E awards, for example. But it is likely that experts also considered private sector RD\&D activity that would be taking place in concert with the RD\&D activity funded by their recommended federal RD\&D budgets when making their estimates. We did not ask experts about their opinion of how private sector activity would change in response to an enhanced federal energy technology RD\&D program. As a result, any changes in private sector funding that they may have foreseen would also have been driven by the changes in federal $\mathrm{RD} \& \mathrm{D}$ funding, so the difference between benefits under the BAU RD\&D funding scenario and other scenarios are only driven by federal funding. 


\subsubsection{Selecting expert answers for simulation}

Expert elicitation is different from surveys in that individual respondents are not treated as observations from a single population. Instead, expert elicitation treats individual respondents as representative of a large body of knowledge. Further, the emphasis of developing a "population" of experts to participate in an expert elicitation is on quality and diversity of expertise, not on the quantity of participating experts (Cooke 1991). The Delphi process or expert consensus methods (such as those used by the reports of the Intergovernmental Panel on Climate Change) are closely related to the methodology of expert elicitations. In the Delphi process, expert judgment is elicited in a group and the emphasis is to reach a consensus judgment (Dalkey 1969). In expert elicitation, each expert's judgment is elicited individually. The advantage of expert elicitation is that each expert offers his or her judgment without being influenced by other experts, avoiding unwanted group dynamic effects obscuring the true diversity of judgments (Oppenheimer et al. 2007). The disadvantage of expert elicitation with respect to the Delphi process is that developing a coherent message from expert judgment is left up to the typically less-expert analyst.

Because of this, to complement the elicitations we conducted qualitative interviews in which we presented the elicitation results to a second set of stakeholders with expertise managing RD\&D budgets for each technology area. We refer to these stakeholders as "program managers" from now on because they have expertise in thinking about investments in technology portfolios, whether they are venture capital or private equity investors, U.S. Department of Energy program managers, or U.S. Congressional staff. This second set of experts helped interpret the answers of the elicitations. Their insights were used to select three experts representing pessimistic, optimistic, and middle-of-the-road technology trajectories per technology area to be examined in MARKAL. We conducted between 2-6 consultations in person or over the phone with program managers in each technology area (a total of 23 consultations). In these, which lasted from 1-2 hours, we showed program experts the technology area experts' budgets and technology parameter estimates. Program experts were asked to give their reactions to the budget allocation recommendations and technology cost and performance forecasts.

We selected three experts per technology area to represent the range of possible outcomes instead of modeling the answers of each of the experts (100 experts gave total and partial answers to the different surveys: 30 participated in the nuclear survey, 25 in the storage survey, 12 in the bioenergy survey, 9 in the buildings survey, 9 in the vehicles survey, 12 in the fossil energy survey, and 11 in the PV survey) because we did not have the resources to simulate every expert opinion for each technology. ${ }^{25}$ In addition, we felt it was not necessary to carry scenarios with every combination of experts because defining

25 We had a total of 58 that answered all questions the surveys: 20 in the nuclear survey, 9 in the storage survey, 4 in the bioenergy survey, 7 in the buildings survey, 4 in the vehicles survey, 7 experts in the fossil energy survey, and 7 experts in the PV survey. 
these three types of technology profiles would essentially bound the range of benefits of RD\&D given expert projections.

\subsubsection{From expert elicitation responses to model-ready scenarios of joint technology cost trajectories}

From the expert elicitations we obtained $10^{\text {th }}, 50^{\text {th }}$, and $90^{\text {th }}$ percentile estimates of technology costs in 2010 and 2030 under different federal energy RD\&D budget scenarios. To understand how these technology improvements are likely to affect the uncertainty around $\mathrm{CO}_{2}$ emissions, carbon prices (in carbon policy scenarios), and oil imports between 2010 and 2050, we translated these estimates into the multi-region U.S. MARKAL model. In order to do this, we first created full probability distributions of technology costs. We then interpolated between the 2010 and 2030 estimates, and extrapolated from 2030 to 2050. To represent the true variance around the metrics we care about, we sampled across these technology distributions utilizing a computationally efficient strategy that allowed us to sample across the distributions of the different technologies accounting for dependence across technology improvements. This process of creating inputs to MARKAL was applied to $4 \mathrm{RD} \& \mathrm{D}$ budget scenarios (BAU, half of recommended budget, recommended budget, and 10-times the recommended budget) and three types of experts (pessimistic, optimistic, and middle-of-the-road), and is described in detail in the next sections.

\subsubsection{Marginal distributions of technology costs}

We elicited $10^{\text {th }}, 50^{\text {th }}$, and $90^{\text {th }}$ percentile estimates of the cost of technologies, denoted here as $x_{10}, x_{50}$, and $x_{90}$, respectively. These costs were elicited for both 2010 and 2030 in each scenario (see section 2.5.4. for a description of the scenarios). For 2030 estimates, the range in an expert's assessment is due to both the heterogeneity within a technology (e.g., different sub-classes of technologies) and the uncertainty in future costs. For 2010 estimates, the range in an expert's assessment is due to heterogeneity and uncertainty stemming from the opaqueness in realized historical costs. In subsequent analysis, we treat the cost of a technology in a year as a random variable, allowing us to estimate a distribution for the cost of each technology and the dependence structure of all technology costs. The distributions we estimated for technology costs are trisected distributions composed of four partial truncated normal distributions. ${ }^{26}$ The points of truncation are set at $x_{10}, x_{50}$, and $x_{90}$ to maintain the exact percentile estimates of

26 Alternatively, if we had elicited a "most probable", or modal, estimate for each technology in conjunction with more dispersed estimates (e.g., $10^{\text {th }}$ and $90^{\text {th }}$ percentiles), we could have more naturally fit a single skewed distribution to the elicited values between the $10^{\text {th }}$ and $90^{\text {th }}$ percentiles rather than joining two partial distributions to preserve the median estimate. This alternative formulation would have allowed us to model the distribution of costs as a truncated normal distribution below the $10^{\text {th }}$ percentile, a skewed normal distribution between the $10^{\text {th }}$ and $90^{\text {th }}$ percentiles, and a truncated normal distribution above the $90^{\text {th }}$ percentile. However, by eliciting the median estimate instead of the modal estimate, as we did, calculations of the distributions of cost are still reasonably straightforward. 
the experts. A full description of the distribution of technology costs is given by Equation 1, the expression for the inverse cumulative distribution, $F^{-1}$.

$$
F^{-1}\left(p \mid x_{10}, x_{50}, x_{90}\right)= \begin{cases}\mathrm{tN}^{-1}\left(\mu=x_{50}, \sigma=s_{1}, a=a, b=\infty\right) & \text { if } 0 \leq p \leq 0.1 \\ \mathrm{tN}^{-1}\left(\mu=x_{50}, \sigma=s_{1}, a=-\infty, b=\infty\right) & \text { if } 0.1<p \leq 0.5 \\ \operatorname{tN}^{-1}\left(\mu=x_{50}, \sigma=s_{2}, a=-\infty, b=\infty\right) & \text { if } 0.5<p \leq 0.9 \\ \mathrm{tN}^{-1}\left(\mu=x_{50}, \sigma=s_{2}, a=-\infty, b=b\right) & \text { if } 0.9<p \leq 1\end{cases}
$$

In Equation 1, $p$ is the probability, and $\mathrm{tN}^{-1}(\mu, \sigma, a, b)$ is the inverse cumulative truncated normal distribution with mean $\mu$, standard deviation $\sigma$, minimum point of truncation $a$, and maximum point of truncation $b$. The expressions for $s_{1}$ and $s_{2}$ are given by Equation 2, where $\Phi$ is the cumulative standard normal probability distribution function.

$$
s_{1}=\frac{x_{10}-x_{50}}{\Phi^{-1}(0.1)} \quad s_{2}=\frac{x_{90}-x_{50}}{\Phi^{-1}(0.9)}
$$

For non-fossil technologies, $\mathrm{a}=0.05 \cdot \times 10$ and $b=\infty$ to disallow the possibility that technology costs will be negative or will drop to unreasonable levels far from the elicited values. For carbon capture technologies (coal with CCS and natural gas with CCS), the minimum point of truncation, a, was set to the $5^{\text {th }}$ percentile of the distribution of their non-capture analogues (i.e., coal and natural gas). For coal and natural gas without CCS, the maximum point of truncation, $b$, was set to the $95^{\text {th }}$ percentile of their capture analogues. Equation 3 gives the full mathematical representation of the inverse cumulative distributions of technology costs.

$$
F^{-1}\left(p \mid x_{10}, x_{50}, x_{90}\right)= \begin{cases}x_{50}+s_{1} \Phi^{-1}\left[p+(1-10 p) \Phi\left(\frac{a-x_{50}}{s_{1}}\right)\right] & \text { if } 0 \leq p \leq 0.1 \\ x_{50}+s_{1} \Phi^{-1}(p) & \text { if } 0.1<p \leq 0.5 \\ x_{50}+s_{2} \Phi^{-1}(p) & \text { if } 0.5<p \leq 0.9 \\ x_{50}+s_{2} \Phi^{-1}\left[(10 p-9) \Phi\left(\frac{b-x_{50}}{s_{2}}\right)+9(1-p)\right] & \text { if } 0.9<p \leq 1\end{cases}
$$

\subsubsection{Technology cost sampling and induced cross-technology dependence}

To estimate the uncertainty in the relevant metrics $\left(\mathrm{CO}_{2}\right.$ emissions from the energy sector, oil imports, and $\mathrm{CO}_{2}$ prices, among others) resulting from each of the different RD\&D investments, we use the 
Monte Carlo sampling technique to sample from the distributions of technology cost and performance provided by experts to MARKAL. For Monte Carlo sampling, the inverse cumulative distribution function $(\mathrm{CDF})$ is the relevant description of a random variable. Monte Carlo sampling is accomplished by transforming a draw from the standard uniform distribution, which is easy to simulate with standard software, by the inverse CDF, as given in Equation 3.

In our analysis, samples from the distributions of technology costs are found using Latin Hypercube sampling (LHS) (McKay, Conover \& Beckman 1979). We use LHS instead of traditional Monte Carlo analysis for our study to reduce the total variance (without introducing bias) in the sampled values of uncertain quantities. Because the costs we sample will serve as inputs to a computationally expensive model, the variance reduction properties of LHS decrease the total number of samples (and therefore the total number of model simulations) that we need to run in order to describe the total variance in the output quantities of interest conditional on the input distributions elicited from the experts and formalized in Equation 3. ${ }^{27}$

In LHS, the domain of each marginal distribution of technology cost is partitioned into equal probability strata. Samples from the strata are calculated by transforming $p_{i}$, an $n$-dimensional vector of probabilities (where $n$ is the desired number of samples), by the inverse CDF, creating representative samples from the distribution of interest. The vector $p_{i}$ can be calculated by two methods. In the first method, the interval $(0,1)$ is divided into $n$ equal width strata. Values of $p_{i}$ are chosen from within each stratum by sampling over the uniform distribution across that stratum. Equation 4 formalizes this description.

$$
p_{i} \sim \mathrm{U}\left(\frac{i-1}{n}, \frac{i}{n}\right) \forall i=1,2, \ldots, n
$$

In the second method, instead of sampling the uniform distribution over each strata, the median value of each strata is used for the vector $p_{\mathrm{i}}$. This method, also known as van der Waerden scores, is recommended by Morgan and Henrion (Morgan, Henrion 1990). Equation 5 gives the vector of van der Waerden scores for $n$ samples.

$$
p_{i}=\frac{i}{n+1} \forall i=1,2, \ldots, n
$$

27 The tradeoff in using LHS is that the samples drawn from the process are no longer independent, and therefore each sample viewed by itself is difficult to interpret. Since our outcomes of interest are calculated over the entirely sampled distribution, the loss of independence between samples is not a concern. 
In our analysis, we use traditional LHS (the first method, described by Equation 4) because we judged the better representation of the extreme tails of the distribution under traditional LHS more important than the consistent representation of the distributions across re-sampling that van der Waerden scores would provide. With a large number of samples (in our case 400), the differences between the two approaches is negligible.

In the first stage of the sampling process, we use traditional LHS to generate 400 samples from each marginal distribution of 2030 technology cost using the elicited values and Equation 3 to represent the distributions. Once these samples are calculated, we combine them to form single samples, each containing a single 2030 cost estimate for each technology. Because technology costs are not independent, the formation of samples cannot be done by combining sampled costs at random. Instead, since we believe that the marginal technology cost distributions are not equivalent to the conditional distributions of technology costs, we select combinations of sampled costs for each technology to induce a desired rank correlation matrix. Without accounting for the dependency between technology costs, subsequent analysis would under-represent what we believe to be high-probability joint outcomes, and over-represent low-probability joint outcomes. (For example, it is unlikely that the future cost of coal power with CCS could be high while the realization of the cost of natural gas with CCS is low.)

To formalize the dependencies in technology costs, we elicited rank (Spearman) correlations across technologies within each technology area as well as across technology areas using our own study group's expertise. Rank correlation, rather than Pearson correlation, is appealing for expert elicitation because we believe that it is cognitively more natural to think of relationships between uncertain quantities in terms of their strength of monotonicity rather than their strength of linearity. Table A-15 in Appendix section A.9 is the rank correlation matrix between 2030 technology costs that we elicited from our research group. For many technology-technology diodes, we did not elicit a correlation and instead assumed that technology costs would be independent. However, for these unforced relationships, while the expectation of the rank correlation is zero, we did not force the realized correlation to be exactly zero.

Following Iman and Conover (Iman, Conover 1982), we implement an algorithm to combine marginal realizations of Latin Hypercube samples to impose the desired rank correlation between 2030 technology costs while preserving the original sampled marginal distributions. We follow Iman and Conover, and use a transformation of the intermediate ranks such that the final dependence structure between any two technologies approximates the Gaussian copula (Wang 1998). Since the algorithm in Iman and Conover works stochastically, we iterate the algorithm until the maximum absolute difference in any one specified rank correlation is below a specified threshold. We use a threshold error of 0.05 in the induced rank correlation from the desired rank correlation, as our experience has shown that insisting on smaller errors increases the run time of the algorithm substantially. 
At this stage, we impose an additional constraint on 2030 technology costs for carbon capture technologies. For coal with carbon capture and natural gas with carbon capture if the 2030 cost of either capture technology is less than its non-capture analogue, we force the 2030 cost of the capture technology to be at least $10 \%$ more than the cost of its non-capture analogue. This adjustment is necessary to make in at most $3 \%$ of the scenarios.

\subsubsection{Longitudinal dependence and extrapolation to 2050}

Once we generated the 2030 cost scenarios (by applying LHS and inducing cross-technology correlation), we generated 2010 cost samples for each technology and then used the 2010 and 2030 samples to create scenarios of 2010-2050 cost trajectories. We elicited longitudinal correlations for the 2010, 2030 joint distribution of each technology's cost (in addition to the cross-technology correlations described in the previous section). Again, we elicited these correlations as rank correlations and using our own group's expertise. These correlations take into consideration how much information relative 2010 technology costs provide for relative 2030 technology costs. We estimate that these longitudinal (rank) correlations will be high for most technologies $(0.7 \leq \rho \leq 0.9)$, as we think experts were assuming that it is highly unlikely that a technology on the high end of costs in 2010 will be on the low end of costs in 2030. Those technologies where factors other than technology (e.g., public perception and licensing) are likely to play a role in costs were assigned a lower time correlation. Table A-16 in Appendix section A.9 includes the 2010, 2030 longitudinal correlations for each technology.

We fit the 2010 costs we elicited from experts as described by Equation 3 in section 2.5.3.1 and we generated samples of 2010 costs by LHS. Then, technology-by-technology, we paired individual 2010 samples with 2030 samples to induce the specified longitudinal correlation using the algorithm described by Iman and Conover (Iman, Conover 1982), and as outlined in section 2.5.3.2. This process preserves the 2030 cross-technology correlations listed in the correlation table in the Appendix, but does not force a crosstechnology correlation between technologies in 2010. Instead, through transitivity, the correlation between two technologies in 2010 with specified 2030 correlation will be positive but of smaller magnitude than the 2030 correlation. (For example, for technologies with $\rho=0.8$ in 2030 and each with $\rho=0.9$ cross-time correlation, the 2010 cross-technology correlation will be approximately 0.65.) For two technologies, fourth generation nuclear plants and modular nuclear reactors, experts provided no 2010 costs. In these cases, the 2030 cost was used as the 2010 cost and an additional parameter was specified to control the year these technologies become available in the economy.

As with the adjustment made for capture technologies in 2030, we impose the constraint for coal with carbon capture and natural gas with carbon capture that if the 2010 cost of either capture technology is less than its non-capture analogue, we force the 2010 cost of the capture technology to be at least $10 \%$ more than the cost of its non capture analogue. In addition, we impose a similar constraint that if the 
cost of a battery-electric vehicle is less than the cost of a plug-in hybrid, we force the 2010 cost of the electric vehicle to be $5 \%$ more than the cost of the plug-in hybrid in that scenario.

Extrapolation and interpolation of technology costs for 2010-2050 are done by two methods. The first method interpolates and extrapolates a technology's cost to generate scenarios of 2010-2050 cost trajectories using only the 2010 and 2030 cost estimates for that technology. In this method, if costs decrease from 2010-2030, the trajectory of costs is calculated by exponential extrapolation (linear fit to the log of costs) with the additional restriction that costs cannot fall below $5 \%$ of the elicited $10^{\text {th }}$ percentile of 2030 costs. If costs increase from 2010-2030, the trajectory of costs is calculated by linear extrapolation. These extrapolation procedures effectively assume that progress will be gradual, and that there will be no discrete step-function changes in the costs of particular technologies.

In the second method of interpolation/extrapolation, the costs of a technology are pegged to a reference technology to force an inequality constraint between the cost of a technology and the cost of its reference technology. For example, we forced an inequality constraint for coal with CCS and coal without CCS to represent the stylized fact that coal with CCS must be more expensive than coal without CCS, independent of the cost of either of the technologies (e.g., even if coal with CCS was projected by an expert to be very cheap, in our modeling it cannot be cheaper than coal without CCS in any individual simulation). It is possible, however, for coal with CCS in one simulation to be cheaper than the value used for coal without CCS in a different simulation. In this method, extrapolation and interpolation are conducted as in the first method, but instead of using the 2010 cost of the technology as a basis for interpolation/extrapolation, the cost difference between the technology and its reference technology is used. The interpolated and extrapolated cost difference is then added to the reference technology's cost to create a 2010-2050 cost trajectory for the technology of interest.

By modeling the cost differences instead of cost levels, the inequality constraint between two technology costs is necessarily satisfied while the desired characteristics of smooth extrapolation/interpolation of the first method are preserved. In two cases, we apply this methodology for a triplet of technologies by modeling cost differences step-wise. For example, we interpolate/extrapolate costs for conventional hybrid vehicles using the first method above, then model the cost differences between plug-in hybrids and conventional hybrids Once this difference is modeled, we model an additional difference between full electric vehicles and plug-in hybrid vehicles. This forces a two-part inequality constraint of electric vehicles being more expensive than plug-in hybrid vehicles being more expensive than conventional hybrid vehicles within any single simulation. (To allow for direct comparison among vehicle drive train technologies, our study required experts to estimate the cost of an electric vehicle with performance characteristics comparable to current gasoline vehicles.) Table 2.2 shows which extrapolation/interpolation methodology was used for each technology modeled in our study. 


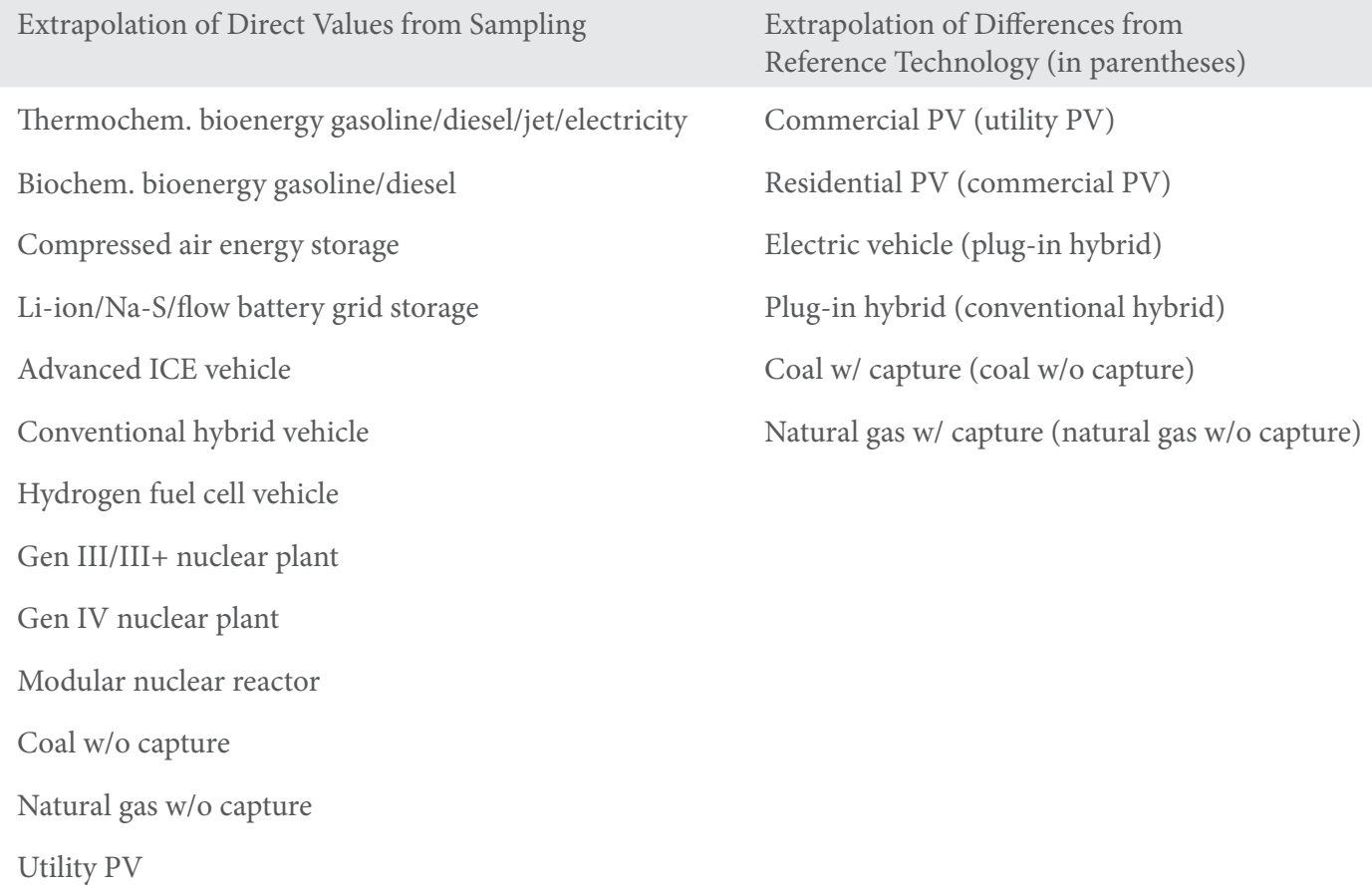

In our study design, when costs decrease within one sample, we extrapolate costs to 2050 and interpolate costs between 2010 and 2030 assuming that cost reductions decrease at an exponential rate. When costs increase from 2010 to 2030 within one sample, we extrapolate and interpolate assuming that costs rise at a linear rate. We hypothesize that, when experts foresaw cost increases in the future, they are caused by events that we deem unlikely to result in exponential increases in cost over time, such as costs stemming from permitting and licensing.

Up to this point in this section, only cost metrics have been discussed. In the elicitations, we also asked experts to estimate performance metrics for each technology. Unlike costs, performance metrics were elicited only at median values. Therefore, no distributional assumptions need to be made for performance metrics and each scenario of technology costs can be paired with the same set of performance metrics (per expert scenario). We use a simpler interpolation/extrapolation model for performance metrics. For 2010-2030, we assume that performance metrics change linearly. For the extrapolation region, we assume that performance metrics stay constant at 2030 levels. Table 2.3 summarizes our choices of functional form relationships for interpolation and extrapolation of cost and performance estimates.

\subsubsection{Description of energy system modeling and scenarios modeled}

The MARKAL model is used to understand the interaction of the elicitation energy technology areas as an energy system. MARKAL is a technology-based, bottom-up model with flexibility to add novel 


\begin{tabular}{lllll} 
Time period & $\boldsymbol{x}_{\mathbf{2 0 1 0}}<\boldsymbol{x}_{\mathbf{2 0 3 0}}$ & $\boldsymbol{x}_{\mathbf{2 0 1 0}}>\boldsymbol{x}_{\mathbf{2 0 3 0}}$ & $\boldsymbol{p}_{\mathbf{2 0 1 0}}<\boldsymbol{p}_{\mathbf{2 0 3 0}}$ & $\boldsymbol{p}_{\mathbf{2 0 1 0}}>\boldsymbol{p}_{\mathbf{2 0 3 0}}$ \\
\hline $2010-2030$ & Linear & Exponential & Linear & Linear \\
$2030-2050$ & Linear & Exponential & Constant & Constant
\end{tabular}

TABLE 2.3. Extrapolation and interpolation functional form assumptions. $x_{2010}$ is a 2010 cost (or cost difference if extrapolation/ interpolation is done on differences), $x_{2030}$ is a 2030 cost, $p_{2010}$ is a 2010 performance metric, and $p_{2030}$ is a 2030 performance metric.

technologies, and widely used by federal decision makers. The DOE and EPA have each developed their own versions for policy analysis. We revised the U.S. multi-region MARKAL model developed by Brookhaven National Laboratory and used by the DOE. By modeling the U.S. as ten separate regions, including trade between regions, we were able to capture the differences in energy resources and investment and the nature of energy demand in each of the regions. MARKAL is a partial equilibrium model that is specifically designed to represent technological evolutions of the physical energy system, occurring over 30- to 50-year periods. As a linear optimization model, it is solved as a cost minimization problem where future states of the energy system are determined by identifying the most cost-effective pattern of resource use and technology deployment over time, given exogenously specified energy demands. The MARKAL objective is thus to minimize the total cost of the system, discounted over the planning horizon. Each year, the total cost includes the following elements:

- Annualized investments in technologies;

- Fixed and variable annual Operation and Maintenance (O\&M) costs of technologies;

- $\quad$ Cost of exogenous energy and material imports and domestic resource production (e.g., mining);

- Revenue from exogenous energy and material exports;

- Fuel and material delivery costs;

- Welfare loss resulting from reduced end-use demands; and

- Taxes and subsidies associated with energy sources, technologies, and emissions.

A more detailed description of energy prices in the model is available in the Appendix. The model optimizes the system while obeying user-defined constraints such as natural resource availability, technology and capital availability, environmental limitations, and policies and regulations. The model is dynamic, meaning that the capital stock in any period is equal to the capital stock in the preceding period plus/minus any additions or retirements. The model thus keeps track of capital stock, and the solution in one period is directly linked to the solution for other periods. Optimization is inter-temporal, which means that the optimization is performed for all periods concurrently, implicitly giving decision-makers 
foresight (Fishbone, Abilock 1981; Loulou, Goldstein \& Noble 2004). There are only practical limits to the number of technology types that can be represented in the MARKAL framework; therefore, it was a suitable tool to accommodate the results of our expert elicitations. For this analysis, the endogenous technology-learning and stochastic programming features of MARKAL were not used. ${ }^{28}$

We use a number of scenarios in the MARKAL model to explore the interactions between various policies and market variables and RD\&D portfolios (see Table 2.4).

The default assumptions in the scenarios are based on the Annual Energy Outlook (EIA 2010a). In particular, these assumptions include crude oil and natural gas prices, as well as existing deployment policies, but they exclude technology cost assumptions as these are taken from the expert elicitations.

\begin{tabular}{|c|c|}
\hline $\begin{array}{l}\text { Technology cost assumption } \\
\text { profiles }\end{array}$ & $\begin{array}{l}\text { - } \text { Middle-of-the-road } \\
\text { - } \quad \text { Optimistic } \\
\text { - } \quad \text { Pessimistic }\end{array}$ \\
\hline RD\&D levels & $\begin{array}{ll}\text { - } & \text { Business-as-usual } \\
\text { - } & \text { Half recommendation } \\
\text { - } & \text { Full recommendation } \\
\text { - } & \text { Ten times recommendation }\end{array}$ \\
\hline Deployment policies & $\begin{array}{l}\text { - } \\
\text { - } \\
\text { - } \\
\text { - Seconomy-wident } \mathrm{CO}_{2} \text { cap-and-trade program } \\
\text { fuel economy standards for electricity, commercial buildings, and vehicle }\end{array}$ \\
\hline Energy prices & $\begin{array}{l}\text { - Annual Energy Outlook } 2010 \text { (AEO2010) reference case prices } \\
\text { - } \quad \text { Low gas price (AEO2011 reference case) and reference case oil price } \\
\text { (AEO2010) } \\
\text { - } \quad \text { High oil price and high gas price (AEO2010 }\end{array}$ \\
\hline Nuclear power expansion & $\begin{array}{l}\text { - Available and deployed where economic } \\
\text { - Unavailable due to unforeseen constraints }\end{array}$ \\
\hline
\end{tabular}

TABLE 2.4. Scenarios analyzed using MARKAL. Combinations of the following assumptions make up the variety of scenarios modeled. Note that not all scenario results will be discussed.

28 Results with the endogenous technology-learning feature are more sensible when MARKAL is optimized in each time period (myopic) rather than over all time periods (perfect foresight). With perfect foresight and the aim of optimizing over the entire time horizon, the model algorithm has a tendency to invest in technologies in order to progress along the learning curve and to reach a low cost in the long-term. In reality, investors seldom have the luxury to invest in technologies purely for the sake of progressing along the learning curve, and must consider short-term returns. Unfortunately, the capability to use both endogenous technology learning and myopic optimization is unavailable for multi-region MARKAL models. It would also require assumptions about the learning curve from deployment, which was not part of our elicitations as we felt questions about deployment were not the experts' main area of expertise. Stochastic programming is used to evaluate the sensitivity of a given policy constraint to various policy designs, and not to analyze uncertainty in technology cost or performance. 
The scenarios with an economy-wide $\mathrm{CO}_{2}$ cap-and-trade policy are based on the President's goal ${ }^{29}$ of $83 \%$ reduction from 2005 GHG emissions by 2050 (The White House 2009). Banking and borrowing are allowed, as are domestic offsets.

Scenarios with new sectoral policies include a federal clean-energy standard, commercial building standards, and vehicle fuel economy standards (CAFE). The federal clean electricity standard requires clean electricity generation to reach $45 \%$ by $2015,80 \%$ by 2035 , and $95 \%$ of sales by 2050 with no special exemptions from the baseline. Generation from natural gas qualifies for a $50 \%$ clean-energy credit; coal with CCS, 90\%; and natural gas with CCS, 95\%. The increased CAFE standard assumes a linear increase from 35 miles per gallon in 2020 to 75 miles per gallon by 2050. Commercial building standards result in a $30 \%$ improvement in building shell efficiency.

Sensitivities to oil and natural gas prices are explored using: (1) the AEO 2010 reference case oil price and a low gas price case based on the AEO 2011 reference case to estimate the value of RD\&D invest-

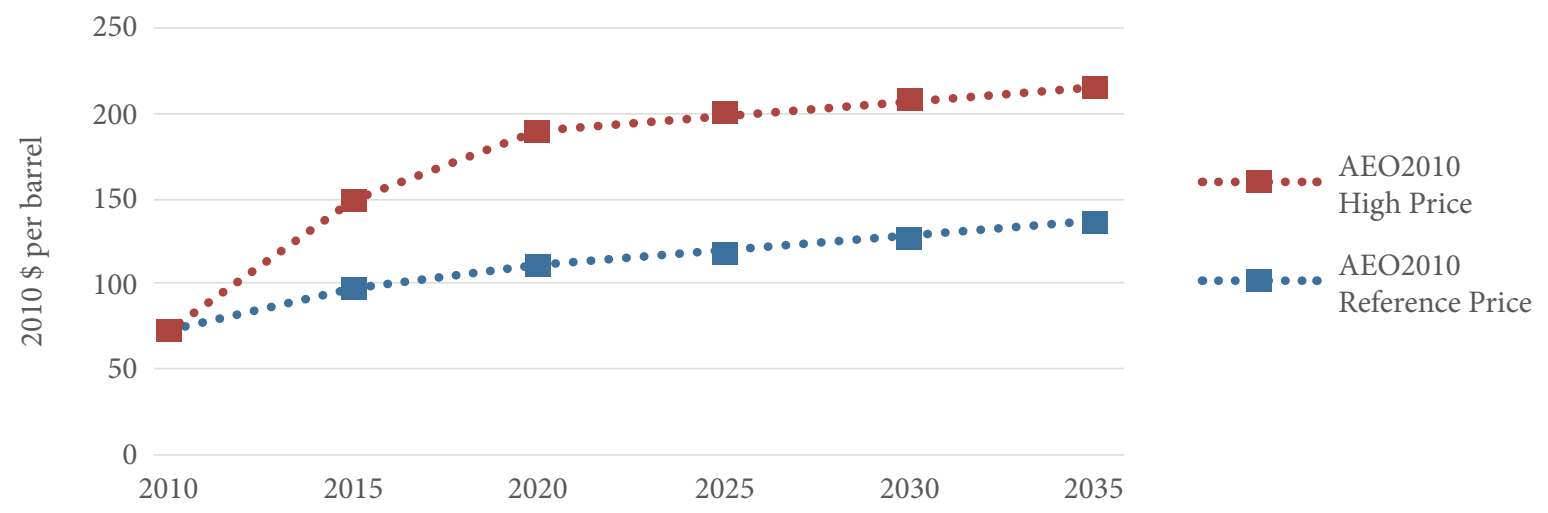

FIGURE 2.2. Average annual world oil prices in high oil price and reference oil price cases, from 2010-2035 in 2010U.S.\$ per barrel (EIA 2010a).

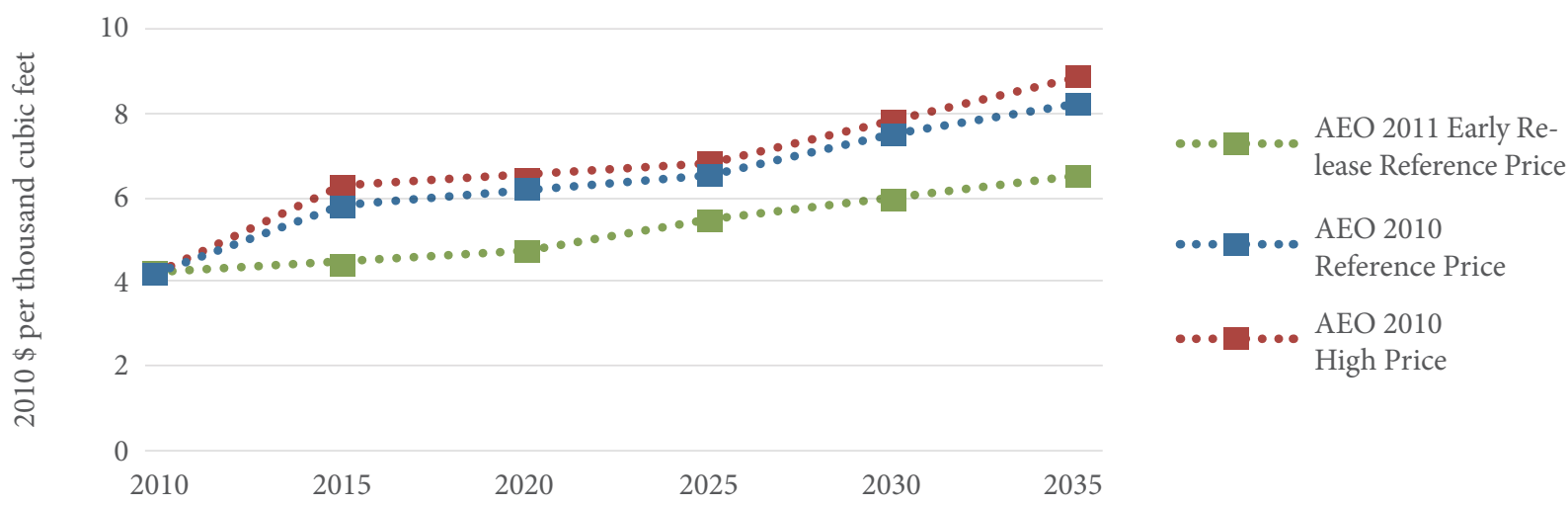

FIGURE 2.3. Average lower 48 wellhead prices for natural gas in three oil price cases from 2010-2035 in 2010U.S.\$ per thousand cubic feet (EIA 2010a). 
ments in a world of plentiful natural gas (given the recent evolution of shale gas development in the United States) (EIA 2010b); and (2) the AEO 2010 high oil and gas price cases, a world of relatively scarce fossil fuels.

\subsection{Quantitative Expert Elicitation Results}

This is the first of the three sections on results (sections 2.6 through 2.8).

Section 2.6 has two parts. Sub-sections 2.6.1 through 2.6.7 discuss our quantitative expert elicitation results, summarizing the range of recommended budgets and allocations, as well as expected changes in technology cost, performance, and deployment resulting from these revamped budgets. Section 2.6.8 summarizes the recommendations of all elicitations.

Section 2.7 summarizes the qualitative insights from the elicitations.

Section 2.8 discusses the results on the broader economic benefits to be gained by implementing select recommended federal RD\&D budgets in the seven technology areas considered. These benefits were estimated using our sampling strategy, MARKAL, and our portfolio optimization work. They include $\mathrm{CO}_{2}$ and clean-energy standard credit prices, aggregate greenhouse gas emissions, oil imports, consumer surplus, and technology deployment.

\subsubsection{Bioenergy}

On average, the twelve bioenergy experts recommended $\$ 680$ million in annual spending on bioenergy RD\&D (Figure A-3, Appendix). This is approximately a three-fold increase over 2009 spending on

bioenergy RD\&D, which was $\$ 220$ million. Experts placed a slight emphasis on pilot and commercial demonstration projects, allocating on average 20\%, 22\%, 29\%, and 29\% (Figure A-4, Appendix) of their recommended budgets to basic research, applied research, experiments and field demonstrations, and commercial demonstrations, respectively. When allocating their recommended budgets among technologies, the greatest fractions of the total budget were allocated to gasification, hydrolysis, and "other" research that most experts specified as feedstock development, harvesting, and transportation.

We reviewed experts' anticipated liquid fuel and electricity costs and conversion yields per their recommended budgets to identify the impact of increasing RD\&D investments over the BAU scenario (Figures A-13 and A-14, Appendix). While experts exhibit considerable disagreement on both 2010 and 2030 BAU costs and yields (Figures A-5 to A-12, Appendix), there is more consensus on their estimates of the cost reductions that can be achieved through increased federal RD\&D. Most experts believed that a revamped federal RD\&D program would reduce costs. For example, Figure 2.5 shows that ex- 
perts projected a median gasoline-substitute production cost reduction of up to $32 \%$ compared to 2030 BAU costs with RD\&D funded at each expert's recommended levels (with a range of $30 \%$ reduction to $33 \%$ increase compared to $2030 \mathrm{BAU}$ at the average recommended funding level of $\$ 682$ million per year, using a linear interpolation, see Figure A-13 in the Appendix). Experts' median cost projections for gasoline substitutes from biomass range from $\$ 0.75$ per gallon to $\$ 5$ per gallon in 2030 under BAU funding levels. The minimum in the range declines to $\$ 0.20$ per gallon in 2030 under experts' recommended funding levels (Figure A-5, Appendix). In comparison, the Office of Biomass Programs at DOE has set a goal of achieving through RD\&D cellulosic biofuels which are cost competitive at $\$ 1.76$ per gallon ethanol ( $\$ 2.62$ per gallon gasoline equivalent) by 2012 and $\$ 2.85$ per gallon of renewable gasoline (which is more versatile) by 2017.

Experts appear more divided about production costs for diesel substitutes, jet fuel substitutes, and electricity. For diesel substitutes, experts projected a cost reduction of up to $58 \%$ compared to $2030 \mathrm{BAU}$ at their recommended funding levels (up to a 55\% reduction at the average funding level). Experts' median cost projections for diesel substitutes from biomass also range from $\$ 0.75$ per gallon to $\$ 5$ per gallon in 2030 under BAU funding levels. The minimum in the range declines to $\$ 0.57$ per gallon in 2030 under experts' recommended funding levels (Figure A-7 Appendix). DOE has a goal of renewable diesel cost becoming cost competitive by 2017 , reaching $\$ 2.84$ per gallon. For jet fuel, experts projected up to a $51 \%$ reduction in cost, at both experts' recommended levels and at the average funding level. Experts' median cost projections for jet fuel substitutes from biomass range from $\$ 1.62$ per gallon to $\$ 6$ per gallon in 2030 under BAU funding levels. The range declines to $\$ 0.57$ per gallon to $\$ 6$ per gallon in 2030 under experts' recommended funding levels (Figure A-9). DOE has a goal of \$2.76 per gallon for renewable jet fuel by 2017. And finally, for electricity generated from biomass, experts projected an increase of up to $11 \%$ in cost compared to $2030 \mathrm{BAU}$ (from a $1 \%$ decrease to an $11 \%$ increase at their average funding level). Unlike the relative clustering that was found in the experts' estimates of cost reductions when compared to the BAU RD\&D scenario, the expected yield improvements over the BAU RD\&D scenario (Figure A-14, Appendix) were evenly spread for gasoline, diesel, and jet fuel substitutes from $19-20 \%$ reduction (one expert thought gasoline yields could decrease by $36 \%$ ) to $43-44 \%$ increase in conversion yields compared to $2030 \mathrm{BAU}$ if RD\&D is funded at the levels each expert recommended. (At the average funding recommendation, the range is similar except one expert at the extreme thought yield could decrease by 52\%.) We believe that this wide range represents the uncertainty in the field when considering future conversion yields.

The bioenergy elicitation was the first of the group and we did not include qualitative questions about market pull policies that experts thought may contribute to accelerate the commercialization of technologies. 


\subsubsection{Storage}

On average, the 25 storage experts recommended \$240 million of annual spending from 2010-2030 on grid-level energy storage RD\&D (Figure A-17, Appendix). This is a four-fold increase compared to FY 2010 spending of $\$ 63$ million by the DOE, but it is comparable to FY 2009 spending of $\$ 208$ million, which included \$185 million of ARRA funding. Experts emphasized later stages of RD\&D slightly more than early stages like basic research. Commercial demonstration received an average of $31 \%$ of the budget; experiments and field pilots, 26\%; applied research, 24\%; while basic research was allocated 19\% (Figure A-18, Appendix). According to the experts, the majority of this budget should be spent on flow batteries, batteries, and compressed air energy storage (CAES), which account for $24 \%, 18 \%$, and $18 \%$ of the average recommended budget, respectively. They believed that flow batteries were close to maturity, allocating $16 \%$ of the average total budget to experiments and pilots or commercial demonstration. Batteries were deemed to need equal amounts of funding at all four stages, and CAES primarily at the commercial demonstration stage.

The experts we surveyed projected median cost reductions of $7 \%$ to $44 \%$ for CAES compared to 2030 BAU at their individual recommended levels of funding for energy storage ( $10 \%$ to $46 \%$ reduction at the average recommending funding level of $\$ 240$ million per year; see Figure A-20). Median cost projections for CAES in 2030 under BAU funding were as low as $\$ 400$ per $\mathrm{kW}$, and as low as $\$ 382$ per $\mathrm{kW}$ under experts' recommending funding levels. Experts projected cost reductions ranging from $3 \%$ to $70 \%$ for flywheels (reductions of $2 \%$ at the average recommended funding level). For flow batteries, reductions projected were from $10 \%$ to $67 \%$ (compared to $12 \%$ to $67 \%$ at the average recommended funding level). Median flow battery cost projections ranged from $\$ 1,500$ per $\mathrm{kW}$ to $\$ 4,500$ per $\mathrm{kW}$ in 2030 under BAU funding, and $\$ 1,000$ to $\$ 2,000$ per $\mathrm{kW}$ under experts' recommended funding levels. Both CAES and flow batteries can provide storage for greater than four hours (except for one expert which provided projections for a fifteen minute dispatch flow battery). As a comparison to the costs projected by the experts, DOE has a goal of demonstrating four-hour storage in a grid-scale application at \$1,300 per kW by 2015 . One expert projected a decline of $14 \%$ in cost for Li-ion batteries (which interpolates to an $18 \%$ reduction at the average recommended funding level). And one expert projected no changes in NaS battery costs. Another expert predicted a 33\% cost reduction in a generic technology (defined as any storage media that can be used in a highly distributed fashion) at his recommended funding level ( $16 \%$ at the average recommended funding level). No changes in the cost of pumped-hydro energy storage were predicted as a result of increased federal $\mathrm{RD} \& \mathrm{D}$ spending, presumably due to the maturity of the technology.

\subsubsection{Nuclear energy}

The average recommendation for the optimal level of federal RD\&D funding for nuclear energy over 30 experts was $\$ 1.8$ billion per year (Figure A-23, Appendix). No expert recommended maintaining or re- 
ducing $\mathrm{RD} \& \mathrm{D}$ funding from current levels (approximately $\$ 466$ million per year excluding investments in facilities of around $\$ 300$ million per year).

As shown in Figures A-22 and A-23 (see Appendix), the experts we surveyed recommended allocating the greatest amounts of spending to very high temperature reactors (note that some experts indicated that research on reactors operating at around $800^{\circ} \mathrm{C}$ should also included in this category), fuel cycle, sodium-cooled fast reactors, fuels, and small and medium factory-built (battery) reactors. Experts recommended RD\&D on several issues in the "Other" category, including: U.S. NRC anticipatory research, methods, advanced power conversion (including supercritical $\mathrm{CO}_{2}$ power cycle), information technologies, LWRs (including extension to 100 years lifetime), licensing and regulatory simplification, fusion, novel applications, and geologic waste disposal. When looking at how experts allocated their spending on a percentage basis (Figure A-24, Appendix) across different innovation stages, we see that experts allocated on average $31 \%$ percent of funding to applied research and almost $30 \%$ to experiments and pilots, and around $20 \%$ for basic research and for commercial demonstration.

The experts' opinions about how their recommended budget levels would affect nuclear technology varied (Figure 2.5). Only 7 out of the 27 experts who provided input on the cost of Gen III/III+ reactors expected that their overnight capital cost in 2030 would be affected a result of federal RD\&D investments, which is not surprising, as these reactors are already designed. Estimates of cost reductions of Gen III/ III+ reactors compared to $2030 \mathrm{BAU}$ costs, at experts' recommended funding levels, ranged up to 33\% (but ranged from $11 \%$ reduction to $6 \%$ increase at the average recommended funding level of $\$ 1.8$ billion per year; see Figure A-28 in the Appendix). All 20 experts that provided input on Gen IV costs under all budget scenarios except one who thought that federal RD\&D funding would affect the overnight capital cost of Gen IV reactors. Gen IV costs estimated by experts ranged from a reduction of 33\% to an increase of $12 \%$ from $2030 \mathrm{BAU}$ (with an even larger range of $30 \%$ reduction to $54 \%$ increase at the average recommended funding level). Finally, 20 experts provided cost of SMRs as a function of budget scenarios. The range of reductions under each expert's recommended budget was from 0-27\%, with one outlier projecting median cost reductions of around $44 \%$ (at the average recommended funding level, this range widens to span from a $42 \%$ decrease to a $79 \%$ increase in costs compared to $2030 \mathrm{BAU})$. International cooperation was another area highlighted as important by the experts. Many pointed to the lack of test facilities and infrastructure in the United States to, for instance, test Gen IV options.

Finally, experts were asked about the year at which Gen IV reactors would become commercially viable under business as usual and the experts' recommended federal RD\&D funding for nuclear energy. On average, experts expected that an optimal federal investment would accelerate commercial viability by 6 years, approximately from 2036 to 2030 .

In the nuclear area, a group of researchers at the Fondazione Eni Enrico Mattei (FEEM) undertook an 
identical survey of a comparable group of European nuclear technology experts, with results that were similar in many respects, though the experts differed in some areas. The Harvard and FEEM teams then organized a workshop with a subset of the U.S. and European participants to discuss the results, explore the issues in greater depth, and allow the experts to modify their responses in response to the discussion if they so choose. Those results are provided in a separate report (Anadon et al. 2011).

\subsubsection{Fossil energy and CCS}

The average recommendation for the optimal level of RD\&D funding for fossil energy and CCS was $\$ 2.3$ billion per year (Figure A-31, Appendix). No expert recommended maintaining or reducing RD\&D funding from current levels (approximately $\$ 400$ million per year). Experts placed strong emphasis on commercial demonstration, on average recommending that over $40 \%$ of the total RD\&D budget for fossil energy be allocated for this purpose (the maximum and minimum fractions experts dedicated for demonstrations are $80 \%$ and 15\%, respectively) (Figure A-32, Appendix). Within commercial demonstration, experts emphasized IGCC, oxy-fired combustion, and retrofitting existing plants for CCS. Across all four stages of $\mathrm{RD} \& \mathrm{D}$, experts allocated over $35 \%$ of their budgets for these purposes, on average (Figure A-32, Appendix). Across all types of research, IGCC was seen as the most important technology area in which to invest RD\&D funds. However, when the enabling technologies for post-combustion/ oxy-fired combustion capture (chemical absorption, physical absorption, adsorption, membranes, oxyfired combustion, and retrofitting existing plants) are aggregated, experts recommend allocating over three times more funding for post-combustion/oxy-fired combustion than for IGCC.

Due to a sparse response from the experts, we ran a Monte Carlo simulation of the group's cost predictions (Chan et al. 2010) (Figure A-35, Appendix). The simulated distributions indicate that experts believe it is very likely that for a new coal plant with CCS, the 2030 BAU capital cost will be lower than technology that could currently be deployed, absent any additional policies. At median values, the simulated 2030 capital cost under the recommended RD\&D portfolios is $\$ 2,400$ per $\mathrm{kW}$ whereas the 2030 capital cost under the BAU portfolio is $\$ 3,600$ per $\mathrm{kW}$, for a median cost reduction of $\$ 1,200$ per $\mathrm{kW}$. This captures both the cost reductions attributable to technical change that will occur over time absent $\mathrm{RD} \& \mathrm{D}$ policy and the cost reductions that will be driven by federal RD\&D policy. The simulated distribution under the recommended and 10-times recommended RD\&D scenarios highlight the experts' perception about the role of $\mathrm{RD} \& \mathrm{D}$ policy driving innovation in the area. Given that absent a price on carbon, CCS will not have a market, it is not surprising that greater cost reductions are estimated for these scenarios. At the $50^{\text {th }}$ percentile of the Monte Carlo distribution, the recommended RD\&D scenario reduces the capital cost from 2030 levels by $\$ 1,220$ per $\mathrm{kW}$ and the 10 -times scenario reduces the capital cost from 2030 levels by $\$ 1,660$ per $\mathrm{kW}$. Adjusted point estimates from the literature for all types of coal-fired CCS technology (post-combustion, pre-combustion, and oxy-fired combustion) span 
$\$ 2387$ per $\mathrm{kW}$ to $\$ 4168$ per $\mathrm{kW}$ (Al-Juaied, Whitmore 2009). The range of adjusted estimates from the literature falls between the $24^{\text {th }}$ and $63^{\text {rd }}$ percentiles on the 2030 BAU distribution, whereas the literature range falls between the $48^{\text {th }}$ and $83^{\text {rd }}$ percentiles on the 2030 distribution of capital costs assuming each expert's recommended level of RD\&D is implemented. This suggests that the literature better captures what the experts described would be likely when RD\&D funding does not change, while placing likely costs on the upper end of the distribution when RD\&D funding is expanded.

Although there is large disagreement on overall rate of technical change, there is greater consensus on the rate of exogenous technical change than on the rate of endogenous technical change. Four experts thought that under BAU funding the capital cost of a new coal plant with CCS would not become less expensive (in real terms) by 2030. The most optimistic expert estimated that capital costs would decrease 27\% from 2010 to 2030 under the BAU scenario, while the most pessimistic expert estimated that capital costs would increase $33 \%$.

\subsubsection{Commercial buildings}

Experts recommended an average of $\$ 680$ million per year for building technology RD\&D, a more than four-fold increase over FY 2010 spending of \$144 million. As shown in Figures A-37 to A-39 (Appendix), on average the greatest amounts of spending are allocated to applied research for windows (4\%) and controls and monitoring (5\%), as well as building metering experiments and pilots (5\%). Experts further defined their recommendations for controls and monitoring and building metering to include full system monitoring as well as metering energy efficiency down to a component level. On average, $31 \%$ of total funding was directed to commercial demonstrations, and $27 \%$ for experiments and pilots.

As mentioned earlier, experts chose to provide information about the costs of commercial, rather than residential, buildings (which is why we cannot incorporate the benefits of buildings RD\&D in residential buildings) and that questions were limited to the cost of improving the efficiency of building shells and its impact on reducing heating and cooling duty (which is why we do not incorporate the benefits of RD\&D on other components of building demand such as water heating and lighting). Thus the benefits from $\mathrm{RD} \& \mathrm{D}$ are very much an underestimate. Experts expected that building costs will decrease over time. However, they appear to disagree about the magnitude of costs for new buildings and renovations (Figures A-40 and A-41, Appendix, respectively), as well as the change in costs resulting from revamped federal RD\&D spending (Figure A-42, Appendix). The experts' predictions about the benefits of additional funding for buildings RD\&D range widely. Current building technology innovation spending is $\$ 144$ million. If annual spending were increased to $\$ 500$ million, 3 experts expect no more than $5 \%$ reduction in building costs but one expert expects $70 \%$ reduction in building costs. Still, all experts think that increasing investments will result in lower building costs with lower heating and cooling energy needs than commercial code-compliant buildings. If annual spending were increased to the experts' average

The Belfer Center for Science and International Affairs | Harvard Kennedy School 
recommendation of $\$ 680$ million, building costs could be reduced 5-52\%. As a comparison, DOE has set a goal for net-zero energy buildings (NZEB) to be cost effective alternatives to traditional construction by 2025. In addition, DOE has a goal of upgrading the model building energy codes to require an increase in energy efficiency in new buildings of 50\% by 2016 for commercial buildings and by 2015 for residential buildings, compared to Standard 90.12004 for commercial buildings, and the 2006 IECC for residential low-rise buildings. This is equivalent to a $28 \%$ increase in efficiency compared to the IECC 2009.

Experts provided their opinion on how to improve the state of the art to reduce energy needs in the building sector. Experts prioritized and made recommendations for controls and metering; occupant training; integrated systems design; stringent and consistent commissioning; developing knowledge capital; and improving simulation models. Additional details are available in the Appendix, but most notably experts called for complementary systems for building development that included operations/ maintenance staff and occupant training, regional centers to test building technologies and serve as clearinghouses for new ideas and professional training, and detailed validated simulation models that accurately represent complex systems and user behavior.

\subsubsection{Vehicles}

The nine vehicles experts we elicited recommended an average of $\$ 2.05$ billion per year in vehicles RD\&D spending (Figure A-45, Appendix). The recommended spending levels were highly skewed; the median recommended RD\&D spending level was $\$ 1$ billion, indicating that, while most experts recommended large increases in RD\&D spending from the current level ( $\$ 485$ million in FY 2010), there is large disagreement over the extent to which the vehicles RD\&D program should expand. On average, experts allocated just over 35\% of their recommended RD\&D budgets to both basic research and applied research, and $20 \%$ to experiments and prototypes, with the remaining allocation to commercial demonstration. The technology areas with greatest RD\&D emphasis were lithium-ion batteries, novel concepts for energy storage, and materials, each receiving 12-15\% of recommended RD\&D funds. Ultracapacitors, battery manufacturing processes, hydrogen storage, and electronic controls were also emphasized, each receiving over $7 \%$ of recommended RD\&D funds.

Four experts provided cost estimates for vehicles with five drive trains: advanced internal combustion (ICE), conventional hybrid, plug-in hybrid, battery-electric, and hydrogen fuel cell. Overall, for each drive train except hydrogen fuel cell, experts did not agree whether costs would increase or decrease from 2010 to 2030 with or without their recommended RD\&D budget. For advanced ICE drive train vehicles, only one of the four experts estimated that vehicle costs would decrease through 2030 under BAU RD\&D funding. At recommended budget levels, experts estimated modest median cost reductions between $0-5 \%$ below their predicted cost of advanced ICE vehicles under BAU RD\&D. Experts were even more pessimistic with respect to the effect of RD\&D on conventional hybrid costs, estimat- 
ing that their recommended RD\&D would reduce conventional hybrid vehicle costs $0-3 \%$ below their predicted costs under BAU RD\&D. For battery-electric and plug-in hybrids, experts estimated that their recommended RD\&D would lower costs between 1-9\% from what they would otherwise be under BAU $\mathrm{RD} \& \mathrm{D}$. However, because of the large disagreement over how plug-in and battery-electric costs would change under BAU RD\&D, even the sign of the estimated change in costs from 2010 to 2030 under recommended RD\&D levels is ambiguous: the most optimistic expert estimated that his/her recommended $\mathrm{RD} \& \mathrm{D}$ budget would reduce median estimated plug-in hybrid vehicle costs $14 \%$ from current costs and battery-electric vehicle costs $23 \%$ from current levels, while the most pessimistic expert estimated that median costs of plug-ins would increase 6\% from current levels and battery-electric vehicle costs would increase $9 \%$ from current levels. For hydrogen fuel cell drive train vehicles, experts agreed that their recommended RD\&D would reduce vehicle costs by 1-31\% below what they would otherwise be in 2030 at BAU RD\&D.

Experts were also asked to estimate performance characteristics for the five vehicle drive trains. For advanced ICEs, experts estimated that under BAU RD\&D the fuel economy of vehicles would increase by 4-14 miles per gallon from 2010 to 2030, while their recommended RD\&D budget could only amplify this increase by an additional 0-2 miles per gallon. Similarly, for conventional hybrid drive train vehicles, experts estimated that under BAU RD\&D fuel economy would increase 2-7 miles per gallon from 2010 to 2030 with accelerated RD\&D boosting 2030 fuel economy by an additional 0-8 miles per gallon. For plug-in hybrids, experts estimated that under BAU RD\&D gasoline fuel economy would decrease between 2-5 miles per gallon from 2010 to 2030 while electricity usage would decrease $7-10 \%$. Additional RD\&D at the experts' recommended levels was estimated to increase fuel economy an additional 0-11 miles per gallon while decreasing electricity consumption an additional $0-11 \%$. For batteryelectric vehicles, experts estimated that from 2010 to 2030, electric efficiency would improve 0-12\% while the all-electric range would improve by $0-50$ miles. The additional effect of recommended RD\&D budgets was estimated to improve electric efficiency by an additional 7-13\% in 2030 while improving the electric range by 10-45 miles. Finally, for hydrogen fuel cell vehicles, experts estimated that under BAU RD\&D hydrogen efficiency would improve $8-31 \%$ and additional RD\&D at the recommended levels would improve hydrogen efficiency by 6-24\% in 2030.

\subsubsection{Solar PV}

The eleven solar PV experts recommended, on average, $\$ 410$ million per year for RD\&D (Figure A-51, Appendix). This is a more than two-fold increase compared to FY 2010 spending of $\$ 175$ million by the DOE (including PV, system integration, and market transformation). Experts recommended on average $37 \%$ for applied research, and $27 \%$ and $25 \%$ for basic research and experiments and pilots, respectively. (Figure A-52, Appendix). On average the experts allocated the highest levels of funding to concentrator PV (primarily applied research and experiments and pilots), thin film PV (primarily applied research), 


\begin{tabular}{|c|c|c|c|c|c|c|c|c|}
\hline & 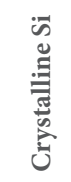 & 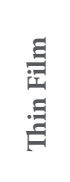 & 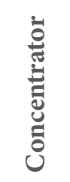 & 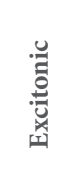 & 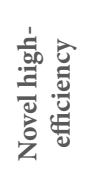 & 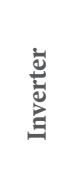 & 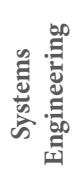 & $\begin{array}{l}\ddot{\Xi} \\
\bar{\Xi}\end{array}$ \\
\hline Basic Research & $2.4 \%$ & $5.1 \%$ & $3.6 \%$ & $3.2 \%$ & $6.6 \%$ & $2.8 \%$ & $1.4 \%$ & $2.2 \%$ \\
\hline Applied Research & $5.5 \%$ & $6.1 \%$ & $5.4 \%$ & $2.2 \%$ & $5.6 \%$ & $4.8 \%$ & $4.4 \%$ & $3.0 \%$ \\
\hline Experiments and Pilots & $2.5 \%$ & $4.3 \%$ & $5.1 \%$ & $1.3 \%$ & $2.5 \%$ & $3.4 \%$ & $3.5 \%$ & $2.2 \%$ \\
\hline Commercial Demonstration & $0.5 \%$ & $1.4 \%$ & $3.5 \%$ & $0.6 \%$ & $1.1 \%$ & $1.3 \%$ & $1.5 \%$ & $1.5 \%$ \\
\hline Total & $10 \%$ & $17 \%$ & $18 \%$ & $7 \%$ & $16 \%$ & $12 \%$ & $11 \%$ & $10 \%$ \\
\hline
\end{tabular}

FIGURE 2.4. Average allocation of recommended annual federal solar PV technology RD\&D budget for 2010-2030 (percentage of total). The percentages may not add to $100 \%$ due to rounding.

and novel high efficiency PV (primarily basic research). Experts recommended funding crystalline silicon, thin film, concentrator, excitonic, and novel high-efficiency technologies (among others), but did focus on thin film, concentrator, and novel high-efficiency technologies. (Figure 2.4 shows the table that experts were asked to use to allocate RD\&D funding and the average allocation recommended across experts - this table, alongside that for the other technologies investigated, is also included in the Appendix.) It should be noted that qualitative reviews of the elicitation results highlighted the predominance of concentrator PV experts among the eleven solar PV experts.

Experts projected that significant commercial, residential, and utility module overnight capital cost reductions can be achieved compared to expected BAU module costs by 2030 . Experts expected $6 \%$ to $30 \%$ reductions in commercial module costs in 2030 at their recommended funding levels when compared to a BAU RD\&D funding scenario; $10 \%$ to $60 \%$ reduction for residential modules; and up to $40 \%$ reduction for utility modules. Median commercial module cost projections ranged from $\$ 0.50$ per $\mathrm{W}$ to $\$ 2.25$ per $\mathrm{W}$ in 2030 under BAU funding, and $\$ 0.35$ per $\mathrm{W}$ to $\$ 2$ per $\mathrm{W}$ under experts' recommended funding levels; for residential, $\$ 0.75$ to $\$ 2.40$ per W under BAU funding and $\$ 0.30$ to $\$ 2.00$ per W under recommended; and for utility, $\$ 0.35$ to $\$ 1.25$ per W under BAU and $\$ 0.30$ to $\$ 0.85$ per W under recommended. DOE's goal of reaching PV costs of $\$ 1$ per W by 2017 appears to fall within the range of costs experts predicted for 2030. At the average recommended funding of $\$ 410$ million, experts' interpolated projections ranged from reductions of up to $24 \%$ to increases of $17 \%$ for commercial modules; reductions of $35 \%$ to increases of $3 \%$ for residential modules; and reductions of $36 \%$ to increases of $19 \%$ for utility modules, compared to 2030 BAU.

Commercial and utility module costs were projected by some experts to increase compared to a BAU funding scenario if funding was not significantly above the FY 2010 level. PV efficiency improvement projections ranged from $6 \%$ to $33 \%$ for commercial modules; up to $67 \%$ for residential; and up to $47 \%$ 
for utility at experts' individual funding recommendations. At $\$ 410$ million of annual funding, the range of improvements is lower.

\subsubsection{Summary of RD\&D budget recommendations from elicitations}

Through the expert elicitations discussed above, we gained insight into the amount of federal RD\&D spending that experts thought would be necessary per industry to increase the prospects of commercializing important energy technologies by 2030. Experts also shared their thoughts about how to best allocate federal RD\&D funding, according to technology and stage of innovation. Almost all experts predicted decreasing marginal returns to federal RD\&D investments beyond their recommended budget, as seen by their estimated technology outcomes under an impact of an investment of ten times their recommended budget.

Average spending level is summarized and compared to current spending level in Table 2.5. As discussed above, experts consistently recommended increased spending, with mixed opinion about the benefit to be gained from this spending. Figures 2.5 and 2.6 show the expected range of cost reduction and performance improvement predicted by experts for the group's average recommended spending level, respectively.

The average recommended increases over fiscal year (FY) 2009 appropriations ranged from 186\% for solar photovoltaic to $963 \%$ for utility-scale storage (where the base for comparison is small and the potential is large). In absolute terms, the average recommended increases in spending ranged from $\$ 221$ million per year for storage to $\$ 1.65$ billion per year for fossil energy.

\begin{tabular}{lccccc} 
Technology & $\begin{array}{c}2009 \\
\text { spending } \\
(\text { million } \$)\end{array}$ & $\begin{array}{c}2009 \\
\text { ARRA spending } \\
\text { (million \$) }\end{array}$ & $\begin{array}{c}\text { Average } \\
\text { recommended } \\
(\text { million \$) }\end{array}$ & $\begin{array}{c}\text { Average increase } \\
\text { over 2009 } \\
\text { recommended } \\
\text { by experts in \% }\end{array}$ & $\begin{array}{c}\text { Absolute increase } \\
\text { over 2009 in } \\
\text { \$million }\end{array}$ \\
Bioenergy & 214 & 777 & 682 & $219 \%$ & 468 \\
Energy storage & $23^{\mathrm{a}}$ & 185 & 244 & $963 \%$ & 221 \\
Nuclear & 466 & 0 & 1,833 & $293 \%$ & 1,367 \\
Fossil & 701 & 3,390 & 2,354 & $236 \%$ & 1,653 \\
Solar PV & 143 & $86^{\mathrm{b}}$ & 409 & $186 \%$ & 266 \\
Vehicles & 432 & 2,839 & 2,050 & $375 \%$ & 1,618 \\
Buildings & 144 & 319 & 678 & $371 \%$ & 534 \\
\hline $\begin{array}{l}\text { Total of technologies } \\
\text { studied }\end{array}$ & 2,123 & 7,596 & 8,251 & $289 \%$ & 6,128
\end{tabular}

a FY 2010 funding was $\$ 63.3$ million, including \$30.5 million for ARPA-E. The average increase over FY2010 spending recommended by experts is $280 \%$.

b This sum is for the photovoltaics, system integration, and market transformation programs.

TABLE 2.5. Expert recommended RD\&D spending and 2009 federal spending, per technology area (or industry) 
As shown in Figure 2.6, grid level energy storage and buildings technology undoubtedly benefit from spending experts' recommended budgets of $\$ 680$ million and $\$ 240$ million. The cost to reduce heating and cooling energy needs in new commercial buildings will be reduced 5-52\% over BAU costs to build new commercial buildings. While the benefits rendered to the various energy storage devices are mixed, such that hydro storage costs can't be reduced over the BAU cost, batteries and generic technologies may achieve up to $14 \%$ and $25 \%$ reductions in cost over the BAU, respectively, and CAES and flow batteries costs will decrease by $7-38 \%$ and $2-58 \%$ respectively. There was considerable uncertainty among nuclear technology experts about the benefits to be gained by spending $\$ 2$ billion on RD\&D. Experts thought that SMR, Gen III/III+, and Gen IV costs could increase by 4\%, 16\%, and 14\%, respectively. But on the optimistic end of the experts' range, SMR, Gen III/III+, and Gen IV costs could decrease by $38 \%, 24 \%$, and $24 \%$, respectively. Lastly, bioenergy experts appeared more certain about the gains to gasoline substitutes than any other biomass derived fuel for $\$ 600$ million of federal RD\&D spending. Gasoline substitute costs would be 51-69\% less than BAU costs. Major cost reductions, 27\%, 86\%, and $56 \%$ respectively, can be achieved for electricity, jet fuel substitute, and diesel costs, but the costs of these fuels may increase as well.

The median of the experts' estimated cost reduction over the cost under a business-as-usual (BAU) ERD\&D funding scenario in 2030 ranged from no cost reduction in the case of sodium sulfur batteries (for which only a small number of experts provided estimates), to around 35\% in the case of residential-scale solar PV and flywheel energy storage technologies. The cost reduction catalyzed by federal ERD\&D funding beyond the BAU scenario is the lowest for vehicle technologies, ranging from a $2 \%$

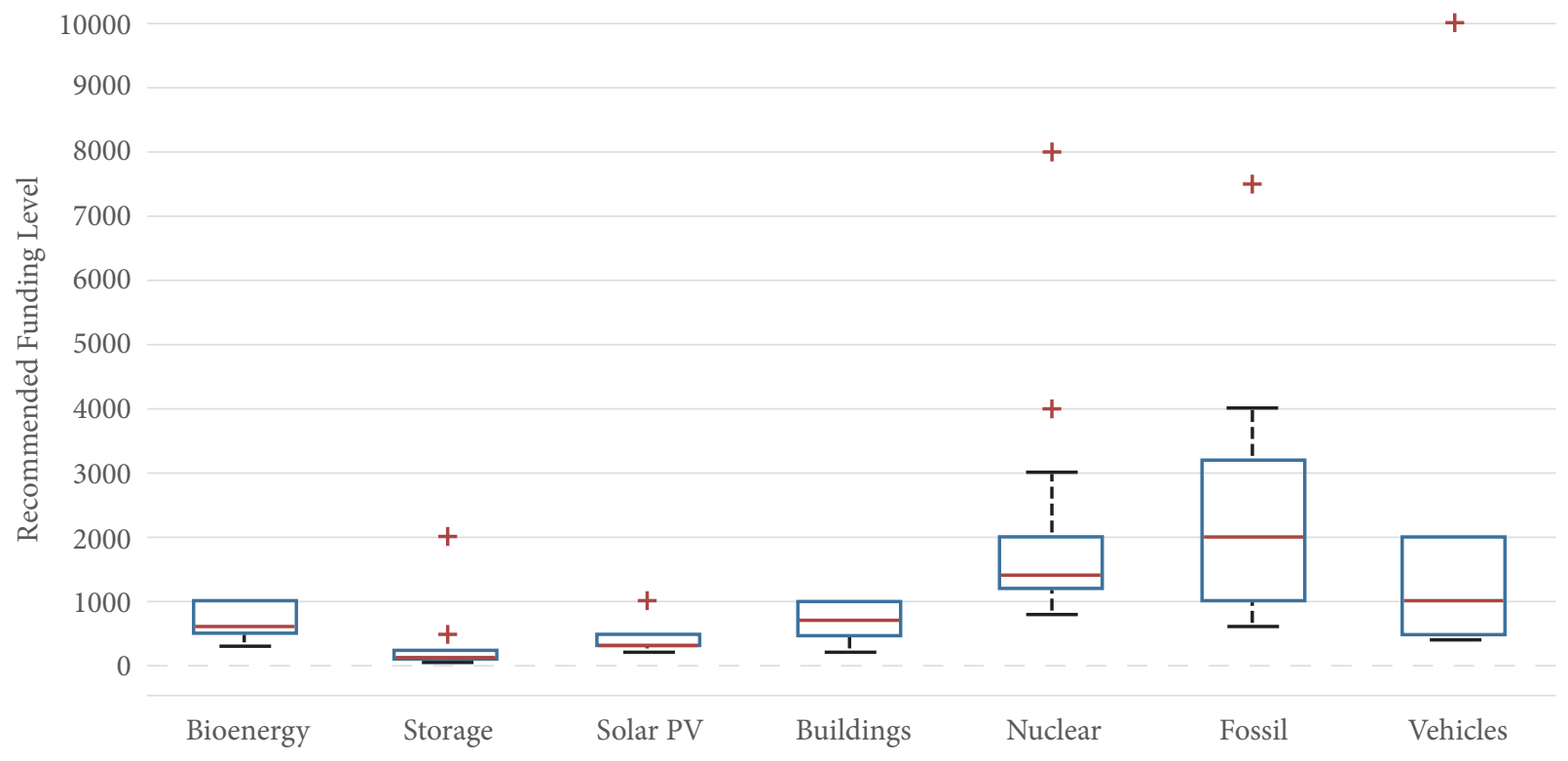

FIGURE 2.5. Range of budget recommendations from experts by technology area. The red line represents the median recommendation; the blue box encompasses the $25^{\text {th }}$ to the $75^{\text {th }}$ percentiles; and the black line represents the highest and lowest recommendations within 1.5 times the interquartile range (IQR) of the budget recommendations. The recommendations outside of this range are shown with cross marks. 


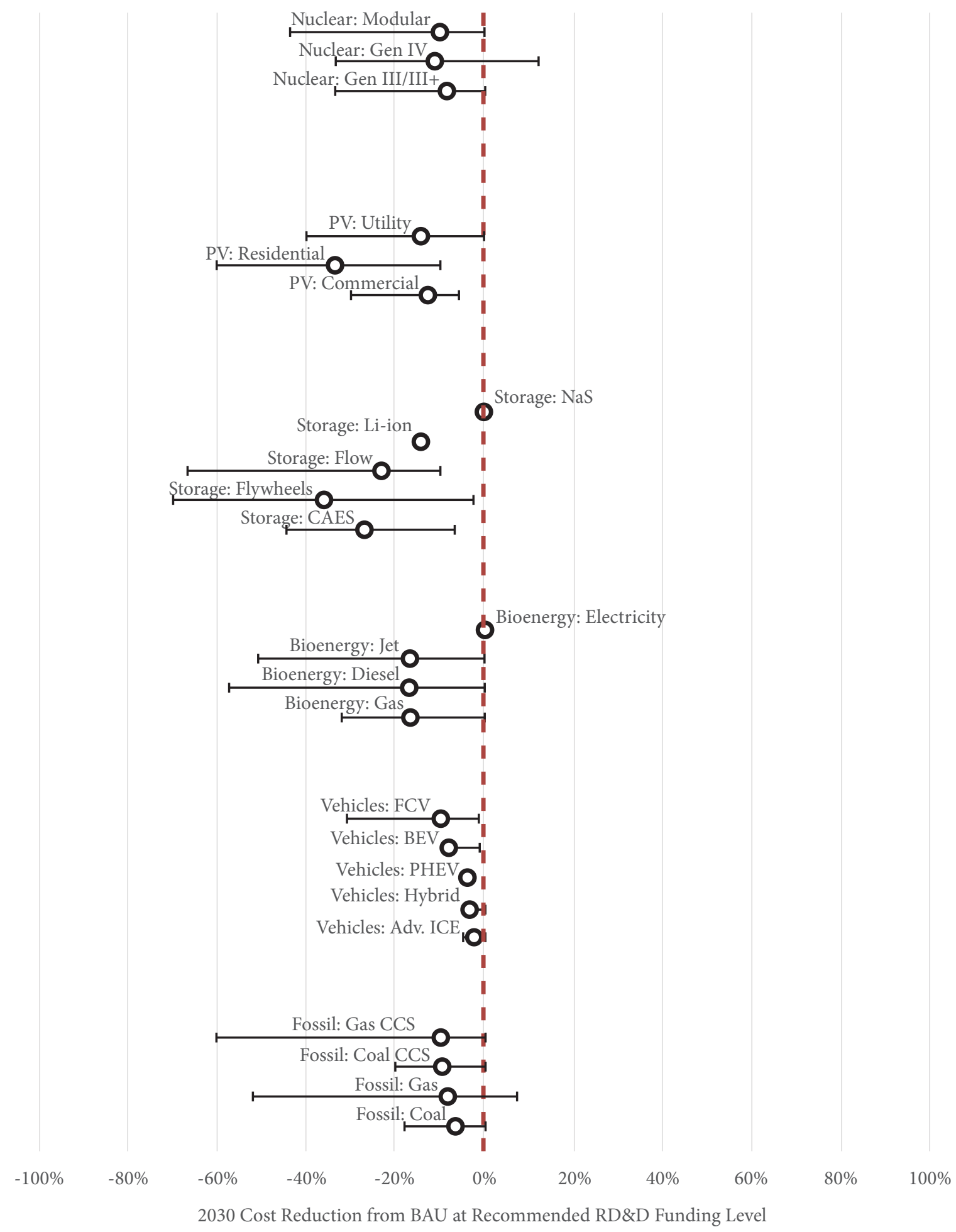

FIGURE 2.6. Range of median cost reduction per technology predicted by each expert under his or her recommended RD\&D spending per industry. Costs cover overnight capital costs for SMR, Generation IV, and Generation III/III+ nuclear power plants; overnight capital costs for grid level energy storage technologies; production costs biomass-based electricity (\$ per $\mathrm{kWh}$ ) and substitutes for jet fuel, diesel, and gasoline (\$ per gallon); unit costs for advanced ICE, hybrid, plug-in hybrid, electric, and fuel cell vehicles (\$ per unit); overnight capital cost of coal and natural gas power plants with and without CCS (\$ per $\mathrm{kW}$ ); and module cost for residential, commercial, and utility scale PV panels (\$ per kW). 
cost reduction for advanced internal combustion engine (ICE) vehicles to a $10 \%$ cost reduction for fuel cell vehicles. (This may reflect a judgment that investments by private firms, rather than federal spending, will be the major driver of improvement in vehicle technologies.)

\subsection{Insights About Non-RD\&D Policies from Expert Elicitations}

\subsubsection{Bioenergy}

The bioenergy was our first survey and experts were not asked about policies or occurrences that may affect deployment.

\subsubsection{Storage}

Experts provided their opinion about how to resolve market structure, incentives, and siting issues to facilitate widespread deployment of grid-level energy storage systems. Expert opinion varied about how energy storage should be categorized for the grid. Most experts-17 of 25-thought that regulations should be clarified so renewables with storage would be considered "renewable" for inclusion in a renewable portfolio standard (RPS). Additionally, 13 of the 20 experts consulted thought that bonus renewable electricity certificates should be awarded for renewables coupled with storage. Many experts believed that energy storage should be considered a separate class from generation and transmission. One expert suggested that all generating technologies be required to be "dispatchable", which would force renewable power generation developers to incorporate energy storage into their systems. Many experts recommended that the cost of storage be calculated into the electric utility rate base, while one expert argued that rate base regulation itself obscures the value of storage. The experts also recommended policies that would encourage energy storage adoption for distributed generation. While many experts believed that a national or regional siting policy is needed for technologies like CAES, one expert pointed out that licensing guidelines for distributed generation are also essential.

Many experts thought that storage should be subsidized as an emerging technology to provide additional incentive to adopt energy storage technologies. Recommendations for an investment tax credit (ITC) ranged from $20 \%$ to $30 \%$ of the investment costs or from $\$ 300$ per $\mathrm{kW}$ to $\$ 500$ per $\mathrm{kW}$, for a period of five years. One variation recommended was a 30\% ITC declining to zero in 10 years. Production tax credit (PTC) recommendations ranged from $\$ 0.02$ per $\mathrm{kWh}$ to $\$ 0.03$ per $\mathrm{kWh}$ for ten to fifteen years. One expert recommended a declining production subsidy, rather than a PTC, that would start at between one-fourth to one-third of the cost of storage. Another expert noted that the ITC favors high capital cost technologies in contrast to the PTC, therefore both may be needed depending on the storage technology. Some experts also recommended subsidy levels equivalent to that of other renewables, since storage is integral to the large-scale expansion of some renewable energy technologies. One expert 
cautioned against subsidizing any specific technology preferentially, or subsidizing storage without requiring the renewable and decarbonization benefits. Additionally, one expert stressed the need for clean renewable energy bonds (CREBs) for cooperatives.

\subsubsection{Nuclear energy}

The experts we surveyed generally agreed that the possible future event that would most reduce future nuclear growth would be a major accident or terrorist attack resulting in a large release of radioactivity. Most thought such an event would lead to 50-100\% reductions in the new deployments that would otherwise occur in the United States. (Our survey did not ask about global deployments.) Experts generally thought such an event was unlikely, however, with a probability of less than $10 \%$. Those experts that participated in the workshop with European experts generally continued to take this view after the Fukushima accident. Other global developments or events that the experts expected would result in significant reductions in future deployments included major cost overruns or proliferation from the civilian nuclear energy system. On the other hand, successful U.S. repository siting would have significant positive impact on construction rates, but experts were uncertain about the impact of international repository siting on U.S. nuclear power. Experts were also asked about the extent to which firms financing nuclear power plant construction would have to pay a risk premium between 2010 and 2030 when compared to the cost of financing natural gas power plants. Of the 26 who answered, sixteen said that they thought there would be a risk premium of around $1 \%$ in 2030, while five said there would be none (the other five said they did not know). Experts appeared to agree that construction delays and cost overruns were the most important factors affecting risk premiums. This suggests that policies that reduced risks and delays in licensing, construction, and financing would be likely to have a large impact on the construction of nuclear plants.

\subsubsection{Fossil energy}

Experts were asked to what extent bioenergy RD\&D could be concurrently conducted with fossil energy RD\&D. While three experts stated that they did not think there were opportunities to conduct concurrent bioenergy and fossil research, seven saw promising opportunities. From the seven experts who recommended concurrent fossil and bioenergy experts, specific efforts were recommended for RD\&D in biomass co-firing with coal feedstock, oxy-fired biomass combustion, and biomass combustion with chemical absorption.

Experts were also asked whether they would recommend international collaboration in fossil RD\&D projects. All experts, except one, recommended international fossil energy RD\&D collaboration. Six experts recommended collaborative RD\&D with China, the most frequently mentioned country. Five experts also recommended collaborative projects with European countries. On specific collaborative 
project recommendations, seven experts recommended focusing on large-scale demonstration projects of capture technologies, two of whom recommended focusing on retrofits for carbon capture, and two experts suggested focusing on carbon sequestration demonstration.

Finally, experts were asked which industries or technologies could potentially have positive spillovers for fossil energy technologies. The most frequently cited industry that could contribute technological spillovers for fossil power and CCS was the petrochemical industry. Experts cited potential spillovers from within the petrochemical industry coming from refinery technology, reservoir geophysical tools, and drilling technologies. Experts also suggested that the cement industry and natural gas industry could contribute technological advances or demonstration opportunities relevant for coal power and CCS. Finally, two experts suggested that the chemical industry might also hold relevant technological promise for fossil power and CCS.

\subsubsection{Commercial buildings}

A majority of experts cited a comprehensive energy policy (including a cap-and-trade $\mathrm{CO}_{2}$ market), more stringent building codes and efficiency standards, or a single standard method for building construction and management as the most important actions necessary, rather than RD\&D in building technologies. Experts stressed the importance of communicating about research programs, demonstration projects through case studies, and collected data to raise awareness in the industry and the general public. More than one expert recommended removing subsidies for fossil fuels and nuclear, and increasing subsidies to renewable energy sources. One expert also recommended financial instruments to incentivize energy efficiency, like property assessed clean-energy (PACE), tax benefits, and floor area ratio (floor area to site area) (FAR) bonuses.

Experts strongly supported policies that could increase renovation rates. When asked about how to increase construction of energy efficient buildings, 3 of 9 experts believed that increasing new building construction rates is undesirable. Instead, experts believe that policies should focus on existing buildings rather than on encouraging new construction because of the material consumption and embodied energy necessary to build new buildings. Experts suggested several ideas to prevent new construction, such as banning new office building construction and implementing policies to discourage new construction by revising permitting and zoning policies to encourage higher urban density and redevelopment. They recommended incentive policies for renovating, such as double tax incentives to reduce payback period of renovation costs to 5 years, retro-commissioning for existing buildings to meet current standards, public disclosure of building performance combined with fines for those that don't meet benchmarks, and tax deductions or credits for those who surpass benchmarks. 


\subsubsection{Vehicles}

Experts cited increasing fuel taxes, feebates, vehicle performance standards that increase fuel economy or reduce GHG emissions, a cap on GHG emissions, an oil price floor, a low carbon fuel standard, incentives for carpooling, pay-at-the-pump insurance, tax credits, transit subsidies, or a combination of these policies as the most important non-RD\&D federal policies that should be implemented to reduce GHG emissions and petroleum consumption in the energy sector. One expert listed creative financing programs like green mortgages for those who take public transit (e.g., in Chicago) or subsidized auto leases for more fuel efficient vehicles. More specifically, one expert recommended an increase in fuel taxes to $\$ 2.00$ per gallon, with revenues returned to individual vehicle owners, while another suggested that revenues pay for transportation infrastructure only. Another expert cautioned that taxes are not a replacement for vehicle efficiency standards. One expert detailed a GHG cap where the majority of allowance revenues collected prior to 2025 are invested in low carbon technologies across the energy sector, from $\mathrm{R} \& \mathrm{D}$ to manufacturing and consumer incentives, and revenues post 2025 are distributed to the public as dividends. One expert noted that driving cycles have to be completely redone in cities, suburbs, and inner cities. One expert recommended the creation of a Presidential Council on Sustainable Development.

Experts were also asked how their recommended RD\&D portfolio would change under a GHG emissions mitigation policy versus a petroleum consumption reduction policy. Many experts stated that their recommendations would not change. However, some would spend more on low-carbon hydrogen generating technology, low-carbon electricity generation, the interactions between plug-in vehicles with the grid to enhance renewable and nuclear resource use, passenger and inter-city rail, and automated highway systems, under a GHG mitigation policy. Under a petroleum consumption reduction policy, some experts would spend more on ultracapacitors for their regenerating capability, lightweight materials, retrofit technologies for existing cars, compressed natural gas and methanol in internal combustion engines, liquefied natural gas for inter-city trucks, and batteries for electric vehicles, and spend less on plug-in hybrids by using less sophisticated charging.

\subsubsection{Solar PV}

Policy questions about siting, transmission, and permitting issues, solar variability, and other policy needs were also posed to the experts. One expert lauded the permitting of support for innovative technology by the California Energy Commission for the California Solar Initiative. A couple of experts noted the lack of information on utility system interconnection capability for project developers and the public to inform site choices. One expert expressed the desire that project approvals be streamlined to take a maximum of three months. Another expert thought that PV should be exempt from local permitting taxes and utilities should be required to accept all PV systems below a certain size. 
Five experts cited the need for energy storage to accommodate the variability of solar PV, while one expert recommended that any new investments in non-renewable generation by utilities should be capable of supporting variable generation (i.e., natural gas). A couple of experts mentioned the need for time-of-day pricing to reflect the true costs of electricity and the benefits of solar variability, possibly aided by a smart grid. Reflecting true costs would provide the most value for the public and drive innovation such that incentives can be phased out. One expert recommended greater DOE support for the utility market because: it is the toughest and most challenging; it can make the largest impact in terms of electricity generated; and residential and commercial markets are already well supported politically and financially.

When asked about policies that would most encourage solar PV deployment, experts on average ranked feed-in tariffs as the most important, while RPS ranked second and PTC ranked third. The minority that disagreed ranked climate change mitigation policy and investment tax credits/grants as most important. For a feed-in tariff, experts recommended from $\$ 0.05$ per kWh to $\$ 0.5$ per kWh in 2010 , falling to between zero and $\$ 0.12$ per kWh by 2030. Experts were fairly split on whether to limit the feed-in tariff to PV, renewable sources, or low-carbon generation. Recommended levels for RPS ranged from $20 \%$ to $50 \%$ of total generation, with less than half of the experts specifying a $10 \%$ carve-out for solar.

\subsection{Results Estimating the Benefits of RD\&D Investments}

\subsubsection{Combined benefits of different levels of RD\&D investments}

In this section we discuss modeling results for energy-related $\mathrm{CO} 2$ emissions, oil imports, $\mathrm{CO} 2$ prices, and clean-energy standard (CES) credit prices. Comparisons are shown between different RD\&D fund-

$\begin{array}{cl}\text { Label } & \text { Definition } \\ \text { M } & \text { Middle-of-the-road technology cost assumptions } \\ \text { O } & \text { Optimistic technology cost assumptions } \\ \text { P } & \text { Pessimistic technology cost assumptions } \\ \text { BAU } & \text { Business-as-usual RD\&D funding level } \\ \text { HALF } & \text { Half of experts' recommended RD\&D funding level } \\ \text { FULL } & \text { Experts' recommended RD\&D funding level } \\ \text { TEN } & \text { Ten times experts' recommended RD\&D funding level } \\ \text { CO2 } & \text { Under a CO2 cap-and-trade policy (83\% below 2005 levels by 2050) } \\ \text { SEC } & \text { Under sectoral policies (CES, CAFÉ standards, commercial building standards) } \\ \text { NN } & \text { No expansion of nuclear power }\end{array}$

TABLE 2.6. Scenario labels and definitions 
ing levels and technology assumptions. Results are presented for scenarios with no new policies, a CO2 cap-and-trade policy, and sectoral policies. Other variations on scenarios include energy prices and sensitivity to the expansion of nuclear power (Table 2.4.) After presenting the results on the impact of $\mathrm{RD} \& \mathrm{D}$ on different metrics over time, we show the decreasing marginal returns to RD\&D that we observed when funding is increased to about 10-times the funding scenario recommended by the experts.

\section{Evolution of $\mathrm{CO}_{2}$ emissions, oil imports, $\mathrm{CO}_{2}$ prices, and CES prices over time}

In order to investigate the impact of different levels of RD\&D funding for each of the seven technology areas, we developed three types of technology assumptions from the experts' responses: "middle-of-theroad", "optimistic", and "pessimistic". The middle-of-the-road (or "middle") technology assumptions include the estimates of the experts for each technology that were the most representative in terms of their median estimate and also their $10^{\text {th }}$ and $90^{\text {th }}$ percentile estimates. As their names suggest, the optimistic and pessimistic assumptions include especially pessimistic and optimistic experts for each technology. These experts were selected with the help of feedback from the qualitative reviews. To simplify the discussion, we summarize results from the middle and optimistic technology assumptions and we do not refer to the modeling results under the pessimistic technology assumptions. ${ }^{30}$ The scenarios referred to in the discussion below use the legend in Table 2.6, with specific scenarios described using combinations of several of the labels. ${ }^{31}$

We refer to the scenario with recommended RD\&D funding levels by the selected experts in each technology area as the "full scenario" (FULL), and to the scenario with ten times the recommended funding level as the "10-times scenario" (TEN). Unless otherwise specified (e.g., when the impact of $\mathrm{RD} \& \mathrm{D}$ on the uncertainty range is mentioned explicitly), the discussion is based on the median results. The figures below show the $5^{\text {th }}, 25^{\text {th }}, 50^{\text {th }}, 75^{\text {th }}$, and $95^{\text {th }}$ percentile projections across approximately 400 samples in each scenario.

The total annual BAU RD\&D funding for the seven technology areas was $\$ 2.1$ billion, corresponding to DOE's FY 2009 appropriations in those areas. The median recommended budget for those seven areas is almost three times greater, or $\$ 6.0$ billion, and the average recommended budget is 3.9 times greater, or $\$ 8.2$ billion. The middle experts' recommended budget for the seven areas was 2.3 times as large as the BAU budgets, or $\$ 4.9$ billion. ${ }^{32}$ Therefore, when we ran scenarios with the technology cost and per-

30 The aim of building a set of pessimistic technology assumptions was to estimate a high-bound of $\mathrm{CO}_{2}$ emissions scenario under a no-policy case and BAU RD\&D funding levels. Because of this, we ran very few scenarios under the pessimistic assumptions. The figures in this section show the wide range of deployment of various technologies under a scenario of no additional policy comparing the results using optimistic technology assumptions under the 10-times funding scenario, with the results using pessimistic technology assumptions under the BAU funding scenario.

31 For example "MBAUCO2" refers to a scenario that uses the middle-of-the-road technology cost assumptions and business-asusual funding levels for all technologies, under a $\mathrm{CO}_{2}$ cap-and-trade policy.

32 Note that the sum of the optimistic expert recommendations is $\$ 12.8$ billion, and that of the pessimistic expert recommendations is $\$ 10.9$ billion. 
formance projections of the middle experts, we also used the middle experts' budget recommendations of $\$ 4.9$ billion a year. But, given that the full group of experts had higher median and average budget recommendations, it may be that it would take more than the middle experts' budget recommendations to achieve their projections of future technology cost and performance. Hence, we consider the full funding scenario as ranging from $\$ 4.9$ billion to $\$ 8.2$ billion per year. Similarly, the 10 -times scenario corresponds to funding from $\$ 49$ billion to $\$ 82$ billion per year.

In these models, projections from the middle-of-the-road experts suggest that even large increases in ERD\&D funding, in the absence of any price on carbon, still lead to a roughly 95\% probability that emissions in 2050 would be greater than those in 2010, far from the goal of more than five-fold reductions. The uncertainty shown in Figure 2.7 only includes the experts' estimates of the uncertainty around the cost and performance of the seven technology areas covered in our surveys, not the myriad other factors that will affect U.S. emissions between now and 2050.

In our modeling, under a no-new-policy scenario, $\mathrm{CO}_{2}$ emissions continue to rise from today to 2050 under BAU funding levels (Figure 2.7). Emissions level off and decline under full and10-times scenarios under both middle and optimistic technology assumptions; however, they are still at levels that would, if progress in other countries was similarly limited, make it impossible to achieve climate goals such as limiting temperature increases to 2 degrees $\mathrm{C}$ above pre-industrial levels. These results indicate that even levels of energy RD\&D funding at ten times that recommended by the experts we surveyed would not be enough to dramatically reduce U.S. carbon emissions on their own. They illustrate the need for additional policies working in conjunction with $\mathrm{RD} \& \mathrm{D}$ to reduce $\mathrm{CO}_{2}$ emissions from the energy system. Under a sectoral policy case with BAU RD\&D funding, median $\mathrm{CO}_{2}$ emissions in 2030 would be

Middle Experts

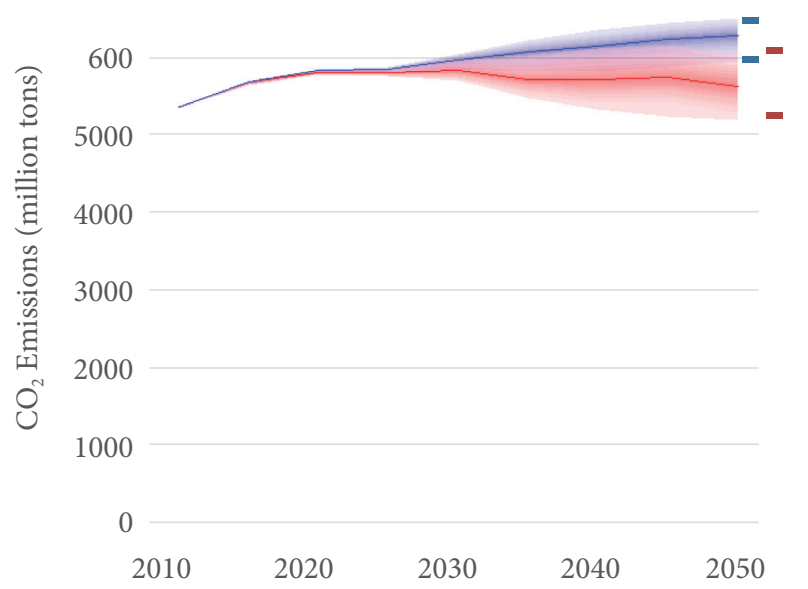

Optimistic Experts

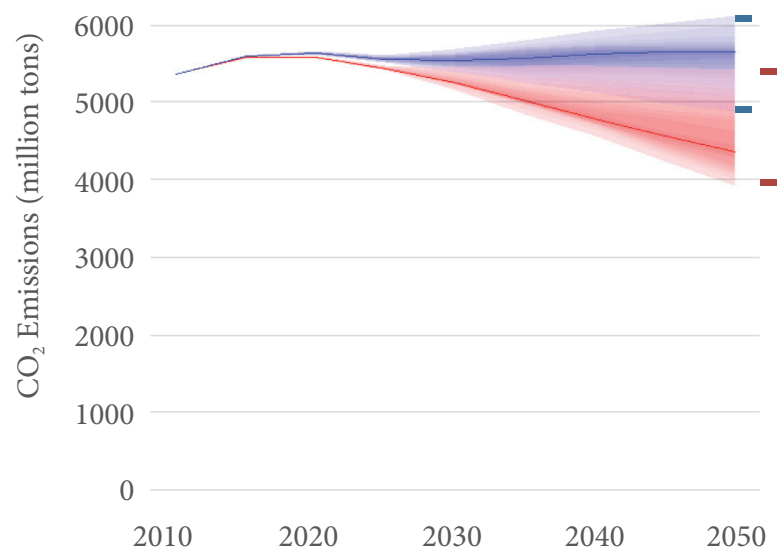

FIGURE 2.7. U.S. energy-related $\mathrm{CO}_{2}$ emissions under business-as-usual federal energy RD\&D investment with no additional demand-side policies (blue) and 10-times the experts' average recommended federal energy RD\&D investments (somewhere between $\$ 49$ and $\$ 82$ billion per year) (red), with no additional demand-side policies, using middle-of-the-road and optimistic experts' technology cost projections. Note that optimistic experts were optimistic about technological progress in general, and not necessarily optimistic about the effects of RD\&D. 


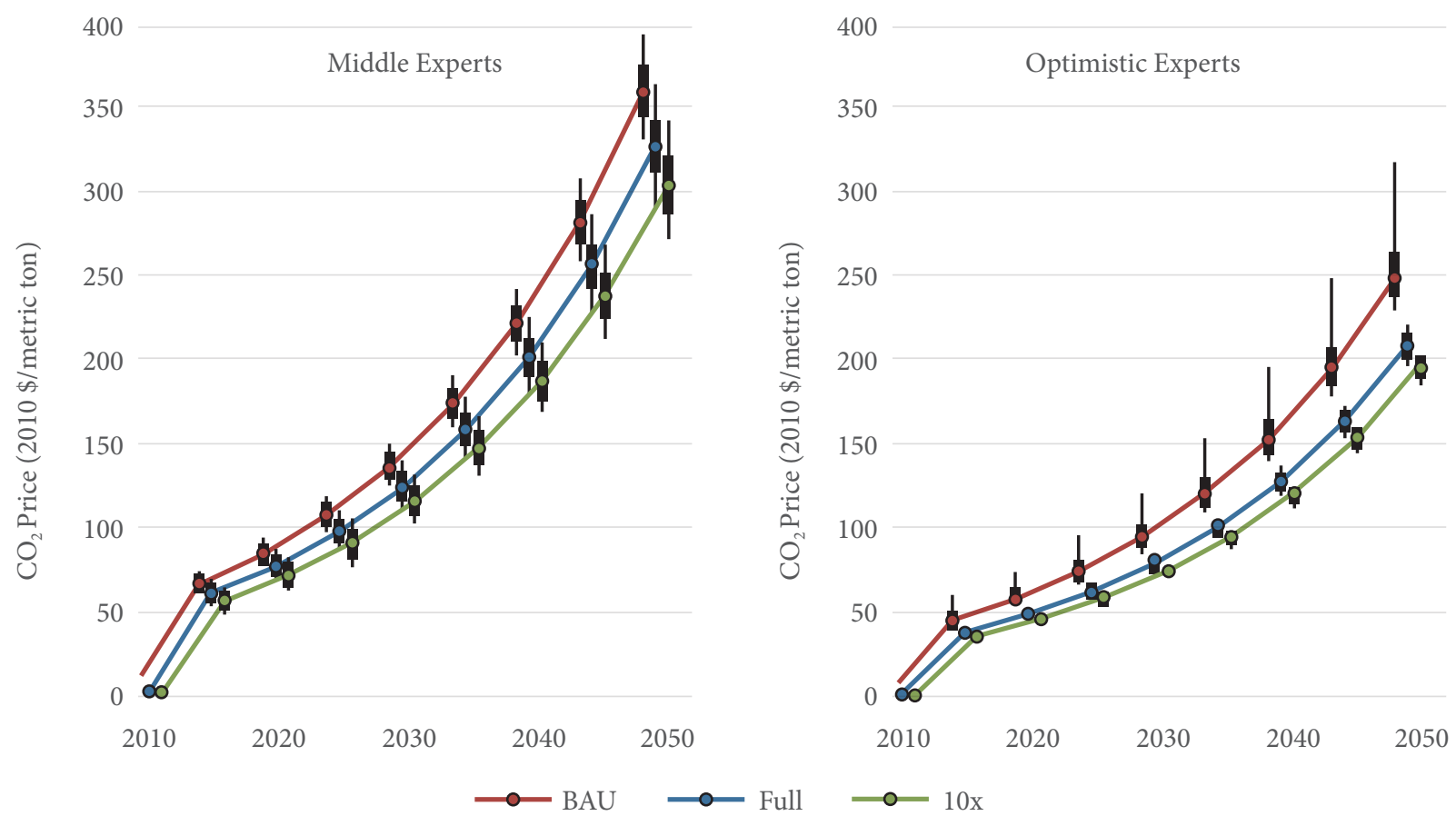

FIGURE 2.8. Trajectory of $\mathrm{CO}_{2}$ prices (\$ per metric ton of $\mathrm{CO}_{2}$ ) under a $\mathrm{CO}_{2}$ cap limiting emissions to $83 \%$ of 2005 levels in 2050, with no international offsets (note that this is a very stringent policy). Three RD\&D funding scenarios are shown - business-as-usual level (red), full recommended level (blue), and 10-times the recommended level (green). The middle (left) and optimistic (right) technology assumptions are compared. The dot corresponds to the $50^{\text {th }}$ percentile, the black rectangle encompasses the $25^{\text {th }}$ and $75^{\text {th }}$ percentiles, and the line encompasses the $5^{\text {th }}$ and $95^{\text {th }}$ percentiles.

5.0 million tons and 4.3 million tons in 2050. As expected, the impact of $\mathrm{RD} \& \mathrm{D}$ investments on $\mathrm{CO}_{2}$ emissions under a sectoral policy is not very significant; under the sectoral policy case, emissions are determined by the sectoral policies and not by RD\&D investments, although RD\&D has some effect on reducing the cost of meeting the sectoral policies, as shown in Figure 2.12.

Just as RD\&D alone is not enough to substantially reduce U.S. $\mathrm{CO}_{2}$ emissions, neither are sectoral policies alone. Median $\mathrm{CO}_{2}$ emissions in 2030 under sectoral policies (clean-energy standard, vehicle fuel economy standards, and building standards) are projected to be approximately $5.0 \mathrm{Gt}$, compared to 5.9 Gt under no-policy, both with BAU technology assumptions. Median emissions in 2030 in the commercial building sector are $0.20 \mathrm{Gt}$ in our model compared to $0.22 \mathrm{Gt}$ under the no-new-policy scenario; in power generation, median emissions are $1.70 \mathrm{Gt}$ under the sectoral policy scenario and $2.50 \mathrm{Gt}$ under the no-new-policy scenario; and in transportation, median emissions under the sectoral policies scenario are 1.8 Gt and under the no-new-policy scenario 1.9 Gt. Different RD\&D funding levels have little effect on emissions since particular efficiency or low-carbon technologies have to be deployed to comply with the policies, regardless of their cost and performance.

While a $\mathrm{CO}_{2}$ cap alone could reduce emissions, $\mathrm{RD} \& \mathrm{D}$ would make it significantly less expensive to do so, reducing the $\mathrm{CO}_{2}$ allowance price needed to meet the cap (Figure 2.8). With the middle technology assumptions, median $\mathrm{CO}_{2}$ prices in 2050 fall from over $\$ 360$ per ton of $\mathrm{CO}_{2}$ under the BAU scenario to 


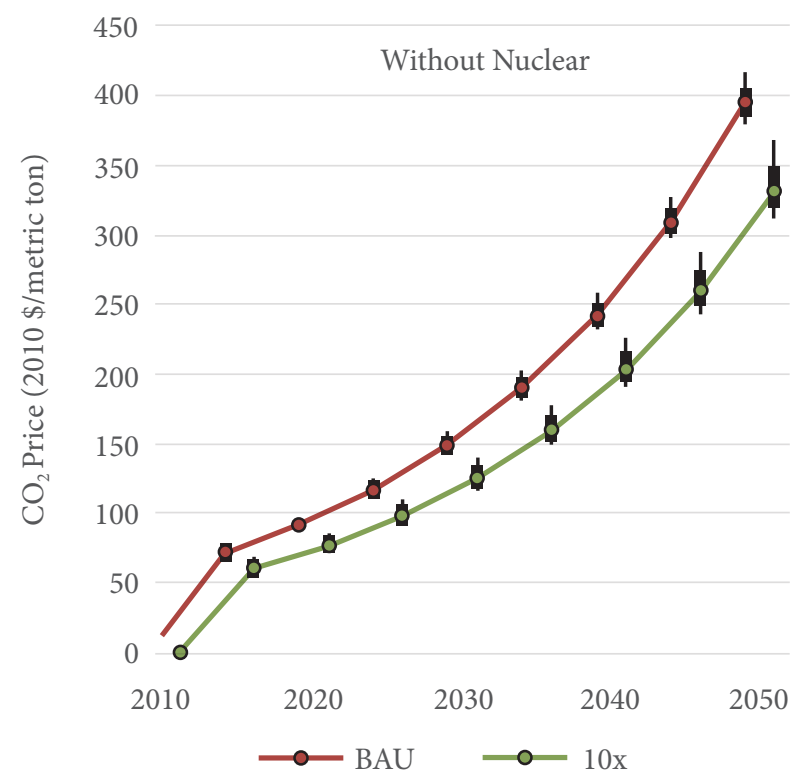

FIGURE 2.9. Comparison of $\mathrm{CO}_{2}$ prices under a $\mathrm{CO}_{2}$ cap case with middle technology assumptions, by RD\&D level, without the availability of new nuclear construction. (For simplicity, we modeled only the BAU and 10-times funding cases for the scenarios without nuclear expansion; the FULL funding case would fall between these lines.)

around \$330 per ton under full to just over $\$ 300$ per ton under 10 -times. ${ }^{33}$ Under the optimistic technology assumptions, the $\mathrm{CO}_{2}$ price declines with higher levels of $\mathrm{RD} \& \mathrm{D}$ funding, but the uncertainty in the price also decreases. When expansion of nuclear power is constrained, $\mathrm{CO}_{2}$ prices rise as expected to just under $\$ 400$ per ton under BAU funding, and increased levels of RD\&D funding at 10-times mitigate that rise to about $\$ 370$ per ton (Figure 2.9).

Oil imports decline until 2035 under a scenario with no new policies and the middle technology assumptions, due mainly to existing vehicle fuel economy standards (Figure 2.10). Under optimistic assumptions and 10-times funding levels, oil imports continue to decline to 2050. Increasing levels of funding from BAU to full to 10-times does have an impact on oil imports, especially post-2035 in the absence of policies. Again, increased levels of funding without new energy policies are insufficient in reducing U.S. oil imports by one-third by 2021 (a goal stated by President Obama in March 2011).

Under a $\mathrm{CO}_{2}$ cap, oil imports continue to decline past 2035 (Figure 2.11). The variation in oil import levels between funding levels is small, primarily because the policy is so stringent and leaves few technology choices.

Under no new policy and middle technology assumptions, median $\mathrm{CO}_{2}$ emissions are highest under reference natural gas and oil prices, decline under low natural gas prices, and decline further under high

33 As noted earlier, our $\mathrm{CO}_{2}$ cap scenario is very stringent, reducing emissions by $83 \%$ without permitting any international trading or offsets, and our modeling does not include the effect of private sector innovation to find new ways to cut carbon emissions that would surely be provoked by high carbon emission prices. It is therefore unlikely that carbon prices would rise as high as they do in our carbon cap scenarios. 


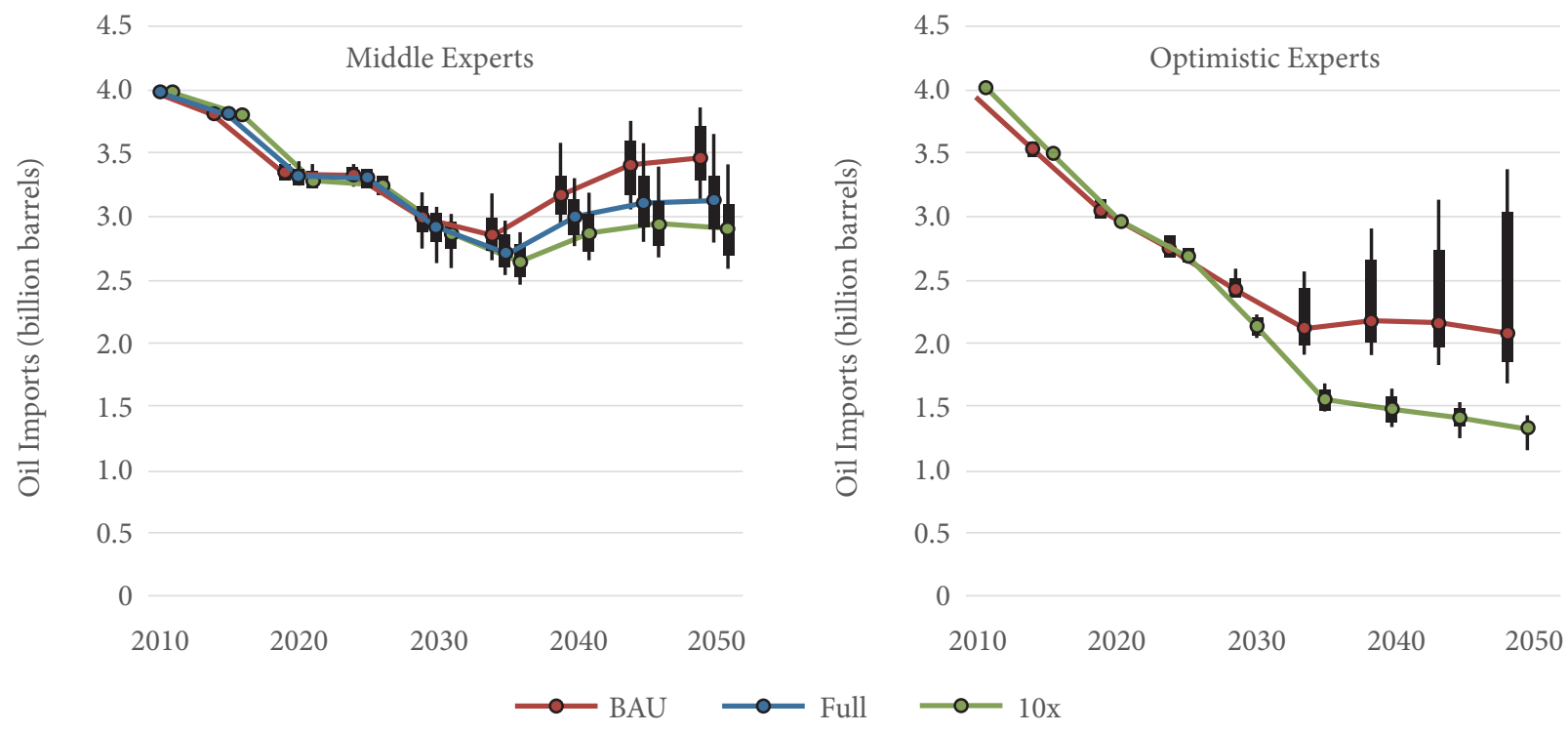

Figure 2.10. Comparison of oil imports per year (excluding other imported petroleum products) under a no-policy case by RD\&D level and type of assumptions. (For simplicity, we modeled only the BAU and 10-times funding cases for the scenarios without nuclear expansion; the FULL funding case would fall between these lines.)

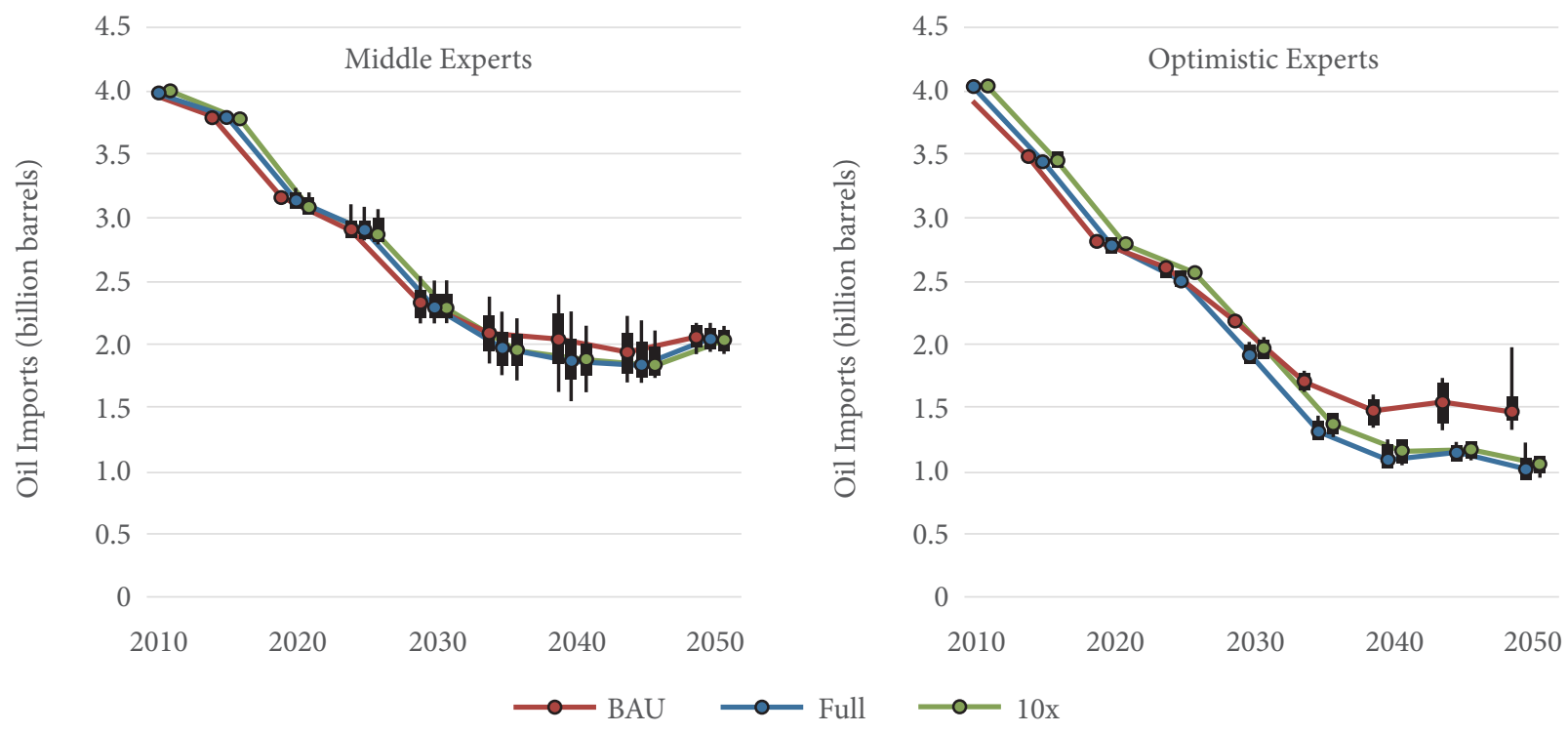

FIGURE 2.11. Comparison of oil imports (excluding other imported petroleum products) under a carbon cap case by RD\&D level and type of assumptions.

natural gas and oil prices (Figure 2.12). The declines are small and the distribution of emissions overlaps between the three energy price scenarios. The same trend occurs under the full recommended funding scenario; however, the emissions levels are slightly lower than BAU funding.

Under sectoral policies, the CES credit price is lower with more RD\&D funding, however the effect is small (Figure 2.13). Increased RD\&D funding also improves costs for "non-clean" technologies, making relative cost differences with clean technologies smaller; and consequently, differences in credit prices 


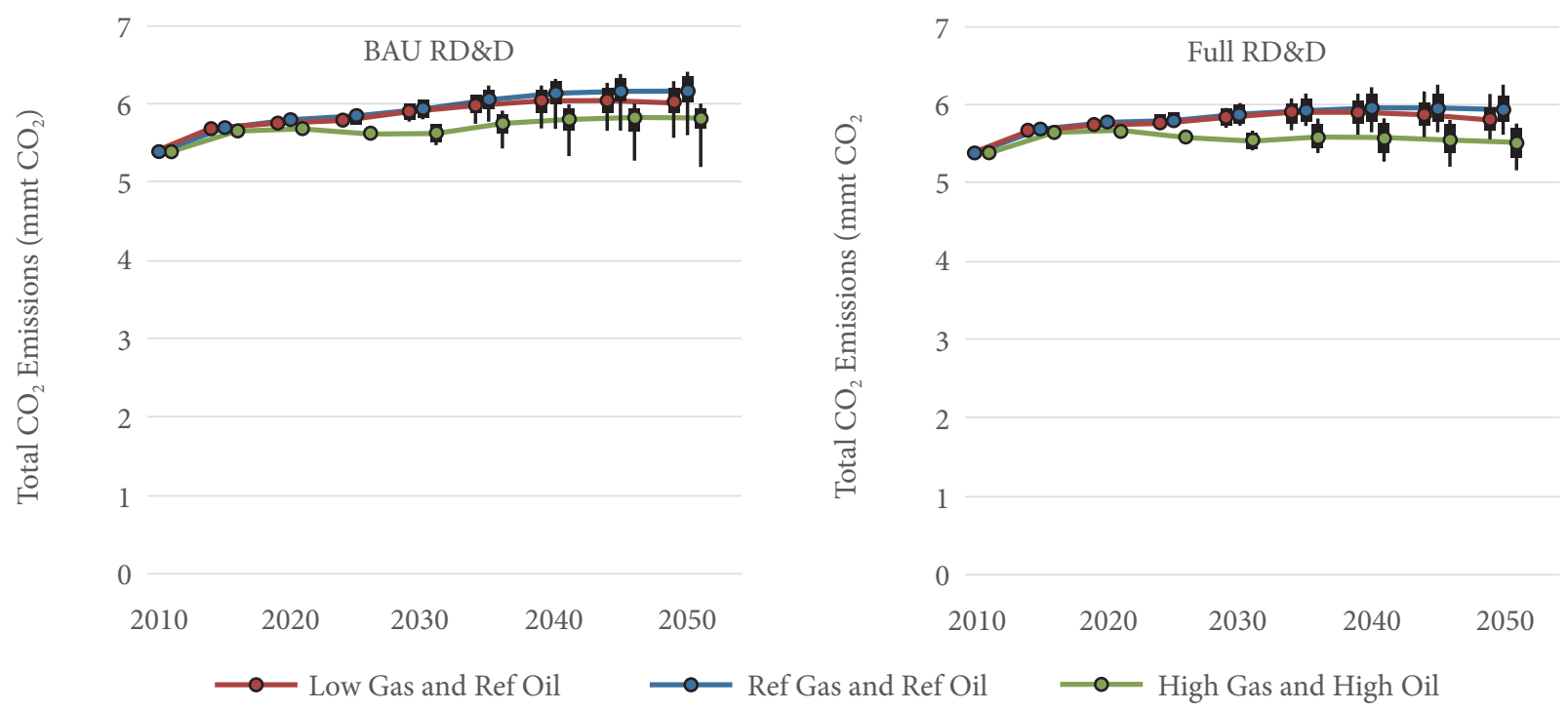

FIGURE 2.12. Comparison of $\mathrm{CO}_{2}$ emissions under a no-policy case by RD\&D level and natural gas and oil price scenarios with middle expert technology assumptions.

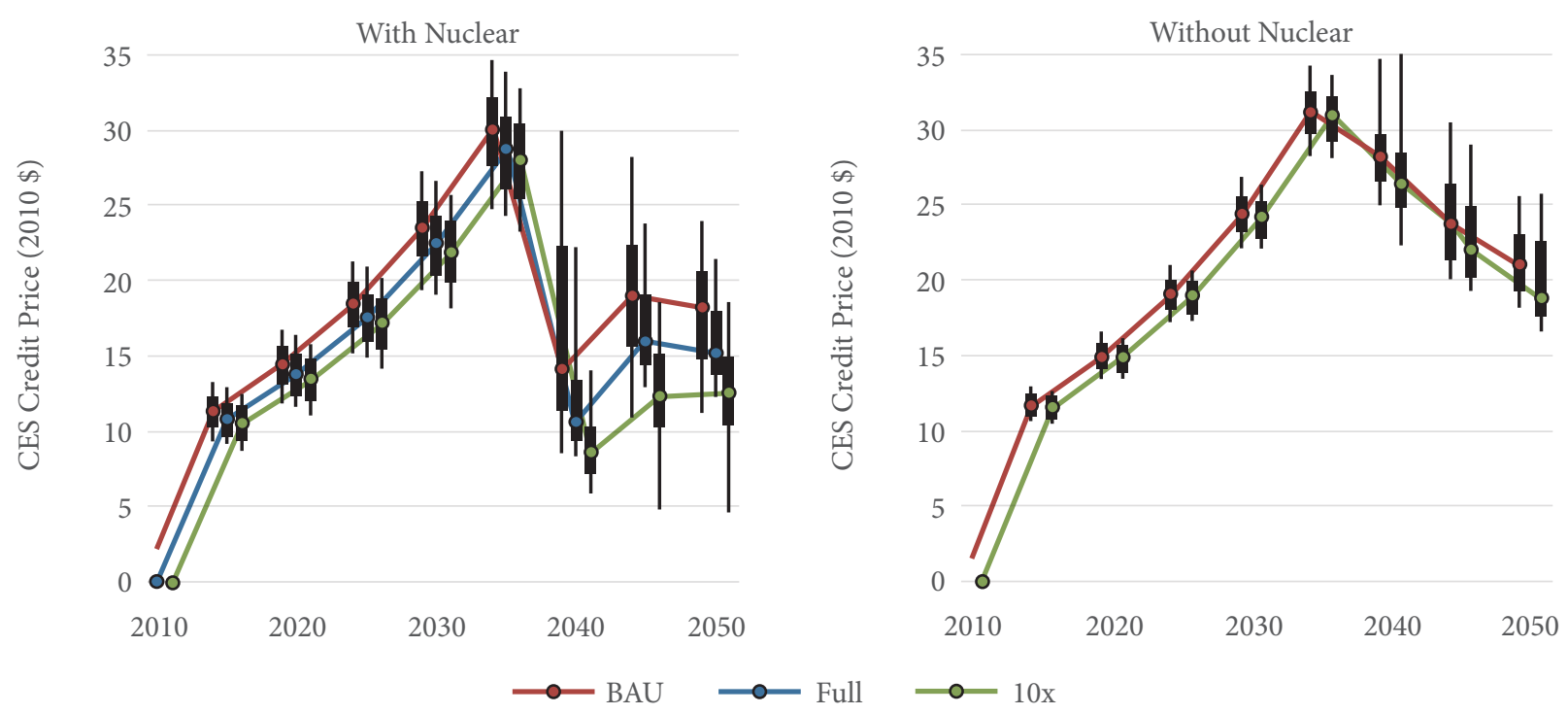

FIGURE 2.13. Comparison of CES credit prices (\$ per GJ) under sectoral policies by RD\&D level with and without allowing nuclear expansion.

are smaller. ${ }^{34}$ The decline in credit prices in 2040 is due to the assumption that banking ends in 2035, consistent with the administration's announced goal. When the possibility of nuclear expansion is removed, credit prices remain high because other clean technologies will be more expensive than nuclear if the experts' cost projections turn out to be correct. When nuclear expansion is not possible, funding levels have even less of an effect on the credit price.

34 This would likely change if the CES policy were based on $\mathrm{CO}_{2}$ intensity rather than an assigned credit portion for difference technologies. 
Under all the scenarios modeled, consumer surplus ${ }^{35}$ increases and total energy system cost declines with increases in RD\&D funding over BAU to the full recommended funding level and the ten-time recommended level at the $5^{\text {th }}$, median, and $95^{\text {th }}$ percentile cases. An investment of a few billion dollars a year to increase energy $\mathrm{RD} \& \mathrm{D}$ funding from the BAU level to the full funding level would result in over $\$ 100$ billion a year in increased consumer surplus by 2050 in a scenario with a stringent carbon capand even larger increases if the optimistic technology experts prove to be correct. Indeed, our modeling suggests that an investment of a few extra billion a year today could develop technologies that could save the economy hundreds of billions of dollars a year by 2050 in scenarios with a stringent carbon cap. Under the scenarios with new demand-side policies (i.e., under the $\mathrm{CO}_{2}$ cap policy and the sectoral policies case), our modeling indicates that energy RD\&D investments have an even greater impact on consumer surplus. Under the CES case and middle assumptions, increasing applied energy RD\&D from $\$ 2.1$ billion to about $\$ 5$ billion would result in an increase in consumer and producer surplus of $\$ 350$ billion in 2050. Under the CO2 case and middle assumptions, the increase in consumer and producer surplus in 2050 , resulting from increasing energy RD\&D from $\$ 2.1$ billion to about $\$ 5$ billion, is about $\$ 110$ billion. The absolute improvement in consumer and producer surplus with two different RD\&D levels under the SEC case is greater than that under the $\mathrm{CO} 2$ case. This could be due to the fact that, under the SEC

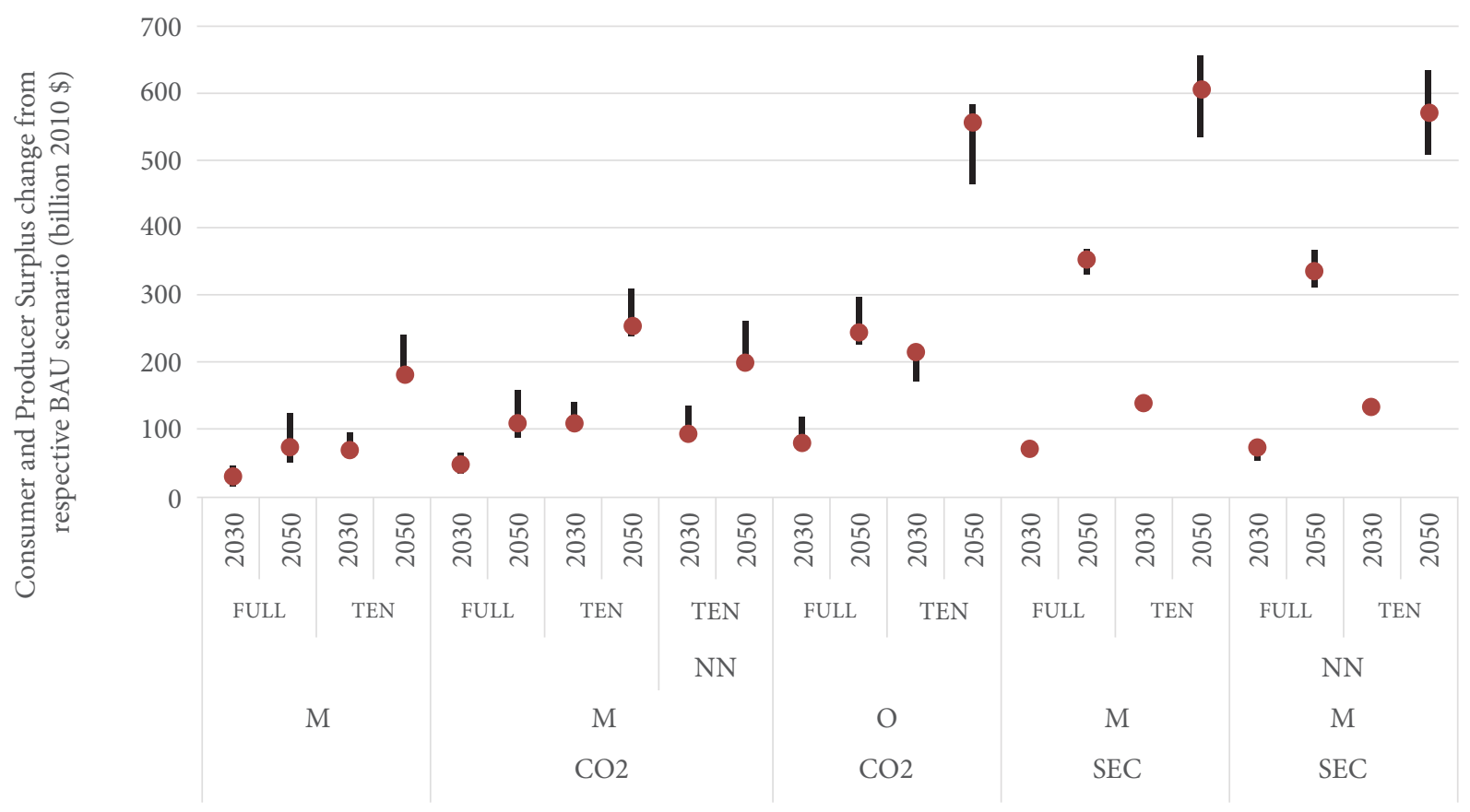

FIGURE 2.14. Consumer and producer surplus projections over respective BAU scenario in 2030 and 2050 under various scenarios. The red dot in the figure corresponds to the median result, and the edges correspond to the $5^{\text {th }}$ and $95^{\text {th }}$ percentiles of deployment.

35 Consumer and producer surplus is a measure of the welfare of consumers. It is calculated as the difference between the total amount that consumers are willing and able to pay for a good or service (indicated by the demand curve) and the total amount that they actually pay. 


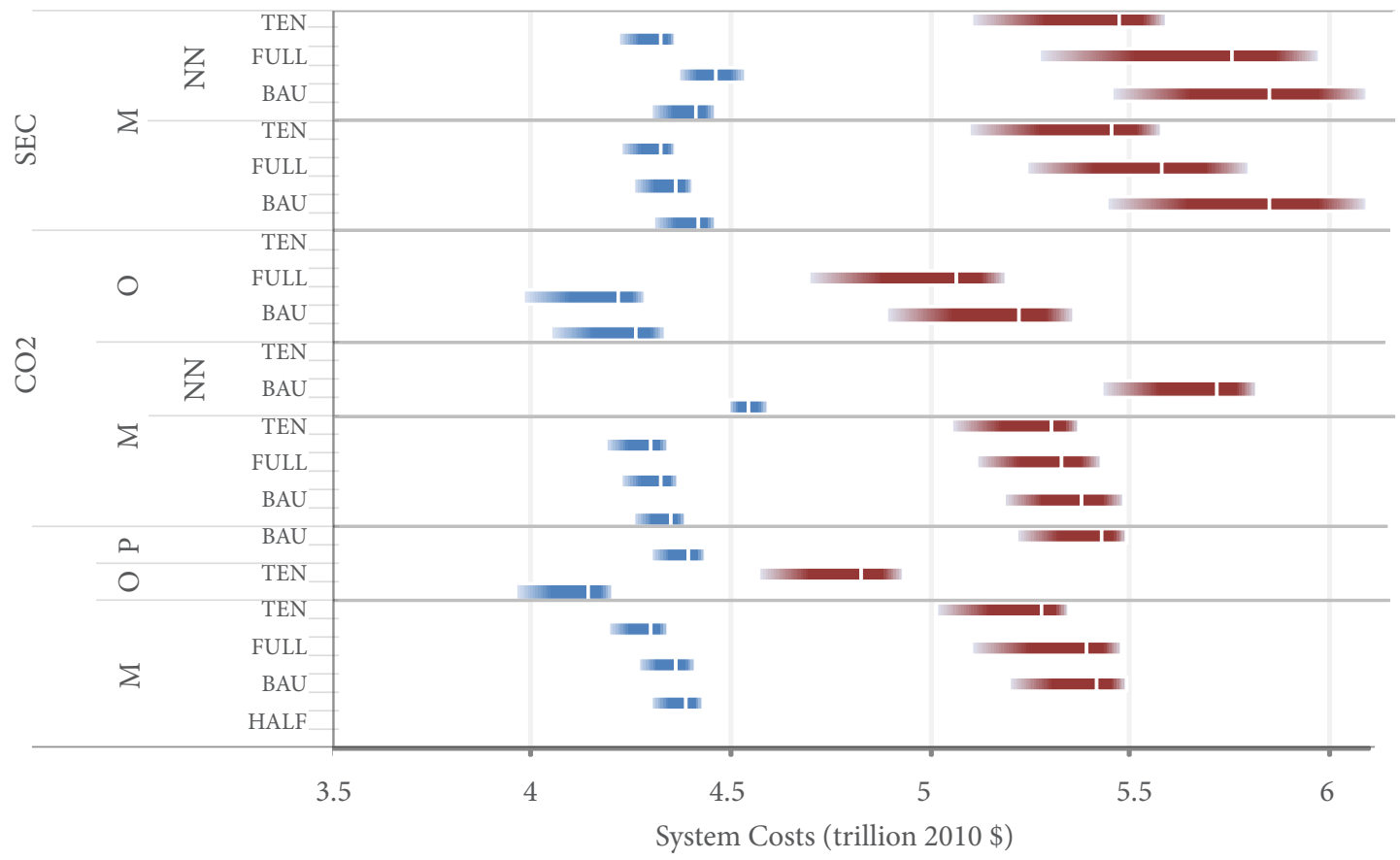

FIGURE 2.15. Total energy system cost projections in 2030 (blue) and 2050 (red) under various scenarios. The vertical white line in the figure corresponds to the median result, and the edges correspond to the $5^{\text {th }}$ and $95^{\text {th }}$ percentiles of deployment. (Shading does not represent the exact probability distribution and is only an aesthetic effect.)

case, most of the technologies that can be used to meet the CES and the increase in CAFE standards are covered by our elicitations and therefore can lead to improvements in $\mathrm{RD} \& \mathrm{D}$, whereas under a $\mathrm{CO}_{2}$ cap many reductions could also come from demand reduction; our elicitations did not cover many options in this area, including lighting, industrial efficiency, etc.

Total energy system costs decrease significantly with increasing energy RD\&D investments in our modeling results. Under the CES case, increasing applied energy RD\&D from $\$ 2.1$ billion to about $\$ 5$ billion per year results in a decrease in total U.S. energy system costs of $\$ 330$ billion in 2050. (An additional increase in applied energy RD\&D to about $\$ 50$ billion per year results in an additional decrease in total energy system costs in 2050 of $\$ 150$ billion.) Under a CO2 case, total energy system costs in 2050 are $\$ 65$ billion lower under annual energy RD\&D funding of $\$ 5$ billion than under a BAU energy RD\&D funding of $\$ 2.1$ billion for the 7 areas considered. Increasing funding to about $\$ 50$ billion/year results in an additional decrease in total energy system costs of $\$ 50$ billion.

Figures 2.14 and 2.15 show the consumer and producer surplus and total system cost results, respectively. (See Table 2.6 for a definition of the scenario naming convention.) 
Substantial returns to RD\&D investments - eventually decreasing

In our modeling, increasing energy RD\&D funding from the BAU level to the FULL level carries substantial benefits, whether measured in reductions in carbon emissions, reduced carbon prices, or increased consumer surplus. The median benefits of investing in RD\&D at the "MFULL" funding level (the FULL funding level, about $\$ 4.9$ billion per year, with the "middle experts", or $\mathrm{M}$, expectation of likely results of that RD\&D) compared to MBAU are significant, especially by 2050 and under a $\mathrm{CO}_{2}$ cap or sectoral policies; however, the uncertainties are large. ${ }^{36}$ In spite of these large uncertainties, our MARKAL results suggest a 90\% probability that investing in energy RD\&D at the MFULLCO2 level would reduce the carbon prices needed to meet a stringent carbon cap between 2030 and 2050.

Most of the experts we surveyed expected decreasing marginal returns as energy RD\&D investment went beyond their recommended levels, and that is reflected in our modeling as well. For example, Figure 2.16 shows how much projected $\mathrm{CO}_{2}$ allowance prices would be reduced (in dollars per ton) for each billion dollars of annual energy RD\&D spending in going from MBAUCO2 (\$2.1 billion per year) to MFULLCO2, and from MFULLCO2 to the 10-times recommended scenario ("MTENCO2"). Both 2030 and 2050 are shown. As can be seen here, increasing RD\&D to the MFULLCO2 level would significantly reduce the carbon prices needed to reach a stringent carbon cap, while further increases in RD\&D funding beyond the MFULL level appear to have little effect.

Decreasing marginal returns to RD\&D investment are also seen when comparing the average $\mathrm{CO}_{2}$ emissions reductions obtained per dollar of RD\&D investment under the two RD\&D funding levels and the case without any new policies. Figure 2.17 shows the reductions in projected U.S. $\mathrm{CO}_{2}$ emissions that might result from expanded $\mathrm{RD} \& \mathrm{D}$ in metric tons of annual $\mathrm{CO}_{2}$ emissions reduced per dollar of annual RD\&D spending in going from MBAU to MFULL, and from MFULL to MTEN scenarios (which are scenarios without a $\mathrm{CO}_{2}$ cap or additional sectoral policies). The median benefits in investing in RD\&D at MFULL compared to MBAU are significant, especially by 2050. Even though this analysis only considers the benefits up to 2050, the benefits of innovation stretch beyond that timeframe. The 2050 timeframe was chosen partly because it is the timeframe of the administration's $\mathrm{CO}_{2}$ reduction goal. In 2050, the median reduction in $\mathrm{CO}_{2}$ emissions is 0.08 metric tons per dollar of $\mathrm{RD} \& \mathrm{D}$. In our models, there was roughly an $80 \%$ probability that expanding RD\&D investments to the MFULL level would lead to lower carbon emissions in 2050 than would otherwise be the case.

Figure 2.18 shows the impact on clean-energy standard (CES) credit prices of increasing funding from MBAU to MFULL and subsequently from MFULL to MTEN under the sectoral policies scenario (SEC). In this case, MFULL results in a median reduction in CES price per billion dollars of RD\&D invested of 
\$6. Under the conditions modeled, there is a 70\% probability of a positive impact of RD\&D investment on CES credit prices under MFULLSEC.

Figure 2.19 shows the increase in consumer surplus in \$ per dollar of RD\&D invested when increasing funding from MBAUCO2 to MFULLCO2 and subsequently from MFULLCO2 to MTENCO2 under the $\mathrm{CO}_{2}$ cap policy scenario $(\mathrm{CO} 2)$. The median result shows that increasing $\mathrm{RD} \& \mathrm{D}$ funding from the BAU to the FULL scenario under a $\mathrm{CO}_{2}$ cap policy results in an increase in consumer surplus in 2050 of about $\$ 35$ per dollar invested in energy RD\&D. Note that, as a measure of impact of RD\&D, consumer surplus is a metric that encompasses more factors than other studies measuring the returns to RD\&D, such as the National Academies report (NRC 2001), but does not consider the opportunity cost of investing the energy RD\&D funds elsewhere in the economy. Strong decreasing marginal returns to RD\&D under the TEN funding scenario are also found when considering the impact of RD\&D on consumer surplus over the BAU RD\&D funding scenario.

This analysis suggests that using the input we obtained from the seven expert elicitations, the multiregion MARKAL model, and our sampling strategy, increasing RD\&D investments in the seven energy technology areas considered beyond about $\$ 5-8$ billion (the former corresponding to the recommendation of the middle experts and the latter corresponding to the mean recommendation of all experts)

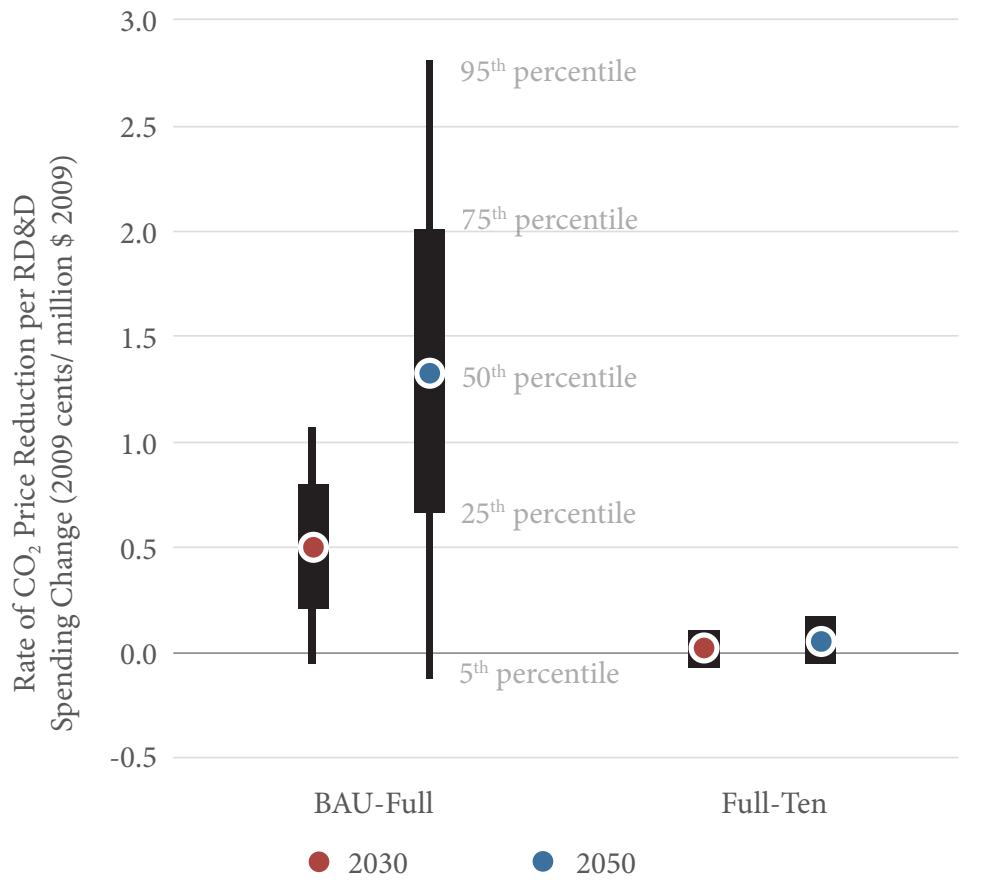

FIGURE 2.16. Average $\mathrm{CO}_{2}$ allowance price reductions ( $\$$ per ton $\mathrm{CO}_{2}$ ) per $\$$ RD\&D invested when comparing the MFULLCO2 to the MBAUCO2 scenario and the MTENCO2 to the MFULLCO2 scenario in 2030 and 2050. The dot corresponds to the $50^{\text {th }}$ percentile, the black rectangle encompasses the $25^{\text {th }}$ and $75^{\text {th }}$ percentiles, and the line encompasses the $5^{\text {th }}$ and $95^{\text {th }}$ percentiles. 
0.25

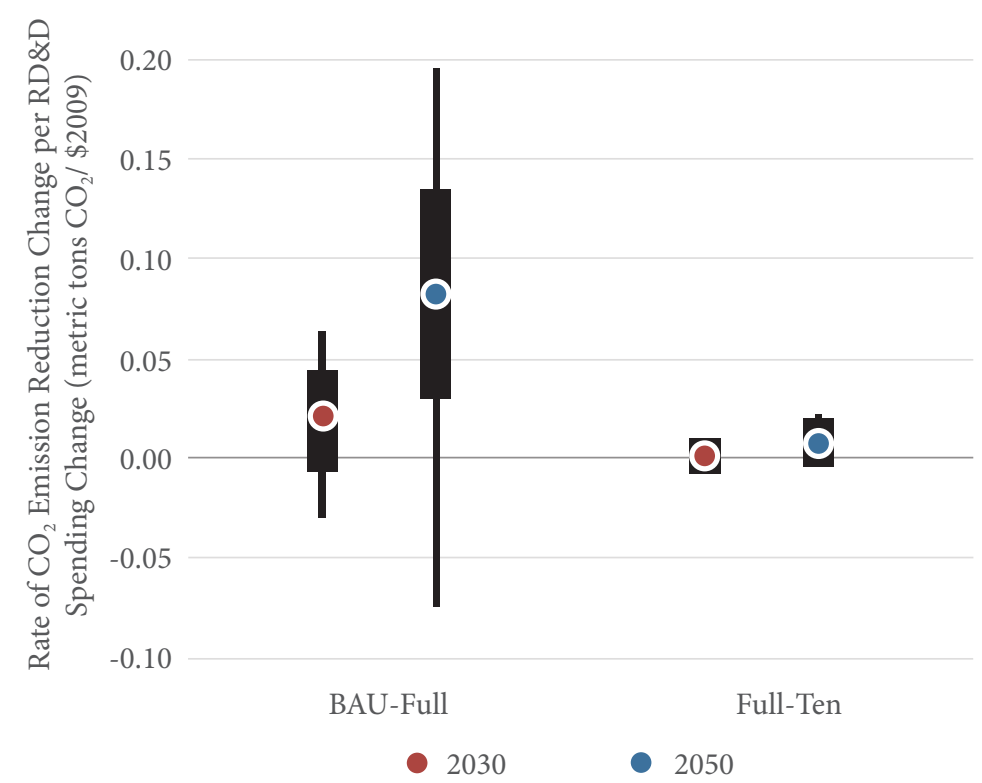

FIGURE 2.17. Average $\mathrm{CO}_{2}$ emissions reductions per $\$ R D \& D$ invested when comparing MFULL to MBAU and MTEN to MFULL in 2030 and 2050 in a scenario with no new policies.

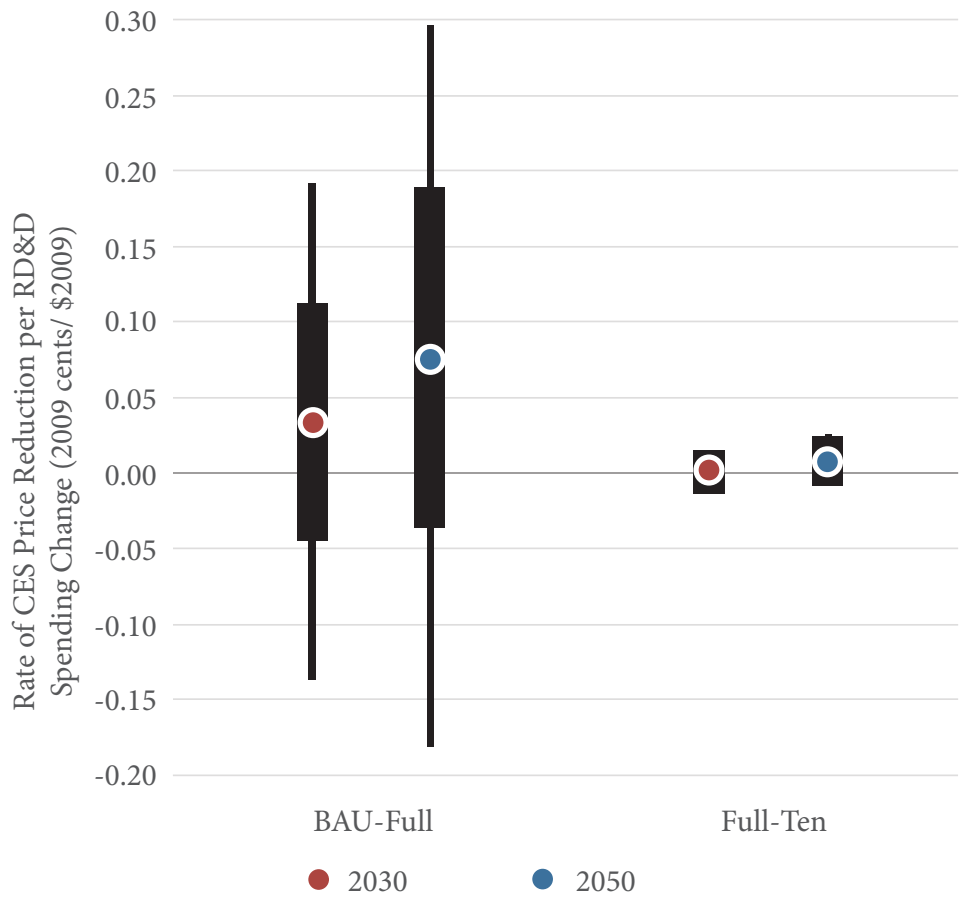

FIGURE 2.18. Average reduction in CES credit prices when comparing MFULLSEC with MBAUSEC and MTENSEC with MFULLSEC in 2030 and 2050 (in cents per million dollars of annual RD\&D). 
would lead to much smaller returns on investment. We recognize that this could just indicate that the experts consulted were unable to identify $\mathrm{RD} \& \mathrm{D}$ projects that would lead to large payoffs, and not that such projects do not exist. However, combined with the fact that significantly increasing (or creating) a major $\mathrm{RD} \& \mathrm{D}$ program in a year or two is unlikely to result in the most efficient allocation of resources due to management challenges, we recommend increasing investments in these seven technology areas from $\$ 2.1$ billion to $\$ 5-\$ 8$ billion over the next 2-3 years, at which point a new evaluation could be undertaken to determine whether larger investments could be beneficial.

\subsubsection{Impact of RD\&D on the diffusion of particular technologies}

The overall benefits of increased RD\&D investments (reductions in energy $\mathrm{CO}_{2}$ emissions, oil imports, and carbon prices) were discussed in section 2.8.1. We now turn to a discussion of the impact of different RD\&D scenarios-of increasing investments from the BAU scenario to the experts' recommended level (which corresponds to approximately a two- to four-fold budget increase over the BAU scenario), and of increasing investments from the recommended budget scenario to a scenario with an investment 10-times greater (about 23-38 times greater than the BAU funding scenario)—on the deployment of different technologies. In the case of buildings, we use emissions reductions from the commercial buildings sector as a proxy for technology deployment.

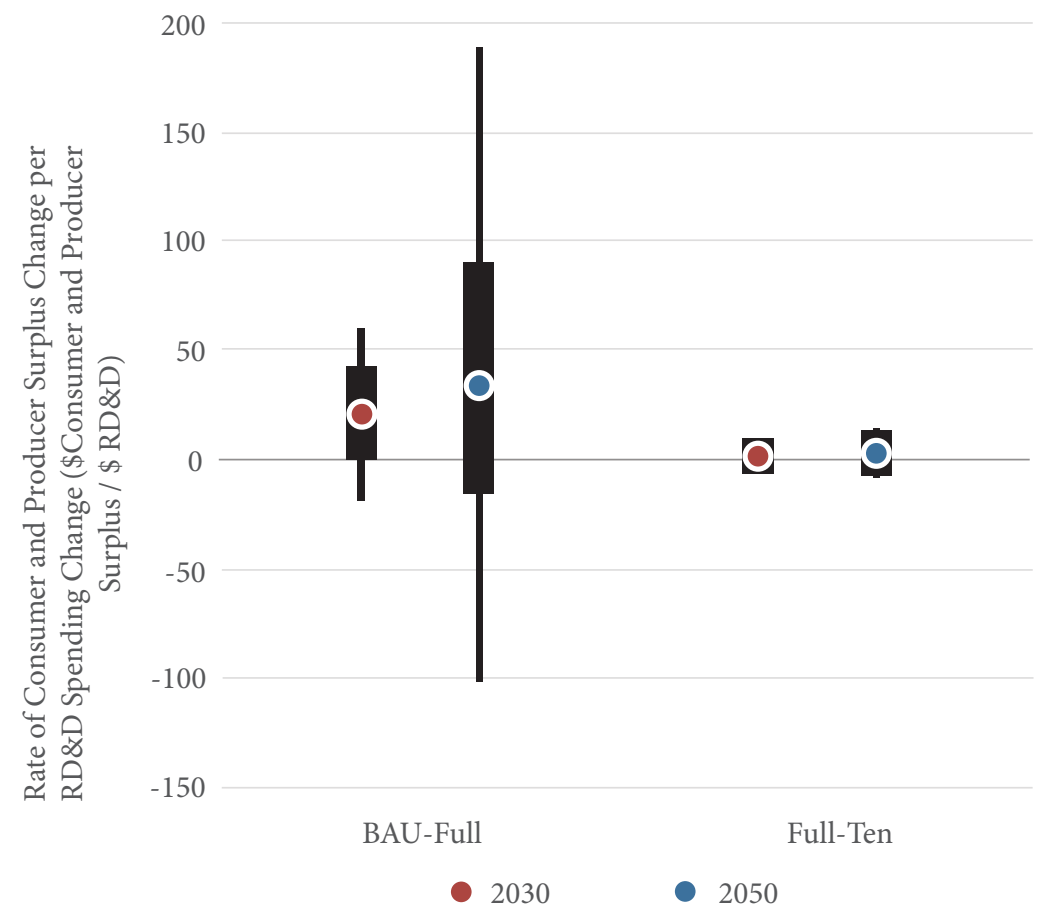

FIGURE 2.19. Average increase in consumer and producer surplus per \$RD\&D invested when comparing MFULLCO2 to MBAUCO2 and MTENCO2 to MFULLCO2 in 2030 and 2050. The dot corresponds to the $50^{\text {th }}$ percentile, the black rectangle encompasses the $25^{\text {th }}$ and $75^{\text {th }}$ percentiles, and the line encompasses the $5^{\text {th }}$ and $95^{\text {th }}$ percentiles. 
As in the previous section, we discuss the impact of RD\&D under three policy scenarios: (1) current policies only, (2) a CO 2 cap-and-trade policy, and (3) sectoral policies. In some scenarios, the construction of new nuclear power plants is restricted. Under current policies only, no additional policies beyond those in place today are put into place. The $\mathrm{CO}_{2}$ cap scenario is described in Table 2.4 and reduces energyrelated $\mathrm{CO}_{2}$ emissions by $83 \%$ compared to 2005 levels by 2050 without allowing international offsets. The sectoral policies include a clean-energy standard (CES), and more stringent vehicle fuel economy standards, and commercial building standards. The particular implementations of these policies are described in sections 2.2.2 and 2.5.4. The scenarios in the discussion below use the legend in Table 2.6.

We discuss the impact of RD\&D on the median result of the deployment of different technologies in terms of installed capacity of solar, nuclear, fossil, storage, and biomass electricity, in terms of total energy use for different types of vehicles, and in terms of $\mathrm{CO}_{2}$ emissions from the commercial buildings sector all in a particular year (either 2030 or 2050). The figures in section 2.8.2 also show the impact of $\mathrm{RD} \& \mathrm{D}$ on the uncertainty range of technology deployment, which we define as the difference between the $95^{\text {th }}$ and the $5^{\text {th }}$ percentile deployment results. The vertical white line in the figure corresponds to the median result, and the edges correspond to the $5^{\text {th }}$ and $95^{\text {th }}$ percentiles of deployment. (Shading does not represent the exact probability distribution and is only an aesthetic effect.)

In some scenarios, deployment of a particular technology is projected to decrease with increases in $\mathrm{RD} \& \mathrm{D}$ funding. This is because other technologies also improve in terms of lower costs and better performance with more RD\&D funding. Other competing technologies may have relatively greater improvements from one funding level to the next, making the particular technology less competitive and resulting in less deployment for the particular technology. This is true in the case of CAES technology and commercial buildings.

At the end of each of the following sub-sections, we make a recommendation about the level of RD\&D funding for the technology area in question based on technology deployment under the different funding and policy scenarios, and also based on insights of the optimization of RD\&D allocation under different policy scenarios discussed in section 2.8.3.

\section{Bioenergy}

Increasing RD\&D funding from BAU to FULL has significant impacts on the deployment of biodiesel from thermochemical plants and cellulosic ethanol production plants, and on the deployment of biomass power plants.

- Under current policies only, increasing RD\&D from MBAU to MFULL results in a lower median deployment of biodiesel. This is driven by the fact that under the MFULL scenario there is a greater increase in the deployment of PHEVs. On the other hand, under CO2 and SEC, increasing RD\&D results in increased deployment of biodiesel (Figure 2.20). 
- For cellulosic ethanol, increasing RD\&D funding from MBAU to MFULL results in less median deployment under current policies, CO2, and SEC. This decrease in cellulosic ethanol deployment is driven by the fact that under MFULL there is an increase in the deployment of plugin hybrid electric vehicles. Under OBAUCO2, 2050 cellulosic ethanol deployment increases dramatically, but increasing RD\&D funding from OBAUCO2 to OFULLCO2 has a negligible impact. Deployment does increase slightly from MBAUSEC to MFULLSEC (Figure 2.21).

- Increasing funding from MBAU to MFULL under current policies would result in an increase in median deployment of bioelectricity plants in 2050 from $7 \mathrm{GW}$ to $11 \mathrm{GW}$. This is about $1 \%$ of electricity capacity in 2009 (961.5 GW). Under the $\mathrm{CO}_{2}$ cap case, bioelectricity deployment increases to 57 and $58 \mathrm{GW}$ under MBAUCO2 and MFULLCO2, respectively.

Increasing funding from FULL to TEN also has an impact on deployment, although at significantly greater RD\&D costs per unit of deployment.

- Biodiesel deployment in 2050 increases from 371 MBOE under MFULL to 449 MBOE under MTEN (from 39\% to 47\% of 2009 diesel consumption, respectively). Increases also occur from MFULLCO2 to MTENCO2 (from $663 \mathrm{MBOE}$ to $770 \mathrm{MBOE}$ ) and from MFULLSEC to MTENSEC (from $448 \mathrm{MBOE}$ to $500 \mathrm{MBOE}$ ) (Figure 2.20).

- The deployment of cellulosic ethanol plants would increase marginally from $125 \mathrm{MBOE}$ under MFULL to 144 MBOE under MTEN. Under CO2 and SEC, increasing funding beyond MFULL would not result in additional cellulosic ethanol deployment (Figure 2.21).

- The deployment of biopower plants stays constant or decreases from MFULL to MTEN, from MFULLCO2 to MTENCO2, from MFULLSEC to MFULLCO2, and from OFULLCO2 to OTENCO2. The exception is a slight increase in deployment from MFULLCO2NN to MTENCO2NN (from $75 \mathrm{GW}$ to $81 \mathrm{GW}$ ) and from MFULLSECNN to MTENSECNN (from $56 \mathrm{GW}$ to $59 \mathrm{GW}$ ) because, with nuclear removed, the competition from electric and hybrid vehicles is reduced.

To illustrate the significance of these biofuel production volumes, it is useful to view them in conjunction with US oil import dependence. In our models, U.S. crude oil imports in 2050 under MBAU and MBAUCO2 were 3,460 MBOE and 2,060 MBOE, respectively. Oil imports in 2010 were approximately 3,980 MBOE. This means that, under the MBAU scenario by 2050 the United States would import 13\% less oil than in 2010, and under MBAUCO2 the United States would import 48\% less oil than in 2010. It is important to note that, under MBAU, by 2020 the United States would import 16\% less oil than in 2010, 


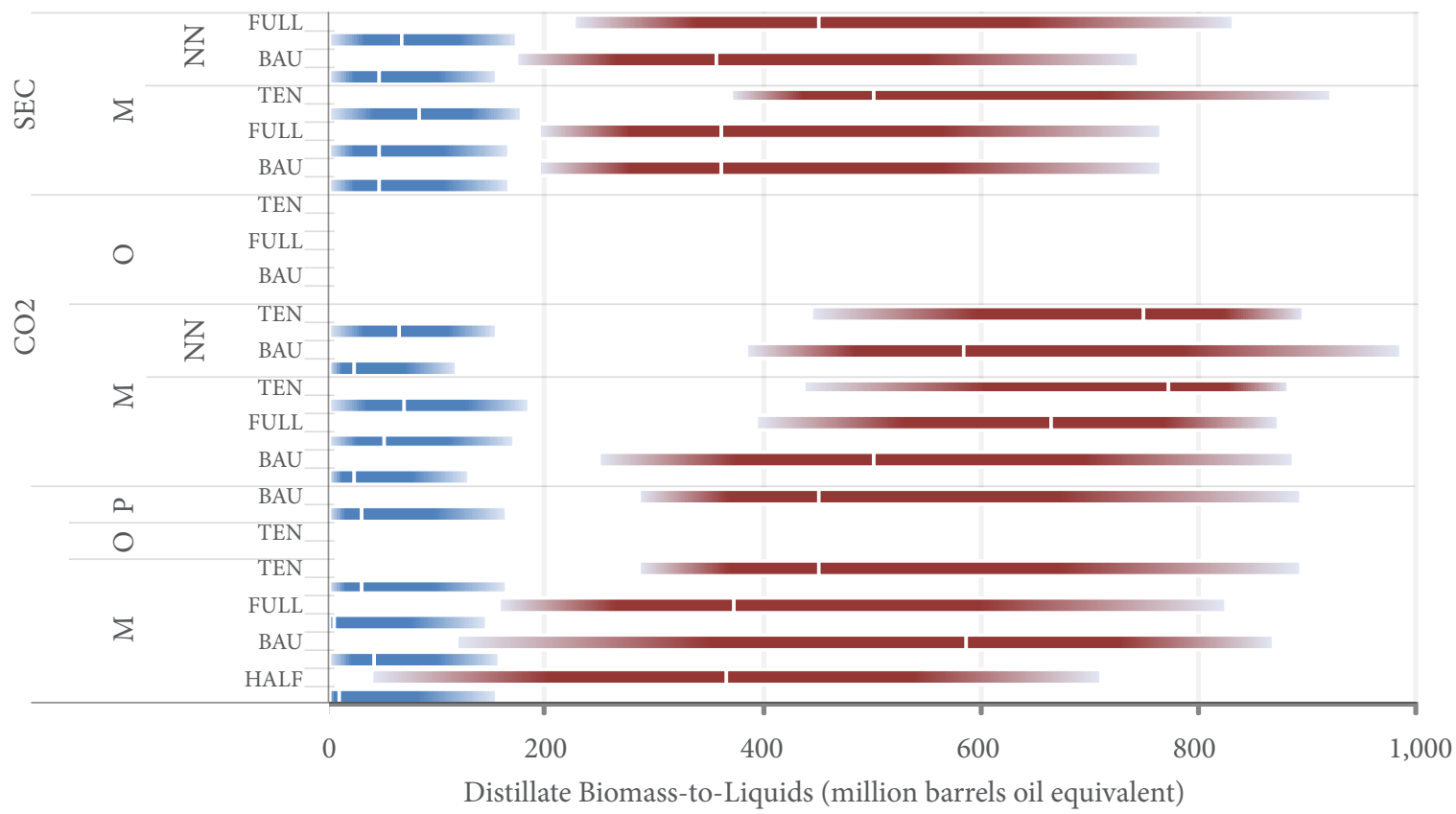

FIGURE 2.20. Deployment of thermochemically produced biodiesel in 2030 (blue) and 2050 (red) under various scenarios in million barrels of oil equivalent (MBOE) per year. The white line corresponds to the median result, and the edges correspond to the $5^{\text {th }}$ and $95^{\text {th }}$ percentiles of deployment. U.S. diesel consumption for transportation in 2009 was $955 \mathrm{MBOE}$.

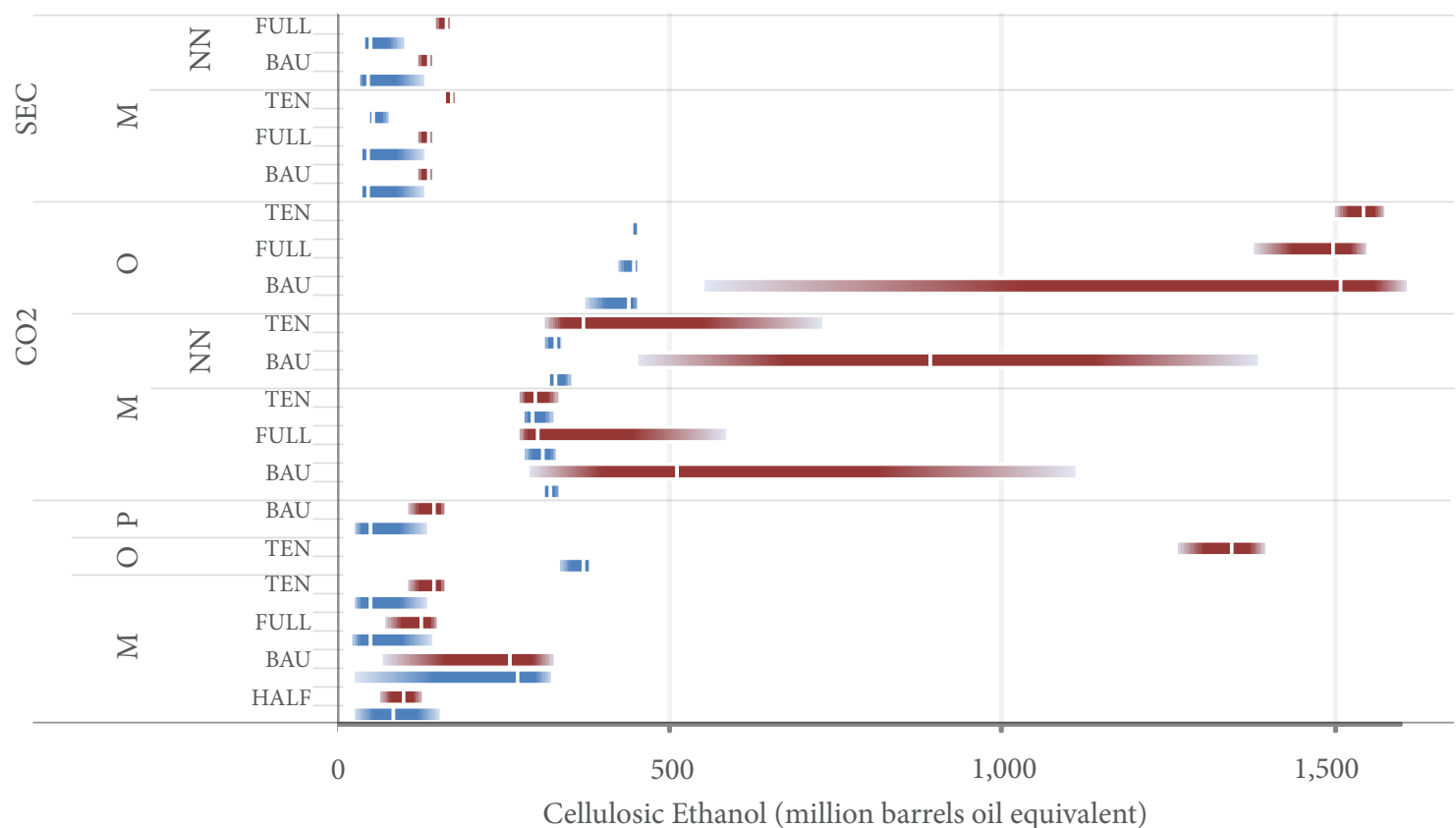

FIGURE 2.21. Deployment of cellulosic ethanol in 2030 (blue) and 2050 (red) under various scenarios in MBOE. U.S. motor gasoline consumption for transportation in 2009 was 2,900 MBOE. 
which falls short of President Obama's goal ${ }^{37}$ of cutting oil imports by one third by 2021. Even by 2030, oil imports would be reduced by only $24 \%$ when compared to 2010 import volumes under this scenario.

This analysis indicates that funding increases for bioenergy RD\&D result in an increase in the deployment of biodiesel under a $\mathrm{CO}_{2}$ policy scenario and a sectoral policies scenario, and to a lesser extent lead to an increase in deployment of cellulosic ethanol under the sectoral policies scenario. The funding increase from MBAU to MFULL has larger benefits in terms of the deployment of bioenergy technologies when compared to the funding increase from MFULL to MTEN. The average allocation of RD\&D from all experts to gasification, pyrolysis, and hydrolysis is similar to the relative deployment of thermochemical and biochemical technologies. Specifically, on average experts allocated more funding to thermochemical technologies, and the modeling results project more deployment of thermochemical biodiesel. It is also important to note that experts allocated $12 \%$ of their recommended RD\&D investments to 'other' technologies, which included the development of novel feedstock materials. Breakthroughs in feedstock development could dramatically affect the deployment of cellulosic ethanol and are not considered in the modeling, which used switchgrass as the main feedstock.

Overall, we recommend increasing biomass funding levels to the mean recommended by all the experts, or $\$ 680$ million, which is over twice as large as what the expert whose estimates were used for the middle technology assumptions recommended. The $\$ 680$ million recommendation largely agrees with the median recommendation among all experts of $\$ 600$ million. An increase in bioenergy RD\&D is further supported by the results from the optimization of a $\$ 5$ billion budget to six of the seven RD\&D areas investigated (see section 2.8.3) under different policy scenarios-namely a no-new-policy scenario, a $\mathrm{CO}_{2}$ cap policy scenario, and a sectoral policy scenario. This optimization showed that there is additional value associated with investing in bioenergy RD\&D because, in a no-new-policy scenario, an increase in bioenergy RD\&D could be an important contributor to $\mathrm{CO}_{2}$ emissions reductions. Under the other two policy scenarios bioenergy RD\&D would play a smaller role in the two benefits considered: reducing $\mathrm{CO}_{2}$ prices or $\mathrm{CES}$ credit prices, respectively.

\section{Grid-Scale Energy Storage}

Due to the limited number of experts and the diversity of energy storage technologies, for each type of battery the same experts were used as middle, optimistic, and pessimistic experts (the costs are the same across these scenarios but different across battery types). For CAES, one expert's projections were used for the optimistic scenario, while another expert's projections were used for the middle and pessimistic

37 President Obama's goal could be reached through more stringent vehicle fuel economy standards and further subsidies related to advanced vehicles, which are not yet established policies and thus not modeled under "current policies". 
scenarios. This model explicitly represents a time-of-use load profile for electricity to better model power plant dispatch. Therefore the availability of storage technologies allows for inter-temporal arbitrage-the storage of electricity generated at off-peak hours when prices are low and subsequent release at peak times when prices are high. In addition, the model includes a capacity requirement, which acts as a proxy for reliability markets. Storage technologies can thus be used as a source of firm power in place of other resources (e.g., natural gas turbines). This can provide significant incentive for investment in storage, particularly in scenarios where there is a high deployment of technologies with low capacity values (e.g., wind or solar), which tends to increase the value of firm capacity and also to widen the price spread between on-peak and off-peak power.

However, the model does not directly represent the intermittency and short-term variability in output of renewable generation technologies such as wind and solar. For this reason, it does not capture the benefits that storage technologies can offer for mitigating problems related to variability when integrating significant amounts of intermittent resources onto a system. Similarly, the geographic granularity is not sufficient to model local transmission congestion, and consequently the value that storage can provide by alleviating these constraints is not captured in this analysis.

The MFULL scenario has little impact on the median deployment of Li-ion batteries under all scenarios, but it has a slightly larger impact on CAES deployment in 2050 when compared to the MBAU scenario.

- Median CAES deployment decreases with increased RD\&D investment under most scenarios in 2050, except under optimistic technology assumptions and $\mathrm{CO}_{2}$ cap policy (from $8 \mathrm{GW}$ under OBAUCO2 to $12 \mathrm{GW}$ under OFULLCO2). (Recall that two different experts' projections were used for the three CAES technology assumptions.) (Figure 2.22).

- Li-ion battery deployment would increase from $45 \mathrm{GW}$ to $49 \mathrm{GW}$ in 2050 from MBAU to MFULL. In other words, the deployment of Li-ion batteries in 2050 under current policies and BAU funding is large - 5\% of the $961.5 \mathrm{GW}$ of total U.S. electricity generation capacity in 2009but increasing RD\&D from MBAU to MFULL does not make a large impact. In addition, under SEC and CO2, deployment increases with increases in RD\&D funding from MBAU to MFULL. As opposed to CAES, median deployment decreases from the OBAUCO2 to OFULLCO2. Recall that the same technology assumptions for Li-ion batteries were used for all technology assumption scenarios ( $\mathrm{M}, \mathrm{O}$, and $\mathrm{P})$, while more optimistic assumptions were used for CAES in the optimistic scenarios $(\mathrm{O})$. Therefore, it is unsurprising that CAES would show a relative advantage over Li-ion in the optimistic scenarios (Figure 2.23).

The TEN scenario has a larger impact on storage deployment over the FULL scenario when compared to the impact of FULL over BAU. 
- Again, CAES deployment decreases with increased funding to TEN under most scenarios except from MFULLSEC to MTENSEC (from $1 \mathrm{GW}$ to $14 \mathrm{GW}$ in 2050), MBAUCO2NN to MTENCO2NN (a significant increase from $1 \mathrm{GW}$ to $234 \mathrm{GW}$ ), and OFULLCO2 to OTENCO2 (another significant increase from 12 to $247 \mathrm{GW}$ in 2050, with most of the growth occurring between 2030 and 2050). Assuming the optimistic expert's CAES cost projections and an RD\&D level beyond FULL, CAES could play an important role in reducing electricity costs by utilizing baseload power to meet the peak, thereby reducing the need for some additional capacity (Figure 2.22).

- The median deployment of Li-ion batteries in 2050 increases under all the scenarios from FULL to TEN (except MBAU to MTEN when nuclear expansion is not possible), though deployment at the $95^{\text {th }}$ percentile case is a decrease between MFULL and MTEN (Figure 2.23).

We recommend increasing $\mathrm{RD} \& \mathrm{D}$ funding for energy storage to $\$ 240$ million per year because there are deployment benefits for CAES and Li-ion batteries with increased funding beyond the median recommended funding level across all experts, which is $\$ 120$ million. In particular, if sufficiently supported by government RD\&D, CAES could play a large role in multi-hour power arbitrage. Li-ion batteries are also important to support as they have a large potential for deployment, even though RD\&D plays a smaller role in the scenarios investigated. The mean of all experts' recommendations was $\$ 240$ million, as a result of an outlier that had recommended $\$ 2$ billion, which is $\$ 1.5$ billion larger than the second largest budget recommendation. The experts who provided the battery technology and middle CAES assumptions recommended an average of $\$ 103$ million, and the average recommendation from the optimistic CAES expert and the battery technology experts was $\$ 128$ million. Thus increasing funding to the mean of the experts recommendation would correspond to technology improvements consistent with funding increases beyond the middle and optimistic experts' recommendations. In addition, the results discussed in section 2.8.3 indicate that $\mathrm{RD} \& \mathrm{D}$ for storage will be particularly valuable if a $\mathrm{CO}_{2}$ cap policy is implemented, especially under the optimistic technology assumptions, or if nuclear power generation expansion is not possible. This further supports a significant increase for storage.

Even though Li-ion batteries and CAES seem to be the most promising technologies for the 2030-2050 timeframe, experts also recommended devoting $7 \%$ of funding to other storage technologies. Flywheels and electrochemical capacitors received $8 \%$ and $9 \%$ of the average funding for storage, respectively, but it is not expected that they will serve for grid-scale multi-hour applications. Government support for these technologies should probably be on the very early stage research, given that short-duration storage technologies already have an established market and many private sector players. 


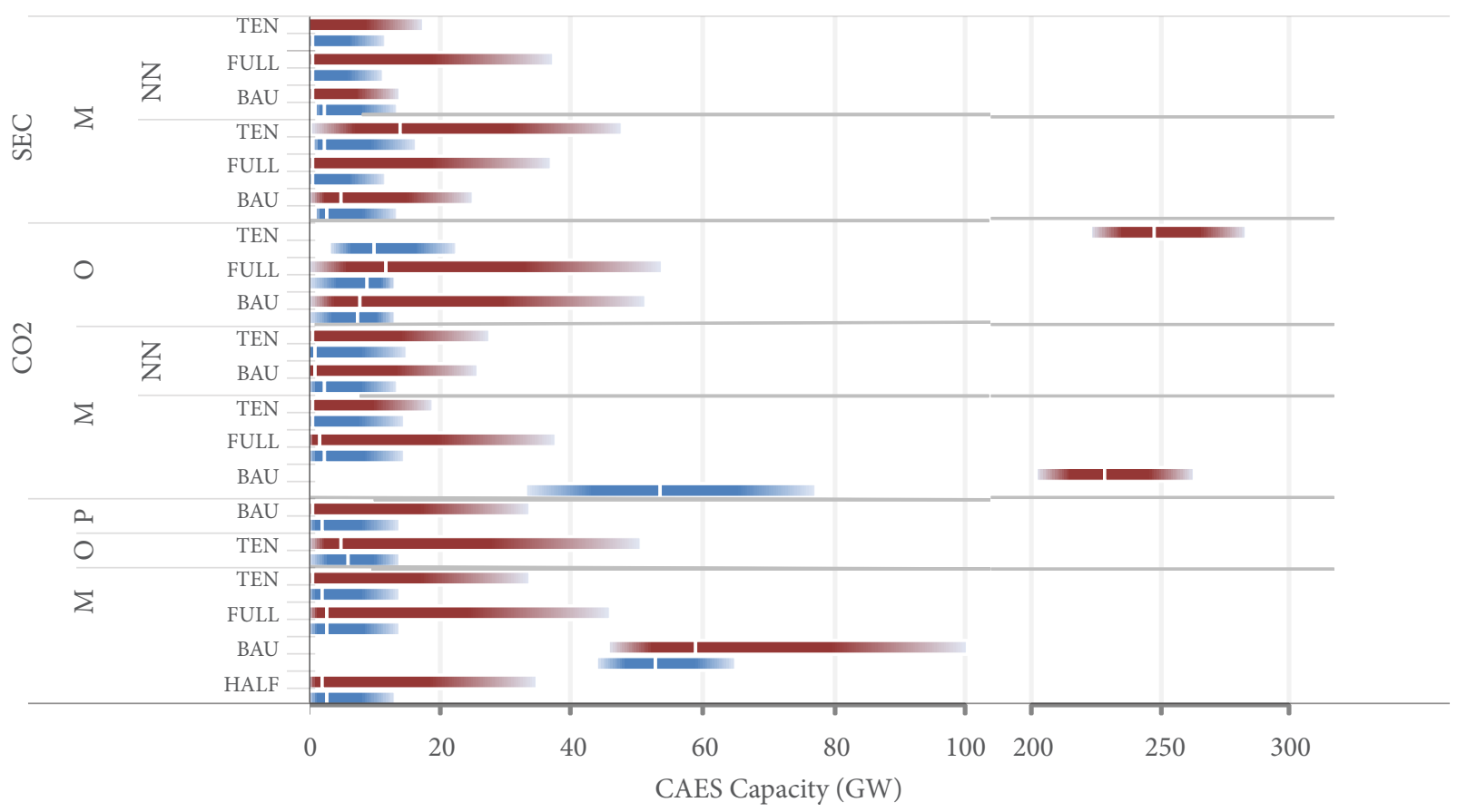

FIGURE 2.22. Deployment of CAES in 2030 (blue) and 2050 (red) under various scenarios in GW. Note the extended horizontal axis and change in scale.

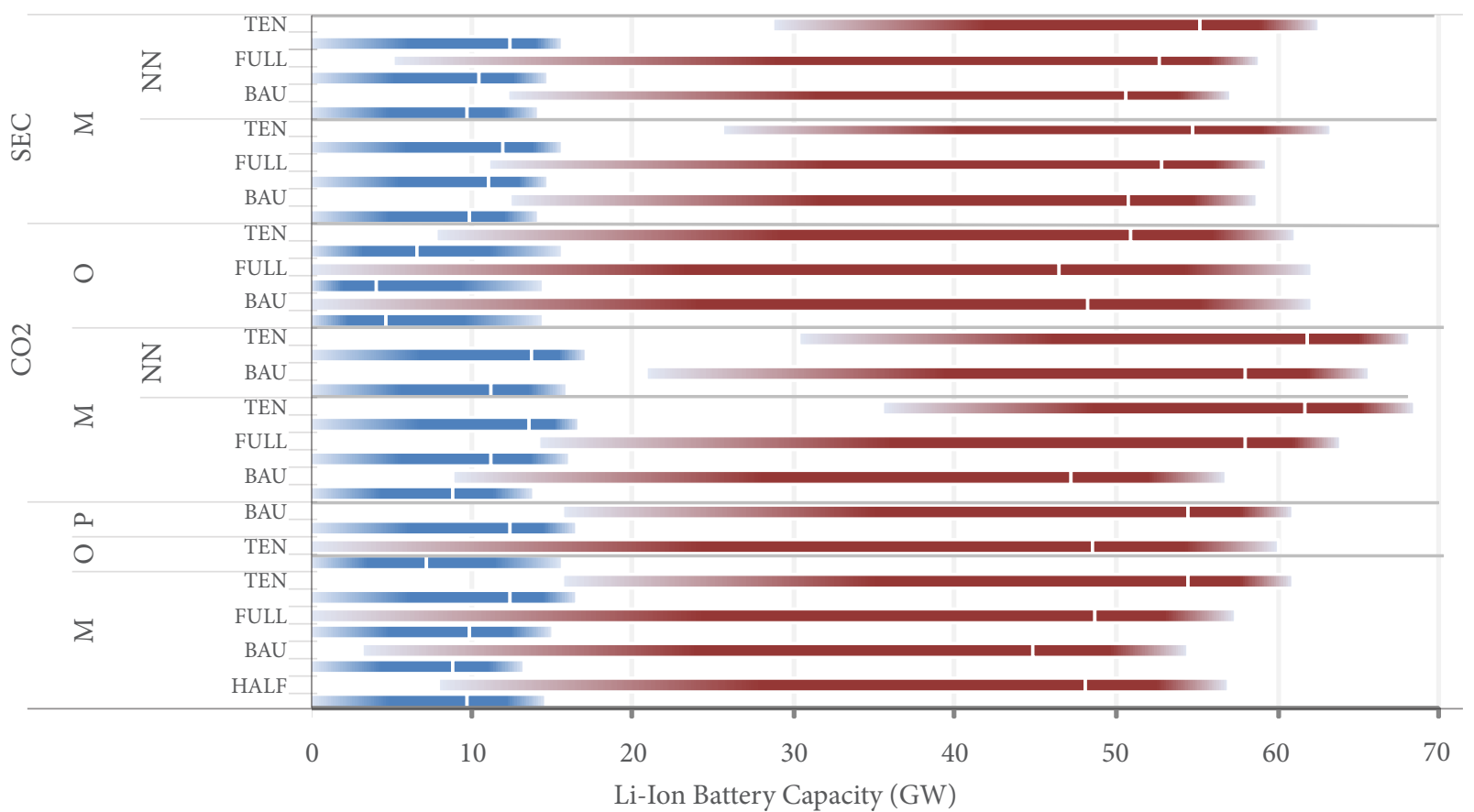

FIGURE 2.23. Deployment of grid-scale Li-ion batteries in 2030 (blue) and 2050 (red) under various scenarios in GW. 


\section{Nuclear}

Increasing RD\&D funding from the BAU to the FULL scenario has no impact (or limited impact in the case of SMRs under a no-new-policy case) on the median deployment of Gen III/III+, Gen IV, and SMR reactors under the no-new-policy case and the $\mathrm{CO}_{2}$ cap case with middle technology assumptions. Under optimistic technology assumptions and in the $\mathrm{CO}_{2}$ cap policy case, however, increasing funding from the BAU to the FULL scenario results in an increase in the deployment of Gen III/III+ reactors from $298 \mathrm{GW}$ to $390 \mathrm{GW}$. Under a sectoral policy case, the FULL scenario has a positive impact on the deployment of Gen III/III+ and SMRs in 2050.

- Under the BAU with middle assumptions in the no-new-policy case, no Gen III/III+ plants are built by 2050 under any of the three RD\&D scenarios considered (BAU, FULL, and 10-times). In the MBAUCO2 and MFULLCO2 cases, $16 \mathrm{GW}$ and $13 \mathrm{GW}$ of nuclear capacity is built, respectively. This would represent a 13\% increase over installed nuclear capacity in 2010 (101 $\mathrm{GW})$. Increasing RD\&D funding from the OBAUCO2 to the OFULLCO2 scenario would result in a median increase in Gen III/III+ deployment from 298 GW to 390 GW. Both levels of new Gen III/III+ reactor deployment by 2050 are extremely high, equivalent to almost 3 times and almost 4 times 2010 installed capacity, respectively. This deployment under the BAU scenario, a $\mathrm{CO}_{2}$ policy, and optimistic assumptions would require an average construction per year of $7.6 \mathrm{GW}$, or about 8 nuclear reactors, over the next 39 years. The deployment under the FULL scenario would require an average construction of about 10 nuclear reactors per year for almost four decades. This rate of construction is over twice as large the rate of construction in the United States from 1972 to 1990, when installed capacity increased from $3 \mathrm{GW}$ to $90 \mathrm{GW}$, and for twice the amount of time ${ }^{38}$ (Figure 2.24).

- Just as in the case of Gen III/III+ plants, under the no-policy case and middle assumptions there is no Gen IV deployment at the median level by 2050 under any of the three funding levels. The MCO2 scenarios show no 2050 Gen IV deployment at the median, but significant deployment in the $95^{\text {th }}$ percentile; moving from the MBAUCO2 to the MFULLCO2 scenario results in a significant decrease in the 95th percentile of 2050 Gen IV deployment (from 190 GW to 115 GW). This decrease under the FULL scenario is caused by the fact that in this scenario, other technologies have costs that are low enough to experience increased deployment: coal cogeneration plants, pulverized coal plants, and natural gas plants with and without CCS. These levels of new Gen IV deployment under the BAU and FULL funding scenarios would imply almost

38 Note that in the case of nuclear power, the optimistic assumptions are in contrast to the historical cost increases of nuclear plants over time. Under the sectoral policy case and middle assumptions, there would be $10 \mathrm{GW}$ of nuclear under the BAU scenario and $12 \mathrm{GW}$ under the full scenario in 2050. The small impact of RD\&D on Gen III/III+ deployment under the middle assumptions with all scenarios is a good representation of the full set of elicitation results; only 6 out of 22 experts expected that public funding for RD\&D would have an impact on Gen III/III+ costs. 
a tripling and doubling, respectively, of 2010 nuclear capacity (101 GW), but only take place at the $95^{\text {th }}$ percentile of the simulation results. Under OBAUCO2 and OFULLCO2 scenarios, no Gen IV reactors are deployed by 2050 at the median level. At the $95^{\text {th }}$ percentile, there is no Gen IV deployment under the OBAUCO2 scenario and $258 \mathrm{GW}$ under the OFULLCO2 scenario. In the MSEC policy case, the median result shows no Gen IV deployment in 2050 under any of the funding scenarios, but the $95^{\text {th }}$ percentile of Gen IV deployment in 2050 shows a decrease in deployment with increasing RD\&D, again because other technologies do better under the FULL scenario and middle technology assumptions (122 GW under the MBAUSEC case and $39 \mathrm{GW}$ under the MFULLSEC case). This means that, under the policy cases, there is some probability of very significant increases in nuclear deployment in 2050, and that RD\&D has a positive impact depending on the type of assumptions (Figure 2.25).

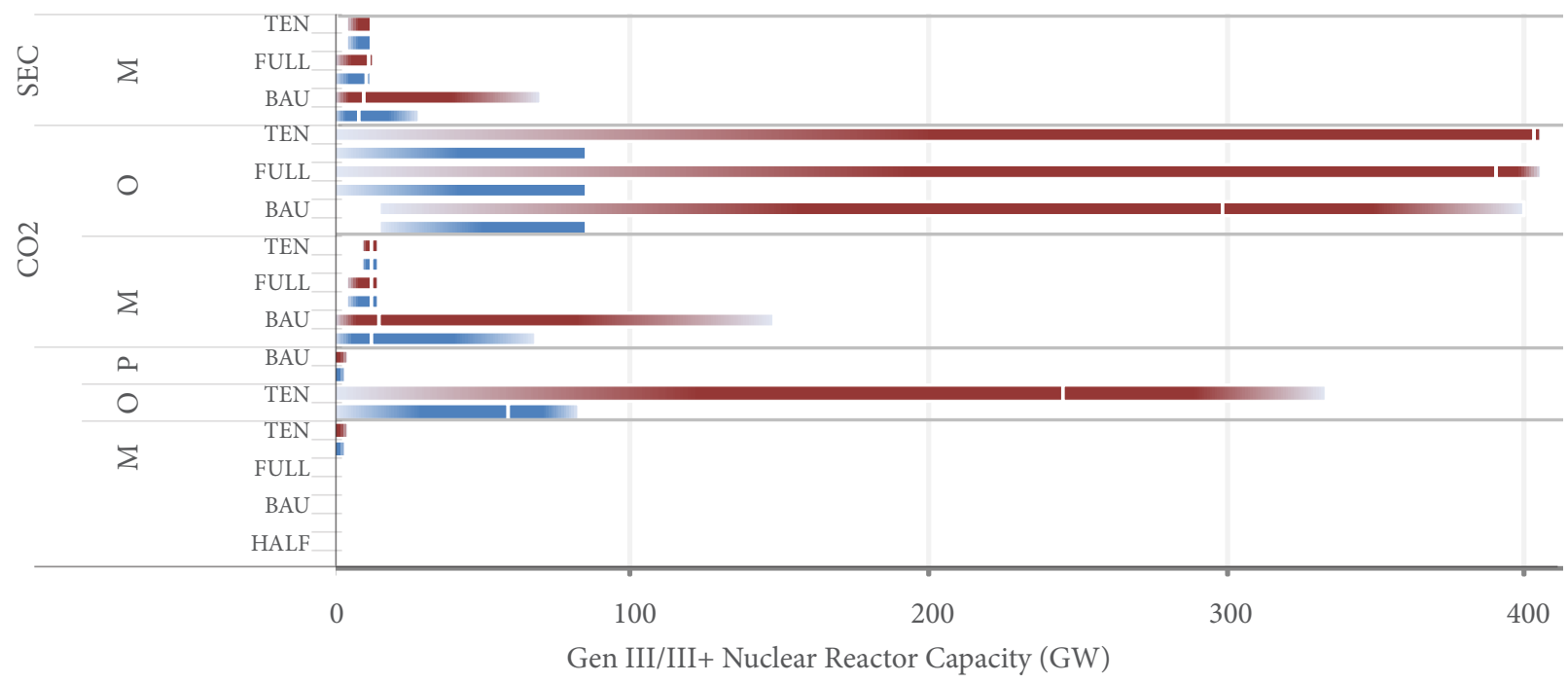

FIGURE 2.24. Deployment of Gen III/III+ power plants in 2030 (blue) and 2050 (red) under various scenarios in GW.

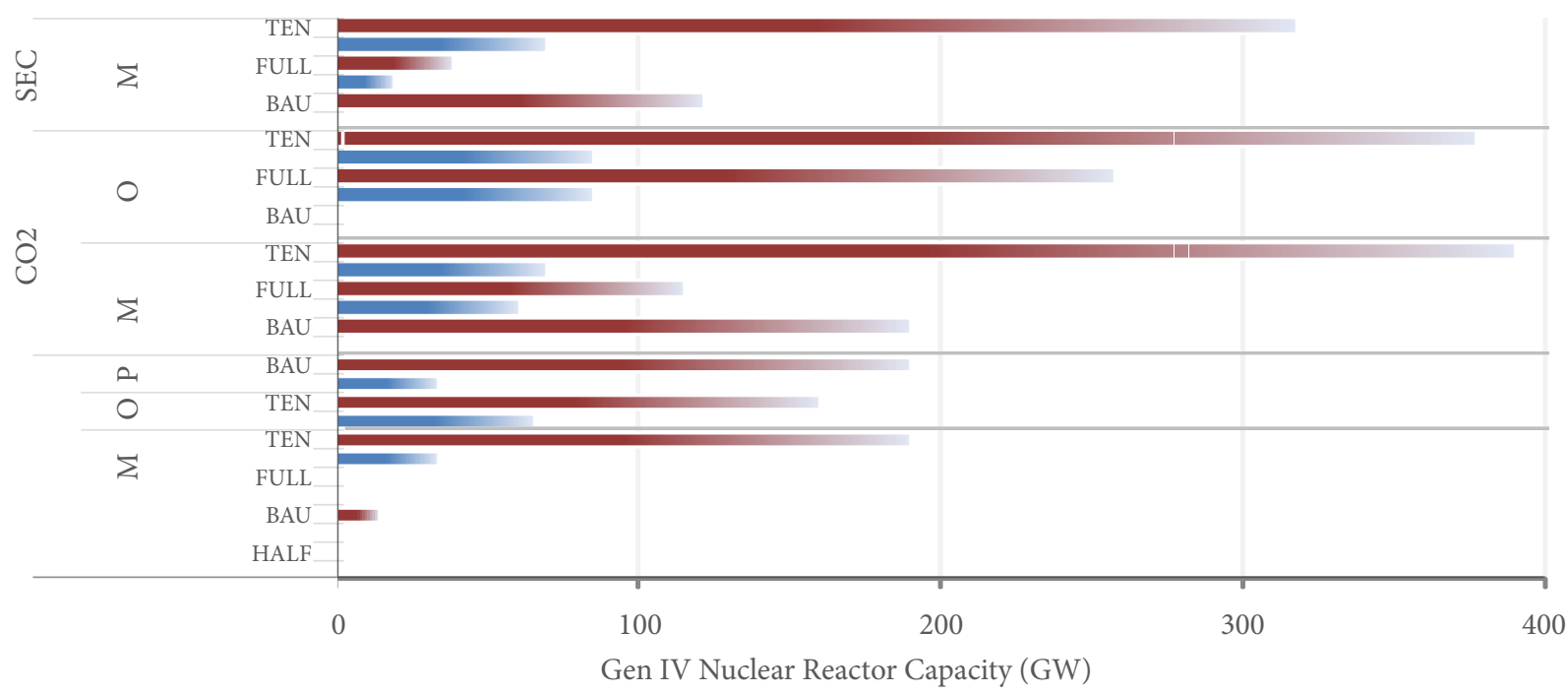

FIGURE 2.25. Deployment of Gen IV power plants in 2030 (blue) and 2050 (red) under various scenarios in GW. 


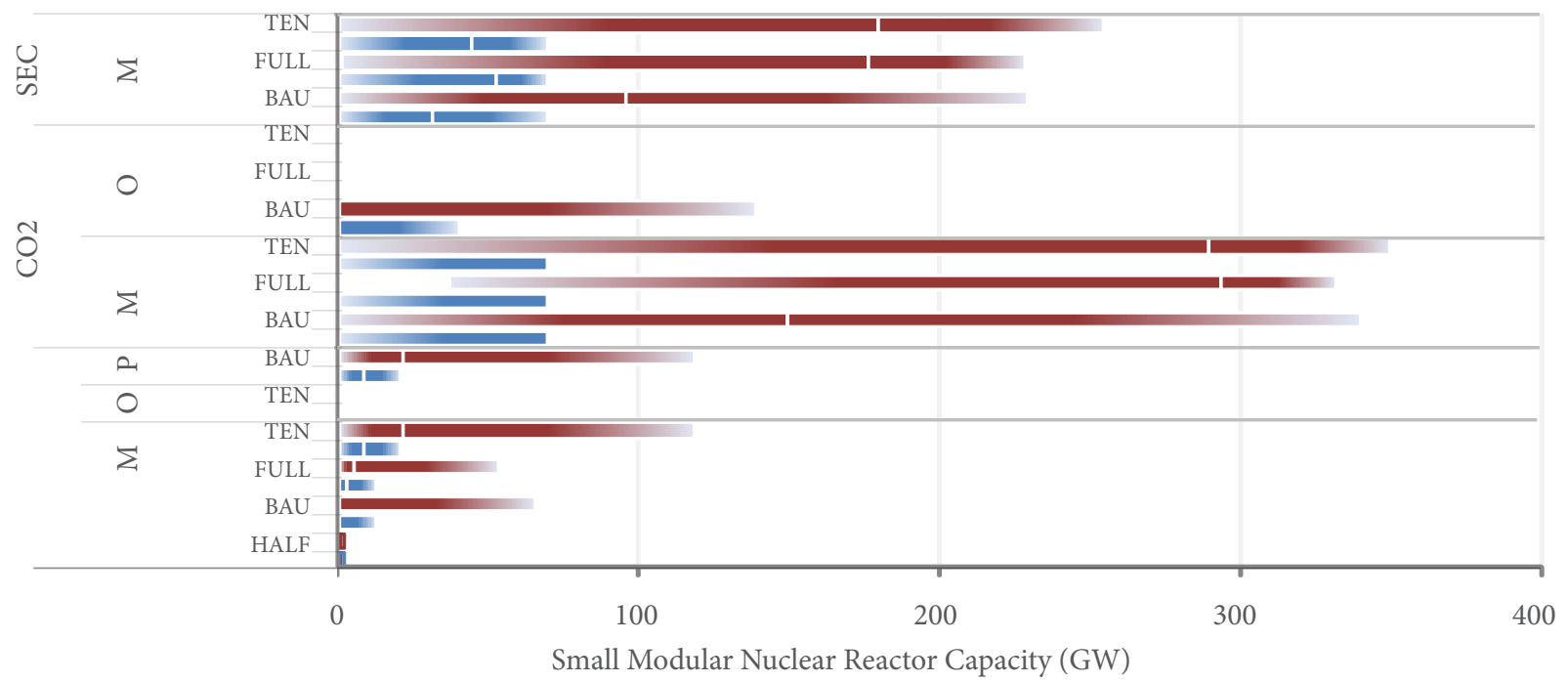

FIGURE 2.26. Deployment of small modular reactors (<300 MWe) plants in 2030 (blue) and 2050 (red) under various scenarios in GW.

- The MFULL scenario would lead to a small level (5 GW) of SMR deployment by 2050 compared to none under the MBAU scenario. The MFULLCO2 scenario would lead to a large SMR deployment (293 GW) in 2050, a significant increase (almost a doubling) over the $149 \mathrm{GW}$ under a BAU scenario. Increasing RD\&D funding from the MBAUSEC scenario to the MFULLSEC scenario results in a significant increase in SMR deployment (from $96 \mathrm{GW}$ to $176 \mathrm{GW}$ ). Building $96 \mathrm{GW}$ of SMRs over 39 years implies an average rate of construction in the United States of 2.5 GW per year, which is below the rate of construction of the U.S. nuclear expansion from 1972 to 1990 of 4.8 GW per year (Grübler 2011) (Figure 2.26).

We now move on to discussing the impact of increasing nuclear RD\&D funding beyond the FULL scenario. Increasing RD\&D funding from the MFULL to the MTEN scenario results in small additional deployment of Gen III/III+ and SMR reactors by 2050. Increasing RD\&D funding from MFULLCO2 to MTENCO2 results in no change in the expected deployment of Gen III/III+ and Gen IV reactors, but does result in a significant increase in the deployment of SMRs.

- Increasing funding from the MFULL to the MTEN scenario does not result in any Gen III/III+ deployment in 2050. Under OTEN, there would be $245 \mathrm{GW}$ of Gen III/III+ plants installed in 2050. Increasing funding from OFULLCO 2 to OTENCO2 would result in small increases in Gen III/III+ deployment (from $390 \mathrm{GW}$ to $403 \mathrm{GW}$ ). Increasing funding from MFULLSEC to MTENSEC results in Gen III/III+ deployment around 10 GW (about a 10\% increase over 2009 installed capacity) in 2050 (Figure 2.24).

- The median deployment of Gen IV reactors in 2050 is zero regardless of RD\&D level, policy scenario, and assumptions, with the exception of a very small deployment ( $3 \mathrm{GW}$ ) under 
OTENCO2. At the $95^{\text {th }}$ percentile level of Gen IV deployment, our simulations indicate that nuclear power could play a major role. In MTEN, the $95^{\text {th }}$ percentile is $190 \mathrm{GW}$ in 2050 , compared to $0 \mathrm{GW}$ under MFULL. Increasing funding from MFULLCO2 to MTENCO2 results in a very significant increase in Gen IV deployment in 2050 (from $115 \mathrm{GW}$ to $389 \mathrm{GW}$ ) at the $95^{\text {th }}$ percentile. Increasing funding from the OFULLCO2 to the OTENCO2 also results in a significant increase in Gen IV deployment at the $95^{\text {th }}$ percentile (from $258 \mathrm{GW}$ to $377 \mathrm{GW}$ ). The increase is most significant under the sectoral policy case at the $95^{\text {th }}$ percentile of Gen IV deployment in 2050 (39 GW under MFULLSEC and $318 \mathrm{GW}$ under MTENSEC, which is almost a 10-fold increase) (Figure 2.25).

- MTEN would result in 21 GW of SMR deployment in 2050, a significant increase over MFULL (8 GW). These levels of deployment correspond to just $1 \%$ and $2 \%$ of total installed power capacity in2009, respectively. Increasing RD\&D funding from MFULLCO2 to MTENCO2 would result in little additional SMR deployment by 2050 (293 GW compared to 289 GW) because other technology areas (natural gas with CCS, cogen coal plants, etc.) are more competitive under this funding scenario. Increasing RD\&D funding from MFULLSEC to MTENSEC would also result in a negligible increase in SMR deployment (from $176 \mathrm{GW}$ to $179 \mathrm{GW}$ ). In short, the 10-times scenario has very limited impact on SMR deployment beyond the FULL scenario (Figure 2.26).

For nuclear energy RD\&D, we recommend increasing the budget to $\$ 1.2$ billion, which is $160 \%$ greater than the FY 2009 nuclear energy budget excluding facilities. The recommended budget corresponds to the recommendation of the middle expert and the median recommendation across experts. Two outliers recommending very high $\mathrm{RD} \& \mathrm{D}$ budgets drove the mean recommendation, which is $\$ 1.8$ billion (50\% greater than the median). SMRs seem to be more promising than Gen IV reactors in terms of deployment during the 2030-2050 timeframe, and should be explored to see whether cost expectations materialize. They could play an important role if the economics forecasted by some experts are demonstrated (partly with RD\&D support). Experts thought that two Gen IV designs have a greater chance of commercialization in the 2030-2050 timeframe: the sodium-cooled fast reactor design, and the very high temperature thermal design. These reactors should be the focus of Gen IV research in the United States. Section 2.8.3 shows that nuclear RD\&D is never the largest component of an RD\&D portfolio of the technology areas considered, but that it plays a role under the three policy scenarios (no-newpolicies, $\mathrm{CO} 2$ cap, and sectoral standards).

\section{Fossil Energy and CCS}

The energy system modeling results indicate that, as expected, gas and coal plants with CCS do not penetrate the market under the no-policy case. Under the CO2 and SEC policy cases, fossil plants with CCS do play a role. As will be discussed below, if no new nuclear power plants are allowed under the 
CO2 and SEC cases, then the fossil energy RD\&D would probably result in greater benefits in terms of the deployment of coal and natural gas plants with CCS.

- The deployment of coal plants using integrated gasification combined cycle (IGCC) technology with CCS is slightly affected by RD\&D under the two main policies considered. In the CO2 and SEC policy cases, there is no IGCC with CCS deployment by 2050. The deployment of IGCC with CCS in 2050 decreases slightly from MBAUSEC to MFULLSEC (from 39 GW to $35 \mathrm{GW}$ ), which implies that other the deployment of technologies (e.g., nuclear power) would increase. The deployment of IGCC plants with CCS would also increase from $90 \mathrm{GW}$ under MBAUSECNN to $100 \mathrm{GW}$ under MFULLSECNN. This level of deployment would make the role of CCS in 2050 comparable with the role of nuclear power as of 2010 (101 GW, or 10\% of U.S. power capacity). Even though the full scenario does not result in a significantly expanded deployment, funding for CCS RD\&D could be the difference between having or not having a low-carbon option to use coal. This could be important not only from a U.S. perspective, but also from an international perspective since two large emerging economies (China and India) have and use a lot of coal and will continue to do so at least in the near- to medium-term (Figure 2.27).

- The deployment of natural gas combined cycle plants with CCS is also not too sensitive to $\mathrm{RD} \& \mathrm{D}$ funding levels. Unlike IGCC with CCS, the CO2 scenario results in some deployment of natural gas with CCS. Increasing RD\&D funding from MBAUCO2 to MFULLCO2 would result in a small decrease in deployment of natural gas with CCS in 2050 (from 76 GW to $67 \mathrm{GW}$ ); part of the reason for this is again the large growth in SMR deployment under these conditions. This level of deployment under the CO2 case would make natural gas with CCS an important component of a $\mathrm{CO}_{2}$ mitigation strategy. Under OBAUCO2 and OFULLCO2, natural gas with CCS would play a role twice as large (135 GW under the BAU scenario and $155 \mathrm{GW}$ under the FULL scenario). The MFULLSECNN scenario would result in a slightly smaller installed capacity of natural gas with CCS when compared to MBAUSECNN (40 GW compared to $42 \mathrm{GW}$ ). ${ }^{39}$ Increasing funding from MBAUSEC to MFULLSEC would result in a decrease in the deployment of natural gas with CCS in 2050 (from 22 GW to 11 GW). Again, the decrease in deployment using the middle technology assumptions under the FULL funding conditions is mainly due to the fact that SMRs would take up a larger share of electricity generation (Figure 2.28).

Increasing funding beyond the full scenario has a limited impact on the deployment of coal and natural gas plants with CCS.

39 This level of deployment of natural gas with CCS is above that of wind as of 2009, with 32 GW of installed capacity, although the output of the capacity would be greater due to the fact that wind has a lower capacity factor. 
- As stated earlier, no coal plants with CCS are deployed under the no-new-policy or CO2 scenarios. The deployment of IGCC with CCS in 2050 would increase slightly from MFULLSECNN to MTENSECNN (from $95 \mathrm{GW}$ to $100 \mathrm{GW}$ ). In the case where new nuclear plants are allowed, there would be a decrease in the deployment of coal with CCS with more RD\&D (32 GW under MFULLSEC compared to $13 \mathrm{GW}$ under MTENSEC). According to this result, there would not be a reason to invest in RD\&D beyond FULL (Figure 2.27).

- Gas plants with CCS are deployed under CO2. The increase in RD\&D funding from the MFULLCO2 to the MTENCO2 scenario resulted in a small increase in natural gas with CCS deployment in 2050 (from $67 \mathrm{GW}$ to $70 \mathrm{GW}$ ). This level of deployment would involve the construction of almost two large coal plants with CCS a year for 39 years. Natural gas with CCS deployment by 2050 increases by $8 \%$ from OFULLCO2 to OTENCO2 (from 155 GW to $167 \mathrm{GW}$ ), and by $10 \%$ from MBAUCO2NN to MTENCO2NN (from $145 \mathrm{GW}$ to $160 \mathrm{GW}$ ). In

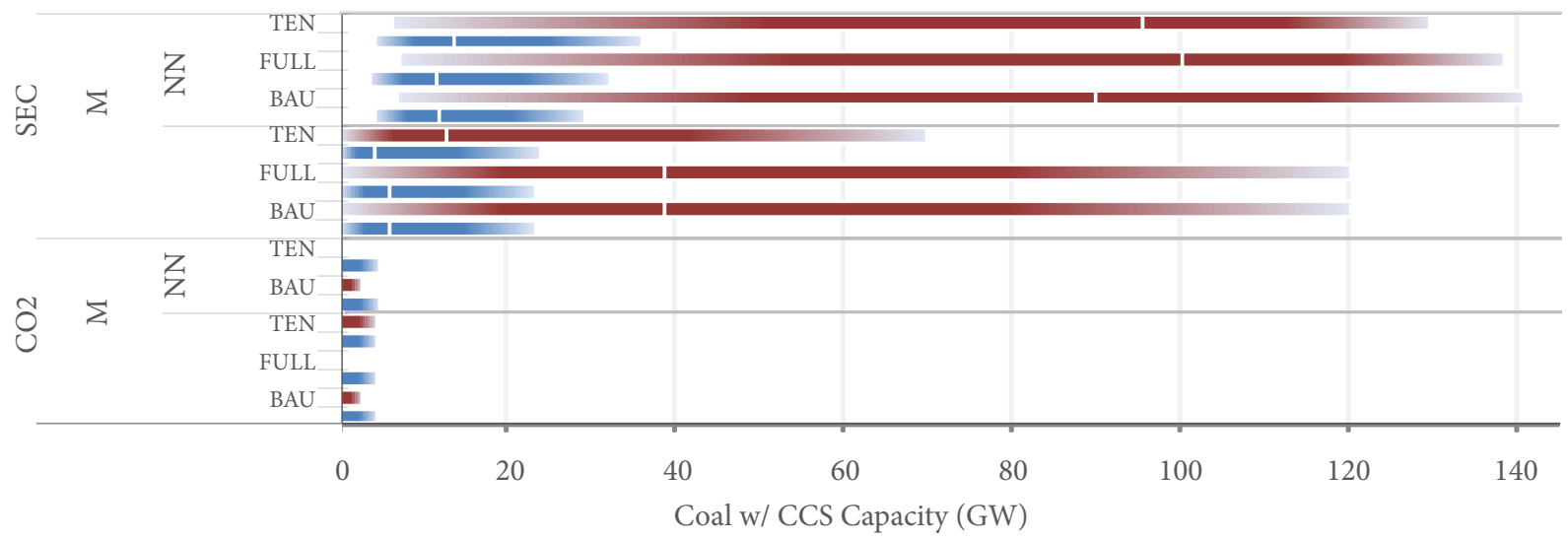

FIGURE 2.27. Deployment of coal plants with CCS in 2030 (blue) and 2050 (red) under various scenarios in GW.

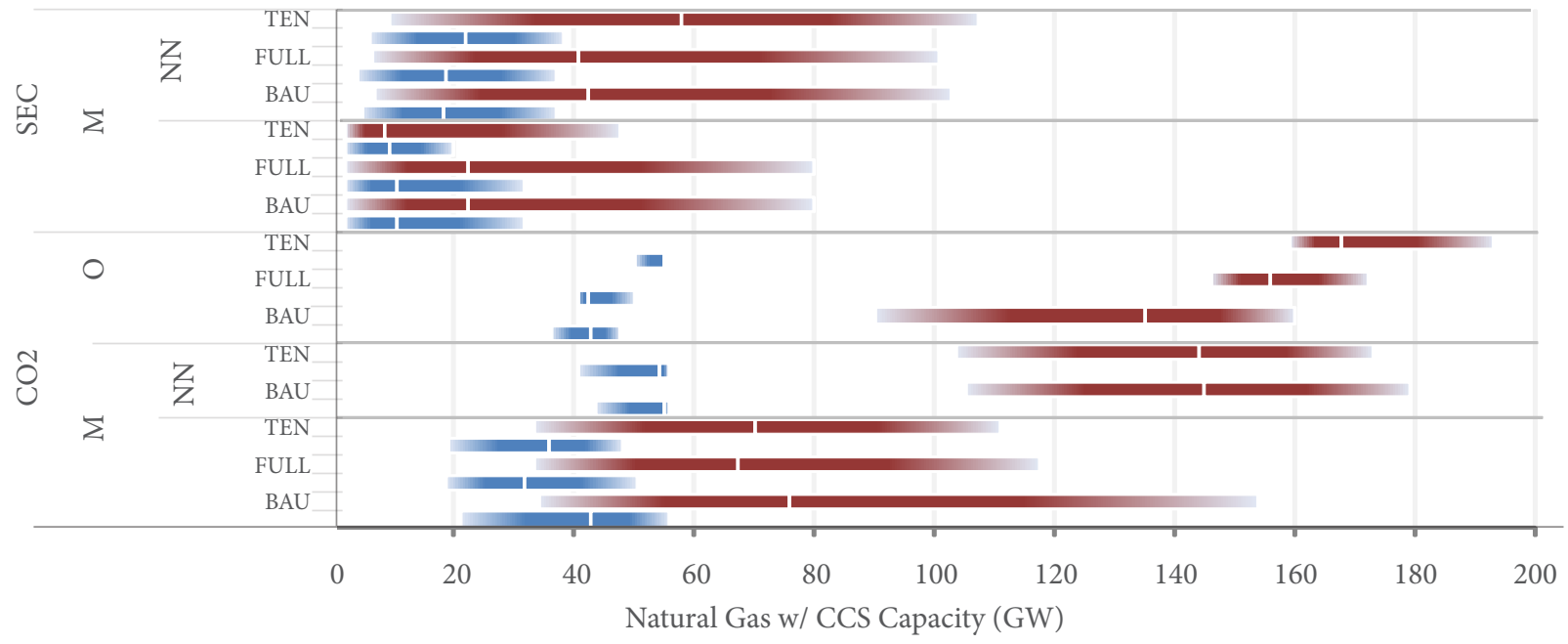

FIGURE 2.28. Deployment of natural gas plants with CCS in 2030 (blue) and 2050 (red) under various scenarios in GW. 
summary, under CO2, natural gas with CCS could play a very important part of a low-carbon grid (equivalent to $7 \%$ to $16 \%$ of today's power generation capacity depending on whether the middle and optimistic assumptions are used, respectively). In SECNN, MTEN funding would result in a $42 \%$ increase in deployment when compared to MFULL (deployment would grow from $40 \mathrm{GW}$ to $58 \mathrm{GW}$ ). Under MTENSEC, the deployment of natural gas with CCS would be only $8 \mathrm{GW}$ (Figure 2.28).

Because of the large amount of funding required to increase funding to the 10-times scenario and the minor returns, we recommend investing $\$ 1$ billion annually in fossil energy RD\&D. Over the years, this would allow the construction of several demonstration projects. The recommended amount of $\$ 1$ billion is in line with the recommendation of the middle expert ( $\$ 1,075$ million), and half of the median recommendation of all experts ( $\$ 2,000$ million). It is important to add that if policy makers decide not to support nuclear power or do not expect its deployment, it becomes even more important to sufficiently fund fossil energy and CCS RD\&D, perhaps even beyond $\$ 1$ billion. As we discuss in section 2.8.3, fossil energy $\mathrm{RD} \& \mathrm{D}$ should be an important part of the $\mathrm{RD} \& \mathrm{D}$ portfolio if a $\mathrm{CO}_{2}$ cap policy is implemented.

\section{Buildings}

In the buildings technology expert elicitation, we asked experts to recommend a federal RD\&D budget for all aspects of building technologies (e.g., lighting, insulation, windows, water heating, etc.), but we only asked experts to estimate the impact of this budget on the heating and cooling needs of buildings. We only obtained sufficient answers on the impact of RD\&D budgets on commercial buildings. (We obtained one estimate on the impact of federal building technology RD\&D on residential buildings.) Therefore, the only benefits of increased $\mathrm{RD} \& \mathrm{D}$ investments in buildings included in our analysis are decreased emissions from reduced heating and cooling loads in commercial buildings, and only commercial building results are discussed below. This means that the benefits estimated for buildings represent an extremely conservative lower bound. Heating and cooling currently accounts for $24 \%$ of primary energy consumption in commercial buildings. ${ }^{40}$ In turn, commercial buildings accounted for almost $18 \%$ of energy-related $\mathrm{CO}_{2}$ emissions in the United States in 2009. Combined, the residential and commercial building sectors accounted for about 38\% of total emissions in 2009 (EIA 2010b)

Under current policies, MFULL would result in a very small (0.2\%) median decrease in energy use for heating and cooling in commercial buildings by 2050 when compared to emissions under MBAU. Median energy use for heating and cooling in the commercial building sector in 2050 is reduced signifi- 


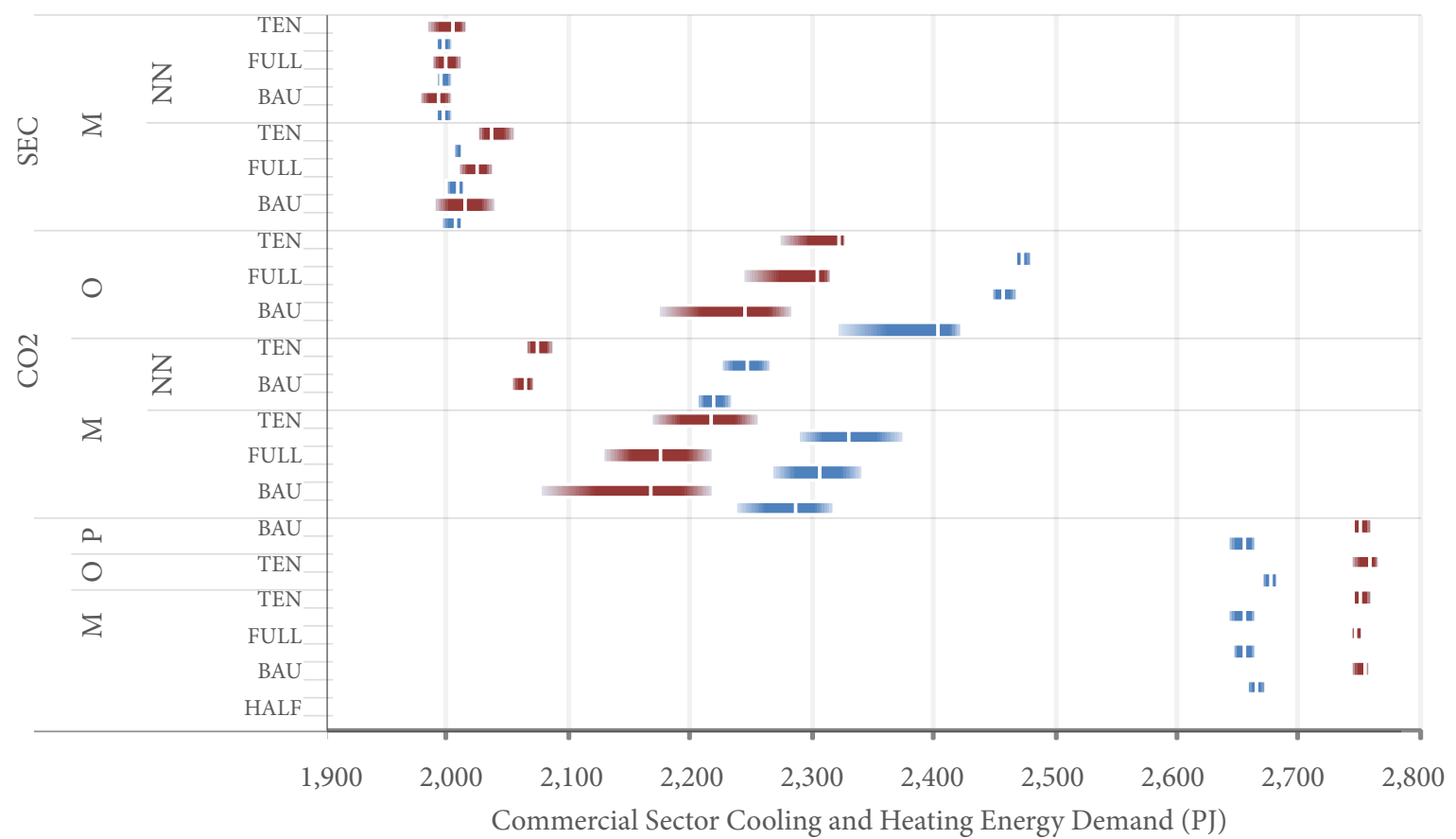

FIGURE 2.29. Energy use for heating and cooling from commercial buildings in 2030 (blue) and 2050 (red) under various scenarios in PJ. The white line corresponds to the median result, and the edges correspond to the $5^{\text {th }}$ and $95^{\text {th }}$ percentiles of deployment.

cantly, compared to MBAU by $21 \%$ under MBAUCO2 and by $27 \%$ under MBAUSEC. Our modeling shows no additional heating and cooling energy savings with increased RD\&D funding because other technologies would become a less expensive way to reduce emissions than building more efficient commercial buildings (Figure 2.29).

Increasing RD\&D funding from MFULL to MTEN would also result in negligible median reductions in heating and cooling energy use for commercial buildings in 2050 (a decrease of 0.08\%), even under $\mathrm{CO} 2$ and SEC.

We recommend at least $\$ 680$ million in federal RD\&D for buildings because, even though its impact on heating and cooling energy in the commercial sector is not expected to be significant, as a whole the building technologies RD\&D budget (on windows, lighting, integrated building design, etc.) could have a significant impact on energy use in commercial and residential buildings. Due to time and resource constraints, our work did not cover such benefits. Our recommendation represents just over a threefold increase over the FY 2009 appropriation. The recommendation coincides with the mean recommendation across experts. In addition, it is just below the median recommendation across experts of $\$ 700$ million, and somewhat below the recommendation of the middle expert ( $\$ 900$ million) used in the energy system modeling analysis. ${ }^{41}$

41 The buildings RD\&D investments were not included in the optimization presented in section 2.8.3 because we did not include 


\section{Vehicles}

Under the technology assumptions provided by experts, EVs and fuel cell vehicles would not play a significant role in the U.S. light-duty vehicle fleet in 2050 (EVs would play a marginal role in the sectoral policy case), and thus are not discussed.

Increasing funding from MBAU to MFULL had a small impact on the deployment of HEVs and a very significant impact on the deployment of PHEVs.

- Total light-duty vehicle miles traveled (VMTs) in 2050 decrease from 4,800 billion under MBAU, to 4,600 billion under MBAUSEC, to 4,500 billion under MBAUCO2. These very significant changes in deployment for different RD\&D scenarios are possible because vehicles have turnover times that are much smaller than buildings or electricity generation plants. Thus, once a technology becomes cost-competitive, it takes fewer years to have a large impact on the lightduty vehicle fleet.

- Under MFULL, HEVs make up 65\% (median) of VMTs in 2050, which represents a significant increase from a 53\% median share under MBAU. In the $\mathrm{CO}_{2}$ cap policy case, HEVs would make up $65 \%$ of light-duty VMTs under MBAUCO2 and 69\% under MFULLCO2. HEVs would make up $80 \%$ of light-duty VMTs under MBAUSEC and 77\% under MFULLSEC (Figure 2.30).

- MFULL would result in PHEVs making up 1.6\% (median) of VMTs in 2050, which represents a significant increase from the $0.5 \%$ median share of PHEVs in MBAU. PHEVs would make up $4.7 \%$ of light-duty VMTs under MBAUCO2 and 12\% under MFULLCO2. PHEVs would make up $16 \%$ of light-duty VMTs under MBAUSEC and 20\% under MFULLSEC (Figure 2.31).

Increasing the funding beyond MFULL to MTEN would result in mixed deployment benefits, depending on technology and policy scenario.

- MTEN would result in HEVs making up 77\% (median) of VMTs in 2050. This represents a significant increase when compared to MFULL, in which HEVs made up 65\% of VMTs. HEVs would make up 79\% of light-duty VMTs under MTENCO2, compared to 69\% under MFULLCO2. Median HEV share would only increase slightly to 78\% under MTENSEC (Figure 2.30).

- MTEN has a significant impact on PHEV median share of light-duty VMTs, increasing to $12 \%$ from only $1.6 \%$ under MFULL. Under MTENCO2 and MTENSEC, median PHEV share declines approximately one percentage point when compared to MFULLCO2 and MFULLSEC, respectively (Figure 2.31).

questions about the $10^{\text {th }}$ and $90^{\text {th }}$ percentile estimates of costs in the buildings expert elicitation. This meant that it was not possible to apply the optimization methodology discussed in section 2.8.3. 


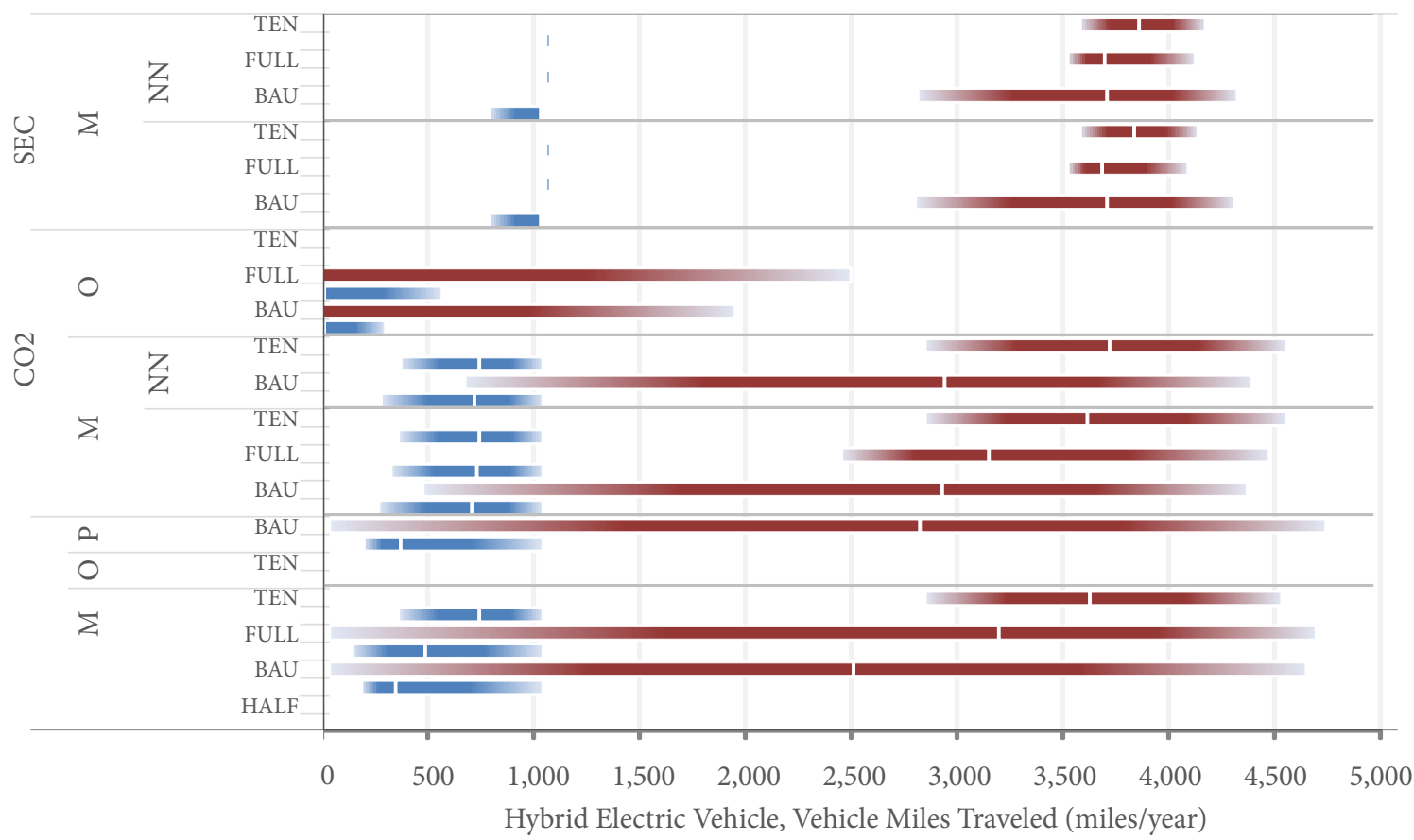

FIGURE 2.30. Vehicle miles traveled (VMT) of HEVs in 2030 (blue) and 2050 (red) under various scenarios in metric tons of $\mathrm{CO}_{2}$.

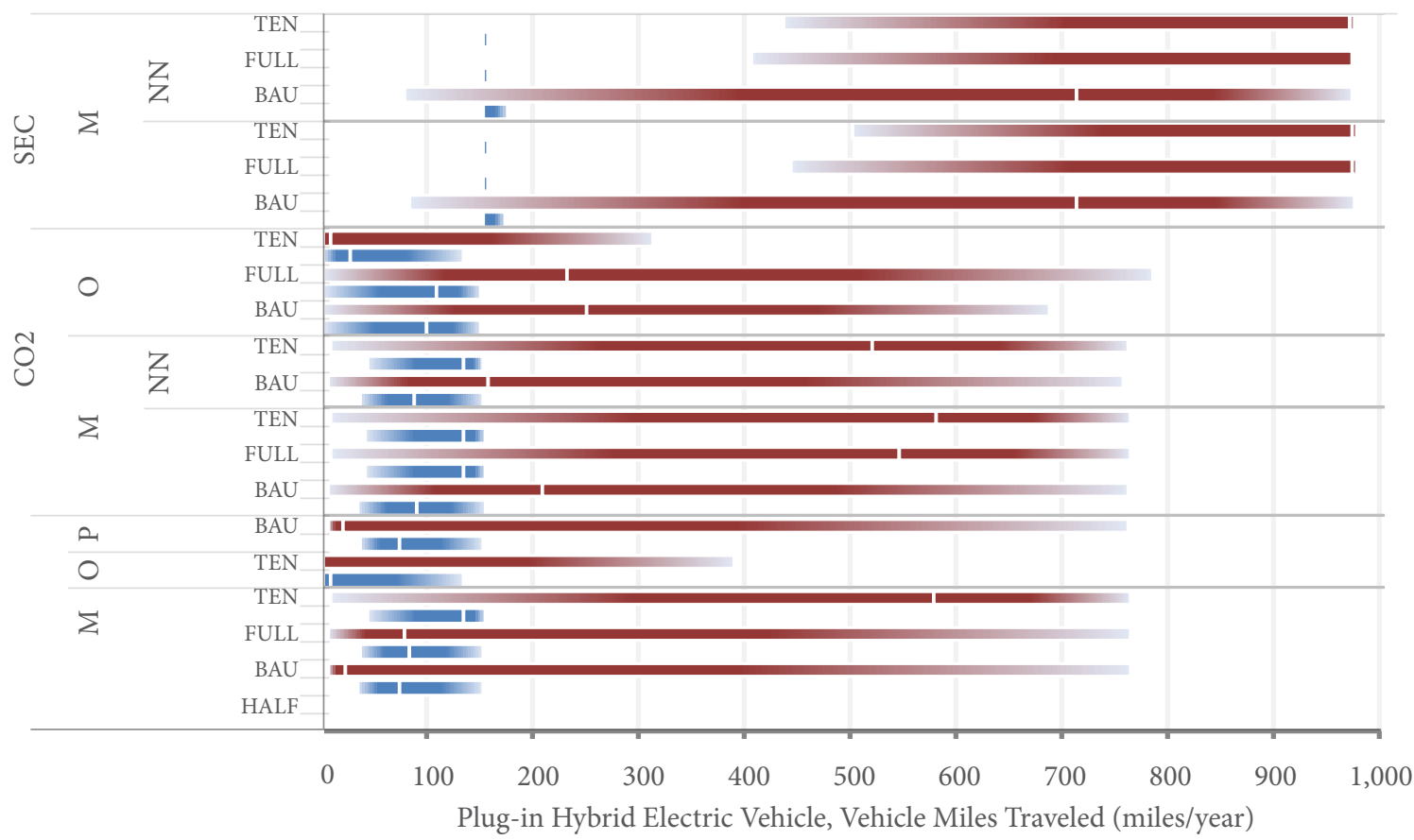

FIGURE 2.31. Vehicle miles traveled (VMT) of PHEVs in 2030 (blue) and 2050 (red) under various scenarios in metric tons of $\mathrm{CO}_{2}$. Note the horizontal scale ends at 1,000 miles per year, as opposed to 5,000 miles per year in Figure 2.30. 
Small reductions in vehicle prices have very significant impacts on the cost of meeting particular emissions reductions goals; in other words, lower vehicle prices have a relatively large impact on $\mathrm{CO}_{2}$ prices (on average, annual U.S. light-duty vehicle sales between 1975 and 2008 have been about 14 million; assuming an average cost of $\$ 20,000$ per vehicle, translates the total cost to $\$ 280$ billion per year). This makes a case for continued support for vehicle RD\&D. In addition, shares of HEVs and PHEVs are projected to increase with greater RD\&D funding under current policies and $\mathrm{a}_{2}$ cap.

We recommend a vehicle technology RD\&D budget of $\$ 1$ billion, which is consistent with the median expert recommendation, is just over twice the current budget, and is greater than the recommendation of the middle expert ( $\$ 650$ million). This is because, as discussed above, large RD\&D budgets beyond the recommended budget could result in significant increases in HEV and PHEV deployment. Even though the mean recommended budget was $\$ 2$ billion, we use the median because an outlier was driving the mean very significantly. The significant budget increase is also supported by the fact that vehicles RD\&D becomes the second most important part of the optimal RD\&D portfolio for both a $\$ 5$ billion and a $\$ 7.5$ billion RD\&D budget constraint under a CO2 cap policy after fossil energy with CCS (see section 2.8.3).

\section{Solar PV}

We discuss the combined deployment of distributed residential and commercial PV systems, and do not discuss the deployment of utility-scale systems because their deployment levels are low and do not increase with greater $\mathrm{RD} \& \mathrm{D}$ funding in most of the scenarios we investigated; the only exception is the scenario with optimistic technology assumptions and $\mathrm{a}_{2}$ cap. The reason why the residential- and commercial-scale systems become competitive before the utility-scale systems is that, unlike the utilityscale systems, residential- and commercial-scale systems do not incur the cost of connecting to transmission lines and transmission losses. Under all scenarios (policy and no-policy), increased RD\&D levels have a negligible or small positive impact on the deployment of residential and commercial solar PV.

Increasing solar PV RD\&D funding from MBAU to MFULL results in a small increase in the deployment of distributed PV by 2050 (from 198 GW to $201 \mathrm{GW}$ ). It is worth noting that, with an installed solar PV capacity in 2050 of about $20 \%$ of the total electric capacity in 2009 , under both RD\&D scenarios solar PV would play a large role in the U.S. electricity system. (This is especially striking when one compares it to the $600 \mathrm{MW}$ of grid-connected solar electric installations, which include solar PV and solar thermal installations, that were in the United States in 2009 (EIA 2011).) ${ }^{42}$ Increasing funding

42 This amount of commercial- and residential-scale solar PV would take up about under one-third of the roof space suitable for PV panels in the United States, estimated to be around $348 \mathrm{GW}$ for residential rooftops and $313 \mathrm{GW}$ for commercial rooftops (Denholm and Margolis 2008). 
from MBAUCO2 to MFULLCO2 only results in a 1\% increase in distributed PV deployment in 2050 (from 205 GW to 207 GW). PV deployment in 2050 increases by 13\% from OBAUCO2 to OFULLCO2 (181 GW and 205 GW of deployment, respectively). Under SEC, solar PV would have an even greater deployment than under $\mathrm{CO} 2$, although increasing $\mathrm{RD} \& \mathrm{D}$ funding from $\mathrm{BAU}$ to full does not have an impact; the results show $254 \mathrm{GW}$ under both the BAU and FULL scenarios (Figure 2.32).

Increasing solar PV RD\&D beyond FULL results in further small increases in deployment. Distributed PV deployment in 2050 would increase slightly from MFULL to MTEN (from $201 \mathrm{GW}$ to $205 \mathrm{GW}$ ). Increasing $\mathrm{RD} \& \mathrm{D}$ funding from MFULLCO2 to MTENCO2 results in a $14 \%$ increase in the median distributed PV deployment in 2050 (from 207 GW to 236 GW). Distributed PV deployment in 2050 under OFULLCO2 and OTENCO2 are similar (205 GW and $207 \mathrm{GW}$, respectively). Increasing RD\&D funding from MFULLSEC to MTENSEC has a very small impact on solar PV deployment at just over $250 \mathrm{GW}$. Even though RD\&D increases do not result in large deployment increases beyond those that would take place under the BAU scenario, these results show that solar PV could play a major role in the U.S. power sector.

As we briefly discussed earlier, RD\&D does not have a significant impact on the deployment of utilityscale solar PV. Deployment of large-scale PV plants is projected to occur only under the $\mathrm{CO}_{2}$ cap with optimistic technology assumptions under the BAU case (26 GW in 2050). Additionally, it is important to mention that these results may have changed if we also had estimates for the impact of RD\&D on

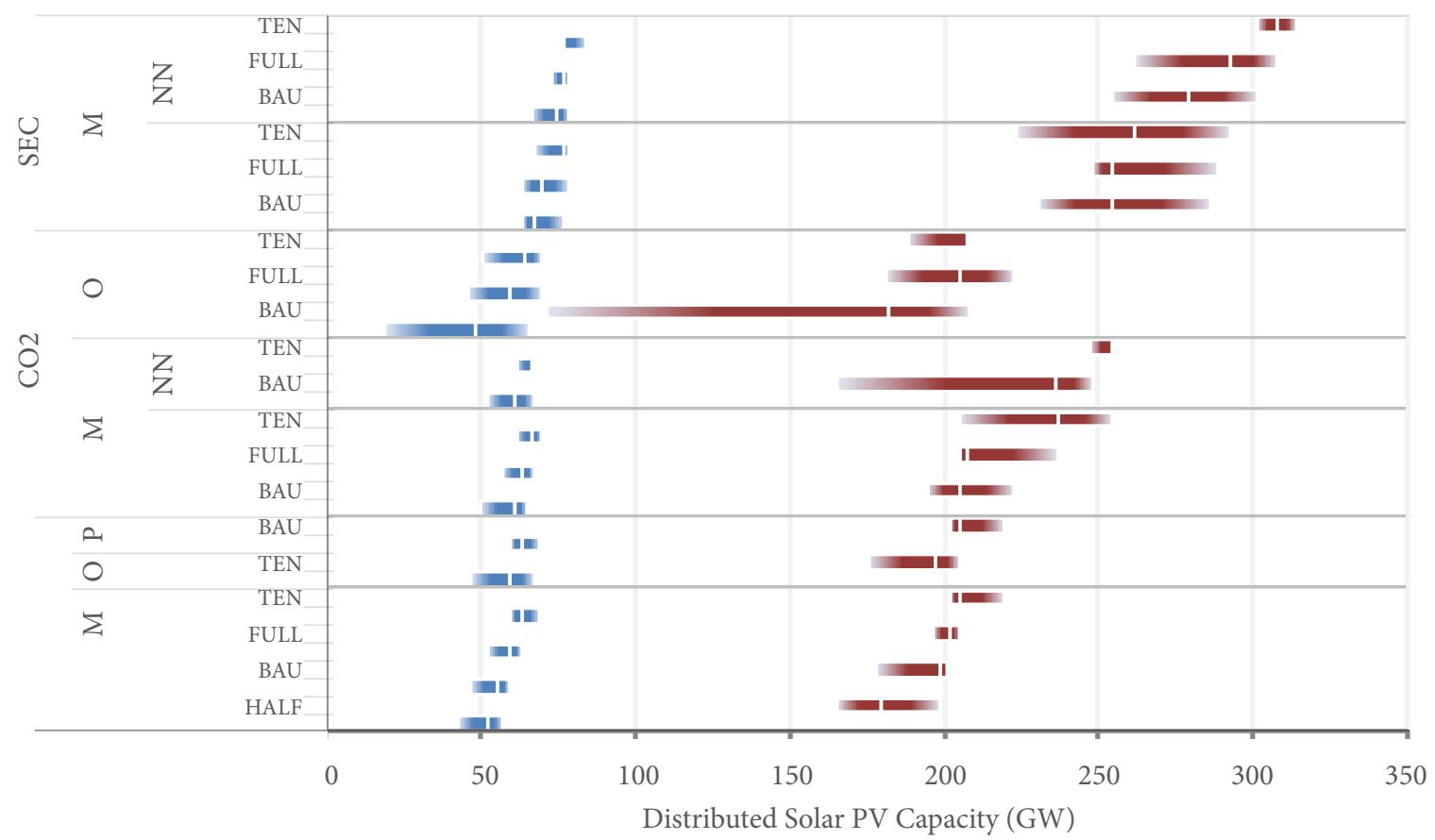

FIGURE 2.32. Residential- and commercial-scale solar PV installed capacity in 2030 (blue) and 2050 (red) under various scenarios in GW. 
wind power costs, which would have competed with solar. The costs of wind power used in the study, taken from the 2010 Annual Energy Outlook, were not changed by RD\&D scenarios.

Overall, based on the deployment increases for solar PV (which starts from just 600 MW in 2009), and the slightly larger penetration of solar PV under funding levels beyond the middle expert's recommended funding, we recommend at least a $\$ 400$ million RD\&D budget for solar PV. This is twice the recommendation of the middle expert, but consistent with the mean of $\$ 409$ million, and greater than the median of the recommendations of all experts of $\$ 300$ million. The optimization results shown in section 2.8.3 indicate that solar PV would be the largest part of an optimized portfolio covering the technology areas under the sectoral policy scenario. This suggests that it may be worth considering solar PV funding even beyond $\$ 400$ million.

\subsubsection{Insights from optimizing the allocation of RD\&D investments under different scenarios}

In this section we develop and apply a methodology for relating technology costs and model output to $\mathrm{RD} \& \mathrm{D}$ portfolios. (Readers interested in the results of our approach and not in the specifics of the methodology can skip ahead to Section 2.8.3.4.) This approach allows us to estimate optimal RD\&D portfolios accounting for uncertainty in technology costs given RD\&D, substitution and complementarities among technologies, non-linearity in the relationship between RD\&D and technology cost, and multiple (although not simultaneous) policy objectives. The initial stage of the approach requires us to develop a method to "invert" the expert elicitation and cost sampling process, estimating RD\&D levels given technology costs rather than technology costs given RD\&D levels (as described in Section 2.5.3). The second stage of the approach fits a multi-dimensional surface to samples of RD\&D levels and to an outcome parameter of the U.S. ten-region MARKAL energy system modeling (such as the $\mathrm{CO}_{2}$ emissions allowance price, CES price, $\mathrm{CO}_{2}$ emissions, total system cost, economic welfare, etc.) and optimizes over this surface to minimize (or maximize) the outcome variable under a total budget constraint.

\subsubsection{The technology cost-technology area $R D \& D$ relationship}

In the expert elicitation phase, experts recommended RD\&D budgets in seven technology areas, and individual technology costs were estimated in six of the technology areas. (Buildings were excluded because building efficiency involves a range of technologies with many different costs; hence the optimizations described in this section cover only six technologies, not the seven covered in our expert surveys.) For example, vehicles is one technology area. Conditional on a recommended level of RD\&D for the vehicles technology area, experts estimated costs for five vehicle technologies: advanced ICE, battery-electric, conventional hybrid, plug-in hybrid, and hydrogen fuel cell drive trains. The goal of this section is to relate RD\&D levels expressed at the cluster level (the only level of aggregation for which the expert elicitation informs) to outputs from MARKAL, but because costs were introduced into 
MARKAL statically from a joint distribution of technology costs conditional on RD\&D constructed via expert elicitation, to extract meaningful information from MARKAL's output requires the expert elicitation process to be inverted. Thus, $\mathrm{RD} \& \mathrm{D}$ levels at the technology area level can be directly matched to MARKAL output.

Mechanically, this process begins with a $400 \times 25$ matrix of projections of the future costs of 25 technologies sampled for 400 cases. (See description in Section 2.5.3 for how we constructed technology cost distributions and sampled from them, and why we deemed 400 samples to be sufficient. $)^{43}$ For the results presented in this document, only the $400 \times 25$ matrix for the middle technology assumptions and full recommended funding level scenario was used. However, as will be described below, the limitation on the range of portfolios for which inferences can be reasonably estimated based on this restriction is only marginally a concern for portfolios in the broad neighborhood of this particular scenario.

The first step of the post-processing calculations is to fully describe the relationship between each of the 25 technologies and the level of RD\&D in the six technology areas. Experts recommended a level of $\mathrm{RD} \& \mathrm{D}$ and estimated $10^{\text {th }}, 50^{\text {th }}$, and $90^{\text {th }}$ percentiles of each of the 25 technologies at three levels $(0.5 \mathrm{X}$, $1 \mathrm{X}$, and 10X of their recommended level) of RD\&D conducted at the technology area level. To fully describe the technology cost-technology area RD\&D relationship, estimates for the $10^{\text {th }}, 50^{\text {th }}$, and $90^{\text {th }}$ percentiles are interpolated or extrapolated for all positive levels of technology area RD\&D based on the three sets of estimates given by the experts. Several functional form relationships were experimented with, and ultimately the method chosen is a compromise between separately estimating a functional relationship for the $10^{\text {th }}, 50^{\text {th }}$, and $90^{\text {th }}$ percentile estimates and estimating the $10^{\text {th }}$ and $90^{\text {th }}$ percentiles relative to the median estimate.

In the process we adopted, the median relationship between one technology cost and its technology area-level RD\&D level is estimated by a weighted least squares regression of sampled 2030 technology cost on the log of its technology area's RD\&D level (given at $0.5 \mathrm{X}, 1 \mathrm{X}$, and 10X the recommended technology area-level total). The three estimates are weighted 1, 5, and 1, respectively, to give additional weight to the $1 \mathrm{X}$ estimate, where we expect the relationship between technology cost and RD\&D to be more precisely estimated. While we experimented with methods to also estimate 10th and 90th percentiles of cost as a function of technology area-level $\mathrm{RD} \& \mathrm{D}$, an alternative approach was taken that didn't require a full estimation of the distribution of technology costs at a given level of RD\&D, making this calculation unnecessary.

43 The process described below can be extended to a larger input matrix, and for the applications we conducted, a natural extension would be to the $1200 \times 25$ matrix that includes the BAU, full, and 10-times budget scenarios simultaneously. The methodology described below naturally extends to include all the scenarios under a single set of technology cost-R\&D assumptions (i.e., middle, optimistic, or pessimistic). 


\subsubsection{Inferring technology area $R D \& D$ levels}

To handle the next steps of the estimation process, we had to estimate technology area-level RD\&D levels for the six technology areas $^{44}$ for each of the 400 cases. The challenge of this was to estimate the technology area-level RD\&D level that was most likely, given the technology costs within the technology areas that were actually sampled. This is an inverse probability problem resulting from the fact that the technology costs were sampled on a conditional level of RD\&D (in this case, the 1X level of R\&D in each cluster). This process is necessary to extract additional information from the 400 MARKAL model runs, allowing us to describe each of the 400 cases by the RD\&D portfolio that would have made the sampled technology costs the most likely. This allows for a more dynamic description of the withinsample relationship between $\mathrm{RD} \& \mathrm{D}$ and the output metrics of interest.

Instead of estimating the full distribution of technology costs at a level of $\mathrm{RD} \& \mathrm{D}$, we used a related approach based on the decision-theoretic concept of a loss function. For any proposed level of RD\&D, the "loss" is calculated as the standardized squared error of the observed (sampled) cost from the estimated median cost at that level of RD\&D. The estimated median cost as a function of the RD\&D level is calculated using weighted least squares, as described above, and the standardization factor used was the inverse of the average distance between the $10^{\text {th }}$ and $50^{\text {th }}$ percentiles for observed costs below the estimated median and the inverse of the average distance between the $50^{\text {th }}$ and $90^{\text {th }}$ percentiles for observed costs above the estimated median. Arbitrarily large losses were assigned to proposed RD\&D levels outside of feasible bounds (i.e., negative RD\&D levels). ${ }^{45}$

Within each technology area, the sum of squared losses was calculated and a numerical optimization algorithm was used to find the single level of technology area-level RD\&D that minimized the sum of squared error loss for all of the technologies within an area. For 6 of the 25 technologies, experts estimated flat relationships between technology cost (in the three estimated percentiles) and RD\&D between $1 \mathrm{X}$ and 10X their recommended RD\&D level. These technologies were not included in the summation of squared error loss because the observed costs of these technologies gives no information for what level of RD\&D had been most likely, since the experts had estimated that RD\&D would have no effect on the distribution of costs of these technologies.

This process was repeated for each of the six technology areas, resulting in a $400 \times 6$ matrix of inferred levels of RD\&D at the technology area-level. For several of the technology areas, the distribution of

44 The building results were excluded from this process because in this technology we did not obtain uncertainty estimates from the experts. Therefore the analysis evaluating the optimal funding allocation included 6 instead of 7 technology areas.

45 In initial analyses, we fully estimated the distribution of technology costs at each level of RD\&D and used maximum likelihood to infer the most likely levels of technology area-level RD\&D, taking the technology costs within a single technology area to be independent. This approach proved problematic as the location and scale of technology costs simultaneously changed with the level of RD\&D. This led to perverse outcomes in the implied levels of RD\&D with under-determined systems and unreasonable results. 


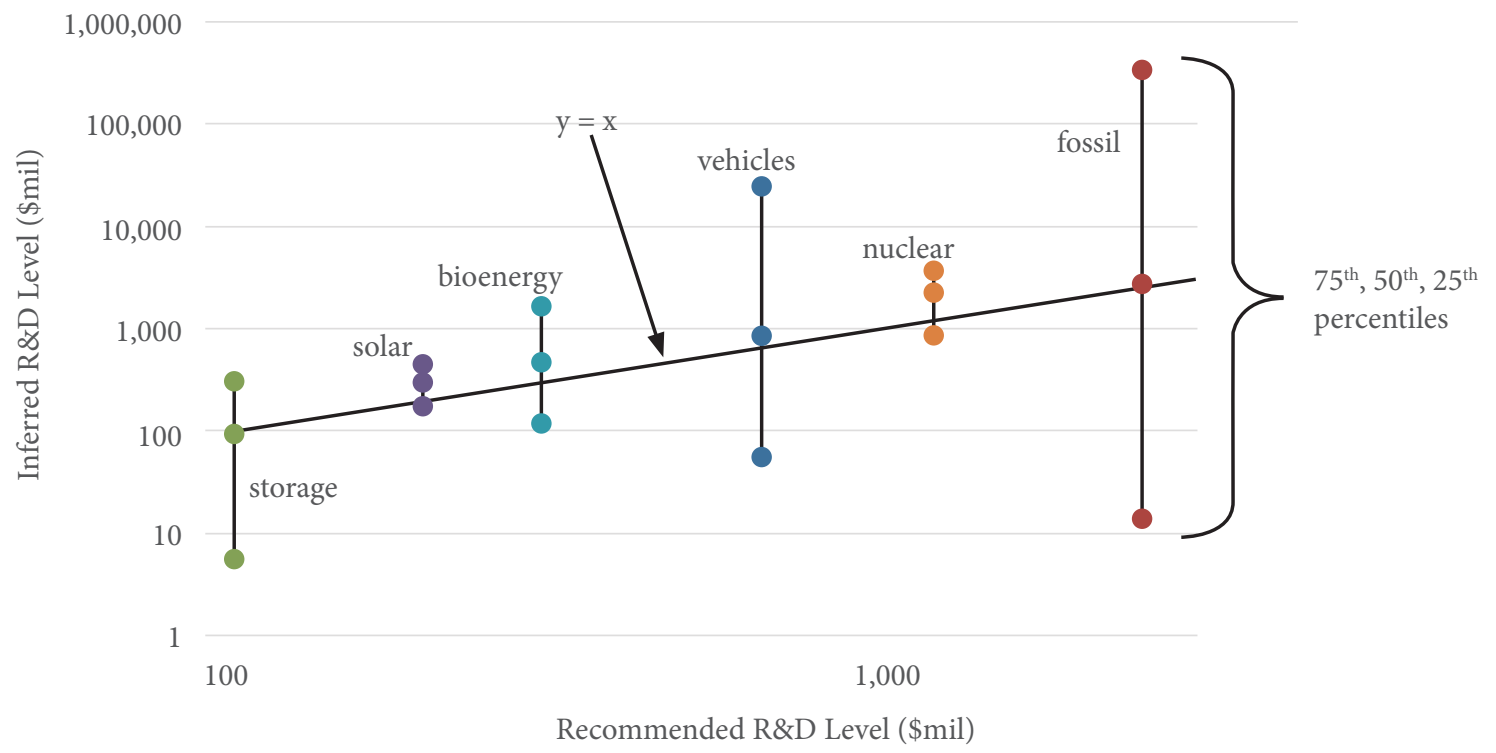

FIGURE 2.33. Recommended technology area RD\&D levels compared to inferred technology area RD\&D levels from minimized squared loss approximation. All six technology areas give implied RD\&D levels near the recommended RD\&D levels, and the inter-quartile range of sampled RD\&D levels covers the recommended level for each technology area.

inferred $\mathrm{RD} \& \mathrm{D}$ levels was very heavily right-skewed. This results from the fact that for many of the expert assessments, the uncertainty (scale) in technology cost at a certain level of RD\&D is substantially greater than the location shift in the distribution of technology cost at different levels of RD\&D. Since high draws from the distribution of technology cost imply near-zero levels of RD\&D, and low draws of technology cost imply infinitely large levels of $\mathrm{RD} \& \mathrm{D}$, the resulting distribution of RD\&D levels is unavoidably right-skewed. As a check on whether the inferred RD\&D levels reasonably correspond to the actual recommendations of the experts (which should occur since this the technology cost data being used is from the $1 \mathrm{X}$ case), Figure 2.33 plots the recommended RD\&D level against the $25^{\text {th }}, 50^{\text {th }}$, and $75^{\text {th }}$ percentiles of the inferred technology costs.

\subsubsection{The technology area $R D \& D$ level-output variable relationship}

After the inferred RD\&D levels are calculated for all six technology areas and for all 400 cases, the resulting $400 \times 6$ matrix is merged with the $400 \times 1$ vector of outcome metrics from the corresponding MARKAL model runs. To reduce bias induced from basing inference on cases with inferred levels of $\mathrm{RD} \& \mathrm{D}$ very far from policy-relevant spaces, all scenarios with at least one inferred technology-area $\mathrm{RD} \& \mathrm{D}$ level greater than twelve times the recommended level is dropped. This leaves 140 of the 400 cases in the middle technology assumptions, full recommended funding level scenario. ${ }^{46}$

46 It is possible to continue the analysis without dropping these cases, but for drawing inference in policy-relevant areas, the tradeoff of better modeling of the tails (far away from politically relevant possibilities) for less precise modeling near the center of the observations is not deemed worthwhile. 
Next, the relationship between the technology area $\mathrm{RD} \& \mathrm{D}$ levels and the outcome metric is modeled with a 73-parameter polynomial surface estimated using least-squares regression. The 73-parameter surface is estimated based on a design matrix with a constant, the log of the six inferred RD\&D levels, the squares of the log of the six inferred RD\&D levels, the interactions of the log of the inferred RD\&D levels with each other, the interactions of the log of the inferred RD\&D levels with the squares of the log of the $\mathrm{RD} \& \mathrm{D}$ levels, and the interactions of the squared $\log$ of the $\mathrm{RD} \& \mathrm{D}$ levels with each other. Estimation of the 73 coefficients that define the 7 -dimensional surface is done with standard least-square estimation.

With the 7-dimensional surface relating the technology-area RD\&D levels and the outcome metric, optimized portfolios are calculated using constrained non-linear multivariable optimization. The function defining the 7-dimensional surface is minimized (or maximized) along the dimension of the outcome metric, allowing the six $\mathrm{RD} \& \mathrm{D}$ levels to vary, but constraining the six $\mathrm{RD} \& \mathrm{D}$ levels to have a sum less than a specified total budget amount.

\subsubsection{Optimizing the RD\&D portfolio under a total funding constraint}

We implemented this methodology to estimate the optimum RD\&D portfolio for three policy cases: no-new-policy, $\mathrm{CO}_{2}$ cap-and-trade, and sectoral policies. Each has its own outcome metric: total $\mathrm{CO}_{2}$ emissions, the $\mathrm{CO}_{2}$ price, and the tradable clean-energy credit price, respectively. We evaluated these policy scenarios under a range of RD\&D budget levels from \$3-10 billion. The outcomes from this methodology are RD\&D budget levels for the six technology areas, both as dollar quantities and as fractions of the total budget.

Tables 2.7 and 2.8 apply this methodology to the $\mathrm{CO}_{2}$ cap-and-trade policy under a wide range of possible RD\&D budgets. Table 2.7 compares the FY 2009 budget allocation in the six technology areas, which totaled $\$ 1.98$ billion, to the RD\&D budget allocations optimized at higher budget levels. Table 2.8 shows the same results but with RD\&D budget allocations expressed as fractions of the total budget. Figure 2.34 presents the data shown in Table 2.8 in graphical form.

Next, we repeat the estimation and optimization steps for other policies. Figure 2.35 shows optimized RD\&D budgets at two total budget levels for the three policies we studied. The figure reveals the relative importance of strategic technologies under different policies. Strikingly, the optimal level of RD\&D of many technology areas varies tremendously depending on the policy.

Because the optimal allocation of $\mathrm{RD} \& \mathrm{D}$ investments to different technology areas is contingent upon policy scenario, and because it is far from clear at which policy scenario we will be in the future (note that it is likely that the future U.S. policy scenario will in fact be different from the ones we modeled), it becomes even more important to have a diversified portfolio along the lines that we have recommended, which is based on the impact of $\mathrm{RD} \& \mathrm{D}$ on technology deployment, as well as insights from the optimizations. 


\begin{tabular}{|c|c|c|c|c|c|c|}
\hline R\&D Level & $\operatorname{trans}$ & fossil & storage & solar & bio & nuclear \\
\hline FY 2009 & 432 & 701 & 23 & 143 & 214 & 466 \\
\hline 3,000 & 1,058 & 831 & 73 & 131 & 124 & 782 \\
\hline 4,000 & 1,228 & 1,366 & 292 & 166 & 173 & 776 \\
\hline 5,000 & 1,416 & 1,875 & 532 & 177 & 198 & 802 \\
\hline 6,000 & 1,592 & 2,392 & 790 & 184 & 215 & 828 \\
\hline 7,000 & 1,754 & 2,915 & 1,062 & 188 & 229 & 852 \\
\hline 8,000 & 1,904 & 3,444 & 1,347 & 191 & 240 & 875 \\
\hline 9,000 & 2,042 & 3,977 & 1,643 & 194 & 248 & 896 \\
\hline 10,000 & 2,170 & 4,514 & 1,947 & 196 & 256 & 917 \\
\hline
\end{tabular}

TABLE 2.7. Comparison of the FY 2009 budget allocation in the six technology clusters to optimized portfolios in terms of minimizing $\mathrm{CO}_{2}$ prices under a $\mathrm{CO}_{2}$ cap policy calculated for higher total R\&D budgets (million 2009\$).

\begin{tabular}{rccccccc}
\hline R\&D Level & trans & fossil & storage & solar & bio & nuclear \\
\hline FY 2009 & 0.22 & 0.35 & 0.01 & 0.07 & 0.11 & 0.24 \\
3,000 & 0.35 & 0.28 & 0.02 & 0.04 & 0.04 & 0.26 \\
4,000 & 0.31 & 0.34 & 0.07 & 0.04 & 0.04 & 0.19 \\
5,000 & 0.28 & 0.38 & 0.11 & 0.04 & 0.04 & 0.16 \\
6,000 & 0.27 & 0.40 & 0.13 & 0.03 & 0.04 & 0.14 \\
7,000 & 0.25 & 0.42 & 0.15 & 0.03 & 0.03 & 0.12 \\
8,000 & 0.24 & 0.43 & 0.17 & 0.02 & 0.03 & 0.11 \\
9,000 & 0.23 & 0.44 & 0.18 & 0.02 & 0.03 & 0.10 \\
10,000 & 0.22 & 0.45 & 0.19 & 0.02 & 0.03 & 0.09
\end{tabular}

TABLE 2.8. Comparison of the FY 2009 budget allocation in the six technology clusters to optimized portfolios in terms of minimizing $\mathrm{CO}_{2}$ prices under a $\mathrm{CO}_{2}$ cap policy calculated for higher total R\&D budgets (fractions of the total budget).

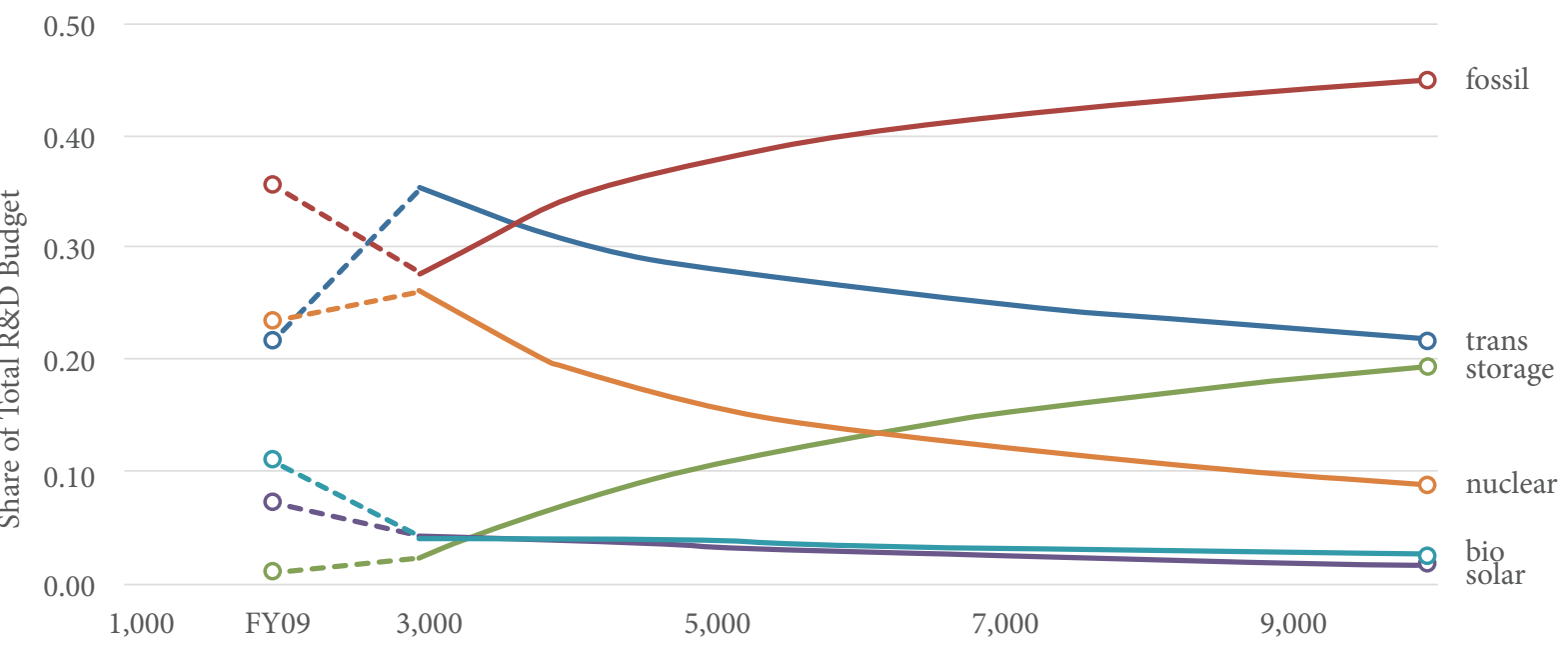

FIGURE 2.34. Fractions of the total RD\&D budget allocated to technology areas for a range of total RD\&D budget levels. 


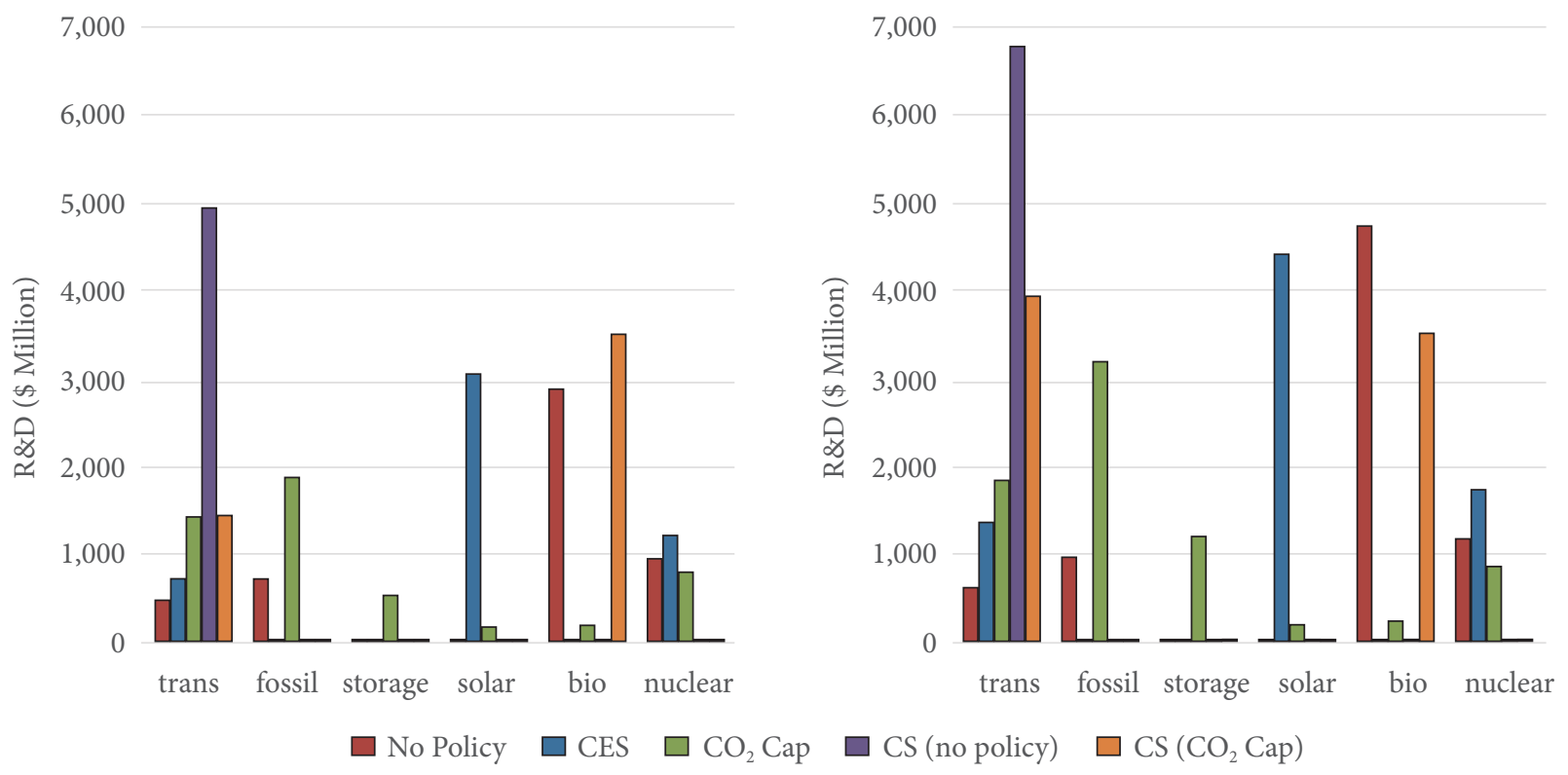

FIGURE 2.35. Optimized budget allocation under different scenarios: no-policy optimized for total $\mathrm{CO}_{2}$ emissions, standards policy (CES) optimized for CES credit price, $\mathrm{CO}_{2}$ cap-and-trade (CO2 cap) optimized for $\mathrm{CO}_{2}$ price, nopolicy optimized for consumer surplus (CS (no-policy)), and $\mathrm{CO}_{2}$ cap-and-trade optimized for consumer surplus (CS (CO2 cap)). The left figure optimizes these scenarios under a $\$ 5$ billion budget and the right figure optimizes the same scenarios under a $\$ 7.5$ billion budget.

\subsubsection{Limitations of this methodology}

As with any other modeling approach, this methodology has limitations. First, future technological breakthroughs are inherently unpredictable, and the experts we surveyed inevitably have limited foresight. The uncertainties we are able to incorporate, for example, are only the uncertainties judged by the experts (and the variations among them); the real uncertainties in outcomes may be much bigger than the experts perceive them to be.

Second, our economic model inevitably incorporates a wide range of assumptions, some of which may prove to be wrong. Some factors are clearly absent from the model, such as the increase in private sector innovation investment focused on ways to reduce carbon emissions that would arise once there was a substantial price on emitting carbon into the atmosphere. Another important element not included in our models is the likelihood that if the United States (and other countries) succeeded in using new technologies to reduce their oil consumption, global oil prices would be reduced, with significant benefits for the U.S. and global economies.

A third factor has to do with the sampling approach used in this section to optimize the portfolios, which leaves out the option value of funding a technology that might turn out to be attractive. We use uncertainty in the estimation of implied RD\&D levels through the loss function, and we capture the uncertainty in the relationship between implied RD\&D levels and outcome variables by using regression over samples. However, once the surface over the RD\&D levels and the outcome variable is calculated, 
all uncertainty drops from the model in the optimization step. We are forced to make this choice because we do not have the means to implement a stochastic optimization algorithm. The consequence of this approach is that the option value of RD\&D investments is not accounted for. Therefore, for technologies with $\mathrm{RD} \& \mathrm{D}$ that affect future technology costs with high variance, $\mathrm{RD} \& \mathrm{D}$ in this technology has high option value, but that will not be reflected in the expected value considered here. Hence, our method understates the value of RD\&D in any area with high uncertainty in future costs.

Fourth, there are a number of key issues that are not incorporated in our modeling. The potential for clean-energy investments to create large numbers of well-paying jobs is clearly an important factor, but given the complexities in estimating how many jobs would be created decades in the future by one investment versus another, we did not attempt to incorporate this issue into our modeling. Similarly, our modeling did not address what fraction of the global market for energy technologies-estimated at tens of trillions of dollars over the next four decades-the United States would be able to supply, in competition with other countries, but it seems clear that increased energy RD\&D will be an important factor in determining what role the United States will play in future energy technology markets. Nor did we attempt to model the benefits for U.S. national security of reduced dependence on oil imports or reduced military dependence on vulnerable fuel supply lines. Perhaps most important, we modeled only deployments in the United States, while many of the technologies that might be developed would have their biggest impacts on reducing carbon emissions or global oil use through their deployments around the world. In all these respects, the modeling in this chapter almost certainly understates, rather than overstates, the case for additional investment in RD\&D.

\subsubsection{Summary of recommendations for the seven technology areas covered by elicitations and modeling}

Table 2.9 includes a summary of FY 2009 appropriations from DOE, statistics of the RD\&D recommendations of the experts in each technology area (mean and standard deviation, median value, maximum value, and minimum value), recommended values of the experts chosen for the scenarios with middle, optimistic, and pessimistic technology assumptions, RD\&D funding recommendations from this report, and the percentage change in recommendations over FY 2009 appropriations. It shows that while the largest absolute recommended investments would go to nuclear, vehicles, and fossil and CCS, the largest percentage increases would go to energy storage, buildings, bioenergy, and solar PV. As discussed previously, funding for fossil and CCS should probably be increased if there are no expectations of nuclear energy expansion. The recommendations for RD\&D investment by technology area are based on technology deployment results under the different funding and policy scenarios (section 2.8.2) and on insights of the optimization of RD\&D allocation under different policy scenarios (section 2.8.3). 
Overall, the ERD3 recommended budget for these seven technology areas would be 2.5 times the FY 2009 appropriation. Table 2.9 shows that while the largest absolute recommended investments would go to nuclear, vehicles, and fossil and CCS (these technologies are capital intensive and some of them are closer to commercialization), the largest increases in terms of percentage change would go to energy storage, buildings, bioenergy, and solar PV. Funding for fossil and CCS should probably be increased further if policymakers do not expect nuclear energy expansion. Note that the sum of the FY 2012 budget request for the seven technology areas was $\$ 2.7$ billion, which means that the recommended increase to $\$ 5.2$ billion is just under twice the FY 2012 request.

This level of investment under a no-policy case would decrease $\mathrm{CO}_{2}$ emissions and oil imports significantly by 2050 when compared to the BAU funding scenario. Subject to our modeling results and assumptions, we can make a conservative estimate of the impact of the recommendation on some of the benefits by assuming that the ERD3 recommended portfolio (which takes into account the results of the optimization in section 2.8.3) has the impact of the portfolio recommended by the middle experts. Median emissions would be reduced from 16\% above those in 2010 under the BAU scenario to less than 12\% above those in 2010 under the ERD3 recommended scenario. Median oil imports would be $2 \%$ below 2010 levels under the BAU scenario, and almost 11\% below 2010 levels under the ERD3

\begin{tabular}{|c|c|c|c|c|c|c|c|c|c|c|}
\hline $\begin{array}{l}\text { DOE } \\
\text { program }\end{array}$ & $\begin{array}{l}\text { FY } \\
2009 \\
\text { appr. }\end{array}$ & $\begin{array}{l}\text { Mean of } \\
\text { experts } \\
\text { (std. dev.) }\end{array}$ & $\begin{array}{l}\text { Median of } \\
\text { experts }\end{array}$ & $\begin{array}{c}\text { Min } \\
\text { of experts }\end{array}$ & $\begin{array}{c}\text { Max } \\
\text { of experts }\end{array}$ & $\begin{array}{c}\text { Middle } \\
\text { expert }\end{array}$ & $\begin{array}{l}\text { Optim. } \\
\text { expert }\end{array}$ & $\begin{array}{c}\text { Pessim. } \\
\text { expert }\end{array}$ & $\begin{array}{l}\text { ERD3 } \\
\text { recs. }\end{array}$ & $\begin{array}{c}\text { Percent } \\
\text { change over } \\
\text { FY } 2009 \text { appr. }\end{array}$ \\
\hline $\begin{array}{l}\text { Bio- } \\
\text { energy }\end{array}$ & 214 & $680(286)$ & 640 & 300 & 1,000 & 300 & 600 & 680 & 680 & $218 \%$ \\
\hline $\begin{array}{l}\text { Energy } \\
\text { storage }\end{array}$ & $23^{a}$ & $240(391)$ & 120 & 50 & 2,000 & 103 & 128 & 103 & 240 & $943 \%$ \\
\hline Nuclear & 466 & $\begin{array}{c}1800 \\
(1,397)\end{array}$ & 1,200 & 800 & 8,000 & 1,200 & 8,000 & 1,200 & 1,200 & $158 \%$ \\
\hline $\begin{array}{l}\text { Fossil and } \\
\text { CCS }\end{array}$ & 701 & $\begin{array}{c}2300 \\
(1,980)\end{array}$ & 2,000 & 600 & 7,500 & 1,550 & 1,550 & 7,500 & 1,000 & $43 \%$ \\
\hline Buildings & 144 & $680(315)$ & 700 & 200 & 1,000 & 900 & 1,000 & 500 & 680 & $372 \%$ \\
\hline $\begin{array}{l}\text { Vehicles } \\
\text { (inc. fuel } \\
\text { cells) }\end{array}$ & 432 & $\begin{array}{c}2050 \\
(3,050)\end{array}$ & 1,000 & 400 & 10,000 & 650 & 1,000 & 650 & 1,000 & $131 \%$ \\
\hline Solar PV & 143 & $\begin{array}{c}337 \\
(226)\end{array}$ & 300 & 200 & 1,000 & 200 & 500 & 300 & 400 & $180 \%$ \\
\hline Total & 2,123 & 8,159 & 5,960 & 2,350 & 29,500 & 4,903 & 12,778 & 10,933 & 5,200 & $145 \%$ \\
\hline
\end{tabular}

TABLE 2.9. Summary information for areas covered by elicitations. From left to right: FY 2009 appropriations from DOE; statistics of the RD\&D recommendations of experts in each technology area (mean and standard deviation, median value, maximum value, and minimum value); recommended values of the experts chosen as middle, optimistic, and pessimistic; recommendations from this report; and percentage change in recommendations over FY 2009 appropriations. All numbers are in million U.S.2010\$. 
recommended budget. Under the $\mathrm{CO}_{2}$ cap and using the middle assumptions, the ERD3 recommended $\mathrm{RD} \& \mathrm{D}$ levels would result in a 50\% probability that $\mathrm{CO}_{2}$ prices in 2030 will be below $\$ 100$ per ton $\mathrm{CO}_{2}$ (under the $\mathrm{BAU}$ scenario, the probability of $\mathrm{CO}_{2}$ prices being below $\$ 100$ per ton $\mathrm{CO}_{2}$ would only be 5\%). ${ }^{47}$ Using the optimistic assumptions under the BAU scenario, there would be just under a 5\% probability that $\mathrm{CO}_{2}$ prices in 2030 being above $\$ 100$ per ton $\mathrm{CO}_{2}$, with a median $\mathrm{CO}_{2}$ price of $\$ 78$ per ton; under the ERD3 recommended budget there would be less than a $5 \%$ probability that $\mathrm{CO}_{2}$ prices would be above $\$ 70$ per ton. The ERD3 recommended budget provides a no regrets answer in so far as we do not know whether there will be no carbon policy, a $\mathrm{CO}_{2}$ cap policy, or a clean-energy standard. However, we stress that, given the inputs from the expert elicitations and the modeling work, there is an absolute need to put in place a demand-side policy to reduce greenhouse gas emissions to achieve any significant reductions.

\subsubsection{Estimates of RD\&D investments for areas not covered by the elicitations}

Even though we did not cover all technology areas or DOE programs supporting energy RD\&D, we complement the recommendations in Table 2.9 with a much more limited analysis of funding for other energy RD\&D areas. We thought that the recommendations would be more valuable if they encompassed a more complete picture of the U.S. government's activities in energy RD\&D through its main funding agency, DOE. However, we recognize that there is a tradeoff, as we do not have estimates of the benefits of our funding recommendations in the areas not covered by the elicitations and the modeling.

Table 2.10 summarizes the FY 2009 appropriations for the applied RD\&D areas not covered by the seven energy elicitations, ARPA-E, the Basic Energy Sciences program, and the fusion program. We introduced a placeholder for the program direction cost, as we have insufficient information to determine how funding for program administration at DOE should increase with increases in funding for RD\&D.

We now discuss the reasons why we recommend increasing the combined funding for the areas above from $\$ 3.1$ billion in FY 2009 to $\$ 4.8$ billion for FY 2012 (a 57\% increase, compared to a 145\% increase in total funding for the areas covered by our detailed work; a different approach would have been to recommend increasing funding in the areas not covered by the elicitations and the modeling by $145 \%$, but we felt unable to make a recommendation about allocation using this approach). Thus, our recommendation includes $\$ 5.2$ billion for the seven technology areas covered by the elicitations and $\$ 4.8$ billion for the other DOE programs (including ARPA-E and Basic Energy Sciences), for a total recommendation of $\$ 10$ billion.

47 The discussion of probability in this section only accounts for the middle or optimistic experts' estimates of uncertainty around the cost and performance of technologies in 2030, and the impact of RD\&D on this cost and performance. Clearly economic growth, oil prices, the weather, and such factors also play a role on $\mathrm{CO}_{2}$ prices, for example. 


\begin{tabular}{|c|c|c|c|c|c|}
\hline \multicolumn{2}{|l|}{ Program } & $\begin{array}{l}\text { FY } 2009 \\
\text { appropriation }\end{array}$ & FY 2012 request & $\begin{array}{l}\text { ERD3 } \\
\text { recommendation }\end{array}$ & $\begin{array}{l}\text { Percentage change } \\
\text { over FY } 2012 \text { Request }\end{array}$ \\
\hline \multirow{7}{*}{$\begin{array}{l}\text { Applied } \\
\text { RD\&D } \\
\text { programs not } \\
\text { covered by } \\
\text { elicitations }\end{array}$} & Wind & 79 & 127 & 127 & $0 \%$ \\
\hline & Non-PV solar ${ }^{\mathrm{a}}$ & 29 & 120 & 120 & $0 \%$ \\
\hline & Geothermal & 43 & 102 & 102 & $0 \%$ \\
\hline & Water power & 49 & 39 & 39 & $0 \%$ \\
\hline & Industry & 94 & 320 & 320 & $0 \%$ \\
\hline & $\begin{array}{l}\text { Transmission and } \\
\text { distribution } \\
\text { (exc. storage) }\end{array}$ & 117 & 151 & 233 & $55 \%$ \\
\hline & Program direction ${ }^{\mathrm{b}}$ & 371 & 467 & $500^{c}$ & $7 \%$ \\
\hline \multicolumn{2}{|l|}{ ARPA-E } & $389^{\mathrm{d}}$ & 550 & 600 & $9 \%$ \\
\hline \multicolumn{2}{|c|}{ Basic Energy Sciences } & 1,536 & 1,985 & 2,400 & $21 \%$ \\
\hline \multicolumn{2}{|l|}{ Fusion } & 380 & 400 & 400 & $0 \%$ \\
\hline \multicolumn{2}{|l|}{ TOTAL } & 3,087 & 4,259 & 4,841 & $14 \%$ \\
\hline \multicolumn{6}{|c|}{$\begin{array}{l}\text { Includes: concentrating solar power ( } \$ 50 \text { million), systems integration, and market transformation (standards, } \\
\text { operability, training). }\end{array}$} \\
\hline \multicolumn{6}{|c|}{ b Includes direction for EERE, FE, NE, and OE corresponding to RD\&D budgets as shown in Gallagher \& Anadon (2011). } \\
\hline \multicolumn{6}{|c|}{$\begin{array}{l}\text { This value is a placeholder. We are unsure of the economies of scale involved in increasing the size of the research pro- } \\
\text { grams. Therefore we tentatively recommend an increase over the FY 2012, although this amount should be crafted. }\end{array}$} \\
\hline $\begin{array}{l}\text { Funding } \\
\text { Reinvest }\end{array}$ & ARPA-E in 2009 did & come from the & $\begin{array}{l}\text { rmal appropriatic } \\
\text { the stimulus pack }\end{array}$ & $\begin{array}{l}\text { s process. Instead it } \\
\text { ge. }\end{array}$ & came from the American \\
\hline
\end{tabular}

TABLE 2.10. Summary of FY 2009 appropriations, FY 2012 requests, ERD3 recommendations, and percentage change of recommendation over the FY 2012 request for applied RD\&D programs not covered by the elicitations, ARPA-E, Basic Energy Sciences, and fusion.

\section{Wind}

Funding for wind RD\&D should be consistent with the FY 2012 request of $\$ 127$ million. This represents an increase of \$48 million over the FY 2009 appropriation. While many of the breakthroughs in wind technology have already been made, this modest increase is justified by the remaining potential of wind, as indicated by the section on "technology improvements on the horizon" in DOE's " $20 \%$ Wind Energy by 2030" study (DOE 2008). These improvements include rotor and blade design, improvement in active controls and the drivetrain, and innovations in tower construction. With continued funding, government innovation institutions such as the national labs can provide equipment for testing wind turbines and components, contributing to private-sector development. 


\section{Non-PV solar}

We recommend increasing funding for non-PV solar research (i.e., concentrating solar power, systems integration, market transformation, and other innovative non-PV technologies) to $\$ 120$ million, the FY 2012 request. This corresponds to a 4-fold increase in funding over the FY 2009 levels, which is consistent with the recommended increase in solar PV.

\section{Geothermal}

We recommend increasing funding for geothermal RD\&D from \$43 million in FY 2009 to the \$102 million in the FY 2012 budget request. This increase by a factor of 2.4 is granted based on the large potential of enhanced geothermal systems (EGS). The MIT Future of Geothermal Energy report (MIT 2006) found that, "with a reasonable investment in R\&D, EGS could provide 100 GWe or more of costcompetitive generating capacity in the next 50 years" and that increasing federal support for geothermal RD\&D on the range of $\$ 55$ million (2011\$) per year for 15 years could provide "performance verification at a commercial scale" within that time frame. Given that funding has been below this threshold since the study was released in 2007, we recommend increasing funding in FY 2012 and beyond to almost twice the funding recommended by the MIT study.

\section{Water program}

We have seen little analysis on the water program, which is why we limit ourselves to recommending funding levels consistent with the FY 2012 request, which is \$39 million (a small decrease over FY 2009 levels).

\section{Industrial efficiency}

We also recommend increasing funding for industrial efficiency RD\&D from $\$ 92$ million in FY 2009 to $\$ 320$ million in FY 2012. By tackling energy-intensive industries and technologies that benefit multiple industries, the industrial technologies program can result in significant energy efficiency improvements in the industrial sector, which used about 28\% of total energy in the United States in 2009.

\section{Transmission and distribution and smart grids}

We recommend doubling funding for transmission and distribution and smart grids from $\$ 117$ million (this number excludes storage) in FY 2009 to \$233 million in FY 2012. This increase is 55\% greater than the FY 2012 budget request. We recommend larger funding because improving transmission and accelerating the modernization of the grid can spur significant innovations and leverage more renewable electricity generation. It is important to prevent the large investments in smart grid demonstrations ( $\$ 3.4$ billion) made in the stimulus package from ending without any follow-on research. 
ARPA-E

We also recommend increasing funding for ARPA-E beyond the $\$ 550$ million in the FY 2012 request to $\$ 600$ million. This is a significant increase over the $\$ 389$ million devoted to ARPA-E in 2009 under the stimulus package, and is a very important part of the U.S. energy innovation system. Funding should not be cut to $\$ 100$ million, as recommended by the House Committee on Appropriations. This would be very detrimental to a new agency that has already demonstrated its effectiveness and nimbleness, and that has been shown to leverage private-sector dollars.

\section{Basic Energy Sciences}

The Basic Energy Sciences program, with its Energy Frontier Research Centers, should be granted \$2.4 billion, which is $\$ 400$ million above the FY 2012 budget request level of just under $\$ 2$ billion. By focusing on fundamental science with energy applications, the program is laying the foundations for future breakthroughs. Combustion, materials science, sensors, catalysis, and other topics can have enormous implications for energy and also for other sectors through technology spillovers. Basic research has been found to be particularly fruitful in producing new industries and spillovers, and we believe it is important to grow this part of DOE's portfolio. Given the large benefits of basic research, a few years down the line it would be important to reconsider an additional increase for the BES program.

\section{Fusion}

Even though fusion is very unlikely to play a role in the U.S. energy system in the 2030-2050 timeframe, it could play a role in the second half of the century. Given that the payoffs of fusion could be large, some effort on fusion RD\&D should be maintained. We recommend cutting funding for fusion from the $\$ 400$ million of the FY 2009 appropriation to $\$ 380$ million, consistent with the FY 2012 budget request. Our recommendation is based on the request, under the assumption that it represents the minimum amount required to maintain a vigorous effort without compromising funding for technologies that should play a role in the short term.

\section{Commercial-Scale Technology Demonstrations}

As we have discussed elsewhere (Narayanamurti et al. 2011), in some cases there is a compelling need for public-private partnerships to support commercial-scale demonstration of a new technology, when it is at a stage where it is almost ready for commercial deployment but the risk is still too high for the project to be financed in private markets. New institutional approaches may be needed for such demonstrations (see Box in Chapter 4). Such demonstrations are likely to be expensive-potentially in the range of billions of dollars for a single project-and the government and the private sector are both likely to have to contribute. While the experts we surveyed allocated small amounts of money to 
demonstrations in their recommendations, the overall funding recommendations just described may not be sufficient to support the full range of large-scale demonstrations that may be needed; funding for an institution intended to carry out such demonstrations might have to be provided in addition to the funding recommended above.

\subsubsection{Total budget recommendation}

In total, we recommend increasing funding for energy RD\&D (including basic research and applied RD\&D) from $\$ 5.4$ billion in FY 2009 (excluding funding in the stimulus package, with the exception of funding for ARPA-E) to $\$ 10$ billion. As new technological possibilities are explored, it may be desirable to increase funding even further. It could also be the case that if a sufficiently strong low-carbon deployment policy is put in place-which, we have argued, is essential to reduce emissions and oil imports to levels consistent with the science of climate change and with the President's goal of reducing oil imports by $33 \%$ by 2021 - after a few years, private actors would be undertaking sufficient innovation so as to reduce somewhat the need for government investments. However, the impact of a $\mathrm{CO}_{2}$ cap or sectoral policies (such as those studied in this work) on technology outcomes or private sector innovation levels are unknown, which means that even if such a policy was implemented it would not be desirable to reduce funding beyond the levels recommended until more evidence is gathered. Furthermore, greater $\mathrm{RD} \& \mathrm{D}$ investments may be justified, as our work did not cover all technology areas, and technological opportunities may become available in the future that the experts we surveyed were not able to envision.

Over time, as more technological pathways are explored, the allocation across technology areas would change, but the recommended allocation should be maintained (at least approximately) for at least 4-5 years to allow programs to gather sufficient information to make decisions about increasing the focus of $\mathrm{RD} \& \mathrm{D}$ efforts in some technologies. Our recommended increased investment should be targeted on a broad portfolio of different technologies and different stages of technology, from basic research to largescale technology demonstrations, and implemented by a portfolio of different institutions appropriate for the different types of innovation (e.g., ARPA-E, the Energy Innovation Hubs, the EFRCs, etc.). It is also essential that policy makers understand that innovation is an uncertain enterprise, and that as a result some failures are to be expected. In fact, if all government programs in ERD\&D succeeded, it would be an indication that the government is not taking sufficient risks - i.e., that it was probably supporting many activities that the private sector would be doing anyway.

The coordination between ERD\&D programs and demand-side programs is also important. Currently, the U.S. government is making large investments in deployment policies ranging from tax subsidies to loan guarantees, often with little coordination with energy research and development programs, and using standards (e.g., vehicle economy standards). To maximize the contribution of federal investments and standards to accelerating energy innovation, these efforts should be closely coordinated, with targeted and appropriate support for each phase of innovation from basic research to initial deployment. 
Federal support should be phased out as technologies become commercially viable, rather than continuing indefinitely. To enable the phase-down of government support for programs or specific projects, the U.S. government should have clear goals and mechanisms to collect and evaluate information about the progress and contribution of projects and technologies from the start. Support programs can also be designed to decrease gradually over time, and to include covenants that allow for program changes based on new information.

\subsubsection{Investing for the future in a time of budget constraints}

We are, of course, aware that the United States faces severe budget constraints. But long-term investments in the U.S. energy future must not be sacrificed to short-term budget expediency. As the modeling in this chapter has shown, there are strong reasons to believe that every dollar of increased annual investment in energy RD\&D today would result in tens or hundreds of dollars in annual savings to the U.S. energy economy in 2050. Expanded investments in energy RD\&D are likely to be essential if we are to avoid climate catastrophes at reasonable cost—and, as just discussed, are likely to also have substantial benefits for U.S. jobs, U.S. competitiveness in the huge coming markets for energy technologies, and U.S. national security.

If, in the current environment, it is too difficult to provide expanded, stable investments through the normal budget process, there are a variety of other options for raising additional funds for ERD\&D, some of which have been implemented successfully on a smaller scale in the past. For example, the Gas Research Institute (GRI), which funded RD\&D managed by a board that included both industry and government representatives, was established with a small charge on interstate transportation of natural gas, approved by the Federal Energy Regulatory Commission (FERC) and supported by industry. In one case managed by GRI, a small amount of RD\&D in coal-bed methane, coupled with tax incentives to encourage initial deployments of the technology, led to a large new source of U.S. natural gas production, worth many times the amount invested. Such off-budget opportunities should be considered and pursued as complements to funding provided through the regular appropriations process.

\subsection{Recommendations for the Budget Decision-Making Process}

\subsubsection{Recommendations from this chapter}

While the level and allocation of RD\&D funding is important, we also realize the importance of other aspects of the budget-making process. Therefore, we make the following recommendations, based on our work and feedback from experts and stakeholders:

- Congress and the administration should work together to design approaches that will provide increased budget stability for these programs from year to year. The volatility in spending from one year to the next reduces the efficiency of $\mathrm{RD} \& \mathrm{D}$ programs. The bipartisan cooperation usu- 
ally maintained in the Energy and Water appropriations subcommittees should be sustained and built on, possibly including the creation of bipartisan task forces focused on particular areas of energy technology.

- $\quad$ Energy RD\&D funding should be coordinated with deployment subsidies, standards, and regulations. Deployment policies include tax subsidies, loan guarantees, renewable fuel standards, and vehicle fuel efficiency standards. To maximize the contribution of federal investments to accelerating energy innovation, these efforts should be closely coordinated, with targeted and appropriate support for each phase of innovation from basic research to initial deployment. Federal support should be phased out as technologies become commercially viable, rather than continuing indefinitely.

- The budget decision-making process should incorporate uncertainty about technical outcomes, market prices, and policies.

- Budget decision-makers should seek input from both technical and market-oriented technology experts from different technology areas.

- If expert elicitations are to be used, it is essential to streamline the process as much as possible. This work took approximately four months per elicitation, with the first elicitations requiring seven months. Delays were due primarily to incomplete responses from experts, requiring follow-up phone calls by researchers. Elicitations done online through the web significantly shortened the process. Interactive, real-time displays of an expert's responses helped experts correct mistakes immediately, avoiding follow-up phone calls from researchers. Experts also had access to researchers while completing online elicitations if necessary. These features provided a good compromise between interactive tools and access to clarification.

- Stakeholder meetings throughout the process are important and useful, especially in improving trust in the process and in gaining valuable insight.

- Going forward, it is important to identify other research areas and other industries that may have technologies that could result in significant reductions in GHG emissions and increased energy security.

\subsubsection{Cross-cutting recommendations from the full report}

As we pursued our research, several themes arose repeatedly. We believe these principles are important to improve the effectiveness of U.S. energy innovation policy.

The first of these themes is the need for stable long-term policies that allow industry to plan and make investments, and that provide researchers with time to collect sufficient information and to explore dif- 
ferent research avenues efficiently. The Quadrennial Technology Review that DOE was undertaking at the time of writing this report is a first step that can help provide more stability by identifying multi-year programs for different technologies. Long-term stability is also needed for policies to pull technologies into the marketplace, such as standards or carbon prices.

The second theme is the need for improved coordination between agencies. Again, the Quadrennial Technology Review will help provide coordination within DOE, but ultimately a government-wide review (such as the Quadrennial Energy Review recommended by the President's Committee of Advisors in Science and Technology) will be needed to align DOE programs with government-wide initiatives. For example, a price on carbon or a clean-energy standard will affect private sector activity in energy innovation and the investments that DOE should make.

The third theme is the need to have a balanced portfolio of: (a) investments in different technologies; (b) investments in different stages of technology development; and (c) mechanisms to interact with the private sector and universities. The outcome of innovation is uncertain, and as a result managing risks requires spreading bets across a range of projects and expecting some failures. At the same time, given that budgets are constrained and bets that are too small are unlikely to yield results, not everything can be supported.

A fourth theme that emerged was the need to strengthen the interaction between the government and the private sector. Although members of the private sector testify to Congress, participate in advisory boards, and respond to requests for information, it would be useful to integrate private sector perspectives more fully in the design of policies and research programs. An extended use of advisory boardssuch as the Energy Innovation Advisory Board we propose-could help strengthen the connections between the public and private sectors.

And fifth, our research indicated that there is a lot of work to be done to design an energy technology innovation strategy that is guided by learning. Today, program managers are often unaware of which approaches worked and which did not in areas related to their own, making it difficult to strengthen these efforts by learning lessons from past experience. Much more work can be done to collect and analyze data on the different approaches that are being implemented, and to determine which ones seem to work best, and under what circumstances. For example, better information is needed for program planning and the budget process. Information required includes: (1) the portfolio of mechanisms and projects that are in place; (2) multi-year program plans that take into account what capabilities and resources will be needed; (3) managers' experience with what partners are able to contribute and what DOE has to contribute, which is as important as the state of technology in deciding what actions to take; (4) the pace of technology development and the challenges that are being encountered by those involved in projects; and (5) the impacts of the programs. ARPA-E is placing an increased emphasis on self-evaluation and data collection, and is an example of an institution that is adopting this "learning" principle. 


\section{REFERENCES}

Al-Juaied, M. \& Whitmore, A. (2009). Realistic costs of carbon capture, Discussion Paper \#2009-08. Energy Technology Innovation Policy group. Belfer Center for Science and International Affairs. Harvard Kennedy School, Cambridge, MA, United States.

American Energy Innovation Council (2010). A Business Plan for America's Energy Future. Full Report. Available at: http://www.americanenergyinnovation.org/full-report [2011, 09/20].

Anadon, L.D. \& Holdren, J.P. (2009). “Chapter 5: Policy for Energy-Technology Innovation.” In Acting in Time on Energy Policy. Gallagher K.S. (Ed). The Brookings Press, Washington D.C., United States.

Anadon, L.D., Bunn, M., Chan, G., Chan, M., Gallagher, K.S., Jones, C., Kempener, R., Lee, A. \& Narayanamurti, V. (2010). DOE FY 2011 Budget Request for Energy Research, Development, Demonstration, and Deployment: Analysis and Recommendations, Energy Technology Innovation Policy research group, Belfer Center for Science and International Affairs, Harvard Kennedy School.

APS. (2008). Energy Future: Think Efficiency. How America Can Look Within to Achieve Energy Security and Reduce Global Warming, American Physical Society. Available at: http://www.aps.org/ energyefficiencyreport/ [2011,09/20].

Baker, E., Chon, H. \& Keisler, J. (2010). "Battery technology for electric and hybrid vehicles: Expert views about prospects for advancement", Technological Forecasting and Social Change, vol. 77, no. 7, pp. 1139-1146.

Baker, E., Chon, H. \& Keisler, J. (2009a). “Advanced solar R\&D: Combining economic analysis with expert elicitations to inform climate policy", Energy Economics, vol. 31, pp. 537-549.

Baker, E., Chon, H. \& Keisler, J. (2009b). "Carbon capture and storage: combining economic analysis with expert elicitations to inform climate policy", Climatic Change, vol. 96, no. 3, pp. 379-408.

Baker, E., Chon, H. \& Keisler, J. M. (2008). Advanced Nuclear Power: Combining Economic Analysis with Expert Elicitations to Inform Climate Policy, Social Science Research Network. Available at: http://papers.ssrn.com/sol3/papers.cfm?abstract_id=1407048 [2010, 01/18].

Baker, E. \& Keisler, J. (2009). Cellulosic Biofuels: Expert Views on Prospects for Advancement. Available at: http://www.ecs.umass.edu/mie/faculty/baker/CellulosicBiofuels.pdf [2010, 01/18].

Bird, L., Chapman, C., Logan, J., Sumner, J. \& Short, W. (2010). Evaluating Renewable Portfolio Standards and Carbon Cap Scenarios in the U.S. Electric Sector, National Renewable Energy Laboratory. U.S. Department of Energy. Washington D.C., United States.

Blanford, G.J. (2009). "R\&D investment strategy for climate change”, Energy Economics, vol. 31, no. 1, pp. S27-S36. 
Bolinger, M., Wiser, R., Cory, K. \& James, T. (2009). PTC, ITC, or Cash Grant? An Analysis of the Choice Facing Renewable Power Projects in the United States, Lawrence Berkeley National Laboratory and National Renewable Energy Laboratory. U.S. Department of Energy.

Bosetti, V., Carraro, C., Duval, R., Sgobbi, A. \& Tavoni, M. (2009). The Role of R\&D and Technology Diffusion in Climate Change Mitigation: New Perspectives Using the Witch Model, Fondazione Eni Enrico Mattei, Venice.

Brown, M.A., Southworth, F. \& Stovall, T.K. (2005). Towards a Climate-Friendly Built Environment, Pew Center on Global Climate Change, Washington D.C., United States.

Brown, M.A. (2001). "Market failures and barriers as a basis for clean energy policies", Energy Policy, vol. 29, pp. 1197-1207.

Chan, G., Anadon, L.D., Chan, M. \& Lee, A. (2010). "Expert Elicitation of Cost, Performance, and RD\&D Budgets for Coal Power with CCS”, Energy Procedia, vol. vol. 4, pp. 2685-2692.

Clarke, J., Weyant, J. \& Birky, A. (2006). “On the sources of technological change: Assessing the evidence", Energy Economics, vol. 28, pp. 579-595.

Cooke, R.M. (1991). Experts in uncertainty: opinion and subjective probability in science, Oxford University Press, New York, United States.

Craig, P.P., Gadgil, A. \& Koomey, J.G. (2002). "What Can History Teach Us: A Retrospective Examination of Long-Term Energy Forecasts for the United States", Annual Review of Energy and Environment, vol. 27, pp. 83-118.

Curtright, A.E., Morgan, M.G. \& Keith, D.W. (2008). “Expert Assessments of Future Photovoltaic Technologies", Environmental Science \& Technology, vol. 42, no. 24, pp. 9031-9038.

Dalkey, N.C. (1969). The Delphi method: an experimental study of group opinion, RAND, Santa Monica, California, United States.

Davis, G.A. \& Owens, B. (2003). “Optimizing the level of renewable electric R\&D expenditures using real options analysis", Energy Policy, vol. 31, pp. 1589-1608.

Denholm, P., Margolis, R. (2008). Supply Curves for Rooftop Solar PV-Generated Electricity for the United States. National Renewable Energy Laboratory. U.S. Department of Energy Technical Report. NREL/TP-6A0-44073. November. Available at: www.nrel.gov/docs/fy09osti/44073.pdf [2011, 07/21].

DOE (2008). "20\% Wind Energy by 2030.” Office of Energy Efficiency and Renewable Energy.

U.S. Department of Energy. Washington, D.C. July. Available at: http://www.nrel.gov/docs/ fy08osti/41869.pdf [2011, 07/21]. 
DSIRE 2010, Renewable Electricity Production Tax Credit (PTC). Database of State Incentives for Renewables \& Efficiency. Available at: http://www.dsireusa.org/incentives/incentive. cfm?Incentive_Code=US13F [2011, 01/04].

EERE (2008). 20\% Wind Energy by 2030: Increasing Wind Energy's Contribution to U.S. Electricity Supply, Office of Energy Efficiency and Renewable Enegy. U.S. Department of Energy, Washington D.C., United States.

EIA (2011a). Natural Gas - Data. U.S. Energy Information Administration. U.S. Department of Energy. Washington D.C., United States. Available at: http://www.eia.gov/dnav/ng/ng_pri_sum_dcu_ nus_a.htm [2011,07/24].

EIA (2011b). Petroleum \& Other Liquids - Data. U.S. Energy Information Administration. U.S. Department of Energy. Washington D.C., United States. Available at: http://www.eia.gov/dnav/ pet/PET_PRI_WCO_K_W.htm [2011, 07/24].

EIA (2011c). Annual Energy Review - Electricity. U.S. Energy Information Administration. U.S. Department of Energy. Table 8.11b. Washington D.C., United States. Available at: http://www.eia. gov/emeu/aer/elect.html [2011,07/22]

EIA (2010a). Annual Energy Outlook 2010 with projections to 2035, Energy Information Administration. U.S. Department of Energy, Washington D.C., United States.

EIA (2010b). Annual Energy Outlook 2011 Early Release Report. Report No: DOE/EIA-0383ER(2011) [Homepage of Energy Information Administration. U.S. Department of Energy], [Online]. Available at: http://www.eia.doe.gov/forecasts/aeo/index.cfm [2011, 01/23].

EIA (2010c). Annual Energy Review. Report No: DOE/EIA-0384(2009), Energy Information Administration. U.S. Department of Energy, Washington, DC, USA.

EIA (2010d). Assumptions to the Annual Energy Outlook 2010, Energy Information Administration. U.S. Department of Energy, Washington D.C., United States.

EIA (2010e). Buildings Energy Data Book [Homepage of Energy Information Administration. U.S. Department of Energy]. Available at: buildingsdatabook.eren.doe.gov/TableOfContents.aspx [2011, 07/2011].

EIA (2009). Energy Market and Economic Impacts of H.R. 2454, the American Clean Energy and Security Act of 2009, Energy Information Administration. U.S. Department of Energy, Washington D.C., United States.

Fischer, C. \& Newell, R.G. (2008). "Environmental and technology policies for climate mitigation", Journal of Environmental Economics and Management, vol. 55, pp. 142-162. 
Fishbone, L.G. \& Abilock, H. (1981). "MARKAL, a linear-programming model for energy systems analysis: Technical description of the BNL version", International Journal of Energy Research, vol. 5, no. 4, pp. 353-375.

Gallagher, K.S. \& Anadon, L.D. (2011). DOE Budget Authority for Energy Research, Development, \& Demonstration Database. Available at: http://belfercenter.ksg.harvard.edu/publication/20807/ [2011, 05/20].

Gallagher, K.S., Holdren, J.P. \& Sagar, A.D. (2006). “Energy-Technology Innovation”, Annual Review of Environmental Resources, vol. 31, pp. 193-237.

Garcia, M.L. \& Bray, O.H. (1997). Fundamentals of Technology Roadmapping, SAND97-0665. Sandia National Laboratories. April. Albuquerque, New Mexico, United States.

Geels, F.W., Hekkert, M.P. \& Jacobsson, S. (2008). “The dynamics of sustainable innovation journeys”, Technology Analysis \& Strategic Management, vol. 20, no. 5, pp. 521-536.

Goulder, L. \& Schneider, S. (1999). "Induced technological change and the attractiveness of CO2 emissions abatement policies", Resource and Energy Economics, vol. 21, pp. 211-253.

Griliches, Z. (1992). “The Search for R\&D Spillovers”, Scandinavian Journal of Economics, vol. 94, pp. S29:S47.

Grübler, A. (2011). “The costs of the French nuclear scale-up: A case of negative learning by doing." Energy Policy 38, pp. 5174-5188

Henderson, R.M. \& Newell, R.G. (eds) (2011). Accelerating Innovation In Energy: Insights from Multiple Sectors, University of Chicago Press, Chicago, Illinois, United States.

Hicks, J.R. (1932). The Theory of Wages, MacMillan, London, United Kingdom.

Holdren, J.P. \& Baldwin, S.F. (2001). “The PCAST Energy Studies: Toward a National Consensus on Energy Research, Development, Demonstration, and Deployment", Annual Review of Energy and the Environment, vol. 26, pp. 391-434.

Howell, K. (2010). Sen. Graham's Plan for Clean-Energy Bill Could Drain RES Support, Greenwire. The New York Times, New York, United States.

Iman, R.L. \& Conover, W.J. (1982). "A distribution-free approach to inducing rank correlation among input variables", Communications in Statistics B, vol. 11, pp. 311-334.

Jaffe, A.B., Newell, R.G., Stavins, R.N. (2005). "A tale of two market failures: technology and environmental policy." Ecological Economics, vol. 54, pp. 164-174.

Kammen, D.F. \& Nemet, G.F. (2005a). “Supplement: Estimating energy R\&D investments required for climate stabilization", Issues in Science and Technology, vol. 22, no. 1, pp. 84-88. 
Kammen, D.M. \& Nemet, G.F. (2005b). "Reversing the incredible shrinking U.S. energy R\&D budget”, Issues in Science and Technology, vol. 22, no. 1, pp. 84-88.

Laitner, J.A. (2009). The National Energy Efficiency Resource Standard as an Energy Productivity Tool [Homepage of American Council for an Energy-Efficient Economy], [Online]. Available at: http:// aceee.org/white-paper/national-eers-energy-productivity-tool-february-2009 [2010, 09/14].

Lester, R.K. (2009). America's Energy Innovation Problem (and How to Fix It). Working Paper 09-007, Industrial Performance Center. Massachusetts Institute of Technology, Cambridge, MA, United States.

Loulou, R., Goldstein, G. \& Noble, K. (2004). Documentation for the MARKAL Family of Models. Available at: www.etsap.org/MrklDoc-I_StdMARKAL.pdf.

Lutsey, N. \& Sperling, D. (2008). “America’s bottom-up climate change mitigation policy”, Energy Policy, vol. 36, pp. 673-685.

Martino, J. (1987). "Using precursors as leading indicators of technological change", Technological Forecasting and Social Change, vol. 32, pp. 341-360.

McKay, M.D., Conover, W.J. \& Beckman, R.J. (1979). "A Comparison of Three Methods for Selecting values of Input Variables in the Analysis of Output from a Computer Code", Technometrics, vol. 21, pp. 239-245.

McNerney, J., Trancik, J.E. \& Farmer, J.D. (2011). “Historical Costs of Coal-Fired Electricity and Implications for the Future", Energy Policy, vol. 39, pp. 3062-3054.

MIT (2006). The Future of Geothermal Energy: Impact of Enhanced Geothermal Systems (EGS) on the United States in the 21st Century, Massachusetts Institute of Technology, Cambridge, MA, United States.

Morgan, M.G. \& Henrion, M. (1990). Uncertainty: a guide to dealing with uncertainty in quantitative risk and policy analysis, Cambridge University Press, Cambridge, UK.

Mowery, D.C., Nelson, R.R. \& Martin, B.R. (2010). “Technology policy and global warming: Why new policy models are needed (or why putting new wind in old bottles won't work)", Research Policy, vol. 39, pp. 1011-1023.

Mowery, D. \& Rosenberg, N. (1979). “The Influence of Market Demand Upon Innovation - A critical Review of Some Recent Empirical Studies", Research Policy, vol. 8, no. 2, pp. 102-153.

Narayanamurti, V., Anadon, L.D., Breetz, H., Bunn, M., Lee, H., Mielke, E. (2011). Transforming the Energy Economy: Options for Accelerating the Commercialization of Advanced Energy Technologies. Report for Energy Technology Innovation Policy research group, Belfer Center for Science and International Affairs. Harvard Kennedy School, Cambridge, MA, United States. 
NCEP, (2009). Forging the Climate Consensus: The Case for Action, National Commission on Energy Policy, Washington D.C., United States.

NCEP, (2004). "Ending the Energy Statemate. A Bipartisan Strategy to Meet America's Energy Challenges", The National Commission on Energy Policy, pp. 99.

Nemet, G.F. (2006). "Beyond the learning curve: factors influencing cost reductions in photovoltaics”, Energy Policy, vol. 34, pp. 3218-3232.

NRC, (2001). Energy Research at DOE: Was it Worth it? Energy Efficiency and Fossil Energy Research 1978 to 2000. Board on Energy and Environmental Systems, National Academy Press, Washington D.C.

Oppenheimer, M., O’Neill, B.C., Webster, M. \& Agrawala, S. (2007). “The limits of consensus”, Science, vol. 317, pp. 1505-1506.

Oster, S.M. \& Quigley, J.M. (1977). "Regulatory Barriers to the Diffusion of Innovation: Some Evidence from Building Codes", The Bell Journal of Economics, vol. 8, no. 2, pp. 361-377.

PCAST (2010). Report to the President on Accelerating the Pace of Change in Energy Technologies Through an Integrated Federal Energy Policy, President's Council of Advisors on Science and Technology. Executive Office of the President.

PCAST (1997). Federal Energy Research and Development for the Challenges of the Twenty-First Century, President's Council of Advisors on Science and Technology, Executive Office of the President, Washington D.C., United States.

Pugh, G., Clarke, L., Marlay, R., Kyle, P., Wise, M., McJeon, H. \& Chan, G. (2010). "Energy R\&D portfolio analysis based on climate change mitigation", Energy Economics, vol. 33(4), pp. 634-643.

Ramseur, J.L. (2007). Climate Change: Action by States to Address Greenhouse Gas Emissions, Congressional Research Service, Washington D.C., United States.

Sagar, A.D. (2004). "Technology innovation and energy", Cleveland, C. (Ed)”, The Encyclopedia of Energy, vol. 6, pp. 27-43.

Sagar, D. J., van der Zwan, B. (2006). “Technological innovation in the energy sector: R\&D, deployment and learning-by-doing”, Energy Policy, vol. 34, pp. 2601-2608.

Schock, R., Fulkerson, W., Brown, M., San Martin, R., Greene, D. \& Edmonds, J. (1999). "How Much is Energy Research and Development Worth as Insurance?", Annual Review of Energy and the Environment, vol. 24, pp. 487-512.

Sciortino, M. (2010). State Energy Efficienct Resource Standard (EERS) Fact Sheet, American Council for an Energy-Efficienc Economy, Washington D.C., United States. 
The White House (2009), Press Gaggle by Press Secretary, Robert Gibbs; Deputy National Security Advisor for International Economic Affairs, Mike Froman; and Assistant to the President for Energy and Climate, Carol Browner, Office of the Press Secretary. The White House, Washington D.C., United States.

Tversky, A. \& Kahneman, D. (1973). "Availability: a heuristic for judging frequency and probability”, Cognitive Psychology, vol. 5.

Wang, S.S. (1998). “Discussion Papers Already Published: 'Understanding Relationships Using Copulas' by Edward Frees and Emiliano Valdez", North American Actuarial Journal, vol. 2, no. 1, pp. 137-141.

Wiser, R.H. \& Pickle, S.J. (1998). "Financing investments in renewable energy: the impacts of policy design", Renewable and Sustainable Energy Reviews, vol. 2, pp. 361-386.

Yang, B. (2005). Residential Energy Code Evaluations Review and Future Directions, Building Code Assistance Project, Providence, Rhode Island, United States. 


\section{\#丮}

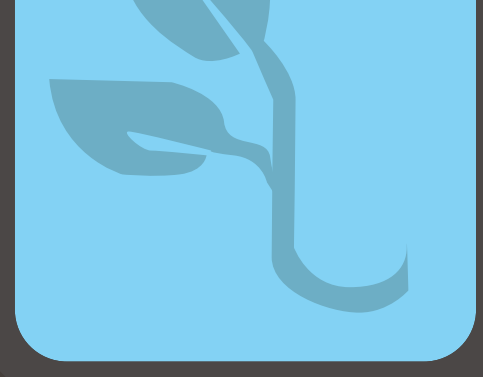




\section{CHAPTER 3}

\section{MANAGING INNOVATION INSTITUTIONS}

\subsection{SUMMARY}

If the U.S. government is going to invest billions of dollars a year in energy innovation, ensuring that these funds are spent in a way that maximizes the potential returns is critical. Some $60 \%$ of United States' applied-energy research and development (RD\&D) funds are spent through the national laboratories. Additional funds are being managed by new institutions such as the Advanced Research Projects Agency-Energy (ARPA-E), the Energy Innovation Hubs, and the Energy Frontier Research Centers. The effectiveness of U.S. energy innovation institutions-particularly the national laboratories-is a key determinant of the pace of energy innovation the United States is likely to be able to achieve. Today, unfortunately, constantly shifting funding, DOE headquarters micromanagement, diffuse missions, risk-averse cultures, new contracting approaches that have diluted the focus on key national objectives, and insufficient ability to connect to the private sector have undermined the efficiency of U.S. energy RD\&D institutions.

This chapter, therefore, represents the initial phase of a research effort to assess U.S. innovation institutions. The project aims to find appropriate models for institutions in energy innovation. Here, we present two case studies, one on the National Renewable Energy Laboratory (NREL) and the other on Semiconductor Research Corporation (SRC). The chapter starts with an exploration of how each institution operates and follows with an assessment of the constraints and opportunities each faces due to the environment in which it operates its management processes and its strategies for innovation. The chapter ends with recommendations that could be applied for energy institutions, such as NREL, to improve their effectiveness.

After evaluating current mechanisms and policies at NREL and SRC, this chapter makes several recommendations concerning operations at NREL and innovation institutions like it. The major themes of these recommendations are: First, the institution must be provided with consistent support and allowed to respond flexibly to new information about technology, policy, or markets. Second, the flow of technical and market knowledge from the private sector ("users") to laboratory staff should be encouraged, as should the flow of knowledge from technically oriented laboratory staff to the DOE headquarters' staff. Finally, institutions must encourage linkages between long-term research, applied research, technology development, and deployment, both through involving technology users in these processes and committing resources to move successful long-term projects forward. The end of this chapter provides specific recommendations for actualizing such guidelines.

The Belfer Center for Science and International Affairs | Harvard Kennedy School 


\subsection{INTRODUCTION AND Motivations}

The national laboratories are one part of the Department of Energy (DOE) science and innovation system. In addition to its goals of nuclear security and scientific exploration, the DOE research also aims to contribute new discoveries in energy. The national laboratories themselves are part of a much larger innovation regime that consists of different actors and institutional models for conducting research. For energy innovation, the key accomplishment of a successful national laboratory endeavor is commercialization of a technology product. Whether it is on the more fundamental or applied end of the research spectrum, the lab must contribute to knowledge or technologies that can eventually find use and enhance the energy system's impact on national security, the environment, and the market.

The federal science funding system has historically relied on the ideal of undirected basic research in the physical sciences (Shapley \& Roy, 1985). Federally-funded science has largely pursued a model that disassociates the idea of useful science from the concept of basic research. None of the national laboratories focuses universally on curiosity-driven fundamental research. Instead, every federal agency's mission points it toward public benefit and social utility.

Policymakers (Brown, 1992; Marburger III, 2005) and scholars (Funtowicz \& Ravetz, 1993; Gibbons et al., 1994; Sarewitz \& Pielke Jr., 2007) have questioned the processes and assumptions that drive much science and technology decision-making and have attempted to institute new frameworks for addressing the problem of funding robust, relevant research. Thus, there has been significant debate on the role of use-inspired basic research as opposed to curiosity-driven research and technology development. At the same time, policymakers have asked for more thinking and new modes of managing science that would facilitate effective linkages between scientific information and public use. This chapter examines two institutions, both focused on innovation, to assess the institutions' capacity to contribute to successful energy technologies. These case studies, on the National Renewable Energy Laboratory (NREL) and Semiconductor Research Corporation (SRC), are the first two of a set that will focus on the management of innovation institutions. The purpose is to make recommendations about managing such institutions and to suggest higher-order science policies that dictate the constraints and opportunities facing energy research so as to promote innovation.

The DOE national laboratories have conducted groundbreaking new research, and much of it has led to innovation. They contain an enormous amount of talent and knowledge and are an asset to the United States. Some examples of ways in which the national labs contribute to energy technology innovation include: (a) the support from national labs during the oil spill in 2010; (b) the fact that international researchers generally value the national labs and attempt to collaborate with them; (c) reports and expertise from the national labs are often used by private companies; and $(d)$ test facilities at the labs can reduce the costs for private firms to innovate. However, as may be indicated by the range of institutions 
created outside the labs, there are areas where the labs lack strength, such as funding high-risk, longterm, application-inspired research (e.g., an area that the Advanced Research Projects Agency-Energy (ARPA-E) was created to address), bridging the basic and applied research divide (e.g., an area that the Energy Innovation Hubs can contribute to), and managing large-scale demonstration projects. In spite of these flaws, the national labs have made significant contributions to developing and commercializing the energy technologies the United States needs (e.g., they played a key role in the development of the thin-film technology underlying First Solar, the largest U.S. photovoltaic (PV) company). In addition, it is likely that some of the investments made in the labs over time will result in more benefits, particularly if some of their barriers to working efficiently are removed.

However, more work to improve upon such successes could aid laboratories in fulfilling their missions at a time when energy research has become important to the United States' continued prosperity. Most of the national laboratories sit within the DOE's Office of Science (OS), which has historically focused on basic research in the physical sciences. Other laboratories work under different DOE offices, including the National Nuclear Security Administration, the Office of Energy Efficiency and Renewable Energy, the Office of Fossil Energy, and the Office of Nuclear Energy. Many analyses have identified a need for altered systems of energy innovation, including at the DOE national labs. In 1983, a report by a Federal Laboratory Review Panel, headed by David Packard, co-founder of Hewlett-Packard, advised that laboratories should work under tightly defined missions, interact closely with research users, reduce bureaucratic constraints to lab managers, and hold external reviews to make managers accountable for scientific excellence and relevance (OSTP, 1983). In an earlier article, some of the authors of this study outlined a broad set of similar recommendations for managing U.S. energy innovation institutions (Narayanamurti, Anadon, \& Sagar, 2009a). The authors argue that the original design of the national labs had a clear mission, stellar leadership, an entrepreneurial culture, block funding, and a structure that allowed researchers to be independent, yet accountable and connected to the larger system. They argue that over time, the mission of the multi-program national labs has become more diffuse and that forprofit management of some of the labs may have increased emphasis on corporate priorities, sometimes at the expense of national priorities. For too long, U.S. policymakers have focused too little attention on maximizing the performance of U.S. energy innovation institutions, including the national laboratories.

Many funders, other decision-makers, and scholars have assumed that there is a strong relationship between research funding and societal benefit. This is certainly the case when innovation institutions are managed effectively and focused on meeting major societal needs. However, in-depth independent assessments are needed to identify when new steps are required to improve these institutions' effectiveness so that the U.S. government can get increased return on its investments in this area. Of course, funders and other parties already undertake some assessments of energy innovation institutions. For example, several groups regularly evaluate the National Renewable Energy Laboratory (NREL), includ- 
ing technical advisory boards and decision-makers in the DOE. These reviews certainly help, bringing outside knowledge and perspective to the organization reviewed. However, the participants in such reviews rarely have the time, resources, or incentives needed for in-depth, comprehensive evaluation, and may not always be in the position to challenge existing U.S. government approaches where necessary.

The National Renewable Energy Laboratory (NREL) is the federal government's chief research institution dedicated to solving applied science problems in renewable energy. As such, NREL must meet the needs of its user groups. It can do this by being flexible and responsive to user needs and by conducting basic research, applied research, and technology development that lend itself toward application. Semiconductor Research Corporation (SRC) is a non-profit, industry-funded group that funds university research in the technology area's surrounding semiconductors. SRC represents a different model for funding research and managing relationships between institutions. As such, examining both allows one to gain more insight into the broad spectrum of energy technology innovation institutions. This case, along with future cases on other national laboratories, like Sandia, and industrial-collaborative institutions, like the Electric Power Research Institute, will allow for a broader understanding of how energy innovation works, with a deeper insight into the operations of a few types of institutional structures.

NREL and the National Energy Technology Laboratory are the two national labs in the energy area with missions that, in addition to specifying public value, guide them to conduct applied research. Thus, NREL is an appropriate choice for studying how laboratories can work to encourage commercialization of their research products. Furthermore, with over 1000 employees, a budget that exceeds $\$ 300$ million, and large-scale user facilities for research and testing, NREL is a lab that is sizeable enough to be a major part of the energy innovation apparatus but still works under a fairly cohesive mission. As the only laboratory the Office of Energy Efficiency and Renewable Energy (EERE) manages, NREL aims specifically at problems of renewable energy. As such, it is appropriate to study the lab's record of innovation, because renewable energy is a growing area of the nation's innovation concerns, with more attention being paid to problems and opportunities of renewable energy in recent years due to the issues of climate change and national security. Most important, newer institutions like ARPA-E, the DOE Energy Innovation Hubs, and Energy Frontier Research Centers (EFRCs) are all working to enhance renewable energy innovation in novel ways. Each of these focuses on a different type of research, with ARPA-E focusing on high risk revolutionary inquiry, Innovation Hubs, on addressing energy problems in a multidisciplinary approach that addresses fundamental work through commercialization; and EFRCs, on fundamental research on barriers to new technology development (Chu, 2009). These new actors participate in an arena where some have claimed that national laboratories are too "siloed" and too fixated on maintaining existing research portfolios (Dunderstadt et al., 2009). NREL is in a place where it must first define its role in a large, complex innovation system, and second, utilize that role to effectively encourage innovation. 
In examining NREL, this section asks: How can those managing NREL best facilitate innovation? Factors brought up by Narayanamurti et al. (2009), such as mission, funding, research culture, and leadership, are all important to addressing this question. Although this inquiry focuses on management policies, it addresses the other factors Narayanamurti et al. bring up because these factors all tie into the management system and how it works. Avenues of inquiry include how NREL decision-makers target users, how they learn about user needs, and what formal or informal mechanisms might accomplish this. The chapter also explores what factors play a role in decisions, what mechanisms enable these things, what constraints exist, and which users might be left out.

This section provides insights from a study of SRC. As a historically successful example of governmentprivate-academic partnership that has led to innovation in the marketplace, we examined SRC for lessons that can be learned from its model. This model fosters cooperative relationships that allow industry users, academic researchers, and funders from both industry and government to work on innovation in a way that benefits all parties. Additionally, SRC has long experience with supporting focused centers for long-term innovation work, with participating in road-mapping activities for strategizing on future innovation, and with developing a workforce through graduate student funding. As a supporter of the semiconductors and integrated circuits industry, SRC has historically focused on funding research close to the area of semiconductors, but it is now also funding centers in Smart Grid technology and photovoltaics (PVs). Technologically, SRC's work relates to NREL through the common thread of PVs. Semiconductors are integral to the development of solar technology. While it is now a diverse research body, NREL began as the Solar Energy Research Institute, and a large portion of its work still concentrates on PVs. In 2008, 25\% of the funding NREL received from EERE went into PV research. An examination of both the DOE lab mostly focused on renewable energy research, and on an industrial consortium in semiconductors that is increasingly involved with similar areas, provides lessons about how to improve NREL's ability to meet its mission and how to improve the DOE's management of its innovation institutions.

After briefly explaining the methods behind this research, this chapter discusses NREL, first by addressing its overriding mission and its context within the DOE, then by examining its decision processes amid the obstacles it faces to illustrate one laboratory's attempts to reconcile its goal of innovation within its constraints. Following the study of NREL, we provide a similar treatment of SRC and a summation of lessons from both that apply to effective governance of energy innovation activities.

\subsection{Methods}

The case studies below contain data about NREL and SRC gathered in semi-structured, qualitative interviews (Rubin \& Rubin, 1995). Interviewees at both institutions ranged from the heads of the organizations to division leaders, laboratory staff, and those working in commercialization and analysis. In addition to interviews, much of the data came from an examination of missions, budget figures, and 
evaluation documents. This information provided both the specifics on how the institution operates and fine detail on the broader world of the DOE national laboratories. We also reviewed records, such as external evaluations of NREL from EERE, numbers on technology transfer and patent activities, press releases, and accounts written of SRC.

For NREL, 20 interviews were held with staff at the institution, along with some members of the user communities. In the case of NREL, users included researchers and decision-makers in the photovoltaic industry, along with energy lobbyists and advocacy groups. The 20 SRC interviewees included SRC staff, member company representatives, and current and former SRC researchers. SRC users consisted largely of staff from SRC's member companies.

Important questions included how research decisions are made, whose input matters in decision-making, how decisions incorporate the needs of users, how outcomes are evaluated, and where successes and failures for the institutions lie. The focus was on the decision processes that govern the institutions, along with how these processes feed into the accomplishment of the mission and user satisfaction. Interviews were aimed at learning processes in the institutions and how such processes have affected performance. While this second issue is subjective, interviews were conducted to find themes and constraints that interviewees spoke about consistently. Such themes were checked against documentary records of the laboratory. Cross-checking of claims with those made by other interviewees was done as well. The interview process continued until everyone with responsibility for management of the institution had been heard, and we felt we had obtained a consistent picture of institutional procedures and outcomes.

\subsection{NREL}

\subsubsection{Mission and Description}

The DOE funds the national laboratories to perform research and provides grants to university, industry, and non-profit organizations. As one of the national laboratories, NREL works within a larger DOE system that includes research in energy, nuclear security, and basic science. NREL's mission supports the idea of renewable energy as a public good and seeks to "transfer knowledge and innovation" to meet energy needs. One of the central tenets of the lab is that it exists to develop technology and to put new discoveries in the hands of industry users: "NREL firmly believes that it is in the nation's best interest to move technologies into the marketplace in an expeditious manner" (Marczewski, 1995). The laboratory succeeds when it delivers useful technology outputs and outcomes to its customers.

NREL is a government-owned, contractor-operated laboratory, as are 16 of the 17 national laboratories. A group called the Alliance for Sustainable Energy, headed by Battelle and the Midwest Research Institute, manages the laboratory under a five-year contract. The most recent contract began in 2008. The 
DOE has the option to extend the contract by up to ten years. NREL Director Dan Arvizu has been at the laboratory since 2005, but much of the management team began in the last two years. The NREL management team, most of whom have been in their positions for five years or fewer, recognize some past shortcomings in the laboratory's ability to deliver on its mission and have been trying to improve the impact of the lab under the new contract.

NREL receives much of its funding from EERE, with a portion coming from the OS, and other DOE offices providing additional money. In 2010, NREL received $\$ 18.8$ million of its $\$ 390.8$ million, or $4.8 \%$ of the total, from the OS and \$15.7 million from other parts of the DOE, including the Office of Electric Delivery and Energy Reliability and other national laboratories. The laboratory director designates a certain amount of this money to be used for laboratory-directed research and development (LDRD). NREL currently sets LDRD around \$8 million per year (2.6\% of the lab's 2009 total), that is applied as an overhead cost to incoming funds. According to one decision-maker at Sandia National Laboratories, LDRD provides a key source for "high risk, potentially high value research" (Physics Today, 2011).

Although most of the laboratories have some component of applied or use-inspired research, many at NREL see it as the lab that most strongly emphasizes application, as reflected in its mission. NREL's organizational divisions include Science and Technology, Commercialization and Deployment, and Outreach, Planning and Analysis. The division of Science and Technology itself consists of three laboratory programs: Renewable Electricity and End Use Systems, Renewable Fuels and Vehicle Systems, and Basic Energy Sciences (BES). The first two focus on applied programs in areas such as photovoltaics and bioenergy. The third holds much of NREL's fundamental research, and receives more funding from the OS than other parts of the lab (Figure 3.1). The OS's BES program exists "to provide the foundations for new energy technologies and to support the DOE missions in energy, environment, and national security" (DOE, 2008). The Science and Technology laboratories do not all focus on developing new technology products. Some attempt to facilitate adoption of energy-efficient technologies in the marketplace; for example, the Residential Buildings program at the laboratory focuses on energy-systems integration and energy analysis rather than new products for use.

As a laboratory, NREL aims at successful commercialization of its research products within the energy industry. One NREL manager stated the central concern as relating to this aim:

In the late 70s, we were developing concentrated solar power and first generation PV cells at Sandia. It was very cool from a scientific perspective, but everyone who looked at it said, "My goodness, how is that relevant in our marketplace?" And here you fast forward 35 years, that technology, developed in that era, is now today's commercial product. . - What do we have to do to have today's innovation not take 35 years to get to the marketplace? 


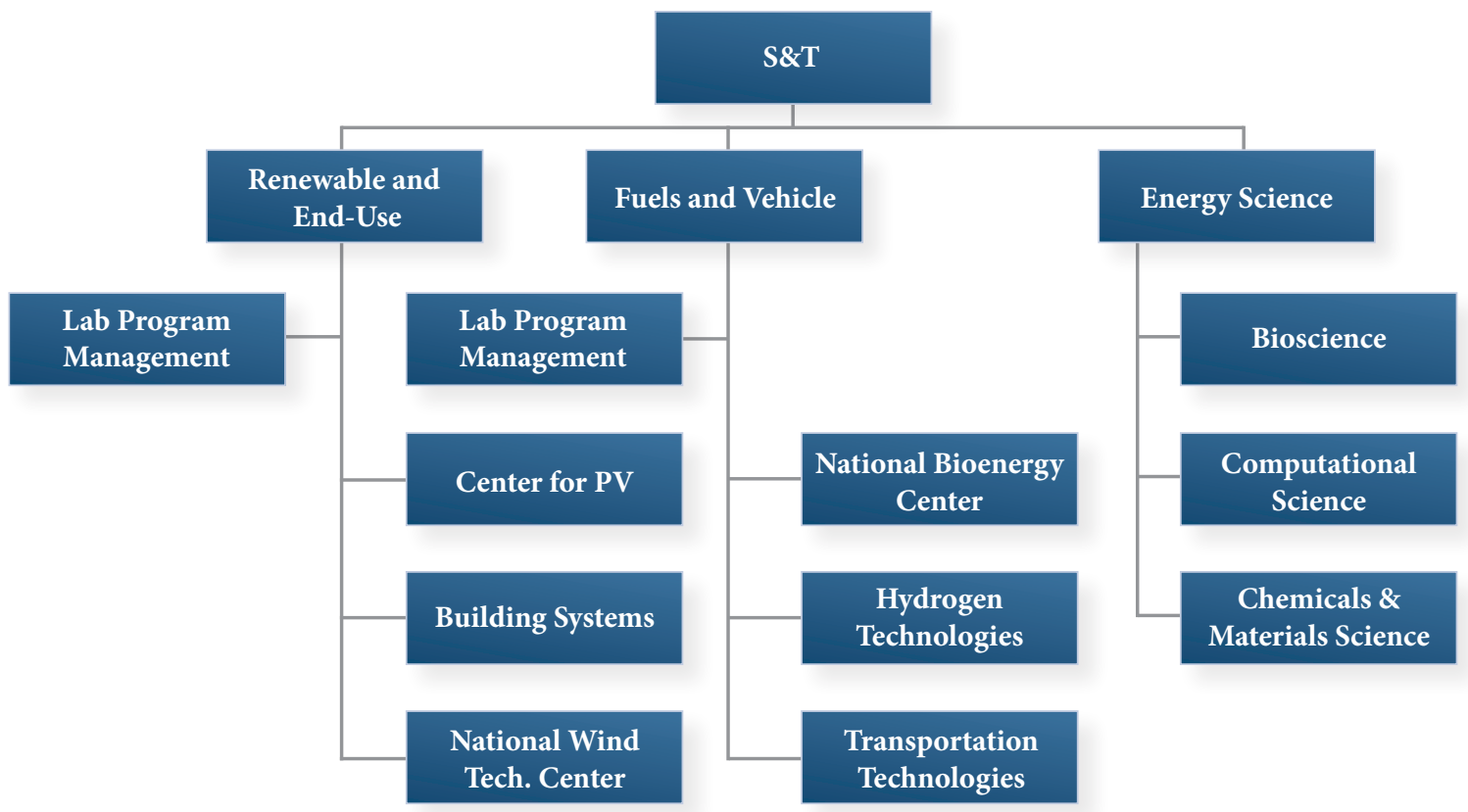

FIGURE 3.1. NREL Organizational Chart

Many at NREL echo the goal of commercialization that is evident in both this statement and the NREL mission. An employee in Renewable Electricity and End Use said about his group, "the role of our center is developing energy infrastructure for commercialization."

As NREL's manager, the Alliance for Sustainable Energy sees its role as accentuating and improving the impact that NREL can have on industry. All members of the management team stressed this part of NREL's role, and the latest contract, was altered to emphasize commercialization. For this reason, NREL instituted the division of Commercialization \& Deployment. With leadership at the laboratory vice-president level, this division is meant to ensure that commercialization concerns become a part of high-level decisions and are wholly integrated with the lab's activities.

\subsubsection{NREL Performance}

The laboratory has had successes in promoting commercialization and in integrating the interests of industry into its processes. In 2009, NREL had 144 active Cooperative Research and Development Agreements (CRADAs), which brought in $\$ 4.9$ million from industry; 67 of these CRADAs were with small businesses; 50 of them were new in 2009. Additionally, 115 Work for Others projects accrued $\$ 10.6$ million, 9 U.S. patents were issued, and the lab had 101 active licenses in that year. The lab also had 34 new licenses and 25 patents (worldwide) issued in 2009. In most of these categories, the laboratory is on the higher end of the other DOE labs, once budget is accounted for, and is, in fact, the first among them in number of CRADAs. 


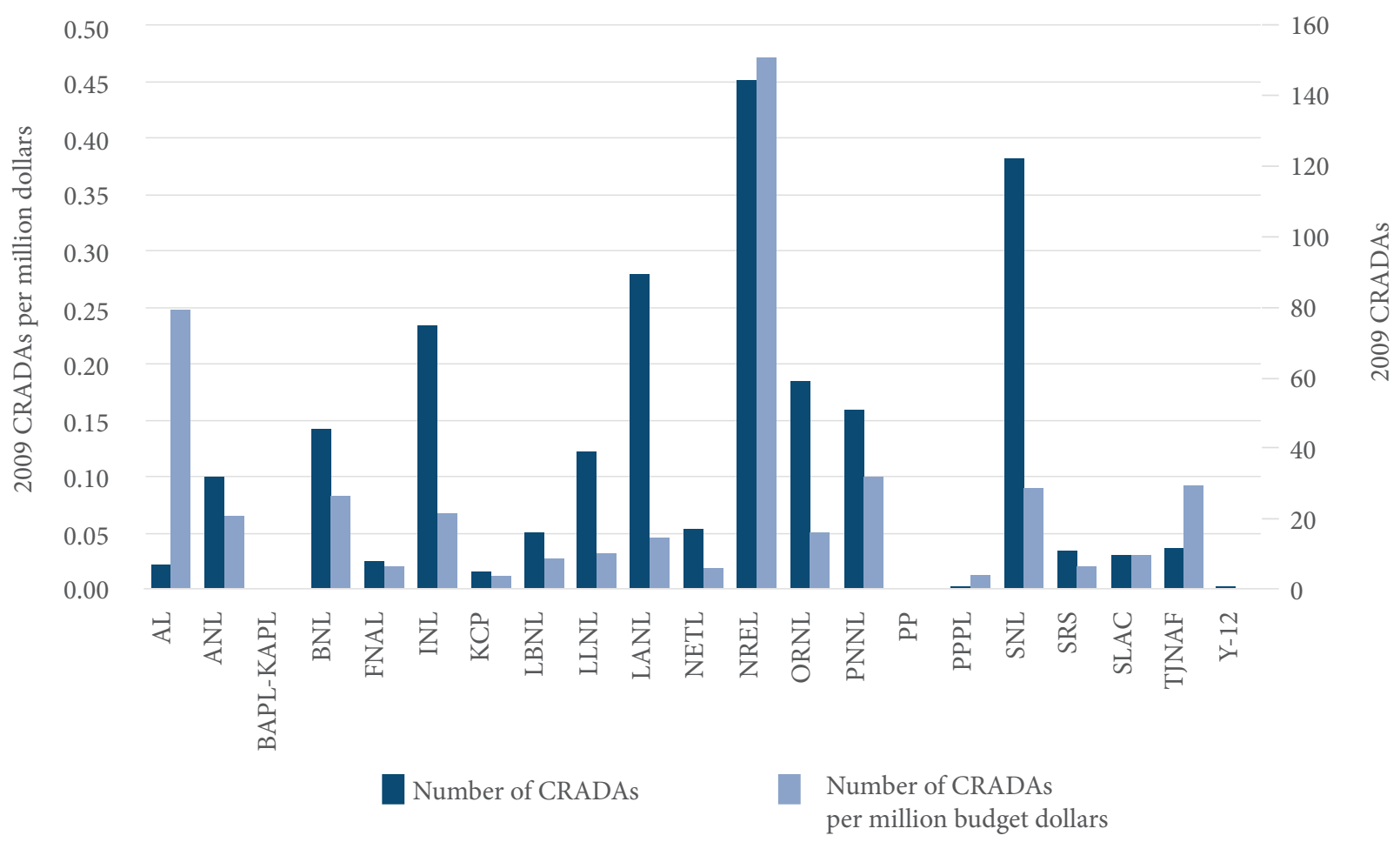

FIGURE 3.2. 2009 CRADAs across national laboratories, along with number of CRADAs per million budget dollars.

Figure 3.2 shows the number of CRADAS for the year 2009 across all national laboratories, along with the number of CRADAs per million budget dollars. The high numbers for CRADAs at NREL relative to other labs might represent one area where its adherence to its applied mission is evident. The laboratory received almost \$5 million dollars from CRADAs in that year. For licenses, NREL has one of the lowest numbers when compared to other laboratories, after accounting for budget, but was in the top quartile in terms of new licenses for 2009 (Figure 3.3). The lab was also second in patents issued per dollar (Figure 3.4), and ranks highly in non-federally sponsored Work for Others project, both in terms of number and amount of funding in (Figure 3.5).

The EERE technology portal allows people to "search for patents, patent applications, and available technologies of energy efficiency and renewable energy technologies" (EERE 2011a) within national laboratories. Of the 1098 patents and patent applications that the technology portal lists for solar, 191 of these come from NREL. Of 480 for wind, NREL has 43. According to the technology portal, NREL does not preside over a majority of patented renewable energy innovations, but it does play a significant role in commercialization of wind and solar technology. The technology portal also does not allow comparison for the patents that occur outside of the national laboratory system.

Staff also had many stories of successful relationships with industry, particularly in the solar sector. Photovoltaic companies, especially those using thin-film technologies, have benefitted from previous relationships with NREL. First Solar, which is now the country's largest thin-film manufacturer, is one 


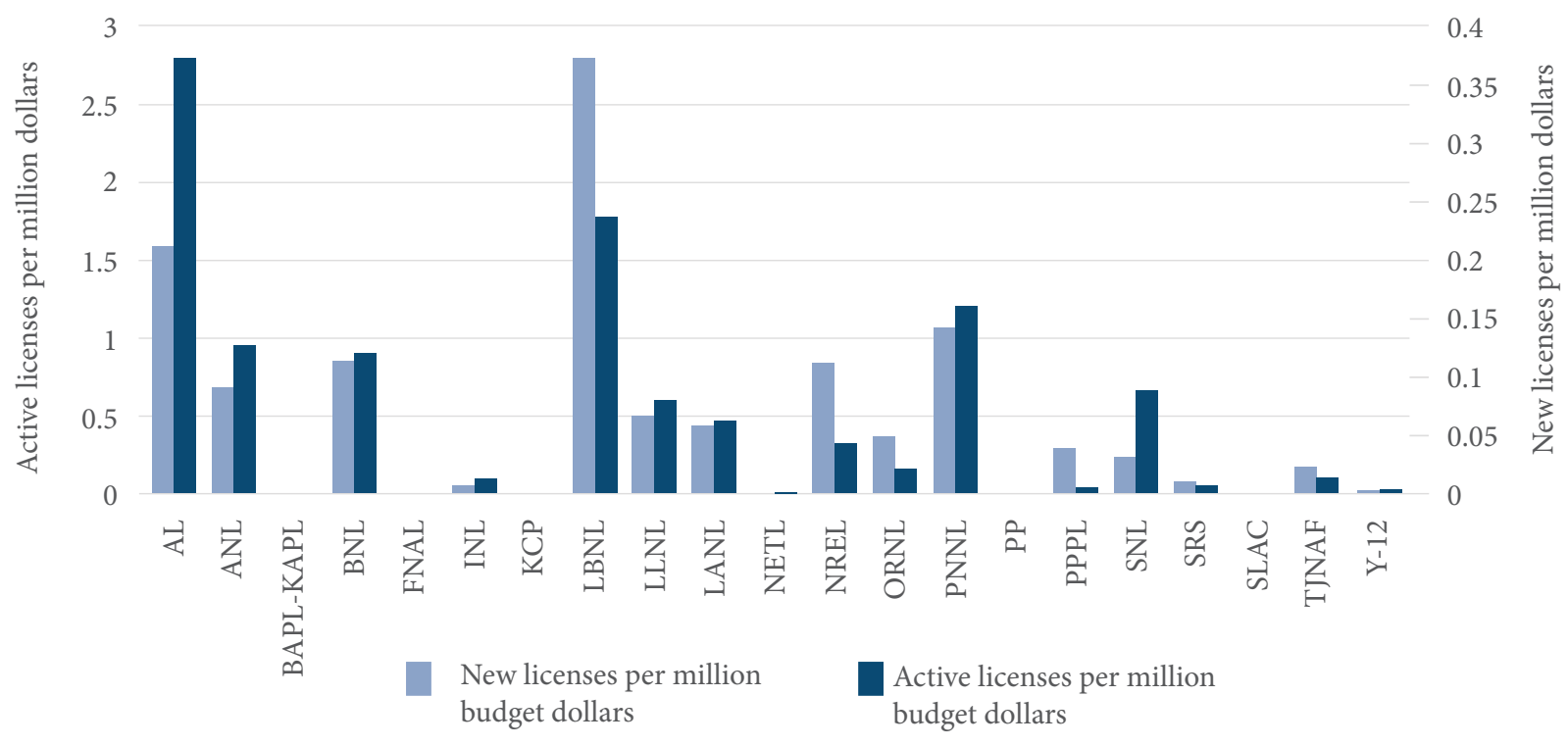

FIGURE 3.3. 2009 Active licenses and new licenses per million budget dollars, across laboratories.

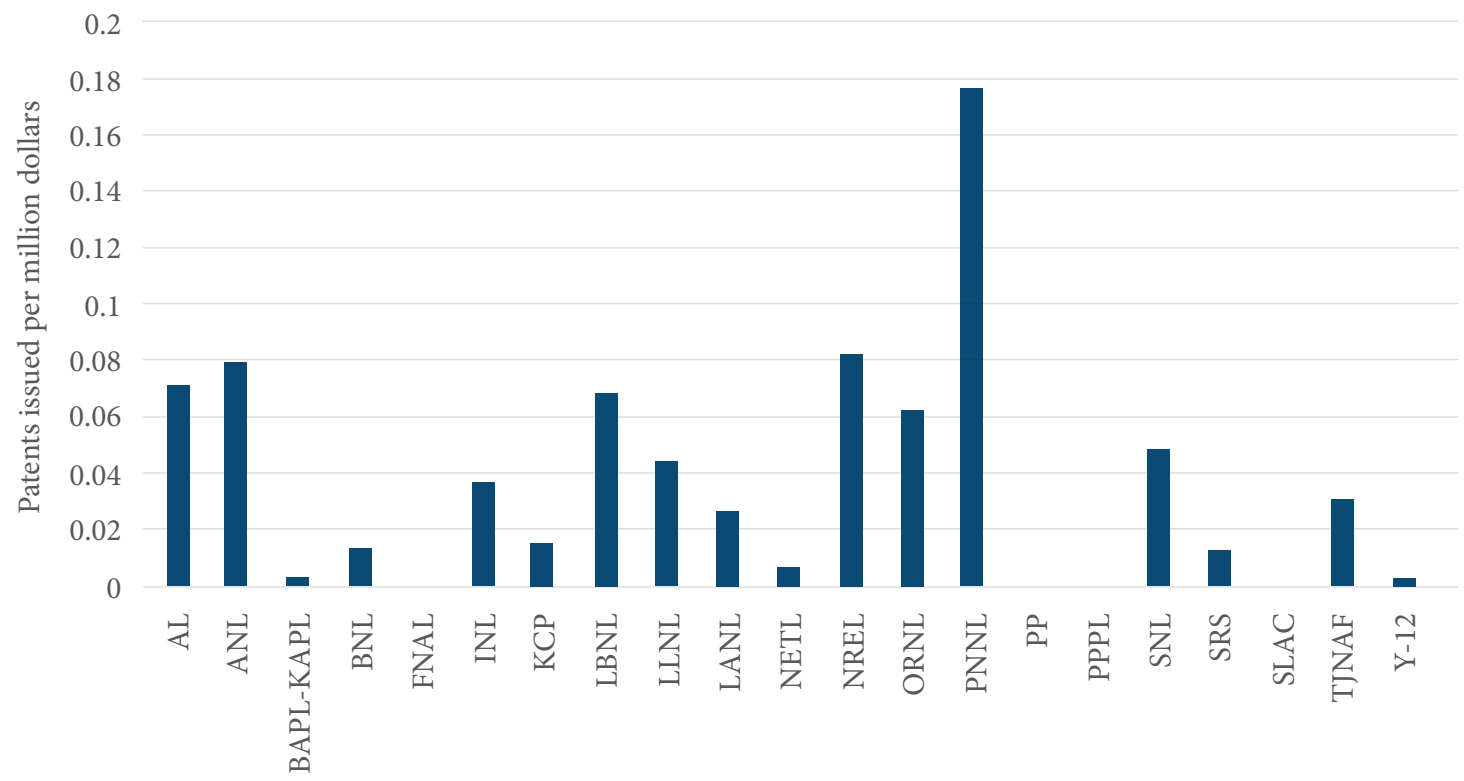

FIGURE 3.4. Patents issued per million dollars in 2009, across laboratories.

such case. NREL began working with people from the company in 1991, when it was still named Solar Cells Inc. NREL's relationship with First Solar is one that has been characterized by many participants as extremely close, with NREL working hand-in-hand with the company during its early years. NREL and First Solar together share an R\&D 100 Award for development of a high-rate vapor transport deposition process for high volume manufacturing (First Solar, 2003).

NREL has also fostered several successful relationships through its testing activities and user facilities. It has worked with companies such as Southwest Windpower and Clipper Windpower to validate de- 


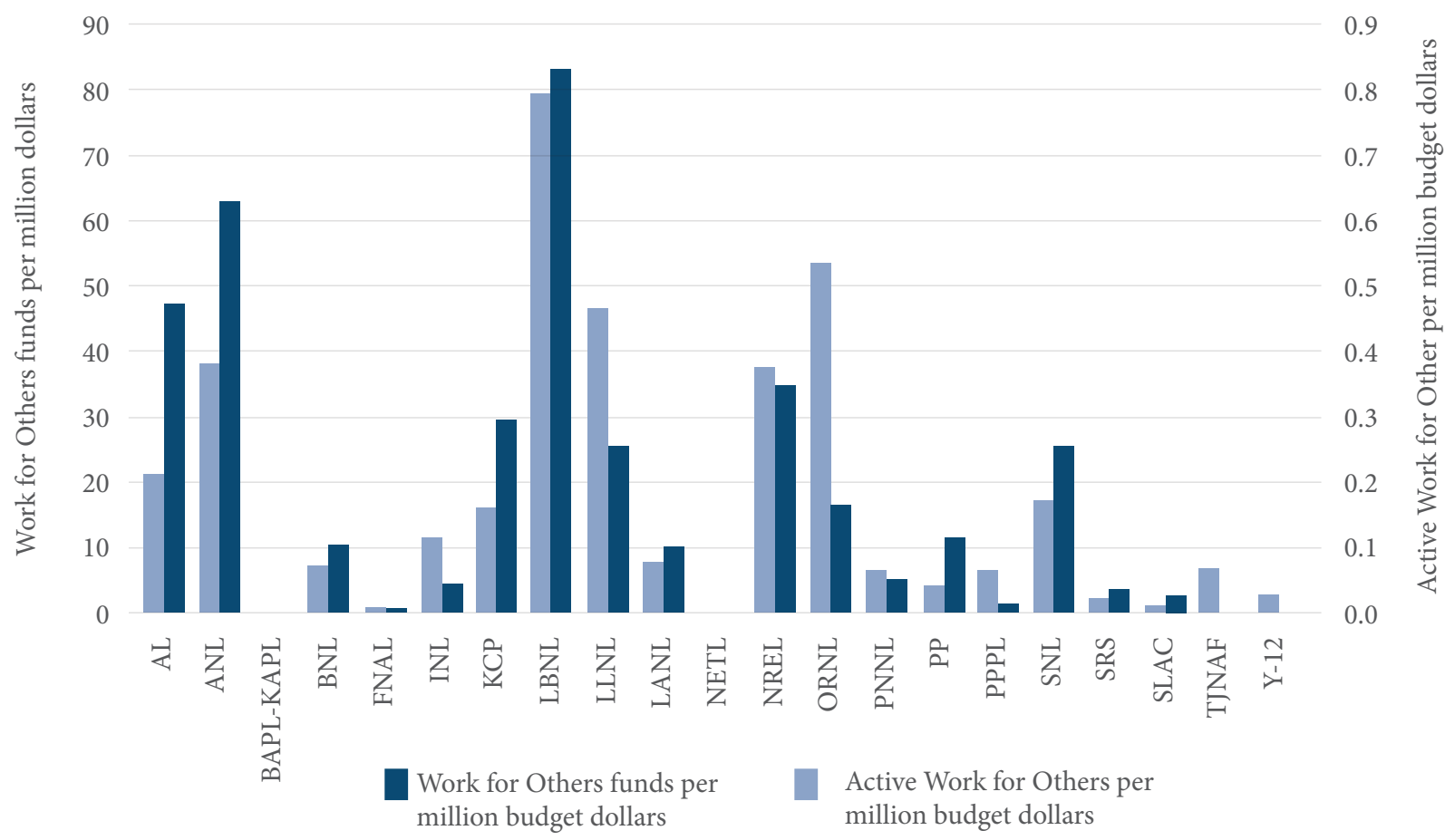

FIGURE 3.5. 2009 Funding in from Work for Others (from Non-federal Sponsors), along with the number of active Work for Others agreements, divided by operational budget.

signs and field-test new turbines (EERE, 2006a). NREL has additional strengths in its testing capabilities and facilities for user-led research. NREL makes many of its laboratories available for industry, or other groups, to perform or benefit from research and development. A few of the many facilities are an Advanced Research Turbines Facility, an Integrated Biorefinery Research Facility, an Outdoor Test Facility for photovoltaics, and Wind Turbine Test Pads. Such facilities allow users to coordinate their own technology products with NREL work and facilitate formal, organized involvement by industry in renewable energy research.

\section{Budgetary Constraints}

NREL also has many obstacles to being successful in fulfilling its missions. The first of these has been the laboratory's budget. The laboratory was incorporated as the Solar Energy Research Institute under President Jimmy Carter, but solar energy began to see a waning of support even during the latter half of Carter's presidency (Laird, 2001). President Ronald Reagan withdrew support even further; the laboratory budget was cut in 1981 from $\$ 135$ million to \$100 million (a cut from \$325 to \$239 million in CPIadjusted 2010 dollars) early in Reagan's presidency, and reached a nadir of \$25 million in the mid-1980s. While the laboratory received more support under Bill Clinton's presidency, funding was still inconsistent. In 1996 the laboratory was faced with a 10\% workforce reduction due to "lower than expected appropriations for renewable energy programs" (NREL, 1995). In 2006, shortly after George W. Bush's State of the Union address in which he proclaimed the United States to be "addicted to oil," NREL again 


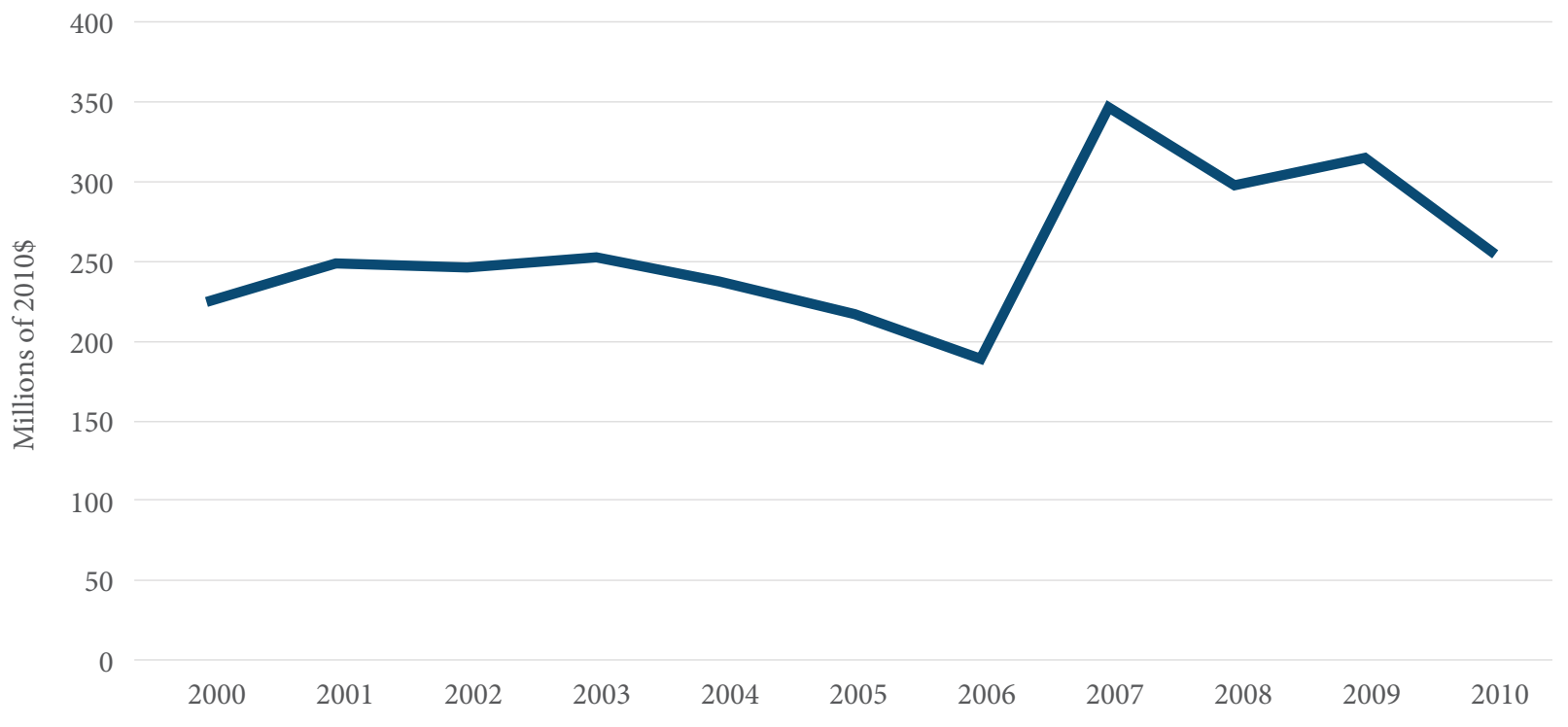

FIGURE 3.6. NREL Operating Budget (in millions of 2010 U.S. dollars)

faced a shortfall of $\$ 28$ million, due to earmarking, and had to lay off 32 staff (EERE, 2006b). NREL eventually was able to offer many of the staff their jobs back, but the shortfall shows that NREL failed to receive strong support. Under the American Recovery and Reinvestment Act, NREL received \$110 million, much of which went toward buildings (NREL, 2009). This infusion is beneficial for the lab; however, it is no guarantee that NREL will avoid suffering from budget shortfalls and wide variations in support. See Figure 3.6 for the NREL budget variations in the past decade.

Such budget variability impedes NREL's ability to conduct its research effectively. For an institution to work on renewable energy problems and to do end-to-end research that includes fundamental research, applied science, and technology development, it requires commitment on a multiyear scale that will allow it to develop and pursue promising projects and programs. Given that the time from concept to market for some solar technologies has been over 30 years, fluctuating support on a yearly basis impedes more rapid development of new technologies. While research programs should be closely evaluated and phased out if they are not working or have achieved enough success that the private sector can carry the technology forward without further help, the effectiveness of the labs will be improved with more stable funding.

There are other DOE institutions that deserve funding stability. In its task to fund potentially transformative energy technologies and to pave the way for their commercialization, ARPA-E has been effective and innovative in forming partnerships with industry and other government departments. The number of meritorious, innovative proposals that ARPA-E has received is far larger than it has been able to support with the budgets it has had available so far. However, in order to determine the effectiveness of the organization, ARPA-E needs stable support for at least ten years. Innovation takes time, and not all of the high-risk technologies ARPA-E is pursuing will succeed. The value of the successful technologies 
developed with ARPA-E funds, combined with the value of the lessons learned from the projects that do not reach commercialization, is likely to far outweigh the cost of supporting ARPA-E.

The Energy Innovation Hubs and the Energy Frontier Research Centers (EFRCs) provide other examples of new institutions that will also require sustained support. The Hubs are aimed at creating a critical mass of researchers who will work on problems requiring an integration of fundamental science breakthroughs and inventive engineering. The EFRCs are located within universities, national laboratories, non-profit organizations, and for-profit firms, singly or in partnerships selected by scientific peer review and funded for a five-year initial award period. These Centers have an in-built mechanism for providing more stable research, in that appropriations are done for five years at a time.

\section{Energy Markets and Policy}

According to the laboratory's management, NREL's most pressing current problem involves navigating the complicated context posed by energy markets, the Department of Energy (DOE), and the broader policy context. Given the complex nature and large size of the energy sector, this context must be taken into account. For example, the year-to-year differences in wind power development closely follow trends in the production tax credit (PTC), where the three individual years in which Congress allowed the PTC to lapse correspond to drastic lows in development of wind power capacity (Wiser, Bolinger, \& Barbose, 2007), highlighting the influence of factors outside of the realm of research and development on the production of commercialization of renewables.

Additionally, the fluctuation in the price of competing technologies, such as power from natural gas, makes pegging an innovation to a specific price difficult. Obtaining a lower price per kilowatt-hour for an electricity technology does not necessarily result in deployment, given the lack of long-term certainty about the price of competitors, along with the infrastructural, behavioral, and institutional hurdles to adoption.

NREL's position as the only EERE laboratory is also problematic in the view of some staff. NREL receives much of its support from the EERE, but must compete with other laboratories for all of its remaining additional funding. In addition, a couple of NREL's management staff see NREL's lack of facilities and computing resources, relative to other national laboratories, as putting NREL at a disadvantage. Many of the other DOE labs can highlight their resources when competing for funding.

\section{Administration and Management}

NREL also faces factors within the DOE that constrain its mission. One of these factors is related to the laboratory's status as a government-owned, contractor-operated lab. NREL's operating contract goes to bid every five years, and while periodic renewal of contracts is necessary to assure the vendor is satisfacto- 
rily doing its work, this renewal can also put the lab in a situation where it is constantly reorganizing itself. These changes are pursued for the purpose of increasing effectiveness, but given the constant change in the renewable energy landscape, what is seen as effective during one contract renegotiation may be out of fashion five years later. While the vagaries of budget, market factors, and regulation add to this uncertainty, contract bidding encourages the institution to reorganize, and perhaps become more complex, in an effort to improve (or reinvent) NREL's previous operating contract and management structures.

Another issue related to bureaucratization is that of procurement. Contracts used to be handled at NREL, but since the early 2000s, they have moved under the purview of EERE. Several people at NREL voiced the opinion that this move reduced NREL's ability to make effective decisions, because these people feel that they have a uniquely deep knowledge of the fields they work within ("the people overseeing the contracts are not technical people, and how would we know what they [industry] are doing"). The move also impedes the ability to produce social capital, due to the reduced interactions between NREL employees and users because this relationship instead occurs between EERE and the user.

While some decisions about budgets and priorities have to come from within the Department of Energy, NREL's staff are both technically qualified in the research area and have numerous relationships with people in industry who can aid them in contributing to decisions about grants, cooperative agreements, and other procurement contracts. In fact, a 1983 Packard report concluded that the national laboratory innovation system would improve if more budgetary control was given to laboratory directors (David, 1983; OSTP, 1983). Thus, the idea that NREL might improve by making a larger proportion of its own decisions is not a new one.

There are other administrative models within the DOE, some of which might take strategies transferable to NREL's management. ARPA-E, which was authorized in 2007 and funded with the 2009 Recovery Act, is an example of a nimble organization, free of some of the hiring and contracting hurdles at the DOE. In addition to the projects it has chosen to fund, ARPA-E has launched several new initiatives, such as the ARPA-E Summit, in which winners and finalists of ARPA-E awards are showcased to attract further funding. In funding both early-state innovation and in facilitating pathways for its awardees to reach commercialization, ARPA-E is attempting to take a more holistic view of innovation. ARPA-E has also made significant efforts to communicate its mission and progress to Congress and collected metrics (such as the VC funding its projects manage to attract after receiving an ARPA_E award) that help it build legitimacy. As a funding, rather than research organization, ARPA-E is fundamentally different from NREL. However, its strategy of nimbly pursuing high-risk high-impact research could be learned. Such work could be useful for national laboratories, especially if connected to eventual applications. 


\section{Basic Research and Applied Research}

Part of a manager's role is to bring all of the parts of an organization together. Fundamental research should be insulated from the concerns of applied research, such as short timelines and immediate commercialization. At the same time, decision-makers cannot isolate research from considerations of eventual application, and the results of basic research must be picked up and integrated into applied-research programs for the research to become a worthwhile investment. NREL faces obstacles in encouraging all of its research to be focused toward the eventual achievement of its mission goals. For the basic research at the laboratory to be successful in working toward the laboratory's mission, the research should, at the minimum, consider the potential application of the work and how it relates to NREL's goals. Ideally, successful basic research projects at the lab would be conceptualized in such a way that they could be picked up by applied research and technology development projects that work toward an output that can be commercialized, either at NREL or other laboratories.

NREL performs both basic and applied research, and many staffers there conceptualize the two as inextricable and, to some extent, essential parts of a process that works toward application and innovation. Evaluators of NREL do see the value of linking basic research to application and have supported working to connect the two (EERE, 2006a). Basic research at NREL is typically defined as being "use-inspired," in the phrasing of Stokes, who conceptualized such research as pursuing fundamental questions with an eye toward eventual uses (Stokes, 1997). However, most of the links between fundamental and applied projects at NREL are informal. Informal linkages can still mean that coordination between basic and applied research occurs, but they do not guarantee a sustained relationship between the two. For example, time constraints could impede staff from building such links if they are not explicitly part of the process. Responsibility for brokering such linkages can always be assumed to belong to someone else. Additionally, real resources need to be committed to building such programs. Whether it is paying for the time the people work on designing basic research for application or committing funding to perform the applied-research program that might continue to build upon the promising findings of successful basic research, building linkages require commitments of funding and time.

If basic research is not connected to application in some way, there is the danger that it becomes isolated from the parts of the organization that are more intimately connected to users. Bridging the "valley of death" between basic and applied research requires connective mechanisms and relationships. The U.S. Global Change Research Program neglected to consider application when promoting its basic research agenda, and as a result conducted ample high-quality science that may not, in the end, fulfill its goals according to its mission (Pielke, Jr., 2003; Pielke, Jr. \& Byerly, Jr., 1998; Pielke, Jr., 1995). From the organizational chart of NREL (Figure 3.1), one can see that there is some isolation between more basic areas and applied research. The Basic Energy Science (BES) division of the lab represents the type of basic research that is typically farther from application than the work done in Renewables and End-Use or in 
Fuels and Vehicle Systems. Energy Sciences at NREL receives funding both from EERE and the OS, but it receives more money from the OS than other parts of the laboratory do.

While the OS funds the BES to support research that is both fundamental and foundational, EERE funding aims at " $[\mathrm{b}]$ ringing clean, reliable and affordable energy technologies to the marketplace"(EERE 2011a). For the OS-supported research to truly serve as a foundation, active effort must be put into linking it to applied work. Linking basic research to eventual application goals is also difficult because there is typically less industry involvement in such areas because they are "not directly invested" in the outcome: Industry is interested in, "Can I fabricate this? Can I make a low cost solar cell?" The answer's yes, but they're not working on the transport and recombination mechanisms. [They would say] "Once you've got that figured out, give me something we can use." (NREL management team member)

One member of NREL's management team noted that the obstacles to connecting basic and applied research were real, and that they were issues the institution was trying to address, but in a "pilot program" capacity at this time. While this awareness is beneficial for the laboratory in future attempts that work to link the two, it also means NREL has not fully achieved integration of application and technology considerations into the basic research process.

\section{User Interaction}

Interaction with user groups can be important for assessing their needs, for keeping them apprised of research results and potentials, and for building social capital between research institutions and stakeholders. According to many of the NREL interviewees, as well as several of the industry interviewees, NREL does have a deep understanding of user needs within the field.

Criticisms by other parties, however, do reflect that some perceive the institution as falling short in providing access to industry (e.g., Serface, 2009), or that the specific subsectors of an industry receive attention according to NREL's expertise or EERE considerations. In these cases, NREL may be using its resources to meet needs where it can, but other sectors might be lacking the input of their research expertise.

There are many examples of companies working cooperatively with NREL. This work can range from testing of technologies, to Work for Others agreements (such as Technology Services Agreements, where companies pay NREL researchers to contribute their time and knowledge) to CRADAs. The Stephenson-Wydler Technology Act of 1980 (PL 96-480) instituted CRADAs as a tool for speeding commercialization, and they serve as a means for the laboratory to work with partners, sharing time or materials toward a common research goal. When compared to other laboratories, NREL is very active in these types of agreements. According to 2009 data NREL has more active CRADAs than any other laboratory, and, when the numbers are normalized for budget amount, NREL has two times as many active CRA- 
DAs as the second highest laboratory. NREL also ranks first in total money received from its CRADAs (per million dollars NREL budget) and has a high amount of funding from non-federal sponsors.

Part of the responsibility of decision-makers at NREL includes maintaining relationships with clients and relating that to the work at NREL. One manager within NREL's research centers described "coordinating NREL's research with client representatives" (Anderson), as a central part of his job. Informal or formal, these NREL-user relationships are often maintained with individual companies or small groups.

NREL has another mechanism to encourage relationship-building in a larger venue. The Industry Growth Forum began at NREL in the late 1980s and has consistently provided a means for the laboratory to bring together companies and venture capital groups for the purpose of building new enterprises in renewable energy. Almost 500 people participated in the 2010 forum, which focuses yearly on new energy technologies and the possibility for business development from such innovations. According to NREL, companies at the forum have raised over $\$ 3.4$ billion dollars in the past eight years (NREL, 2010).

NREL has also utilized EERE's Entrepreneur in Residence Program (EIR) (NREL, 2010) that began in 2008 to encourage interaction and commercialization (EERE, 2011b). EIRs are a pilot program that EERE runs for the purpose of putting venture capitalists from firms in labs for eighteen months, where they are supposed to learn about the technologies and find some that they can help to transition into profitable innovations. EIRs existed in Silicon Valley firms before the national labs began using them. The program, however, has not had positive results to date. One EIR venture capitalist, at Oak Ridge National Laboratory, said, "It was fascinating but also very disappointing. I looked at 1500 invention disclosures and walked away from 1500 ideas" (Vance \& Miller, 2010). Michael Bauer, the entrepreneur, attributed the failure to a difference between the information technology field and the energy arena, where failures of commercialization are tolerated more often in Silicon Valley. Joel Serface, who was an EIR at NREL, thought it was more of an issue of timeframe:

In the 11 months that I had the privilege to work inside NREL, I met with more than 300 researchers, identified around 30 promising technologies that I thought could reach commercial potential over the next several years, and honed in on three technologies that showed imminent promise. Unfortunately, the EIR program was timed too short to reach its full potential and to get the first one of these ideas set up as a company (Serface 2009).

However, Serface also regarded the experience as one that probably aided NREL and the DOE: DOE's calculus was that if they inserted a serial entrepreneur/investor backed by a brandnamed VC firm into a lab that magic would happen and that an innovation would turn immediately into a company. At worst, DOE would learn a lot about what it and its labs need to do better to in order to accelerate ideas to market. 
The EIR program at NREL and other labs may not have led directly to commercialization, but the ancillary benefits, in the form of social capital and knowledge of the market context, could aid labs in future attempts.

\section{Commercialization and Deployment}

NREL, and its funders at EERE, have tried to stress increased activity in commercialization as a means to enhance the impact of laboratory activities. Through licensing innovation to industry and other means of knowledge transfer, NREL attempts to facilitate the transfer of new renewable discoveries into the marketplace. NREL often licenses nonexclusively to those who want to utilize its technologies. For example, the institution licensed copper indium gallium selenide technologies on six to eight occasions to different industry concerns. NREL does retain some royalty on annual sales, but it is typically small, because the goal of the organization is getting the industry started, not making more money from industry.

Normalization of cross-laboratory data based on funding level shows where NREL stands with respect to licensing (Figure 3.3). In 2009, NREL had a very low number of active licenses compared to other laboratories. However, when taking into account its budget, it is above the mean across national labs for new licenses and patents issued. One NREL employee in commercialization claims that NREL's overriding focus on building industries led to the success of companies like First Solar, but that NREL did not pay attention to garnering licensing fees because it wanted the industry to easily acquire and use the results of laboratory research. For this reason, First Solar is seen as a huge success at NREL even though it does not supply many royalties or contracts to NREL currently because NREL played a huge role in First Solar's early years and was able to transfer technologies to the company without high prices.

Continued focus on analysis, commercialization, and deployment can help NREL to move new innovations into the marketplace, to maintain relationships and build social capital with involved industries and state and local governments, and to provide context for the scientific research NREL conducts. One means for providing such context and guidance is evident in the laboratory's Strategic Energy Analysis (SEA) division.

\section{Strategic Energy Analysis}

The SEA division of NREL encourages systems integration and attempts to "increase the understanding of the current and future interactions and roles of energy policies, markets, resources, technologies, environmental impacts, and infrastructure." Many of the NREL management regard SEA as a means for the agency to stay relevant. First, SEA allows the laboratory to do relevant social science and policy assessment. Second, increased knowledge of the sociotechnical space allows employees at NREL to understand the context of the innovations they are working on and enables strategic planning activities that can consider the future of the laboratory. In addition to assessing the innovation system for technologies, SEA can serve as a means for integrating considerations of use into future NREL products. 
SEA also has the potential to aid in integrating NREL strategy, bench-level research, industry needs, and higher-level concerns. If SEA researchers can go beyond performing studies to learning about the needs and expectations of groups in industry and the technical possibilities for research and inform that with its knowledge of regulatory, policy, and economic issues, SEA may be able both to provide input to many important research prioritization and planning decisions and to form needed connections between different groups. Recently, NREL has worked to aggressively grow the strategic energy-analysis component of NREL, moving from a few employees to over 100 in the division.

SEA alone does not guarantee that NREL's work has relevance, completes its mission, or does transformation research in renewable energy. However, it does represent a step that the laboratory is taking to place its work within the larger context of the energy innovation system. NREL faces constraints, both external and internal, but it can also work within these constraints to adapt its processes to changing energy contexts and new innovation regimes. NREL's constraints include those mentioned above, such as the budget, the ability to apply its technical knowledge to decisions, and the ability to conduct both basic and applied research that work toward industry needs. However, the laboratory is attempting to apply its technical abilities to solving pressing renewable energy innovation problems in a way that includes the user communities and transfers innovation into their hands. Progress in these areas may not be complete, and NREL and EERE might have to work further to continue such work in the face of changing policy regimes, budgets, and governmental priorities. Part of ensuring that the lab can be effective in the future involves assessing the activities of other institutions, and identifying what they do to improve the relevance of their work.

\subsection{Semiconductor Research Corporation}

One strategy to inform future directions at NREL, the other national laboratories, and energy research in general is to examine other institutions, organizations, and sectors. Study of SRC, an industry consortium that has enjoyed sustained support from its members and is now beginning to work on energy problems, brings out several recommendations for institutional management that can apply to the question of managing NREL and the broader issue of managing national labs.

\subsubsection{Mission and Description}

Robert Noyce, a co-founder of Intel and co-creator of the integrated circuit, announced the creation of SRC in 1981 as an endeavor by the Semiconductor Industry Association. A group of paying industry members founded SRC to invest in relevant academic research, intending it to help the United States compete in the international semiconductor market. Over time, SRC has expanded from its original research program, now called the Global Research Collaboration (GRC), to include two additional major initiatives also focused on semiconductor-related research, called the Focus Center Research Program 
(FCRP) and the Nanoelectronics Research Initiative (NRI). SRC also established two newer topical research programs, the National Institute for Nanoengineering and the Energy Research Initiative (ERI). Each program is a legally distinct entity that is a wholly-owned subsidiary of SRC. The programs address different timeframes and technology areas and, thus, also differ somewhat in industry membership, structure, and management.

The mission of SRC is specific and clear: It is "to manage a range of consortial, university research programs some of which are worldwide, each matching the needs of their sponsoring entities. SRC maximizes synergy between programs to optimally address members' research needs and minimizes redundancy to maximize value to common members" (SRC, 2011b). SRC works toward these goals by working at the boundary between the industry members who pay into SRC and the university academics that SRC funds to perform research. SRC reinforces the clarity of its mission with abundant involvement of the industry members. Central to the achievement of the mission is graduate training in semiconductor research and other efforts to continue semiconductor innovation in the medium and long terms.

As a type of industry consortium, the institution is not subjected to many of the management issues that institutions within the government face. For example, the funders are from the same organizations as the customers so that SRC is forced to meet user needs to retain its funding. Because the member companies fund the work, serve on SRC evaluation boards, and interact with the academics who perform the research, the system guarantees that a company can be actively involved in working to get what it wants from the process. Additionally, the companies have the ability to leave SRC if they are not pleased with its direction and results, providing incentive for SRC to keep its members satisfied.

Finally, where all funds from companies used to go into one common pool, SRC has changed policy in recent years to allow companies to direct a portion of their funding to projects that they believe are promising. This allows members to continue leveraging the larger pool of funding that SRC provides because they are not the only group contributing to a particular research thrust. (Thrusts are topical subdivisions within these science areas, and they can change depending on where the member companies believe significant academic developments can help them. ) Members direct a portion of their funds to further buttress a research area that they would like to support. SRC has shown itself to be flexible in its policymaking as well, with the ability to alter other processes to meet member companies' needs evident in many of its decisions. Because it requires the continued approval and participation of members, SRC is forced to be entrepreneurial. All of these characteristics point to SRC as an institution that has a mission that its member companies buy into and continue to produce results that these companies believe are pertinent. This institution is not useful for every semiconductor corporation; many companies in the field do not buy in. Those that abstain often do so because they do not see SRC research as useful to them. For example, relatively few companies work in semiconductor fabrication, which some 
SRC research is more pertinent to, although SRC does prioritize design work and other aspects of the industry as well. Many start-ups do not join because of their relatively small size. While such companies might also gain in social capital and in relationships with other businesses from working together in a consortium, and while they might also see workforce benefits from student development, they do not see these as worth the price of admission due to their typically smaller budgets.

Added to this clarity of mission is a simplicity in process that allows SRC to operate cleanly and efficiently. The member companies pay money according to set rules that consider the size of the company. Once it has paid its operating cost, SRC distributes the money per the recommendations of advisory boards sent from the same industry members. Once projects are chosen based on their desirability to industry, both SRC and member companies interact with the researchers at annual reviews, conferences, and liaison interactions. The number of actors is relatively few, as is the number of transactions. Moreover, while oversight is present, the amount of guidance/steering that SRC boards conduct during research implementation is limited.

\subsubsection{SRC Programs}

SRC used to consist of a single program, but it has added several more over the years. Each program has its own set of member companies that buy into the mission of that program. While many companies buy into more than one program, participation is contingent on the corporations' interest and willingness to become involved in each program individually.

The Global Research Collaboration (GRC) is the part of SRC that encompasses the original program. The GRC exists to fund relevant research that can help to extend the capabilities of complementary metal-oxide semiconductors (CMOS). The purpose is to keep stride with Moore's Law, which describes the trend of doubling the number of transistors on integrated circuits every two years and, thus, increasing attributes like memory and processing speed. The GRC typically operates through three-year contracts between SRC and the university researchers. In addition to the money that industry contributes, the GRC leverages significant funding, often from government sources, to contribute to the research. Between 1997 and 2010 the amount of leveraged funding-including collaborative funding, SRC-directed money, and SRC-influenced funding - varied between 8 and $73 \%$ of total funding. The amount of funding has been over $60 \%$ for the last six years. ${ }^{48}$ The overhead costs for the GRC are typically 12 to $13 \%$ of the funding provided by industry.

48 The types of leveraged funding are: "directed"-funds from a non-industry sponsor are transferred to and managed by SRC; "collaborative" - funding by a third party, usually a government funding agency, that is invested jointly with SRC but that is transferred directly to the university; and "influenced" - funding by a third party that is invested in SRC-relevant research based on input from SRC. 


\begin{tabular}{|c|c|c|c|c|}
\hline & $\begin{array}{l}\text { Global Research } \\
\text { Collaboration } \\
(\mathrm{GRC})\end{array}$ & $\begin{array}{l}\text { Focus Center } \\
\text { Research Program } \\
\text { (FCRP) }\end{array}$ & $\begin{array}{l}\text { Nanoelectronics } \\
\text { Research Initiative } \\
\text { (NRI) }\end{array}$ & $\begin{array}{l}\text { Energy Research } \\
\text { Initiative } \\
\text { (ERI) }\end{array}$ \\
\hline $\begin{array}{l}\text { Nature of } \\
\text { Research }\end{array}$ & $\begin{array}{l}\text { Narrowing options- } \\
\text { individual researchers } \\
\text { and centers }\end{array}$ & $\begin{array}{l}\text { Creating options- } \\
\text { multi-university centers }\end{array}$ & $\begin{array}{l}\text { Discover next-logic } \\
\text { switch-individual } \\
\text { researchers (at NSF } \\
\text { centers) and multi- } \\
\text { university centers }\end{array}$ & $\begin{array}{l}\text { Approaches to electrical } \\
\text { energy generation, } \\
\text { storage, distribution, } \\
\text { and infrastructure }\end{array}$ \\
\hline $\begin{array}{l}\text { Technology } \\
\text { Spectrum }\end{array}$ & CMOS & $\begin{array}{l}\text { CMOS + "hooks" to } \\
\text { beyond CMOS }\end{array}$ & Beyond CMOS & $\begin{array}{l}\text { Enabling technologies } \\
\text { in PV and smart grid }\end{array}$ \\
\hline $\begin{array}{l}\text { Industry } \\
\text { Involvement }\end{array}$ & $\begin{array}{l}\text { Strategic and in } \\
\text { execution }\end{array}$ & High-level strategic & $\begin{array}{l}\text { Influence through } \\
\text { highly leveraged co- } \\
\text { investment }\end{array}$ & $\begin{array}{l}\text { Strategic and in } \\
\text { execution }\end{array}$ \\
\hline $\begin{array}{l}\text { Government } \\
\text { Involvement }\end{array}$ & $\begin{array}{l}\text { Limited; leverage } \\
\text { funding }\end{array}$ & $\begin{array}{l}\text { 50:50 with DoD; } \\
\text { program direction }\end{array}$ & $\begin{array}{l}\text { Major funding - state } \\
\text { and federal (NSF and } \\
\text { NIST) }\end{array}$ & $\begin{array}{l}\text { None, but SRC is open } \\
\text { to the possibility }\end{array}$ \\
\hline $\begin{array}{l}\text { University } \\
\text { Autonomy }\end{array}$ & $\begin{array}{l}\text { Collaborative (Industry/ } \\
\text { University) }\end{array}$ & Significant & Significant & $\begin{array}{l}\text { Collaborative (Industry/ } \\
\text { University) }\end{array}$ \\
\hline Membership & Global & United States only & United States only & Global \\
\hline $\begin{array}{l}\text { Technology } \\
\text { Transfer }\end{array}$ & $\begin{array}{l}\text { Industry-driven } \\
\text { processes (e.g., } \\
\text { Industrial liaisons, } \\
\text { e-workshops, etc.) }\end{array}$ & $\begin{array}{l}\text { Primarily faculty-driven } \\
\text { processes (e.g., periodic } \\
\text { reviews, seminars, etc.) }\end{array}$ & $\begin{array}{l}\text { Combination of } \\
\text { industry and faculty } \\
\text { driven processes (e.g., } \\
\text { industrial assignees, } \\
\text { e-workshops, etc.) }\end{array}$ & $\begin{array}{l}\text { Industry-driven } \\
\text { processes (e.g., } \\
\text { Industrial liaisons, } \\
\text { e-workshops, etc.) }\end{array}$ \\
\hline
\end{tabular}

TABLE 3.1 SRC Research Programs (adapted from SRC figure)

Because the member companies ultimately manage the GRC, the Board of Directors consists of representatives from the companies and has overall responsibility for the GRC's direction. Additionally, there is an Executive Technical Advisory Board to direct the program. In the five science areas within the GRC, a Science Advisory Coordinating Committee participates, and a Technical Advisory Committee helps to direct each thrust. Science committees include Device Sciences, Computer-Aided Design and Test Sciences, Integrated Circuits and Systems, Nanomanufacturing Sciences, and Interconnect and Packaging Sciences.

The Focus Center Research Program (FCRP) looks to work on technological changes that are farther out than the three- to five-year span addressed by the GRC. In doing so, FCRP works by funding interdisciplinary centers that are typically led by researchers at one university, but integrate multi-university teams for solving problems. In addition to its member companies, FCRP receives approximately half of its funding from the Defense Advanced Research Projects Agency (DARPA). 
$\mathrm{NRI}$ is another program under the SRC umbrella. It exists to look beyond the incremental changes that comprise fulfilling Moore's Law and to harness open industry participation in next generation technologies (Apte \& Scalise, 2009). In addition to its corporate members, NRI has the participation of the National Institute of Standards and Technology and strategic partnerships with the National Science Foundation, the Semiconductor Industry Association, and four state-governments.

SRC's most recent program is the Energy Research Initiative (ERI), which exists to leverage industry member funding into academic discovery in precompetitive energy technologies. The mission states that it will "enable reliable, low-cost renewable energy systems and efficient energy use and distribution through an enabled and optimized smart grid" (SRC, 2011a). ERI currently focuses in two places: Smart Grid technology and photovoltaics. While the program is just beginning, ERI provides insight into how SRC might extend its model to be influential in new fields. Members of ERI include some companies that participate in other SRC programs, like IBM and Applied Materials, and some companies that are closely tied to the energy industry, such as thin-film manufacturer First Solar, power-technology company $\mathrm{ABB}$, and cabling-system manufacturer Nexans.

\section{Leadership and Advice}

SRC's leadership structure is fairly simple, allowing for efficient management within the corporation along with participation by industry members through a number of advisory boards. Many of the leaders of SRC have been involved with the institution for a long time, and its president, Larry Sumney, has been running the institutions since its inception in 1982. In the face of changing market dynamics and industry needs, this 30-year consistency speaks to the ability of SRC leadership to continue delivering results to its members. Much of the role of SRC leadership is to serve as a middleman or liaison between the interests of industry and the academic researchers whom it funds. As such, the institution's advisory boards play a large role. These advisory boards consist of representatives from the member companies and direct both the short-term technical direction and the strategic planning of SRC.

Interactions during the prioritization process and during research itself drive SRC. According to one author, "Inputs from SRC member companies through the board of Directors, the Technical Advisory Board and the mentors assure the continued responsiveness of SRC research to industry technology needs. The challenge is to distill from the variety of inputs, a coherent agenda that is consistent with both the needs of a majority of the membership" (Burger, 2000). One of the ways that industry advisors have inputs is by rating projects that SRC is considering or conducting. Members can rate projects using a Success and Impact (SI) score, which stands for a number that is the product of ratings for both the project's impact and chances of success. By integrating such scores into the decision process, SRC can alter its path toward those ideas that users feel are more likely to contribute benefit and can thus be flexible to keep their members satisfied. 


\section{Other Processes}

In addition to broad guidance by the advisory boards, many of the projects in SRC programs receive guidance from yearly program reviews. These reviews serve as a means for researchers to disseminate their results within SRC and for members to critique the work and steer the direction for the next year. While projects usually fulfill their three-year terms, SRC programs can use annual reviews to guide and shape them as they develop.

A more personal, iterative relationship is also encouraged by the existence of industrial liaisons. Liaisons, who are employees from the members, work with the university researchers to provide input on a project so that it has a better chance of meeting an industry need and of eventually being commercialized. By making regular personal contact with the researchers, liaisons can help both the mentoring process for graduate students and the likelihood of a usable outcome.

Finally, SRC operates Techcon, a research conference and job fair that allows people working on SRC research to present to, and interact with, people in the industries who are paying them. According to interviewees who were past SRC-funded graduate students, Techcon was both a useful venue for learning about the state of the research and industry, and for securing the jobs they worked in following their studentships.

\subsubsection{SRC Performance}

In 2005, SRC won the National Medal of Technology:

For building the world's largest and most successful university research force to support the rapid growth and advance of the semiconductor industry; for proving the concept of collaborative research as the first high-tech research consortium; and for creating the concept and methodology that evolved into the International Technology Roadmap for Semiconductors (U.S. Patent and Trademark Office, 2010).

Several large companies have consistently funded SRC over almost thirty years. The willingness of companies such as IBM, Intel, and Texas Instruments to stay involved with SRC is evidence that the organization has been consistently meeting the expectations that its member companies set for it. This ability to keep its constituents satisfied manifests itself in several outcomes.

In terms of results, SRC has been successful in three ways. First, the research has helped to push technology forward to keep pace with Moore's Law and to contribute to other developments that will move innovation. While this first success does not solely aid the member companies, it does help them meet emerging market needs. The National Medal of Technology credits SRC with supporting growth in the industry. In 2009, 12 patents were issued for the GRC research and 12 for FCRP. This is far from 
the only way success in technology can be measured, and it does neglect all non-market benefits, like workforce development, capacity building, strategic orientations, and knowledge transferred through interactions between researchers and users.

Second, SRC has continually educated graduate students in semiconductor science and engineering, thereby providing a workforce for its member companies. When SRC began, the vast majority of graduate student research was aimed at materials other than silicon. SRC's strategy was to inject academic funding into the field they operate in. By ensuring a significant number of emerging $\mathrm{PhDs}$ with research skills in pertinent areas, SRC has created a valuable commodity. Building human capital, both through the relationships created between industry and academic experts and by actually developing a workforce fluent in semiconductors, is an important part of technology transfer that has been often overlooked in trying to measure the effectiveness of technology activities (Bozeman, 2000).

Finally, SRC has continuously contributed to road-mapping activities for the semiconductor industry. Semiconductor road-mapping has been a successful way to strategize the future direction not only for SRC and its companies specifically but also for the larger semiconductor area they operate within. SRC utilizes such roadmaps in deducing the direction of its thrusts and science areas.

\subsubsection{Applying Lessons from SRC}

Utilizing all of the SRC's decision-making flexibility and accountability to customers in a federal institution may be difficult, but there are transferable lessons and strategies. SRC operates in a market and context that is arguably simpler than that of NREL, since the semiconductor market does not have the regulatory, policy, or complexity issues that energy does. SRC has, in its simplicity of process and flexible decision-making, instituted policies that would benefit other institutions as well. Both institutions have been successful at building and maintaining relationships with a large portion of the industry that concerns them, but the direct relationship between evaluator, funder, and user at SRC adds effectiveness. While the funder for NREL will always be the government, more accountability to its user groups may aid it in serving them.

The user group buy-in is ensured at SRC because the institution would not be able to exist without it. In contrast, the relationship between national laboratories and the named customer-industry-is not as tight due to the realities of the DOE funding structures. The national laboratories could conceivably fail in their mission and continue receiving funding from appropriators if they are unaware of, or unconcerned with, such failures to adequately meet user needs. For this reason, building accountability to user groups is a necessity for the labs. Formal decision-making responsibility should always lie within the agency or the laboratory itself because someone needs to be held accountable for the final decision, but institutions should allow inputs and guidance by including customers in mechanisms that could 
be similar to those that SRC incorporates with its yearly reviews. An advisory process that formally included members of the industries served by laboratory research could enhance the incentives for the laboratories to work toward industry benefit.

Since SRC membership is based on yearly dues, its funding is quite stable, and the funding it gives to academics is stable as well. The situation is such that funding will only change drastically if multiple members were to leave the organization or to join. Unlike NREL, which has to cope with the vagaries of federal budget politics, this stability is likely as long as SRC keeps its members satisfied.

SRC has successfully integrated academic and industry concerns for years and, in some of its programs like the FCRP and NRI, has included active participation of government entities as well. One potential outcome of the new ERI could be the development of valuable collaborative relationships among government, industry, and universities within the field of energy. SRC has been attempting to use its past successes in industry/university partnerships to promote new kinds of partnerships with federal laboratories that could be useful in addressing problems of energy innovation.

Additionally, SRC excels in its organizational flexibility. The administrative underpinnings of the institution are small, but it, along with the cooperation of its advisory boards and other member inputs, can change its research thrusts yearly to make new, more effective research policy when needed. Much of NREL's direction is managed outside of the laboratory, in EERE, the DOE, and Congress. To allow them to adapt, NREL and other labs should have some influence over their program direction. While its current influence takes place through advising and giving recommendations to those making the decisions, placing more decision power with NREL itself, especially in the form of discretionary, lab-directed money, could aid the lab by making it responsive to upcoming problems or opportunities within its field, where it is both more expert and more able to respond quickly than the whole DOE could. Increased responsibility would also lead to greater accountability at NREL.

The use of industry funding to produce a generation of young people expert in the semiconductor field is also integral to the success of SRC. SRC has put effort into building a base of graduate students to comprise its talent base. The number of U.S. dissertations with the descriptor "silicon" almost tripled, from 162 to 470, between 1982 and 1990. In the same time period, dissertations using the key word “integrated circuits" went from 31 to 110 (Burger, 2000). Many of these dissertations emerged from SRC funding. Their authors contribute valuable semiconductor research during their graduate careers, and many go on to work in the semiconductor industry, ensuring continued innovation.

Finally, the willingness of SRC and the semiconductor industry to come together and look at its future direction has proven to be one of its strengths. A recent Presidential Council of Advisors on Science and Technology (PCAST) presentation stressed the importance of technology roadmaps in its proposals; 
SRC's long participation in SIA road-mapping is an important one. Examination of the road-mapping process could lead to more insight for energy projects going forward that impact on technology (Moniz \& Savitz, 2010). The DOE roadmaps would have input from the external community and manifest "goals and milestones, critical decision points, projections of cost, benefits and analysis."

\subsection{RECOMMENDATIONS}

\subsubsection{Recommendations for NREL}

NREL's problems relate to the need for the institution to maintain consistency and flexibility in the face of changing markets, policy regimes, political realities, and budgets. While the American Reinvestment and Recovery Act was a financial boon, there is no guarantee that NREL's funding will be stable for the longer term. Additionally, the lab's priorities have changed from administration to administration. Even given a stable budget, it often needs to alter its course. The ability for the lab to address these challenges is limited, due to the authority of EERE, the DOE, the executive branch administration, and the legislature. However, the laboratory can work within its boundaries to have an impact. NREL is already addressing this to a large extent by working with user groups, encouraging CRADAs and other relationships with industry, and attempting to address gaps between basic and applied research. However, budget variability, the level of administrative separation, and the lack of formal connections between basic and applied research could all be remedied with different policy approaches. The recommendations below are suggested as a means for the laboratory to improve upon its current performance. Some of them also apply beyond NREL, as will be discussed in the next section.

- Continue building relationships with user communities: NREL has proven its technical competence through innovative research and the organizational benefits from a workforce that identifies strongly with its mission. NREL should continue to focus on building relationships with the user community, both at the Principal Investigator level and higher. There is ample evidence that NREL researchers and decision-makers have a deep knowledge of their constituents, especially in areas such as thin-film photovoltaics, but more breadth in technology area and representation from companies in all areas of renewable energy could help the lab understand its innovation problems systematically and comprehensively.

- Encourage innovation through employee entrepreneurship: The laboratories might encourage users to interact with their researchers, but allowing researchers to undertake entrepreneurial activities could also improve the ability of the laboratory to learn from industry partners and transfer technologies into the market. NREL allows employees to take leave, but only for six months, and these actions are not encouraged. Unlike NREL, Sandia has a program, called Entrepreneurial Separation to Technology Transfer, which allows researchers to be on leave from the laboratory for up to two years. According to one study on such programs, NREL's tech- 
nology transfer staff argued "that because researchers are selected on their research skills rather than entrepreneurial talent or business acumen, they are not optimal founders of companies, as they neither have the interest nor the credibility from investors." (Kim, 2011). However, at Sandia, researchers do participate in the leave program, and $60 \%$ of these do so with preexisting companies, meaning that they may not need entrepreneurial or business skills. Rather, they may add necessary technical skills to existing entrepreneurial activities. Increased focus on allowing such activities at NREL could further aid it in transferring knowledge and expertise to business ventures.

- Ensure that technically proficient researchers and those who have experience in energy analysis participate regularly in decision processes: EERE could support high-level interaction between NREL staff, the DOE decision-makers, and technology consumers by increasing NREL's authority and accountability; NREL staff should be able to gain from social capital-enhancing activities such as procurement and contracting, since those who are close to being finished have experience and input necessary for making the decisions. This does not dictate that such programs are managed at the NREL level, but it does support high-level interaction. Strong relationships between researchers, people in commercialization, and industry must be ensured.

- Active management strategies linking fundamental research, application, technology development, and deployment should be considered: While interaction and mission orientation are both important steps in this process, the inclusion of formal guidelines for such processes can benefit the laboratory. Examples exist in other federal institutions and non-governmental research institutions. For example, DARPA, NIST (Logar, 2009), and private industries (Tennenhouse, 2004) have instituted the Heilmeier Questions, named after a former director of DARPA, that encourage consideration of technical demands along with the applicability of the project and fit to mission. One version of the Heilmeier Questions is:

What is the problem; why is it hard?

How is it solved today, and by whom?

What is the new technical idea; why can we succeed now?

Why should NREL do this?

What is the impact if successful, and who would care?

How will you measure progress?

How much will it cost, and how long will it take? 
The questions guide both prioritization and implementation and are a practical means for considering both scientific values and the impact of a project. By instituting formal heuristics in decision processes, policy makers can induce a culture that encourages consideration of the usability of products. However, usability need not be encouraged at the expense of long-term research. As some efforts to ensure application can unintentionally encourage a trend toward shorter-term, "commercializable" projects, NREL must also manage to retain a balance that allows for support of some high-risk fundamental research. Given this risk, NREL management must be savvy enough to strike an appropriate balance between short-term applications and long-term, high-risk research.

- Increase funding for Laboratory-Directed Research and Development: This would provide the lab with a means for addressing needed research areas, or pursuing high-risk research that EERE or the OS is not funding. The DOE Order 413.2B sets an upper limit for LDRD at $8 \%$ of a "laboratory's total operating and capital equipment budgets", but does not set a lower limit. Setting a minimum would ensure that a significant amount of money is available for pursuing unfunded but promising high-risk research, proof-of-concept work, and development work on basic research that has paid off. According to decision-makers at NREL, increasing the percentage at smaller labs is difficult because it must come out of direct funding, and it dramatically drives up overhead costs. Therefore, augmenting LDRD amounts might require changes to the funding mechanisms. However, allowing for more base funding and manager-directed funding at the laboratory could create both consistency and flexibility at the lab. NREL currently uses $\$ 8$ million per year for laboratory-directed research and development, which is only $2.6 \%$ of its 2009 Congressional budget, and much lower than the $8 \%$ limit. A larger amount of discretionary funding could help the director fill holes in knowledge that are missed by higher level decisionmakers, continue funding for promising areas that have been cut off, or explore new areas that are missed by current policy initiatives.

\subsubsection{Recommendations beyond NREL}

- Consistent institutional support: A stable vision and guiding principles for laboratories can enable development of long-term projects, allow for planning beyond the next budget period, and enhance the likelihood that knowledge gains can be developed into eventual technology products. These principles should also be central to the new DOE innovation institutions, including ARPA-E, the Joint BioEnergy Institute, and the Energy Innovation Hubs. Three main activities can facilitate this.

- Encourage stable budgets in institutions: At NREL, the current, unstable situation both detracts the ability of the laboratory to plan for the future and sends the message that the government does not consistently support the NREL mission. Without a more consistent 
approach, this trend will likely continue. For the federal organizations above NREL and other laboratories that suffer from budget vagaries, giving the laboratories the stability of funding and mission that they need to perform consistently is necessary.

- Maintain a consistent mission and consistent implementation of mission: The laboratory's mission, as worded, has not changed greatly over time, but external factors have altered the degree to which NREL prioritizes commercialization, advancement of knowledge, or both to fulfill its mission goals. Furthermore, the higher-level rhetoric surrounding renewable energy has changed and altered NREL's implementation of its mission. For example, George W. Bush stressed hydrogen and biofuels during his administration while President Barack Obama has continued prioritizing biofuels, but not hydrogen to the same extent. These changes affect conduct and budgets at the institutional level, but are out of the control of the DOE. Additionally, while much of the laboratory receives its funding from EERE and, thus, works under the umbrella of that mission, the OS funding is not linked to the same goals. Lack of reconciliation between these higher-level missions constrains the lab in ensuring that all of its research works toward its own mission. While awareness of new needs and opportunities is also necessary, the system should maintain stability of purpose and area of work.

- Manage contracting to allow for insulation of the national laboratory: More complicated administrative operations are not a definite outcome of the contracting model that most national laboratories operate under, but they are a risk. Narayanamurti et al. (2009b) warn that the laboratory management used to follow an "insulate but not isolate" principle, where the government funded and managed contracts, but labs were somewhat free to pursue their missions without frequent subjection to political considerations. They warn that changing political climates have altered contractor management of laboratories from an entrepreneurial system to one that resembles typical civil-service institutions. One place where this could manifest is in contract management, where the terms of success and failure are negotiated. The DOE management of such contracts to allow the laboratories some independence and flexibility is necessary.

- Develop a workforce for the future by funding mission-specific graduate and post-doctoral education: Explicitly aim a portion of research dollars at encouraging research in energy innovation. SRC attributes much of its success to its ability to produce future researchers by funding students in its field. For the DOE, a vacuum exists where graduate training for future energy research should be. Some amount of the DOE funding should be geared specifically toward training new professionals in energy science and technology, especially in cases where crossdisciplinary or multidisciplinary experience is needed. More grant programs within the DOE and national labs should address such needs, especially within the growing field of renewable 
energy. Some programs, such as ARPA-E and the EFRCs, do fund university programs, but all units could benefit from more programs aimed explicitly at addressing graduate education within their program areas, and labs like NREL could have strong results from mission-directed graduate research funding. Such programs for university research could serve as an important means for acquiring a long-term, sustainable, skilled workforce.

- Expand methods for industry collaboration: CRADAs are one way to promote partnerships and innovation, but the DOE should explore other means of linking industry efforts to federal research. CRADAs have had value, but they have also been criticized for being slow and burdensome for industry partners. While laboratory testing and Work for Others are useful, they do not enable the laboratory to effectively harness the expertise of their industry partners. Additionally, licensing is valuable when technologies are transferred, but occasionally, a useful project can only be the result of partnership in concert on a research topic. Discussion of new ways to explore such relationships that can lower the hurdles for industry, without allowing them to free ride on the laboratories' effort, could produce new means for partnering. In addition to bilateral partnerships, the labs should have the flexibility to contribute to multi-institution centers devoted to addressing central problems of energy innovation. These centers could be virtual rather than physical, but should integrate strategic energy analysis and long-term thinking with research, technology development, and planning. Such centers might be similar to the Energy Innovation hubs that have begun in the past few years, but should include the expertise of laboratory staff and their partners.

- Integrate the DOE energy-research system: In addition to the national laboratories, the Department of Energy now operates through a variety of mechanisms, including ARPA-E, Energy Frontier Research Centers (EFRCs), and Energy Innovation Hubs. While support of overlapping, distinct thrusts in energy innovation can be useful, some amount of coordination between all of the actors in energy innovation is necessary. Coordination could include integrating the fundamental research projects performed at EFRCs with applied programs at hubs and labs, inclusion of laboratory staff in hub or EFRC activity, communication between ARPA-E and other institutions, and collaborative long-term planning. Such activities should include the three recommendations below:

- Support both fundamental research and technology development: NREL is working to tie its basic research to applied research and development, but both EERE and the OS need to ensure that such work does not go neglected. Part of the impetus behind basic research that eventually leads to good outcomes can be knowledge of and direction toward the field of application. In addition to considering application-oriented fundamental research, programs must institute means for picking up where basic research leaves off, and supporting the 
project across the "valleys of death" that can ensue when such linkages go unsupported. The OS funds much useful fundamental research, but should connect such research to eventual application in an effort to enhance energy innovation. This should be an explicit part of its mission and operations.

- Continue focusing on strategic analysis of energy problems: The DOE currently supports such activities at several labs. It should also widely support planning for future innovation efforts through road-mapping activities. Such activities have been proposed by members of PCAST, and are one place where lessons in research prioritization and management could be taken from SRC. Organized formal interactions between analysts, researchers, and decisionmakers can also increase fluency in energy contexts and opportunities.

- Continue supporting a portfolio of institutions supporting energy innovation: The administration and Congress should provide support for a portfolio of energy innovation institutions designed to sustain all stages of the innovation chain, while avoiding gaps and "valleys of death." In particular, they should provide sustained support for ARPA-E, the Energy Innovation Hubs, and the Energy Frontier Research Centers.

\subsection{Conclusions}

The recommendations above can provide some guidance in directing energy innovation institutions toward more relevant work by allowing both strategic and technical knowledge to flow between actors and sectors, by maintaining stability of mission, and by allowing for some flexibility for institutional decision-makers to shape the agenda and respond to impending needs. NREL and SRC are only two innovation institutions, but from such cases, along with data on other types of institutions (e.g., Logar, 2009; Logar \& Conant, 2007), we can begin to build information on how to manage innovation. Given the size of the energy economy and the pressures to reform our energy system, the need to continue innovating is high. While pumping more money into the U.S. innovation system would likely accomplish more innovation, programs that deliver results through effective management, long-term vision, and consistency of purpose could do much to improve the state of our innovation system. While such work only creates options, that can possibly be made moot by regulation, market pricing, behavioral issues, or other unpredictable futures, working to deliver these options and alternatives should be a goal of any research institution. 


\section{REFERENCES}

Apte, P., \& Scalise, G. (2009). The recession's silver lining. IEEE Spectrum, 46 (10), 46-51.

Bozeman, B. (2000). Technology transfer and public policy: A review of research and theory. Research Policy, 29, 627-655.

Brown, G. (1992). Guest comment: The objectivity crisis. American Journal of Physics, 60, (9), 779-781.

Burger, R. M. (2000). Cooperative research: The new paradigm. (Unpublished manuscript). Retrieved from Semiconductor Research Corporation.

Chu, S. (2009). Testimony of Secretary of Energy Steven Chu, FY 2010 Appropriations Hearing.

David, P. (1983). Packard report urges more autonomy without change. Nature, 304, 199.

DOE. (2008). DOE selects ASE to manage and operate its National Renewable Energy Laboratory. Retrieved July 29, 2008 from http://science.energy.gov/bes/

Dunderstadt, J., Was, G., McGrath, R., Muro, M., Corradini, M., Katehi, L., Shangraw, R., \& Sarzynkski, A. (2009). Energy discovery - Innovation institutes: A step toward America's energy sustainability. The Brookings Institution, Washington D.C.

EERE. (2006a). Performance evaluation of the Midwest Research Institute for the Management and Operation of the National Renewable Energy Laboratory; October 1, 2005 through September 30, 2006 Performance Period.

EERE. (2006b). President Bush promotes the Advanced Energy Initiative.

EERE. (2011a). Energy Innovation Portal. Available: techportal.eere.energy.gov [2011, 07/17].

EERE. (2011b). Entrepreneur in Residence Program. Retrieved July 17, 2011 from http://www1.eere. energy.gov/commercialization/entrepreneur_in_residence.html

First Solar. (2003). First Solar's breakthrough technology wins RઐD 100 Award. Retrieved from www. nrel.gov/pv/thin_film/docs/first_solar_breakthrough.doc

Funtowicz, S. O., \& Ravetz, J. R. (1993). Science for the post-normal age. Futures, 25 (7), 735-755.

Gibbons, M., Limoges, C., Nowotny, H. Schwartzman, S., Scott, P., \& Trow, M. (1994). The new production of knowledge: The dynamics of science and research in contemporary societies. London: SAGE Publications.

Kim, H. (2011). Commercializing Low-Carbon Energy Technologies from Research Laboratories through Start-Ups. Unpublished MS Dissertation. Oxford University.

Laird, F. N. (2001). Solar energy, technology policy, and institutional values. Cambridge, England: Cambridge University Press. 
Logar, N. (2009). Towards a culture of application: Science and decision making at the National Institute of Standards \& Technology. Minerva, 47, 345-366.

Logar, N., \& Conant, R. (2007). Reconciling the supply and demand for carbon cycle science in the U.S. agricultural sector. Environmental Science \& Policy, 10 (1), 75-84.

Marburger, III, J. H. (2005). Wanted: Better benchmarks. Science, 308 (5725), 1087.

Marczewski, R. (1995). Testimony of Richard Marczewski, Manager, Technology Transfer Office, National Renewable Energy Laboratory. U.S. House of Representatives, Committee on Science, Subcommittee on Technology and Subcommittee on Basic Research; Hearing on Technology Transfer. 104th Congress. Congressional Record, volume 141, Issue 106. June 27.

Moniz, E., \& Savitz, M. (2010). Accelerating the pace of change in energy technologies through an integrated federal energy policy. President's Council of Advisors on Science and Technology, September 2, 2010.

Narayanamurti, V., Anadon, L. D., \& Sagar, A. D. (2009a). Transforming energy innovation. Issues in Science \& Technology, 26 (1), 57-64.

Narayanamurti, V., Anadon, L.D., \& Sagar, A.D. (2009b) Institutions for Energy Innovation: A Transformational Challenge. Paper, Energy Technology Innovation Policy research group, Belfer Center for Science and International Affairs, Harvard Kennedy School, September. Cambridge, MA, United States.

NREL. (1995). NREL funding reductions to further impact lab's workforce. Retrieved from http://www. nrel.gov/news/press/1995/layoff.html

NREL. (2009). Recovery Act money invested at NREL. Retrieved from http://www.nrel.gov/ features/20090501_chu.html?print

NREL. (2010). NREL's Clean Energy Forum attracts nearly 500 participants from investment community. Retrieved from http://www.nrel.gov/news/press/2010/902.html

OSTP. (1983). Report of the White House Science Council Federal Laboratory Review Panel. May.

Physics Today. (2011). U.S. weapons labs determined to retain funding. Retrieved May 11, 2011 from blogs.physicstoday.org/politics/2009/08/us-weapons-labs-determined-to.html

Pielke, Jr., R. A. (1995). Usable information for policy: An appraisal of the U.S. Global Change Research Program. Policy Sciences, 38, 39-77.

Pielke, Jr., R. A. (2003). Wanted: Scientific leadership on climate change. Issues in Science and Technology, Winter, 27-30.

Pielke, Jr., R. A., \& Byerly Jr., R. (1998). Beyond basic and applied. Physics Today, 51 (2), 42-46. 
Rubin, H. J., \& Rubin, I. S. (1995). Qualitative interviewing: The art of hearing data. London: SAGE Publications.

Sarewitz, D., \& Pielke, Jr., R. A. (2007). The neglected heart of science policy: Reconciling supply of and demand for science. Environmental Science \& Policy, 10 (1), 5-16.

Serface, J. (2009). My year as NREL's entrepreneur in residence. Retrieved from http://www. cleantechblog.com/2009/05/my-year-as-nrels-entrepreneur-in.html

Shapley, D., \& Roy, R. (1985). Lost at the frontier: U.S. science and technology policy adrift. Philadelphia: ISI Press.

SRC. (2011a). ERI mission and objectives. Retrieved July 17, 2011 from http://www.src.org/program/ eri/about/mission/

SRC. 2011b). SRC vision, mission, charter and values. Retrieved July 17, 2011 from http://www.src.org/ about/mission/

Stokes, D. E. (1997). Pasteur's quadrant: Basic science and technological innovation. Washington, D.C.: Brookings Institution Press.

Tennenhouse, D. (200). Intel's open collaborative model of industry-University research. ResearchTechnology Management, July-August, 19-25.

U.S. Patent and Trademark Office. (2010). The National Medal of Technology and innovation recipients. Retrieved July 24, 2011 from http://www.uspto.gov/about/nmti/recipients/2005.jsp

Vance, A., \& Miller, C. C. (2010). 6 Months, \$90,000 and (maybe) a great idea. Retrieved from http:// billionaires.forbes.com/article/05dkbwA2Ey3Gu

Wiser, R., Bolinger, M., \& Barbose, G. (2007). Using the Federal Production Tax Credit to build a durable market for wind power in the United States. The Electricity Journal, 20, 77-88. 

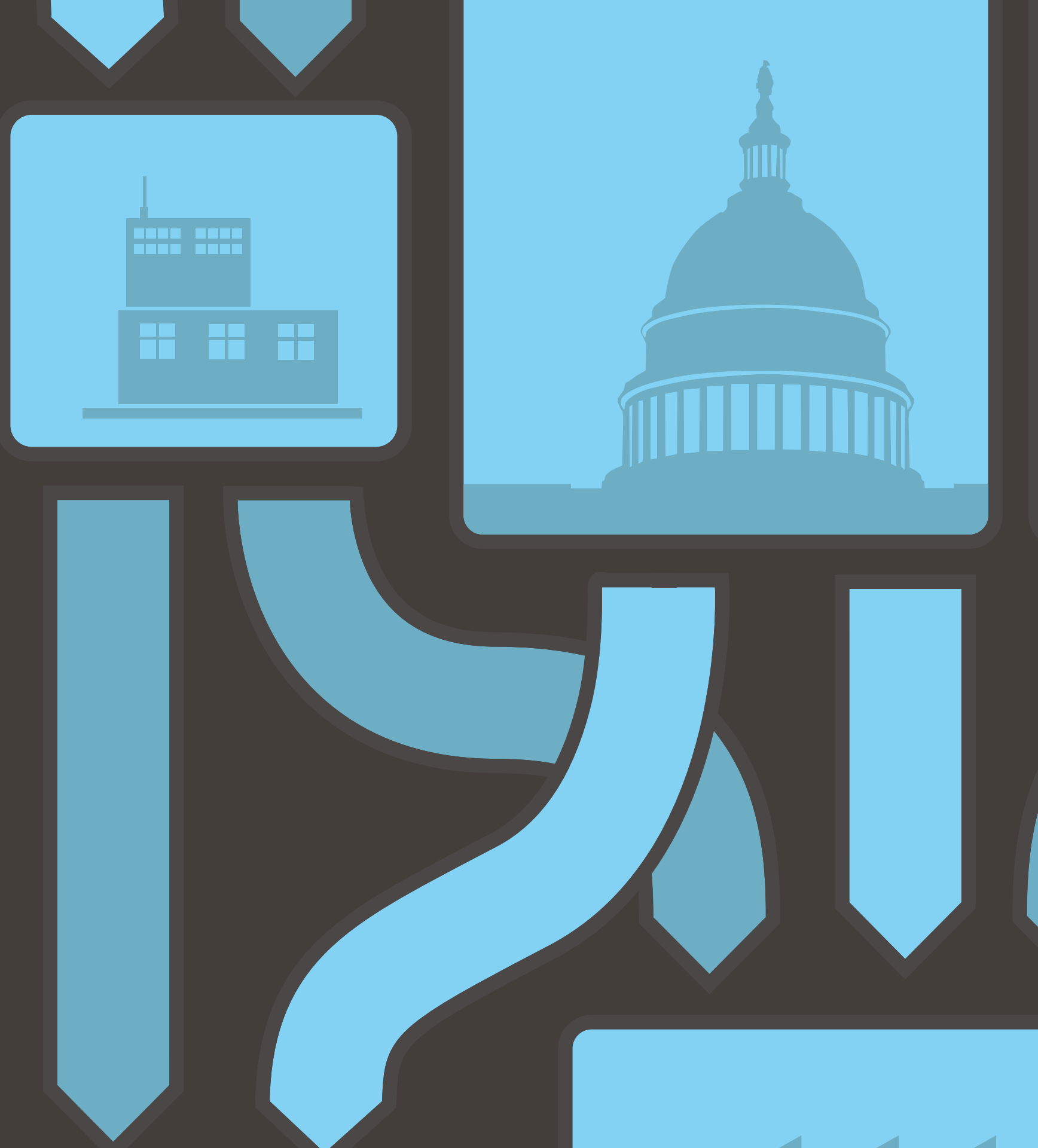
CHAPTER 4

\section{INNOVATION IN THE PRIVATE SECTOR AND PUBLIC- PRIVATE PARTNERSHIPS}

\subsection{INTRODUCTION}

Private sector firms are critical players in energy technology innovation. As described below, the private sector funds and carries out the majority of energy research, development, and demonstration (ERD\&D) in the United States, and new energy technologies can only make significant contributions to major energy challenges if they are adopted on a broad scale by the private sector.

In this chapter, therefore, we explore two sets of questions. First, what are private sector firms in the United States doing today in energy innovation, and how can the U.S. government best encourage them to do more? Second, how can U.S. government ERD\&D partnerships with the private sector-a major part of the federal investment in ERD\&D—be made more effective?

Government, academic, and private sector research all have roles to play in energy technology innovation. In general, work in academia and in government scientific institutions dominates the early stages of discovery, while the private sector plays an increasingly important role as development leads toward general production or use (Gallagher, Holdren, \& Sagar, 2006). Both private firms and governments often sponsor research in universities, and governments often support innovative activities in private firms and otherwise create the conditions in which private companies make decisions about innovation. Encouraging an increased effort by the private sector has been a goal of public policy in energy and innovation in general (DOE, 2006; CCTP, 2006; DOE, 2011b; EOP, 2009). Though the Department of Energy is the largest single investor in energy technology innovation, the private sector collectively funds and carries out the majority of ERD\&D in the United States. New energy technologies can only make significant contributions to the major energy challenges if they are adopted on a broad scale by the private sector.

The effectiveness of investments in energy technology innovation can depend on the quality of the interaction between sectors. Private sector innovation benefits from services, facilities, and information provided by the national laboratories. Government research benefits from the skills and resources of private-sector partners. Funding can be better allocated if funders understand the potential of technologies and the barriers being faced by the companies creating them. Many important projects require skills and resources that no one organization could provide, making partnerships the best strategy. Collaboration and communication across sector boundaries is vital. 
Government plays an important role in the energy technology effort, and cooperation with the private sector is an important part of the government's effort. Imperfect current estimates of total government and private investments in energy R\&D represent less than $0.8 \%$ of expenditures on energy (see section 4.2.2), much lower than the ratio of $R \& D$ to total sales in other industries. Department of Energy (DOE) funding represents $39 \%$ of these rough estimates of total public and private funding in the United States. Grants and cooperative agreements with private firms represent about $30 \%$ of the ERD\&D budget and 55\% of the Science budget within the DOE. An effort to formulate a new strategy (DOE, 2011b) and a comprehensive review of energy technology (DOE, 2011a) are both underway. For all these reasons, it is vital to understand more about the role of public-private partnerships and the private sector in energy technology.

In this chapter we first offer data from a new Survey of Energy Innovation conducted for this study, which assessed both the scope of private sector energy innovation and key drivers of these investments. Based on the insights from that survey, we offer recommendations for U.S. government policies to strengthen private incentives to invest in energy technology innovation. The survey found energy technology innovation to be widespread, particularly among smaller-scale participants who had not been measured previously. The survey was a pilot-scale study and should be expanded to provide better estimates and more detail, but the results underscore the need for, and the enormous benefit that would result from, a more strategic support for private sector innovation by the U.S. government, and from further incentivizing private sector innovation through demand-side policies. The lower bound on the fraction of U.S. business establishments for whom energy is important is between 2.3 and $4.5 \%$; the lower bound for establishments involved in energy-related innovation is between 1.1 and 3.7\%. With an estimated 10.8 million active establishments in the sample pool, our survey results indicate that there are currently at least 120,000 businesses involved in energy technology innovation (each of them a potential partner for government energy RD\&D programs), and at least 250,000 businesses which would be potential beneficiaries of new energy technologies. Demand-side policies, such as a clean energy standard or a price on carbon emissions, would certainly increase the number of entities engaged in energy innovation and expand the efforts of those already involved, thereby increasing the prospects for more advanced energy technologies. The survey also indicates that innovation is particularly important to start-up energy companies, who report investing $75 \%$ of start-up capital in innovation. Cost-related issues, including energy prices, are the most important drivers of innovation, and issues related both to the lack of markets for a technology at current costs and the difficult innovation process are equally important barriers.

Second, in this chapter we analyze DOE efforts that involve funding energy technology innovation in the private sector and universities. From 2000 through 2009, DOE awarded $\$ 9.1$ billion to support basic science, and $\$ 7.2$ billion to support applied ERD\&D. ERD\&D projects attracted $\$ 9.5$ billion in outside matching funds, indicating the value placed on these projects by the private sector. The distribution of 
support is volatile, and information about projects is limited. We use public data, management lessons, and expert interviews to uncover opportunities for improving the effectiveness of public and privatesector investments through project management, strategic planning, and learning and adaptation.

The survey results, existing data, and expert interviews lead us to conclude that changes to strategy would improve the interaction between the Department of Energy and the private sector, including: partnerships in strategic decisions; creating a means for learning and adaptation for management practice; and improving the relationship with and knowledge about industry. An improved interaction with business would likely increase the involvement of the private sector in energy technology innovation, and create benefits for even more businesses. These changes will help get the most value from investments in energy technology innovation and speed the transformation of the nation's vital energy systems.

\subsection{BACKGROUND}

Although all sectors-academic, governmental, non-profit, and private-have a role in energy technology innovation, the trajectory of a technological advance cannot be successful until a product or process is in use, which, in market economies, means it must be produced and sold by the private sector. Research conducted at universities or the national laboratories risks being wasted if it does not transfer to firms that are able to commercialize discoveries (FLC, 2007a), or if it does not at least inform subsequent research efforts. Large private research labs once dominated the technology development process, with basic research at universities acting as a reservoir of common knowledge. The current system is much more complex, and a policy of merely supporting basic research and waiting for commercial results is no longer effective (Mowery, Nelson, \& Martin, 2010; Block \& Keller, 2008). Two problems compound the difficulty, especially in the private sector: the amount and distribution of investment is uncertain, and what indicators we do have suggest that investment levels are low compared to the need and potential for energy technology innovation.

\subsubsection{Uncertainty in energy technology innovation investment}

Businesses fund and perform most R\&D in the United States when totaling across all sectors and applications. In 2008, $\$ 398$ billion worth of R\&D was performed by all sectors. Private-sector firms performed $\$ 289$ billion (73\%) of the total, and funded $\$ 268$ billion $(67 \%)$ of it. The private sector overwhelmingly concentrates on the later stages of innovation: $4 \%$ of its funding goes to basic research, $21 \%$ to applied research, and $75 \%$ to development. The result is that $84 \%$ of all development in the United States is funded by the private sector (NSF, 2010a). A complex flow of resources is involved in funding and performing R\&D (for more on which see section 4.2 .3 below). Of the United States' approximately $\$ 14$ trillion GDP in 2008, R\&D represented about 2.8\% with non-federal funding constituting about $1.9 \%$ (NSF, 2010b). 
Information on private-sector energy R\&D investments is much more limited. The most recent energyspecific data comes from the Survey of Industrial Research and Development (SIRD), last conducted in 2005 (NSF, 2009). SIRD sent a longer version of the survey, which included one question on energy applications, to known large R\&D performers who were deliberately selected based on prior surveys. Because of how the companies were selected, there is no way of accurately extrapolating to the total population. The results from this longer survey indicate that in 2005 , of the 2,731 companies responding to this long-form version, 102 reported performing energy-related R\&D and investing a total of $\$ 2.9$ billion, of which $\$ 2.8$ billion was privately funded. This level of private energy R\&D investment represents a floor, and is likely to be well below the actual total private R\&D investment in energy.

A successor of SIRD, the Business R\&D and Innovation Survey (BRDIS), is collecting information for the National Science Foundation (NSF) publications Science and Engineering Indicators (NSF 2010b) and National Patterns of R\&D (NSF, 2010a). BRDIS asks all respondents one question about what fraction of their R\&D effort has energy applications, but data including this question is not scheduled for release until 2011 for 2008 data (Wolfe, 2010). In addition, the definition of "energy applications" is, like in the SIRD, vague and only found in the detailed instructions (Census, 2009).

Similar to the long-form of the SIRD in concept, the Energy Information Administration (EIA) collects financial information-including R\&D expenditures-from the largest major energy companies (27 companies in 2008, predominantly oil and gas) (EIA, 2009). In 2008, these energy companies expended $\$ 2.2$ billion in energy and unassigned R\&D (i.e., not counting federal funds or non-energy R\&D); $\$ 1.3$ billion of that was spent on oil and gas recovery research. Energy R\&D reported to EIA is less than that reported in the SIRD over time, but tends to go up and down with the SIRD figures, indicating a large overlap between the two estimates. Nemet and Kammen (2007) make use of the NSF surveys and U.S. federal budget data to conclude that investment in energy innovation by U.S. firms is significantly less than what is necessary, and call for an increase in investment. A report by Pacific Northwest National Laboratory (Dooley, 2010) notes the overlap between EIA and NSF estimates, and their correlation to oil prices. Dooley adds estimates of Electric Power Research Institute (EPRI) and Gas Research Institute (GRI) expenditures to the data from $\mathrm{NSF}^{49}$ for an estimate of $\$ 3.4$ billion (in 2010 deflated dollars), or $\$ 3.02$ billion current dollars of private-sector energy R\&D in 2005 (Dooley, 2010).

A report for the European Commission Joint Research Centre (Wiesenthal et al., 2009) found a similar level of uncertainty in EU energy technology R\&D. Energy R\&D is funded by the EU, the member states, and by industry with both overlap and gaps in the available funding data sources. Although some EU records on the private sector are more comprehensive than those in the United States, Wiesenthal 
et al. resorted to collecting data from 136 large R\&D performers from filings, corporate reports, and interviews. Their estimates include a total of $€ 3.32$ billion (roughly $\$ 4.5$ billion in 2007) in EU-wide lowcarbon energy R\&D, 72\% of which went to non-nuclear technologies; they estimate the funding split to be $11 \%$ by the EU, $33 \%$ by member countries, and $56 \%$ by industry (Wiesenthal et al., 2009). These estimates do not include any fossil fuel or energy efficiency R\&D.

Another indicator of innovative activity is venture capital (VC) investments. Bloomberg New Energy Finance (BNEF) has been collecting information on VC and other investments (e.g., asset finance and private equity) in areas of "new energy"50 (a large subset of energy innovation) since the year 2000; but the information collected does not include R\&D investments in corporations, and not all VC investments are dedicated to R\&D. To compare with NSF data, which reported $\$ 2.8$ billion of energy R\&D investments in 2005 in the United States, the BNEF database reported \$2.2 billion in new energy VC funding. In 2009, BNEF reported $\$ 3.3$ billion of new energy VC funding. BNEF also tracks asset financing, which generally measures renewable energy or energy efficiency projects; in 2005 there was $\$ 4.6$ billion in new energy asset financing, in 2009, \$3.4 billion (Bloomberg New Energy Finance, 2009).

\subsubsection{Underinvestment in energy technology innovation}

As limited as the data are regarding investments in energy innovation, evaluations in the literature generally conclude that investment is inadequate (Nemet \& Kammen, 2007; Dooley, 2010). This fits into a long tradition of economic evidence pointing to a general underinvestment in innovation. For decades, the literature has stressed the role of innovation in economic growth (Solow, 1957; Schumpeter, 1934), and the fact that some benefits from innovation cannot be captured by individual firms means that the private sector tends to under-invest in innovation, and that policies are necessary to stimulate more appropriate levels of investment (Arrow, 1962). Investment in innovation may not be fully appropriable and subject to spillovers. In fact, evidence suggests that technology development as a good supplied by firms is subject to additional market failures (Cohen \& Levinthal, 1989; Margolis \& Kammen, 1999; Stoneman \& Diederen, 1994). In addition, research and development require long lead times, and the outcomes are uncertain, resulting in shareholder-focused firms under-investing in RD\&D (Anadon et al., 2009). As a result of these market failures, econometric studies have consistently estimated that the social returns to investments in innovation are far higher than the returns experienced by any one company, suggesting that the government has a major role to play in stimulating socially optimal levels of innovation (Margolis \& Kammen, 1999; Audretsch et al., 2002; Brown, 2001; Jaffe, Newell, \& Stavins, 2005).

50 Bloomberg New Energy Finance analysts track financial markets, filings, announcements, transactions and other indications of activity in clean energy, low carbon and carbon markets, including wind, solar, biomass, geothermal, efficiency, carbon capture and sequestration, carbon trading, services \& support, etc. (Bloomberg New Energy Finance 2009). 
To compound the problem, all energy-related issues are also subject to multiple market failures (Brown, 2001; Jaffe, Newell, \& Stavins, 2005; Jaffe, 1998). Energy availability and reliability are public goods, and energy use and production create externalities ranging from local pollution to global damage (Kammen \& Pacca, 2004). As an element of infrastructure, the energy system often requires large-scale investments, oversight, and coordination. Energy is a relatively small part of most corporate and household budgets, and thus improving the efficiency of energy use, for example, attracts insufficient attention by potential adopters (Brown, 2001). Incumbent industries and firms have both market and political advantages over newcomers-derived from returns to scale, accumulated resources, long lifetimes, and institutional legitimacy, among other reinforcing feedbacks-which lead to technology lock-in (Unruh, 2000). In short, innovation in energy technologies suffers from all the usual troubles inherent in technology innovation and energy systems (Gallagher, Holdren, \& Sagar, 2006; Fri 2003).

The results of these market failures are apparent, even though some of the measures of energy R\&D investments (particularly in the private sector) are uncertain. In 2005, measures of energy R\&D were \$3.0 billion by large R\&D performing companies (Dooley, 2010) (an under-estimate of R\&D by companies), $\$ 2.2$ billion in venture capital (Bloomberg New Energy Finance, 2009) (an over-estimate of R\&D by new companies in some-not all-energy-related sectors), and $\$ 3.3$ billion by the DOE (including funding for Basic Energy Sciences and energy RD\&D) (Gallagher \& Anadon, 2010). In the same year, expenditures on energy were \$1.1 trillion (EIA, 2010). ReD Magazine likewise estimated \$3.14 billion in energy sector industry R\&D, or about $0.3 \%$ of revenue (Battelle, 2010)

By these imperfect measures, energy R\&D is less than $0.8 \%$ of energy expenditure in the United States, compared to a total $R \& D$ of $2.8 \%$ of the total economy (making the ratio of $R \& D$ to total expenditure 3.5 times lower for energy than for the economy as a whole). Furthermore, the DOE funds $39 \%$ of the energy R\&D that is known, whereas in the economy overall, the private sector funds $67 \%$ of all $\mathrm{R} \& \mathrm{D}$. Wiesenthal et al. (2009) estimate that in total, U.S. energy R\&D was $1.1 \%$ of all U.S. R\&D in 2007, while in the EU energy was $2.9 \%$ and in Japan $15.2 \%$ of total R\&D. Top firms in information, computers, and health care each invest more in R\&D than all energy R\&D put together (Battelle, 2010). In spite of the huge uncertainties in private energy R\&D investments, it seems clear that total U.S. energy R\&D investment is too low, and that the private-sector share is comparatively low. The small energy R\&D investment by the U.S. is striking, given the enormity of the energy-related challenges-environmental, security, and economic - that the United States and the world are facing (for more discussion on the urgency and importance of developing and deploying advanced energy technologies, see Chapter 1). Thus, from the information available on private-sector investments in ERD\&D (which is limited) it would seem that these investments are low compared to energy expenditures, to $R \& D$ in other industries, and to energy $\mathrm{R} \& \mathrm{D}$ in other countries. Government policies that shape private sector incentives for energy innovation investments are particularly important in determining the pace at which new energy 
technologies will be developed and deployed. Moreover, the long-term stability and predictability that private sector actors need to make investments is currently lacking.

\subsubsection{Funding and performance of energy R\&D}

To address the general innovation market failures, governments have long supported innovation through direct investments, particularly in the early stages (Jaffe, 1998). In the category of energy innovation, this role falls primarily on the Department of Energy, which is also a major supporter of basic research in the physical and life sciences. (Other agencies that support innovation in energy technologies include the Departments of Agriculture, Defense [including the Defense Advanced Research Projects Agency, or DARPA], and Interior, as well as NASA.) Although many DOE activities are unrelated to energy innovation, ${ }^{51}$ the fraction that is dedicated to energy innovation represents a large share of the total U.S. activity in ERD\&D (roughly $40 \%$ of total funding, as described above). Using its activity to attract private-sector investment, to increase the value of private-sector efforts, and to push new technology into the marketplace are all goals of DOE strategy (DOE, 2006).

Finally, innovation is a social as well as a technological enterprise. What this means is that the systems for technological change cross organizational, field, and political boundaries and involve multiple interactions, feedbacks, and delays (Carlsson \& Stankiewicz, 1991; Garud \& Karnøe, 2003), making technology innovation a difficult process to manage.

Multiple goals and the needs of the different actors, along with pressures for open competition and transparency, all lead to complexity in funding and performing energy innovation. Any party can conduct its own $R \& D$, pay others to conduct it, conduct it on behalf of others, or induce others to fund or conduct their own. The web of funding flows is shown in Figure 4.1. Through mechanisms discussed in section 4.5.1, the federal government distributes funding for energy RD\&D to academic institutions, national laboratories, private firms, and partnerships, and provides facilities and services (primarily from the national labs) for research on behalf of other actors. Requirements for matching funds serve to draw resources from other parties, while research and experimentation tax credits serve to make R\&D more attractive. Firms, meanwhile, fund energy R\&D from revenue or capital, and conduct it themselves, outsource it to other firms or the national labs, or use the funds to sponsor academic research. Many of the flows depicted in Figure 4.1 are of unknown magnitudes; we have included what values we could estimate, calculated by a variety of measures, including:

51 DOE's budget request for fiscal year 2011 includes \$10 billion for Energy Programs and Science (which includes funding through the DOE Office of Science and the "applied" offices for EERE, FE, NE, and EDER), compared to \$11 billion for the National Nuclear Security Administration and \$6 billion for clean-up activities (DOE, 2010). 


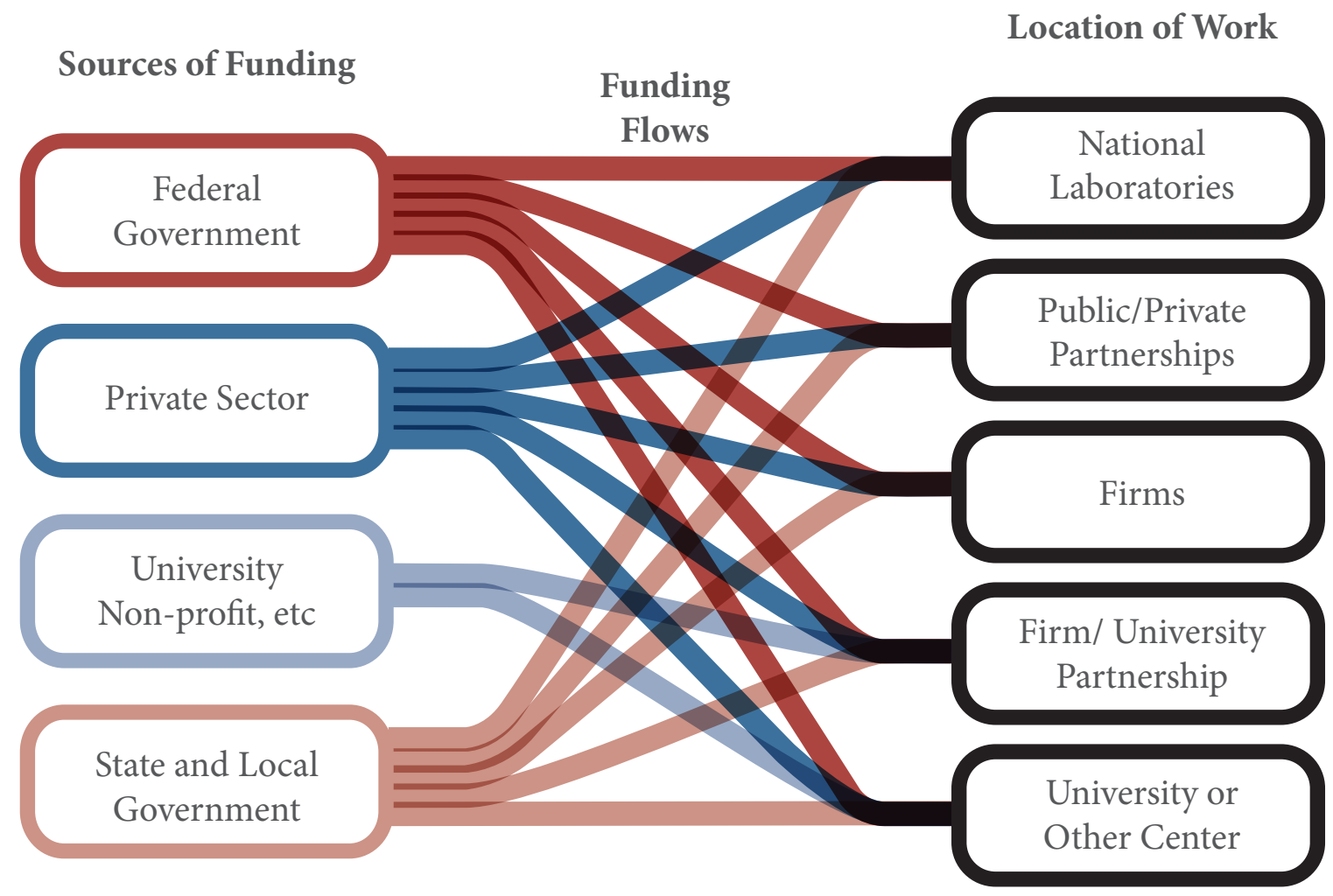

FIGURE 4.1. Funding for and location of work on energy research, development, and demonstration. The federal government, the private sector, and state governments fund all research locations (albeit to different extents).

- $\quad$ Budget expended for the U.S. National Laboratories by DOE applied energy offices in 2008 (from FY09 DOE budget justification): $\$ 1.7$ billion.

- $\quad$ DOE assistance in energy RD\&D in 2008 mainly through grants and cooperative agreements (from USA Spending database): \$836 million overall (\$797 million of which was dedicated to cost-shared projects and $\$ 38$ million of which was dedicated to projects solely funded by the federal government). DOE assistance funding for energy RD\&D had the following breakdown by recipient (figures may not sum due to rounding):

- \$529 million with for-profit recipients, \$512 million of which went to cost-shared projects;

- \$211 million to universities, \$194 million of which went to cost-shared projects;

- \$36 million to state, local, and tribal governments; \$33 million of which went to costshared projects;

- \$61 million to non-profits and others, \$57 million of which went to cost-shared projects.

- Non-federal contributions to cost-shared projects in the USA Spending database were $\$ 771$ million in 2008: $\$ 89$ million to projects at universities, $\$ 43$ million to projects in governments, and $\$ 610$ million to projects in the private sector. 
- $\quad$ Payments to the National Laboratories for work from firms were worth $\$ 308$ million in 2009 (Farris, 2010).

The need to understand energy innovation in the private sector and in public-private partnerships is becoming ever more urgent. The amount and distribution of investment in energy technology innovation by the private sector is uncertain, but both evidence and theory suggest that it is low compared to the need and opportunity. Policymakers are attempting to correct market failures and to encourage privatesector innovation without knowing what activities are currently taking place or what is needed in what technology arena, and without having accurate information about what types of projects produce the best results under different situations. This chapter is an attempt to present the best information available (some of it having resulted from our research) to improve the effectiveness of public and privatesector investments in energy technology innovation.

Demonstration and Commercialization: Roles for Public-Private Partnerships

The transition from the research and development phase to the commercial phase has long been recognized as a particular challenge for energy technology innovation. Demonstration projects-construction and operation of technologies at near-commercial scale (see more on demonstrations at the end of this box) - ease the transition by providing information to market participants. These projects are often too large or too risky to be done by the private sector, but too close to the commercial market to be conducted under normal government R\&D support. In December of 2010, a group of senior representatives from government, industry, finance, and academia convened at the Harvard Kennedy School for a workshop to discuss options for accelerating the commercialization of advanced energy technologies. A report on the workshop (Narayanamurti et al. 2011) describes the findings and

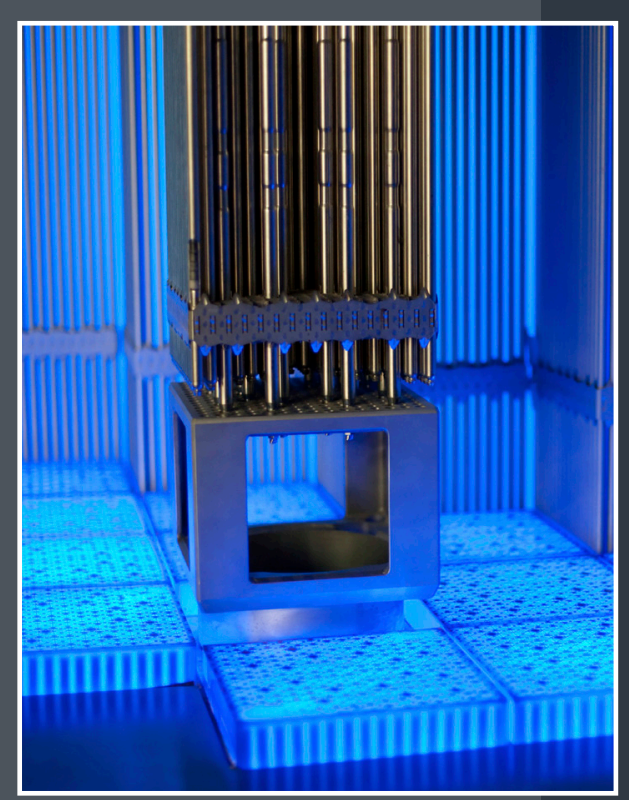

(Source iStockphoto) policy principles that emerged from these discussions.

Current policies do not adequately address the private sector's inability to overcome the demonstration "valley of death" for new energy technologies. Investors and financiers fear that the technological and 
operational risks at this stage of the cycle remain too high to justify the level of investment required to build a commercial-sized facility. Many participants agreed that demonstrations are particularly important to the energy innovation system because: (a) they are currently a bottleneck and a rate-limiting step to the commercialization of energy technologies; (b) they test new business models that provide critical knowledge to different stakeholders; and (c) without a clear price signal, the need to support innovative energy technologies becomes more urgent.

Several policy principles and recommendations are outlined in the report. The most important of these are:

- Long-term policy. The most consistent theme from the workshop was that if the government wants to unlock private-sector investment, it must create a predictable and sustainable policy environment.

- Materiality. Government support for accelerating the commercialization of energy technologies should focus on projects that have the potential to have a material impact on one or more of the objectives of energy security, economic competitiveness, and environmental sustainability.

- Public-private partnerships. Because the ultimate objective is to enable the private sector to move new capabilities into the market, government policy should emphasize working with industry, obtaining private-sector input, and enabling private sector investment.

- Unproven technologies. Currently there are no permanent mechanisms for supporting the demonstration of unproven innovative technologies. While some of these may "fail," even the failures provide useful lessons, and the potential benefit from those that do succeed would likely dwarf the results of a more risk-averse portfolio. Further, it is the unproven as opposed to proven technologies that benefit most from government support.

- Information dissemination. There is a clear public interest in making the information acquired from demonstration projects more widely available, although this will need to be balanced with the protection of private intellectual property rights to ensure private-sector participation in these projects.

- Exit strategy. Government support for technology demonstration and deployment projects should be conditional on performance and based on transparent performance benchmarks, and if these are not met, funding should be discontinued. In other words, the government should have a clear strategy for ending its support of under-performing projects. 
- Targets and objectives. Targets for demonstration programs should be based on technical performance criteria as opposed to far-reaching, large-scale production targets, which can be expensive and inefficient because their achievement often depends on technological advances and commodity prices.

- Portfolio approach. The government should adopt a portfolio approach that supports a range of competing technologies, a range of development stages, and a variety of policy and financial mechanisms. However, given the large scale of investments, not all projects and technologies can be supported, and real-world constraints dictate a need to be selective. For instance, some workshop participants prioritized support for CCS and nuclear energy due to their potential to address overarching policy objectives, and their high cost, which makes it very difficult to attract private financing.

There was widespread, though not unanimous, agreement that a new institutional mechanism was needed to manage demonstration projects in partnership with the private sector, that existing institutional approaches at the DOE were not likely to be effective for that purpose. In particular, there was broad, although not universal, support for two policy initiatives currently being discussed by policy makers. One is the Quadrennial Energy Review (QER), which was recently proposed by the President's Council of Advisors on Science and Technology (PCAST) to bring much-needed coherence, stability, and predictability to energy policy in the United States. The other is the Clean Energy Deployment Administration (CEDA), which was viewed by many as a useful policy tool for enabling energy technology demonstrations. The fact that CEDA has already received bipartisan support in the Senate was an important factor in the support for the workshop's own initiative.

* Note on demonstrations: The intent of a commercial scale demonstration is to show that a technology can be effectively used at full commercial scale in an economically useful way, i.e., at a reasonable cost. However, such a scale-up is also the first opportunity to learn how a technology works at full scale, whether the design features are reasonably workable, controllable, and optimal. As such, the beginning of operation of a full-scale demonstration plant is an experiment, designed for learning and 'debugging.' A new plant needs adjustment, particularly in control systems and their use, sometimes alterations in hardware (hopefully minor), and always requires some accumulation of experience in operating the plant. It is, in fact, a late stage of development. It provides an opportunity to learn what changes might be made in the next plant(s) to be built. Such projects are not demonstrations of what is already fully understood, but experiments at the frontiers of knowledge and practice. 


\subsection{MethodS}

Several types of information are needed to gain insight into public and private-sector energy innovation and how energy R\&D efforts could be made more effective. We derived quantitative estimates from two sources: a new database constructed from public data on DOE funding for energy innovation support outside of the DOE, and a survey we conducted of business establishments to improve information about private-sector activities. Managerial and strategic lessons are drawn from interviews with experts, prior studies, and the aforementioned survey of business establishments. The methods for collecting and analyzing the data are described here.

\subsubsection{Database on DOE support for energy technology innovation}

The quantitative database on DOE activities is built from complete data for fiscal years 2000-2009, downloaded from USA Spending (OMB, 2010). Located at www.usaspending.gov, USA Spending is a public disclosure project that resulted from the Federal Funding Accountability and Transparency Act of 2006 (S. 2590) (Transparency Act, 2006), which mandates disclosure of contracts and assistance by the White House Office of Management Budget (OMB). In fiscal year (FY) 2008, the DOE obligated $\$ 24.53$ billion in contracts (or "procurement"), and $\$ 2.19$ billion in assistance (often labeled "grants" although grants are only part of assistance $)^{52}(\mathrm{OMB}, 2010)$. The data are some 62 thousand transactions within over 20 thousand awards that were active at some point between fiscal years 2000 and 2009 (excluding corrections to completed projects, see Appendix A4.1). The data were corrected for format errors, spelling variations, and changes in code use to yield a reliable description of DOE activities. The full dataset is available at http://belfercenter.ksg.harvard.edu/publication/.

\subsubsection{Interviews}

Two types of interviews formed the basis of analyzing management practices and strategic planning for partnerships at the DOE. First, eight open-ended, semi-structured interviews were conducted with a total of 10 current and past senior managers from business and government. Between them they have extensive experience managing technology development at all stages, and managing business operations, government agencies and offices, research facilities, and technology projects. The interviewees also have extensive experience with planning, selecting, and working in firm-to-firm and public-private partnerships. The interviews lasted two hours on average, and were designed to elicit the interviewee's

52 "Assistance" includes categories of: Cooperative Agreements, Grants, Direct Payments, Subsidies, Indirect Assistance, and Other Assistance. Grants and Cooperative Agreements make up over $99 \%$ of assistance by both obligations and number of awards in the database $(\mathrm{OMB}, 2010)$. USA Spending database entries are by transaction, but can be organized by project; some entries are changes to past projects, including de-obligations, which are indicated as negative values. Thus, the data reported are net obligations. 
management experience by asking questions targeted at how the innovation environments with which they were most familiar operated. Interviewees responded with a variety of perspectives and levels of aggregation, ranging from the planning of individual projects, to strategic planning of enterprises, to national systems of innovation.

The second type of interview was conducted in conjunction with the design of the private sector energy innovation survey described below. To design the questionnaire, five senior managers of private sector firms participated in structured interviews covering their firms' activities in energy innovation, as well as their interpretation of and suggestions for interview questions. The interviewees represented firms from small single-product-line start-ups to divisions of diversified multinationals. The structure was provided by the evolving draft of the survey instrument (see Appendix A4.2). Interviewees received the draft questionnaire one day prior to the interview, and were instructed to read and consider how the questions could be answered. During the approximately one-hour interviews, interviewees responded with their reaction to the questions, the answers they would give in the survey environment, and commentary on how the questions related to their business practices. In addition to improvements in the survey, these interviews provided insight into management decision making, strategic direction, and industry trends in innovation, and provided a cross-check against the open-ended interviews with senior managers.

\subsubsection{Survey of energy innovation in U.S. businesses}

The largest part of this research effort is the Survey of Energy Innovation, a survey of business establishments in the United States designed to estimate private sector investment in, use of, and process of innovation related to energy. The survey is a short, easy to answer questionnaire, split into two parts-screener and follow-up. Each question covers a specific area of activity designed to disaggregate types of energy innovation and to reduce the need for respondent interpretation. The survey as a whole covers a broad range of activity across relevant aspects of energy use and innovation, from new types of energy equipment to techniques for reducing energy use. We designed questions so they could be easily understood and their answers easily and accurately recorded, rather than to fit theoretical constructs from the innovation literature.

Survey questions are mapped to fit the types of respondents and the types of activity considered to be energy-related innovation. The population of interest is made up of non-farm business establishments in the United States. The sample is, however, heavily stratified to concentrate on those industries where energy innovation is likely to be important. The sample frame is the Dunn and Bradstreet (D\&B) business list, which has over 12 million establishments in our population of interest. The variables for stratification are the North American Industry Classification System (NAICS) code and the indicator for headquarters establishments. We sampled a small number of establishments in trade, services, finance, etc., and a larger number of establishments from specific manufacturing sectors; energy-related mining, construction, and 
utilities; R\&D service providers, and other technical services. We over-sampled headquarters locations and focused more on manufacturing, mining, utilities, and construction firms than on trade, finance and service companies (a complete breakdown of the sample is included in Appendix A4.3).

The questionnaire was tested for clarity and validity over several rounds of review. Our advisory board of experts from industry, government, non-profit, and academia provided critical feedback, as did an external researcher with experience in industry surveys. The survey instrument was also tested by five cognitive testers from different areas of energy-related businesses, all of whom were engaged in different types of innovation activities. As discussed in section 4.3.2, the testers participated in one-hour interviews after having had a chance to review the draft survey. The tests were conducted in a sequence of three cognitive interviews; revision and further expert and academic review; two more cognitive interviews; and finally revisions incorporating all feedback. The interviews revealed that testers understood the questions as intended, gave consistent answers, and could complete the survey instrument easily.

The research services company Westat provided survey and statistical expertise during survey design, and conducted the survey. A large-scale pilot was conducted from August through November 2010, which both tested the survey in support of future larger-scale implementation, and gathered useful data for this report. The sample included 1,502 establishments in three groups: 32 establishments selected deliberately to test the procedures, 50 start-up firms in the clean energy business selected from the Bloomberg New Energy Finance database, and the main sample of 1,420 drawn from the D\&B business list. The survey instruments were mailed to the CEO or senior manager at each sampled establishment, with introductory and follow-up reminders to encourage participation. 197 were returned as non-deliverable or were no longer in operation, leaving 1,305 as the sample size, and 10.8 million (with a standard error of 0.4 million) as the estimate of active businesses in the business list. We received 192 responses for a response rate of $14.7 \%$. An aggressive follow-up with a sample of 258 of the non-respondents yielded 82 additional data points for non-response bias testing. The non-response bias test served to determine whether nonrespondents were on average as likely as respondents to engage in energy-related innovation.

Because energy and innovation industries were sampled more heavily than others, we applied a weight to each respondent that reflects how much that respondent represents the population as a whole. Only establishments from the main sample (the $\mathrm{D} \& \mathrm{~B}$ business list) were used for population estimates because only they have a statistically meaningful chance of being selected from the pool from which we calculated the weights for each respondent. The weights take into account both the probability of each establishment being selected and the response rate of similar establishments. Similarly, estimates of the standard errors take into account the variable response rate and complex sample design. We accomplished this using the multiple-unit jackknife (JKn) method (Brick, Morganstein, \& Valliant, 2000) in Westvar survey analysis software. 
Analysis was conducted in an iterative manner over the course of the project, and early qualitative results were used to inform the design of later interviews and the survey. We also examined qualitative data from the interviews and survey for common themes. Respondents were granted more weight in their main areas of expertise, but all of the information they relayed was taken into consideration. The analysis proceeded toward a description of government support for energy innovation and toward recommendations for improving this support, rather than toward any theoretical development. Quantitative data from existing databases and from the survey were used to describe current activities and identify areas for potential future activities. The results from this analysis are presented in the next sections.

\subsection{Private Sector Activities in Energy Innovation}

\subsubsection{Energy innovation landscape}

The "energy industry" does not exist as a coherent entity: there is no trade association, industrial classification or code, or product category that encompasses it. The creation of an "energy industry" code would leave out important energy activities. At the same time, such a code would inevitably include too many non-energy-related activities. Absent a proper definition, it is impossible to estimate the $R \& D$ expenditures of the energy industry with the information publicly available, using industry codes. It is also impossible to determine the R\&D expenditures by industry related to energy without significant caveats. Instead, in this work, we sought to determine what firms undertake activities in energy, and in innovation, and then to examine the investments and perspectives of establishments that are engaged in energy-related innovation.

To identify and describe entities involved in energy technology innovation, we developed a classification from the NAICS code and SIC code definitions and our own expert interviews, which included both producers and consumers of energy technologies, including:

- Firms in energy resource extraction, conversion, or distribution. Some firms extract fuels and convert, develop, or distribute energy. This segment includes mining companies, utilities companies, refineries, independent power producers, biofuels producers, and so on. These entities would be included in a basic definition of the energy industry. These actors might use or develop new or improved energy systems, and they are the customers for energy equipment.

- Firms supplying energy equipment. Some firms supply energy equipment, such as turbines, boilers, solar panels, transformers, etc. Others provide specialized construction, such as for power lines, or provide equipment to manufacture energy equipment, such as photovoltaic manufacturing equipment. Energy technology is their core business, and innovation helps energy consumers or other energy companies. 
- Firms that supply resources to energy equipment or services firms. Upstream of the energy industry are suppliers of capital goods, important components, and important materials. Though energy might be a small part of their business, innovation could be important if it enables improved energy equipment or services.

All of these actors could be grouped into energy and related equipment, and they might invest in R\&D to develop or to improve their products.

The next three categories denote businesses that are outside of energy services or equipment but have a large stake in energy innovation:

- $\quad$ Firms that use large amounts of energy in their businesses. Users of large amounts of energy may attempt to reduce their own use and we would want to capture whatever part of those efforts is truly innovative.

- Firms manufacturing products that are energy intensive. Manufacturers of products that use significant energy develop new products and improve existing lines, and some fraction of that effort is energy innovation. What counts as "large" or "significant" energy use is open to debate. In our analysis, we made this determination by whether managers declared energy use as playing a role in decision making.

- Firms producing equipment that affects the energy efficiency of buildings. Other firms manufacture equipment that does not use energy or that is not energy-intensive to manufacture, but that affects how energy is used, e.g., insulation, high-efficiency windows, thermostats, and other controls. These firms' innovative efforts make energy reduction more affordable.

Finally, two types of actors provide services for other firms' energy technology. As a measurement issue, the activities of these actors could be found either by asking the clients how much they outsource, or by asking the providers how much energy-related business they conduct; care must be taken in statistical estimates to prevent under- or over-counting. These two types of firms are listed below:

- Firms providing engineering or R\&D services. Engineering or R\&D service providers might support a variety of customers or work on a variety of projects, some of which should count as energy innovation.

- Consultants and ESCOs. There are also consultants and energy service companies which help customers reduce or manage energy use. These firms might innovate to provide better solutions for their clients.

The diversity of the types of businesses potentially engaged in energy innovation complicates the mea- 
surement of the energy innovation effort (the incidence of R\&D among energy-related companies was not known). In addition, the data that is available indicates that less than $4 \%$ of large R\&D performers questioned by the NSF survey had energy applications in 2005 (NSF, 2009). We take this to indicate that energy innovation is relatively scarce within most industry groups, further complicating the question of measuring the activity.

Along with the comprehensive meanings of energy and technology, we consider a very broad definition of innovation. Considering energy innovation activities beyond traditional $R \& D$ results in a more diverse set of actors, and what they recognize and how they describe innovation varies as well. With the cognitive interviews developed in the survey, we found that the following categories encompassed what energy innovation meant to business leaders:

- Basic and applied research. Discovering new knowledge through answering scientific and technical questions related to new technology.

- Technology development. Applying knowledge for new or significantly improved products and services-although there is some overlap, this generally refers to new technology as opposed to new products in an existing technology.

- Pilots or field demonstrations. Pre-commercial-scale or nearly commercial-scale experiments to gain experience, test the technology, or prove the viability of the product or methods of making the product.

- Initial commercial-scale activities. Either the first product or first facility to manufacture the product; there is an experimental aspect but the activity is expected to transition to normal commercial operations.

- Product design or improvement. Sometimes this is the last phase of technology development, but can also apply to later iterations of product lines under existing technology, or products in existing lines.

- Process design or improvement. Innovation aimed at improving how current products and services are created, or at enabling the creation of improved products or services. Efficiency and quality initiatives are important examples.

- Technology search or evaluation. Finding or adapting technology solutions from other fields or industries to enable innovation in one's own field. Our interviews revealed this to be especially important to start-up and venture capital firms.

- Intellectual property management. OObtaining and selling licenses for patented technology, to capitalize on or to enable one's own firm's innovation. 
Each of these relationships to energy and each of these types of innovative activity are important to the energy technology effort. Not knowing the players in the energy innovation effort makes planning and providing services for them, or engaging in the best set of partnerships, impossible. With this in mind, we set out to develop a better measurement of the energy innovation landscape.

\subsubsection{Estimates of private sector energy innovation}

The Survey of Energy Innovation consisted of two questionnaires, administered in stages: the first to identify establishments involved in energy and innovation; the second to collect details from those so identified. A separate telephone questionnaire was administered to a sample of non-respondents to estimate bias. Of the 192 respondents to the screener questionnaire 107 (56\%) reported some level of involvement with energy, as we describe in section 4.4.1; 88 (46\%) reported innovative activities or use of the results or innovation in other locations; and 54 (28\%) reported that their innovation activities and energy activities are related. The establishments of greatest interest are those that report actual performance, funding, or direction of innovation-61 (32\%) of respondents conduct innovation themselves, and 38 of these ( $20 \%$ of the total) conduct innovation in energy. The 82 establishments that did not answer the screening questionnaire but were interviewed thereafter were slightly less likely to engage in energy innovation, but the differences were not statistically discernable: $45 \%$ reported energy-related activities, $22 \%$ conduct innovation, and $16 \%$ performed innovation related to energy.

Accounting for the design of the survey (the stratification) and the differing response rates allows us to make estimates of the energy innovation landscape in the United States. By the sample estimates, about a fifth of business establishments are involved in energy and about a fifth in innovation. These are likely to be overestimates due to response bias (discussed below). Of the 192 respondents, 33 described themselves as start-ups. Establishments that reported innovation activities related to energy activities were sent a follow-up survey instrument; 57 were sent and 29 establishments completed it. Of the 57, 20 identified as start-up companies; 15 start-ups and 14 non-start-ups completed the questionnaire.

258 of the non-respondents were contacted in an attempt to measure response bias. 82 of these completed a telephone interview; 37 (45\%) reported being involved in energy and 13 (16\%) in energy-related innovation. Accounting for the sample design, an estimated $9.9 \%$ of the non-respondents are involved in energy and $4.3 \%$ in energy-related innovation-less than the estimate from those completing the survey proper, and evidence of response bias. Further evidence of response bias is that the weighted estimates of energy / energy-related innovation are $28.6 \%$ / 24.0\% among those answering the first survey, and only $8.3 \% / 2.6 \%$ from the follow-up survey.

Assuming the worst in response bias, i.e., that none of the non-respondents are involved in energy or innovation, the survey still shows that $3.4 \%$ of all establishments surveyed are involved in energy, and $2.4 \%$ are involved in energy-related innovation (with an approximate error of $1.3 \%$ ). Table 4.1 presents 


\begin{tabular}{lll} 
Activity & Estimate & Standard Error \\
Involved in Energy & $21.0 \%$ & $4.6 \%$ \\
- Services, goods, equipment & $15.8 \%$ & $10.7 \%$ \\
- Energy use & $9.8 \%$ & $7.1 \%$ \\
- Innovation providers & $5.4 \%$ & $4.6 \%$ \\
\hline Involved in Innovation & $19.1 \%$ & $10.7 \%$ \\
- Perform, fund, direct & $12.7 \%$ & $10.2 \%$ \\
- Use of others & $18.8 \%$ & $10.7 \%$ \\
\hline Both Energy and Innovation & $17.3 \%$ & $10.6 \%$ \\
Involved in Energy-related Innovation & $16.0 \%$ & $10.6 \%$ \\
Conducting Energy-related Innovation & $11.1 \%$ & $10.3 \%$ \\
\hline Start-up Companies & $0.64 \%$ & $0.3 \%$ \\
- Involved in Energy & $0.57 \%$ & $0.3 \%$ \\
- In Energy-related Innovation & $0.27 \%$ & $0.2 \%$ \\
\hline Floor estimate of establishments involved in Energy & $3.4 \%$ & $1.1 \%$ \\
\hline Floor estimate of establishments in Energy-related Innovation & $2.4 \%$ & $1.3 \%$ \\
\hline
\end{tabular}

TABLE 4.1 Prevalence estimates from the Survey of Energy Innovation

the detailed estimates from the main survey with standard margins of error, ${ }^{53}$ and the main findings are presented below. A larger survey would be very useful to provide estimates of total private sector ERD\&D investment by industry sector, and to help identify trends by industry, but total private ERD\&D investment is certain to be larger than previously known, although still low compared to the technology opportunities and society's need for improved energy technologies.

Below we summarize the key findings from our survey:

- Energy technology innovation is widespread. Based on the weighted sample, $17 \%$ of establishments are involved in both energy and innovation, with $16 \%$ specifically involved in energy innovation. About a tenth of establishments actually perform, fund, or direct energy innovation and another $5 \%$ consider energy innovation by others as important to their business. Although these are likely to be overestimates, a floor on the actual value of establishments involved in energy innovation is between 1.1 and 3.7\%. Thus, energy innovation seems far more common than prior estimates of energy R\&D.

53 Estimates are calculated from only the main sample (180 respondents from the D\&B business list). Standard errors are calculated using the multifactor jackknife method and 95\% confidence interval. Factors for the jackknife method factors are not valid for non-respondents, so the floor estimate standard error is an approximation, assuming a similar distribution of factors. See Methods section 4.3.3. 
- Start-up companies are more engaged in energy innovation. Over the entire population, just over six-tenths of a percent of all establishments are start-ups; and nearly half of those are engaged in energy technology innovation. 33 respondents reported \$394 million in capital raised to date. 20 of these were both start-ups and energy innovation participants, representing most (\$330 million) of the capital raise to date. The sample yields an estimate of 29,000 (se=20,000) start-ups engaged in energy innovation, with $\$ 31$ billion (se $=\$ 30$ billion) in capital raised to date.

- Energy innovation is both normal business and special projects. Most establishments (17) report conducting energy innovation as a normal part of business; eight conduct energy innovation only as special or one-off projects; and four only use energy innovation developed by others. More start-ups conduct energy innovation as a normal part business (12/15) than do established firms (5/14).

- Small-scale energy innovation is important. The 17 establishments that conduct energy innovation as a normal part of business report $\$ 33$ million ( $\pm \$ 21$ million) in innovation expenses in 2009. Most of these businesses (11/17) report less than $\$ 200,000$; the total value is dominated by two start-ups in the \$5-20 million range. In the special-project only businesses (8/17), the most recent projects were reported as totaling $\$ 5.4$ million for an average cost of $\$ 768,000$ per project.

- $\quad$ Private sector energy innovation spans the innovation spectrum. Even our small sample of only 17 establishments represents all stages of innovation and all parts of the energy innovation landscape. Every establishment engages in more than one stage of innovation; technology development (15) and pilots or field demonstrations (14) are the most commonly reported. Innovation for products to reduce customers' energy use (9) and to provide technical or R\&D services to clients (7) are the most common purposes for innovation. Of the special projects, three had purposes related to saving energy, three mentioned developing a product of some kind, and two were related to processes. Most energy technologies are found even in a small sample. Among the 29 companies, 70 technology areas were mentioned in which they are involved with innovation: solar is the most common (11); 17 kinds of efficiency; and wind, electric generation, industrial processes, and energy storage were each mentioned by six establishments.

- Additional incentives for energy innovation are needed. Given the many market failures impeding private sector investment in energy innovation, additional incentives are justified, if they could cost-effectively leverage additional private sector spending. Our survey indicated that government cost-sharing and deployment-related incentives (such as production tax credits) are generally more important in private sector innovation investment decisions than R\&D tax credits, but further research is needed to design the optimal package of incentives for private sector energy innovation. 


\subsubsection{Process of private sector energy innovation}

The follow-up survey collected information on how businesses that are active in energy technology innovation made decisions, and what factors promoted or hindered energy innovation in their industry. In addition to the source of funds and the location of work, respondents were asked to rate the three most important factors in a number of areas: information, sources of innovation, related fields, policy and market factors, and trends and barriers. The insights provided by their responses are valuable in understanding how the energy technology innovation effort works:

- Most funding and performance is internal. 53\% of reported funding was from the reporting establishment itself, followed by federal grants and contracts (24\%). 86\% of the innovation work was performed at the reporting establishment, with $10 \%$ outsourced to other U.S. companies; only $0.1 \%$ of the company-funded research was done at the national labs.

- Short payback times dominate decision-making. Whether for normal business activities or for special projects, the businesses use similar criteria to evaluate the financial impact of energy innovation investments. Most common (10 out of 24) was estimating a period to recoup the cost of innovation, with the average time being 2.8 years. Nine out of the 24 reported that they do not formally measure financial impact.

- Information that businesses use to make energy innovation decisions comes from a variety of sources. Institutional sources such as government and academia are used by 17 of the 24 businesses that specified; private sector sources are mentioned by 20 respondents but these sources encompass internal sources, sources up or down the supply chain, and sources from competitors.

- Costs drive innovation more than opportunities. Energy prices are mentioned by nine out of the 24 as a driver of energy innovation decisions, and are the most-mentioned factor for promoting innovation by 16 respondents, followed by cost-cutting opportunities (11). There are 19 mentions of various market or market creation policies, but there is no dominant, single market factor.

- Grants have more impact than tax credits. Policies that encourage innovation itself are mentioned 20 times as factors for promoting innovation, with government R\&D grants or support (9) being the most important of these.

- The innovation process and the lack of markets are equal barriers. The single most challenging factor for innovation is high commercialization cost. If the types of barriers faced by businesses are grouped by increasing level of challenge, they are: intellectual property issues (2), regulatory barriers (6), state of science / technology issues (12), market barriers (25), and the difficulties associated with the innovation process (26). 
- Cooperation is important. The most beneficial trends mentioned by respondents were cooperation with government (12), universities (10) and with other companies (6), and in mergers and acquisitions (11). Process improvement (10) is the most mentioned beneficial trend not related to cooperation.

- Most important innovations come from within the industry. Both respondents' own firms (18) and other firms in the same industry (20) are listed as the most important sources of innovation. National laboratories (12), universities (11), and other industries (10) are all frequently cited as the second or third most important origins of innovation. Electrical and electronic engineering (13) and materials science (12) are the fields producing the innovations that have the most positive impact.

- Innovation is central to start-up businesses. The 15 start-up respondents report, on average, that $75 \%$ of their start-up capital has been spent on energy innovation. These respondents represent \$284 million in capital raised to date. 12 were using founder capital for operations in 2009, including five for whom it was the only source of funding; the next most common source (5 out of 15) was government grants or contracts. 13 of the 15 own some amount of intellectual property, and eight of the 13 describe their IP as being generated after start-up.

\subsubsection{Reflections on private sector energy innovation}

Estimates in this pilot study should be treated with caution. With the response rate of $14.7 \%$ there is likely a difference between those who did and those who did not answer the survey. Among those who answered after the first mailing, 37 of 107 (35\%) reported being involved in energy innovation. Of responders to the second mailing-who may be more similar to the non-responders-only $17 / 85$ (20\%) reported being involved in energy innovation. In follow-up calls to judge the scale of non-response bias, $13 / 82(16 \%)$ reported energy innovation. There is possible response bias even in the non-respondent bias study, so we assume all establishments we failed to reach would have answered "no" to the energy and innovation questions in order to find the floor for energy innovation. Even this extreme assumption gives an estimate for involvement in energy innovation of $2.4( \pm 1.3) \%$, or at least 120,000 establishments. If being involved in energy implies potential benefit from energy technology, the floor on the impact of energy innovation is $3.4( \pm 1.1) \%$.

In an attempt to understand the private-sector energy R\&D picture in the EU member countries Wiesenthal et al. collected data from 136 large R\&D performers, but only concentrated on (a) specifically $\mathrm{R} \& \mathrm{D}$ and (b) certain priority low-carbon technologies. ${ }^{54}$ The results led to an estimate of $€ 1.66$ billion

54 Low carbon energy sources ("SET Plan") include wind, PV, CSP, CCS, biofuels, hydrogen and fuel cells, smart grids, fission and fusion, fossil fuels, energy efficiency, other biomass energy, etc., and are not included. 
in annual private-sector funding for non-nuclear low carbon energy R\&D (Wiesenthal et al., 2009). Their approach, however, did not explore how many firms were engaged in such R\&D, or how firms decided on their energy R\&D investments, and did not include everything we consider to be energy technology innovation.

An important purpose of the Survey of Energy Innovation was to test the procedures for a larger-scale survey in the future. A simple survey, answerable in a few minutes by managers, can provide much insight into innovation processes. A future survey backed with greater resources should be able to address both the response rate and the response bias problems, to provide more reliable estimates.

Even though respondents are more involved in energy technology innovation than the general population of business establishments, this study does provide evidence that energy innovation is important to far more businesses than prior studies have found, and that it is conducted by more companies than prior estimates. Even though most of the funding comes from the largest volume businesses, most of the firms engaged in ETI are making small investments that have not been previously captured. Firms that only conduct special projects in energy innovation might be missed by a more narrow focus on R\&D providers. The broad impact of energy technology indicates that it should be a priority for federal resources.

In addition, the respondents' answers provide insight into how businesses which engage in ETI operate. Markets and market policies can drive innovation, but it is the lack of markets, lack of market policies, and the difficulty of bringing products to market that are the most significant barriers. Energy prices and cost-cutting opportunities are the largest drivers of innovation. Based on business observations, a mechanism to price carbon should encourage innovation by setting a price signal and creating a market. From information supplied by survey respondents, the most significant roles for government agencies are as a source of information and partners for collaboration; the government also was seen to play a role in creating policies that ensure that the full costs and benefits of energy technologies are priced in the market and in creating targeted grants and contracts.

\subsection{DOE And Partnership Activities in Energy Innovation}

\subsubsection{Types of DOE activities}

The DOE is appropriated funds by Congress, but also collects funds from industry and enters into multiyear agreements, making it impossible to give a single answer as to how much it invests in energy technology development in one particular year. The DOE was appropriated $\$ 34$ billion by Congress for 2009 (DOE, 2010), and received almost $\$ 39$ billion from the American Recovery and Reinvestment Act 


Office or Level (example)
Congress
Administration
Office of Management and Budget
Secretary of Energy
Office of Policy and Intl. Affairs
Office of Management
Chief Financial Officer
Inspector General
Office of Scientific and Technical Information
Program Offices (EERE)
Programs (Solar)
Operations Offices (Golden)
National Laboratory
ARPA-E
Office of Science
NETL

\section{Roles}

Authorize programs, Appropriate funds, Oversight

Direction, Strategy, Budget

Accumulate and evaluate budget requests across departments

Direction, Strategy, Budget

Analysis to support budget and program decisions

Policy, Data collection, Oversight

Assemble DOE budget requests, Fiscal oversight

Reviews, Oversight

Data collection

Write FOAs, Select recipients, Planning, Budget input

Technical expertise, FOA and planning input

Issue FOAs, Manage awards

Negotiate CRADAs, WFOs, UF, licensing; Technical expertise

Merge of Program Office, Program, and Ops Office

Program Office plus all SBIR/STTR

Both a NL and Ops Office plus all unsolicited proposals

TABLE 4.2. Roles of Federal entities in ETI support. Source: descriptions throughout the DOE website (www.energy.gov).

(ARRA) of 2009 (ARRA, 2009). ${ }^{55}$ The DOE’s obligations in 2009 were $\$ 54.4$ billion (DOE, 2009b) or $\$ 65$ billion (DOE, 2009a) depending on the source. As discussed in Chapter 2, in the FY 2010 budget, $\$ 5.3$ billion was appropriated for energy technology and energy-related science, out of a total appropriation of $\$ 26.6$ billion (Gallagher \& Anadon, 2010; DOE, 2010). Only after adding half of the American Recovery and Reinvestment Act of 2009 (ARRA) investment in energy RD\&D and basic energy sciences (about $\$ 3.7$ billion) does the investment in energy technology approach the inflation-adjusted levels of the late 1970s.

The DOE conducts research on its own through the national laboratories, awards grants and contracts to conduct research, and conducts R\&D projects with partners. Along with conducting research, the DOE strives to introduce technologies into the market and provides support to state agencies and local governments. Although there is some overlap, funding to the private sector falls under activities that the DOE refers to as "R\&D Support" (transfer of funds to a non-Federal party) and "Technology Transfer" (mechanisms for transferring federal intellectual property to a non-Federal party) (DOE, 2009c). Either type can originate at the national labs, Operations Offices, at the DOE headquarters, or through the initiative of the non-Federal partner. Most activities have, at some point, a Funding Opportunity An-

55 The Recovery and Reinvestment Act includes: $\$ 16.8$ billion for the Office of Energy Efficiency and Renewable Energy (EERE). Of this, $\$ 3.2$ billion is for EE and Conservation Block Grants, $\$ 5.0$ billion is for Weatherization Assistance, $\$ 3.1$ billion is for State Energy Programs, $\$ 2.0$ billion is for Batteries, $\$ 4.5$ billion is for the DOE Office of Electricity Delivery and Energy Reliability (EDER) to modernize the electric grid; $\$ 3.4$ billion is for the DOE Office of Fossil Energy; $\$ 1.6$ billion is for Science; $\$ 400$ million is for ARPA-E; $\$ 6$ billion is for the Innovative Technology Loan Guarantee program; and \$6 billion is for environmental cleanup programs, and $\$ 3.5$ billion is left unspecified (ARRA, 2009). 


\begin{tabular}{llll}
$\begin{array}{l}\text { Types of DOE interactions } \\
\text { with non-DOE entities }\end{array}$ & Sub-category & Funding & Work \\
\hline R\&D Support & Cooperative Agreement & Shared & Shared \\
& R\&D Consortia & Shared & Shared \\
& Grant & DOE* & Firm \\
& Contract & Shared & Firm \\
\hline \multirow{2}{*}{ Technology Transfer } & CRADA & Firm & Shared \\
& Work for Others & Firm & DOE \\
& User Facility & Firm & Firm \\
& IP Agreements & Firm & DOE \\
& Personnel Exchanges & None & Host \\
& VC initiatives & Firm & Either \\
\hline
\end{tabular}

TABLE 4.3 Types of R\&D Support and Technology Transfer Mechanisms at the DOE.

${ }^{\star}$ Grants are government-funded, but may include provisions requiring matching funds; contracts within R\&D support are usually cost-shared, but wholly government-funded contracts are typical in other DOE activities, such as facilities management.

nouncement (FOA) that solicits applications, although unsolicited proposals may also be accepted. The roles involved in funding, selecting, managing, and monitoring these activities are complex (see Table 4.2). Because each type of agreement has its own set of procedures, there exists no central record of partnerships, or even of any particular type of partnership.

The DOE engages in $\mathrm{R} \& \mathrm{D}$ support through mechanisms labeled financial awards (also known as grants), contracts, cooperative agreements, management and operations contracts, personnel exchange programs, R\&D consortia, and Cooperative Research and Development Agreements (CRADAs) (DOE, 2009c). Technology transfer activities include intellectual property (IP) agreements, CRADAs, licensing, work-for-others agreements (WFOs), user facility (UF) agreements, technical consulting, and personnel exchanges (DOE, 2007). Recent additions to these mechanisms include pilot programs involving venture capital firms (DOE, 2007). These types of agreements are discussed below, and key characteristics are shown in Table 4.3.

Various R\&D support mechanisms are used and defined differently by government departments. Support may also be called "assistance" or "awards" in different data sources, and often overlap with technology transfer mechanisms. The mechanisms and definitions in use by the DOE (DOE, 2009c) are described here. Cooperative Agreements are used to either completely or partially fund (cost-share) projects, and are the most commonly used and highest funded of the mechanisms that meet our definition of "real" partnering. R\&D Consortia involve multiple federal and non-federal partners in cost- and work-sharing agreements. However, no active projects are referred to as Consortia in available references. Major initiatives of this type (e.g., FutureGen, FreedomCar) are structured as multiple Cooperative Agreements. In 
such agreements, grants are used to transfer funds to the non-federal party on a competitive basis (project grants), or through programs that distribute funds based on population or other measures (formula grants). In some cases, grants require the grantee to secure additional funding in order to be eligible for the grant. Occasionally, assistance may come in the form of equipment, service, direct payment, or other forms. Finally, the DOE may issue a procurement contract to commission research by another party; usually such work is required to be cost-shared and mutually beneficial.

Technology Transfer activities are also used differently in different agencies (FLC, 2007b). ${ }^{56}$ The Technology Transfer activities at the DOE are under the control of the laboratories and facilities and do not involve a transfer of funds to the non-federal party. For example, CRADAs involve shared personnel, services, equipment, or facilities; as well as shared results. In CRADAs, the cost of government work is usually covered by the non-federal partner. In WFO agreements, the government conducts work on behalf of another party, while in UF agreements, the party conducts its own work using government equipment. Personnel exchanges allow temporary transfer of researchers either to or from a national lab to share knowledge. Finally, all types of intellectual property transactions-patents, copyright, sales, licensing, or negotiated agreements-are considered to be Technology Transfer activities.

Directed at supporting U.S.-owned small businesses, Small Business Innovation Research (SBIR) and Small Business Technology Transfer (STTR) grants involve both support and transfer. They are similar programs, with STTR grants requiring significant participation by a university or other research partner. All federal agencies conducting significant R\&D must set aside $2.8 \%$ of funding for these programs. Phase I grants are meant to be feasibility studies, and are usually 9 -month activities awarded $\$ 100,000$. If successful, Phase II grants can be awarded up to $\$ 750,000$ over two years. Awardees often receive technical assistance or advice from DOE researchers (DOE, 2009d).

All of these mechanisms involve interaction between the DOE or national lab researchers and researchers at universities or private firms, but the sharing of risk, resources, and discretion-which we take as the elements that make up a true partnership—is an element of only a minority of agreements. CRADAs, Cooperative Agreements, and R\&D Consortia are structured to allow partnerships as we define them. Of these, only CRADAs and Cooperative Agreements are found in the data.

\subsubsection{Trends in DOE activities}

Of the 21,326 awards for assistance that were active between FY 2000 and 2009, 5,648 are classified as energy RD\&D (funded by the DOE applied offices) and 10,601 as science (funded by the DOE Office of Science). In this period, the DOE invested $\$ 7.2$ billion in energy RD\&D assistance (60\% of which was directed to the private sector), and $\$ 9.1$ billion in Science ( $74 \%$ of which was directed to academic 


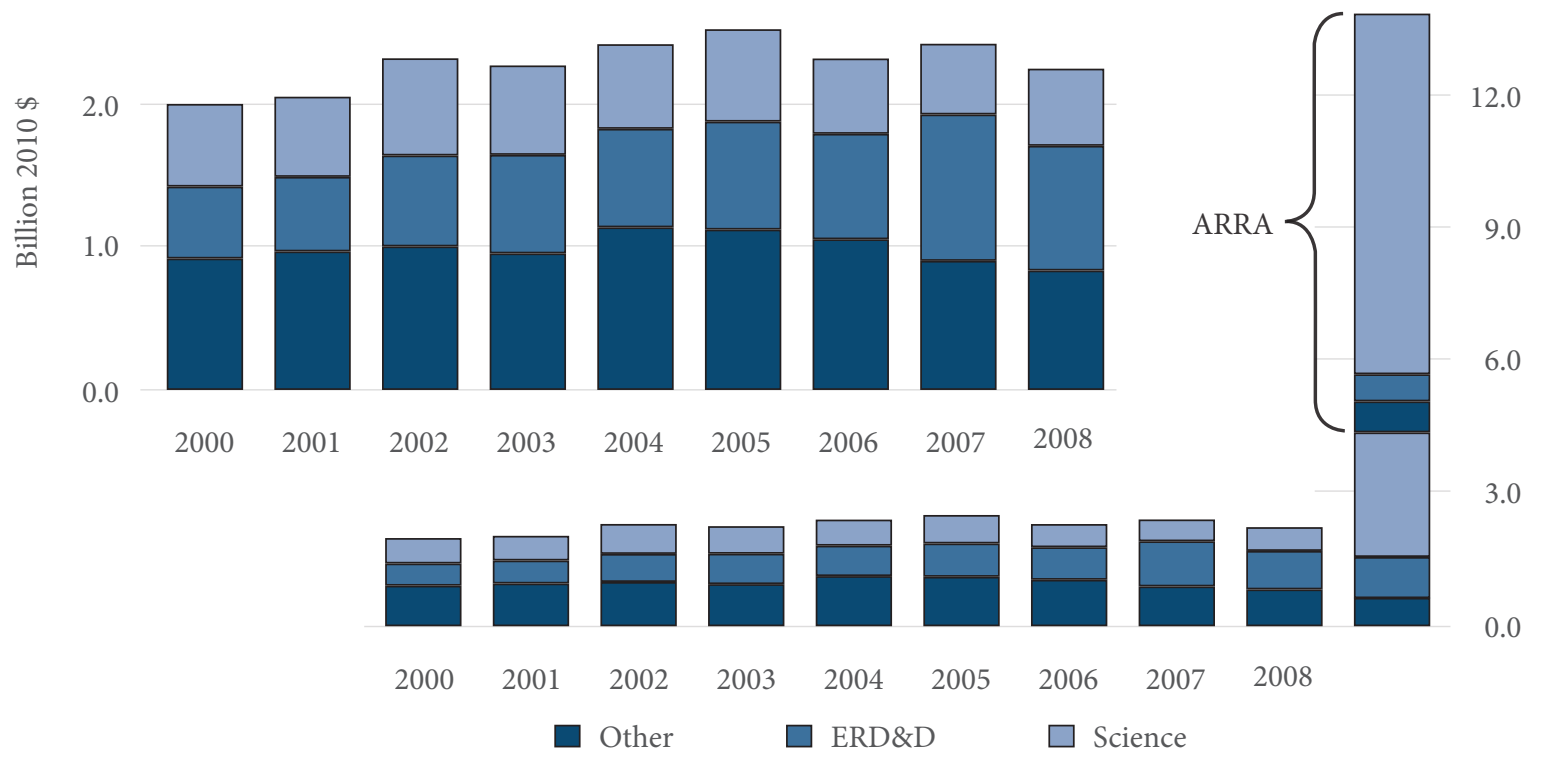

FIGURE 4.2 Funding for assistance, mostly in the form of cooperative agreements and grants, to private firms, academic institutions, and other institutions, by the DOE in major categories (ERD\&D, Science, and "other"). The fluctuation in spending through fiscal year 2008 on all three categories of assistance is apparent when examined; the scale is expanded to show the spending under ARRA.

institutions). These totals include funding for SBIR and STTR programs, which are set at a fixed percentage of the R\&D investments. Because funding for these programs is a constant fraction of total DOE investments-which is less volatile than funding for individual technology areas or programs-SBIR and STTR funding is less volatile than that for other programs (DOE, 2009d). As a whole, assistance comprises a large segment of the DOE budget for energy innovation, fluctuating at about 55\% for Science and 30\% for energy RD\&D, making it important to treat it strategically.

Figure 4.2 shows how the assistance portion of the DOE's budget has been spent on energy RD\&D $(E R D \& D)$, Science, and "other" programs unrelated to ERD\&D. The fluctuation in spending through fiscal year 2008 on all three categories of assistance is apparent when examined; the scale is expanded to show the spending under ARRA. The Recovery Act increased all types of assistance. From 2000-2008, the total science plus ERD\&D spending increased on average 3\% per year in real dollars, but that trend is almost lost amid the fluctuation. Over the same period, the mix of spending has generally shifted away from science toward the ERD\&D programs-from 65/35 in favor of Science to 53/47 in favor of ERD\&D.

Volatility is a trend apparent in many of the spending categories. Narayanamurti, Anadon and Sagar (2009) calculate the volatility in budgets by the standard deviation in year-to-year changes, which averages $27 \%$ for major technology categories (e.g., coal, petroleum, gas, transportation, industry, and buildings), indicating that in about 1 out of 3 fiscal years, the budget for a particular technology pro- 


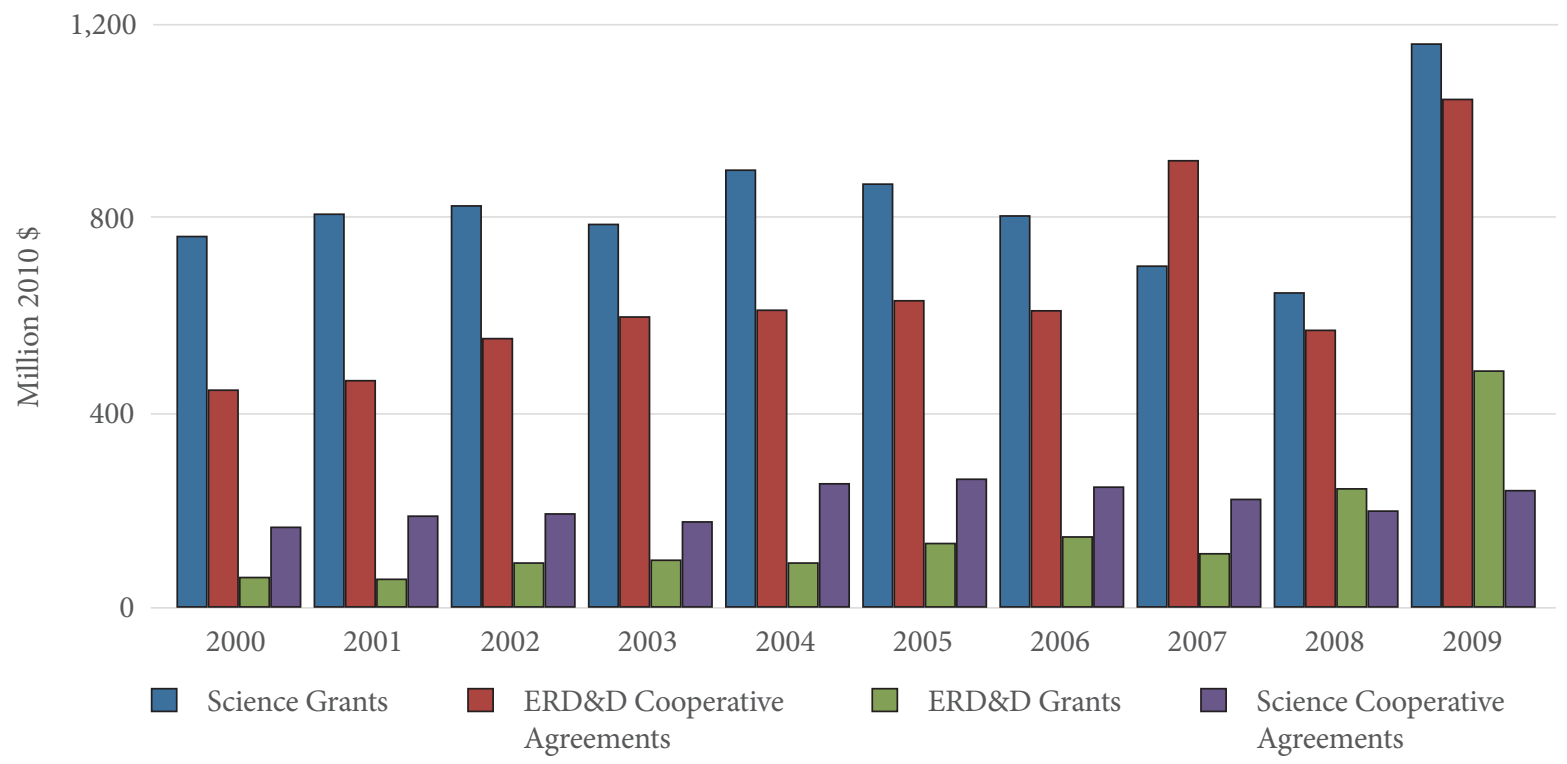

FIGURE 4.3. Funding for DOE Grants and Cooperative Agreements in Science and ERD\&D.

gram changed by at least 27\%. Funding for ERD\&D and Science in the form of cooperative agreements and grants as a whole is less volatile than that for coal, petroleum, gas, transportation industry, and buildings. Standard deviation in year-to-year spending changes $6 \%$ for all assistance, $9 \%$ in Science and $14 \%$ in ERD\&D. In specific categories detailed below, however, volatility is much higher, as moderate changes in overall funding multiply by larger changes in priority (in this case, and in cases below, the large funding increases in fiscal year 2009 are not included in volatility calculations).

The two main mechanisms-grants and cooperative agreements-make up over $99 \%$ of assistance by the DOE, whether by funding or number of agreements. Grants may come with technical advice, but are, in general, simple transfers of funds to the recipient. Cooperative agreements allow for much closer partnerships. Figures 4.3 and 4.4 show the trends in the two main types of agreements, as reported in USA Spending. The Office of Science consistently awards more than 15 times as many grants as cooperative agreements, whereas the ERD\&D programs award 1.5 times as many cooperative agreements as grants. Science awards 2.5 times as many projects as ERD\&D, but the average project is far smaller. Science grants are usually the largest part of the 4 funding categories shown in Figure 4.3 (except in 2007), but only by about $28 \%$ over ERD\&D cooperative agreements.

Two trends are apparent in the data. First, the Office of Science encourages research through a large number of relatively small, arms-length transactions, while the offices supporting ERD\&D use far more partnerships and larger projects. Second, the ERD\&D effort is far less stable. By the number of awards, Science has a standard deviation of yearly changes of only $3 \%$ compared to $17 \%$ in ERD\&D. By the level of funding, the standard deviation of yearly changes is $13 \%$ in Science and $34 \%$ in ERD\&D. These large variations are not explained by any stated strategy. The fact that basic research is less controversial than 


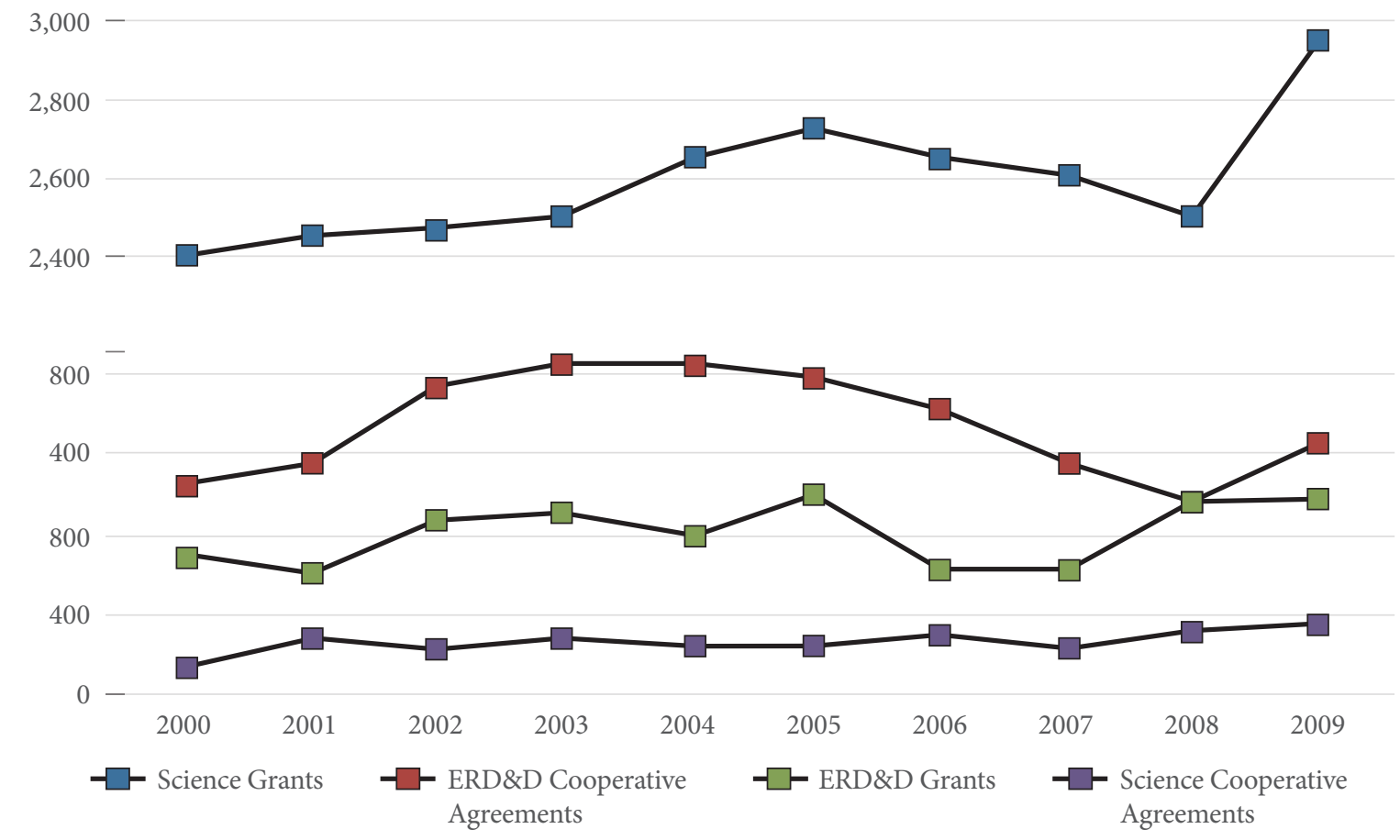

FIGURE 4.4. Number of DOE Grants and Cooperative Agreements in Science and ERD\&D.

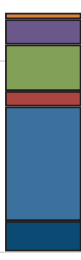

2000

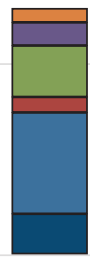

2001

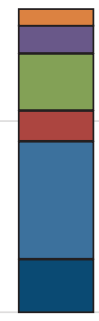

2002

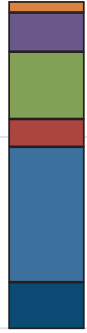

2003

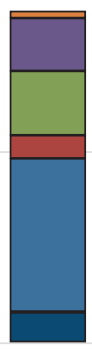

2004

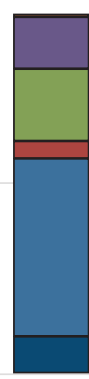

2005

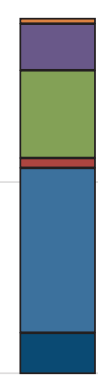

2006

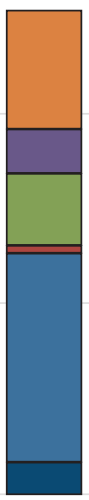

2007

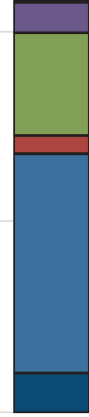

2008

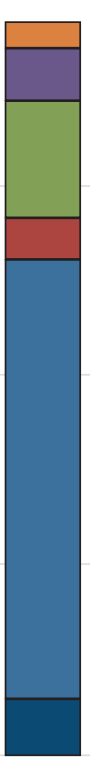

2009

Small Business

Other For-Profit

Government

Higher Education

$\square$ Non-Profit

Other

FIGURE 4.5 DOE funding for ERD\&D funding by type of recipient. The vast majority of these projects are funded by grants or cooperative agreements. 


\begin{tabular}{cllll}
\hline Year & $\begin{array}{l}\text { Total Active } \\
\text { Projects }\end{array}$ & $\begin{array}{l}\text { Active Cost-Shared } \\
\text { Projects }\end{array}$ & $\begin{array}{l}\text { Percent of Shared } \\
\text { Projects }\end{array}$ & $\begin{array}{l}\text { Contribution of Federal Funds } \\
\text { to Yearly Funding of Projects }\end{array}$ \\
\hline 2000 & 866 & 519 & $60 \%$ & $44 \%$ \\
2001 & 884 & 467 & $53 \%$ & $54 \%$ \\
2002 & 1,218 & 669 & $55 \%$ & $55 \%$ \\
2003 & 1,289 & 626 & $49 \%$ & $55 \%$ \\
2004 & 1,220 & 648 & $53 \%$ & $44 \%$ \\
2005 & 1,296 & 603 & $47 \%$ & $41 \%$ \\
2006 & 1,018 & 345 & $34 \%$ & $20 \%$ \\
2007 & 879 & 291 & $33 \%$ & $56 \%$ \\
2008 & 960 & 445 & $46 \%$ & $53 \%$ \\
2009 & 1,121 & 316 & $28 \%$ & $46 \%$ \\
\hline Total & 5,648 & 3,888 & $69 \%$ & $43 \%$ \\
$(2000-2009)$ & & & &
\end{tabular}

TABLE 4.4 Cost-shared projects and level of cost-sharing in DOE assistance (mostly grants and cooperative agreements) for ERD\&D

applied R\&D as a role for government (Merrill, 1984) is likely to be at least partly responsible for the more stable DOE funding for Science. In addition, ERD\&D projects are larger on average than Science projects, so the start and end of particular projects contributes to more volatility. Whatever the cause, instability poses a challenge to effective management for both the government and its partners.

Science and ERD\&D also have quite different patterns of recipients and cost-sharing. The Office of Science awards $74 \%$ of its funding to colleges and universities, and $13 \%$ to small businesses. Almost all Science awards (97\%) go to projects entirely funded by the DOE. The distribution of cost-sharing and partners within ERD\&D offices is more complex. As seen in Figure 4.5, larger businesses ${ }^{57}$ receive nearly half of all ERD\&D assistance, on average. Higher education receives the next highest amount of assistance, followed by small businesses and non-profits. This distribution is once again volatile, with an average standard deviation of yearly changes of $26 \%$ (counting neither the large change in 2009 nor the small and variable "other" category).

Most ERD\&D projects involve some cost-sharing, which can be measured in several ways. Table 4.4 shows the number of projects that include DOE and partner contributions in a particular year and over the duration of the project, along with the allocation of funding. The percent of projects that are shared each year ranged from $28 \%$ in 2009 to $60 \%$ in 2000 (note that the total percentage of shared projects

57 Government agencies' definition of "small business" is set by 13 CFR 121, and varies by industry. The most common limits are: 500 employees for most manufacturers, 100 employees in wholesale, and \$6 million sales receipts in retail and services. Other industries have different limits; see www.fedaccess.com/what-is-small-business.htm. 


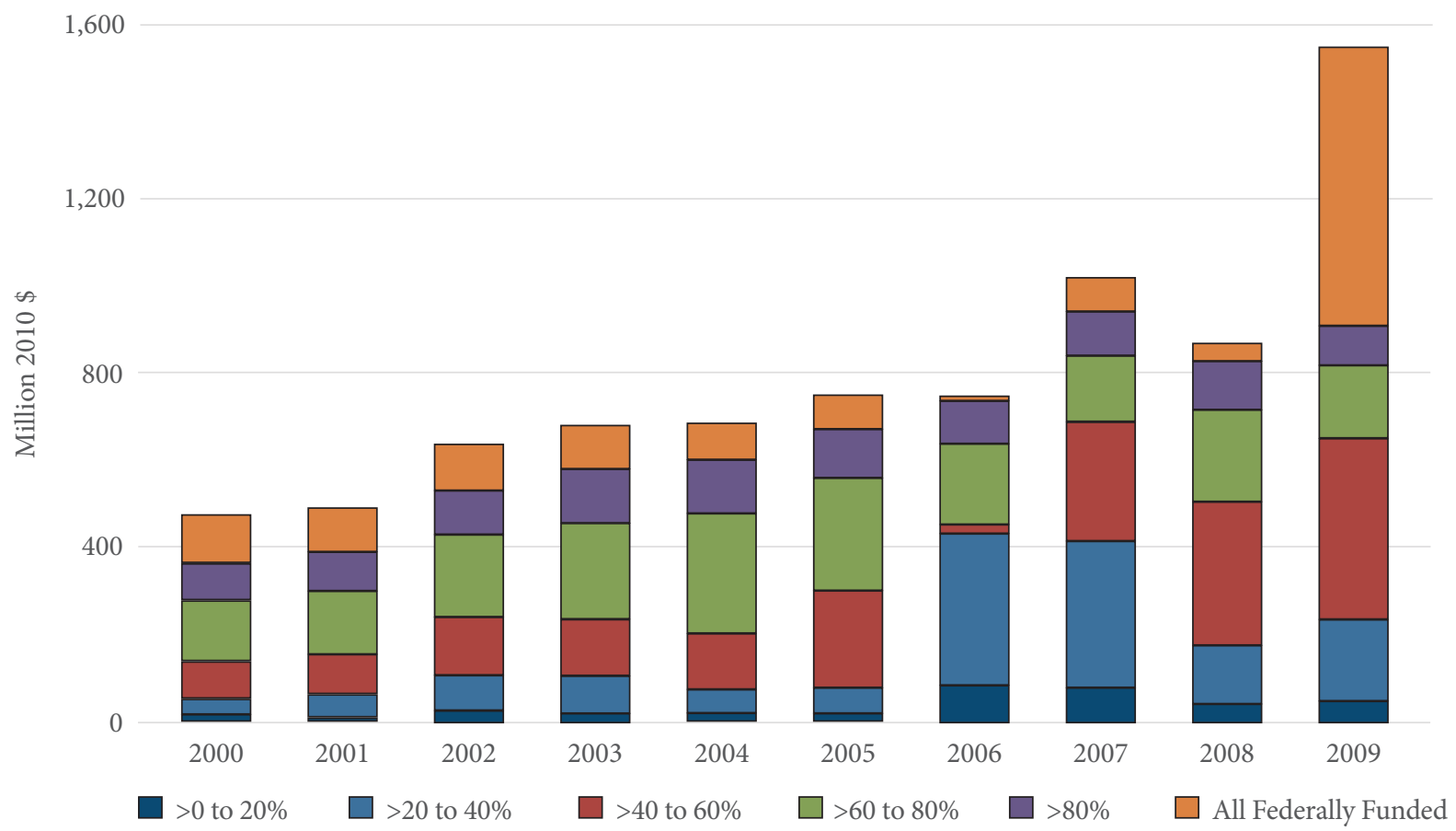

FIGURE 4.6 DOE funding for ERD\&D assistance (mostly grants and cooperative agreements) by federal share of project funding.

$-69 \%$-is greater than that in any other year because each party may contribute in different years to a multiyear project). For example, if the DOE gives a million dollars in 2002 and a firm gives a million dollars in 2003, to the same project, the stats will show "no sharing" in both 2002 and 2003, since neither year had both federal and non-federal funding. Aggregated over the decade, there is both federal and non-federal funding and there are more shared projects in total than there are in any year because partners may contribute in different years toward the same multi-year project). The DOE contributes just under half of the total funding over the time period under consideration, with an especially low contribution in 2006 (an abnormality due to a $\$ 2$ billion private contribution to a coal plant). Overall, non-federal partners contributed $\$ 9.7$ billion to projects from 2000 through 2009, $\$ 9.5$ billion of which was in ERD\&D.

Figure 4.6 shows the distribution of DOE funding to projects by the degree of total project cost-sharing, using information from the USA Spending database. ${ }^{58}$ For most years, the largest part of funding goes to projects where the DOE contributes between $40 \%$ and $80 \%$ of the cost of the project. In 2007, the DOE allocated $41 \%$ of its funding for ERD\&D assistance to projects where a partner contributed at least $60 \%$ of the total, while in $2009,41 \%$ of funding went to projects that are (thus far, see footnote 7 ) solely

58 Some projects will have received funding in years prior to those covered by the database, or will receive funding in future fiscal years, which might affect measures of cost-sharing. 
federally funded. The average standard deviation of yearly changes across cost-sharing categories is $50 \%$.

\subsubsection{Reflections on trends in DOE activities}

Details concerning grants and cooperative agreements are important because they represent about 30\% of the ERD\&D budget and 55\% of the Science budget. Yet, it is difficult to find data on these agreements beyond their number and total investment, which creates barriers to learning from past experiences. Information that is missing includes the design of agreements, the outcomes of partnerships, the technology areas supported (what funds were directed toward entities working on biomass, solar power, buildings, etc.), and the lessons learned. Without this type of information strategic planners cannot have been aware of the allocation of funding for projects and project types among technologies, technological stages (e.g., basic research, applied research, pilot, or demonstration stage), or partners. It would be difficult to conclude that partnerships are an element of strategic decisions if the DOE does not even have an organized method for counting them. For R\&D managers, there does not seem to be a way that project design can take into account lessons from past projects, other than the personal experience of the researchers involved. Though the circumstances of each partnership differ to some extent, it seems very hard to learn what elements of partnership agreements are associated with projects that were/are useful and what elements are associated with projects that were/are not.

Over the past decade, there has been an overall upward trend in assistance spending by the DOE-especially in ERD\&D. Special spending under ARRA increased all types of DOE assistance, but still not to the levels seen in the late 1970s. Though the broad trends are promising, the funding volatility is high, particularly for specific programs, and volatility on cost-sharing is significant. This volatility has negative implications on several levels of the energy technology innovation effort. First, it is evident that, despite the value placed on partnerships in strategic documents, partnership is neither an element of strategy, nor does its use seem to follow a plan. Further, the funding volatility makes evaluation and planning more difficult-it is impossible to attribute outcomes to actions in such a noisy environment. DOE project and program managers are subjected to such uncertainty that planning and execution can be extremely difficult. For the DOE's active and prospective partners in the private sector, uncertainty limits their ability to plan, discourages participation, and makes assistance less valuable. Each of these effects hinders the energy technology effort.

\subsection{Project Management for Public-Private Partnerships}

Innovation is a difficult enterprise that often crosses the boundaries between organizations, industries, and research fields (Carlsson \& Stankiewicz, 1991; Garud \& Karnøe, 2003). Innovative projects are notoriously difficult to manage (Cohen \& Levinthal, 1989; Ngai, Jin, \& Liang, 2008; Saeed, 1998). Respondents to the Survey of Energy Innovation (section 4.4.3) cited difficulties in the process of innovation 
more than any other type of challenge; if we include commercialization cost as an innovation process rather than a market barrier, this is even more the case. Firms turning to partnerships as a means to address the challenges of innovation is a trend found in our survey and others (Cosner, 2010). Technology partnerships can have cost advantages (Hemphill \& Vonortas, 2003) and strategic value (Mowery \& Teece, 1996; Wessner, 2002) but add new challenges to managing projects (Stiglitz \& Wallsten, 1999; Friend, 2006). These are all indications that management issues can be as important to the success of innovation as resources, technology, and markets.

Experts that were interviewed for this research agreed that management practices were important. The interviews included both extended interviews about management and strategy with top leaders from government, universities, labs, and the private sector; and interviews obtained in the course of our survey design with company and R\&D leaders covering industry, management, innovation, and data topics. In this section, we present findings on the challenges of managing within public-private partnerships. A real partnership involves sharing resources, risk, and discretion. The level of entanglement or interaction implied by this is far greater than a simple transaction, or a form of cooperation that involves only resources and one-sided risk. Drawing on lessons from the literature and the experiences of our interviewees and survey respondents, we offer the following principles that the DOE could use to make decisions about real partnerships and transactions:

- Choosing partners with similar work cultures. A match in organizational culture between the parties was noted by informants as an important factor for resolving problems during the project, and for developing agreements ahead of time. Common cultural expectations and principles toward dispute resolution increase the possibility of successful projects.

- Selecting partners with overlapping interest and complementary abilities. Interviewees note the importance of overlapping interest and complementary abilities for successful technological partnerships. The interests of the parties will not be the same, but should be aligned in the specific area of the partnership, not just in a vague or general way, but also in terms of priority to each organization. The overlap should include similar goals and level of importance given to achieving those goals, so that the parties have similar levels of commitment to the project. If the parties have matching abilities, there is a higher risk of conflict as each tries to do the same thing; complimentary abilities result in division of labor, interdependence, and synergies within the project. Combined with common culture, overlapping interests and complimentary abilities lead to higher levels of trust through common commitment and mutual oversight.

- Using partnerships only when priority is high. Given the conditions and preparation needed for success, partnerships may not be appropriate for every interaction. Partnership, collaboration, 
and cooperation are valued ideals, referenced frequently in DOE materials. One informant reports being steered toward a CRADA — a long and detailed agreement involving disclosing intellectual property and an application for federal funding - when a short-term transaction was all that was necessary and desired by the private firm. The effort needed to build a good partnership is sometimes wasted on projects of moderate importance, or of differing levels of importance to the parties, or where the conditions for a successful partnership are lacking. In these cases, a transaction, rather than a partnership approach, may be more suitable. Mechanisms that are appropriate for a partnership are probably not appropriate for other activities. In many cases, missing capabilities can be brought into a technology project through transactions, without the level of interaction of a full partnership. Work for Others and User Facility agreements allow the national laboratories to "participate with talent" (as one informant put it) or with resources in supporting the priorities of its clients. Grants and contracts allow the DOE to use the talents of firms to support its priorities. In fact, a set of projects over time, from informal contacts to small transactions and then onto larger ones, may build the relationship between parties necessary to having a successful partnership. Relationship and trust should be seen as both inputs to and outcomes of successful projects-precursors to success as well as indicators of success.

- $\quad$ Preparing detailed agreements that include planning for contingencies and operational details. Agreements for partnerships have to cover contingencies and definitions in sufficient detail that the boundaries of shared decision making and the risk of losses are clear to both parties. There has to be agreement regarding accounting systems, chains of command, information flow, and other systems that are unique, even defining, to individual organizations. The difficulty of partnership agreements is not unique to public-private partnerships (Friend, 2006; Teece, 1992), but it can be particularly difficult when the parties hold different motivations and expectations, as may be the case between private and federal partners. As such, the agreements that cover partnerships are, or should be, extensive, representing a significant expenditure of effort before project work, or even planning for the work, begins. Careful planning and design of the partnership agreement can both reduce the range of events not covered by the agreement, and increase the ability to agree on the handling of unforeseen events. A detailed agreement provides guidance for unforeseen circumstances through analogy, and the drafting of a detailed agreement builds understanding between the parties of the principles by which problems can be resolved.

- Planning jointly before and after a partnership has started. Technological development projects worthy of forming a partnership are complex and require detailed planning. Planning has to be a joint process between partners, deciding not only the steps to be taken, but also the milestones, decision points, evaluation criteria, and contingency actions. Project planning will ideally proceed in parallel with negotiating the partnership agreement, since the two aspects are interrelated. Like building the agreement, planning the work of a project increases trust between the parties by developing a shared understanding with regard to expectations, responsibilities, and 
commitment. Critically, the planning should explore multiple paths that could lead to a project failing to meet its objectives, and the means by which the project can be abandoned or the partnership dissolved. Understanding the failure modes increases the chance of avoiding them; it also increases the chance that a technological setback can still be an opportunity for learning. Moreover, an amicable dissolution of a partnership leaves open the possibility of future ones. Finally, informants report a rule of thumb: Ten to twenty percent of the total project time should be spent in planning.

- Contrast between planning and agreements. Interviewees noted a disconnect between the amount of time it took to begin work within a partnership and the quality of the project plan (often a long planning process did not result in a good plan). From the description of interviewees, time spent at the beginning of projects usually includes too many financial and intellectual property details and not enough contingency planning and relationship building. An excessive focus on accountability leads to burdensome procedures, accounting systems, and documentation requirements; and pressure to have every project be a success leads to ignoring contingencies. In addition, the schedule does not account for time spent in planning and negotiation, so planning is too often neglected.

- Building trust and relationships between the organizations. However detailed the agreement, trust is an important component in the success of partnerships (Teece, 1992). In complex, uncertain technology development work, difficulties are likely to arise and no agreement can cover all possibilities. One group of informants contrasted two recent CRADAs conducted at a national lab with private firms. One was primarily assembled by management. The researchers participating were merely assigned to the project and were not necessarily involved in project planning. The collaboration lasted only a year and accomplished nothing. A more successful partnership was driven by contacts between researchers. Other collaborations and deals followed. And even though the partner firm is having trouble with an original equipment manufacturer for commercialization, there has been great progress. The lesson is that if the balance between relationship and task tips too much toward task, neither gets accomplished. If it tips too much toward relationship, then there might be a technical failure, but in that case at least there can be learning.

- A technological failure is not necessarily a project failure. Innovation is an uncertain enterprise and not every technological idea will work. If there is too much pressure to succeed, managers will not take risks and will only communicate their successes. If the objectives are too timid, a project will have little benefit even if all of the objectives are met. An aggressive set of projects can produce valuable knowledge even if many of them fail to produce tangible products (Frosch, 1996; Euchner, 2009). Good planning makes learning more likely. To make use of knowledge, it is important to have a culture where "learning from failure" describes not just individual actors avoiding the repetition of mistakes but also the dissemination of negative results to a wider group. 


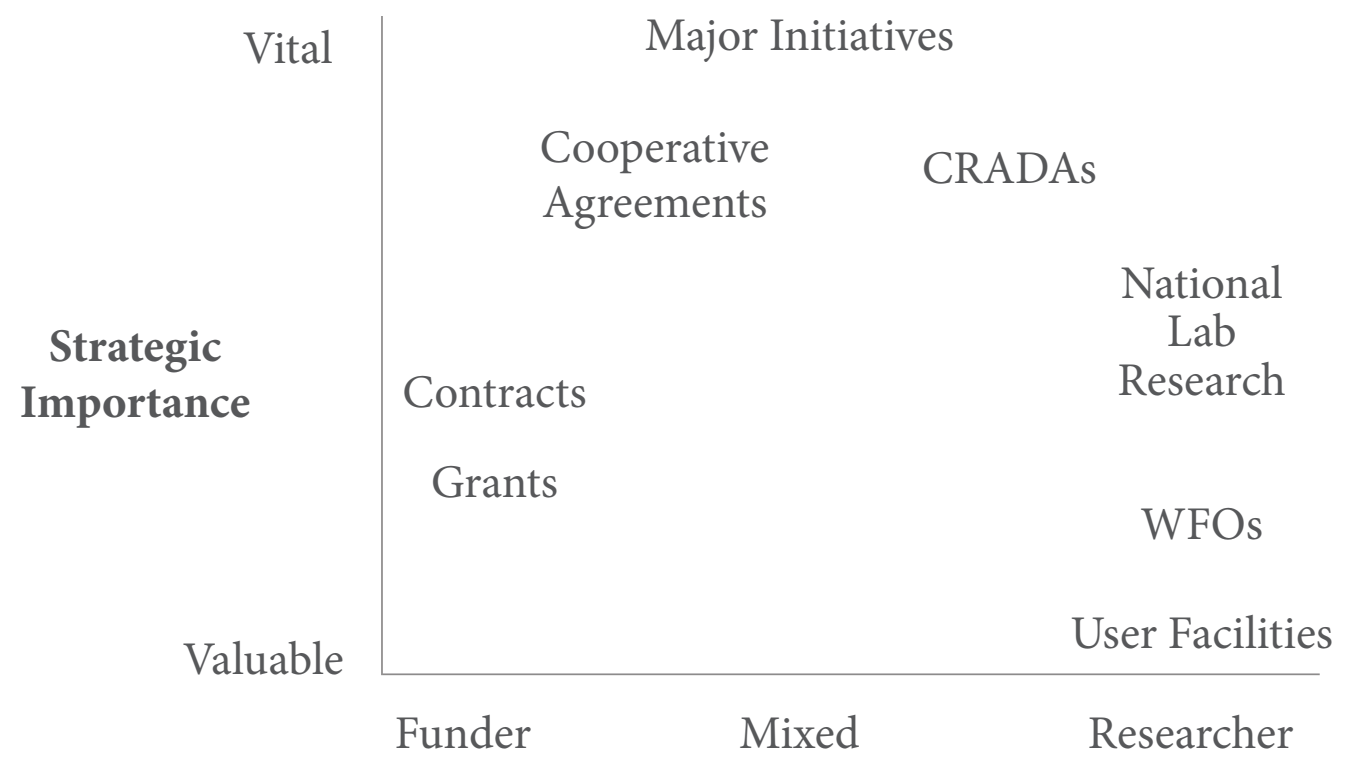

\section{Government Role}

FIGURE 4.7 Typology of ERD\&D partnership and transaction activities by priority level and type of government involvement.

These observations lead to a typology of activities, as shown in Figure 4.7. Government participation ranges from being a funding source only to being the principal researcher, with various degrees of partnerships in between. At the same time, the outcome of the work may range from vital to the nation's energy strategy to merely valuable (leaving aside those projects not contributing to desired goals). The position on this matrix corresponds to a variety of appropriate mechanisms. The most important work calls for major initiatives, likely to require many partners. For sufficiently important work, it is worth engaging in partnerships through CRADAs or Cooperative Agreements. Other work may be important, but may be better accomplished through less complicated support or technology transfer mechanisms.

\subsection{Strategic Planning in Both Public and Private Sectors, and in Partnerships}

In order to capture the maximum value from investments in energy technology innovation, there must be sound strategy guiding those investments. Elsewhere in this report are discussions of strategy for allocating effort (Chapter 2), designing innovative institutions (Chapter 3), and engaging in international cooperation (Chapter 5). In the realm of public-private partnerships, problems are likely to be experienced at the project level: as failed projects, timid projects, and technology that does not progress into use. But good projects are enabled by a strategic environment that supports project success, which results in conducting a variety of projects that support the DOE's goals, and which adjusts to changing conditions. Since successful partnerships are so difficult to achieve, planners have to treat partnerships, as well as other activities, as elements of strategy. To do that effectively requires flexible mechanisms and good information flow. 
Experts from government, universities, labs, and the private sector interviewed for this study provided lessons about strategy from their combined extensive experience with innovation and partnerships. Interviewees described the way that current strategy manifests in practice, and gave insight regarding possible areas for improvement. Some of the needs of firms involved in energy innovation are gleaned from their answers on the Survey of Energy Innovation. Strategic guidance documents and DOE practices are contrasted with the literature on strategic decision making. For example, there may be problems in the current strategy in the way in which cooperative agreements and grants are initiated and evaluated. The outcome of the energy technology effort will be improved if the process by which strategies are developed is improved.

\subsubsection{Current process for making decisions about energy innovation partnerships at the DOE}

Strategic decisions on funding for energy RD\&D within the DOE, for each broad technology area, are made through an interaction between budget and policy planners and senior program managers. Strategy reflects administration priorities, and also the perceived opportunities, hurdles, and potential contribution of each energy technology to increasing security of supply, reducing cost and environmental impacts, and increasing U.S. competitiveness, globally. Program offices, the national labs, and technology experts participate in forming technology roadmaps and multiyear plans (e.g., NREL, 2007), which are influenced by, but also inform, department-wide priorities. The multiyear plans help to determine the technological potential of each energy source, which is then used by policy makers at the DOE headquarters level, at $\mathrm{OMB}$, and at the White House to formulate budget requests. Budget documents and the program plans are the most visible strategic guidance; they seem to embody a great deal of technological information, but are very much focused on allocating funds among programs and rarely discuss a rationale or strategy for partnering with private firms in different technology areas.

The mission of the DOE is to "ensure America's security and prosperity by addressing its energy, environmental, and nuclear challenges through transformative science and technology solutions." The DOE has the stated goal to "catalyze the timely, material, and efficient transformation of the nation's energy system and secure U.S. leadership in clean energy technologies" (DOE, 2011b). With its R\&D support and technology transfer mechanisms (section 4.4.1 above), the DOE can serve both the researcher and the research funder, and provider of unique services to each. The DOE acts as a clearinghouse for information on energy, and has grants and load guarantees to support deployment. The DOE tries to target its support and services to areas that the private sector cannot sufficiently support on its own.

From the strategic guidance and within budget and rules, program offices generate funding opportunity announcements. Firms and other potential partners are able to respond to the announcements with proposals and applications, or they may submit unsolicited proposals within the published areas of interest. Proposals are evaluated through peer review. Partnerships are seen as inherently valuable, so awards fa- 
vor proposals with groups collaborating. Based on the data in section 4.3 above, $88 \%$ of DOE assistance in ERD\&D goes to shared-cost projects (mostly Cooperative Agreements) with industry. The national laboratories are assigned some work directly, but they also compete for work amongst themselves, and sometimes they are secondary assets of firms making proposals. In addition, the national laboratories make decisions about technology transfer projects. They work to attract projects that will further strategic goals, but must also rely on proposals from partners.

Certain features of the current system are either weaknesses at the strategic level or weaknesses at the project level that have to be addressed department-wide:

- There is no guidance on partnership in strategic plans. The main strategic guidance on partnerships from the DOE includes DOE-specific strategic plans (DOE, 2006; DOE, 2011b), budget documents (DOE, 2010), multiyear program plans (EERE, 2008), and internal directives. All of the above state the importance of partnership, but none provide guidance on partnership development. Interviewees, whether from the government or from the private sector, could not point to documents explaining when or why the DOE would use one mechanism (i.e., a grant, a cooperative agreement, etc.) over another. All of the documents contain great detail about technology and goals in terms of volume or performance, but not about appropriate types of mechanisms or what kinds of partnerships have worked in the past. Project management occurs in isolation from strategic decisions.

- Partnerships are not considered in budget and strategic decisions. Likewise, budgets and planning occur in isolation from project management. The types of mechanisms to be used in a program, and the contributions from cost-sharing, should affect how much a program will cost or what funding will be needed to obtain the desired results. The capabilities brought in by partners affect what capabilities need to be developed by the DOE. Program managers must use their knowledge of projects when formulating project plans and budget requests, but the knowledge that they use is not yet made explicit in strategic documents.

- Partnerships are not treated as strategic relationships. The selection of Cooperative Agreements and CRADAs relies on a fairly passive announcement-application-review process. Private firms might seek out and court partners that meet their strategic interests (Hemphill \& Vonortas, 2003; Hagedoorn, 1993), but the government is generally prohibited from such practices by competitive bidding rules. The relationship between partners is important for project success (Teece, 1992), but factors like cultural fit and complementary capabilities do not factor into the decision process until after the projects are selected. The best relationships described by interviewees developed through ad hoc contacts - that is, informal, or formed incidentally over the course of grants or transactions-not by design. 
- Cooperation mechanisms are inflexible. Limitations inherent in the mechanisms available for collaborating with partners interfere with the ability to implement strategy. Unlike private sector technology partnerships, the government cannot promise deliverables and has limited ability to take on risk, so some partners have been disappointed with the results. Agreements are limited in time and scope, thereby preventing the exploration of new avenues for innovation if any are uncovered during the project. Finally, requirements intended to increase accountability force the private partner to use government procedures that are often at odds with normal business practices.

- Administrative requirements are not streamlined. The complexity of administrative requirements is a recurring theme at all stages of the budget and management decision process. This is more of a project-level problem than a strategic one, but it nevertheless requires department-wide action to be addressed. Informants with private-sector experience describe the applications, agreements, record-keeping, and reporting requirements as both more difficult than, and inconsistent with, standard business practices. Detailed planning was cited as an important factor in project success, but this must not be confused with just adding more bureaucracy; in fact, the complexity of requirements can get in the way of effective use of the time spent on planning. For example, negotiators of agreements spend more time on accounting systems than on technical and partnership contingencies.

- Information collected does not support learning. As noted in section 4.4.1, it is difficult to determine the number of, and expenditures on, projects using DOE data systems, much less the technology, development stages, processes, and outcomes associated with them. One would suspect that the appropriate mix of projects and partners would vary by technology and stage of development, but the data that might provide a way of measuring this is lacking. The current reports are intended for accountability and not for learning, although interviewees questioned the degree to which they served their intended purpose.

- Some political barriers exist to supporting the best projects. Finally, informants perceived systemic political barriers to implementing a strategy. Federal entities are prohibited from competing with private enterprise, yet, by design, partnerships with the government provide value to private firms. In some cases, this prevents the types of support that might aid innovation, and in other cases it results in interference with projects. The review process and availability of services are meant to assure fairness, but not all parties accept the outcomes. When there are successful partnerships that lead to commercial value, non-participant (and sometimes competing) firms have complained about unfair support by the DOE of its partners in the project. In another example, informants report having experienced pressure from Congressional offices to avoid helping a competitor of their constituents. 
There seems to be a paradox: the requirements are too rigid on the one hand, but there is a lack of direction and focus on the other. Given the issues identified by informants, there seem to be opportunities to improve the pace of technological innovation through strategic and management improvements. The expanded role of the government in funding energy technology innovation (ARRA, 2009) should be matched by a process which supports better management of that enterprise. In the following section, we propose changes to accomplish this goal.

\subsubsection{Improving DOE decision-making process on partnerships}

Scientists, managers, policy makers at the DOE and in the national labs, and their partners have done an admirable job promoting energy technology innovation, bringing innovations to market, and developing the innovation system. They can point to many specific successes (FLC, 2007a; DOE, 2007) and have been important in energy technology trajectories (DOE \& EPRI, 1997; EIA, 2001; Norberg-Bohm, 2000). Yet, the experience of interviewees suggests that impediments remain to implementing the kind of energy innovation enterprise required to solve the major energy-related challenges of the present and the future. To improve the strategic process would require changes in the way information flows, so that the types of information flow further, even if less detail is transmitted to the top. To improve the success of individual projects would require not only management changes, but system-wide changes to support the likelihood of better management.

In the abstract, the system described by informants is similar to Figure 4.8: knowledge about technology is widely distributed and used for planning, but information about strategy and partnerships is localized at the top and bottom of the management chain. Everyone may read the DOE strategy but it contains little to help the program offices select or manage projects. There are some interactions between those designing multiyear program plans and those making budget decisions, but at the project level, managers experience mostly input in a one-way direction. Project selection is separated from both strategic decisions and project design, and projects are only designed after they are selected.

An idealized system would be more like Figure 4.9. Strategic decisions on budgets, program plans, and partnerships are made together in an integrated manner; project design is considered as part of selection and not left as an afterthought. Strategic direction is useful to project managers, and their experience reaches strategic decision-makers to inform policy-making. There are ways to improve the fit of proposals and selected projects into the country's strategic interest by improving budgets, program plans, and funding opportunity announcements. Adopting certain principles would lead to more useful information flow and address some of the weaknesses in the current process:

- Articulate how the roles the DOE serves fit with its mission and goals. The DOE acts as a researcher, research funder, technical expert, provider of unique research services, clearinghouse 


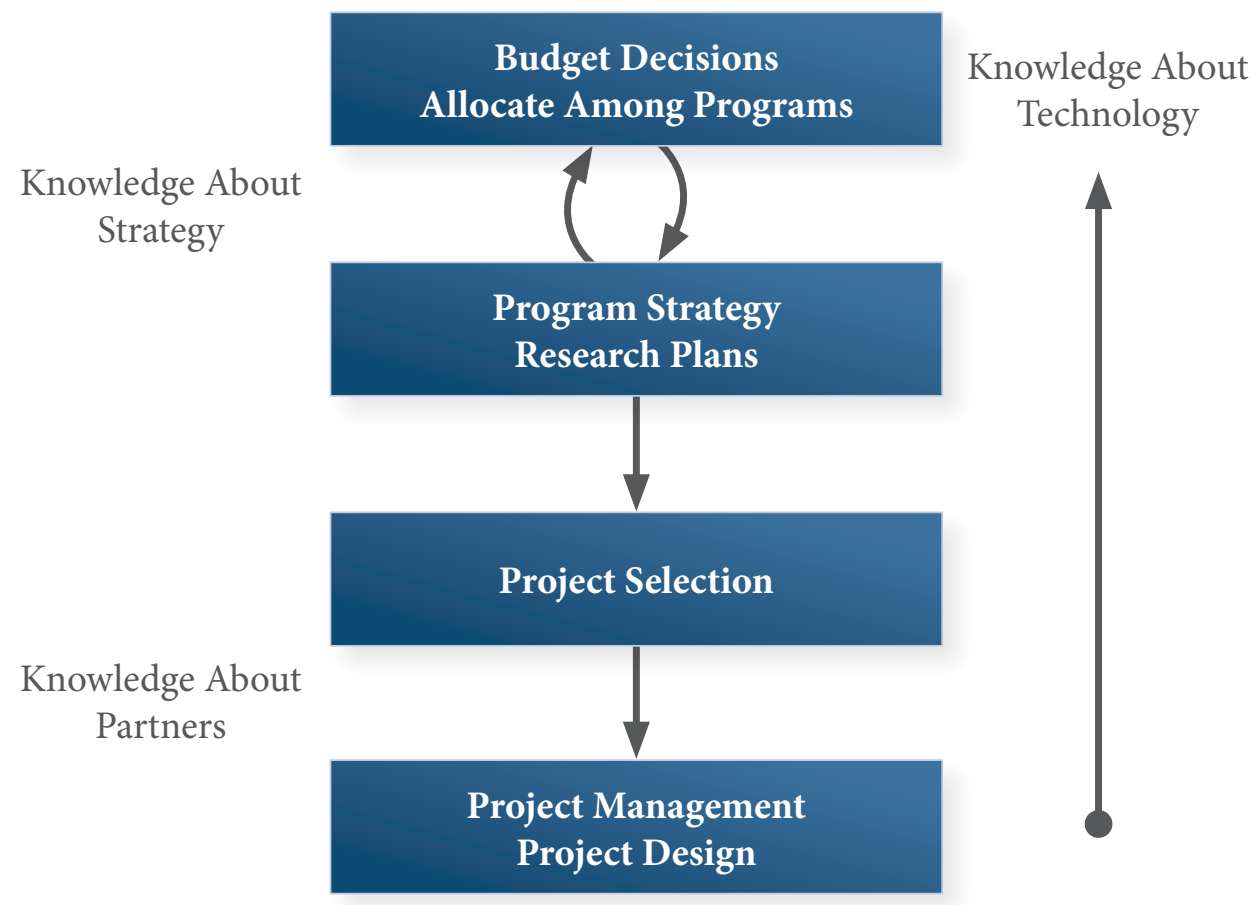

FIGURE 4.8. Conceptual map of current DOE practice-limited information flow, one-way direction.

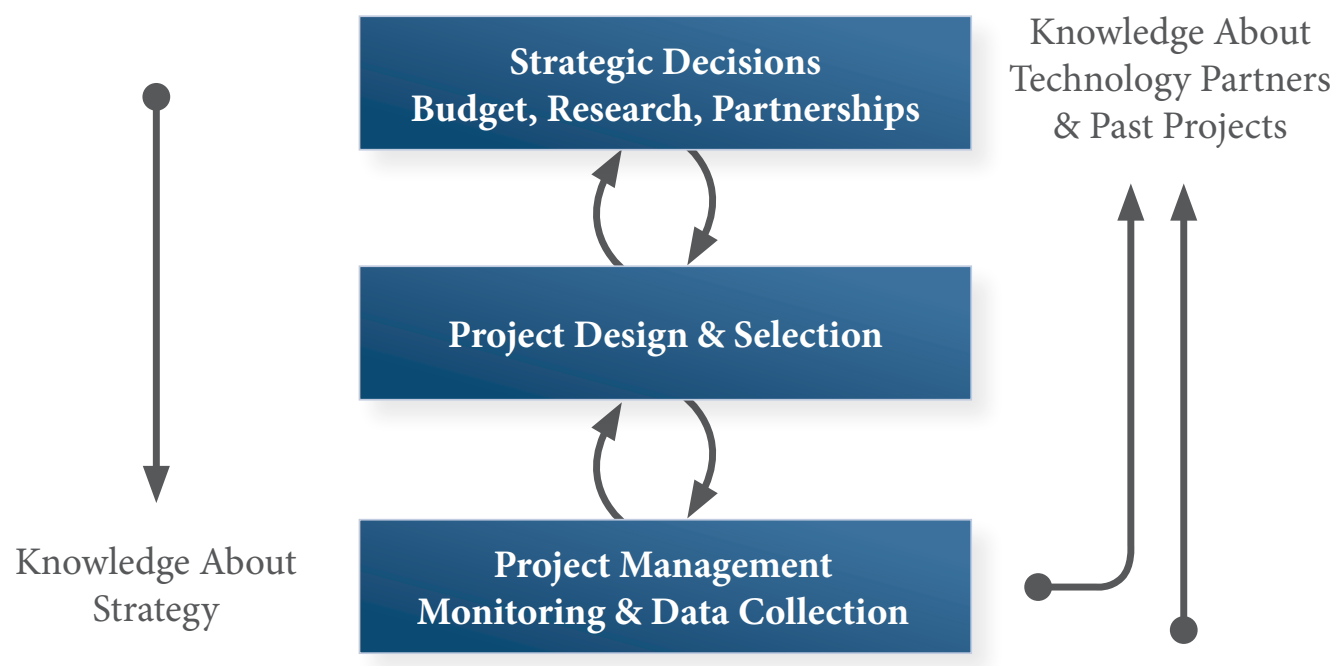

FIGURE 4.9. Conceptual map of idealized practice—feedback, information flow, and learning. 
for information, and financier for deployment. For each role, there should be a positive statement of what goals are supposed to be served by that role and how those goals can be reached (Audretsch et al., 2002; Hagedoorn, 1993). Managers will be better able to incorporate strategy into decision-making if it is clear what they are meant to achieve through energy innovation support, partnerships, and services. There has been some progress in explaining new mechanisms such as ARPA-E and Energy Innovation Hubs, but even the metaphors used to explain these are geared toward Congress rather than managers.

- Set forth principles for when and how to use different mechanisms. Government support and services are grounded in market failure and strategic interest, but this is only vaguely referred to in strategic documents. Managers can be more deliberate in the mechanisms they choose if there is a match with the problem to be addressed (Fri, 2003; Hagedoorn, Link, \& Vonortas, 2000; Martin, 2003). The DOE can make research less expensive for firms, or can create an incentive for firms to do research, or can conduct the research that firms will not conduct-appropriate to address scale, public goods, or spill-over problems. These principles should include how to decide what is important enough to justify partnerships and what can be done through funding and other transactions.

- Use information about strategy for project design and selection. Project design and selection can implement policy in accordance with strategy only if policymakers have the information to understand which actors can best play which roles, and what funding and cooperation mechanisms are likely to work best for a particular purpose. Funding opportunity announcements should take into account the strategic interests related to the project, market needs, and the structure of projects, as well as the technology areas. Most activity supporting work in the private sector and academia would not be true partnerships (as defined by sharing resources, risk, and discretion) but the decisions should be deliberate about when to undertake true partnerships and when to use other mechanisms. Non-partnership types of support and services are valuable and should be provided when consistent with strategic goals.

- Use information about partnership in program planning. Multiyear program plans should take into account what capabilities and resources from the private firm will be needed, and how they can be best leveraged based on information collected about previous efforts. Managers' experience with what a particular partner is able to contribute and what the DOE has to contribute is as important as the state of technology in deciding what actions to take. Through the interaction between DOE employees and experts in the private sector, partnerships are good sources of information about the pace of technology development and about what troubles are being experienced.

- Use information about partnership in the budget process. Project funding is a large part of the DOE's budget. In what programs partnerships are, or should be, occurring impacts what re- 
sources are needed, how much matching funding partners will have to contribute, and how much funding projects are expected to attract. The capabilities provided by offices, labs, and partners all represent costs to be incurred.

- Develop strategic relationships where strategic interest justifies. Relationships between private and government partners develop over time, often starting from informal contacts and building into CRADAs or cooperative agreements. Over time, either a sufficient level of trust develops or the relationship ends. An arms-length approach can prevent favoritism, but if the relationship impacts strategic priorities, it may be necessary to be proactive. Being open and transparent about what a partnership entails can help mitigate dissatisfaction on the part of other parties. Building relationships with all industry players should be a part of strategy so that fewer firms will be left out; good relationships with industry will help produce both successful partnerships and communication channels for technology planning.

- Create a new mechanism to enable learning. To accomplish this change in the strategy process would require a new mechanism for recording the processes and outcomes of projects. Aside from its inadequacy for learning, the record-keeping currently required is perceived by interviewees as cumbersome. Any new requirements should occur only in parallel with paperwork reduction. Information that connects project results to strategic, design, and management decisions is necessary for there to be a dynamic strategy that adjusts to changing conditions. There would have to be various levels of detail available-from lessons learned to be shared with other managers and for use in training, to the ability to do summary statistics and tests in support of policy research. To be useful for learning, recording systems should be separate from reward or renewal systems (Paper \& Chang, 2005) so that there would be no incentive to inflate scores. In such a system, it would be particularly useful to examine what was learned from projects where the technical goals were not met.

- Simplify administrative requirements and increase flexibility in partnering mechanisms. There should be an effort to move toward standard business practices in the ways the national labs interact with firms: simplifying requirements wherever possible, updating the form of CRADAs, WFO, and other agreements to conform to modern practices, and allowing labs to take on risk and make commitments as part of agreements. Since informal contacts and small projects begin the relationships that lead to successful partnerships, DOE strategy should explicitly include funding to support activities other than full partnerships and the flexibility for researchers to make contact with industry on an informal and smaller-project level.

- Allow projects to fail. If the DOE only takes on the most promising projects, it will be doing work that industry could do itself (Martin, 2003). A culture of risk and experimentation is needed to find the technologies that will transform the energy system (Fri, 2003). Programs should take 
on a portfolio of projects knowing that some will not work as desired. If a technology does not work, research can still produce new knowledge (Frosch, 1996; Euchner, 2009). If the project itself goes poorly, there is an opportunity to learn management lessons. Managers should not be punished for either so that lessons are more likely to be shared.

- Allow projects to succeed. In contrast, stakeholders have to accept that some firms will benefit from successful projects. To alleviate any sense of unfair support, part of the strategic priority in each technology area should be to engage in problems useful to multiple parties, and to share the results widely. Try to engage industry as a whole in developing roadmaps and program plans in the traditions of SEMETECH, GRI and EPRI (see Chapter 3).

With improved information flow brought about through these strategic adjustments, funding and technology transfer opportunities would be more in line with strategy, since they would result from an interactive communication. The project, partnership or otherwise, would be selected based on: (a) technology area, (b) identified needs within a roadmap, (c) overlapping interest within those needs, and (d) desired complementary capabilities. Strategic planning would incorporate a better picture of innovation that includes how projects work in addition to the state of technology. Strategy that supports better management will produce greater satisfaction on the part of partners and greater value for the investments made.

\subsection{LEARning AND Adaptation}

Changes to the strategic process should be seen as developing a means of adjusting strategy to a dynamic environment, not some attempt at an optimal final plan. In its overall policy for energy technology innovation, not just in its policies toward partnerships and transactions, the Department of Energy should foster a management culture that embraces experimentation and learning, just as it fosters those attitudes toward solving technical problems. Considering partnerships as elements of strategy, engaging in real partnerships only when they are worth the effort, expending the effort in planning needed for project success, and improving the information systems for projects are important steps in leading a successful innovation enterprise.

Becoming a learning organization is vital for being an innovative organization (Senge, 1990). Learning is not only discovery through research, at which the DOE is already adept, but also changing practices in response to information. The ability of an organization to learn is, in part, a cultural orientation, and requires occasional renewal to maintain the necessary commitment and vision to learn (Calantone, Cavusgil, \& Zhao, 2002). Learning organizations must be able to adjust their strategy in response to changing conditions or performance problems (Lant \& Montgomery, 1987). Conditions that the DOE would need to adjust in order to improve its strategy toward partnership include: 
- External conditions in the energy industry. Factors like energy prices, supply security, industry structure, and market conditions are largely outside of the DOE. They affect what research needs to be done, and also the interest and ability of the private sector to conduct energy innovation. The DOE will have to change how it supports innovation and therefore how it engages in partnerships.

- Technology development. What is known, what is possible, and what needs to be done to get new technologies into service changes over time-progress on the DOE's own goals changes what the DOE should do. This is both an internal and external issue; industry, universities, and DOE programs all result in technology development. There are also both positive and negative developments. Technology gets closer to market, and new possibilities appear, but new problems emerge and some ideas turn out to be dead ends. What stages of development to engage in, what technologies and fields to engage in, and how to engage all have to adjust.

- Performance of DOE's programs. Largely due to internal factors, some actions within any organization yield better outcomes than others and there is learning to be gained from these differences in performance. A learning organization monitors and adjusts its own practices and does not blame failures on external factors. The DOE will have to make adjustments to program performance in order to promote continual improvement.

- The interaction of factors. Of course, the three above factors are interrelated. As technology progresses in any area, it changes the nature of the industry and the markets it serves. New barriers can become apparent and new technologies become important for development. As different actions become appropriate for the $\mathrm{DOE}$ to take, there will be new lessons on how to manage them better.

As important as it is to adjust strategies around lessons learned and changing conditions, it is harmful to suddenly shift direction with every discovery or each budget or election cycle. Gradual, deliberate, and transparent adjustment is appropriate, and the strategy should include variables to monitor and conditions under which the strategy itself will change.

Technology roadmapping is a major source of information about technology and industry factors, both external and internal to the DOE. Roadmapping as a practice for innovation institutions is discussed in Chapter 3, and is already a practice for developing program plans and national laboratory plans. Following the best practices of roadmapping is important for innovation: good practices include concentrating on barriers and how to overcome them, estimating the potential of and common value of different steps that might be taken, and avoiding research wish lists (Fri, 2003; Whalen, 2007; Garcia \& Bray, 1997). In the context of learning about management, partnerships, and the needs of the private sector, the roadmapping process is a good opportunity to build relationships with industry - to gather information but also to set the stage for partnerships. In the process, industry has the opportunity to help shape the DOE's strategic direction, and in so doing, reduce the chance of political problems referred to in sec- 
tion 4.7.1. Roadmapping in the development of program plans should include the kind of projects and the appropriate mechanisms to be used-i.e., how to work on problems, not just what barriers exist. To improve the learning value, the roadmapping process should include what the effects of the prior plans were, and how the recent energy innovation projects have changed the state of technology.

While roadmapping is an excellent tool for information and learning for technology areas, there is a need for a more systemic equivalent. The Quadrennial Energy Review proposed by PCAST (PCAST, 2010) or a similar periodic exercise would be valuable. Again, to increase the learning value, such a review should include identifying the strategic elements that were in place over the past period, and what their effects have been on the nation's energy system. Other reviews, periodic or special purpose at whatever level, should be likewise structured to stimulate learning.

For internal factors, learning depends on having information on actions and outcomes with enough detail to make connections between the two. As section 4.2 made apparent, very basic information on projects is not widely available; nothing is available to make inferences about the connection between project structure and outcome. The Inspector General and the Office of Management at the DOE do occasionally conduct reviews of programs and projects. These are forensic-style reports attempting to uncover whether actions were in accordance with policy or what went awry with a failed project. It is not clear that the findings of these reports are widely used for training, or if they help managers design better programs. Positive examples are highlighted (DOE, 2007) and inserted into strategic documents (DOE, 2006; DOE, 2011b; DOE, 2008) but not with enough detail. Project management is learned apparently only through individual experience.

A more useful learning program should be based on a system for collecting information at various levels of detail, applicable for different consumers. Record keeping should be an integral part of project management from solicitation and planning through completion, so that managers do not have to rely on only their memory at the end. At the highest level of abstraction, basic variables that could be used for summarizing DOE activities and generating statistics should be kept in a database as easy to access as USA Spending (OMB, 2010). Variables such as technology area, stage of development, type of agreement, program and subprogram, outcome measures, and so on are missing from USA Spending but would be valuable in measuring DOE activities. Ideally, this data would be able to be linked with the financial data required by OMB, perhaps through Federal Award ID numbers. Using this data to infer trends and problems should be a part of policymaking and oversight.

Managers at the program and project level need greater detail. To enable managers to learn from each other's experience, there should be a practice of recording lessons learned or project narratives. Important elements have to include relationship with partners, problems that arise and their solutions, contributions and expectations of each party, scientific questions posed and answered, and project out- 
comes. No one manager will be able to read all the lessons from all the projects, so some searchable database should be maintained. However, some program of study should encourage managers to use the information to improve their own knowledge-particularly to learn from peers outside their own area. Personnel in the Office of Management or the Office of Policy can use the reports to research best practices in various subject areas. To be useful, these reports cannot be used against managers or partners in performance evaluations. There can be a reward system for writing the most useful reports, especially the most useful reports of "failed" projects.

A learning organization will use its internal and external information to learn from the past and adjust to changing conditions. Members are free to discuss problems without consequences; every failure being seen as an opportunity for improvement. The work of learning and adaptation is never finished-what constitutes best practice changes over time as technology develops, and new problems are constantly being introduced. A learning organization has to re-commit itself to continuous improvement periodically, and even has to monitor and adapt how it learns, and how it learns how to learn.

\subsection{RECOMMENDATIONS}

Consistent with the findings of other studies (Mowery, Nelson, \& Martin 2010; PCAST 2010; OECD \& IEA, 2003; Grubb, Köhler, \& Anderson, 2002), the most effective single factor for driving innovation in the private sector would be a price on, or a market for, greenhouse gas emissions. Experts interviewed, and the findings from the Survey of Energy Innovation on energy prices and market issues, all support the idea that the private sector responds to price signals by innovating. This result reinforces the findings from Chapter 2 in which we concluded that without a carbon price or other demand-side policies, $\mathrm{CO}_{2}$ emissions are unlikely to decrease to the levels needed. It indicates that a carbon tax or a limit on $\mathrm{CO}_{2}$ emissions implemented through an economy-wide cap and trade program, or as a second-best policy such as a clean energy standard for the power sector, could have a significant impact on the extent and intensity of private sector innovation in energy, and therefore on the cost of mitigating $\mathrm{CO}_{2}$ emissions.

To go along with this however, the government will have to support innovation to enable the market to work with acceptable costs, and to speed up the transition to a new energy system. Supporting the private sector and working in public-private partnerships will contribute to a clean energy transition. To do so more effectively, the Department of Energy should:

Include partnership in strategic decisions. Set forth how roles, support mechanisms, and partnerships fit in with national priorities. If a role does not fit into the missions and goals of national priorities, it should be moved outside the DOE; if a mechanism does not serve its needs it should be changed; if a capability is missing it needs to be developed. Provide guidance on when to use partnership and what kind of support suits what kind of innovation. 
Become a learning organization. Collect data and information on practices, problems, solutions, and outcomes, and use that information to set policies and educate managers. Create an atmosphere wherein people feel free to discuss problems, and where adaptation and learning are priorities.

Build a strategic relationship with industry. Use roadmapping and other meetings to collect information on what the private sector needs and build support for DOE efforts. Because the private sector is diverse, provide services and promote innovation tailored for each particular segment. Consider a member / advisor / ownership model for interaction with industry, like the SRC member board. Understand that markets and short-term decisions are important for firms and adapt interventions to account for their decisions. In addition, the DOE should establish an Energy Innovation Advisory Board (EIAB) with representation from the private sector, academia, the national laboratories, and other key stakeholders, to advise on how best to accelerate private sector energy technology innovation. This advisory board would supplement the existing Secretary of Energy Advisory Board by providing a specific focus on policies designed to accelerate the pace of improvement in energy technologies in collaboration with the private sector. It would also complement and inform the Quadrennial Technology Review, which is currently being undertaken. The board's mission should include consideration not only of DOE investments in energy technologies, but also of the broader set of U.S. government policies that affect the pace of energy technology innovation.

Use strategy in partnership decisions. Match the the type of support to the needs and priority of the project. Write the Funding Opportunity announcements to attract the kinds of partners that suit strategic interests. Devote efforts to improve planning and relationship building in order to increase the chance of project success, and increase the ability to learn from problems. Engage in partnership only when it serves a strategic priority, and recognize the value of other forms of support.

Expand information about the private sector. A follow-up to the Survey of Energy Innovation will provide valuable data for serving private sector needs. The proposed Quadrennial Energy Review can provide valuable information about the needs of the energy innovation system. Contacts with industry can provide information about technological barriers and opportunities as well as the needs of industry.

Be strategic about information. Whatever data collected from all these sources, as well as internal data, must be kept in a way that is accessible to internal managers and external researchers in order to be of the greatest use.

The most important task is to build a process for adapting strategy to changing conditions and lessons learned. There is no optimal strategy that can be followed forever. Just as important, strategy has to adjust smoothly and transparently rather than with a shocking change at every election or budget cycle. Learning occurs if questions being asked about technology change in any direction. Leaders of the energy technology innovation system have to monitor the pace of learning and adapt strategy to improve the pace of learning. 


\section{REFERENCES}

Anadon, L. D., Gallagher, K. S., Bunn, M., \& Jones, C. A. (2009). Tackling U.S. energy challenges and opportunities: Preliminary policy recommendations for enhancing energy innovation in the United States. Cambridge, MA: Energy Technology Innovation Policy research group, Belfer Center for Science and International Affairs, Harvard Kennedy School.

ARRA, (2009, February). American Recovery and Reinvestment Act of 2009, P.L. 111-5, 111th Congress, session 1.

Arrow, K. J. (1962). Economic welfare and allocation of resources. In R. R. Nelson (Ed.), The rate and direction of inventive activity: Economic and social factors (pp. 609-626). Cambridge, MA: National Bureau of Economic Research, Inc.

Audretsch, D. B., Bozeman, B., Combs, K. L., Feldman, M., Link, A. N., Siegel, D. S., Stephan, P., Tassey, G., \& Wessner, C. W. (2002). The economics of science and technology. Journal of Technology Transfer, 27, 155-203.

Battelle, (2010). 2011 global R\&D funding forecast. RઐD Magazine. Elk Grove Villiage, IL, Retrieved from http://www.battelle.org/aboutus/rd/2011.pdf [2011, 03/15].

Block, F., \& Keller, M. R. (2008). Where do innovations come from? Transformations in the U.S. national innovation system, 1970-2006. Washington, DC: The Information Technology \& Innovation Foundation.

Bloomberg New Energy Finance, (2009). NEF Desktop 3.0. Retrieved from www.newenergymatters. com $[2010,03 / 17]$.

Brick, J. M., Morganstein, D., \& Valliant, R. (2000). Analysis of complex sample data using replication. Westat.

Brown, M. A. (2001). Market failures and barriers as a basis for clean energy policies. Energy Policy, 29, 1197-1207.

Calantone, R. J., Cavusgil, S. T., \& Zhao, Y. (2002). Learning orientation, firm innovation capability, and firm performance. Industrial Marketing Management, 31 (6), 515-524.

Carlsson, B., \& Stankiewicz, R. (1991). On the nature, function, and composition of technological systems. Journal of Evolutionary Economics, 1 (2), 93-118.

CCTP, (2006). U.S. climate change technology program strategic plan. Washington, DC: Climate Change Technology Program.

Census, (2009). Business R\&D and innovation survey. Web page, U.S. Census Bureau. Retrieved from bhs.econ.census.gov/BHS/BRDIS/index.html [2009, 12/18] 
Cohen, W. M., \& Levinthal, D. A. (1989). Innovation and learning: The two faces of R \& D. Economic Journal, 99 (397), 569-596.

Cosner, R. R. (2010). Industrial Research Institutute's R\&D trends forecast for 2010. Research Technology Management, 53 (1), 14-22.

DOE, (2006). U.S. Department of Energy strategic plan. Washington, DC: Department of Energy.

DOE, (2007). Report on technology transfer and related technology partnering activities at the National Laboratories and other facilities, fiscal year 2006. Washington, DC: Department of Energy.

DOE, (2008). Annual procurement and financial assistance report, FY 2008. Washington, DC: Department of Energy.

DOE, (2009a). Agency financial report. Washington, DC: Department of Energy.

DOE, (2009b). Annual procurement and financial assistance report, FY2009. Washington, DC: Department of Energy.

DOE, (2009c). R\&D support. Web page, Department of Energy. Retrieved from www.doe.gov/ r\&dsupport.htm [2009, 08/19]

DOE, (2009d). SBIR \& STTR. Web page, Department of Energy. Retrieved from sbir.er.doe.gov/sbir [2009, 08/19]

DOE, (2010). FY 2011 congressional budget request: Budget highlights. Washington, DC: Department of Energy.

DOE, (2011a). Department of Energy quadrennial technology review framing document. Washington, DC: Department of Energy.

DOE, (2011b). Strategic plan (draft). Washington, DC: Department of Energy.

DOE, \& EPRI (1997). Renewable energy technology characterizations. Washington, DC: Department of Energy and Electric Power Research Institute.

Dooley, J. J. (2010). The rise and decline of U.S. private sector investments in energy R\&D since the Arab Oil Embargo of 1973. Springfield, VA: NTIS.

EERE, (2008). Building technologies program planned activities for 2008-2012. Washington, DC: Office of Energy Efficiency and Renewable Energy.

EIA, (2009). Energy \& finance. Web page, Energy Information Administration. Retrieved from eia.doe. gov/emeu/finance/index.html [2009, 07/13]

EIA, (2010). Annual energy review, 2009. Washington, DC: Energy Information Administration.

EIA, (2001). Renewable energy 2000: Issues and trends. Washington, DC: Energy Information Administration. 
EOP, (2009). A strategy for American innovation: Driving towards sustainable growth and quality jobs. Washington, DC: Executive Office of the President.

Euchner, J. A. (2009). Innovation’s family tree. Research Technology Management, 52 (6), 9.

Farris, W. (2010). FY09 Department of Energy technology transfer data. [Personal communication, 2010, 04/10]

FLC, (2007a). Federal laboratories \& state and local governments: Partners for technology transfer success. Cherry Hill, NJ: Federal Laboratory Consortium.

FLC, (2007b). Technology transfer mechanisms used by federal agencies: A quick reference guide. Federal Laboratory Consortium.

Fri, R. W. (2003). The role of knowledge: Technological innovation in the energy system. The Energy Journal, 24 (4), 51-74.

Friend, J. K. (2006). Partnership meets politics: managing within the maze. International Journal of Public Sector Management, 19 (3), 261-277.

Frosch, R. A. (1996). The customer for R\&D is always wrong! Technology Management, 39 (1), 22-27.

Gallagher, K. S., \& Anadon, L. D. (2010). DOE budget authority for energy research, development, and demonstration database. Cambridge, MA: Energy Technology Innovation Policy Report.

Gallagher, K. S., Holdren, J. P., \& Sagar, A. D. (2006). Energy-technology innovation. Annual Review of Environment and Resources, 31, 193-237.

Garcia, M. L., \& Bray, O. H. (1997). Fundamentals of technology roadmapping. Albuquerque, NM: Sandia National Laboratories.

Garud, R., \& Karnøe, P. (2003). Bricolage vs. breakthrough: Distributed and embedded agency in technological entrepreneurship. Research Policy, 32 (2), 277-301.

Grubb, M., Köhler, J., \& Anderson, D. (2002). Induced technical change in energy and environmental modeling: Analytic approaches and policy implications. Annual Review of Energy and the Environment, 27, 271-308.

Hagedoorn, J. (1993). Understanding the rationale of strategic technology partnering: Interorganizational modes of cooperation and sectoral differences. Strategic Management Journal, 14 (5), 371-385.

Hagedoorn, J., Link, A. N., \& Vonortas, N. S. (2000). Research partnerships. Research Policy, 29 (4), 567-587.

Hemphill, T. A., \& Vonortas, N. S. (2003). Strategic research partnerships: A managerial perspective. Technology Analysis \& Strategic Management, 15 (2), 255-271. 
Jaffe, A. B. (1998). The importance of "spillovers" in the policy mission of the Advanced Technology Program. Journal of Technology Transfer, 23 (2), 11-19.

Jaffe, A. B., Newell, R. G., \& Stavins, R. N. (2005). A tale of two market failures: Technology and environmental policy. Ecological Economics, 54 (2-3), 164-174.

Kammen, D. M. \& Pacca, S. (2004). Assessing the costs of electricity. Annual Review of Environment and Resources, 29, 301-344.

Lant, T. K., \& Montgomery, D. B. (1987). Learning from strategic success and failure. Journal of Business Research, 15 (6), 503-517.

Margolis, R. M., \& Kammen, D. M. (1999). Evidence of under-investment in energy R\&D in the United States and the impact of Federal policy. Energy Policy, 27, 575-584.

Martin, S. (2003). The evaluation of strategic research partnerships. Technology Analysis \& Strategic Management, 15 (2), 159-176.

Merrill, S. A. (1984). The politics of micropolicy: Innovation and industrial policy in the United States. Policy Studies Review, 3 (3-4), 445-452.

Mowery, D. C., Nelson, R. R., \& Martin, B. R. (2010). Technology policy and global warming: Why new policy models are needed (or why putting new wine in old bottles won’t work). Research Policy, 39, 1011-1023.

Mowery, D. C., \& Teece, D .J. (1996). Strategic alliances and industrial research. In R. S. Rosenbloom (Ed.), Engines of innovation: U.S. industrial research at the end of an era (111-130). Cambridge, MA: Harvard Business School Press.

Narayanamurti, V., Anadon, L. D., Breetz, H., Bunn, M., Lee, H., \& Mielke, E. (2011). Transforming the energy economy: Options for accelerating the commercialization of advanced energy technologies. Cambridge, MA: Belfer Center for Science and International Affairs, Harvard Kennedy School.

Narayanamurti, V., Anadon, L. D., \& Sagar, A. D. (2009). Transforming energy innovation. Issues in Science and Technology, (fall), 57-64.

Nemet, G. F., \& Kammen, D. M. (2007). U.S. energy research and development: Declining investment, increasing need, and the feasibility of expansion. Energy Policy, 35 (1), 746-755.

Ngai, E. W., Jin, C., \& Liang, T. (2008). A qualitative study of interorganizational knowledge management in complex products and systems development. R\&D Management, 38 (4), 421-440.

Norberg-Bohm, V. (2000). Creating incentives for environmentally enhancing technological change: Lessons from 30 years of U.S. energy technology policy. Technological Forecasting and Social Change, 65, 125-148. 
NREL, (2007). Wind energy multiyear program plan for 2007-2012. Washington, DC: National Renewable Energy Laboratory.

NSF, (2009). Research and development in industry, 2005. Arlington, VA: National Science Foundation Division of Science Resource Statistics.

NSF, (2010a). National patterns of R\&D resources: 2008 data update. Arlington, VA: National Science Foundation Division of Science Resource Statistics.

NSF, (2010b). Science and engineering indicators, 2010. Arlington, VA: National Science Foundation.

OECD, \& IEA (2003). Technology innovation, development and diffusion. Paris, France: Organization for Economic Cooperation and Development \& International Energy Agency.

OMB, (2010). USA spending. Web site, Office of Management and Budget. Retrieved from www. usaspending.gov [2010, 06/01].

Paper, D., \& Chang, R. (2005). The state of business process reengineering: A search for success factors. Total Quality Management \& Business Excellence, 16 (1), 121-133.

PCAST, (2010). Report to the President on accelerating the pace of change in energy technologies through an integrated federal energy policy. Washington, DC: President's Committee of Advisors on Science and Technology.

Saeed, K. (1998). Maintaining professional competence in innovation organizations. Human Systems Management, 17 (1), 69-87.

Schumpeter, J. A. (1934). The theory of economic development. Cambridge, MA: Harvard University Press.

Senge, P. M. (1990). The fifth discipline: The art and practice of the learning organization. New York, NY: Doubleday/Currency.

Solow, R. M. (1957). Technical change and the aggregate production function. Review of Economics and Statistics,. 39 (3), 312-320.

Stiglitz, J. E., \& Wallsten, S. J. (1999). Public-private technology partnerships: Promises and pitfalls. American Behavioral Scientist, 43 (1), 52-73.

Stoneman, P., \& Diederen, P. (1994). Technology diffusion and public policy. Economic Journal, 104 (425), 918-930.

Teece, D. J. (1992). Competition, cooperation, and innovation: Organizational arrangements for regimes of rapid technological progress. Journal of Economic Behavior and Organization, 18 (1), 1-25.

Transparency Act, (2006, September). Federal Funding Accountability and Transparency Act of 2006, P.L. 109-282, 109th Congress, session 2. 
Unruh, G. C. (2000). Understanding carbon lock-in. Energy Policy, 28 (12), 817-830.

Wessner, C. W. (2002). Government-industry partnerships for the development of new technologies. Washington, DC: National Academies Press.

Whalen, P. J. (2007). Strategic and technology planning on a roadmapping foundation. Research Technology Management, 50 (3), 40-51.

Wiesenthal, T., Leduc, G., Schwarz, H., \& Haegeman, K. (2009). R\&D investment in the priority technologies of the European Strategic Energy Technology Plan. Seville, Spain: Joint Research Centre of the European Commission.

Wolfe, R. M. (2010). U.S. businesses report 2008 worldwide R\&D expense of $\$ 330$ billion: Findings from new NSF survey. Arlington, VA: National Science Foundation Division of Science Resource Statistics. 


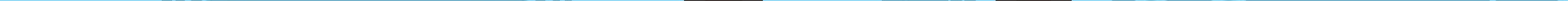


CHAPTER 5

\section{INTERNATIONAL COOPERATION ON ERD3: TRANSFORMING THE U.S. APPROACH}

\subsection{Motivation AND OUTLINE}

Energy technology innovation is not a U.S. phenomenon, it is a global phenomenon. All over the world, research institutions, companies, and governments alike are intensifying their investments in energy research, development, demonstration, and deployment (ERD3) activities. A growing proportion of these activities take place outside of the United States. China and India account for $61.9 \%$ of the growth in global primary energy consumption between 2000 and 2010 (BP 2011), and at the same time their public expenditure on energy research development and demonstration (RD\&D) continues to increase (Gallagher et al. 2011). The U.S. government can seize this growing window of opportunities for U.S. innovators by promoting international cooperation-drawing ideas and experiences from many sources, pooling resources, taking advantage of the best locations to carry out $\mathrm{R} \& \mathrm{D}$ projects or technology demonstrations, and more. Such cooperation can also help U.S. firms get more business in the burgeoning global energy technology market, estimated to be worth tens of trillions of dollars over the next several decades (IEA, 2010f). Moreover, as carbon emissions from the energy system everywhere threaten to disrupt the climate for everyone, it is in the United States' interest for countries all over the world to transition to cleaner energy technologies on a large scale as rapidly as possible-a goal which heavily depends upon international cooperation on ERD3.

International cooperation can strengthen directly and indirectly the United States' position in the global energy sector. First, international cooperation can accelerate the process of energy technology innovation in the United States in two ways: (1) by reducing the costs of U.S. government programs by lowering or sharing the costs of expensive test facilities or large technology demonstration projects; and (2) by supporting ERD3 activities by U.S. innovators requiring access to specific knowledge, resources, technologies, or deployment opportunities overseas. With several energy technologies moving into the costly phase of demonstration projects and growing energy markets overseas, either opportunity provides a sufficient reason to intensify U.S. government efforts on international cooperation.

Second, international cooperation is equally important for addressing global challenges like energy security and climate change issues. On the one hand, the United States addresses these challenges by collaborating with those nations in which primary energy consumption is growing and there is a dire need to secure and build new, efficient, and low-carbon energy infrastructures. On the other hand, the United States can partner with countries like the E.U. and Japan, which are facing similar challenges in terms of transforming an existing infrastructure into one that is clean and less dependent on energy imports. 
Furthermore, international cooperation can create international goodwill and address foreign policy objectives in the longer term, and as such contribute to a more stable geopolitical environment.

At the same time, however, international ERD3 cooperation also has the potential to introduce new delays and inefficiencies, or to result in technology transfers that undermine U.S. interests; it is certainly possible for the risks and transaction costs to be greater than the benefits of cooperation. Hence the U.S. government must develop a strategy to maximize the benefits and to minimize the risks of its international ERD3 cooperation efforts. The purpose of this chapter is to outline the landscape of global energy innovation that such a strategy must confront, and to describe some central elements that such a strategy should include.

The growth in global ERD3 activities has consequences for the role of the U.S. government in international cooperation. First, increased global ERD3 activities also means increased competition-for businesses competing for market share, for governments seeking economic development and employment, and for innovators competing for support for their projects or ideas. Second, an increasingly complex and fast-paced international energy innovation environment makes it more difficult for the U.S. government to prioritize activities and make trade-off decisions-highlighting the need for approaches that empower front-line innovators themselves, rather than attempting to direct all government-supported international ERD3 cooperation from the top down.

The key question in this section is: How can the U.S. government best support international ERD3 cooperation, and balance cooperation with competition, to accelerate energy innovation and to support U.S. and global interests? In particular, choosing where to work together and where to compete depends on many factors and circumstances, and such decisions become increasingly complex as the number of players increases. No simple rule can provide the answer in every case.

In this chapter, we start with a description of our research questions and methods (section 5.2), followed by a quantitative analysis of the changing characteristics of the global ERD3 landscape (section 5.3). We then outline the current U.S. government approaches to and involvement in international ERD3 cooperation (section 5.4). We continue with a critique of existing approaches for selecting, executing, and evaluating international ERD3 cooperation, and provide some lessons about what does and does not work (section 5.5). In section 5.6, we highlight and demonstrate the importance of a more strategic and coordinated approach to ERD3 cooperation throughout the federal government. We conclude with recommendations on how the U.S. government can support U.S. innovators more effectively by increasing the support for bottom-up initiatives, by connecting existing support activities to the innovators on the ground, by providing guidance for U.S. policymakers involved in the design, execution, and evaluation of existing government-supported international ERD3 activities, and by improving the accountability of international cooperation efforts, ensuring that international ERD3 activities are implemented to support and to accelerate the U.S. ERD3 system (section 5.7). 


\subsection{ReSEARCH Questions AND Methodology}

The aim of this chapter is to reassess the changing international ERD3 landscape and the role of U.S. ERD3 cooperation efforts within that landscape, and to offer recommendations for making U.S. ERD3 cooperation more effective and beneficial in accelerating the pace of energy innovation. To this end, we ask the following questions:

- How have energy markets and international approaches to ERD3 changed over the past two decades, and what are the implications for the U.S. government strategy on international cooperation (section 5.3)?

- What is the current state of U.S. government involvement in international ERD3 cooperation, and how do U.S. policymakers coordinate their international ERD3 activities among the different U.S. agencies and with U.S. innovators outside of the government (section 5.4)?

- How does an increasingly complex and diverse landscape of global ERD3 activities impact the ability of U.S. policymakers to coordinate, decide, design, and evaluate international ERD3 cooperation (section 5.5)?

Our analysis is based on literature reviews, semi-structured interviews, and quantitative databases. Our literature reviews mainly focused on policy documents and academic papers describing international cooperation activities on energy technology innovation, but we have also included lessons from reports on international cooperation activities in related technology areas (mainly agriculture, biology, and oceanography). We conducted semi-structured interviews with officers in the United States government and with policymakers in governments of foreign countries (Brazil, Russia, India, Mexico, China, and the Netherlands). The U.S. interviewees included policymakers involved in international cooperation at the Department of Energy (DOE), the State Department (State), the Environmental Protection Agency (EPA), the Council on Environmental Quality (CEQ), and the Office of Science and Technology Policy (OSTP), as well as scientists managing international cooperation projects at national laboratories and within academic or research institutions. Furthermore, we interviewed industry managers with international cooperation experience and project managers of international cooperation projects at the state level. The interviews took place either by telephone or in person and lasted from 30 minutes to two hours.

We used three existing quantitative databases and built two new databases for our analysis of how international ERD3 cooperation between scientists, firms, and governments has evolved over time. These databases include:

- An analysis of international co-authorship in academic papers:

- An analysis of U.S. involvement in IEA's Implementing Agreements between 1974 and 2009: 
- An analysis of import and export flows of energy technologies between the United States and other countries around the world between 1989 and 2009, based on data provided by the United States International Trade Commission (USITC);

- An overview of international interfirm R\&D partnerships on energy technologies between 1965 and 2006 based on data from the Cooperative Agreements and Technology Indicators (CATI) database developed by Hagedoorn (2006); and

- An analysis of overseas development aid (ODA) for "energy" projects between 2000 and 2009 based on OECD's Creditor Reporting System database (OECD, 2010).

A detailed discussion of the features, limitations, and results of these databases can be found in Appendix A5.2.

\subsection{Changing Dynamics in a Global ERD3 Landscape}

In 1999, a report by the President's Committee of Advisors on Science and Technology (PCAST) titled Powerful Partnerships: The Federal Role In International Cooperation on Energy Innovation called for more than doubling U.S. federal spending on international ERD3 cooperation, and for establishing new institutions to develop a strategy and to oversee the effort (PCAST, 1999). It recommended a wide range of international ERD3 cooperation activities over a large number of different energy technologies.

The international energy landscape has been transformed since then, in particular by the rise of emerging economies such as China (now the world's largest energy consumer) and India both as energy markets and as energy innovators. Overall, these changes have only made the case for such cooperation stronger. Seven key trends are apparent:

- A shift in the growth of energy consumption away from developed countries to emerging economies;

- An increase in government funding for energy research, development, and demonstration $(\mathrm{ERD} \& \mathrm{D})$ in emerging economies;

- An increase in the number of research institutions across the world participating in scientific publications on energy technologies;

- A continuing growth in the import and export value of energy technologies around the world;

- Heightened global competition for world energy technology markets;

- The establishment of a large variety of bilateral and multilateral agreements addressing international ERD3 cooperation;

- An intensification of the debate around intellectual property rights and trade rules for energy technologies. 


\subsubsection{The critical importance of the private sector}

Before discussing these global trends in the next eight sub-sections, it is important to remember that government-led ERD3 cooperation is only one part of the broader picture of international flows of ERD3 effort. As discussed in Chapter 1, the private sector plays a critical role in ERD3. In the United States and in many other developed countries, private firms fund and perform the majority of ERD\&D, and deployment of energy technologies ultimately succeeds or fails in the private sector. Although there is limited data available, it is clear that private firms' investment in ERD3 efforts that span national boundaries far exceeds U.S. government investments in international ERD3 cooperation.

Much international cooperation on ERD3 takes place without direct government involvement. Private firms, research groups at universities, local councils, states, investors, non-government organizations, and other entities cooperate internationally in ERD3 when opportunities arise that seem to serve their interests. Private sector cooperation efforts will generally be larger, more dynamic, and more responsive to immediate private-sector needs than government efforts will be. (The complicating factor in making this distinction is the large role played by state-owned firms, particularly in emerging economies such as China and Russia, where they undertake a large fraction of the energy markets and of ERD3 efforts.) One of government's most important roles is to enable this bubbling flow of bottom-up cooperation and to avoid standing in the way, limiting the obstacles posed by tariffs, export controls, visa restraints, and the like. The surest way to stop any technical cooperation is to require that governments must negotiate a legally binding agreement covering every step to be taken before it can begin. ${ }^{59}$

Because environmental protection and energy security are public goods, not priced in the market, and because firms cannot capture all the benefits arising from their innovations, private firms alone will always invest less in energy technology innovation than would be best for society overall. On top of this, international engagements on energy technology innovation are restricted by a lack of information, trust, and accountability. This rationale also underpins the role of governments supporting cooperation with other countries through agreements, programs, or individual projects; particularly in cases where such cooperation results in:

- $\quad$ shared or lower costs in research, development, and demonstration projects through the sharing of information, facilities, and personnel;

- $\quad$ access to complementary expertise and facilities;

- increased business prospects for American companies through a better understanding of new markets and their needs; or

59 For example, Table 3.1 in Chapter 3 shows how government involvement in two of SRC's research programs limits the institution's ability to conduct research on a global scale. 
- environmental, security, and economic benefits to the United States from an accelerated development and deployment of advanced energy technologies globally.

By its nature, such bottom-up coordination is not centrally controlled and tracked, and therefore data on it is difficult to collect and very diverse. Private sector involvement in international ERD3 cooperation can include a large range of activities, such as establishing foreign $R \& D$ centers, creating international joint ventures, forming technology alliances, cross-border marketing, establishing foreign subsidiaries, and making foreign direct investments (Beamish \& Killing, 1996). Unfortunately, there is little quantitative data available on how patterns of these activities have changed over time; ${ }^{60}$ anecdotally, however, it appears that private sector ERD3 cooperation is also on the rise, and increasingly involves partners in emerging economies.

\subsubsection{Shifting energy consumption}

Global energy technology markets have changed dramatically in the last two decades with both energy demand and manufacturing capabilities of clean energy technologies expanding rapidly in emerging economies. The United States is (or soon will be) no longer the world's largest energy consumer, having been displaced by China (BP, 2010; IEA, 2010f). ${ }^{61}$ China and other non-OECD countries currently account for the majority of the energy use in the world, and their consumption will continue to increase while energy use in the OECD countries is projected to stall (IEA, 2010f; Gallagher et al. 2011). Indeed, almost all projected growth of energy demand over the next quarter of a century will take place in nonOECD countries, making their markets-and the cooperation that may help ensure the U.S. role in them-particularly crucial. ${ }^{62}$ See Figure 5.1.

In addition to being surging energy markets, China and several other emerging economies (such as Brazil, Russia, India, Mexico, and South Africa) have become major players in energy technology innovation. Large-scale foreign investment in ERD3 of advanced energy technologies poses both challenges and benefits for the United States. The large investments in solar, wind, and nuclear technologies in China in particular have provoked some justifiable concern about the United States being left behind and becoming less competitive in global energy technology markets. At the same time, however, widespread global development and deployment of advanced energy technologies can serve U.S. interests through reduced climate change risks as other countries deploy low-carbon technologies; increased

60 The CATI database, developed by Prof. Hagedoorn, is one of the few databases that provides longitudinal data on international interfirm R\&D partnerships. It includes only those partnerships with mutual technology transfer or joint R\&D. In collaboration with Prof. Hagedoorn, our quantitative analysis includes the results of this database (Hagedoorn, 2006).

61 BP's estimates for primary energy in 2009 are 2182 million tons oil equivalent (Mtoe) for the United States and 2177 Mtoe for China, while IEA's estimates are 2169 Mtoe for the United States and 2265 Mtoe for China.

62 For example, the recent World Energy Outlook 2010 from the International Energy Agency estimates that under a current policies scenario, almost all of the increase in energy use between 2010 and 2035 (a 36\% increase) would take place in non-OECD countries (IEA, 2010f). 


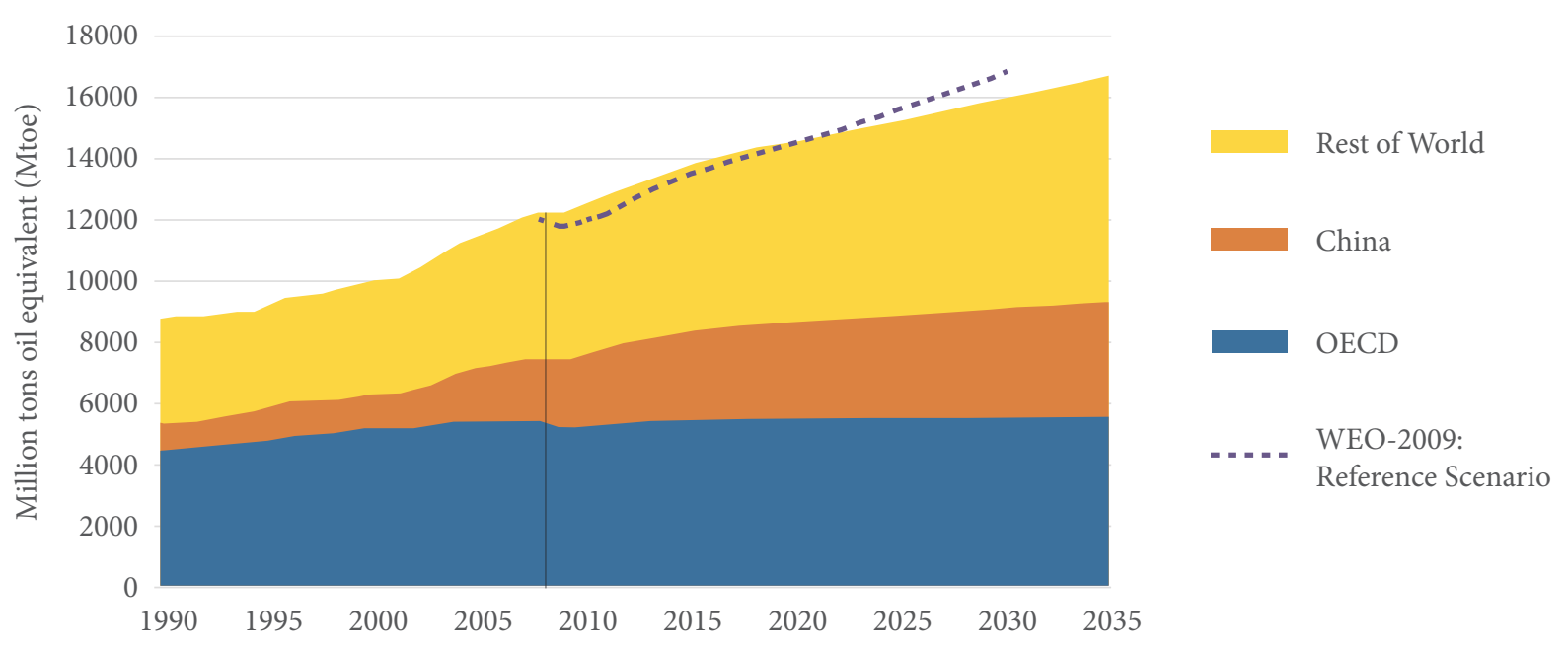

FIGURE 5.1. World primary energy demand according to the International Energy Agency's World Energy Outlook 2010 (IEA, 2010f) under a "new policies" scenario, which includes full implementation of commitments countries made by mid-2010.

opportunities to develop energy technologies with improved cost and performance without the United States bearing the whole cost of doing so; reduced global dependence on constrained oil resources (potentially leading to lower prices and less risk of resource conflicts); new market opportunities for U.S. firms (to the extent they remain competitive in global energy technology markets); and potentially a reduced risk of nuclear proliferation.

\subsubsection{Shifting patterns of ERD\&D}

Patterns of investment in ERD\&D are also shifting, with investment in the emerging economies surging, shifting the balance away from the developed economies. Depending on the indicator used, the U.S. government might no longer be the world's largest funder for ERD\&D. As pointed out by two recent reports (AEIC, 2010; PCAST, 2010), other industrialized countries continue to build on their energy technology expertise, and many of them are investing a larger fraction of the GDP in energy RD\&D. Several of the International Energy Agency ${ }^{63}$ (IEA) member countries, including South Korea and Japan, invest larger fractions of their GDP in government ERD\&D than does the United States (IEA, 2010b). Other IEA countries, like Canada, Finland, Germany, South Korea, and the U.K., are rapidly expanding their public expenditure on energy RD\&D with growth rates exceeding those of the United States (IEA 2011). ${ }^{64}$

63 The International Energy Agency (IEA) includes Australia, Austria, Belgium, Canada, Denmark, Finland, France, Germany, Greece, Hungary, Ireland, Italy, Japan, Korea, Luxembourg, the Netherlands, New Zealand, Norway, Portugal, Spain, Sweden, Switzerland, Turkey, the United Kingdom, and the United States. Due to missing data, the Czech Republic, Poland, and the Slovak Republic are not included in the estimated IEA total.

64 The energy RD\&D budget of the United States has increased 68\% between 2000 and 2010, while the energy RD\&D budgets of Canada, Finland, Germany, South Korea, and the U.K. have expanded with 258\%, 216\%, 104\%, 371\%, and 669\%, respectively. 


\begin{tabular}{|c|c|c|c|c|c|c|c|}
\hline $\begin{array}{l}\text { in Million } 2008 \text { PPP } \\
\$ \text { Int }^{*}\end{array}$ & $\begin{array}{r}\text { Fossil } \\
\text { (incl. CCS) }\end{array}$ & $\begin{array}{r}\text { Nuclear } \\
\text { (incl. fusion) }\end{array}$ & $\begin{array}{r}\text { Electricity, } \\
\text { transmission, } \\
\text { distribution } \\
\& \text { storage }\end{array}$ & $\begin{array}{r}\text { Renewable } \\
\text { energy } \\
\text { sources }\end{array}$ & $\begin{array}{r}\text { Energy } \\
\text { Efficiency }\end{array}$ & $\begin{array}{r}\text { Energy } \\
\text { technologies } \\
\text { (not specified) }\end{array}$ & Total \\
\hline United States - Gov't & 659 & 770 & 319 & 699 & 525 & 1160 & 4132 \\
\hline United States - Other & 1162 & 34 & no data & no data & no data & 1350 & 2545 \\
\hline Brazil - Gov’t & 79 & 8 & 122 & 46 & 46 & 12 & 313 \\
\hline Brazil - Other & 1167 & no data & no data & no data & no data & 184 & 1351 \\
\hline Russia - Gov’t & 20 & no data & 22 & 14 & 25 & 45 & 126 \\
\hline Russia - Other & 411 & no data & no data & no data & no data & 508 & 918 \\
\hline India - Gov't & 106 & 965 & 35 & 57 & no data & no data & 1163 \\
\hline India - Other & 694 & no data & no data & no data & no data & no data & 694 \\
\hline Mexico - Gov't & 140 & 32 & 79 & no data & no data & no data & 252 \\
\hline Mexico - Other & $0.1^{\mathrm{a}}$ & no data & no data & no data & $263^{\mathrm{b}}$ & $19^{\mathrm{c}}$ & 282 \\
\hline China - Gov't & 6755 & 12 & no data & no data & 136 & 4900 & 11803 \\
\hline China - Other & 289 & 7 & no data & no data & 26 & 985 & 1307 \\
\hline South Africa- Gov't & no data & 133 & no data & no data & no data & 9 & 142 \\
\hline South Africa - Other & 164 & $31^{\mathrm{d}}$ & 26 & 7 & no data & no data & 229 \\
\hline BRIMCS - Gov't & 7100 & 1149 & $>259$ & $>117$ & $>208$ & $>4966$ & $>13799$ \\
\hline BRIMCS - Other & 2724 & $>>38$ & $>>26$ & $>>7$ & $>>289$ & $>1696$ & $>4781$ \\
\hline BRIMCS - GRAND & 9824 & $>1187$ & $>285$ & $>124$ & $>497$ & $>6662$ & $>18580$ \\
\hline
\end{tabular}

* Data from United States, Brazil, Russia, India, China and South Africa based on 2008, Mexico on 2007.

'Other' includes (whenever available) funding from state and local governments, partially state-owned enterprises, NGOs, and industry.

U.S. data on industry expenditure is from 2004 (NSF 2008).

a Based on PEMEX's fund for Scientific and Technological Research on Energy (PEMEX 2008)

b Based on 2005 R\&D expenditure in car manufacturing industry (CONACYT 2008)

c Based on 2005 R\&D expenditure in utilities sector (CONACYT 2008)

d Based on total non-governmental investments into PBMR Ltd. (Department of Public Enterprises, 2010)

> These cumulative values are based on data from only three to four BRIMCS countries, so actual expecteditures are likely to be higher.

>> These cumulative values are based on data from two BRIMCS countries or less, so actual expenditures are expected to be much higher.

TABLE 5.1. Overview of energy RD\&D investments in the BRIMCS countries and the United States (Kempener, Anadon, \& Condor Tarco, 2010). 
The shifts are also dramatic in the emerging economies. Our research has shown that six of the large emerging economies (Brazil, Russia, India, China, Mexico, and South Africa, which we refer to as the BRIMCS countries ${ }^{65}$ ) are now major players in energy RD\&D globally (Atkinson et al., 2009; Kempener, Anadon, \& Condor Tarco, 2010; Levi et al., 2010). With a minimum of $\$ 13.8$ billion in energy RD\&D investments by governments and $100 \%$ in government-owned enterprises in $2008,{ }^{66}$ the governments in the BRIMCS countries may have control over greater amounts of ERD\&D funding than the member countries of the IEA, whose government investments in 2008 were estimated at $\$ 12.7$ billion (PPP). Based on market exchange rates, however, public expenditure on energy RD\&D in the BRIMCS countries amounts to $\$ 7.3$ billion, which is higher than the United States' budget of $\$ 4.1$ billion but much lower than the total public expenditure of the IEA countries.

\subsubsection{Expanding and shifting scientific collaborations}

Concurrently, the global science enterprise is growing at an accelerated rate and the share of U.S. publications in comparison to global publication authorship is slowly decreasing, from 26\% between 1999 and 2003 to $21 \%$ between 2004 and 2008 (The Royal Society, 2011). This trend is also evident in scientific publications on energy technology. Figure 5.2 displays the analysis of scientific publications in the top 10 renewable energy journals between 2000 and 2008 (Appendix A5.2.1. describes the methodology behind this analysis). The chart shows two kinds of data. First, it displays longitudinal data for the United States', India's, and China's trajectory from 2000 to 2009, with each marker denoting the position of the country in a particular year. The horizontal axis displays the number of publications involving at least one institute from a country, ${ }^{67}$ while the vertical axis displays the percentage of publications with international collaborations of a particular country in each year. The results show that both the number of publications and the number of international collaborations are rising, especially for the United States, China, and India. It also shows that South Korea, starting from almost no collaborations in 2000, has managed to establish itself in the international scientific community. The data suggests that South Korea has established this position through intense collaborations between 2000 and 2005. The graph shows the position of IEA countries like Canada, Finland, Germany, and the United Kingdom in 2009.

65 Brazil, India, Mexico, China, and South Africa are known as the outreach countries (“O5” countries) after the G8 members invited these countries to be involved in discussions on global energy issues in 2005. Together with Russia, they are also some of the largest growing economies where much of the energy consumption growth will take place.

66 These figures are in purchasing power parity adjusted dollars (PPP). The collection of the data available on energy RD\&D investments in the BRIMCS countries indicated that: (a) data is limited and thus it is necessary to improve data reporting in these countries; (b) state-owned enterprises (SOEs) control $82 \%$ of the known investments of $\$ 13.8$ billion PPP (90\% of China's energy RD\&D investments were from SOEs); and (c) like IEA member countries, energy RD\&D investments by the BRIMCS are concentrated on fossil and nuclear energy.

67 China and India were chosen to represent the growing presence of emerging countries. Germany and Spain had the highest number of publications of any European country in 2000 and 2009, respectively. South Korea was chosen because of its strategic focus on clean energy technologies. 


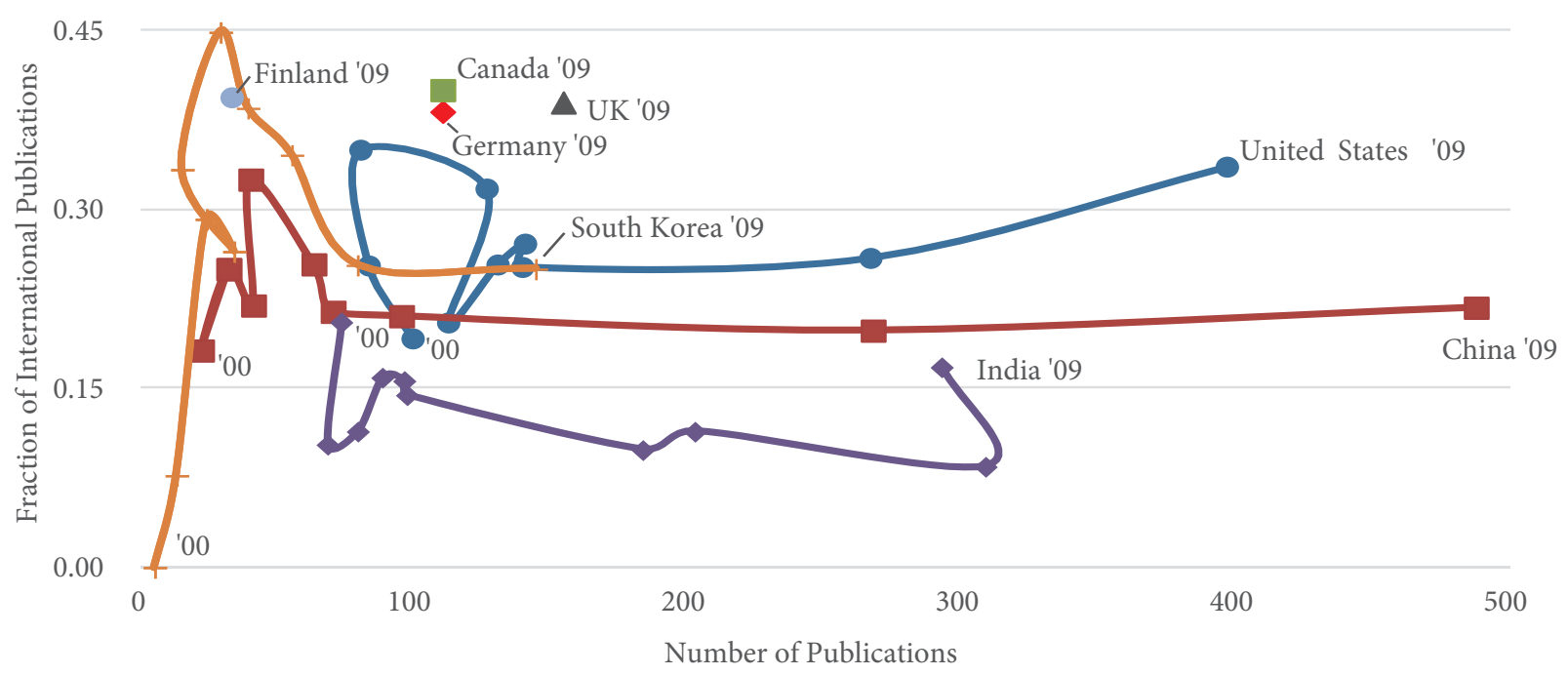

FIGURE 5.2.International scientific collaborations on renewable energy technologies between 2000 and 2009. The horizontal axis represents the number of publications in the 10 top-ranked renewable energy journals with at least an author from an institution in a particular country; the vertical axis represents the fraction of publications in these journals by institutions from a particular country with at least one author from an institution in a different country.

This data shows that these countries have a much higher percentage of international collaborations than countries like China and India, although the total output of publications is now far behind those of countries with a larger population. Based on these results, and on similar analyses for nuclear and fossil energy technologies, one can conclude that the United States is still a leader in energy technology publications, but that options for international science collaborations are becoming larger and more diverse in number.

\subsubsection{Increasing import and export values for energy technologies}

The global market dynamics for energy technologies have changed. In particular, new investments in clean energy technologies between 2004 and 2010 have multiplied six-fold with the highest investment increases over this period in countries like Turkey, Brazil, and China (PEW Charitable Trusts, 2011). Furthermore, manufacturing leadership in clean energy technology is shifting from Europe to Asia, with China producing $40 \%$ of the world's global solar PV supply, 30\% of the world's wind turbines, and 77\% of the world's solar hot water collectors (REN21, 2010a). With Germany (47\%), Spain (16\%), Japan (13\%), and the United States (6\%) as the countries with the largest installed capacity in 2009 (REN21, 2010a), these dynamics have increased the international flow of clean energy technologies around the world. ${ }^{68}$

Clean energy technologies are not the only category where import and export patterns have changed.

68 For wind turbine, imports into the United States increased from $\$ 60$ million in 2004 to $\$ 2.5$ billion in 2008, while wind turbine exports grew from $\$ 4$ million to \$22 million over the same period (David, 2009). 
The monetary value of the import and export of "power generating machinery and equipment" ${ }^{69}$ in both the United States and other countries has been growing steadily since 1990, and the value of the global market for energy technologies continues to increase (UN COMTRADE, 2011). For example, Figure 5.3 shows that the average annual growth rate between 1989 and 2009 for the import and export value of energy technologies from and to China are $16 \%$ and $28 \%$, respectively.

Given the ongoing economic growth in the large emerging economies, the global market for energy technologies is only going to grow. Globally, tens of trillions of dollars of energy technology investment are expected over the next two decades, and to the extent that international ERD3 cooperation could result in increased exports of U.S. technologies, the benefits to be gained could be large. For example, a recent NREL report estimated that under certain assumptions, a modest increase and reform of U.S. approaches to international ERD3 cooperation could lead to $\$ 40$ billion per year in additional exports (NREL, 2008). ${ }^{70}$

\subsubsection{Heightened global competition in energy technology markets}

Countries are not only cooperating, but also competing in global energy markets-and there is evidence that the United States is facing ever-stiffer competition. China and South Korea, in particular, have clearly made a strategic decision to compete aggressively in the markets for solar, wind, nuclear, and other clean-energy technologies, and while the United States must respond to that competitive challenge, the opportunities for cooperation are enormous as well.

The markets for "conventional" energy technologies (defined in Figure 5.3. as "power generating machinery and equipment") also continue to increase. Comparing the growth rates between 2001 and 2009 in export value for the United States (1\%), the EU-27 (10\%), and China (24\%) makes it clear that the United States lags behind in creating value from the export of energy technologies. These changing global energy technology trade dynamics have direct implications for the U.S. trade balance. Our analysis shows that between 1989 and 1999 the United States had positive trade balances for all of the main energy technology categories (steam turbines, nuclear reactors, gas turbines, and hydraulic turbines). After 2000, the United States has faced negative trade balances for each of these four energy technology categories (see Appendix A5.2.6).

69 The category "power generating machinery and equipment" (SITC code) includes steam or other generating boilers (SITC 711), steam turbines and other vapor turbines (SITC 712), internal combustion piston engines and parts thereof (SITC 713), nonelectric engines and motors (SITC 714), rotating electric plants and parts thereof (SITC 716), power generating machinery (SITC 718) including nuclear reactors and parts thereof (7187), and wind engines (7189) (UN COMTRADE, 2011).

70 These results were derived by estimating the fraction of increased investment in renewable energy and energy efficiency technologies globally ( $\$ 300-600$ billion/year by 2020 according to the IEA BLUE Map Scenario and McKinsey (2008)) taking place outside the United States. Subsequently, NREL estimated the fraction of that market that could successfully be positioned by U.S. exporters. 


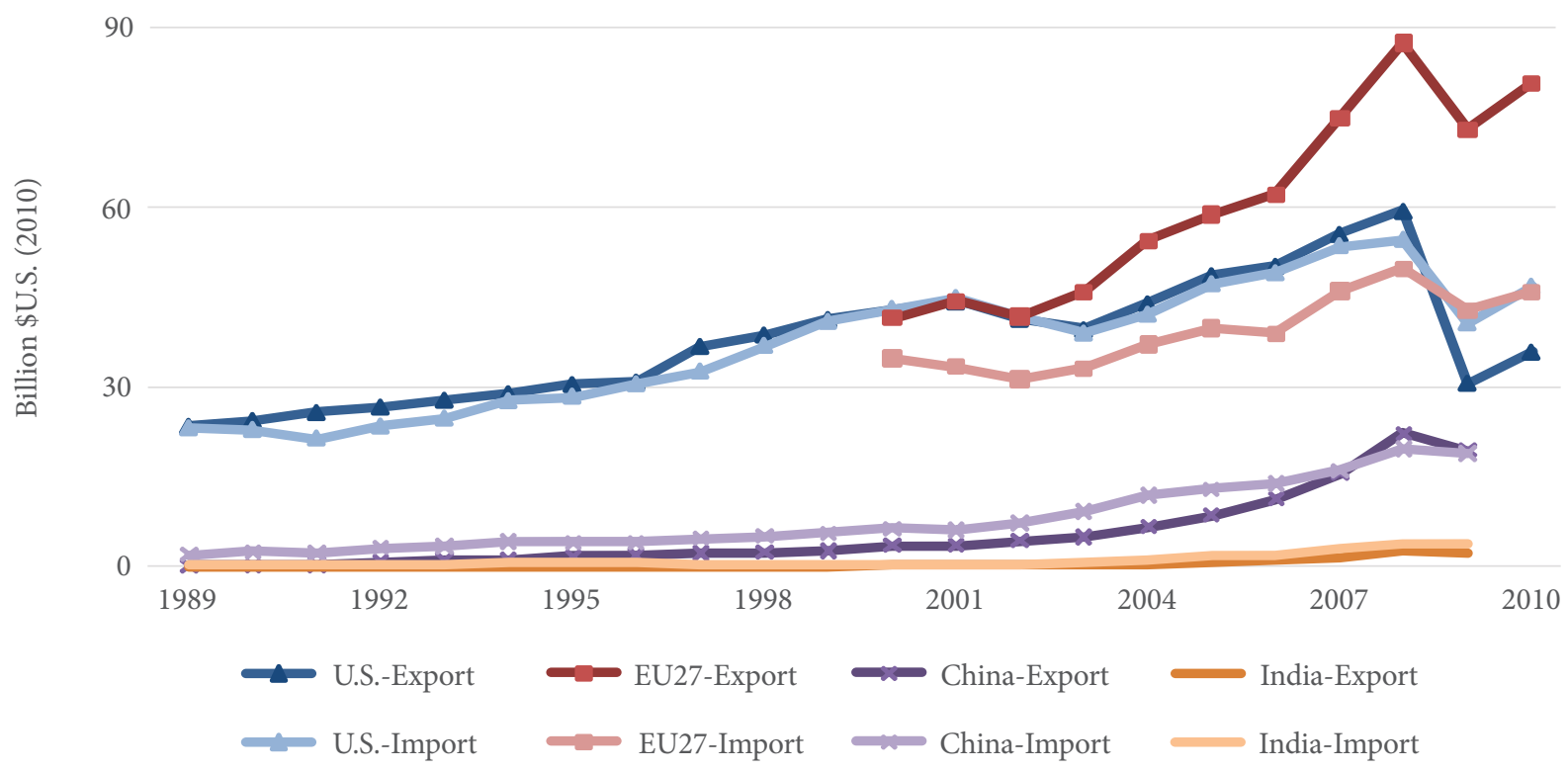

FIGURE 5.3. Import and export value of "power generating machinery and equipment" (SITC code 71) in the United States, the EU-27, China, and India between 1989 and 2010.

\subsubsection{More bilateral and multilateral agreements}

The rate of new bilateral and multilateral agreements on energy technology innovation has substantially increased since 1999. In the last ten years, the U.S. government has signed 121 new bilateral agreements on ERD3 cooperation (see our analysis in Appendix A5.2). Furthermore, the U.S. government has established two large multilateral frameworks focused in significant part on energy technology innovation (the Asia-Pacific Agreement on Energy and Climate and the Clean Energy Ministerial), and has signed at least 11 other energy technology-specific multilateral agreements. There have also been two new multilateral funds established to promote the deployment of clean energy technologies around the world, and since 2007 the UNFCCC has included a separate track on enhanced action on technology development and transfer within the Bali Action Plan (UNFCCC, 2008). From a global perspective, these developments have led to a considerable fragmentation of global governance architectures (Biermann et al., 2009). From a U.S. perspective, these developments have led to the situation in which the U.S. government is involved in 175 bilateral agreements, at least 21 international multilateral agreements with an ERD3 component, ${ }^{71}$ and ERD3 programs and projects in 9 U.S. government departments ${ }^{72}$ and

71 Some of the key ERD3-related agreements that the U.S. government participates in include: the U.N. Commission on Sustainable Development, the Bali Action Plan, the International Energy Agency, the Clean Energy Ministerial of the Major Economies Forum, the Asia-Pacific Partnership, the Global Environmental Facility of the U.N. Environment Program and the World Bank, the World Bank's Clean Technology Fund (CTF) and its Scaling Up of Renewable Energy in Low-Income Countries (SREP) program, and U.S. Agency for International Development (USAID).

72 The Departments of Energy, Treasury, State, Commerce, Transport, Defense, Agriculture, Interior, and Housing and Urban Development. 
10 agencies. ${ }^{73}$ In such a situation, it is very difficult for both U.S. policymakers and U.S. innovators to determine what avenues are most effective, and therefore should receive priority.

\subsubsection{Intensified debate over intellectual property rights and global trade rules}

Heightened competition in the global market for clean energy technologies, and increased government efforts to support their national energy technology industries, have sparked an intensified debate over intellectual property issues (CEPP, 2009; Ockwell et al., 2010) and global trade rules (Huang, 2011). On the one hand, policymakers in Western countries are concerned about the lack of enforcement of intellectual property rights in emerging economies (Reuters, 2008), and the possible leakages of technological capabilities to other countries. The World Trade Organization (WTO) Agreement on Trade-Related Aspects of Intellectual Property Rights (TRIPS), which passed in 1994 during the Uruguay Round, impacts international ERD3 cooperation in this context. It mandates patent protections for nearly all inventions, establishes minimum IP protection standards, and enforces this mandate with the threat of trade sanctions (Oliva, 2008). Under TRIPS, the least-developed countries have a transition period during which they are to move toward reinforcing their IP protection; during that period, they are allowed access to energy technologies through channels like imitation and reverse engineering (Sagar \& Anadon, 2009). On the other hand, policymakers in Non-Annex I countries ${ }^{74}$ ask for financial assistance in obtaining technologies and their licenses, because they regard the high costs charged by developed countries for new energy technologies as the most important barrier to technology transfer (UNFCCC, 2006).

In contrast to the political discourse around IPR issues, the international business literature does not see IPR issues as a barrier to international cooperation, but rather as an important administrative feature of interfirm relations that needs to be resolved at the start of any joint venture, subsidiary arrangement, or foreign direct investment. Instead, this literature mentions unfamiliarity with foreign legislation, cultural differences, lack of market knowledge, communication problems, and lack of trust as the important barriers to international innovation activities (Beamish \& Killing, 1996; von Zedtwitz \& Gassmann, 2002). Similarly, in the scientific community the lack of trust in foreign scientific capabilities is more difficult to resolve than intellectual property issues, for which there have been established several good practices (Kasprzycki, Ozegalska-Trybalska, \& Mayr, 2008).

73 The U.S. Agency for International Development (USAID), the U.S. Trade and Development Agency (USTDA), the U.S. ExportImport Bank (Ex-IM), the Overseas Private Investment Corporation (OPIC), the Environmental Protection Agency (EPA), the Office of Science and Technology Policy (OSTP), the Council on Environmental Quality (CEQ), the National Aeronautics and Space Administration (NASA), the National Science Foundation (NSF), and the U.S. embassies.

74 Non-Annex I Parties are mostly developing countries, and excludes OECD countries or economies in transition, such as Russia, the Baltic States, and several Central and Eastern European States. 
Regardless of IPR issues, the increasingly competitive environment for energy technologies is creating mistrust at a government level with disputes over what efforts constitute reasonable support for national ERD3 activities and what constitute unfair subsidies. In 2007, Brazil and Canada challenged the U.S. subsidies for corn and other agricultural projects in the context of biofuels, and Brazil challenged the U.S. subsidies for domestic ethanol use under the WTO trade rules. In addition, the United States has a tariff on Brazilian ethanol. In 2009, the EU complained about Canada's requirement for domestic content for its renewables feed-in tariff, and in 2011 the United States challenged China's export subsidies for its domestic wind turbine companies (Huang, 2011).

\subsubsection{Consequences for government involvement in international ERD3 cooperation}

The multi-trillion-dollar global energy technology market and the increase of ERD3 activities worldwide create a tremendous potential for international ERD3 cooperation for both the U.S. government and other U.S. actors. The data has shown that these opportunities are with and within both emerging and developed countries. Yet the trends just described also make it more complex and difficult to make choices and implement effective policies. In a more interdependent world, the role of governments on both a national and an international level becomes less straightforward. If knowledge, technology, and people are flowing more easily from one country to another, U.S. policies will have global implications, and other countries' policies will have implications in the United States. Consequently, U.S. policymakers will have to take the global nature of ERD3 into consideration, and will need to evaluate their actions in the context of this larger whole. International ERD3 cooperation on a government-to-government level can play a crucial role in both protecting and advancing national interests. However, new frameworks are needed to help policymakers understand the national and global implications of the trade-offs they must make.

The crucial importance of the ERD3 cooperation bubbling up through non-government channels, and the wide range of stakeholders involved in energy innovation domestically and internationally, makes the policy problem still more complex. Indeed, in a more complex world game-changing opportunities for innovation often arise in unexpected places that are not easily accessible to policymakers working on a national level (Tyfield, Jin, \& Rooker, 2010).

At first glance, these dynamics point to two, possibly contradicting, strategies for the U.S. government. On the one hand, an increased potential for international ERD3 cooperation and larger interdependencies between national policies suggest a need for greater U.S. government involvement in coordinating international ERD3 activities. On the other hand, an increasing involvement of non-governmental entities in international ERD3 points to a role for the U.S. government that is facilitating rather than leading. Such a view would require a U.S. strategy that primarily focuses on support for bottom-up initiatives, and consists of a more flexible and opportunistic approach toward international ERD3 cooperation. 
Finally, these dynamics also point to the need for a more complex view of the possible benefits and risks of cooperation versus competition. With international ERD3 cooperation taking place through many different channels (scientists, businesses, and governments), it is more difficult to evaluate which types of cooperation might strengthen U.S. competitiveness, such as working together to develop new technologies that can expand the market share of U.S. firms, and which might undermine it,such as cooperation that had the effect of transferring technology to foreign firms that became strengthened competitors as a result. (A classic example is that the pressurized water reactor technology being marketed with considerable success by the French energy giant AREVA and by a South Korean consortium came from the U.S. firm Westinghouse, which transferred it in an effort to win additional contracts; Westinghouse's nuclear business is now owned by the Japanese firm Toshiba. On the other hand, Germany's feed-in tariff for solar panels has benefitted Chinese solar panel manufacturers, but has also benefited Germany's export of solar panel manufacturing equipment to China.) Choosing where to work together and where to compete is difficult, and must be done case by case.

\subsection{INTERNATIONAL ERD3 COOPERATION ACTIVITIES WITHIN THE U.S. GOVERNMENT}

\subsubsection{Current U.S. government ERD3 cooperation initiatives}

U.S. government initiatives on international ERD3 cooperation efforts have a long history, from nuclear energy cooperation in the 1950s to the first comprehensive multilateral frameworks developed after the 1973 oil shock to today's Clean Energy Ministerial (CEM). Many of the initiatives by the Obama administration are a continuation of the bilateral and multilateral initiatives established by the Bush administration, although they have intensified in two ways: an increased focus on implementation and intensified interagency coordination.

A primary example of the intensification of international ERD3 cooperation is the Memorandum of Understanding (MOU) between the United States and China signed in July 2009, which elaborates on earlier agreements signed by President Bush. ${ }^{75}$ In November 2009, President Barack Obama and President $\mathrm{Hu}$ Jintao announced seven U.S.-China clean energy initiatives that the United States and China would carry out under the terms of the MOU. ${ }^{76}$ Each of these initiatives has been translated into separate programs and projects. One of these initiatives resulted in the creation of a U.S.-China Clean Energy Research Center, to which both countries are contributing $\$ 150$ million over 5 years from public and private sources. The Center embodies three consortia on "Building Energy Efficiency", "Clean Vehicles",

75 In June 2008, the U.S.-China Ten Year Framework for Cooperation on Energy and the Environment (TYF) was established with task forces for 1) clean, efficient, and secure electricity production and transmission, 2) clean water, 3) clean air, 4) clean and efficient transportation, 5) and, conservation of forest and wetland ecosystems (Office of Public Affairs, 2008).

76 The seven initiatives included the initial five task forces established under the Ten Year Framework and two additional task forces on "energy efficiency" and "protected areas/nature reserves." 
and "Advanced Coal Technology", each consortium involving a mixture of U.S. and Chinese universities, national laboratories, departments, and companies. Besides this Center, the agreement has resulted in activities ranging from renewable energy workshops and studies to shale gas assessments to collaborative experiments on coal gasification (DOE, 2011). A range of commercial energy technology deals were established during the Chinese state visit to the United States in January 2011 involving a large number of U.S. companies organized under the U.S.-China Energy Cooperation Program. ${ }^{77}$ For example: Duke Energy and the ENN Group signed an MOU to cooperate in a demonstration project named "Eco-City" to test clean coal, electric vehicles, and energy efficient buildings in Langfang (China); AEP signed cooperation agreements with three companies-China Huaneng, State Grid Corporation of China, and China National Offshore Oil Corporation (CNOOC). As an example of the content of these types of agreements, CNOOC will invest in AEP's Mountaineer Plant commercial-scale carbon capture and storage, and enhanced oil and gas recovery efforts. A similar intensification process has taken place in the United States-India bilateral agreement (described in more detail in Appendix A5.3).

Interagency coordination has also become more important in the Obama administration. ${ }^{78}$ The Director of the Office of Science and Technology Policy (OSTP) filled the position of associate director for National Security and International Affairs, responsible for overseeing U.S. science and technology cooperation with other countries, which was vacant during the Bush administration (Stine, 2009). Specific to energy, the administration has set up two interagency working groups, one on biofuels and one on carbon capture and storage, and both groups have stressed the need to coordinate efforts to ensure maximum effectiveness of international cooperation activities (Interagency Task Force on Carbon Capture and Storage, 2010; IWG, 2010). ${ }^{79}$

\subsubsection{A new analytical perspective for international ERD3 cooperation}

The new international ERD3 cooperation initiatives introduced by the Obama administration are a positive development, but also highlight the complexity of international ERD3 cooperation. The complexity in which decision making on international cooperation takes place includes:

- Multiple platforms for international cooperation that are operating simultaneously;

- The involvement of a large number of different stakeholders, ranging from the White House to departments to regulatory agencies to national laboratories to industry;

77 www.uschinaecp.org/

78 The National Science Board highlighted the lack of coordination of international science and technology partnerships in a report in 2001 (NSB, 2001). This report was followed up by a report in 2008 that again called for a "coherent and integrated U.S. international science and engineering strategy" due to "shifts in the international landscape, along with the unfulfilled recommendations of its 2001 report" (NSB, 2008).

79 A similar interagency task force for Hydrogen and Fuel Cells was established by the Bush administration after EPAct 2005. 
- Different channels through which cooperation can takes place (i.e., government-to-government; university-to-university; industry-to-industry; or mixed), often involving different sets of actors;

- Multiple and overlapping activities within each platform or channel, which are subsequently divided into smaller projects.

Most international cooperation includes combinations of different platforms, channels, stakeholders, and activities. In order to understand and to analyze international cooperation projects, the connections between these different elements need to be considered. Take the case of the long-standing international cooperation on fusion energy technologies, the International Thermonuclear Experimental Reactor (ITER). The proposal for ITER was made during the end of the Cold War, and had clear geopolitical significance for the signatories at the time. Nowadays, ITER has established national agencies that are responsible for the national coordination of activities and/or tenders for industry. Program officers involved in these activities often have different concerns than those that operate at a geopolitical level, such as how to maintain funding for the ITER project while its project costs are rising. Finally, there are the scientists concerned with the practicalities of solving the workings of nuclear fusion. At this level, concerns might arise around the number of training places, the scientific contributions of the different teams, and other risks associated with international scientific projects.

Most U.S. government engagements in international ERD3 cooperation are a function and consequence of multiple platforms, stakeholders, channels, and activities at the same time, which complicates the analysis. We therefore distinguish three levels of international cooperation activities:

- high-level international cooperation agreements (either as signed agreements or in the form of discussion agendas for international dialogues);

- international cooperation programs (a broad set of activities often coordinated by one or more U.S. departments or agencies in collaboration with their foreign counterparts); and

- actual international cooperation projects.

These levels are analytically distinct in three ways: (1) the role of policymakers involved in these different levels of activities; ${ }^{80}(2)$ the strategic and technological dimensions that policymakers need to consider; and (3) the concerns regarding cooperation and competition. They are often, though not always, nested: that is, projects often take place within an overall program, which is often underway under the

80 The terms "high-level official", "program officer", and "project manager" are used to refer to three different kinds of decision makers in the U.S. government. "High-level officials" are those U.S. policymakers that negotiate the conditions of an international agreement. "Program officers" are those U.S. policymakers that, within the context of an agreement, need to propose specific international cooperation projects. "Project managers" are those U.S. civil servants that are responsible for a specific international cooperation project and need to manage or provide sufficient information to evaluate its progress. 
terms of a high-level agreement. It is important to note, however, that this analytical conceptualization of different levels does not pre-suppose some kind of hierarchical structure. In contrast, our analysis has shown that activities at these different levels evolve over time. In practice, this means that projects or programs often form the basis for new agreements, or that programs survive while agreements expire. This evolutionary process makes it difficult to pinpoint a particular starting point for international cooperation, or one single decision maker who is in control of these activities. However, using this analytical approach provides a tool to examine the different channels, agencies, and international developments at each of these levels in a more structured manner:

High-level agreements are concerned with international relations and the strategic position of the countries involved. The strategic dimensions of high-level agreements are of a geopolitical nature, such as the potential consequences of international cooperation on natural resource availability, economic competitiveness (jobs), or security issues. Government decision-makers and other stakeholders involved in signing international high-level agreements are often required to make trade-off decisions that include geopolitical concerns beyond the actual ERD3 cooperation-including signing agreements in some cases for primarily political reasons.

Programs have a more pragmatic role. They often take place at a departmental or agency level, and set specific agendas to address particular needs for both countries involved. The government decisionmakers and other stakeholders in programs are often specialists in a particular technology area, who are concerned about the value of international cooperation activities to the national innovation systems of the countries involved and the specific technological, systemic, and institutional barriers or opportunities for international cooperation. Here, competitiveness concerns are more sector-specific. For example, program officers might be concerned about helping to create new markets for energy technology in partnering countries without guaranteeing access to these markets for U.S. companies. Another concern might be the departure of U.S. companies to other countries. IP issues are less important than creating opportunities for accelerating, directly or indirectly, energy innovation activities $(\mathrm{R} \& \mathrm{D}$, demonstration, or deployment) in both the United States and partnering countries.

Finally, stakeholders involved in the actual projects are more concerned with the immediate value of the project to the participants involved. Projects can be conceptualized based on their strategic and technological dimensions. The strategic dimension concerns the allocation of responsibilities and time schedules, while the technological dimension of their project is defined by which participant will contribute what resources and activities. At a project level, IP issues can become crucial, especially if the project involves joint development of new technologies.

Using this analytical framework as a basis, the rest of this section will provide an overview of the different platforms at which international cooperation activities are taking place, and the stakeholders involved. 


\subsubsection{Platforms for government international ERD3 cooperation activities}

On a government-to-government level, the U.S. government engages in three different platforms for international ERD3 cooperation: (1) bilateral agreements; (2) different forms of multilateral agreements; (3), and international development and financial institutions.

Between the 1950s and 1973, bilateral agreements were the main channel through which the U.S. government pursued international cooperation on energy technology innovation. State is the main actor involved in bilateral science and technology agreements, because they have to approve them. However, the agreements can be signed by any department. DOE and DOC each have several bilateral agreements on energy technology innovation. The first large multilateral agreement was initiated after the 1973 oil crisis, when the U.S. government was actively involved in founding the International Energy Agency. There are now at least 21 different multilateral platforms through which the U.S. government engages in international cooperation on energy technology innovation.

Table 5.2a-d provides an overview of the international ERD3 cooperation that takes place through different platforms and sketches a rough landscape of the types of technologies that are covered. We have limited our focus here to cooperation with the BRIMCS countries rather than the OECD countries, even though it is likely that international ERD3 cooperation with OECD countries still consumes the majority of the ERD3 cooperation resources, ${ }^{81}$ because (a) cooperation with the BRIMCS countries has been a more recent development; (b) more extensive data is available on cooperation with OECD countries from other sources; (c) the BRIMCS countries will be the main source of energy demand growth (and therefore of new energy markets) over the next few decades; (d) the BRIMCS countries, together with

\begin{tabular}{|c|c|c|c|c|c|c|c|}
\hline Bilateral Agreements^ & U.S.A. & Brazil & Russia & India & Mexico & China & South Africa \\
\hline fossil energy & 13 & 1 & & & & 3 & \\
\hline nuclear energy & 79 & 2 & 9 & 1 & & 8 & 1 \\
\hline renewables & 19 & & & 5 & & 3 & 1 \\
\hline energy efficiency & 14 & & & 1 & & 4 & 1 \\
\hline $\begin{array}{l}\text { transmission, distribution, } \\
\text { and storage }\end{array}$ & 5 & 1 & & & & 1 & \\
\hline $\begin{array}{l}\text { generic (including environment/ } \\
\text { climate change) }\end{array}$ & 52 & 1 & 2 & 3 & 2 & 12 & 5 \\
\hline
\end{tabular}

TABLE 5.2a. Overview of DOE's active bilateral ERD3 agreements (first column) and of U.S. engagement with the six BRIMCS countries.

81 Unfortunately, the data that would be needed to make a definite determination concerning the amounts of ERD3 cooperation targeted on the OECD and on the BRIMCS countries are not publicly available. 


\begin{tabular}{llcccccccc} 
Broad Multilateral Agreements & U.S.A. & Brazil & Russia & India & Mexico & China & South Africa \\
\hline Kyoto Protocol & $\begin{array}{l}\text { Clean Development } \\
\text { Mechanisms }\end{array}$ & s & r & r & r & r & r & r \\
\hline Bali Action Plan & $\begin{array}{l}\text { energy technology coop. } \\
\text { and transfer }\end{array}$ & r & r & r & r & r & r & r
\end{tabular}

\begin{tabular}{|c|c|c|c|c|c|c|c|c|}
\hline \multicolumn{2}{|c|}{ Country-specific Agreements } & \multirow{2}{*}{$\begin{array}{c}\text { U.S.A. } \\
3\end{array}$} & \multirow{2}{*}{$\begin{array}{c}\text { Brazil } \\
1\end{array}$} & \multirow[t]{2}{*}{ Russia } & \multirow[t]{2}{*}{ India } & \multirow{2}{*}{$\begin{array}{c}\text { Mexico } \\
1\end{array}$} & \multirow[t]{2}{*}{ China } & \multirow{2}{*}{$\begin{array}{c}\text { South Africa } \\
1\end{array}$} \\
\hline International Energy & cross cutting & & & & & & & \\
\hline Agency (IEA) & buildings & 5 & & & & & 1 & 1 \\
\hline & electricity & 3 & & & 1 & & & 1 \\
\hline & industry & 2 & 1 & & & & & \\
\hline & transport & 4 & & & & 1 & 2 & \\
\hline & fossil fuels & 5 & & 1 & 1 & 2 & 1 & 2 \\
\hline & fusion power & 9 & & 4 & 1 & & 1 & \\
\hline & renewables \& hydrogen & 9 & 2 & & & 6 & 1 & 3 \\
\hline \multirow{8}{*}{$\begin{array}{l}\text { Asia-Pacific } \\
\text { Agreement on } \\
\text { Energy and Climate } \\
\text { (APP) }\end{array}$} & aluminium & 1 & & & $\mathrm{p}$ & & $\mathrm{p}$ & \\
\hline & buildings and appliances & 1 & & & $\mathrm{p}$ & & $\mathrm{p}$ & \\
\hline & cement & $\mathrm{p}$ & & & $\mathrm{p}$ & & $\mathrm{p}$ & \\
\hline & cleaner fossil energy & $\mathrm{p}$ & & & $\mathrm{p}$ & & 1 & \\
\hline & coal mining & 1 & & & 1 & & $\mathrm{p}$ & \\
\hline & $\begin{array}{l}\text { power generation and } \\
\text { transmission }\end{array}$ & 1 & & & $\mathrm{p}$ & & 1 & \\
\hline & $\begin{array}{l}\text { renewables and } \\
\text { distributed generation }\end{array}$ & $\mathrm{p}$ & & & $\mathrm{p}$ & & $\mathrm{p}$ & \\
\hline & steel & $\mathrm{p}$ & & & 1 & & $\mathrm{p}$ & \\
\hline \multirow{11}{*}{$\begin{array}{l}\text { Clean Energy } \\
\text { Ministerial (CEM) }\end{array}$} & appliances & $\mathrm{p}$ & & & $\mathrm{p}$ & $\mathrm{p}$ & & $\mathrm{p}$ \\
\hline & buildings and industry & $\mathrm{p}$ & & $\mathrm{p}$ & $\mathrm{p}$ & $\mathrm{p}$ & & $\mathrm{p}$ \\
\hline & smart grid & $\mathrm{p}$ & & & $\mathrm{p}$ & $\mathrm{p}$ & $\mathrm{p}$ & \\
\hline & electric vehicles & $\mathrm{p}$ & & & & & $\mathrm{p}$ & $\mathrm{p}$ \\
\hline & capacity building & $\mathrm{p}$ & & & $\mathrm{p}$ & $\mathrm{p}$ & & $\mathrm{p}$ \\
\hline & carbon capture & $\mathrm{p}$ & & & & c & $\mathrm{p}$ & $\mathrm{p}$ \\
\hline & solar and wind & c & & & & $\mathrm{p}$ & & c \\
\hline & hydropower & & $\mathrm{p}$ & & & & & \\
\hline & bioenergy & & $\mathrm{p}$ & & & & & \\
\hline & solar and LED access & $\mathrm{p}$ & & & & & & \\
\hline & women in energy & $\mathrm{p}$ & & & & $\mathrm{p}$ & $\mathrm{p}$ & $\mathrm{p}$ \\
\hline $\mathrm{IAI}^{1}$ & climate change research & $\mathrm{p}$ & $\mathrm{p}$ & & & $\mathrm{p}$ & & \\
\hline $\mathrm{ECPA}^{1}$ & clean energy & $\mathrm{p}$ & $\mathrm{p}$ & & & $\mathrm{p}$ & & \\
\hline
\end{tabular}

TABLE 5.2b. Overview of U.S. multilateral ERD3 agreements (first column) and of U.S. engagement with the six BRIMCS 


\begin{tabular}{|c|c|c|c|c|c|c|c|c|}
\hline \multicolumn{2}{|c|}{ Interest-specific multilateral agreements } & \multirow{2}{*}{$\begin{array}{c}\text { U.S.A. } \\
\text { r }\end{array}$} & \multirow[t]{2}{*}{ Brazil } & \multirow[t]{2}{*}{ Russia } & \multirow{2}{*}{$\begin{array}{c}\text { India } \\
\qquad \mathrm{r}\end{array}$} & \multirow{2}{*}{$\begin{array}{c}\text { Mexico } \\
\text { r }\end{array}$} & \multirow[t]{2}{*}{ China } & \multirow{2}{*}{$\begin{array}{c}\text { South Africa } \\
\mathrm{r}\end{array}$} \\
\hline IRENA $^{1}$ & renewables & & & & & & & \\
\hline REN21 $1^{1}$ & renewables & st & st & & st & & st & st \\
\hline $\mathrm{GBEP}^{1}$ & bioenergy & $\mathrm{p}$ & $\mathrm{p}$ & $\mathrm{p}$ & o & $\mathrm{p}$ & $\mathrm{p}$ & o \\
\hline IES $^{1}$ & $\begin{array}{l}\text { environmental impacts } \\
\text { energy }\end{array}$ & 15 & 1 & & 2 & 4 & 3 & \\
\hline $\mathrm{IPHE}^{1}$ & hydrogen and fuel cells & $\mathrm{m}$ & $\mathrm{m}$ & $\mathrm{m}$ & $\mathrm{m}$ & & $\mathrm{m}$ & $\mathrm{m}$ \\
\hline CLASP $^{1}$ & labeling & 4 & & & 8 & 2 & 7 & \\
\hline IPEEC $^{1}$ & energy efficiency & s & s & s & s & s & s & \\
\hline CSLF $^{1}$ & carbon sequestration & $\mathrm{m}$ & $\mathrm{m}$ & $\mathrm{m}$ & $\mathrm{m}$ & $\mathrm{m}$ & $\mathrm{m}$ & $\mathrm{m}$ \\
\hline $\mathrm{GMI}^{1}$ & methane & $\mathrm{m}$ & $\mathrm{m}$ & $\mathrm{m}$ & $\mathrm{m}$ & $\mathrm{m}$ & $\mathrm{m}$ & \\
\hline \multirow{5}{*}{$\begin{array}{l}\text { Generation IV } \\
\text { International Forum } \\
\text { (GIF) }\end{array}$} & $\begin{array}{l}\text { sodium-cooled fast } \\
\text { reactor }\end{array}$ & 4 & & & & & & \\
\hline & $\begin{array}{l}\text { supercritical-water- } \\
\text { cooled reactor }\end{array}$ & & & & & & & \\
\hline & $\begin{array}{l}\text { very-high-temperature } \\
\text { reactor }\end{array}$ & 3 & & & & & & 1 \\
\hline & gas-cooled fast reactor & & & & & & & \\
\hline & $\begin{array}{l}\text { R\&D cooperation } \\
\text { agreement }\end{array}$ & $\mathrm{r}$ & na & $\mathrm{r}$ & & & $\mathrm{r}$ & $\mathrm{r}$ \\
\hline INPRO $^{1}$ & nuclear technology & $\mathrm{m}$ & $\mathrm{m}$ & $\mathrm{m}$ & $\mathrm{m}$ & & $\mathrm{m}$ & $\mathrm{m}$ \\
\hline $\mathrm{GSGI}^{1}$ & shale gas & MOU & & & MOU & & MOU & \\
\hline
\end{tabular}

TABLE 5.2c. Overview of U.S. technology-specific multilateral ERD3 agreements (first column) and of U.S. engagement with the six BRIMCS countries.

\begin{tabular}{|c|c|c|c|c|c|c|c|c|}
\hline Multilateral funds & & U.S.A. & Brazil & Russia & India & Mexico & China & South Africa \\
\hline $\mathrm{GEF}^{1}$ & $\begin{array}{l}\text { global environment } \\
\text { facility* }\end{array}$ & $\mathrm{cb}$ & 12 & 8 & 14 & 9 & 19 & 7 \\
\hline $\mathrm{CTF}^{1}$ & clean technology fund & $\mathrm{cb}$ & & & & $\mathrm{rc}$ & & $\mathrm{rc}$ \\
\hline SREP $^{1}$ & $\begin{array}{l}\text { Scaling up renewable } \\
\text { energy }\end{array}$ & $\mathrm{cb}$ & & & & & & \\
\hline
\end{tabular}

TABLE 5.2d. Overview of U.S. engagement in multilateral ERD3 funds (first column) and of U.S. engagement with the six BRIMCS countries. 
the United States, the European Union, and Japan, are and will continue to be the main contributors of greenhouse gas emissions; and (e) focusing on the BRIMCS countries, where many initiatives have begun in recent years, allows us to examine the extent to which the U.S. government engages with these "new" countries through particular channels of cooperation.

Table 5.2a is based on the COMmitment Management International Tracking (COMMIT) database, which includes DOE's active international commitments. ${ }^{82}$ The data shows that $35 \%$ of U.S. bilateral agreements on energy technology innovation are with these six BRIMCS countries. The overviews in Tables $5.2 \mathrm{~b}$ - $\mathrm{d}$ are based on the memberships as published on the agreements' websites. ${ }^{83}$ The overview of IEA Implementing Agreements is based on their latest publication (IEA, 2010a). The agreements show that the United States engages with each of these countries through more than one channel, although not every country participates in every platform. Furthermore, the overview shows that almost every energy technology category is covered by multiple agreements.

Unfortunately, there is little aggregate information about the activities that take place within each of these programs. Table 5.3 provides a brief description of activities that take place in some of these agreements.

A more detailed description of the programs and projects that are taking place in each of these international cooperation platforms can be found in Appendix A5.1.3. Summarizing these descriptions, one can conclude that most international cooperation projects supported by the U.S. government are deployment activities. They include cooperation on the development of databases, handbooks, best practice examples, state-of-the-art literature reviews, standards and codes, computer models, regulatory issues, or policy reform advice. This is to be expected, because generally these activities are cheaper and easier to arrange than projects in which equipment is being purchased and new processes being developed. There are several international cooperation projects that support the exchange of experimental data, collaborative testing of materials, or the coordination of experimental testing in facilities. Only a small number of international cooperation projects actually work on the development of new energy technologies, and these projects mainly concern fusion and fission energy technologies.

Four important lessons can be learned from this overview:

1. The decision of countries throughout the world to engage in cooperation through some agreements and not others does not seem to be based on the countries that participate in each agreement or the technologies that are covered by each agreement but rather points to political reasons

82 Our analysis is based on the content of the COMMIT database on 26 April 2010. The COMMIT database is still under development.

83 The names and websites can be found in Appendix A5.1. The overview is based on data available in December 2010. 
as the main drivers. For example, India is in the steering committee of the REN21 (Renewable Energy Policy Network for the $21^{\text {st }}$ Century) and was the first BRIMCS country to ratify IRENA (International Renewable Energy Agency), but the country is not a partner of GBEP (Global Bioenergy Partnership) and is not involved in any CEM (Clean Energy Ministerial) initiatives on renewables. In other words, the reasons why India chose to participate involve its views on the politics of particular initiatives, not its belief in the promise of particular technologies.

2. A categorization of U.S. government initiatives based on broad energy technology categories and countries is insufficient information to determine the extent to which activities overlap. Bilateral and multilateral agreements often have very broad mission statements, which can comprise many different projects. Furthermore, many agreements contain programs that are part of other agreements. For example, the "appliance" and "smart grid" initiatives under the Clean Energy Ministerial (CEM) are organized as projects under multilateral platforms like the International Partnership for Energy Efficiency Cooperation (IPEEC) and the IEA's Implementing Agreements,

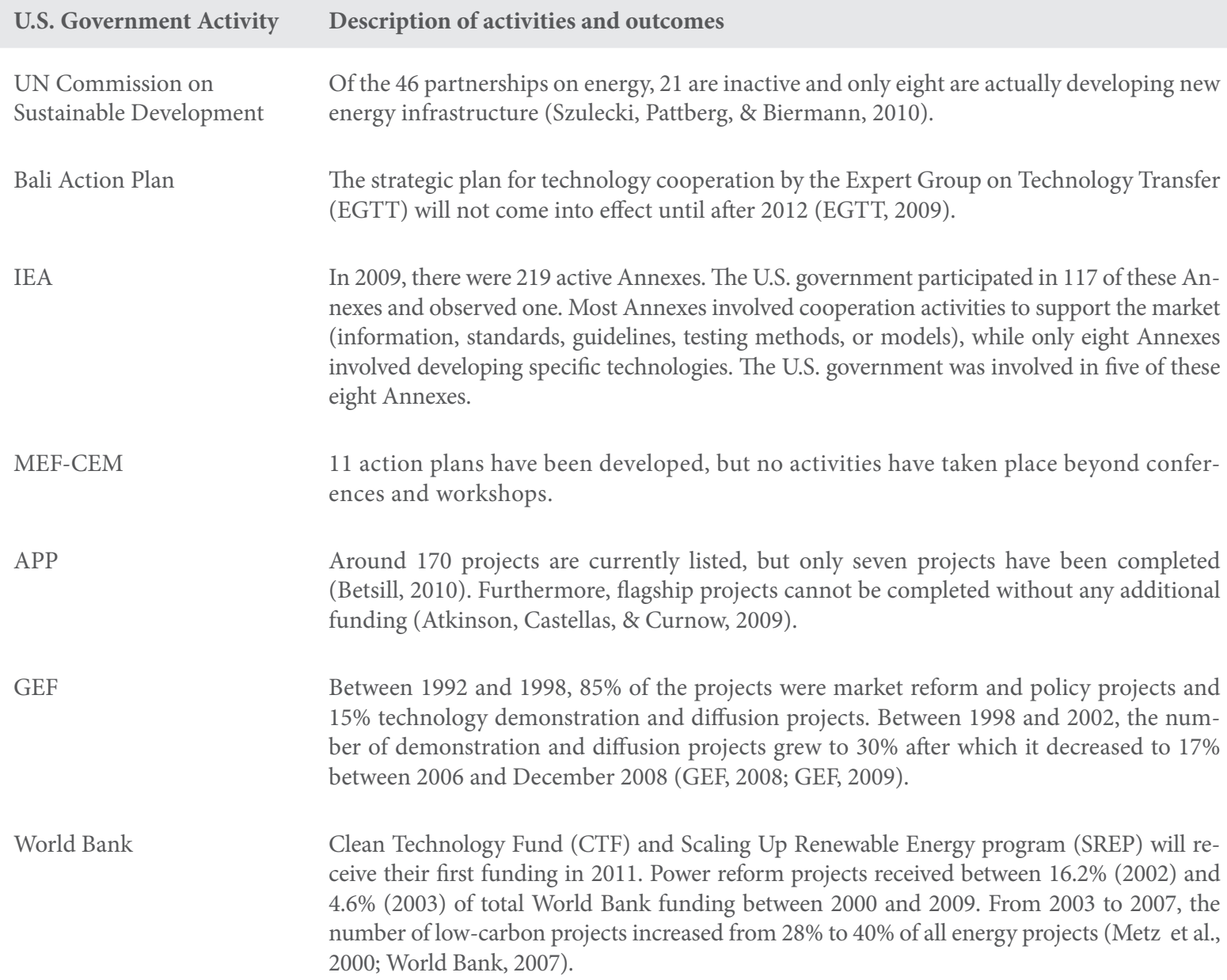

UN Commission on Sustainable Development

Bali Action Plan

IEA

MEF-CEM

APP

GEF

World Bank

Of the 46 partnerships on energy, 21 are inactive and only eight are actually developing new energy infrastructure (Szulecki, Pattberg, \& Biermann, 2010).

The strategic plan for technology cooperation by the Expert Group on Technology Transfer (EGTT) will not come into effect until after 2012 (EGTT, 2009).

In 2009, there were 219 active Annexes. The U.S. government participated in 117 of these Annexes and observed one. Most Annexes involved cooperation activities to support the market (information, standards, guidelines, testing methods, or models), while only eight Annexes involved developing specific technologies. The U.S. government was involved in five of these eight Annexes.

11 action plans have been developed, but no activities have taken place beyond conferences and workshops.

Around 170 projects are currently listed, but only seven projects have been completed (Betsill, 2010). Furthermore, flagship projects cannot be completed without any additional funding (Atkinson, Castellas, \& Curnow, 2009).

Between 1992 and 1998, 85\% of the projects were market reform and policy projects and 15\% technology demonstration and diffusion projects. Between 1998 and 2002, the number of demonstration and diffusion projects grew to $30 \%$ after which it decreased to $17 \%$ between 2006 and December 2008 (GEF, 2008; GEF, 2009).

Clean Technology Fund (CTF) and Scaling Up Renewable Energy program (SREP) will receive their first funding in 2011. Power reform projects received between $16.2 \%$ (2002) and 4.6\% (2003) of total World Bank funding between 2000 and 2009. From 2003 to 2007, the number of low-carbon projects increased from $28 \%$ to $40 \%$ of all energy projects (Metz et al., 2000; World Bank, 2007).

TABLE 5.3. Description of some of the most important international ERD3 cooperation institutions and organizations in which the United States is engaged and some of their achievements. 
respectively. Coordination of these initiatives requires a more in-depth understanding of what projects and activities are carried out and which stakeholders are involved.

3. All mechanisms for international cooperation are used in parallel. The U.S. government has bilateral, broad multilateral, country-specific multilateral, and interest-specific multilateral agreements with each of the BRIMCS countries and simultaneously engages with each of them through MDBs or informal dialogues or partnerships. The existence of multiple channels of communication makes central planning and coordination of international cooperation activities challenging. Furthermore, these platforms are intertwined-for example, some initiatives under the CEM being organized as IEA Implementing Agreements, while others under the IPEEC, and still others creating separate organizational forms altogether.

4. A large number of agreements contain no projects that actually require close cooperation. For example, many of the energy partnerships under the UN Commission on Sustainable Development are inactive (i.e., few or no activities are taking place under some of these partnerships), many of the APP projects are not completed or are awaiting funding, and many multilateral agreements provide data and reports that support international cooperation activities but do not entail more involved activities.

In summary, international ERD3 cooperation activities in the U.S. government consist of a large number of platforms, each with different aims, different stakeholders, and composed of different programs and projects. The next section discusses the U.S. government agencies involved in these activities and the current efforts to coordinate them.

\subsubsection{U.S. agencies involved in international ERD3 cooperation}

Agreements are often led by a single U.S. agency, but there is often more than one agency involved in the execution of international ERD3 agreements. For example, the APP was led by State but included six task forces (each of which can be considered a separate program), each coordinated by one or more government agencies. Similarly, the CEM is led by DOE but has 11 initiatives (programs), and each initiative involves different U.S. agencies. Overall, there are at least 9 U.S. government departments (see Table 5.4.) and 10 U.S. agencies (see Table 5.5.) involved in different international ERD3 cooperation programs.

Table 5.5. provides an overview of the main sub-cabinet agencies and their role in international cooperation on energy technology innovation.

This overview indicates that several departments and agencies have programs that affect the same innovation stages (R\&D, demonstration, market formation, and deployment), and the same energy tech-

nologies (in particular, renewable energy and energy efficiency technologies). In addition, in many 


\begin{abstract}
U.S. Departments
Department of the Treasury

(Treasury)

Department of State (DOS)

\section{Role in international ERD3 cooperation}

Treasury administers funds for the Clean Technology Fund (approved by the World Bank and funded by MDBs), the Strategic Climate Fund (including SREP), and the Global Environment Facility (a joint project of the World Bank and UNEP).

DOS's Bureau of Oceans and International Environmental and Scientific Affairs (OES) is responsible for reporting its Climate Action Plans to the UNFCCC and for managing several international agreements. Within OES, the Office of Science and Technology Cooperation (OES/STC) is responsible for all legally binding international agreements on science and technology. The Office of International Energy and Commodity Policy (IEC) is responsible for U.S. international energy policy. Finally, State manages the budget for the United States Agency for International Development (USAID).
\end{abstract}

Department of Energy (DOE)

Department of Commerce (DOC)

Department of Transport (DOT)

Department of Defense (DOD)

Department of Agriculture (USDA)

Department of Interior (DOI)

Department of Housing and Urban Development (HUD)

DOE has the largest direct impact on international energy technology cooperation with activities taking place within its technology programs, program offices, and the national laboratories. DOE has less funding for international activities than State or Treasury.

DOC's International Trade Administration (ITA) provides information on and organizes events about fast growing energy markets around the world; the National Institute of Standards (NIST) is involved in developing international energy technology standards such as internationally compatible biofuels standards (Chum, 2009); and the National Oceanic and Atmospheric Administration (NOAA) indirectly affects energy technology deployment through its international science collaborations collecting and analyzing international air and water quality data (DOC, 2010a). DOC has also set up advisory committees to help them craft policies promoting the export of renewable energy and energy efficiency technologies (DOC, 2010b).

DOT is involved in bilateral and multilateral agreements on climate change issues; international monitoring of environmental impacts of energy technologies; international efforts to curtail environmental impacts of transportation; and policy support for foreign governments.

DOD conducts international collaborative R\&D projects and is responsible for energy infrastructure development in countries like Iraq and Afghanistan.

USDA is involved in setting international standards for biofuels; science and technology collaborations on sustainable and renewable bioenergy technologies and use; and partners with the interagency organizations for climate change technology policy (CCTP) and climate change research (USGCRP).

DOI coordinates projects in the APP; is a partner of CCTP, USGCRP and USAID; and administers the International Technical Assistance Program, which supports projects preventing the decline of environmental quality through science and technology cooperation and aid.

HUD designs and manages bilateral and multilateral information exchange programs on housing and urban policies; and partners with USAID, State, American Embassies, CCTP and USGCRP.

TABLE 5.4. Overview of U.S. departments and their role in international ERD3 cooperation. 
cases, agencies and departments also have common purposes for engaging in international cooperation (economic, environmental, developmental, and political). However, each department and agency has different organizational and administrative structures, different finance mechanisms at their disposal, different channels of involvement with industry and scientists, and different levels of engagement with Congress and within the White House.

As we discuss below, the large number of agencies and purposes has made it difficult to coordinate the activities of the different agencies effectively. This lack of internal coordination structure limits the ability to learn from any activity and reduces the ability of the government's departments and agencies to complement each other's activities. It is important to recognize, however, that overlap in activities is unavoidable and cannot (and should not) be resolved through centralized management. The nature of innovation, in particular the uncertainty about its outcomes, means that a number of diverse approaches in which different stakeholders make multiple attempts is beneficial.

\subsubsection{Activities in government international ERD3 cooperation}

The project level is where real international cooperation activities are taking place-however, it is also the level where there is the least information about who is involved, what activities are going on, or what financial and technical resources the projects are using. Projects are often coordinated and managed by sub-organizations within U.S. departments or agencies. Within DOE, the 21 national laboratories, containing more than 30,000 scientists and engineers, play a very important role in coordinating and carrying out projects on international ERD3 cooperation. For example, the China Energy Group and the International Energy Studies Group at Lawrence Berkeley National Laboratory, the U.S.-Brazil agreements coordinated at the National Renewable Energy Laboratory (NREL), the International Group at the National Energy Technology Laboratory, and the U.S. ITER team at Oak Ridge National Laboratory all play a central role in managing, executing, and coordinating international cooperation activities. Many individuals and groups within these national laboratories also run and manage many of the bilateral and multilateral agreements signed by the U.S. government.

National laboratories are not only involved in managing projects derived from agreements and programs, but they are also a major source for international cooperation activities themselves. For example, our analysis of scientific collaborations has shown that NREL has about $30 \%$ of its publications in collaboration with research institutions outside of the United States. ${ }^{84}$ With increasing international ERD3 cooperation activities, the number of non-government entities involved in U.S. government-supported

84 From 1995 to 2009, between 27\% and 31\% of NREL's publications were in collaboration with foreign institutions. Our analysis of renewable energy technology papers reveals that U.S. research institutions publish on average 15\% of their publications with foreign institutions in 1995, 19\% in 2000, 25\% in 2005, and 34\% in 2009. 
U.S. Agency
United States Agency for International
Development (USAID)

United States Trade and Development Agency (USTDA)

United States Export-Import Bank $(\mathrm{Ex}-\mathrm{Im})$

Overseas Private Investment Corporation (OPIC)

Environmental Protection Agency (EPA)

Office of Science and Technology Policy (OSTP)

Council on Environmental Quality (CEQ)

National Aeronautics and Space Administration (NASA)

National Science Foundation (NSF)

U.S. Embassies

\section{Role in international ERD3 cooperation}

Bilateral agreements to support foreign countries in power sector reforms, developing energy access, and deployment of clean energy projects reducing greenhouse gas emissions.

Bilateral agreements, trade missions, and financial support encouraging export of U.S. energy technologies. Provides funding for energy-related projects in foreign countries.

Trade missions and financial support (insurance, working capital, loan guarantee programs) encouraging export of U.S. energy technologies. Environmental Exports Program (EEP) provides enhanced financial support for renewable energy, clean coal, energy efficiency, and fuel cells (State, 2010).

Provides project financing and political risk insurance for U.S. companies, including independent power projects, and supports private investment funds in emerging economies.

Involvement in bilateral and multilateral agreements on climate change issues, international monitoring of environmental impacts of energy technologies, international efforts to curtail environmental impacts, and policy support for foreign governments and regulators.

OSTP engages directly with technical experts and leadership teams in different Federal agencies, and it visits foreign countries and directly communicates and discusses international cooperation opportunities with its counterparts in other countries.

CEQ has a domestic role coordinating Federal environmental efforts. Through its initiatives on the Interagency Carbon Capture and Storage Task Force and the Interagency Climate Change Adaptation Task Force, CEQ has some involvement in international cooperation.

International science collaborations on energy technologies, such as space solar energy, and support for deployment of energy technology through its Earth Observation Data.

Grants for international science collaborations on energy technologies. In the 1970s NSF had specific grants for "international energy technology cooperation", but current grants are either energy-specific or country-specific.

Science and technology counselors at U.S. embassies provide information and help facilitate international cooperation activities. However, recent analysis indicating what embassies have anyone in this position is unavailable. The latest analysis shows that there have been large fluctuations in the number of science counselors and that support for their activities has been limited (NRC, 1999). However, science and technology counselors often form the first step in identifying potential areas for collaboration. In addition, DOE now has offices in embassies in Russia, Japan, China, and India; these DOE offices play an important role in collecting information on energy developments in these countries and facilitating cooperation.

TABLE 5.5. Overview of government agencies directly involved in international ERD3 cooperation. 
international ERD3 activities increases as well. The U.S. government engages the private sector, state and local governments, or non-profit organizations in both the management of and as participants in international ERD3 cooperation, while at the same time these actors are increasingly engaging in international ERD3 activities themselves. ${ }^{85}$

Besides patents, people, knowledge, and laboratory facilities within national laboratories, U.S. agencies do not have many resources that they can freely share with foreign partners. Consequently, an important distinction, often unacknowledged, is that within this space of international ERD3 cooperation, the possibility for direct involvement by U.S. policymakers is relatively small, although they can contribute indirectly by creating enabling environments for other stakeholders (including national laboratories).

Policymakers can also directly engage in international ERD3 by exchanging information, training their counterparts in other countries, or engaging in collaborative work on the establishment of legal frameworks governing ERD3 activities. Furthermore, policymakers can create instruments that support scientists and businesses by providing them with information or by opening up new opportunities for international cooperation. Policymakers can also directly support international ERD3 activities by providing financial instruments like financing or loan guarantees, procurement opportunities, development aid, or sponsoring international RD\&D activities.

At the moment, most international ERD3 cooperation enabled by the U.S. government involves the dissemination of information and/or knowledge between a small number of stakeholders (mostly, universities, national laboratories, and government agencies). Only a small number of international ERD3 cooperation projects actually involve the transfer or joint development of technologies, and there is little involvement of companies in such activities.

\subsubsection{Coordinating ERD3 cooperation within the U.S. government}

There is no single process or structure for coordinating international ERD3 cooperation within the U.S. government, and no overall strategic plan for such efforts. Instead, there is a sophisticated network of personal contacts, both within the different U.S. agencies and across other agencies, through which coordination of international cooperation activities takes place.

For example, DOE has established a series of briefing discussions, where it informs policymakers from different U.S. agencies of progress within its programs. However, the value of this personal network is limited to its constituencies, and depends on a small number of highly connected individuals. Furthermore, this system of coordinating international cooperation activities is not replicable (every time there

85 The R20, an international organization connecting states, local governments, and cities globally, is one of those examples whereby non-federal actors initiate international ERD3 activities. 
are new opportunities for international cooperation, policymakers will have to go through the effort of collecting information through their personal networks), its knowledge is tacit, and its information is not easily accessible to private firms, university or laboratory researchers, or NGOs.

We now discuss the potential role that different attempts to coordinate international ERD3 cooperation at various levels can play within the U.S. government.

- At the Federal level, the government has issued the Open Government Directive, which requires executive departments and agencies to publish government information online. For energy issues, this has resulted in the creation of OpenEI, ${ }^{86}$ an online platform that publishes information about U.S. government activities on energy. OpenEI also publishes information concerning existing and new international cooperation activities, but the data does not allow for systematic comparison of activities.

- The Office of International Science and Technology Cooperation (ISTC) within the Office of Policy and International Affairs (PI) collects and disseminates information about DOE's international commitments, including international agreements but excluding any international agreements from its national labs. Although DOE has the technical expertise to coordinate energy technology cooperation across agencies, it does not have the mandate to do so.

- The Council on Environmental Quality (CEQ) or the Office of Science and Technology Policy (OSTP) could provide formal guidelines or priorities for international cooperation, but they do not control the budgets of any of the agencies that would be implementing ERD3 cooperation activities, and they do not have the necessary staff or the mandate to operate internationally. (CEQ and OSTP do, however, influence budget decisions made by the Office of Management and Budget.)

- State does have the mandate to deal with international issues, but is neither equipped for nor responsible for advancing energy technology innovation goals.

- The national laboratories, like NREL and LBL, coordinate many DOE-led international cooperation projects (for example, in 2004, NREL coordinated projects involving 5 different political objectives, 14 different activities, and 5 different groups of stakeholders (Taylor, 2004)), but they do not have the mandate to coordinate international cooperation activities across federal agencies.

- The Climate Change Technology Program (CCTP) and the United States Global Change Research Program (USGCRP) ${ }^{87}$ attempt to coordinate a subset of energy technology-related activities across the government. Although they support other departments in their initiatives and report on their international cooperation activities, the CCTP has yet to establish any

86 http://en.openei.org

87 Formally known as the United States Climate Change Science Program (USCCSP). 
means to coordinate international cooperation activities (CCTP, 2006; CCTP, 2009). USGCRP has an Interagency Working Group on International Research and Cooperation ${ }^{88}$ which coordinates the inputs into major scientific international efforts, such as the Intergovernmental Panel on Climate Change (IPCC) or Inter-American Institute for Global Change Research (IAI) (USGCRP, 2009). However, the main focus is on climate change research and the measurement of global environment change rather than on energy technology RD\&D.

- The recently established Renewable Energy and Energy Efficiency Export Initiative spans eight federal agencies and involves a coordinated action plan, which consists of: developing new financing products and investment vehicles; addressing trade barriers; creating new export opportunities; ranking new markets; increasing the exposure of foreign buyers to U.S. renewable energy and energy efficiency technologies; and providing U.S. companies with better information on U.S. government export programs (TPCC, 2010). This initiative, however, does not include all agencies, all activities, or all technologies relevant to energy technology innovation.

\subsubsection{Summary of current state of government-supported international ERD3 cooperation}

We have identified several factors that make it difficult for the U.S. government (as well as for many other governments throughout the world) to undertake an effective and flexible effort on international ERD3 cooperation. These factors include: (1) the multiplicity of objectives that drive ERD3 cooperation; (2) the wide range of activities involved (e.g., information sharing, standard design, joint R\&D projects, etc.); (3) the large number of platforms and channels through which it takes place; (4) the large number of government stakeholders; (5) the lack of information about the activities taking place within existing bilateral and multilateral platforms; (6) the growing number of non-government international cooperation activities by scientists, national laboratories, industry, and non-governmental organizations; (7) the wide range of technologies that are needed to meet the energy challenge; and (8) the difficulty of balancing cooperation versus protecting intellectual property and potential competitive advantages.

The increase in the number of platforms, agencies, and activities has created more options and opportunities for international ERD3 cooperation, but it also has contributed to a lack of direction and systematic coordination among government agencies, which results in:

- $\quad$ little continuation and follow up between activities;

- duplication and repetition of activities supported across the government;

- $\quad$ restructuring of existing projects with little evaluation;

88 The Working Group includes representatives from USDA, DOC, DOD, DOE, HHS, DOI, State, DOT, USAID, EPA, NASA, NSF, and the Smithsonian Institute. 
- a large number of inactive agreements; and

- limited efforts to extract lessons from international cooperation activities and to provide them to the wider community.

\subsection{The Challenge of Selecting, Executing, and Evaluating International ERD3 COOPERATION}

Given the complexities just described, making choices about what ERD3 projects to pursue in cooperation with other countries and how to manage and coordinate them poses an enormous challenge. Even assuming a perfect world in which the U.S. government acts as a single agent and the needs for U.S. innovators are known, prioritization of international ERD3 activities would face three fundamental conundrums:

1. Cooperation activities take (at least) two parties. The U.S. government will need to consider the interests and values of partnering governments.

2. Measuring the impacts of international ERD3 activities is very difficult. Unintended consequences, uncertainties, and the long-term nature of the innovation process are some of the factors inhibiting simple comparison or prioritization between activities.

3. International cooperation activities do not start from a clean slate. Historical relations, or the conditions under which new activities are initiated, often constrain the range of choices or the implementation of activities.

The U.S. government can draw from literature on and lessons learned by private firms operating globally to identify an approach that will maximize their risk-adjusted profit (Ronstadt, 1978; Patel \& Vega, 1999; Belderbos, Kyoki, \& Iwasa, 2009). However, even within the single overriding metric of maximizing profit, complexities, tradeoffs, and preferences arise: is it better to pursue projects that pose little risk but offer only moderate payoffs; or is it better to pursue high-risk efforts with the potential for large returns? How does a firm identify cooperative efforts that offer substantial net benefits both to the firm and to its potential partners-without which the projects are unlikely to move forward? For the U.S. government, the complexities of making the judgment are far greater because the U.S. government has many different goals that might be served by cooperative ERD3 activities, many different stakeholders pursuing these activities, and pursues these activities through many different platforms and pathways.

Similarly, there is a considerable amount of literature on how "national systems of innovation" are globally connected (Edquist, 1997; Archibugi \& Iammarino, 1999; Archibugi \& Iammarino, 2002). However, strategies for international cooperation go beyond the establishment of policies that support national companies operating in global sectors. Furthermore, international cooperation often has political implications that go beyond the value that such activities might have for national innovation activities (Haas, 
1975; Putnam, 1988; Young, 1989; Iida, 1993). Given this complexity, how can the U.S. government improve its efforts to choose, plan, coordinate, and learn from cooperative international ERD3 activities? Here, we focus first on choosing which efforts to pursue, starting with existing studies that have proposed criteria for selecting priority areas for international ERD3 cooperation, principles for designing specific projects, and a range of metrics for evaluating the impact of projects (Pollack \& Congdon, 1974; PCAST, 1999; IEA, 2005; NREL, 2008; Asia Society, 2009; Bazilian et al., 2009). We then compare these proposals with the approaches the U.S. government is now using to manage international ERD3 cooperation and offer suggestions for improvement.

\subsubsection{Decision criteria for international ERD3 cooperation}

The literature identifies several sets of strategic criteria that can help U.S. government officials prioritize which countries and technology areas should be the focus of international ERD3 cooperation efforts. Table 5.6 provides an overview of three sets of criteria that have been proposed. The criteria put forward by the Interagency TaskForce on "International Cooperation in Energy Research and Development" were specifically created to support priority ranking (Pollack \&Congdon, 1974), while the NREL criteria were proposed for selecting potential countries and technology partnerships (NREL, 2008). In contrast, the PCAST strategic criteria were developed to describe the space or "overall portfolio" of international cooperation activities on energy technology innovation with separate "project criteria" and "public-private interface criteria" to choose among projects within this space (PCAST, 1997). Although there is some overlap between the different proposed criteria, there are also major differences, reflecting the diversity of policy drivers for international ERD3 cooperation, and how these drivers have shifted and expanded over time. ${ }^{89}$

In our analysis, we have applied these criteria to evaluate the potential contribution of existing international cooperation activities. This analysis has revealed two observations: First, our analysis shows that based on these criteria it is not feasible to differentiate between potential countries and/or technologies. Depending on the weights associated with these criteria, a very large number of countries could be potential partners for the United States. Second, despite the fact that most international cooperation activities potentially fall within the possible "space for cooperation" as described by these criteria, there

89 Our historic analysis of policy documents on international ERD3 cooperation shows at least eight different political drivers that, at different points throughout history, have shaped the policy debate. These drivers are: (1) accessing knowledge on hightech energy technologies; (2) retaining or gaining technological competition; (3) increasing energy security; (4) accelerating the commercialization of new energy technologies; (5) reducing the negative environmental impacts of the production and consumption of energy; (6) promoting reforms in the energy sector; (7) providing energy access to the poor; and (8) increasing U.S. access to emerging markets. None of these drivers has become less important. Instead, this amalgamation of different historical and contemporary drivers for international ERD3 cooperation has led to a more complex situation for U.S. decisionmakers in their process of selecting areas of international ERD3 cooperation. 


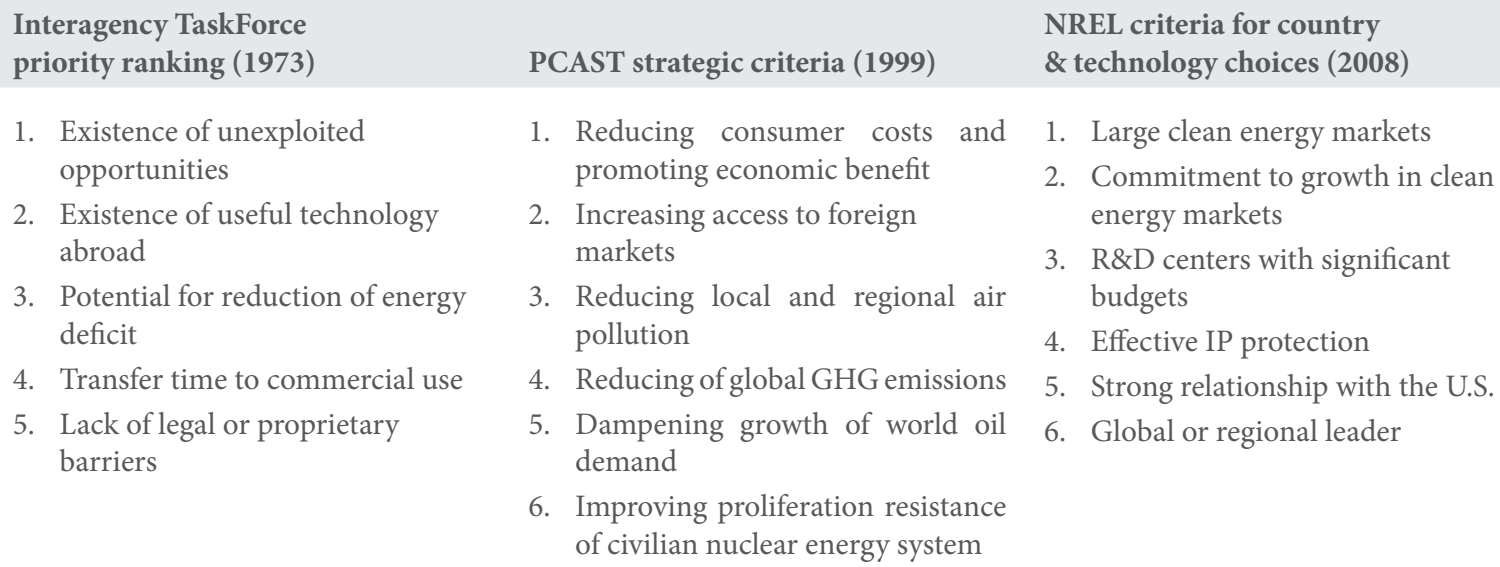

1. Existence of unexploited opportunities

2. Existence of useful technology abroad

3. Potential for reduction of energy deficit

4. Transfer time to commercial use

5. Lack of legal or proprietary barriers

NREL criteria for country \& technology choices (2008)

PCAST strategic criteria (1999)

1. Reducing consumer costs and promoting economic benefit

2. Increasing access to foreign markets

3. Reducing local and regional air pollution

1. Large clean energy markets

2. Commitment to growth in clean energy markets

3. $R \& D$ centers with significant budgets

4. Effective IP protection

4. Reducing of global GHG emissions

5. Dampening growth of world oil demand

5. Strong relationship with the U.S.

6. Global or regional leader

6. Improving proliferation resistance of civilian nuclear energy system

TABLE 5.6. Strategic criteria for areas (technology and country choices) for international ERD3 cooperation projects (based on Polack \& Congdon, 1974; PCAST, 1999; and NREL, 2008).

are only a limited number of international cooperation activities that are actually a result of the application of these criteria. Instead, our analysis shows that, unsurprisingly, many U.S. bilateral agreements on ERD3 are driven by political or project-specific objectives, and not by the criteria put forward by the Interagency Taskforce in 1973, the NREL stakeholder report in 2008, or USAID guidelines for energy projects (see Appendix A5.2.4.). This does not mean that the decision criteria that have been put forward by previous reports or analysis are wrong, but instead indicates that decision making in the U.S. government is much more complex and therefore cannot be captured by a small set of decision criteria.

Furthermore, our interviews, databases, and analysis of changing political drivers for international ERD3 cooperation indicate that no single set of decision criteria can reflect the diversity of policy objectives within the U.S. government agencies and the diversity of international ERD3 cooperation activities that take place. The reason is that many departments do not have energy technology innovation as their main goal, and therefore other goals (e.g., geopolitical objectives) may override the strategic criteria outlined by PCAST (1999); instead, many interviewees characterized their decision strategy as "opportunistic". Similarly, one interviewee stated that generalized strategic frameworks for international cooperation activities do not mean much, because each engagement has its specific conditions and as such, "One does not choose between countries and technologies, one does different stuff with different countries."

The State Department provides an example of how goals beyond energy technology innovation shape international cooperation. The State Department structures cooperation agreements around the potential "ends" that they provide, such as poverty alleviation, rural development, and/or climate change, and only sees technology choices as a "means" to achieve these ends. In contrast, agencies like the Trade and Development Agency (TDA) or the Commerce Department make cooperation choices to support the transfer of specific technologies, and are less concerned about the potential wider implications of these 
technologies within different countries. Even within one government agency, several offices might not have the same agenda. For example, the energy and climate change bureaus at the State Department both work on energy issues within an international context, but they have different policy objectives.

In conclusion, our analysis shows the PCAST strategic criteria provide a baseline for identifying international ERD3 cooperation activities that can contribute to solving our country's energy challenges, but that none of these criteria can provide a single, unified set of decision criteria that would guide all U.S. policymakers engaged in ERD3 cooperation. Although it might seem obvious, this has profound implications for any strategy that attempts to coordinate international cooperation projects: if implemented strictly, a single decision framework for setting priority areas for ERD3 cooperation in all agencies and programs would either be too generic to be useful for prioritization or would rule out many international cooperation activities that are of interest to scientists, firms, national laboratories, or other U.S. organizations involved in ERD3 activities. On the other hand, section 5.4. has shown that a decentralized approach to international ERD3 cooperation activities results in an approach with little prioritization, which involves multiple decision makers at different levels doing different projects, for different reasons, without any agency responsible for identifying the high priority areas for international ERD3 cooperation and ensuring that agencies pursue them. In response to this situation, we recommend the use of heuristics to aid decision making and the implementation of a two-track approach to international ERD3 cooperation (see section 5.6.).

\subsubsection{Designing international ERD3 cooperation activities}

In addition to identifying the priority countries and technology areas for collaboration that are of strategic interest to the United States, policymakers in the U.S. government must make choices about what kind of activities in which they should engage; namely, what the portfolio of activities should look like, what financial or human resources should be invested, which partners should be involved, and what the time-scales and objectives of the projects should be.

The PCAST study of 1999 recommended a portfolio approach toward international ERD3 activities, with programs and projects spanning across:

- The time scales of the activities: near-term $(<5)$, medium-term (5-20), and long-term $(>20)$;

- The different technological pathways that government activities support; ${ }^{90}$

- The stage of innovation $\mathrm{R} \& \mathrm{D}$, demonstration, market formation, and deployment;

90 The term "technological pathway" instead of "technology area" was defined within the PCAST (1997) report on Federal energy research and development to reflect that the notion that multiple pathways can occur within a particular technology area. 
- The participants involved (local and national governments, the private sector, local, national, and international NGOs, multilateral development banks, and other international institutions).

The overview of U.S. government international cooperation activities presented in sections 5.4.3.-5.4.5. already showed that U.S. government agencies engage in multiple channels of cooperation. These projects already span a range of time scales. Some have short-term goals, such as support for building energy infrastructures or energy policy support for governments through USAID. Other activities have longterm goals, such as the U.S.-China Science \& Technology agreement on energy (which was signed in 1979), the U.S.-Euratom-Japan-Switzerland cooperation on plasma technologies and superconducting magnets (which was signed in 1977), or the U.S-Euratom-Japan agreement underpinning collaborations on tokamaks and stellarator concepts (which was signed in 1985).

Similarly, the U.S. government already supports a wide range of technologies. For example, as shown in the analysis of U.S. government engagements within the International Energy Agency Implementing Agreements (IAs) (see section 5.4.3.), the U.S. government is the only government in the world that is engaged in all Implementing Agreements, which cover many technology areas; in addition, within each of these IAs, the U.S. government supports a wide range of different projects, or Annexes.

There is less diversity in the stages of innovation that are covered by U.S. government-supported international ERD cooperation. The majority of activities are related to the deployment of energy technologies. For example, out of the 117 IEA Implementing Agreements, fewer than a third of them support R\&D activities (37), and even fewer than that support demonstration (10). Except for solar PACES, there are no IEA IA projects where countries are jointly building demonstration projects, although they share testing procedures, evaluation tests, and results from their individual demonstration projects. Similarly, of the 37 IEA IA projects supporting R\&D, only 5 projects actually involve joint R\&D developing new technology, and all five projects are in the area of fusion energy. There might be several reasons why there is a lack of international demonstration projects: (1) the increased costs in this stage of the innovation chain; (2) increased competitiveness between industries and associated IPR issues; (3) an increase in the number of stakeholders involved in the process of building new facilities; and (4) increased uncertainties about the end-of-life functionality of demonstration sites.

In our review, we also found that there are many more stakeholders engaged in national ERD3 activities than in international ERD3 cooperation, and only a few stakeholders are engaged in both. For example, the U.S. government has at least four international cooperation activities on clean fossil energy and carbon capture and storage: (1) several Implementing Agreements within the IEA; (2) the Clean Fossil Energy Task Force within the APP; (3) the Carbon Sequestration Leadership Forum (CSLF); and (4) the Carbon Capture, Use, and Storage (CCUS) action group within CEM. The latter agreement also includes support for the Global CCS institute. There are 139 unique U.S. stakeholders involved in at least one of 
these four platforms ${ }^{91}$ ranging from consultancy firms to foundations to energy companies to city councils. However, there are 430 unique stakeholders involved in the seven regional carbon sequestration partnerships (administered by DOE) throughout the United States. Of the 139 stakeholders involved in international agreements, only 48 are involved in these domestic U.S. regional partnerships (see for the full analysis Appendix 5.2.7.). Given that only a fraction of the parties interested in ERD3 take part in international activities, there should be mechanisms that allow these national stakeholders to access information and learn from international activities.

In summary, the U.S. government supports projects covering a diverse range of time frames and technological pathways, but its support for demonstration projects-and to some extent on R\&D projects-is somewhat limited. In addition, in some cases, U.S. organizations involved in international cooperation activities are not the same U.S. organizations involved in national ERD3 activities. These two findings point to the need to pay specific attention to the support of joint demonstration projects, and to create mechanisms that allow lessons from international cooperation activities to be available to U.S. organizations not participating in cooperation.

\subsubsection{Structural versus procedural criteria for designing cooperation projects}

Table 5.7. provides two sets of criteria developed by PCAST (1999) and the IEA that should be considered by policy-makers when designing specific ERD3 cooperation projects. Both sets of criteria describe the structural features of an international cooperation project, but not the procedural steps that create such features.

On the basis of project descriptions of the Annexes in the IEA Implementing Agreements, one could conclude that the structural features of international ERD3 projects adhere to these design criteria. Most annexes start with a description of why the project is of interest to the participants, define their "purpose and objective", identify an "operating agent" that administers the project, define subtasks and assign responsibilities, and provide a timeline for progress and milestones. For example, the IEA Implementing Agreement on Hydrogen provides such descriptions for nine out of its 11 currently operating Annexes. Similarly, State's handbook on drafting international science and technology agreements specifies that each agreement needs to include a description of the scope, funding, joint committees and councils, clauses about intellectual property allocation, and a description of the duration, amendment, and termination of agreements (State, 2001).

Academic literature on interorganizational relationships, however, stresses that the ultimate form of the project, as defined by its objectives, goals, and milestones, is often less important than the personal relationships and tacit understanding that is created in the time before any project comes to paper. These

91 Some stakeholders are involved in more than one international agreement or partnership, so they are counted only once. 


\begin{tabular}{|c|c|}
\hline PCAST project criteria (1999) & IEA Implementing Agreement criteria (2010) \\
\hline - Mutual interests, evident to all participants. & - Determine shared objectives and mutual benefits. \\
\hline $\begin{array}{l}\text { - Mutual investments demonstrating commitment and } \\
\text { common standing to participants. }\end{array}$ & $\begin{array}{l}\text { - Demonstrate mutual commitment of partners. } \\
\text { - Develop equitable funding, sharing, or subsidy } \\
\text { arrangements. }\end{array}$ \\
\hline $\begin{array}{l}\text { - Agreements on goals and milestones, timetables, } \\
\text { responsibilities, sharing of intellectual property rights. }\end{array}$ & $\begin{array}{l}\text { - Set implicit and explicit goals. } \\
\text { - Identify "champions" if required. } \\
\text { - Set parameters of rights and responsibilities. } \\
\text { - Develop procedures for bringing in new partners or } \\
\text { opting out of existing partners. } \\
\text { - Establish intellectual property and patent rights. }\end{array}$ \\
\hline $\begin{array}{l}\text { - Streamlined management, including clear lines of } \\
\text { communication. }\end{array}$ & $\begin{array}{l}\text { - Develop common vision and strategic intent. } \\
\text { - Delineate tasks with skills and resources required. } \\
\text { - Develop internal and external communication. }\end{array}$ \\
\hline $\begin{array}{l}\text { - Continuity of support matched to timeline and } \\
\text { milestones. }\end{array}$ & $\begin{array}{l}\text { - Set initial term and procedures for extension and } \\
\text { termination. }\end{array}$ \\
\hline - Periodic independent oversight. & $\begin{array}{l}\text { - Set milestones and metrics for effectiveness. } \\
\text { - Develop tracking and evaluation procedures. }\end{array}$ \\
\hline
\end{tabular}

TABLE 5.7. Criteria to consider when designing specific international cooperation projects.

initial relationships are often governed by a range of short-term, ad hoc efforts (Van de Ven \& Gordon, 1984), and it is important to provide sufficient support to allow these personal relationships to grow. Especially in international cooperation activities, these so-called procedural aspects are often more important than the specific text on which the parties ultimately agree, because personal relationships and tacit understanding is more effective in mitigating any risks and uncertainty associated with interorganizational collaborations (Parkhe, 1993; Das and Teng, 1998). This is particularly relevant in the context of international ERD3 cooperation, where lack of information, cultural differences, communication problems, and the unpredictable nature of innovation itself create high levels of uncertainties.

Our interview results confirm the importance of the procedural aspects in creating effective international ERD3 cooperation projects. On the one hand, the interview results confirmed that the process leading up to the design of an international cooperation agreement or project is much more important than the structure of the project itself. Both scholars involved in international cooperation projects and project managers at DOE mentioned that the key to successful projects is the organization of effective meetings in which people (scientists, technologists, companies, or policymakers) can share their problems and possible solutions. A clear set of questions, related to shared problems, often enhances communication and the creation of trust. This process of creating trust among the participants often takes a substantial period of time. ${ }^{92}$

92 One interviewee mentioned that it took five years until all participants really trusted each other, but the creation of this shared 
On the other hand, our interview results also indicated that there is no single structural design for international ERD3 projects that can explain their success. Instead, international ERD3 cooperations come in many shapes and sizes, and their structures result from the particular circumstances under which the projects were established. For example, the EPA is involved in four large international cooperation agreements, ${ }^{93}$ and each of these agreements has different structural features that were the result of the circumstances under which the partnerships were developed rather than the result of a pre-defined plan. Again, this suggests that U.S. policymakers involved in international ERD3 cooperation should focus their attention on the creation of just and fair procedures, and that success in the initial stages of any international ERD3 cooperation can lead to projects that are well-defined and adhere to the structural criteria suggested by the PCAST study or the IEA instructions.

Finally, the interview results highlighted the need for flexibility as a procedural feature of international ERD3 cooperation activities. International ERD3 cooperation projects are evolutionary processes, and it is not uncommon for unforeseen developments to occur and dramatically change the impact and direction of the innovation process. A procedure that creates trust and commitment among participants can more easily cope with these kinds of changes. This also points to the need to address any intellectual property issues at a very early stage throughout the process; not through armies of lawyers, but by agreeing to respect each other's existing IPRs and to share those IPRs that result from the collaboration. By addressing any IPR issues at an early stage, participants can benefit from their contributions even if the direction of the project changes over time.

\subsubsection{Evaluating the impacts of ERD3 cooperation}

Once a decision has been made to launch a particular international ERD3 cooperation project-which may be made using a broad range of decision criteria, as discussed above-what criteria can be used to evaluate the project's progress? Here, too, the wide range of objectives and types of projects makes it problematic to attempt to focus on a single, unified design and evaluation approach.

In Table 5.8, we have classified IEA criteria for evaluating their Implementing Agreements into three categories: (1) project evaluation; (2) outcome evaluation; and (3) technology progress criteria. The first two categories are common evaluation categories for international development aid projects (UNDP, 2009), and they are also present within IEA's "structural and management criteria" and IEA's "valuebased criteria". The latter category is specific to the IEA and attempts to measure progress in projects that include basic science and research.

belief was a major factor in the successful outcome of this large international cooperation project.

93 EPA is involved in the Methane 2 Market (M2M) program, their Partnership for Clean Fuels and Vehicles (PCFV), Fuels in Shipping and Aviation, and EnergyStar. Each of these programs and projects has different funding structures, different levels of involvement from U.S. agencies, and different administrative structures, which are the result of the particular circumstances under which these partnerships have been developed. 
There is little systematic evaluation of international cooperation projects by the U.S. government or by most other governments. For example, there are no requirements to evaluate the outcomes of formal international science and technology agreements signed by the State or created during participation in international fora (State, 2001). Country-specific multilateral agreements, such as APP, and departmental programs that involve international cooperation activities have internal evaluation reports, however the results of these reports are generally not publicly available. Other international cooperation activities are also evaluated on a yearly or bi-annual basis (for example, the U.S. - Brazil MOU to Advance Cooperation on Biofuels), but these evaluations are not systematic and cannot be used to compare projects to each other, or to learn lessons about what works and what does not, under what circumstances, in carrying out such projects.

The one exception is that there have been some evaluations of development-oriented energy technology innovation activities supported by the World Bank or other international organizations (JICA, 2001; Boeren, 2005; UNDP, 2009). Szulecki, Pattberg, \& Biermann et al. (2010) analyzed 34 international energy partnerships registered under the United Nations Commission on Sustainable Development; they found that most of these partnerships were inactive. Effectiveness was therefore defined by the level of activity or output, and not by the outcome or impact of the partnership. Similarly, the key achievements of IEA Implementing Agreements are mostly formulated in terms of the number of publications and presentations, visitors to workshops, or users of a database, and not in terms of outcomes to the stakeholders or to solving the problem at hand.

There are several reasons why evaluation of international ERD3 cooperation projects is difficult. First, many international cooperation activities supported by the U.S. government do not involve the develop-

\begin{tabular}{|c|c|c|}
\hline Project Evaluation & Outcome Evaluation & Technology Progress \\
\hline 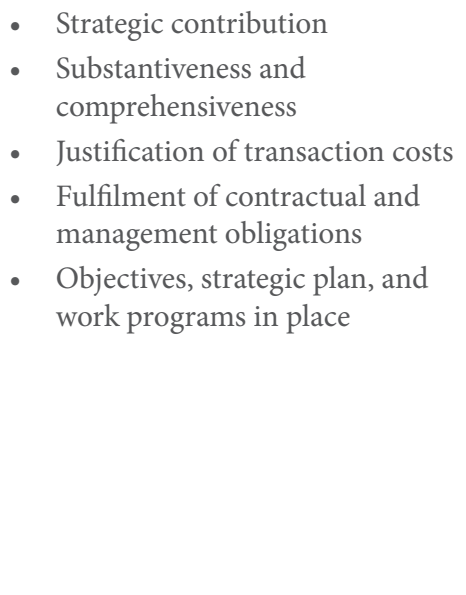 & 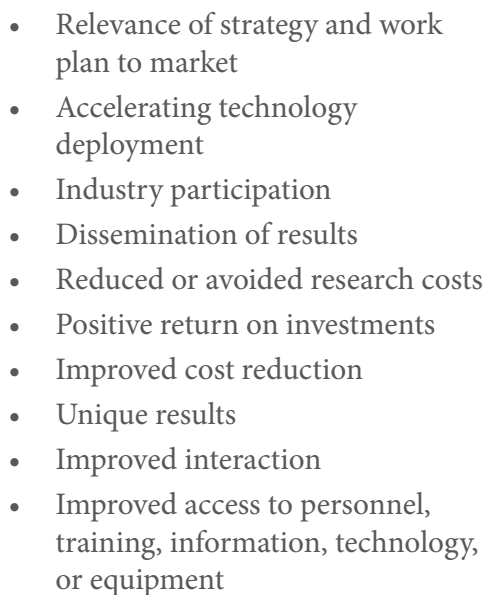 & $\begin{array}{l}\text { - } \begin{array}{l}\text { Contribution to technology } \\
\text { - }\end{array} \text { Citation and awards } \\
\text { - Use of results by institutions } \\
\text { - } \quad \text { Significant success stories } \\
\text { - Spillovers to other energy } \\
\text { technology areas }\end{array}$ \\
\hline
\end{tabular}

TABLE 5.8. Evaluation criteria used by UNDP and the International Energy Agency. 
ment of new technologies. Of the 117 Annexes within the IEA Implementing Agreements signed by U.S. agencies, only four Annexes involve the actual development of new technologies. Instead, most Annexes focus on activities that involve the development of new standards or models for energy technologies, or market support through information dissemination and coordination. The benefits of these nontechnology development cooperations are difficult to evaluate.

Second, collecting and analyzing information about activities and results takes effort. Even if participants are interested in disseminating their work and allowing other people to evaluate it, the process of collecting, updating, and coordinating information is cumbersome. In those cases in which project evaluation is mandatory, the information that is currently being collected is not necessarily useful for other stakeholders or for future cooperation projects. For example, the IEA Implementing Agreements are reviewed every five years, and their most significant achievements are published every two years. However, the overview reports of success stories provide little systematic analysis of progress made, the problems tackled, the solutions provided, or how projects are related to other international cooperation activities. Instead, the reports provide incremental updates of previous project descriptions or a summation of outputs without contextualizing applicability. ${ }^{94}$ Similarly, foreign or international initiatives to create "information portals" lack the sophistication that is required to aid policy makers at different levels throughout the government or innovators in their decisions to design or engage in international ERD3 cooperation activities. ${ }^{95}$

Third, the value and benefits of international ERD3 cooperation are often intangible. The value of a cooperation project is often the relationship itself, and it is important to also assess the impact of a project on networks and relationships. One interviewee mentioned that the network established to set up an international cooperation project was as important, or even more important, than the project itself. Because of this network, the interviewee assisted high-level policymakers in Brazil in the development of integrated resource planning, relying on both hydropower and biomass sources for electricity. Without any international cooperation projects, the interviewee would not have had the connections and standing to assist and to influence the decisions of the Brazilian officials.

94 It is very important to note that "collecting information" does not equate to an evaluation. A bad example of an evaluation effort is the Interagency Working Group (IAWG), which collects information annually on all international exchange and training programs within the U.S. government. These reports are very long (200 to 450 pages), have little structure, and do not explicitly provide lessons and insights. In other words, they create a lot of work but add little value.

95 Several IEA Implementing Agreements (like the greenhouse gas R\&D program or the Clean Coal Centre) have built online databases to facilitate international ERD3 cooperation, but these databases are structured around technologies or "types of information" (publications, policy documents, meetings, etc.) and do not break down the data into tangible information for policy makers or participants. Similarly, EC's initiatives to create databases of R\&D policies (ERAWATCH) or the Strategic Energy Technology Information System (SETIS) structure around broad technology areas or countries rather than specific information needs. 
Despite these difficulties, interviewees acknowledged the need for reporting and evaluating. For example, an analysis of several international cooperation activities focused on sustainable development issues has shown that institutionalizing mechanisms for communication, translation, and mediation has proven to be crucial for enhancing the effectiveness of international innovation activities in the context of sustainable development (Cash et al., 2003). Some interviewees argued that an annual timeframe for reporting allows participants sufficient time to make progress, to contain any administrative burden, to refocus their activities, and to reflect on their progress. Annual reporting is also required for project management purposes. Both IEA (2005) and PCAST (1999) studies agree that effective project management is crucial to the success of even the most promising ERD3 projects. Finally, as one interviewee put it, any evaluation of project management needs to take into consideration the fact that the success rate of any innovation process is unlikely to be high, and that international innovation partnerships have an even lesser chance of succeeding. In such uncertain situations, assessment and evaluation are the only means by which investigators can learn from and reflect on the value of these high-risk projects, even if they do not achieve their full initial goals or ambitions.

These findings suggest that the focus on evaluation has to shift away from measuring generic project, outcome, and technology progress metrics to assessing indicators of outcomes that are specific to the participants' goal and objectives. These outcome indicators should allow participants to assess the value of these projects, to reflect on the direction of the project as well as on their own contributions and expectations, and they should be formulated so that non-participants can understand and learn from them as well. Finally, project evaluation criteria should support the managers of the projects while they are active in the project, and should provide feedback to government officials after the projects have finished.

\subsection{Managing International Cooperation in a Complex World}

In the complex and dynamic global ERD3 environment just described, new opportunities for international ERD3 cooperation arise at many different levels within the U.S. government, as well as in many different places around the world. Only a bottom-up approach, which harnesses the insights of many different U.S. innovators involved in international cooperation networks, is flexible enough to seize these opportunities, and, as such, to maximize the benefits the United States can gain from international ERD3 cooperation. But a bottom-up approach provides little opportunity to prioritize, minimize overlaps, find and fix gaps, or learn from experience about what works, what does not, and under what circumstances for each category. A top-down approach, based on information about bottom-up activities and designed as a complement, rather than an alternative, could address some of the weaknesses of an exclusively bottom-up approach.

Based on these two findings, we suggest a two-track approach, incorporating both bottom-up and topdown elements. The aim of this approach is to support bottom-up activities, collect bottom-up information, and use this information to guide interagency coordination mechanisms that collect, assess, and 
evaluate U.S. government involvement in international ERD3 cooperation. The interagency approach we propose would also have the ability to instigate international ERD3 cooperation efforts that fill gaps or seize synergies among existing national and international ERD3 activities.

\subsubsection{A bottom-up approach}

New opportunities can arise at any level, from a state visit that results in a bilateral agreement to personal relations between scientists at the national laboratories. With an increasingly complex and fast-changing world, innovators involved in international networks have the highest chance of identifying such opportunities. Allowing and supporting this bottom-up process is essential for capturing the potential benefits that a more global and diverse landscape of ERD3 activities offers to the United States. Furthermore, agencies have a wide range of reasons for pursuing specific international ERD3 cooperation activities.

Benefits of international cooperation can be large, and small pockets of seed money to support international ERD3 activities can leverage large increases in support for ERD3 within the United States. However, international ERD3 cooperation is also more uncertain than national activities, because of the lack of information, communication difficulties, and/or administrative procedures. Our interviews indicate that the U.S. government can support U.S. innovators by creating an "incubator fund" at departmental levels. The aim of such "incubator funds" is to support those activities, such as international flights, workshops, or other practical/administrative expenses, that improve the establishment of personal relationships, shared understanding, and trust at the initial stages of international $\mathrm{R} \& \mathrm{D}$, demonstration, or deployment projects and support the establishment of long-lasting networks of innovators. We suggest that a portion of the incubator funds be made available for these important activities. Since each department has different objectives, these "incubator funds" should be introduced at a departmental level but should share their practices and administrative procedures. The structure for administering incubator funds should include members from outside the department, who should be able to make decisions about allocations in short timescales.

These additional initial costs for organizing international ERD3 cooperation are easily recuperated in the long-term because of increased efficiencies and productivity. We therefore recommend that departments and agencies put "incubator" funding in place that allows for comprehensive procedures in the embryonic stages of new bottom-up initiatives. Furthermore, departments and agencies should never exclude international ERD3 cooperation whenever it makes sense to match U.S. capabilities with capabilities in other countries. In general, these activities include:

- Energy RD\&D activities that require specific local knowledge;

- Energy RD\&D activities of interest to U.S. innovators that are currently taking place in foreign countries; 
- The design or operation of expensive test facilities;

- High-cost energy RD\&D activities, such as demonstration projects; and

- Activities that support the early deployment of energy technologies in new markets.

However, a decentralized approach to support international ERD3 cooperation activities can also lead to inefficiencies if U.S. policy-makers and innovators are not fully informed about other international ERD3 cooperation activities underway, or about how their specific opportunities can create complementary opportunities for international ERD3 cooperation at different levels throughout and outside of the U.S. government. Therefore, information about existing international ERD3 activities is essential for reducing the inefficiencies of the current system. As such, we recommend a process by which agencies collect information about their international ERD3 cooperation activities in a coherent and comparable way.

The U.S. government should establish mechanisms to collect and disseminate information on these international ERD3 activities in order to: (a) assure continuity and follow-up between activities; (b) avoid duplication and repetition of activities supported across the government; (c) create complementarities between and across projects, programs, and agreements; and (d) provide opportunities for technical and social (e.g., public engagement) learning (Markusson et al., 2011) within the U.S. government and its wider community. Since multiple U.S. agencies are active at each level, it is necessary to provide an information system that crosses agency borders and includes high-level officials, program officers, and project managers in all U.S. agencies. A management system to collect and distribute information about existing and new agreements, programs, and projects should provide comparable and coherent information, while at the same time acknowledging that information needs are different at each level.

Based on the need for a robust and flexible information system, we have developed three heuristics to support information collection and dissemination of (1) agreements; (2) programs; and (3) projects. We have designed these heuristics to be used in multiple ways: (1) as guiding principles for collecting information; (2) as tools to inform U.S. policymakers in their decision making; (3) as a way to identify potential risks; and (4) as tools to communicate and negotiate the value and risks of international ERD3 cooperation activities with foreign partners.

\section{Managing projects}

As described by PCAST (1999), international cooperation on ERD3 encompasses a wide range of activities, and crosses many countries, technologies, and innovation stages. Information about the countries, technologies, and innovation stages targeted in international ERD3 cooperation projects is a first step to inform U.S. policymakers, but it is insufficient for understanding the value of international ERD3 projects to the wider community. Figure 5.4 presents a heuristic to characterize international ERD3 projects on the basis of three dimensions: (1) stakeholders; (2) actions; and (3) resources. 


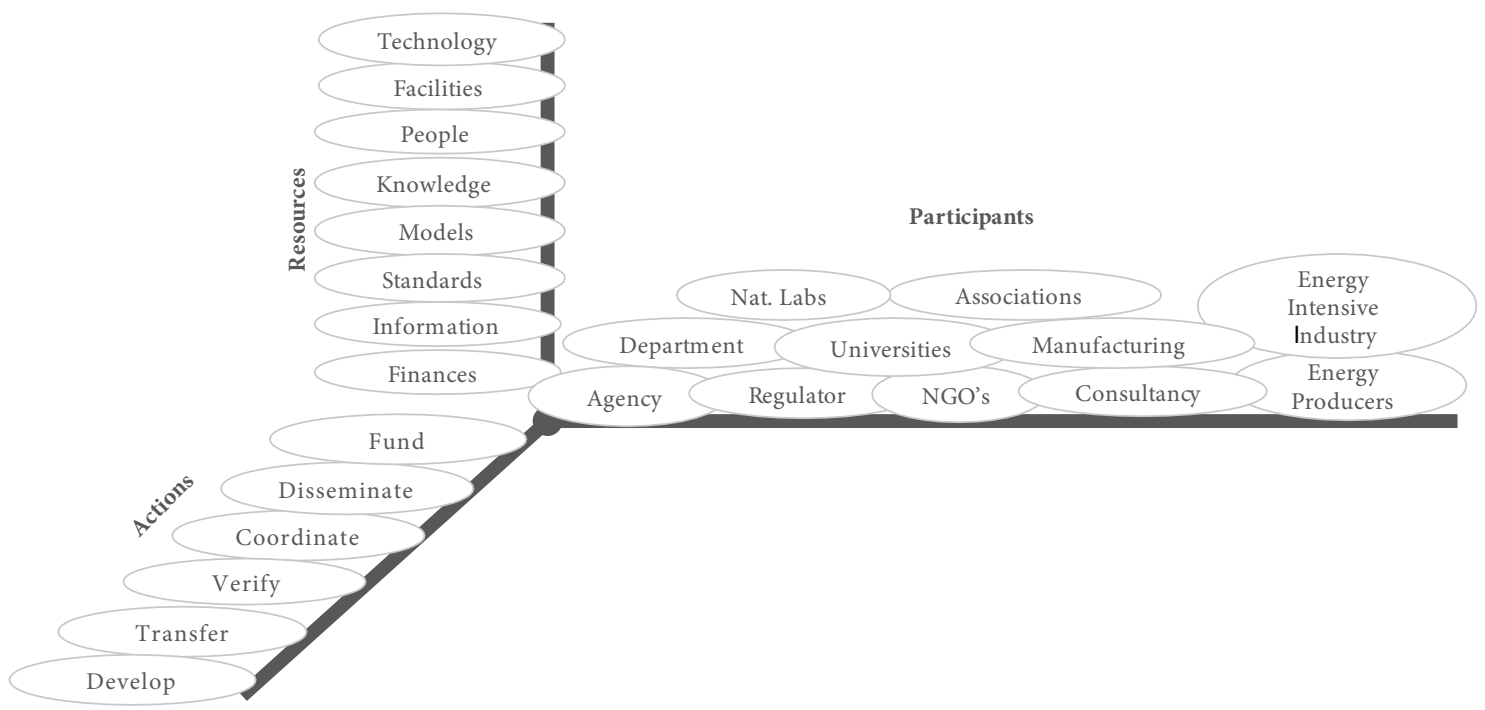

FIGURE 5.4. Types of international cooperation activities characterized by participants, actions and resources.

This characterization is based on a large quantitative survey of existing international cooperation activities within the IEA Implementing Agreements and other multilateral agreements. The verbs and nouns used in this description are exemplary for a range of other actions, participants, or resources. For example, the noun "disseminate" is exemplary for comparable actions like "collect", "share", "create an overview", or "compile." Similarly, the noun "information" represents a range of comparable resources like "databases", "test results", "source books", "handbooks", "studies", "case studies", or "maps".

On the basis of these three dimensions, one can not only collect information about existing international ERD3 projects, but also envision the possible space for future international ERD3 projects. For example, most international ERD3 projects supported by the U.S. government in the IEA IA consist of collaborations between universities and national laboratories, the dissemination of information or standards, the development of new models, or the transfer of knowledge. If these projects are characterized according to these dimensions, policymakers or innovators within the United States can more easily identify those projects that are of value to them. Furthermore, international ERD3 projects are often not symmetrical. This heuristic allows participants or external innovators interested in ERD3 projects to identify the combination of resources, actions, and participants that each country contributes to a project.

Information about the content of international ERD3 cooperation is obviously not sufficient to support learning from international ERD3 projects. Projects should also report their annual targets and the progress that they have made toward these targets. A description about why these targets were or were not achieved is often more important than the target itself. Managers' judgments about best practices, obstacles encountered, and whether and how obstacles were overcome all provide important lessons to other project managers within and outside the U.S. government.

\section{Managing programs}

Managing information about programs is essential for creating coherence and complementarities between all of the programs run by the different agencies within the U.S. government, but it also can in- 
form the creation of new agreements. Program reports should contain information about technologies, countries, and innovation stages targeted as well as the following specific elements (Ruggie, 1975):

- Where is the cooperation going to take place-domestically or in the partnering country or both?

- What is the value of the international ERD3 program to the participating countries? Will it provide opportunities to acquire new knowledge or technologies (new solutions for existing problems), or will it address particular constraints by using existing knowledge or technologies (existing solutions for new problems)?

- What is the role of the government in the international ERD3 cooperation? Will it facilitate or enable international cooperation activities by others? Or is the government a direct participant in the international cooperation activities?

From a technological perspective, the question is which specific elements of the ERD3 innovation system are addressed within an international cooperation program. We have broadly characterized three possible areas in which programs can make a contribution:

- International cooperation programs can be technology-specific when participants are working on improving the principles, components, or the design of a particular technology. An example of such an international cooperation program is the previously mentioned ITER project;

- International cooperation programs can address the larger system in which the technology is developed, for instance, improving manufacturing, enabling infrastructures, or supply chains; and

- International cooperation activities can also address institutional issues to improve innovation, such as the development of regulation, market support, or addressing consumer behavior. Each of these different levels would require different kinds of projects with different stakeholders involved.

A categorization of international cooperation programs on the basis of these different elements within the innovation system is important for finding complementarities between different programs across technologies, countries, and agencies. For example, collaborative programs on regulatory issues for renewable energy technologies in India can complement collaborative programs on regulatory issues for energy efficiency, transmission, distribution, and storage technologies, or generic technology innovation measures taking place in other agencies.

\section{Managing agreements}

Agreements can be the result of a state visit, trade missions, planned efforts to create bilateral or multilateral relations, or can arise out of existing projects or programs. Once an agreement is signed, information about the technologies covered, the countries involved, and the activities supported is often 
communicated through press releases or recorded within internal systems, but these systems are often not compatible with each other. ${ }^{96}$ Furthermore, there is no central database where innovators, program officers, or project managers can search existing agreements and identify those that can be of value to their programs or projects.

Although information about the status, goals, agencies, technologies, and countries associated with agreements is useful for categorizing existing agreements, it is insufficient to inform the risk/reward judgments that high-level officials require to undertake when engaged in the creation of new agreements. To assist high-level officials in this judgment, we have identified six important geopolitical concerns for ERD3 agreements that may be used to identify possible areas of collaboration with mutual benefits:

- Natural resource concerns: does cooperation impede or promote the availability of natural resources for the countries involved?

- Economic competitiveness: does cooperation impede or promote economic competitiveness of the countries involved?

- Military force: does cooperation increase or decrease the military capabilities of the countries involved?

- Local/regional conditions: does cooperation promote or impede social and political stability in the countries and/or regions involved in international cooperation?

- Public perception: is cooperation accepted by the public?

- Environment: does cooperation improve our global environment?

Of course, the answers to these questions depend on the technology and country under consideration. However, within a particular technology area, the answers to these questions might differ depending on whether cooperation takes place on energy resource technologies, energy conversion technologies, or energy use technologies. For example, international cooperation on enriching technologies for uranium creates more geopolitical concerns with regard to military force than cooperation on nuclear reactor design.

96 For example, DOE has created the COMmitment Management International Tracking (COMMIT) database which collects information about international cooperation activities on the basis of seven categories: (1) status, (2) goal, (3) milestones timeframe, (4) programmatic focus, (5) participating DOE Labs, (6) type of agency involved (both domestic and foreign), and (7) document types. Although this system provides information to policymakers within DOE, it is not extended to include U.S. agreements signed by other agencies. There is an informal understanding that State's Office of Science and Technology Cooperation informs and is informed by offices in other agencies whenever new agreements are signed that touch upon science and technology, but there is no consistent database that provides comparable data on each agreement and the programs and projects taking place within it, available to all parts of the U.S. government and to others who might wish to participate. 


\subsubsection{A top-down approach}

A decentralized system of managing U.S. government involvement in international ERD3 cooperation could lead to gaps in international ERD3 cooperation, especially if these gaps pertain to potential benefits for the United States as a whole. For example, our analysis has shown that there is a serious gap in international ERD3 activities involving joint development of technologies or joint commissioning of demonstration projects, ${ }^{97}$ two areas of collaboration with large potential to support ERD3 in the United States. Furthermore, our analysis has shown that many activities are terminated before any long-term goals can be achieved. Neither of these shortcomings can be resolved without a holistic perspective of the direction and value of international ERD3 activities as a whole. We therefore suggest the introduction of a top-down approach in the form of an interagency institution that has the ability to identify: (1) international ERD3 activities that create coherence between existing activities; and (2) international ERD3 activities that create synergies or seize opportunities between U.S. national ERD3 policies and national ERD3 policies from foreign countries.

The identification of gaps and opportunities requires two pieces of information: (1) information about existing international ERD3 activities, and (2) a systematic analysis of the energy innovation systems in place in the countries involved. The former can be achieved by introducing a data collection system within the U.S. government. The latter, comparing national innovation systems, is notoriously difficult (Nelson \& Chandler, 1993).

Here, we have developed a simplistic procedure to analyze and compare the ERD3 systems of two or more countries, which we will demonstrate on the basis of a comparison between government-supported ERD3 activities in the United States and India. The aim of such comparison is to determine potential areas for collaboration. The procedure classifies ERD3 policies and institutions along three dimensions: (1) the stages of innovation that they affect ( $\& \& D$, demonstration, or deployment) (Sagar and Gallagher, 2004; Gallagher, Holdren, \& Sagar, 2006); (2) the actors that they affect (suppliers of knowledge or technology, demand actors of knowledge or technologies, intermediary actors facilitating the interface between suppliers and demand actors, or support actors that provide conditions under which each of the other three actors operate) (Smits \& Kuhlmann, 2004; Sarewitz \& Pielke, 2007); and (3) functions of innovation (Johnson \& Jacobsson, 2001; Hekkert et al., 2007). The scientific concepts and theories on which this procedure is based are described in Appendix A5.3.

Tables 5.9.-5.12. show the results of such analysis for India and the United States. An application of this procedure to the other BRIMCS countries can be found in Kempener, Anadon, \& Condor Tarco (2010). The comparative frameworks provide a quantitative overview of the number of policies and/or institu-

See our analysis in section 5.5.2. 


\begin{tabular}{|c|c|c|c|c|c|c|c|c|c|c|c|c|}
\hline \multirow[t]{2}{*}{ India } & \multicolumn{4}{|c|}{$R \& D$} & \multicolumn{4}{|c|}{ Demonstration } & \multicolumn{4}{|c|}{ Deployment } \\
\hline & supply & interm. & demand & support & supply & interm. & demand & support & supply & interm. & demand & support \\
\hline FE & 8 & 4 & 0 & 0 & 3 & 0 & 2 & 0 & 5 & 1 & 2 & 1 \\
\hline NE & 3 & 0 & 1 & 0 & 1 & 0 & 1 & 0 & 3 & 0 & 1 & 0 \\
\hline $\mathbf{R E}$ & 8 & 0 & 0 & 0 & 4 & 0 & 1 & 0 & 13 & 6 & 3 & 1 \\
\hline EE & 1 & 2 & 0 & 0 & 3 & 1 & 0 & 0 & 2 & 2 & 6 & 5 \\
\hline TDS & 5 & 2 & 0 & 0 & 0 & 0 & 0 & 0 & 1 & 2 & 0 & 2 \\
\hline GE & 0 & 1 & 1 & 0 & 0 & 0 & 0 & 0 & 0 & 1 & 1 & 0 \\
\hline
\end{tabular}

TABLE 5.9. Number of Indian governmental institutions and policies affecting stages and actors in the innovation process within each of the energy technology categories.*

\begin{tabular}{|c|c|c|c|c|c|c|c|}
\hline India & $\begin{array}{c}\text { knowledge } \\
\text { creation }\end{array}$ & $\begin{array}{c}\text { knowledge } \\
\text { diffusion }\end{array}$ & $\begin{array}{c}\text { resource } \\
\text { mobilization }\end{array}$ & $\begin{array}{c}\text { entrepreneurial } \\
\text { activities }\end{array}$ & $\begin{array}{c}\text { guidance of } \\
\text { search }\end{array}$ & $\begin{array}{c}\text { creation of } \\
\text { legitimacy }\end{array}$ & $\begin{array}{c}\text { market } \\
\text { formation }\end{array}$ \\
\hline FE & 10 & 1 & 1 & 1 & 0 & 0 & 0 \\
\hline NE & 3 & 0 & 0 & 0 & 1 & 1 & 0 \\
\hline RE & 8 & 2 & 5 & 1 & 2 & 2 & 7 \\
\hline EE & 1 & 2 & 1 & 0 & 1 & 4 & 4 \\
\hline TDS & 4 & 1 & 0 & 1 & 1 & 1 & 2 \\
\hline GE & 0 & 1 & 0 & 0 & 1 & 0 \\
\hline
\end{tabular}

TABLE 5.10. Number of Indian governmental institutions and policies affecting functions of the innovation process within each of the energy technology categories.*

\begin{tabular}{|c|c|c|c|c|c|c|c|c|c|c|c|c|}
\hline \multirow{2}{*}{$\begin{array}{c}\text { United } \\
\text { States }\end{array}$} & \multicolumn{4}{|c|}{ R\&D } & \multicolumn{4}{|c|}{ Demonstration } & \multicolumn{4}{|c|}{ Deployment } \\
\hline & supply & interm. & demand & support & supply & interm. & demand & support & supply & interm. & demand & support \\
\hline FE & 15 & 6 & 1 & 0 & 4 & 4 & 1 & 0 & 1 & 6 & 0 & 0 \\
\hline NE & 18 & 3 & 1 & 1 & 3 & 1 & 0 & 0 & 6 & 1 & 0 & 1 \\
\hline RE & 24 & 2 & 0 & 0 & 2 & 4 & 0 & 0 & 18 & 8 & 20 & 5 \\
\hline EE & 15 & 1 & 2 & 0 & 1 & 2 & 2 & 0 & 18 & 18 & 38 & 2 \\
\hline TDS & 16 & 0 & 1 & 0 & 3 & 1 & 1 & 0 & 6 & 7 & 1 & 2 \\
\hline GE & 14 & 3 & 0 & 0 & 0 & 1 & 0 & 0 & 7 & 1 & 0 & 2 \\
\hline
\end{tabular}

TABLE 5.11. Number of U.S. governmental institutions and policies affecting stages and actors in the innovation process within each of the energy technology categories.*

\begin{tabular}{|c|c|c|c|c|c|c|c|}
\hline $\begin{array}{c}\text { United } \\
\text { States }\end{array}$ & $\begin{array}{c}\text { knowledge } \\
\text { creation }\end{array}$ & $\begin{array}{c}\text { knowledge } \\
\text { diffusion }\end{array}$ & $\begin{array}{c}\text { resource } \\
\text { mobilization }\end{array}$ & $\begin{array}{c}\text { entrepreneurial } \\
\text { activities }\end{array}$ & $\begin{array}{c}\text { guidance of } \\
\text { search }\end{array}$ & $\begin{array}{c}\text { creation of } \\
\text { legitimacy }\end{array}$ & $\begin{array}{c}\text { market } \\
\text { formation }\end{array}$ \\
\hline FE & 16 & 7 & 0 & 1 & 2 & 5 & 0 \\
\hline NE & 18 & 3 & 2 & 0 & 5 & 2 & 4 \\
\hline RE & 22 & 3 & 26 & 2 & 7 & 11 & 12 \\
\hline EE & 15 & 8 & 24 & 5 & 11 & 12 & 27 \\
\hline TDS & 15 & 3 & 4 & 1 & 7 & 6 & 5 \\
\hline GE & 14 & 3 & 4 & 1 & 1 & 11 & 0 \\
\hline
\end{tabular}

TABLE 5.12. Number of U.S. governmental institutions and policies affecting functions in the innovation process within each of the energy technology categories.*

* FE: fossil energy; NE: nuclear energy; RE: renewable energy; EE: energy efficiency;

TDS: transmission, distribution, and storage; GE: general (or unspecified) energy technology support. 
tions in place in 2009 affecting different energy technologies and different stages, actors, or functions. In other words, the number in each category represents the total number of government interventions that affect that particular stage, actor, function, and energy technology. One policy or institution can apply to multiple technologies, stages, actors, or functions. The overview does not determine the impact of each institution and/or policy or compare their effectiveness. Five main databases have been used to collect information: (1) the WRI SP-PAMs Database (2010); (2) the REN21 Renewables Interactive Map (2010b); (3) the IEA Global Renewable Energy Database (2010e); (4) the IEA Energy Efficiency Database (2010d); and (5) the IEA Addressing Climate Change Database (2010b). However, these databases mainly contain policies focused on renewable energy technologies and are poorly maintained. Therefore, these databases are augmented with the Clean Coal Projects database of the IEA Clean Coal Center (IEA, 2010c) and the World Nuclear Association's country briefings (World Nuclear Association, 2010). Subsequently, these databases are cross-referenced with secondary literature, academic papers, and national policy reports.

Secondly, we have compared the energy technology priority areas as defined by national policies by the U.S. government and the Government of India (see Table 5.13.).

A quick comparison of the ERD3 systems in the United States and India, combined with a comparison of their "energy technology priorities", suggests that there are several technology areas that are worth exploring for U.S.-India international cooperation:

1. New materials: New materials are a priority area for India, but the Indian government has few policies in place supporting the development of new materials. In contrast, the United States has several national laboratories that conduct R\&D related to new energy materials.

2. Energy storage systems: Energy storage is a priority for both the United States and India, and both countries have several policies in place to support R\&D and deployment of storage technologies (in particular hydrogen storage). The United States' experience with "learning

\footnotetext{
Country Energy technology priorities

United Improved vehicle fuel economy, including electrification; increased biofuel production; improved energy

States efficiency in appliances and buildings; solar energy; geothermal energy; marine and hydrokinetic energy; energy storage; CCS; smart grid (U.S. Congress, 2007).

India New materials; R\&D in biofuels; combustion research; energy R\&D for railway transportation; hydrogen; advanced coal technologies; ultra-super-critical technologies; energy storage systems; gas hydrates and oil shale; energy efficiency; silicon crystals for PV applications; LEDs; electric vehicles (Planning Commission, 2008).
}

TABLE 5.13. A comparison of energy technology priorities by the U.S. government and the Government of India. 
demonstrations" ${ }^{\prime 98}$ might provide opportunities in the context of India's challenges for rural electrification, and shared demonstration projects can lower the costs for both nations.

3. Solar energy: The Indian government has developed both R\&D programs and financial support for solar energy demonstration projects. The United States has more support for entrepreneurial activities, test centers, solar resource assessment, and the development of codes and standards.

4. Advanced coal: Although the United States' focus is on carbon capture and storage rather than on advanced coal technologies, opportunities exist for cooperation on demonstration and procurement projects for clean coal in India (Gopalakrishan, 2000; Chikkatur \& Sagar, 2007; Chikkatur, Sagar, \& Sankar, 2009).

5. Energy efficiency in small- and medium-sized enterprises: India has many policies in place promoting the deployment of energy efficiency, but little support for entrepreneurial activities in small enterprises and energy-intensive industries. In contrast, the United States has several policies in place promoting innovation and technology transfer in small enterprises.

6. Entrepreneurial activities in renewable energy technologies: Both the United States and India promote knowledge creation, resource mobilization, guidance of search, legitimacy creation, and support for markets, but place less emphasis on knowledge diffusion and entrepreneurial activities in renewable energy technologies. This is an area that the literature identifies as particularly important.

\subsubsection{Connecting the bottom and the top}

The introduction of a two-track approach that supports both bottom-up projects for international ERD3 cooperation and top-down guidance to identify potential gaps and opportunities for national energy priorities requires the introduction of several new mechanisms: (1) the introduction of an "incubator" funding for international ERD3 cooperation; (2) a procedure for annual information collection on international ERD3 cooperation activities; (3) an institute for information processing, analysis, and dissemination; and (4) the establishment of an interagency committee to provide strategic guidance. Besides these four mechanisms, we believe that an effective U.S. government strategy toward international ERD3 cooperation activities should embrace the aforementioned four guiding principles and should embody the following considerations.

A U.S. government strategy toward international ERD3 should explicitly recognize the diversity of objectives and constraints within the different government agencies, and recognize that the benefits or risks of international cooperation are different depending on the level of engagement and the stakehold-

98 DOE's National Hydrogen Learning Demonstration started in 2004 and established teams of private companies and national laboratories to test, demonstrate, and validate hydrogen fuel cell vehicles, hydrogen infrastructure, and their interface. 
ers involved. On the basis of this notion, an effective U.S. government strategy for international ERD3 cooperation should attempt to create coherency between the different government departments and/or agencies, and should attempt to create complementarities between the activities taking place at the different governance levels (agreements, programs, and projects).

In addition, a U.S. government strategy should be based on the notion of "creating value for U.S. innovators". This means that an effective U.S. government strategy for international ERD3 cooperation should attempt to create synergies between the international activities it supports and its national priorities, and that each new project, program, or agreement should connect to existing innovation activities by either supporting existing collaborations or addressing existing gaps. Together, these four guiding principles, underpinned by their supporting mechanisms, can create an environment in which U.S. policy makers and U.S. innovators work together to capture the benefits and mitigate the risks of international ERD3 cooperation to address U.S. energy challenges in an increasingly complex and interdependent world. Figure 5.5. provides a visual representation of these four principles.

\subsection{ConClusions And ReCOMmENDATIONS}

The United States needs a more adaptive and effective approach to international ERD3 cooperation to meet the challenges of energy innovation in a rapidly changing international landscape. The discussion in this chapter has made it clear that greater coordination and learning from experience is needed-but also that there are so many different goals of international ERD3 cooperation, and so many actors engaged in it, that it is unlikely to be practical to centralize all decisions on what efforts to undertake.

Instead, we recommend that the U.S. government adopt a two-track approach that supports international ERD3 activities by U.S. innovators from the bottom up, and simultaneously supports U.S. policymakers by addressing potential gaps or synergies from the top down. Both approaches require a more diligent and systematic effort of collecting and disseminating information about what projects are currently supported, what problems they address, and what solutions they may provide. In particular, we propose:

- Setting aside a portion of the budgets of each major energy RD\&D program for international cooperation to finance efforts identified bottom-up by program officers or project managers involved in international energy $\mathrm{RD} \& \mathrm{D}$ efforts, and providing incubator funding to support the procedural aspects for creating large-scale technology-focused cooperation projects;

- A new system to collect information on international ERD3 cooperation activities that will make it possible for programs to become more effective over time by learning from experience; and

- A new interagency working group to identify gaps in international ERD3 cooperation, identify projects that can create synergies between countries, develop lessons learned and best practices, 
Principle 1

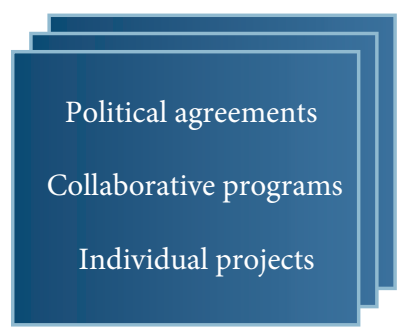

Collect coherent information about agreements, programs, and projects across agencies
Principle 2

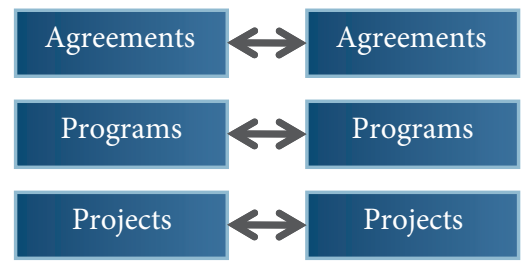

Create complementarities among agreements, programs, and projects
Principle 3

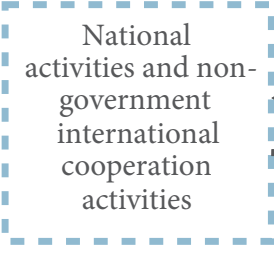

Create synergies between international cooperation activities and national priorities
Government

support

for

international

cooperation

activities

FIGURE 5.5. Four guiding principles for managing international cooperation activities within the U.S. government.

and create long-term visions and strategic guidance. The creation of this working group would be complemented by funding for programs that represent strategic priorities identified by this working group.

In this chapter, we have also made suggestions for:

- A new approach to balancing cooperation and competition in clean energy technologies by differentiating international ERD3 activities into agreements, programs, and projects;

- An increased emphasis on joint technology development and large-scale technology demonstration projects; and

- A new foundation to support coordination of energy-related development aid and market diffusion projects.

Below, we highlight each of our first three proposals in turn:

Instructing departments and agencies to set aside "incubator" funding to support bottom-up ERD3 cooperation projects. In an increasingly complex, diverse, and fast-changing global landscape of ERD3 activities, one has to rely on innovators connected to international networks to identify new opportuni- 
ties for international ERD3 cooperation. These bottom-up projects, which are already taking place to some extent, increase the ability of both U.S. policymakers and U.S. innovators with contacts in other countries to respond to needs and opportunities in a flexible and timely manner. Often those engaged in particular technology programs at the national laboratories, or in a particular bureau at the State Department, have good ideas for ERD3 cooperation activities that will help them advance their objectives. Departments and agencies should be directed to set aside a portion of their energy technology innovation budgets to support projects that involve researchers from other countries as well. This mechanism is necessary because the wide variety of motivations for ERD3 cooperation throughout the government makes it both impossible and undesirable to centralize all decision making in one agency or committee, or to use one set of criteria to guide all cooperation activities-and because a single approach is insufficiently flexible to accommodate the diverse needs and objectives of both U.S. policymakers and U.S. innovators, potentially missing opportunities for fruitful international collaboration along the way. This approach would significantly increase the total funding directed to international cooperation efforts.

Establishing an information-sharing platform for ERD3 cooperation in the U.S. Energy Information Administration. To eliminate the lack of continuity, the risks of duplication and repetition, and the lack of evaluation and learning within the U.S. government, a system to collect and share information on international ERD3 cooperation projects should be created. This system could be hosted by the Energy Information Administration. The system should collect information about existing international cooperation projects, programs, and high-level agreements across the different U.S. agencies. Incentives should be put in place to ensure that those responsible for the projects consistently introduce information on the details of the projects and their progress on a yearly basis. Incentives could include offering followup funding for the projects contingent (among other conditions) on providing information about the project and/or making information sharing part of future personnel evaluations. The platform should also enable private firms and not-for-profit organizations to access and share information about their projects. Information needs to be comparable at different levels and across agencies, and accessible to both U.S. policymakers and other stakeholders who may be interested in cooperating with other parties internationally.

Creating a Working Group on Energy Technology Cooperation in a reestablished Committee on International Science, Engineering, and Technology (CISET) under the National Science and Technology Council at OSTP. In 2010, PCAST recommended the re-establishment of CISET (PCAST, 2010). Our research supports the need to reestablish such an institution and to create a Working Group focused on Energy Technology Cooperation that would be co-chaired by DOE and the Office of Science and Technology Policy (OSTP) and have active participation from the other agencies involved, including the State Department, the U.S. Department of Agriculture, and the U.S. Agency for International Development, as well as private sector actors. The Working Group should be guided by an "adaptive strategy" to identify 
two types of activities: (1) activities that create coherence between existing international ERD3 cooperation activities; and (2) activities that create synergies or seize opportunities between U.S. national ERD3 activities and those of its partnering countries. These key activities, along with a more reflexive view on the direction of international ERD3 activities as a whole, should be reported every year to Congress, the White House, and the different departments. The Working Group should work directly with OMB to ensure that the initiatives the Working Group identifies as the highest priorities will receive adequate funding. It would be responsible for identifying and communicating strategic guidelines for cooperation on energy technology innovation every year and produce a report to Congress, the White House, and the different departments. It is important to note that a bill that passed the House, the International Science and Technology Cooperation Act of 2009 (U.S. Congress, 2009), would have required the OSTP Director to establish CISET under NSTC to identify and to coordinate priority areas for science and technology cooperation.

This two-track approach, based on pursuing activities initiated from within the agencies (bottom-up), supported by guidelines and activities from an interagency committee (top-down), and supported by an information-sharing platform to allow learning over time would result in a virtuous cycle. The creation of funds to enable bottom-up projects with sufficient emphasis on the procedural features would also promote nimbleness and creativity from program officers and project managers. This is important as the research in this study found that many projects and agreements result in little activity but take up significant administration time. The creation of the Committee at the NSTC would identify and create coherence between activities, increasing the likelihood that they will contribute to meet the U.S. energy challenges. Finally, more information about the results of programs (successes, as well as dead-ends) would make the selection and the execution of international ERD3 activities more effective and more productive over time. 


\section{REFERENCES}

AEIC, (2010). A business plan for America's energy future. American Energy Innovation Council. Retrieved December 2010 from http://www.americanenergyinnovation.org/full-report

Archibugi, D., \& Iammarino, S. (1999). The policy implications of the globalisation of innovation. Research Policy, 28(2-3), 317-336.

Archibugi, D., \& Iammarino, S. (2002). The globalization of technological innovation: Definition and evidence. Review of International Political Economy, 9(1), 98-122.

Asia Society, (2009). A roadmap for U.S.-China cooperation on energy and climate change. Pew Center on Global Climate Change. Retrieved December 2009 from http://www.pewclimate.org/ docUploads/US-China-Roadmap-Feb09.pdf

Atkinson, M., Castellas, P., \& Curnow, P. (2009). Independent review of Asia-Pacific partnership flagship projects. Prepared for the Department of Resources, Energy and Tourism on behalf of the Asia-Pacific Partnership on Clean Development and Climate (APP). Retrieved from http://www. asiapacificpartnership.org/pdf/shanghai/flagship_reviews/Final_Flagship_Review_-_English.pdf

Atkinson, R., Shellenberger, M., Nordhaus, T., Swezey, D., Norris, T., Jenkins, J., Ewbank, L., Peace, J., \& Borofsky, Y. (2009). Rising tigers, sleeping giant. The Breakthrough Institute. Retrieved from http://thebreakthrough.org/blog/Rising_Tigers.pdf

Bazilian, M., De Coninck, H., Cosbey, A., \& Neuhoff, K. (2009). Mechanisms for International LowCarbon Technology Cooperation: Roles and Impacts. Climate Strategies. Retrieved from http:// www.climatestrategies.org/research/our-reports/category/43/221.html

Beamish, P. W., \& J. P. Killing (1996).Introduction to the special issue. Journal of International Business Studies, 27(5): iv-xxxi.

Beinhocker, E., Oppenheim, J., Irons, B., Lahti, M., Farrell, D., Nyquist, S., Remes, J., Naucler, T., \& Enkvist, P. (2008). The carbon productivity challenge: Curbing climate change and sustaining economic growth. (June 2008). McKinsey Global Institute, McKinsey Climate Change Special Initiative. Retrieved March 2010 from http://www.mckinsey.com/mgi/reports/pdfs/Carbon_ Productivity/MGI_carbon_productivity_full_report.pdf

Belderbos, R., Kyoki, F., \& Iwasa, T. (2009). Foreign and domestic R\&D investment, Economics of Innovation \& New Technology, 18(4), 369-380.

Betsill, M. M. (2010). Introduction: Is the Asia-Pacific partnership a viable alternative to Kyoto? An editorial essay. Wiley Interdisciplinary Reviews: Climate Change, 1(1), 9-9.

Biermann, F., Pattberg, P., van Asselt, H., \& Zelli, F. (2009).The fragmentation of global governance architectures: A framework for analysis. Global Environmental Politics, 9(4), 14-40. 
Boeren, A. (2005). A bird's eye view: Lessons from evaluations of international cooperation programmes in higher education, research and manpower development. A Changing Landscape - Making Support to Higher Education and Research in Developing Countries More Effective. Retrieved December 2010 from http://www.nuffic.nl/pdf/os/em/boeren02.pdf

BP, (2010). Statistical review of world energy, 2010. Retrieved August 2010 from http://www.bp.com/ sectiongenericarticle.do? categoryId $=9033088 \&$ contentId $=7060602$

BP, (2011). Statistical review of world energy, 2011. Retrieved September 2011 from http://www. bp.com/statisticalreview

Cash, D. W., Clark, W. C., Alcock, F., Dickson, N. M., Eckley, N., Guston, D. H., Jäger, J., \& Mitchell, R. B. (2003). Knowledge systems for sustainable development. Proceedings of the National Academy of Sciences of the United States of America, 100(14), 8086-8091.

CCTP, (2006). U.S. Climate Change Technology Program Strategic Plan. U.S. Climate Change Technology Program. Retrieved December 2009 from http://www.climatetechnology.gov/ stratplan/final/CCTP-StratPlan-Sep-2006.pdf

CCTP, (2009). Strategies for the commercialization and deployment of greenhouse gas intensityreducing technologies and practices. Committee on Climate Change Science and Technology, Department of Energy. Retrieved September 2010 from http://www.osti.gov/bridge/purl.cover. jsp?purl=/946831-tMYnXw/

CEPP, (2009). Who owns the clean tech revolution. Center for Environmental Public Policy, Goldman School of Public Policy, University of California, Berkeley. Retrieved January 2011 from http:// gspp.berkeley.edu/IPR/whoowns.pdf

Chikkatur, A. P., \& Sagar, A.D. (2007). Cleaner power in India: Towards a clean-coal-technology roadmap. Energy Technology Innovation Policy Group, Belfer Center for Science and International Affairs, Harvard Kennedy School of Government. Retrieved October 2010 from http://belfercenter.ksg.harvard.edu/files/Chikkatur_Sagar_India_Coal_Roadmap.pdf

Chikkatur, A. P., Sagar, A. D., \& Sankar, T. L. (2009). Sustainable development of the Indian coal sector. Energy, 34(8), 942-953.

Chum, H. (2009). U.S. - Brazil MOU to advance cooperation on biofuels. Golden, CO: 2009 US-Brazil Innovation Learning Laboratory 6. Retrieved November 2010 from http://www.compete.org/usbrazil/uploads/resources/Denver_Lab_Agenda.pdf

Conacyt, (2008). Informe Genereal de Estado de la Ciencia y la Tecnologia. Gobierno Federal. Mexico: Consenjo National de Ciencia y Tecnologia.

Das, T. K., \& Teng, B. S. (1998). Between trust and control: Developing confidence in partner 
cooperation in alliances. The Academy of Management Review, 23(3), 491-512.

DOC, (2010a). Annual report on technology transfer: Approach and plans, fiscal year 2009 activities and achievements. U.S. Department of Commerce. Retrieved November 2010 from http://www. nist.gov/tpo/publications/upload/2009-Tech-Transfer-Rept-FINAL.pdf

DOC, (2010b). Charter of the renewable energy and energy efficiency Advisory Committee. International Trade Agency, Department of Commerce. Retrieved November 2010 from http://ita. doc.gov/td/energy/REEEAC\%20Charter\%207-14-10.pdf

DOE, (2011). U.S.-China clean energy cooperation: A progress report by the U.S. Department of Energy. U.S. Department of Energy. Retrieved September 2011 from http://energy.gov/sites/prod/ files/piprod/documents/USChinaCleanEnergy.pdf

Edquist, C. (1997). Systems of innovation: Technologies, institutions, and organizations. New York, NY: Pinter.

Department of Public Enterprises, (2010). Address by the Minister of Public Enterprises, Barbara Hogan, To the National Assembly, on the Pebble Bed Modular Reactor. 16 September 2010. Retrieved October 15, 2010 from http://www.dpe.gov/za/news-971

EGTT, (2009). Strategy paper for the long-term perspective beyond 2012, including sectoral approaches, to facilitate the development, deployment, diffusion and transfer of technologies under the Convention. Report by the Chair of the Expert Group on Technology Transfer. Retrieved October 2010 from http://unfccc.int/resource/docs/2009/sb/eng/03.pdf

Gallagher, K. S., Anadon, L. D., Kempener, R., \& Wilson, C. (2011). Trends in investments in global energy research, development, and demonstration. Wiley Interdisciplinary Reviews: Climate Change, 1757-7799. doi: 10.1002/wcc.112

Gallagher, K. S., Holdren, J. P., \& Sagar, A. D. (2006). Energy-technology innovation. Annual Review of Environment and Resources, 31(1), 193-237.

GEF, (2008). Transfer of environmentally sound technologies: The GEF experience. Global Environment Facility, 1-40. Retrieved October 2010 from http://www.thegef.org/gef/sites/thegef. org/files/publication/GEF_TTbrochure_final-lores.pdf

GEF, (2009). Investing in energy efficiency. Global Environment Facility. Retrieved from http://www. thegef.org/gef/sites/thegef.org/files/publication/Investing-Energy-Efficiency-English.pdf

Gopalakrishan, A. (2000).For synergy in energy. Frontline, 17(6).

Haas, E. B. (1975). Is there a hole in the whole? Knowledge, technology, interdependence and the construction of international regimes. International Organization, 29(3), 827.

Hagedoorn, J., (2006). Understanding the cross-level embeddedness of interfirm partnership 
formation. Academy of Management Review, 31 (3), 670-680.

Hekkert, M. P., Suurs, R. A. A., Negro, S. O., Kuhlmann, S., \& Smits, R. E. H. M. (2007). Functions of innovation systems: A new approach for analysing technological change. Technological Forecasting and Social Change, 74(4), 413-432.

Huang, Z. (2011). Clean energy subsidies and the law of the WTO. Cambridge, MA: Harvard China Project, Harvard School of Engineering and Applied Sciences. Retrieved March 31, 2011 from http://chinaproject.harvard.edu/seminar\%20folder/seminar/Huang110331

IEA, (2005). International energy technology collaboration and climate change mitigation: Synthesis report . International Energy Agency. Organisation for Economic Co-operation and Development. Retrieved September 2011 from http://www.oecd.org/dataoecd/62/42/35798801.pdf

IEA, (2010a). Energy technology initiatives: Implementing through multilateral co-operation. International Energy Agency. Retrieved October 2010 from http://www.iea.org/papers/2010/ technology_initiatives.pdf

IEA, (2010b). IEA addressing climate change database. Retrieved from http://www.iea.org/textbase/ $\mathrm{pm} /$ index.html

IEA, (2010c). IEA clean coal projects database. Retrieved August 2010 from http://www.iea-coal.org. uk/site/ieacoal/databases/clean-coal-projects

IEA, (2010d). IEA energy efficiency database. Retrieved September 2010 from http://www.iea.org/ textbase/pm/index.html

IEA, (2010e). IEA global renewable energy database. Retrieved September 2010 from http://www.iea. org/textbase/pm/index.html

IEA, (2010f). World energy outlook 2010. IEA, OECD, 1-738, Retrieved December 2010 from http:// www.worldenergyoutlook.org/

IEA (2011). Energy Technology RD\&D Budgets (2011Edition). Detailed Country RD\&D Budgets. Retrieved September 2011 from http://www.iea.org/stats/rd.asp

Iida, K. (1993). Analytic uncertainty and international cooperation: Theory and application to international. International Studies Quarterly, 37(4), 431.

Interagency Task Force on Carbon Capture and Storage, (2010). Report of the Interagency Task Force on Carbon Capture and Storage. U.S. Department of Energy. U.S. Environmental Protection Agency. Retrieved February 2011 from http://www.fe.doe.gov/programs/sequestration/ccstf/ CCSTaskForceReport2010.pdf

IWG, (2010). Growing America's fuel. Biofuels Interagency Working Group. U.S. Department of Agriculture, U.S. Department of Energy, U.S. Environmental Protection Agency. Retrieved 
February 2011 from http://www.whitehouse.gov/sites/default/files/rss_viewer/growing_americas_ fuels.pdf

JICA, (2001). Participatory evaluation and international cooperation. Institute for International Cooperation, Japan International Cooperation Agency. Retrieved September 2011 from http:// www.jica.go.jp/english/publications/reports/study/topical/participatory/pdf/par.pdf

Johnson, A., \& Jacobsson, S. (2001). Inducement and blocking mechanisms in the development of a new industry: The case of renewable energy technology in Sweden. In R. Coombs (Ed.), Technology and the market: Demand, users and innovation, (89-111). Cheltenham, UK: Edward Elgar.

Kasprzycki, D., Ozegalska-Trybalska, J., \& Mayr, A. (2008).How Proactive intellectual property management can improve research collaborations: Good practices in EU and BRIC higher educational institutions. IP-Unilink. Retrieved February 2011 from http://www.ip-unilink.net/ public_documents/Good_Practice_Guide_web.pdf

Kempener, R., Anadon, L. D., \& Condor Tarco, J. (2010). Governmental energy innovation investments and policies in the major emerging economies: Brazil, Russia, India, Mexico, China, and South Africa. Energy Research, Development, Demonstration and Deployment Project, Energy Technology Innovation Policy Group, Belfer Center of Science and International Affairs. Retrieved November 2010 from http://belfercenter.ksg.harvard.edu/publication/20517/

Levi, M. A., Economy, E. C., O’Neil, S. K., \& Segal, A. (2010). Energy innovation: Driving technology competition and cooperation among the U.S., China, India and Brazil. Council on Foreign Relations. Retrieved November 2010 from http://www.cfr.org/publication/23321/energy_ innovation.html

Markusson, N., Issii, A., Stephens, J.C. (2011). The social and political complexities of learning in CCS demonstration projects. Global Environmental Change 21: 293-302.

Metz, B., Davidson, O., Martens, J., Van Rooijen, S., \& and Van Wie Mcgrory, L. (Eds.) (2000). Methodological and technological issues in technology transfer. Cambridge, UK: Cambridge University Press.

Nelson, R. R., \& Chandler, A. (1993). National innovation systems: A comparative analysis. New York, NY: Oxford University Press.

NRC, (1999). The persuasive role of science, technology, and health in foreign policy: Imperatives for the Department of State. Committee on Science, Technology, and Health Aspects of the Foreign Policy Agenda of the United States, National Research Council. Retrieved January 2011 from http://www.nap.edu/catalog/9688.html

NREL, (2008). Strengthening U.S. leadership of international clean energy cooperation. National 
Renewable Energy Laboratory. Retrieved from http://www.nrel.gov/international/pdfs/44261.pdf

NSF, (2008). Research and Development in Industry: 2004. Division of Science Resources Statistics

(SRS), National Science Foundation. December 2008. Retrieved March 2010 from http://www. nsf.gov/statistics/nsf09301/

Ockwell, D. G., Haum, R., Mallett, A., \& Watson, J. (2010). Intellectual property rights and low carbon technology transfer: Conflicting discourses of diffusion and development.Global Environmental Change, 20(4), 729-738.

OECD, (2010). Development database on aid activities: CRS online. Organisation for Economic Cooperation and Development. Development Co-operation Directorate (DCD-DAC). Retrieved December 2010 from http://stats.oecd.org/Index.aspx?DatasetCode=CRSNEW

NSB, (2001). Towards a more effective role for the U.S. government in international science and engineering. National Science Board. 15 November 2001. Retrieved February 2011 from http:// www.nsf.gov/nsb/documents/2002/nsb01187/pdfs/nsb01187.pdf

NSB, (2008). International science and engineering partnerships: A priority for U.S. foreign policy and our nation's innovation enterprise. National Science Board. 14 February 2008. Retrieved February 2011 from http://www.nsf.gov/nsb/publications/2008/nsb084.pdf

Office of Public Affairs, (2008). Joint U.S.-China fact sheet: U.S.-China Ten Year Energy and Environment Cooperation Framework. U.S. Treasury Department. 18 June 2008. Retrieved February 2011 from http://www.treasury.gov/initiatives/Documents/uschinased10yrfactsheet.pdf

Oliva, M. J. (2008). Climate change, technology transfer and intellectual property rights. International Centre for Trade and Sustainable Development. Retrieved March 2011 from http://ictsd.org/ downloads/2008/10/cph_trade_climate_tech_transfer_ipr.pdf

Parkhe, A. (1993). Strategic alliance structuring: A game theoretic and transaction cost examination of interfirm cooperation. The Academy of Management Journal, 36(4), 794-829.

Patel, P., and Vega, M. (1999). Patterns of internationalisation of corporate technology: Location vs. home country advantages. Research Policy, 28(2-3), 145-155.

PEMEX, (2008). Annual report 2007/2008. Petroleos Mexicanos. Retrieved December 18, 2009 from http://www. ri.pemex.com/index.cfm?action=content\&sectionID=135\&catID=12320

PCAST, (1997). Report to the President on federal energy research and development for the challenges of the twenty-first century. President's Committee of Advisors on Science and Technology. Retrieved from http://clinton3.nara.gov/WH/EOP/OSTP/Energy/

PCAST, (1999).Power partnerships: The federal role in international cooperation on energy innovation. President's Committee of Advisors on Science and Technology. Retrieved September 
2009 from http://www.whitehouse.gov/sites/default/files/microsites/ostp/pcast-08021999.pdf.

PCAST, (2010). Report to the President on accelerating the pace of change in energy technologies through an integrated federal energy policy. Executive Office of the President, President's Council of Advisors on Science and Technology Retrieved December 2010 from http://www.whitehouse. gov/sites/default/files/microsites/ostp/pcast-energy-tech-report.pdf

PEW Charitable Trusts, (2011). Who's winning the clean energy race? PEW Charitable Trust, PEW Environment Group. Retrieved March 2011 from http://www.pewenvironment.org/ uploadedFiles/PEG/Publications/Report/G-20Report-LOWRes-FINAL.pdf

Planning Commission, (2008). Eleventh five year plan 2007-12: Volume I, Inclusive Growth. Retrieved August 2010 from http://www.planningcommission.gov.in/plans/planrel/fiveyr/11th/11_v1/11th_ vol1.pdf

Pollack, H., \& Congdon, M. B. (1974). International cooperation in energy research and development. Law and Policy in International Business, 6(3), 677-726.

Putnam, R. D. (1988). Diplomacy and domestic politics: The logic of two-level games. International Organization, 42(3), 427-460.

REN21, (2010a). Renewables 2010: Global status report. REN21 Secretariat. Deutsche Gesellschaft fur Technische Zusammenarbeit (GTZ). Retrieved September 2011 from http://www.ren21.net/ REN21Activities/Publications/GlobalStatusReport/tabid/5434/Default.aspx

REN21, (2010b). Renewables interactive map. Renewable Energy Policy Network for the 21st Century. Retrieved from http://www.ren21.net/map/

Reuters, (2008). US says lax China IPR hampers clean tech trade. Financial Express, Beijing, China.

Ronstadt, R. C. (1978). International R\&D: The establishment and evolution of research and development abroad by seven U. S. multinationals. Journal of International Business Studies, 9(1), 7-24.

Ruggie, J. G. (1975). International responses to technology: Concepts and trends. International Organization, 29(3), 557.

Sagar, A. D., \& Anadon, L. D. (2009). Climate change: IPR and technology transfer: Background paper prepared for the United Nations Framework Convention on Climate Change. UNFCCC, 1-48.

Sagar, A. D., \& Gallagher, K. S. (2004). Energy research, development, demonstration and deployment. Harvard Kennedy School of Government. Retrieved November 2010 from http://belfercenter.ksg. harvard.edu/files/energytechdd.pdf

Sarewitz, D., \& Pielke, R. A. (2007). The neglected heart of science policy: Reconciling supply and demand for science. Environmental Science \& Policy, 10(1), 5-16. 
Smits, R., \& Kuhlmann, S. (2004). The rise of systemic instruments in innovation policy. International Journal of Foresight and Innovation Policy, 1(1/2), 4-32.

State, (2001). Supplementary Handbook on the C-175 Process: Routine Science and Technology Agreements. Office of Science and Technology Cooperation, Bureau of Oceans and International Environmental and Scientific Affairs, Department of State. Retrieved November 2010 from http:// www.state.gov/g/oes/rls/rpts/175/index.htm

State, (2010). Chapter 7: Financial resources and technology transfer. In Fifth U.S. Climate Action Report (99-120). Washington, DC: Department of State..

Stine, D. D. (2009). Science, technology, and American diplomacy: Background and issues for congress. Congressional Research Service. Retrieved November 2010 from http://www.fas.org/ sgp/crs/misc/RL34736.pdf

Szulecki, K., Pattberg, P., \& Biermann, F. (2010). Explaining variation in the performance of energy partnerships. The Global Governance Project. Retrieved April 2010 from http://www.glogov.org/ images/doc/WP39.pdf

Taylor, R. (2004). NREL international program overview. Retrieved November 2010 from http:// www1.eere.energy.gov/solar/pdfs/nrel_international.pdf

The Royal Society, (2011).Knowledge, networks and nations: Global scientific collaboration in the 21st century. The Royal Society. Retrieved March 2011 from http://royalsociety.org/uploadedFiles/Royal_ Society_Content/Influencing_Policy/Reports/2011-03-28-Knowledge-networks-nations.pdf

TPCC, (2010). Renewable energy and energy efficiency export initiative. Trade Promotion Coordinating Committee, an interagency group chaired by the U.S. Secretary of Commerce. Retrieved September 2011 from http://export.gov/build/groups/public/@eg_main/@reee/ documents/webcontent/eg_main_024171.pdf

Tyfield, D., Jin, J., \& Rooker, T. (2010). Game-changing China: Lessons from China about disruptive low carbon innovation. NESTA. Retrieved from http://www.nesta.org.uk/library/documents/ game-changing-china.pdf

U.S. Congress, (2007). Energy Independence and Security Act of 2007. 110th Congress. Retrieved from http://www.govtrack.us/congress/bill.xpd?bill=h110-6

U.S. Congress, (2009). International Science and Technology Cooperation Act of 2009. 111th Congress, 1st Session. Retrieved October 2010 from http://frwebgate.access.gpo.gov/cgi-bin/ getdoc.cgi? dbname=111_cong_bills\&docid=f:h1736rfs.txt.pdf

UN COMTRADE, (2011).United Nations Commodity Trade Statistics Database. United Nations Statistics Division. Retrieved March 1, 2011 from http://comtrade.un.org 
UNDP, (2009). Handbook on planning, monitoring and evaluating for development results. United Nations Development Programme. Retrieved December 2010 from http://www.undp.org/ evaluation/handbook/documents/english/pme-handbook.pdf

UNFCCC, (2006). Synthesis report on technology needs identified by parties not included in Annex I to the convention. United Nations Framework Convention on Climate Change. Retrieved February 2011 from http://unfccc.int/resource/docs/2006/sbsta/eng/inf01.pdf

UNFCCC, (2008). Bali Action Plan. United Nations Framework Convention on Climate Change, 13th Conference of the Parties. Retrieved September 2010 from http://unfccc.int/resource/docs/2007/ cop13/eng/06a01.pdf\#page $=3$

USGCRP, (2009). Our changing planet: The U.S. climate change science program for fiscal year 2010. Subcommittee on Glboal Change Research. United States Global Change Research Program. Retrieved November 2010 from http://downloads.globalchange.gov/ocp/ocp2010/ocp2010.pdf

Van de Ven, A., \&Gordon, W. (1984). The dynamics of interorganizational coordination.

Administrative Science Quarterly, 29(4), 598-621.

von Zedtwitz, M., \& Gassmann, O. (2002). Market versus technology drive in R\&D internationalization: Four different patterns of managing research and development. Research Policy, 31(4), 569-588.

World Bank, (2007). Clean energy for development investment framework: Progress report of the World Bank Group Action Plan. Development Committee. Retrieved from http://siteresources. worldbank.org/DEVCOMMINT/Documentation/21510693/DC2007-0018(E)CleanEnergy.pdf

World Nuclear Association, (2010). Nuclear power country briefings. Retrieved October 2010 from http://www.world-nuclear.org

WRI, (2010). SD-PAMs database. Retrieved December 2009 from http://projects.wri.org/sd-pamsdatabase

Young, O. R. (1989). International cooperation: Building regimes for natural resources and the environment. Ithaca, NY: Cornell University Press. 


\section{ABOUT THE AUTHORS}

\section{Laura Diaz Anadon}

Associate Director of the Science, Technology, and Public Policy Program, Director of the Energy Technology Innovation Policy research group, Project Manager of the Energy Research, Development, Demonstration \& Deployment (ERD3) Policy Project, and adjunct lecturer of public policy at the Harvard Kennedy School.

Dr. Diaz Anadon's research focuses on understanding the process of technology innovation, particularly in the energy and water sectors, and the role of public policy shaping this process. Her work includes modeling the impact of including technical uncertainty in policy decisions, and a comparative analysis of innovation policies in energy across countries. She has advised several international institutions, including the International Energy Agency, and worked as a consultant for various international organizations on energy innovation. She has also carried out process engineering research at DuPont and Bayer Pharmaceuticals, collaborated extensively with Johnson Matthey Catalysts, and worked as a financial consultant for banks on credit risk models for financing technology projects. Dr. Diaz Anadon holds a Ph.D. in Chemical Engineering from the University of Cambridge, a Master in Public Policy from the Harvard Kennedy School, and an undergraduate degree in Chemical Engineering from the University of Manchester.

\section{Matthew Bunn}

Associate Professor of Public Policy; Co-Principal Investigator, Project on Managing the Atom; Co-Princi-

pal Investigator, Energy Research, Development, Demonstration, and Deployment (ERD3) Policy Project

Dr. Bunn's research interests include nuclear theft and terrorism; nuclear proliferation and measures to control it; the future of nuclear energy and its fuel cycle; and policies to promote innovation in energy technologies. Dr. Bunn holds a doctorate in technology, management, and policy from the Massachusetts Institute of Technology.

\section{Gabe Chan}

Research Assistant, Energy Research, Development, Demonstration \& Deployment Policy Project, Energy Technology Innovation Policy research group

Gabe Chan is a doctoral candidate in the Public Policy Program at the Harvard Kennedy School as well as a Giorgio Ruffolo Doctoral Research Fellow in Sustainability Science at Harvard's Center for International Development, a Pre-Doctoral Fellow in the Harvard Environmental Economics Program, and a member of the Harvard Graduate Consortium on Energy and the Environment. Prior to Harvard, Gabe 
received Bachelor of Science degrees in Earth, Atmospheric, and Planetary Science and Political Science from the Massachusetts Institute of Technology (MIT) and worked in the Climate Change Technology Program (CCTP) at the U.S. Department of Energy.

\section{Melissa Chan}

Former Research Fellow, Energy Research, Development, Demonstration \& Deployment Policy Project, Energy Technology Innovation Policy research group, January 2009-December 2010.

Dr. Chan is a Managing Consultant in Navigant's Energy practice. She has extensive experience in evaluating energy technology innovation to satisfy regulatory and policy goals related to energy efficiency, greenhouse gas emissions, energy security, and environmental issues. During her tenure as a research fellow at Harvard University and a program analyst at the National Energy Technology Laboratory, she advised policy makers, scientific researchers, government R\&D program managers, and published in peer reviewed journals about current and novel energy technologies. She is an expert in life cycle analysis, carbon accounting, systems analysis and modeling, expert elicitation, and technology and policy analysis.

\section{Charles (SKuk) Jones}

Research Fellow, Energy Technology Innovation Policy research group

Dr. Jones studies investments in innovation in the private sector and in public-private partnerships, as part of the Energy Research, Development, Demonstration, and Deployment (ERD3) Policy project. He holds a Ph.D. in Public Policy from the University of Massachusetts Boston where he studied the dynamics of the local photovoltaic industry, and an undergraduate degree in physics. Skuk served for nine years in the U.S. Navy in nuclear submarines. Prior to joining ETIP, he was an adjunct professor at UMass Boston College of Management.

\section{RUUD KEMPENER}

Former Research Fellow, Energy Technology Innovation Policy research group"s Energy Research, Development, Demonstration \& Deployment (ERD3) Policy project.

Dr. Kempener studies long-term energy and climate change policy, bioenergy networks, personal carbon trading, emissions trading schemes, and the development of quantitative multi-scale (or agentbased) models for sustainable development. Dr. Kempener worked as a research fellow at Science and Technology Policy Research (SPRU) at the University of Sussex (UK). He has a Ph.D. in Chemical Engineering from the Complex Systems and Sustainability group at the University of Sydney (AUS) and a Masters in Technology \& Innovation Policy from Eindhoven University of Technology (NL). 


\section{Audrey LeE}

Research Fellow, Energy Technology Innovation Policy research group

Audrey Lee is an Energy Research, Development, Demonstration \& Deployment (ERD3) Policy project research fellow and an economist in the Office of Policy and International Affairs at the U.S. Department of Energy.

Dr. Lee's work focuses on the economic analysis of energy and climate change policies, using a variety of models and covering an extensive array of technologies. She was awarded a Presidential Management Fellowship in 2005 and was a co-author of the World Energy Outlook 2007 at the International Energy Agency. Dr. Lee holds a B.S. in applied physics from the California Institute of Technology and a Ph.D. in electrical engineering from Princeton University.

\section{NATHANiEL LOgaR}

Research Fellow, Science, Technology, and Public Policy Program/Energy Technology Innovation Policy research group

Dr. Logar has a Ph.D from the University of Colorado-Boulder, where he did research at the university's Center for Science \& Technology Policy Research. His graduate research focused on climate science policy, and on managing federal institutions for usable science. His dissertation case studies addressed science policies in the USDA's Agricultural Research Service, the Naval Research Laboratory, and the National Institute of Standards and Technology. His research at the Kennedy School, in Energy Technology Innovation Policy, addresses the policies at innovation institutions, and managing for useful science and technology outputs.

\section{VenKATESH “Venky" NARAYANAMURTi}

Benjamin Peirce Professor of Technology and Public Policy; Professor of Physics, Harvard; Director, Science, Technology, and Public Policy Program; Co-Principal Investigator, Energy Technology Innovation Policy research group ;Co-Principal Investigator, Energy Research, Development, Demonstration, \& Deployment Policy Project; Co-Principal Investigator, Explorations in Cyber International Relations Dr. Narayanamurti was formerly the Dean of the School of Engineering and Applied Sciences and Dean of Physical Sciences at Harvard. He obtained his Ph.D. in Physics from Cornell University. He lectures widely on solid state, computer, and communication technologies and on the management of science, technology, and public policy. 



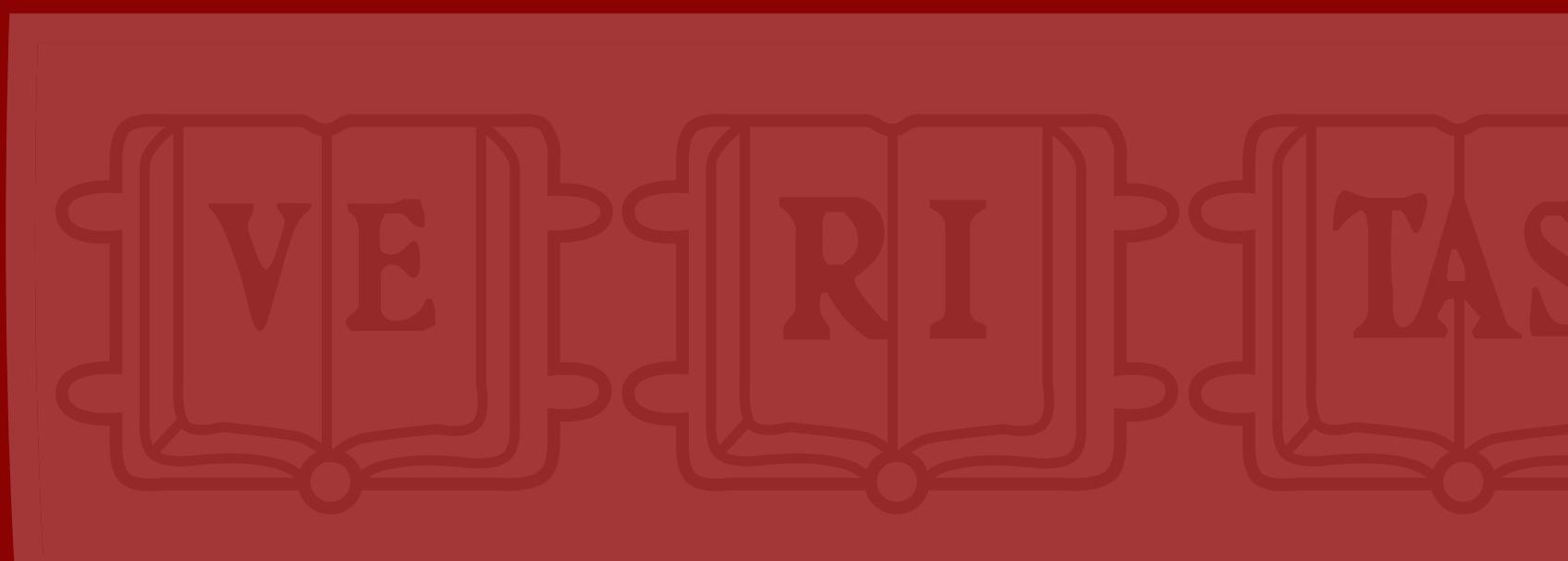

\section{Belfer Center for Science and International Affairs}

Harvard Kennedy School

\section{JFK Street}

Cambridge, MA 02138

Fax: (617) 495-8963

Email: belfer_center@harvard.edu

Website: http://belfercenter.org

Copyright 2011 President and Fellows of Harvard College 